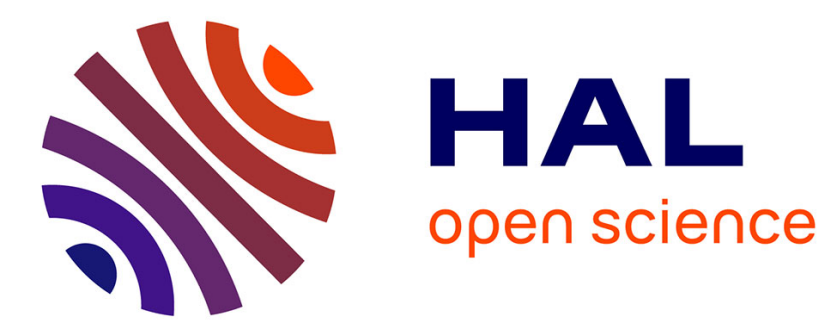

\title{
Geminal Dianions Stabilized by Main Group Elements
}

Marie Fustier-Boutignon, Noel Nebra, Nicolas Mézailles

\section{To cite this version:}

Marie Fustier-Boutignon, Noel Nebra, Nicolas Mézailles. Geminal Dianions Stabilized by Main Group Elements. Chemical Reviews, 2019, 119 (14), pp.8555 - 8700. 10.1021/acs.chemrev.8b00802 . hal03012936

\section{HAL Id: hal-03012936 https: / hal.science/hal-03012936}

Submitted on 27 Oct 2021

HAL is a multi-disciplinary open access archive for the deposit and dissemination of scientific research documents, whether they are published or not. The documents may come from teaching and research institutions in France or abroad, or from public or private research centers.
L'archive ouverte pluridisciplinaire $\mathbf{H A L}$, est destinée au dépôt et à la diffusion de documents scientifiques de niveau recherche, publiés ou non, émanant des établissements d'enseignement et de recherche français ou étrangers, des laboratoires publics ou privés. 
Geminal Dianions Stabilized by Main Group Elements

Marie Fustier-Boutignon, Noel Nebra, Nicolas Mézailles*

Université de Toulouse, UPS, CNRS, LHFA UMR 5069,

118 route de Narbonne, 31062 Toulouse, France

E-mail: $\underline{\text { mezailles@chimie.ups-tlse.fr }}$

Tel: +33561556292 


\section{Abstract}

This review is dedicated to the chemistry of stable and isolable species that bear two lone pairs at the same $\mathrm{C}$ center, i.e. geminal dianions, stabilized by main group elements. Three cases can thus be considered: the gem dilithio derivative, for which the two substituents at $\mathrm{C}$ are neutral, the ylidiide derivatives, for which one substituent is neutral while the other is charged, and finally the geminal bisylides, for which the two substituents are positively charged. In this review the syntheses and electronic structures of the geminal dianions are presented, followed by the studies dedicated to their reactivity toward organic substrates and finally to their coordination chemistry and applications. 
1. Introduction

2. Geminal dianions of type I (A and B: neutral fragments)

2.1. Synthesis of geminal dianions of type I

2.2. Electronic structure of the geminal-dianions

2.3. Reactivity of geminal-dilithio derivatives

2.4. Coordination of Type I geminal dianions

2.4.1. Group 2: Alkaline-earth metal dianions

2.4.2. Rare earths elements: group 3 and lanthanides

2.4.3. Actinide complexes

2.4.4. Group 4 complexes

2.4.5. Group 6 complexes

2.4.6. Group 8 complexes: Syntheses and reactivity

2.4.7. Group 9 complexes

2.4.8. Group 10 Complexes

2.4.9. Group 11 Complexes

2.4.10. Group 12 complexes

2.4.11. Group 13 complexes: synthesis and reactivity

2.4.12. Group 14 complexes:

3. Geminal dianions of type II (A neutral fragment, B cationic fragment)

3.1. Synthesis of geminal dianions of type II

3.2. Structural properties

3.2.1. X-ray diffraction

3.2.2. NMR Spectroscopy

3.2.3. Ab initio and DFT modeling

3.3. Reactivity of yldiides

3.4. Coordination chemistry of type II geminal dianions

3.4.1. Group 3 and Rare Earths

3.4.2. Complexes of uranium

3.4.3. Group 4 metal complexes

3.4.4. Group 5

3.4.5. Group 6

3.4.6. Group 7

3.4.7. Group 8

3.4.8. Group 9.

3.4.9. Group 10

3.4.10. Group 11

4. Geminal dianions of type III (A and B: cationic fragments)

4.1. Synthesis of carbodiphosphoranes and other related heteroatom-stabilized bis(ylide)s.

4.2. Electronic strucutre of carbodiphosphoranes and other related heteroatom-stabilized bis(ylide)s. 
4.3. Reactivity of double ylides towards organic compounds.

4.4. Coordination chemistry of double ylides to metallic species.

4.4.1. Coordination to Group 2 Metals.

4.4.2. Coordination to Actinides: Uranium Complexes

4.4.3. Coordination to Group 4 Metals: Zirconium Complexes

4.4.4. Coordination to Group 6 Metals: Tungsten Complexes

4.4.5. Coordination to Group 7 Metals: Manganese and Rhenium Complexes

4.4.6. Coordination to Group 8 Metals: Iron Complexes

4.4.7. Coordination to Group 9 Metals: Rhodium and Iridium Complexes

4.4.8. Coordination to Group 10 Metals

4.4.9. Coordination to Group 11 (Coinage) Metals

4.4.10. Coordination to Group 12 Metals

4.5. Reactivity of double ylides towards main group elements.

4.5.1. Group 13

4.5.2. Group 14

4.5.3. Group 15

4.5.4. Group 16

4.5.5. Group 17

4.6. Carbodicarbenes

4.6.1. Synthesis

4.6.2. Reactivity

4.6.3. Coordination chemistry

4.6.4. Reactivity with main group elements

5. Conclusion

6. Acknowledgements

7. References

\section{Introduction}

Geminal dianionic compounds are species that possess two lone pairs of electrons at a single atom. It is most often a $\mathrm{C}$ atom, for which the archetypical example is dilithiomethane, $\mathrm{CH}_{2} \mathrm{Li}_{2}, \mathbf{1}$, synthesized by Wittig, West and Ziegler in pioneering works more than 70 years ago. ${ }^{1}{ }^{3} \mathrm{CH}_{2} \mathrm{Li}_{2}$ is highly reactive toward oxygen and moisture as well as unstable and poorly soluble in organic solvents, which complicated its structural characterization as well as its reactivity. Klumpp has developed an easy synthesis of unstabilized aliphatic geminal-dilithium derivatives based on low temperature Li-halogen exchange in the late $80 \mathrm{~s}^{4}$ The in situ generated dilithium species could then be subsequently trapped by various 
electrophiles, showing their potential in synthesis. Modulation of the substituents at $\mathrm{C}$ allows a fine tuning of the acidity of the two $\mathrm{H}$ atoms as well as provides means of stabilization of the resulting geminaldianionic species. This review is dedicated to the chemistry of stable and isolable species that bear two lone pairs at the same $\mathrm{C}$ center, i.e. geminal dianions, stabilized by main group elements. Depending on the nature of the stabilizing moieties, three cases can be envisioned (Scheme 1). First, the two moieties can be neutral, which imply the compensation of the two charges by metal centers (I, scheme 1), such as the first isolated stable geminal dilithio derivative $\left(\mathrm{SiMe}_{3}\right) \mathrm{C}(\mathrm{Li})_{2}\left(\mathrm{SO}_{2} \mathrm{Ph}\right) \mathbf{2} \mathbf{c} \mathbf{L i}_{\mathbf{2}}$ synthesized in 1985 and crystallized in 1988. ${ }^{56}$ Secondly, when only one metal center is used for charge compensation, two different stabilizing groups have to be used: a cationic and a neutral one. These compounds belong to the class of yldiides (II, scheme 1). Finally, when two cationic stabilizing groups are present, the overall species is neutral (III, scheme 1), the most emblematic example of such geminal dianions being the carbodiphosphorane $\mathrm{Ph}_{3} \mathrm{P}=\mathrm{C}=\mathrm{PPh}_{3}$. This review is thus separated in three parts treating independently these cases. In each part, we have chosen to present first the synthesis of the geminal dianions and their electronic structure, followed by the studies dedicated to their reactivity toward organic substrates and finally to their coordination chemistry and applications.

\section{Scheme 1: Geminal dianions}




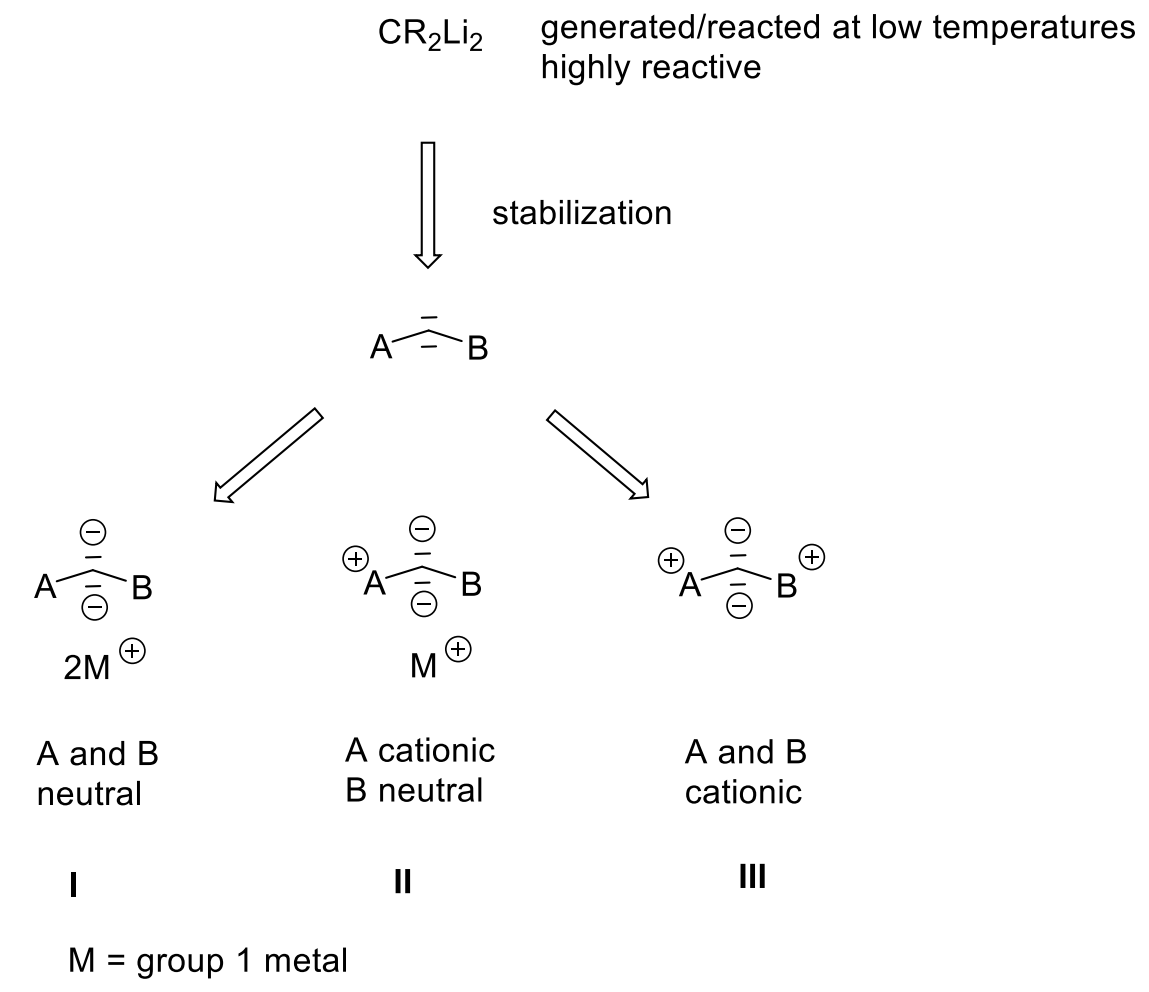

\section{Geminal dianions of type I (A and B: neutral fragments)}

\subsection{Synthesis of geminal dianions of type I}

The use of $\alpha$-stabilized carbanions in organic chemistry is more than a century old, and the understanding of the aggregation and bonding in organolithium derivatives has largely relied on their study. The second deprotonation of various $\alpha$-stabilized carbanions was studied in the 1970 s. ${ }^{7},{ }^{8}$ Starting from $\mathrm{PhCH}_{2} \mathrm{Y}$ (where $\mathrm{Y}=\mathrm{CN}, \mathrm{SO}_{2} \mathrm{Ph}, \mathrm{SOPh}, \mathrm{SO}_{2} \mathrm{NMe}$ and $\left.\mathrm{NO}_{2}\right)$ or from $\mathrm{FcCH}_{2} \mathrm{Y}(\mathrm{Fc}=$ ferrocene, $\mathrm{Y}=$ $\mathrm{CN}, \mathrm{POPh}_{2}, \mathrm{PO}(\mathrm{OEt})_{2}$ and $\left.\mathrm{SO}_{2} \mathrm{Ph}\right)$, species proposed to be geminal-dianions $\mathrm{RCLi}_{2} \mathrm{Y}(\mathrm{R}=\mathrm{Ph}$ or $\mathrm{Fc})$ were obtained by addition of excesses of bases. Indeed, these species reacted with various electrophiles (E-X) to form the expected geminal C-E bonds. However, in 1985, Gais and coworkers studied the low temperature second deprotonation of allyl or benzyl phenylsulfones anions $\mathrm{RCHLiSO}_{2} \mathrm{Ph}, \mathbf{2 H L i}$, in 
THF. ${ }^{9}$ Instead of the expected formation of the geminal-dilithio derivatives, selective lithiation at the phenyl ring was observed (scheme 2). However, warming to $50^{\circ} \mathrm{C}$ resulted in the formation of the thermodynamically preferred $\alpha, \alpha$-dilithio species. Deuteration with $\mathrm{DCl} / \mathrm{D}_{2} \mathrm{O} / \mathrm{THF}$ formed the $\left[1,1-\mathrm{D}_{2}\right] 2 \mathrm{a}$ in $82 \%$ yield with $\geq 98 \%$ incorporation of $\mathrm{D}$.

\section{Scheme 2: Dianions of phenylsulfones}

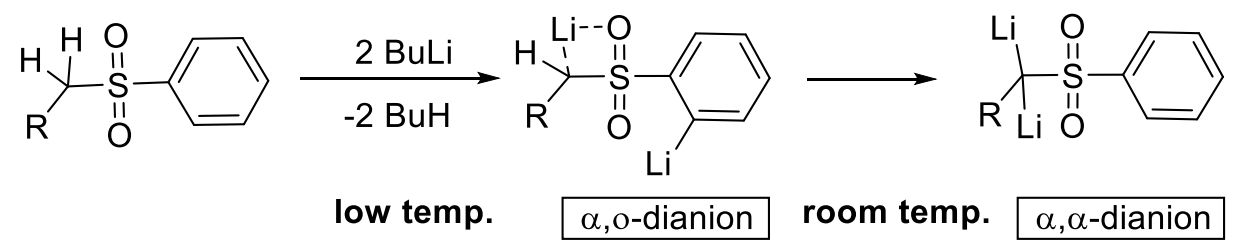
2a, $\mathrm{R}=\mathrm{CH}=\mathrm{CH}_{2}$
2b, $\mathrm{R}=\mathrm{Ph}$
$2 \mathrm{aLi}_{2}$
2b $\mathrm{bi}_{2}$
$2 \mathrm{aLi}_{2}$
$2 \mathbf{b L i}_{2}$

In parallel, Meth-Cohn proved by ${ }^{13} \mathrm{C}$ NMR that deprotonation of $\mathrm{PhCH}_{2} \mathrm{CN}$ with an excess of LiHMDS (lithium hexamethyldisilazide) did not form the $\alpha, \alpha$-dianion but rather a heterodimer, called a "QUAsi-DiAnion Complex" or "QUADAC", with a proposed PhCHCN.Li 2. HMDS structure (scheme

3). ${ }^{10}$ Boche and coworkers presented in 1989 the first X-ray diffraction of such species. ${ }^{11}$

\section{Scheme 3: Double deprotonation of $\mathrm{PhCH}_{2} \mathrm{CN}$, formation of QUAsi-DiAnion Complex}




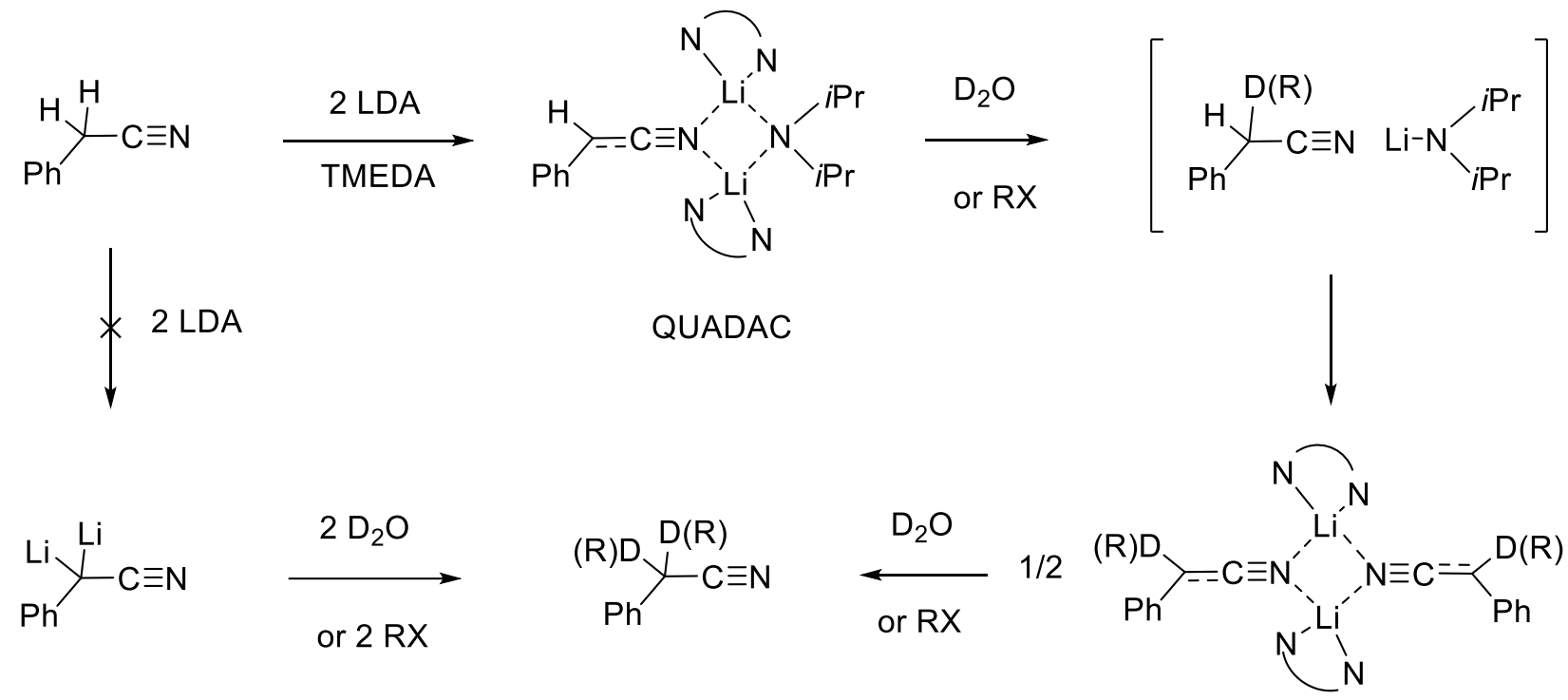

Meanwhile, Gais reported in 1988 that with the trimethylsilyl phenyl sulfone $\mathbf{2} \mathbf{c H}_{\mathbf{2}}$, the $\alpha, \alpha$ dilithio species was formed directly, without prior ortho-metalation of the $\mathrm{Ph}$ ring. This species, soluble and stable in THF, could be crystallized. In fact, two different structures were obtained. In the presence of $\mathrm{Li}_{2} \mathrm{O}$, sparingly soluble crystals form for which the X-ray analysis shows a hexamer with six THF molecules and assembled around the $\mathrm{Li}_{2} \mathrm{O}$ : $\left.\left[\left(\mathrm{SiMe}_{3}\right) \mathrm{CLi}_{2} \mathrm{SO}_{2} \mathrm{Ph} \cdot \mathrm{Li}_{2} \mathrm{O} \text {.(THF }\right)_{6}\right] \mathbf{2} \mathbf{c} \mathbf{L i}_{2}{ }^{6}$ In the absence of $\mathrm{Li}_{2} \mathrm{O}$, readily soluble octahedral crystals (X-ray structure not reported) formed which further allowed NMR investigation of the structure and aggregation state in solution. Low temperature ${ }^{6} \mathrm{Li}$ and ${ }^{13} \mathrm{C}$ NMR spectroscopy proved that the $\alpha, \alpha$-dilithio structure prevails in solution (scheme 4 ).

Scheme 4: Double deprotonation of $\mathrm{SiMe}_{3} \mathrm{CH}_{2} \mathrm{SO}_{2} \mathrm{Ph} ; 1^{\text {st }} \mathrm{X}$-ray structure of a "type I" geminal dianion

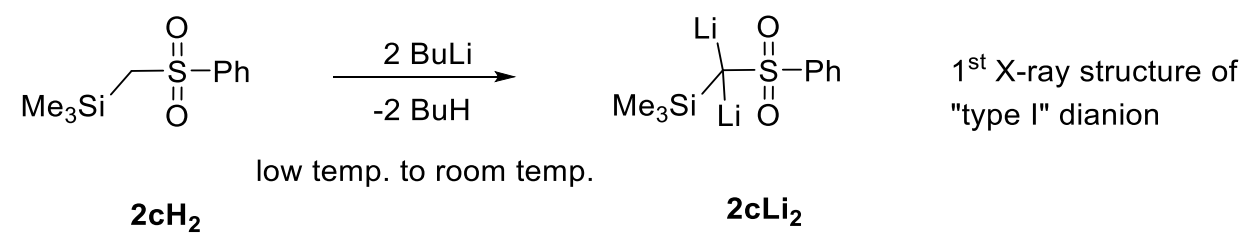


Also in 1989, Boche and co-workers reported the double deprotonation of $(\mathrm{TMS}) \mathrm{CH}_{2}(\mathrm{CN})$ by either LDA or BuLi (in excess) in mixtures of ether/hexanes to form the expected (TMS)C(CN)Li 2 species. ${ }^{12}$ An aggregate of the twelve molecules of dianions, six molecules of $\mathrm{Et}_{2} \mathrm{O}$ and a single hexane $\left[\left\{\mathrm{Li}_{2}\left(\mathrm{SiMe}_{3} \mathrm{CCN}\right)\right\}_{12}\left(\mathrm{Et}_{2} \mathrm{O}\right)_{6}\left(\mathrm{C}_{6} \mathrm{H}_{14}\right)\right]$ crystallized from the mixture. The X-ray structure showed three groups of dianions which differ in the number of their NLi and CLi contacts. Unfortunately, the yield of the crystallized product was not given.

Further studies on the $\mathrm{PhCH}_{2} \mathrm{CN}$ system by Castellà-Ventura and co-workers showed that the heterodimer can evolve to the dianion only when excess of $n$-BuLi was used. ${ }^{13}$ Indeed, a mixture of heterodimer and dianion was observed with 2.2 eq. of $n$-BuLi, whereas quantitative formation of the dianions was observed with 2.7 eq. of n-BuLi. The same authors later showed that the efficiency of both alkylation and deuteriation strongly depended on the excess of base. Indeed, the larger excess of BuLi

the lower the yield of di-alkylation indicating the formation of other species. ${ }^{14}$ These seminal results highlight the difficulty to generate efficiently the geminal-dimetallic species. Spectroscopic techniques (NMR, IR) as well as X-ray diffraction are needed to definitely prove the nature of the dianionic species. Moreover, for further use, pure geminal-dianionic species, i.e. free of excess of base, are required. As will be shown below, this can be achieved if the double deprotonation is stoichiometric in base and/or if the dianion can be separated from excess of base, typically by crystallization. Early studies by Gais and Boche pointed that two strongly electron accepting substituents at $\mathrm{C}$ indeed allow for the quantitative double deprotonation under stoichiometric conditions, which clearly lead the way. All the known geminal dilitho compounds are presented in the two following schemes (schemes 5 and 6).

\section{Scheme 5: "type I" geminal dianions for which X-ray structure is known (1985-2012)}




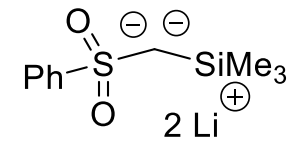

$2 \mathrm{cLi}_{2}$

1985/1988

2BuLi/THF

crystallization

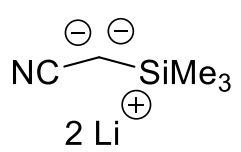

$3 \mathrm{Li}_{2}$

1989

xs base/

crystallization

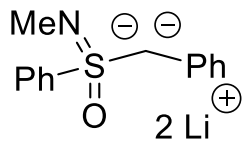

4 $\mathrm{Li}_{2}$

1999

xs base/

crystallization

yield: $17 \%$

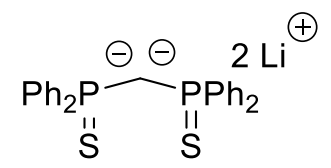

$8 \mathrm{Li}_{2}$ 2004/2006 $2 \mathrm{MeLi} / \mathrm{Et}_{2} \mathrm{O}$ crystallization yield: quant.

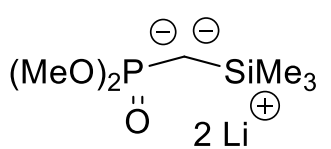

$\mathbf{5} \mathrm{Li}_{\mathbf{2}}$ 1999 xs base/ crystallization
$6 \mathrm{aLi}_{2}$

1999

$2 \mathrm{MeLi}$

crystallization yield: $68 \%$<smiles>[R]S(=O)(=O)CCC#N</smiles>

$7 \mathrm{a}-\mathrm{bLi}_{2}$ 2002 $2 \mathrm{MeLi} / \mathrm{THF}$ yield: $92 \%$

a: $\mathrm{R}=\mathrm{Ph}$

b: $\mathrm{R}=t-\mathrm{Bu}$

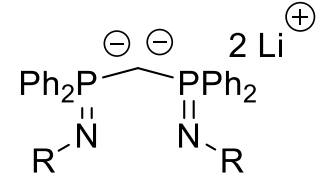

6b-d Li $\mathbf{i}_{2}$ 2006 $2 \mathrm{MeLi} / \mathrm{Et}_{2} \mathrm{O}$

b: $\mathrm{R}=\mathrm{Ph}$

c: $R=i P r$

d: $R=(R)-C H M e P h$

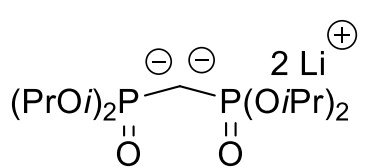

$9 \mathrm{Li}_{2}$ 2006 $2 \mathrm{MeLi} / \mathrm{Et}_{2} \mathrm{O}$ yield: $94 \%$

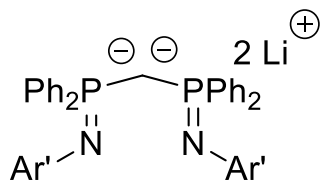

6e-fLi ${ }_{2}$ 2010-2011 $2 \mathrm{MeLi} / \mathrm{Et}_{2} \mathrm{O}$

e: $\mathrm{Ar}^{\prime}=2,4,6-\mathrm{Me}_{3} \mathrm{Ph}$ f: $A r^{\prime}=2,6-(i-P r)_{2} P h$<smiles>O=S(=O)(CP([O-])(=S)c1ccccc1)c1ccccc1</smiles>

$11 \mathrm{Li}_{2}$ 2012 $2 \mathrm{MeLi} / \mathrm{THF}$ yield: $73 \%$

Scheme 6: "type I" geminal dianions for which X-ray structure is known (2012-2018) 


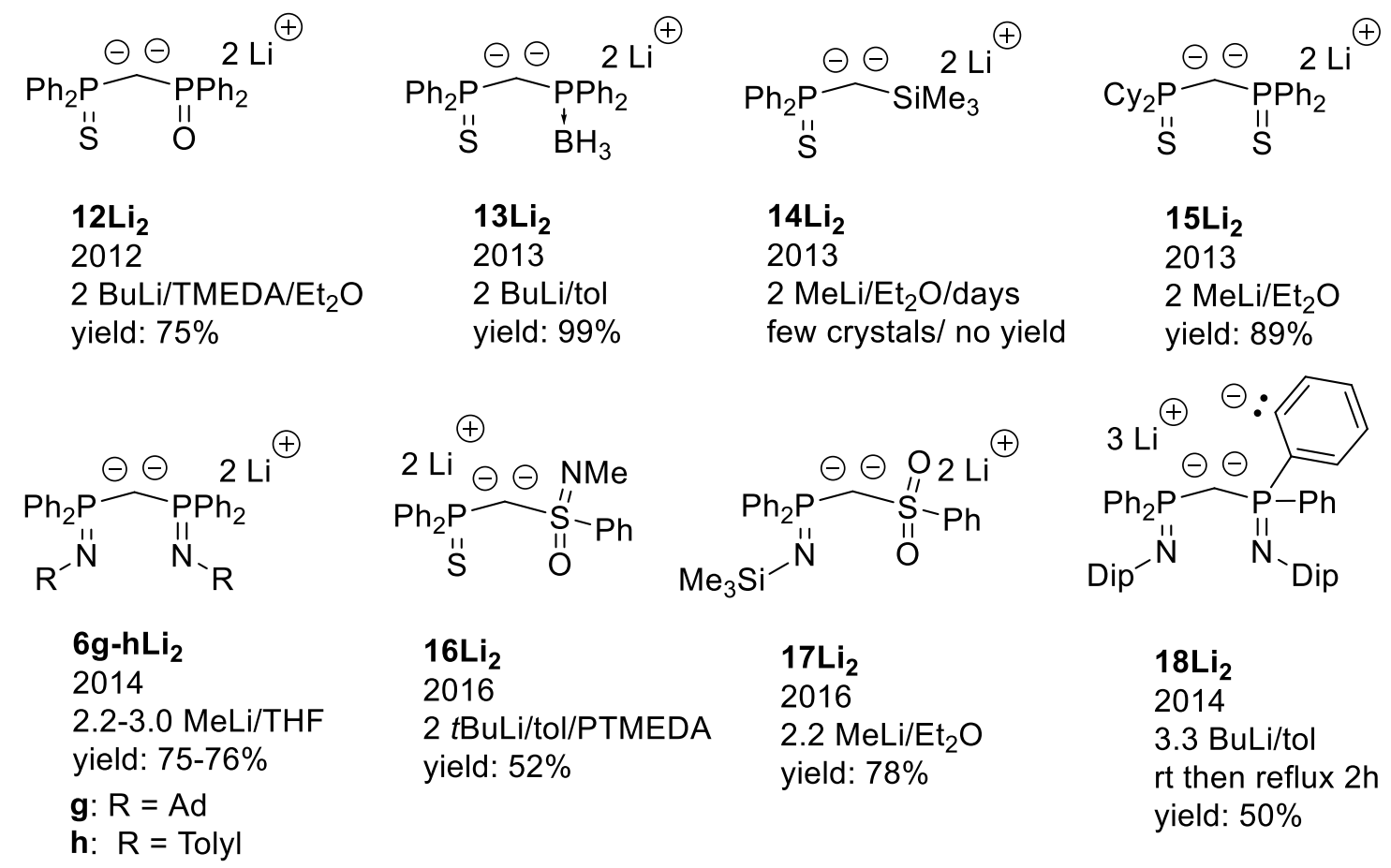

The next report of crystallized geminal dianions was done ten years later, when Müller presented the synthesis of the sulfoximine compound $4 \mathrm{Li}_{2}$, the first chiral substituted dilithiomethane derivative. Again, an excess of n-BuLi (2.5 eq.) was used to favor double deprotonation. The presence of $\mathrm{Li}_{2} \mathrm{O}$, generated in situ by hydrolysis of $\mathrm{H}_{2} \mathrm{O}$ added on purpose, allowed crystallization and thus separation of the dianion from excess base, although in poor yield $(17 \%) .{ }^{15}$ Chiral geminal-dianions could lead to interesting developments in organic synthesis. Indeed, the two Li atoms are diastereotopic and selective reactivity at $\mathrm{C}$ could lead to the generation of a stereogenic $\mathrm{C}$ center. Such developments are yet to be reported. Phosphonate moieties were used for the first time by Müller, together with $\mathrm{SiMe}_{3}$ to stabilize the geminal-dianion $5 \mathrm{Li}_{2} .{ }^{16}$ In this case also the authors used an excess of $n$-BuLi (2.5 equiv.), together with TMEDA. The latter is partly decomposed in the course of the reaction into dimethylamido. Both TMEDA and dimethylamido, incorporated in the crystal, allowed isolation of the dianion in a very good 
$67 \%$ yield, but did not preclude decomposition even in the solid state under inert atmosphere within $24 \mathrm{~h}$ (scheme 7).

\section{Scheme 7: double deprotonation of $5 \mathrm{H}_{2}$}

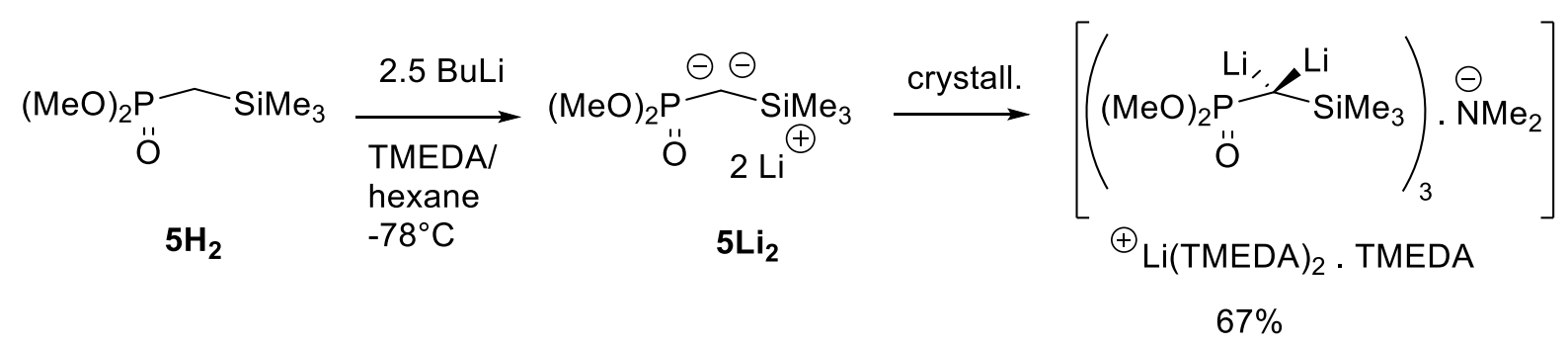

Two most significant reports were made in 1999 by the groups of Cavell and Stephan. Indeed, dianion $6 \mathrm{aLi}_{2}$ featuring two strongly accepting $\mathrm{PPh}_{2} \mathrm{NTMS}$ moieties was synthesized as the sole species (as shown by ${ }^{31} \mathrm{P}$ NMR) under stoichiometric conditions (either 2 eq. of MeLi or PhLi in toluene or benzene). It could moreover be crystallized in $68 \%$ yield. ${ }^{17},{ }^{18}$ The molecular structure reveals a dimeric nature in which the two $\mathrm{C}$ and four $\mathrm{Li}$ atoms form a distorted octahedron. The two $\left[\mathrm{Li}_{2} \mathrm{C}\left(\mathrm{PPh}_{2} \mathrm{NTMS}\right)_{2}\right]$ fragments are arranged in a "head-to-head" fashion (scheme 8).

Scheme 8: double deprotonation of $6 \mathrm{aH}_{2}$
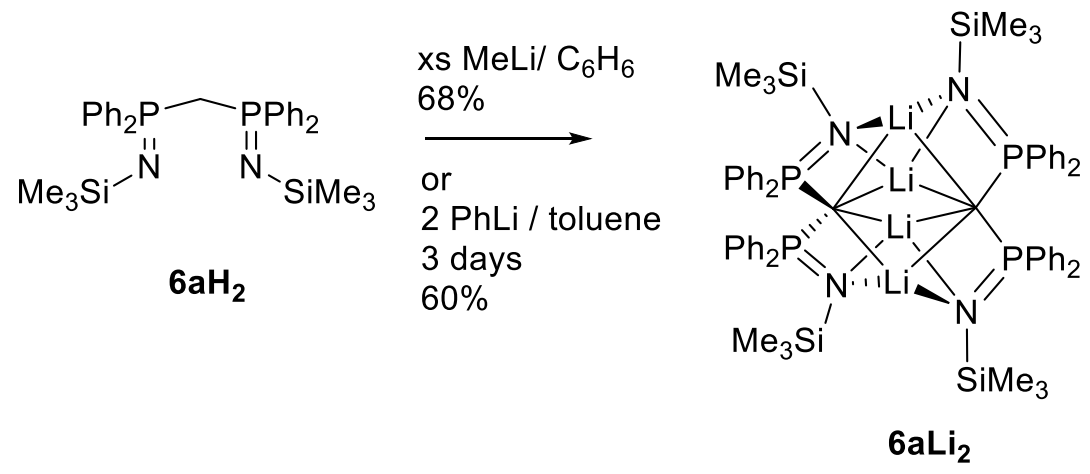
The N-P-C-P-N units are nearly planar. Unlike previous structures of geminal-dianions, Li cations do not need to be coordinated by "external" ligand or solvent molecules. Here, the PN moieties complete the coordination sphere of the $\mathrm{Li}$ cations. The important metrical features are the PN (av. $1.630 \AA$ ) and CP (av $1.694 \AA$ A) bond distances which are respectively elongated and significantly shortened compared to the neutral species. These features are explained by the electronic structure (vide infra) of the geminal-dianions. In the following ten years, researchers mostly expanded on this discovery that two neutral $\mathrm{P}(\mathrm{V})$ moieties could efficiently stabilize two charges at the same $\mathrm{C}$ center. In the meantime, Henderson reported in 2002 the successful synthesis of sulfonyl/nitrile stabilized geminal dianions 7a-bLi ${ }_{2 .}{ }^{19}$ The Phenyl and t-Bu sulfonyl derivatives were obtained in excellent 84 and $74 \%$ yield respectively because of a fast precipitation from the reaction medium (slow addition of MeLi in THF at ambient temperature). The absence of methylene signal in the ${ }^{1} \mathrm{H}$ spectrum $\left(\mathrm{D}_{6}\right.$-DMSO) confirmed the formation of geminated dilithio derivative rather than the possible QUADAC species. In 2004, the bis $\mathrm{PPh}_{2} \mathrm{~S}$ geminal-dianion $8 \mathrm{Li}_{2}$ was reported by LeFloch and co-workers to be generated quantitatively and used in situ. ${ }^{20}$ Two X-ray structures of $\mathbf{8} \mathbf{L i}_{2}$ were disclosed in 2006 (scheme 9). ${ }^{21}$ If crystals are grown from diffusion of hexanes into toluene/ $\mathrm{Et}_{2} \mathrm{O}$ mixture of dianions, a symmetrical dimer is formed 8Li $\mathbf{L i}_{2} \cdot\left(\mathrm{Et}_{2} \mathrm{O}\right)_{2}$; whereas when a $\mathrm{Et}_{2} \mathrm{O}$ solution of the dianions is slowly evaporated an unsymmetrical dimer is obtained $\mathbf{8} \mathbf{L i}_{2} \cdot\left(\mathrm{Et}_{2} \mathrm{O}\right)_{3}$.

\section{Scheme 9: double deprotonation of $\mathrm{8H}_{2}$}




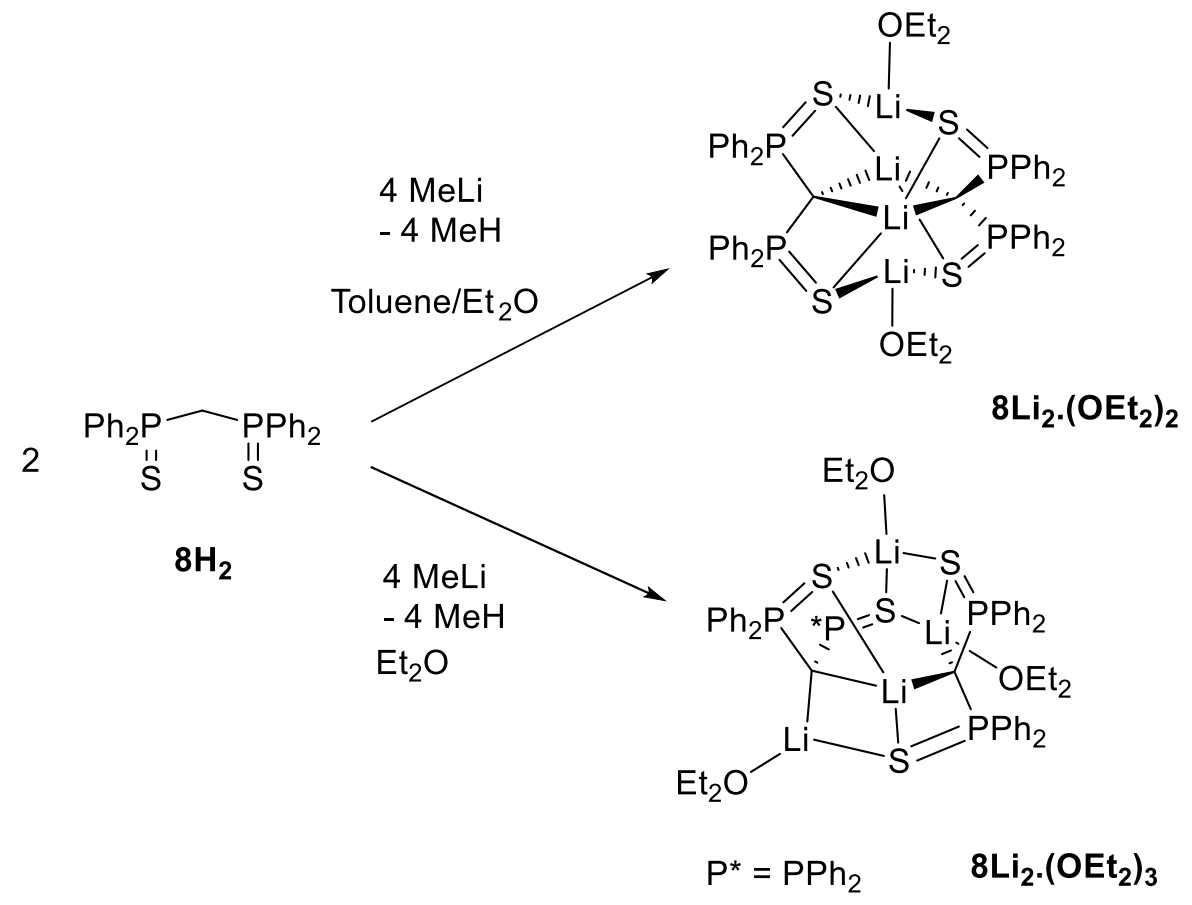

In the structure $\mathbf{8} \mathbf{L i}_{2} \cdot\left(\mathrm{Et}_{2} \mathrm{O}\right)_{2}$ each $\mathrm{C}$ coordinates two $\mathrm{Li}$ centers, which coordination sphere is completed by two $\mathrm{S}$ atoms of the $\mathrm{P}=\mathrm{S}$ moieties. The two other Li centers are only tricoordinated (trigonal planar geometry), by two $\mathrm{P}=\mathrm{S}$ moieties and a single molecule of $\mathrm{Et}_{2} \mathrm{O}$. In the second dimeric structure, $\mathbf{8} \mathbf{L i}_{2}$. $\left(\mathrm{Et}_{2} \mathrm{O}\right)_{3}$, each monomeric fragment possesses similar bond distances, also similar to the ones of the symmetrical dimer. Each monomeric fragment however differs markedly by the respective orientation of the P-S bonds relative to the PCP planes. Moreover, four different environments are found for the four Li cations. A variable temperature ${ }^{31} \mathrm{P}$ and ${ }^{7} \mathrm{Li}$ NMR study of the dianion $\mathbf{8} \mathbf{L} \mathbf{i}_{2}$ was performed (toluene/ $\mathrm{Et}_{2} \mathrm{O} 5 / 1$ mixture) to probe the nature of the species in solution. Below $-50^{\circ} \mathrm{C}$, four signals of 1.0:1.0:1.0:1.0 intensities are found in the ${ }^{31} \mathrm{P}$, and at least four different signals are seen at $-90^{\circ} \mathrm{C}$ in the ${ }^{7} \mathrm{Li}$ spectrum, pointing several species in 1:1 equilibrium or a single species with different $\mathrm{Li} / \mathrm{P}$ environments (as in the unsymmetrical dimer). This study showed nonetheless that the crystallized symmetrical form is not retained in solution. The synthesis of the bis phosphonate dianion $9 \mathbf{L i}_{2}$ was presented in 
the same article. The kinetics of the second deprotonation varied tremendously between the bis-PS and bis-PO systems. Indeed, if the first deprotonation of bis-PO derivative 9 occurs almost instantaneously, the second deprotonation required more than ten days at room temperature (with MeLi as base), vs few hours for the bis PS system. Addition of TMEDA (2 equiv. per MeLi) accelerated the reaction, which was complete after 3 days. Compound $\mathbf{9} \mathbf{L i}_{2}$, isolated in $94 \%$ yield, is highly insoluble, most likely polymeric, and TMEDA is not incorporated in the solid as proved by hydrolysis studies. In 2006, 2010,

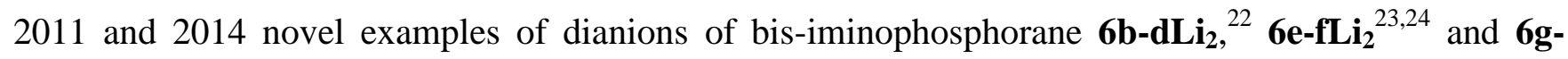
$\mathbf{h L i}_{2}{ }^{25}$ were reported by Le Floch and co-workers, Liddle and co-workers and Gessner and co-workers respectively. The neutral derivatives $\mathbf{6 b}$-d were conveniently synthesized using the Kirsanov reaction. This opened the way to bis-iminophosphorane dianions featuring substituents at $\mathrm{N}$ for which the azide is not readily available (required for the Staudinger reaction). In particular, alkyl as well as a chiral substituent at $\mathrm{N}$ were introduced $((\mathrm{S})-\mathrm{MeCH}(\mathrm{i}-\mathrm{Pr}))$ and the dianion $\mathbf{6} \mathbf{d L \mathbf { i } _ { 2 }}$ crystallized. Derivatives $\mathbf{6} \mathbf{e}-\mathbf{h} \mathbf{L} \mathbf{i}_{\mathbf{2}}$ were devised to increase the steric bulk at $\mathrm{N}$. The neutral derivatives $\mathbf{6 e - h}$ were obtained via the Staudinger reaction. The double deprotonation leading to the $\mathbf{6} \mathbf{d}-\mathbf{h} \mathbf{L} \mathbf{i}_{\mathbf{2}}$ derivatives in excellent isolated yields was readily achieved following synthetic procedures derived from the one leading to $\mathbf{6} \mathbf{a L i} \mathbf{i}_{2}$. Apart from $\mathbf{6} \mathbf{f L i} \mathbf{i}_{2}$ (vide infra) they all presented the same head-to-head dimer arrangement as in $\mathbf{6 a L i} \mathbf{i}_{2}$ : planar $\mathrm{Li}_{4}$ and planar $\mathrm{C}_{2} \mathrm{Li}_{2}$ ring, arranged perpendicularly. Compound $\mathbf{6 f}$ featuring very bulky substituent (Dipp: 2,6-diisopropyl-phenyl) at the $\mathrm{N}$ center was synthesized in order to test the possibility of achieving planar geometry at the $\mathrm{C}$ center in the corresponding dianion $\mathbf{6} \mathbf{f} \mathbf{L} \mathbf{i}_{2}$. Indeed, theoretical calculations by von Ragué Schleyer in 1976 predicted that replacing H by alkali metals results in increased stabilization of the planar tetracoordinate arrangements $\left(c i s-\mathrm{R}^{1} \mathrm{R}^{2} \mathrm{CLi}{ }_{2}\right) \cdot{ }^{26}$ Twenty years later, Stalke, von Ragué Schleyer and co-workers showed that lithiated cyclopropenes bearing either anionic O or NR fragments 
in vinylic position formed dimers in which the desired cis-planar geometry was almost achieved. In fact in the amide derivative the twist angle between the LiCLi and cyclopropenyl ring plane is measured at $17.4^{\circ}$ in one monomeric unit and $29.7^{\circ}$ in the second, thanks to the coordination of the amide moiety to the Li centers (scheme 10). ${ }^{27}$

Scheme 10: Attempts and successes in the synthesis of geminal dianions with planar environment at $\mathbf{C}$. 

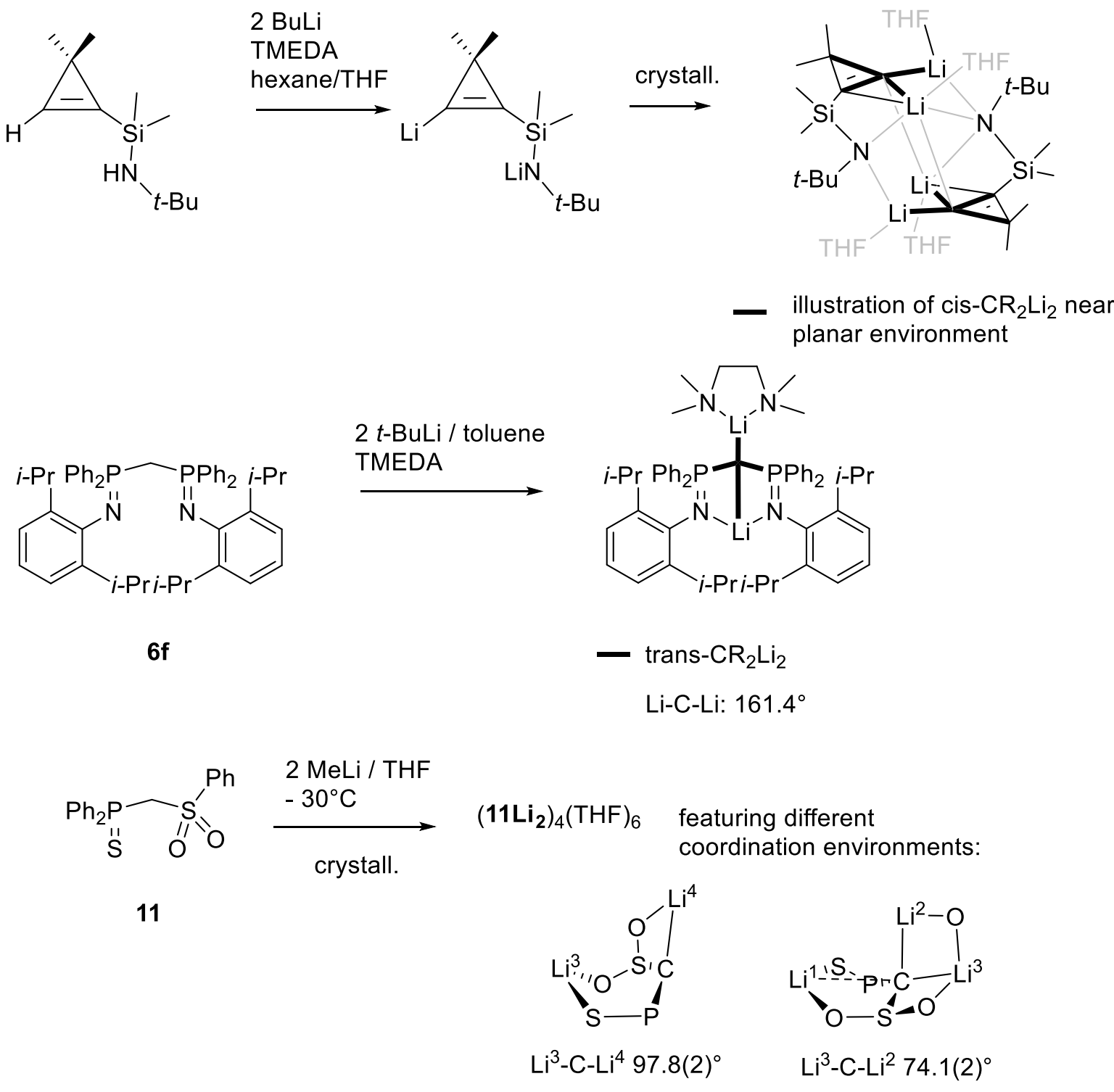

Instead, Liddle and co-workers obtained the first trans-planar tetracoordinate $\mathrm{R}^{1} \mathrm{R}^{2} \mathrm{CLi}_{2}$ monomeric compound $\mathbf{6} \mathbf{f} \mathbf{L} \mathbf{i}_{2}$ upon cristallization. ${ }^{24}$ Notably, double deprotonation was achieved only when TMEDA was used in conjunction to the two equivalents of $t$-BuLi in toluene. The ${ }^{7} \mathrm{Li}$ NMR spectrum exhibited two broad signals at 1.95 and $2.37 \mathrm{ppm}$ suggesting two different environments, confirmed by the $\mathrm{X}$-ray structure. Indeed, one $\mathrm{Li}$ cation is bound to the $\mathrm{C}$ center and the two PN moieties, whereas the second is bound to the $\mathrm{C}$ center and the two $\mathrm{N}$ of the TMEDA. In the solid state the LiCLi angle is 17 
$161.41(12)^{\circ}$, slightly distorted from linearity to allow the close fit of the Li(TMEDA) moiety in the pocket formed by the four $\mathrm{P}-\mathrm{Ph}$ rings. This also accounts for the small displacement of the $\mathrm{C}$ atom from the $\mathrm{Li}_{2} \mathrm{P}_{2}$ plane.

In 2012, Gessner and co-workers probed the effect of thiophosphinoyl/sulfone moieties on the planarity at $\mathrm{C}$ of the corresponding $\mathrm{CLi}_{2}$ species. ${ }^{28}$ The desired dianion $\mathbf{1 1 L \mathbf { i } _ { 2 }}$ was obtained in $73 \%$ yield via the stoichiometric double deprotonation $\left(\mathrm{THF} / \mathrm{Et}_{2} \mathrm{O}\right.$ mixture, $-50^{\circ} \mathrm{C}$ to $\left.\mathrm{rt}\right)$. An unusual X-ray structure was revealed, consisting of four methanediide and six THF molecules without regular Li polyhedron. Two different geometries were found for methanediide carbon atoms. The first exhibits an approximately planar C-P-S-Li unit from which the second Li atom coordinates almost perpendicularly (Li-CP-Li of $\left.97.8(2)^{\circ}\right)$. The second geometry contains three Li atoms. A plane consisting of Li3-C13-P-S-Li1

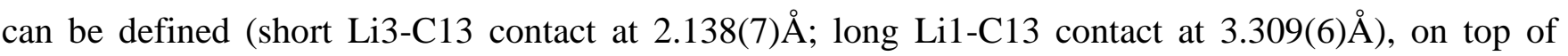
which Li2 is coordinated (Li2-C13 contact 2.332(7) $\mathrm{A}$ ) (see scheme 10 for representation of the two environments). A variable temperature multinuclear NMR study was carried out to probe the nature of the species in solution. In the X-ray structure, four and two different Li and $\mathrm{P}$ environments are seen. However, the ${ }^{31} \mathrm{P}\left\{{ }^{1} \mathrm{H}\right\}$ spectrum only exhibited a single resonance from room temperature to $-80{ }^{\circ} \mathrm{C}$, whereas two sharp singlets appear in the ${ }^{7} \mathrm{Li}$ spectrum below $0^{\circ} \mathrm{C}$. The NMR data indicated either fast exchanges processes even at low temperature within the cluster, or breaking of the aggregate in solution to monomeric species.

Mixed dianionic species containing at least one $\mathrm{PPh}_{2} \mathrm{~S}$ moiety were reported from 2009. Indeed, the first example of unsymmetrical geminal dianion, $\mathbf{1 0 L \mathbf { L } _ { 2 }}$ featuring $\mathrm{P}=\mathrm{S}$ and $\mathrm{P}=\mathrm{N}$ moieties, was developed by So, ${ }^{29}$ followed in 2012 by the $\mathrm{P}=\mathrm{S} / \mathrm{SO}_{2} \mathrm{R}$ derivative $\left(\mathbf{1 1} \mathbf{L i}_{\mathbf{2}}\right)^{28}$ mentioned above and mixed $\mathrm{P}=\mathrm{S}$ and $\mathrm{P}=\mathrm{O}$, (12Li $\mathbf{2}$, in 2012) by Mézailles. ${ }^{30}$ In 2013, So, Mézailles and coworkers studied the possibility 18 
to obtain geminal dianions with derivatives containing one strongly electron witdrawing substituent such as $\mathrm{PPh}_{2} \mathrm{O}$ or $\mathrm{PPh}_{2} \mathrm{~S}$ and a weaker electron withdrawing substituents, such as $\mathrm{SiMe}_{3}$ and $\mathrm{PPh}_{2} \rightarrow \mathrm{BH}_{3}{ }^{31}$ The stepwise deprotonation of $\mathrm{PPh}_{2}(\mathrm{X}) \mathrm{CH}_{2} \mathrm{PPh}_{2} \rightarrow \mathrm{BH}_{3} \quad(\mathrm{X}=\mathrm{O}, \mathbf{1 3}, \mathrm{S}$, 13) and $\mathrm{PPh}_{2}(\mathrm{~S}) \mathrm{CH}_{2} \mathrm{SiMe}_{3}(\mathbf{1 4})$ was thus studied. If the monoanions were all obtained as expected $\left(\mathbf{1 3 L i},{ }^{32,33}\right)$, the second deprotonation step was more problematic as only $\mathbf{1 3 \mathbf { L i }} \mathbf{2}$ could be synthesized efficiently. Indeed, the low temperature deprotonation in toluene with 2 equiv. of BuLi resulted in near quantitative precipitation of the desired compound, which was crystallized from DME. The X-ray structure is highly unusual as it is monomeric, with DME completing the coordination sphere of the Li cations, together with one $\mathrm{H}$ atom of the $\mathrm{BH}_{3}$ moiety. Similar procedure was used for the double deprotonation of $\mathrm{Ph}_{2} \mathrm{P}(\mathrm{O}) \mathrm{CH}_{2} \mathrm{PPh}_{2} \rightarrow \mathrm{BH}_{3}$. After $12 \mathrm{~h}$ at room temperature, a mixture of $\mathbf{1 3}^{\prime} \mathbf{L i}_{2} / \mathbf{1 3}^{\prime} \mathbf{L i}$ (70/30) was observed by ${ }^{31} \mathrm{P}$ NMR and confirmed by deuteration experiment. After one day, in addition to these species several compounds start to appear which again highlights the importance of a fast second deprotonation to avoid side reactions. The attempted double deprotonation of $\mathbf{1 4}$ followed a similar path, i.e. fast formation of $\mathbf{1 4 L i}$ at room temperature and slow formation of a mixture of compounds from which crystals of $\mathbf{1 4 L i _ { 2 }}$ deposited. ${ }^{34}$ Notably, $\mathrm{Me}_{3} \mathrm{SiOLi}$, resulting from the reaction between the base and silicon grease, is incorporated in the structure. However, no yield of isolated product was given in this case.

In 2013 also, Gessner reported the synthesis of the unsymmetrical $\mathrm{Ph}_{2} \mathrm{PS} / \mathrm{Cy}_{2} \mathrm{PS}$ derivative $\mathbf{1 5} \mathbf{L i}_{2}$ in excellent $89 \%$ isolated yield (double deprotonation with 2.0 equiv. of $\mathrm{MeLi}$ in $\mathrm{Et}_{2} \mathrm{O}$ ). ${ }^{35}$ Surprisingly, $\mathbf{1 5}_{\mathbf{L}}$ precipitated from solution whereas the tetraphenyl derivative $\mathbf{8} \mathbf{L} \mathbf{i}_{2}$ is fully soluble in the same conditions. In the crystal structure the phenyl and cyclohexyl moieties are disordered with $50 \%$ occupancy for both positions. Apart from this feature, the central $\mathrm{C}_{2} \mathrm{Li}_{2}$ core adopted the same geometry as in 
$\mathbf{8} \mathbf{L i}_{2}$. Compound $\mathbf{1 5} \mathbf{L i}_{2}$ was developed to probe the influence of electronic modification at the P substituents on the properties of metal complexes.

The use of mixed $\mathrm{PPh}_{2} \mathrm{~S} / \mathrm{SO}_{2} \mathrm{Ph}$ dianion 11Li 2 in "ligand/metal cooperative catalysis" (vide infra) prompted the group of Gessner to synthesize in 2016 the related chiral mixed $\mathrm{PPh}_{2} \mathrm{~S}-\mathrm{S}(\mathrm{O})(\mathrm{NMe}) \mathrm{Ph}$ sulfoximine compound $\mathbf{1 6} \mathbf{L i}_{2}{ }^{36}$ Starting from the $(S)$ and $(R)$-thioanisole, a multistep procedure was followed to get the neutral $(S)$ and $(R)$-16 species. Careful optimization of the conditions of deprotonation was done. In fact, the successful conditions for the synthesis of $\mathbf{1 1 L i} \mathbf{L}_{\mathbf{2}}$ (2 equiv. MeLi or $n$-BuLi in THF) showed only incomplete formation of $\mathbf{1 6} \mathbf{L} \mathbf{i}_{2}$. The use of excess of base did not allow full conversion but favored crystallization of the dianion together with one equivalent of $\mathrm{SiMe}_{3} \mathrm{OLi}$. A more convenient and efficient synthesis relied on the use of stoichiometric amounts of t-BuLi/PMDTA in toluene/hexane mixtures or $\mathrm{t}-\mathrm{BuLi}$ in $\mathrm{THF} / \mathrm{hexane}$. If the former allowed isolation of the highly air and moisture sensitive $(S)-\mathbf{1 6} \mathbf{L i}_{2}(\mathbf{P M D T A})_{2}$ species in 52\% yield, the latter method was preferred for subsequent coordination. The $(S)-\mathbf{1 6} \mathbf{L i}_{\mathbf{2}}(\mathbf{P M D T A})_{\mathbf{2}}$ species is characterized by two signals in the ${ }^{7} \mathrm{Li}$ NMR spectrum (at 0.60 and $1.28 \mathrm{ppm}$ ). Still in 2016, Gessner and co-worker reported the synthesis of the $\mathrm{PPh}_{2}\left(\mathrm{NSiMe}_{3}\right) / \mathrm{SO}_{2} \mathrm{Ph}$ mixed derivative and the efficient isolation of the corresponding dianion $\mathbf{1 7} \mathbf{L i}_{2}$ in $78 \% .^{37}$

The synthesis of heavier analogues of geminal dilithio derivatives has been studied thoroughly by Henderson with the bis iminophosphorane derivative $\mathbf{6 a H}_{2}$. Compound $6 \mathbf{a N a}$ required the use of the very strong base $n$-BuNa and 6aLiNa was obtained via sequential deprotonations with sodium hexamethyldisilazide (NaHMDS) followed by $t$-BuLi. ${ }^{38}$ Interestingly, reversing the order of addition of the base only yielded the 6aHLi derivative, presumably because of the lower basicity of the Na amide. Com- 
pound 6aLiNa can also be synthesized by mixing equimolar amounts of $6 \mathbf{a N a}_{2}$ and $6 \mathbf{6 L i} \mathbf{i}_{2}$ in arene solvent (scheme 11).

Scheme 11: Heavier analogues of $6 \mathrm{aLi}_{2}$ : mixed LiNa derivatives
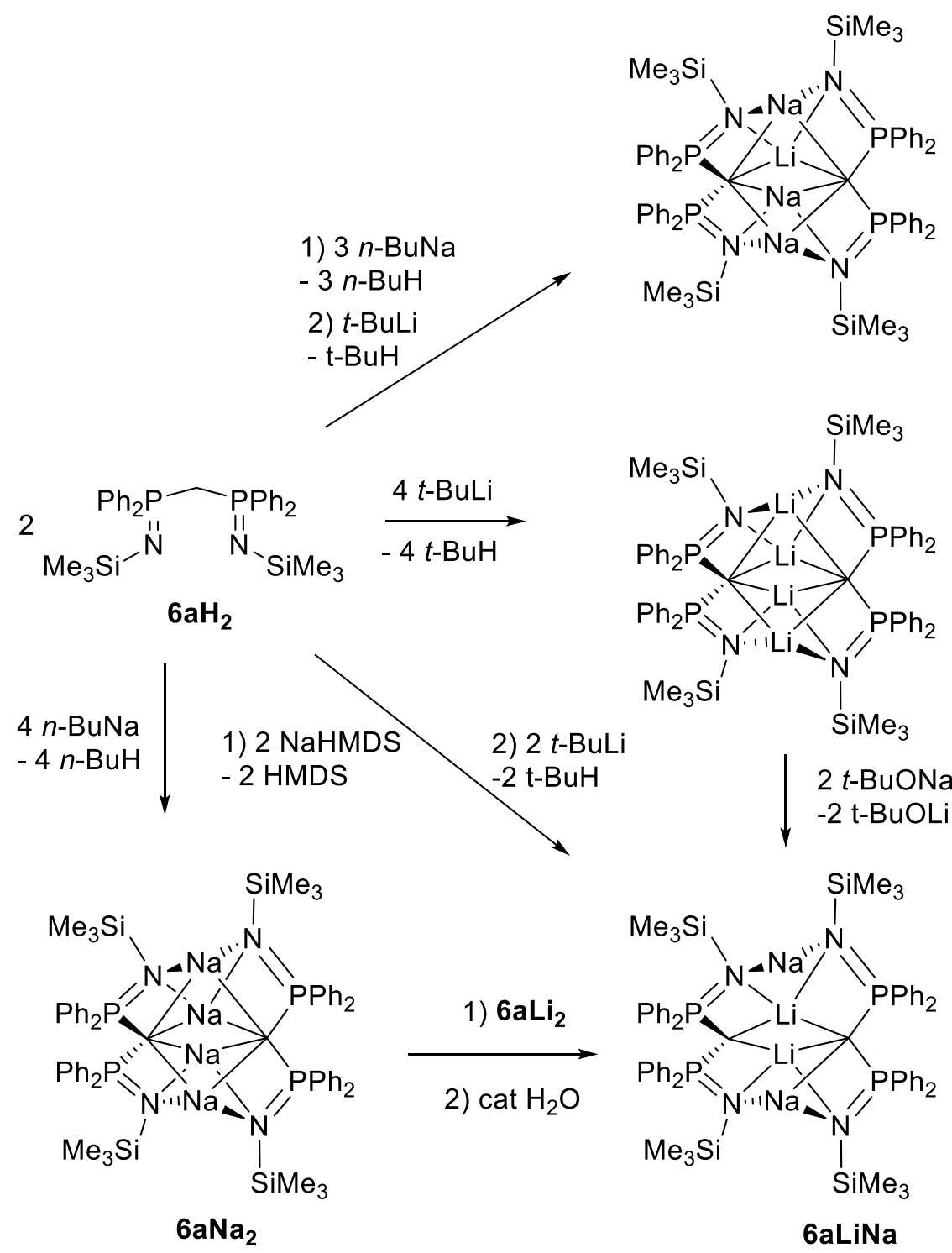

$6 \mathrm{aLi}_{0.5} \mathrm{Na}_{1.5}$

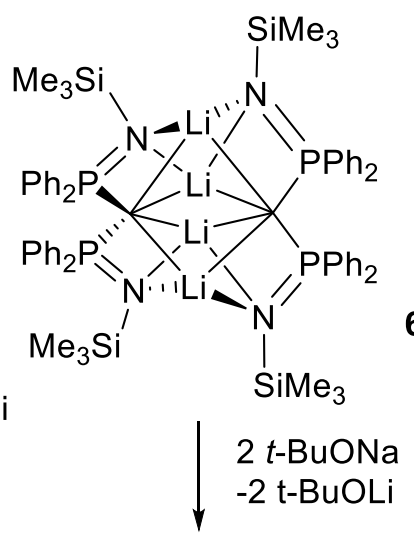

$6 \mathrm{aLi}_{2}$

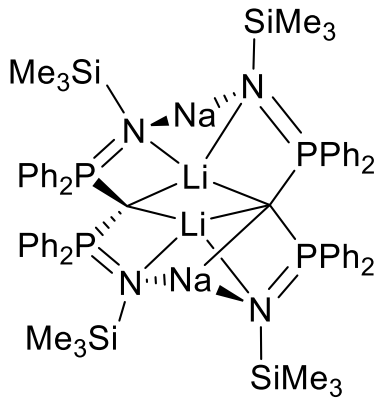

6aLiNa

The syntheses of the $\mathrm{K}$ analogues were then studied following similar strategies, as well as transmetalation using $t$-BuOK, yielding the mixed species $\mathbf{6} \mathbf{a L i K}, \mathbf{6} \mathbf{a N a K}$ and $\mathbf{6} \mathbf{a N a} \mathbf{a}_{\mathbf{3} / \mathbf{2}} \mathbf{K}_{\mathbf{1} / \mathbf{2}}{ }^{39}$ Interest- 
ingly, the crystal structures of the whole family of geminal dianions were obtained. All form dimers of the ligands NPCPN (W-shaped) in staggered conformation, in which the four metals form a plane. In the structures, relatively close contacts between the lighter metals and $\mathrm{C}$ are observed, while the heavier ones are pushed outward to the point that they are hardly bound to the central carbon. The stronger interactions between the inner two metals and the $\mathrm{C}$ centers result in a facile transmetalation of only two of the four metals of the dimers (scheme 12).

\section{Scheme 12: Heavier analogues of $6 \mathrm{aLi}_{2}: \mathrm{C}-\mathrm{M}$ bond distances}

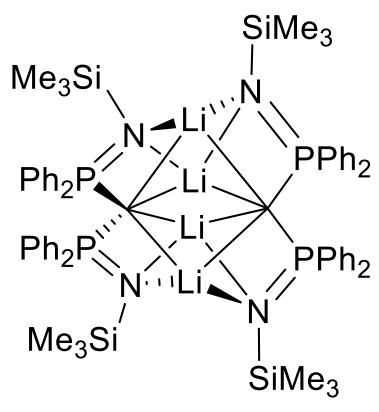

$6 \mathbf{a L i}_{2}$

C-Li: $2.40 \AA$

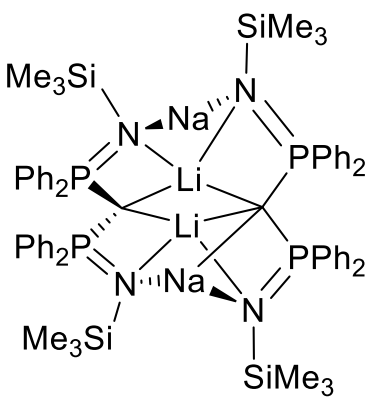

6aLiNa

C-Li: $2.28 \AA$

C-Na: $3.11 \AA$

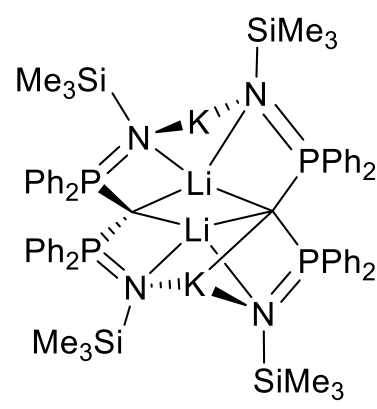

6aLiK

C-Li: $2.25 \AA$

C-NK: $3.44 \AA$

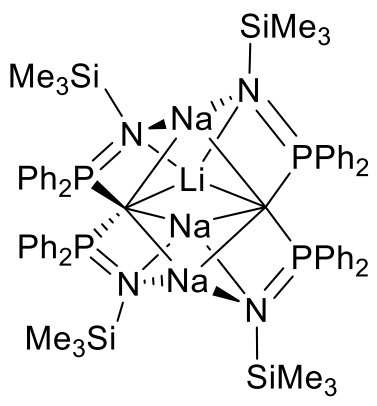

$6 \mathrm{aLi}_{0.5} \mathrm{Na}_{1.5}$

C-Li: $2.27 \AA$

C-Na: $2.59 \AA$

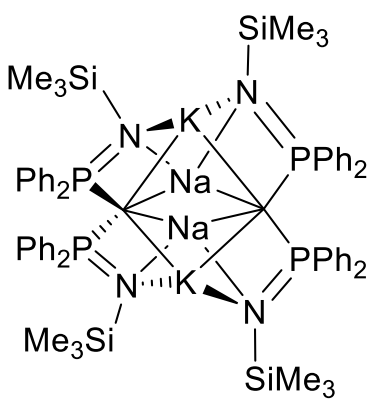

6aNaK

C-Na: $2.54 \AA$

C-K: $3.81 \AA$

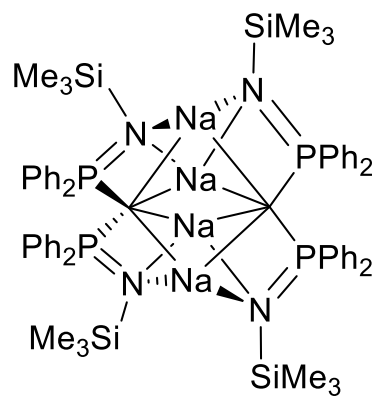

$6 \mathrm{aNa}_{2}$

C-Na: $2.79 \AA$

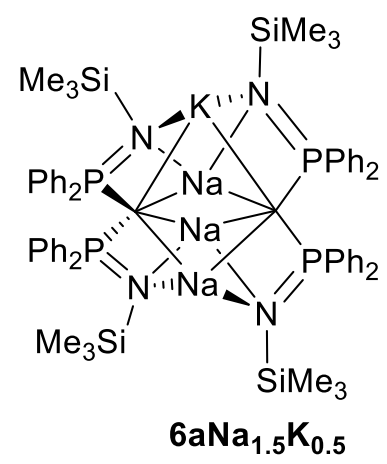

C-Na: $2.48-3.10 \AA$ C-K: $3.69 \AA$ 
A thorough NMR study $\left({ }^{1} \mathrm{H},{ }^{13} \mathrm{C},{ }^{7} \mathrm{Li},{ }^{31} \mathrm{P}\right.$ and $\left.{ }^{29} \mathrm{Si}\right)$ was conducted on these compounds. Together with cryoscopic measurements, they revealed that the dimeric form remained in solution. Previous reports on the dilithio species pointed that the ${ }^{13} \mathrm{C}$ signal for the carbanionic center could not be located, rationalized as a consequence of signal broadening because of Li. In accord, this signal could be located for $6 \mathbf{a N a}_{2}, 6 \mathbf{a L i K}$ and $6 \mathbf{a N a K}$ but not for the $6 \mathbf{a L i}_{2}$ and $6 \mathbf{a L i N a}$. Quite surprisingly, the chemical shifts $(41.0,33.5$ and $38.0 \mathrm{ppm})$ are similar to the one of the neutral ligand (37.8 ppm) and downfield shifted compared to the monometalated compounds 6aHLi, 6aHNa and 6aHK $(22.9,27.5$ and 22.1ppm respectively). The formation of heterometallic complexes via mixing the homometallic ones was conveniently followed by NMR, and showed a slow dynamic exchange (hours to days to reach equilibrium).

Henderson et al. also performed calculations to determine the relative energies of the homo- and heterometallic complexes (see electronic structure). The reactions involving $\mathrm{Li}$ and $\mathrm{Na}$ appeared almost thermoneutral, with the most favorable LiNa derivative being $3.2 \mathrm{kcal} / \mathrm{mol}$ lower than the $\mathrm{Li} 2$ and $\mathrm{Na} 2$ derivatives $\left(\mathrm{Li}_{3 / 2} \mathrm{Na}_{1 / 2}:-1.8 \mathrm{kcal} / \mathrm{mol}, \mathrm{Li}_{1 / 2} \mathrm{Na}_{3 / 2}:-2.4 \mathrm{kcal} / \mathrm{mol}\right)$, in accord with NMR investigations which showed the co-existence of all combinations. Formation of $6 \mathbf{a L i} / \mathbf{K}$ and $\mathbf{6 a N a} / \mathbf{K}$ is predicted more exothermic (-8.9 and $-11.4 \mathrm{kcal} / \mathrm{mol}$ respectively), again confirmed by NMR in which only the heterometallic species is seen. Shortly thereafter, formation of the heavier Rb and Cs analogues was studied by Harder et al.. DFT calculations were used to predict the extent for the exchange of Li in $\mathbf{6 a L i} \mathbf{i}_{2}$ by $\mathbf{M}$ (from M-OR; $\mathrm{M}=\mathrm{Na}, \mathrm{K}, \mathrm{Rb}, \mathrm{Cs}){ }^{40}$ The authors also found that if the first exchange is favorable for any element, the second $\mathrm{Li}$ cation is not readily displaced (almost thermoneutral for $\mathrm{Na}$ ). An alternative strategy, relying on the use of the benzyl-M (M=K, Rb, Cs) had to be developed to synthesize $\mathbf{6}_{\mathbf{2}}$, $\mathbf{6 a R b _ { 2 }}$ and $6 \mathbf{a C s} \mathbf{s}_{2}$. The crystal structures of $\mathbf{6} \mathbf{a K}_{2}$ and $\mathbf{6} \mathbf{a R b _ { 2 }}$ were obtained, and showed a highly symmetric dimeric aggregate, in which the four cations bridge the dianionic ligands. However, the central 
carbon is connected only to two M+ ions. Indeed, the C-K distances are 2.910(3) $\AA$ (bond) and 3.927(5) $\AA$ (no bond), and the C-Rb distances are 3.047(3) $\AA$ (bond) and 4.197(5) $\AA$ (no bond). The dimers are held together by $\mathrm{N}-\mathrm{M}$ interactions $(\mathrm{M}=\mathrm{K}, \mathrm{Rb})$. Unfortunately, the structure of $\mathbf{6 a C s} \mathbf{2}$ was not obtained, but a related dicesiated methandiide species $\mathbf{1 9 C s _ { 2 }}$ was crystallized from the "superbase method": 2 $\mathrm{CsOCMe}_{2} \mathrm{Et}+\mathbf{6} \mathbf{a} \mathbf{L i}_{2} . \mathbf{1 9 C \mathbf { C s } _ { 2 }}$ is a cyclic decomposition product of $\mathbf{6} \mathbf{L i}_{2}$. The authors proposed a mechanism (Scheme 13) involving the desired $\mathbf{6} \mathbf{a C s}_{\mathbf{2}}$ as a first intermediate. Intramolecular orthometalation of one $\mathrm{PPh}_{2}$ group then occurs because of the large size of $\mathrm{Cs}^{+}$, followed by intramolecular nucleophilic attack at the opposite $\mathrm{PPh}_{2} \mathrm{NTMS}$ generating the cyclic structure. Elimination of the basic PhCs leads to final deprotonation of the central $\mathrm{C}$ center.

\section{Scheme 13: Toward Cs analogue of $6 \mathrm{aLi}_{2}$; formation of $19 \mathrm{Cs}_{2}$}

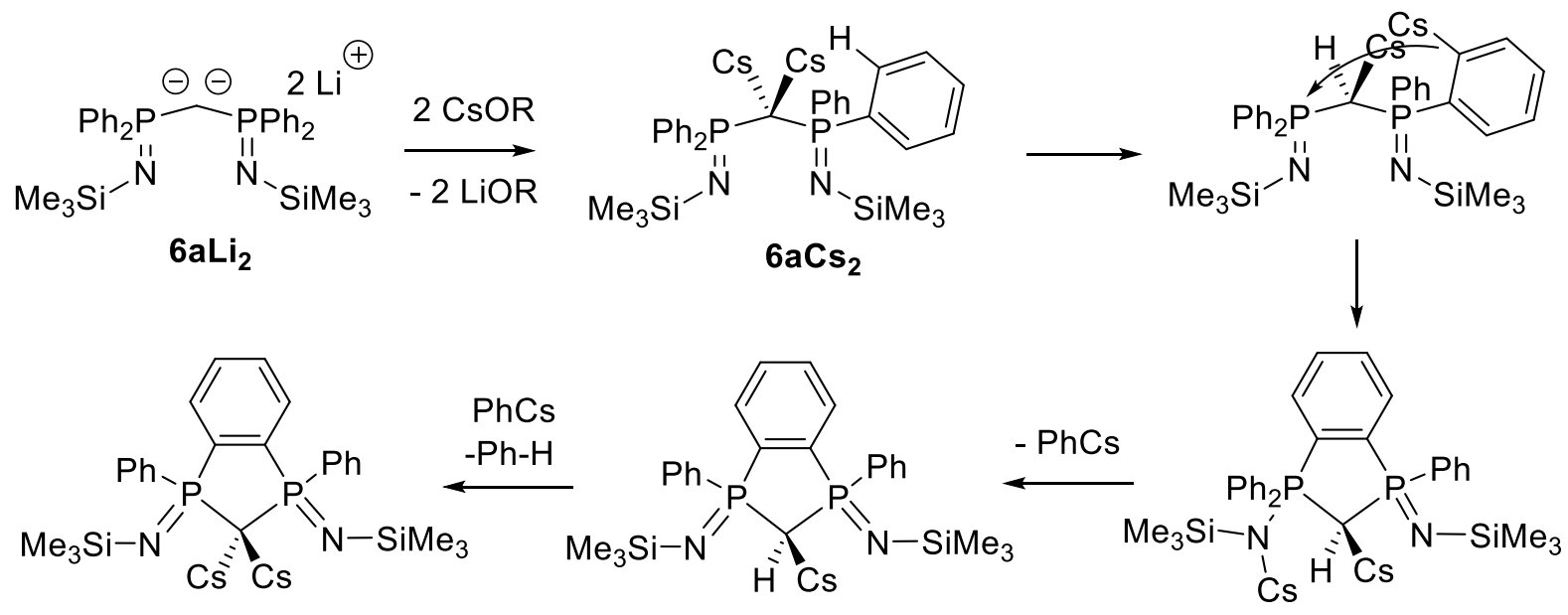
$19 \mathrm{Cs}_{2}$

Such mechanism highlights a possible competitive path to the desired double deprotonation in geminal position. Indeed, the strongly electron withdrawing substituents that are needed to stabilize the final product are prone to nucleophilic attacks (either intramolecular or intermolecular). It thus rational- 
izes the fact that there are only few known geminal dianions. In 2014, the deprotonation at one $\mathrm{Ph}$ ring was evidenced by Stasch and co-worker in a thorough study using derivative $\mathbf{6} \mathbf{f H}_{2}{ }^{41}{ }^{\text {They }}$ probed the effect of base stoichiometry and solvent/additive on the outcome of reaction, and crystallized both the dianionic $\mathbf{6 f L \mathbf { i } _ { 2 }}$ and tri-anionic $\mathbf{1 8} \mathbf{L i}_{3}$ species. Impressively, several crystal structures were obtained for each of the species depending on the nature of the solvent (scheme 14).

\section{Scheme 14: Deprotonation of $\mathbf{6 f H}_{2}$; Solvent effects, formation dianions and trianion}

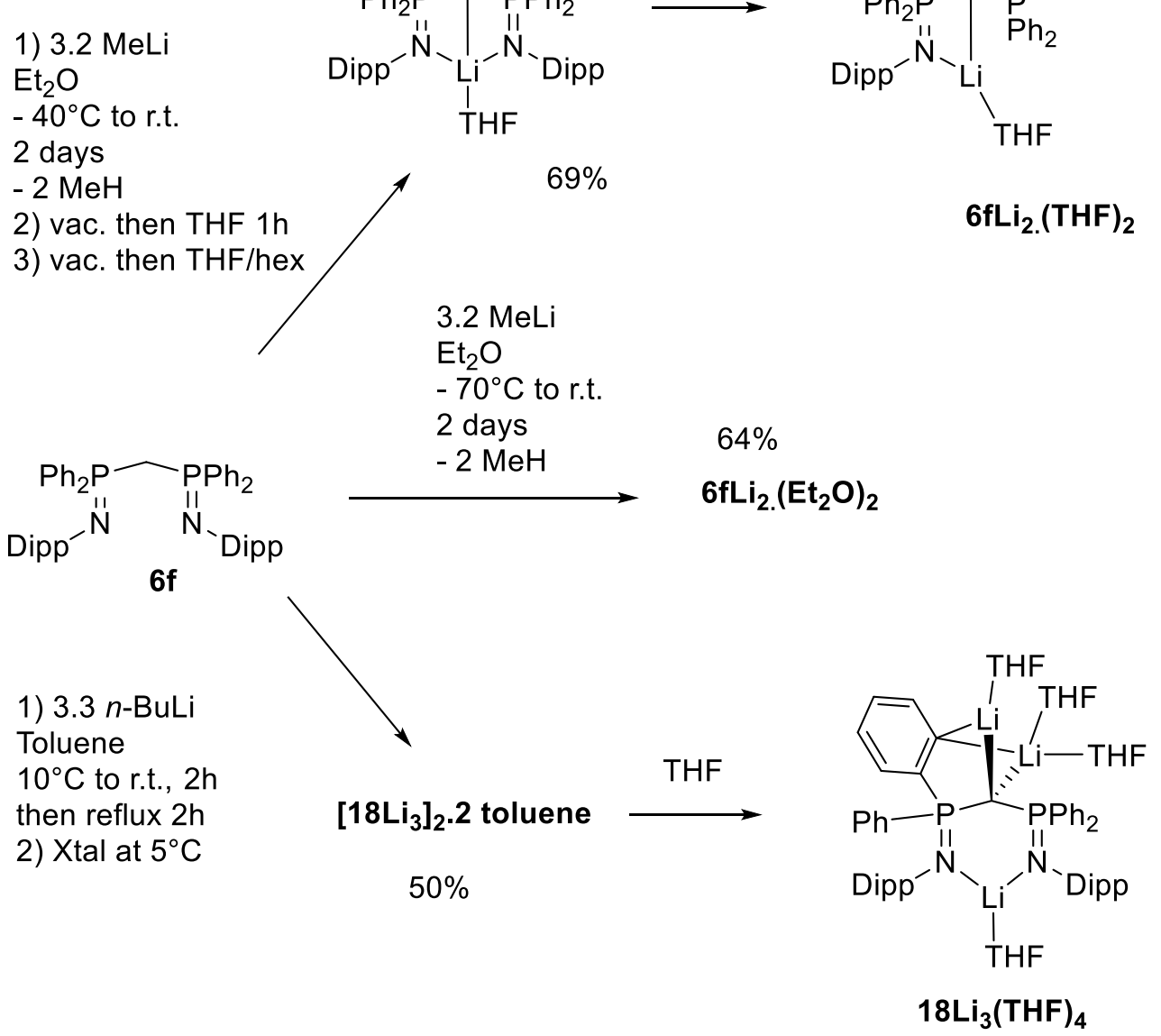


In conclusion, seminal reports dealing with the synthesis of geminal dianions appeared in the 1980s. They proved that formation of the desired species could be in competition with the QUADAC species. They pointed that the geminal dianions would form only if two strongly electron withdrawing substituents are present at the C center. A major achievement was reached in 1999 by Cavell and Stephan, who used $\mathrm{P}(\mathrm{V})$ stabilizing moieties, which allowed the very efficient synthesis of the corresponding dianions under stoichiometric conditions. Not only crystallization in good yields, but also subsequent reactivity without isolation of the highly reactive dianions, was possible. The presence of NMR probes $\left({ }^{31} \mathrm{P},{ }^{7} \mathrm{Li}\right)$ is a great asset for careful optimizations (nature of base, solvent) of the experimental conditions for the "quantitative" synthesis of the desired geminal-dianion, which explains why the vast majority of the known geminal dianions possess at least one $\mathrm{P}(\mathrm{V})$ stabilizing substituent.

\subsection{Electronic structure of the geminal-dianions}

The electronic nature of several of the dianions has been probed by calculations. The results are gathered in the following table (table 1). NBO analysis was carried out mainly with simplified model compounds which allows a comparison of the results (scheme 15). The results pertaining to 6'aLi $\mathbf{i}_{2}$ are difficult to compare to the others since the atomic charges were not calculated with the same method. There is a large charge change between $\mathbf{6}^{\mathbf{9}} \mathbf{a L i}_{\mathbf{2}}$ monomer and dimer. The authors rationalize this observation by an accumulation of the electron density towards the " $\mathrm{Li}_{4}$ " moiety in the dimer, thereby reducing the charges in the ligand backbone. The changes are not so important with the NPA charges given by $\mathrm{NBO}\left(7^{\prime} \mathbf{L} \mathbf{i}_{2}\right.$ monomer $v s$ dimer). Most importantly, the charges at $\mathrm{C}$ are strongly negative (-1.51 in $\mathbf{1 1}^{\prime} \mathbf{L i}_{2}$ to -2.01 in $9^{\prime} \mathbf{L i}_{2}$ ), in accord with the two lone pairs at C. The charges vary to a large extent obviously because of the nature of the neighboring moiety. The charges at $\mathrm{Li}$ are $0.82-0.93$, and the $\mathrm{C}$ - $\mathrm{Li}$ and $\mathrm{X}-\mathrm{Li}(\mathrm{X}=\mathrm{S}, \mathrm{O}$ or $\mathrm{N})$ Wiberg bond indexes lower than 0.1 , indicative of an almost pure electrostatic 26 
interaction between charged ions. The NBO analysis also showed single bonds between P-C and P-X bonds (Wiberg bond indexes of 1.13 to 1.24 for P-C and from 1.01 to 1.16 for P-X and ca 1.0 for S-O and P-B).

Table 1: NBO analysis of geminal-dilithio derivatives. * MKS Merz-Kollman-Singh charges

\begin{tabular}{|c|c|c|c|c|c|c|c|c|c|c|c|}
\hline \multirow{3}{*}{$\begin{array}{l}\text { Compound } \\
\text { (or model of } \\
\text { compound) } \\
\text { 6'aLi }{ }_{2} \\
\text { Monomer* }\end{array}$} & $\mathrm{qC}$ & $\mathrm{qP}$ & $\mathrm{qX}$ & $\mathrm{qLi}$ & & & nP-C & $\mathrm{nP}-\mathrm{X}$ & $\begin{array}{l}\mathrm{nS}-\mathrm{O} \\
\text { or nP-B }\end{array}$ & \multicolumn{2}{|c|}{$\begin{array}{l}\text { Lone pair at } \\
\text { C: hybridiza- } \\
\text { tion }\end{array}$} \\
\hline & \multicolumn{3}{|c|}{ NPA charges } & & \multicolumn{2}{|c|}{ Moiety } & \multicolumn{3}{|c|}{ Wiberg Bond index } & LP1 & LP2 \\
\hline & -1.79 & 1.18 & $\begin{array}{l}\mathrm{qN} \\
-1.09\end{array}$ & 0.82 & & & & & & & \\
\hline $\begin{array}{l}\text { 6'aLi } \\
\text { Dimer* }\end{array}$ & -1.25 & 0.90 & $\begin{array}{l}\mathrm{qN} \\
-0.86\end{array}$ & 0.59 & & & & & & & \\
\hline $\begin{array}{l}\mathbf{7}^{\prime} \mathbf{L i}_{\mathbf{2}} \\
\text { monomer }\end{array}$ & -1.77 & 0.91 & $\begin{array}{l}\mathrm{qS} \\
-0.80\end{array}$ & $\begin{array}{l}0.82 \\
\text { av. }\end{array}$ & & & 1.19 & 1.10 & & $\mathrm{sp}^{2.17}$ & $\mathrm{p}^{1.00}$ \\
\hline $\begin{array}{l}7^{{ }^{\prime} \mathbf{L i}_{2}} \\
\text { dimer }\end{array}$ & -1.88 & 0.88 & $\begin{array}{l}\mathrm{qS} \\
-0.76\end{array}$ & 0.86 & & & 1.13 & 1.16 & & $\mathrm{sp}^{2.11}$ & $\mathrm{p}^{1.00}$ \\
\hline $9^{\prime} \mathbf{L i}_{2}$ & -2.01 & 2.37 & $\begin{array}{l}\mathrm{qO} \\
-1.23\end{array}$ & 0.93 & & & 1.15 & 1.03 & & $\mathrm{sp}^{3.74}$ & $\mathrm{p}^{1.00}$ \\
\hline $6 f \mathrm{Li}_{2}$ & -1.60 & 1.56 & $\begin{array}{l}\mathrm{qN} \\
-1.14\end{array}$ & $\begin{array}{l}0.89 \\
\text { av. }\end{array}$ & & & 1.24 & 1.01 & & $\mathrm{sp}^{3.21}$ & $\mathrm{sp}^{70.3}$ \\
\hline $11^{\prime} \mathbf{L i}_{2}$ & -1.51 & 1.37 & $\begin{array}{l}\mathrm{qS} \\
-0.79\end{array}$ & & $\begin{array}{l}\mathrm{qS} \\
2.05\end{array}$ & $\begin{array}{l}\mathrm{qO} \\
-1.07 \\
\text { av. }\end{array}$ & 1.16 & 1.12 & $\begin{array}{l}\mathrm{n}_{\mathrm{S}-\mathrm{O}} \\
1.03 \\
\text { av. }\end{array}$ & $\mathrm{sp}^{1.99}$ & $\mathrm{sp}^{99.9}$ \\
\hline $13^{\prime} \mathbf{L i}_{2}$ & -1.76 & 1.41 & $\begin{array}{l}\mathrm{qS} \\
-0.8\end{array}$ & $\begin{array}{l}0.87 \\
\text { av. }\end{array}$ & $\begin{array}{l}\mathrm{qP} \\
1.35\end{array}$ & $\begin{array}{l}\text { qB } \\
-0.7\end{array}$ & $\begin{array}{l}1.21 \\
\text { av. }\end{array}$ & 1.12 & $\begin{array}{l}\mathrm{N}_{\mathrm{P}-\mathrm{B}} \\
0.96\end{array}$ & $\mathrm{sp}^{2.75}$ & $\mathrm{p}^{1.00}$ \\
\hline
\end{tabular}




\begin{tabular}{|c|c|c|c|c|c|c|c|c|c|}
\hline $15 \mathrm{Li}_{2}$ & -1.69 & $\begin{array}{l}\mathrm{qP}_{\mathrm{Ph}} \\
1.42\end{array}$ & $\begin{array}{l}\mathrm{qS} \\
-0.79\end{array}$ & $\begin{array}{l}0.84 \\
\text { av. }\end{array}$ & $\begin{array}{l}\mathrm{qP}_{\mathrm{Cy}} \\
1.42\end{array}$ & $\begin{array}{l}\mathrm{qS} \\
-0.82\end{array}$ & $\begin{array}{l}1.24 \\
\text { av. }\end{array}$ & $\begin{array}{l}\mathrm{P}_{\mathrm{Ph}} \mathrm{S} 1 \\
.05\end{array}$ & $\begin{array}{c}\mathrm{n}_{\text {P-S PCy }} \\
1.06\end{array}$ \\
\hline
\end{tabular}

Scheme 15: Models of dianions used in calculations

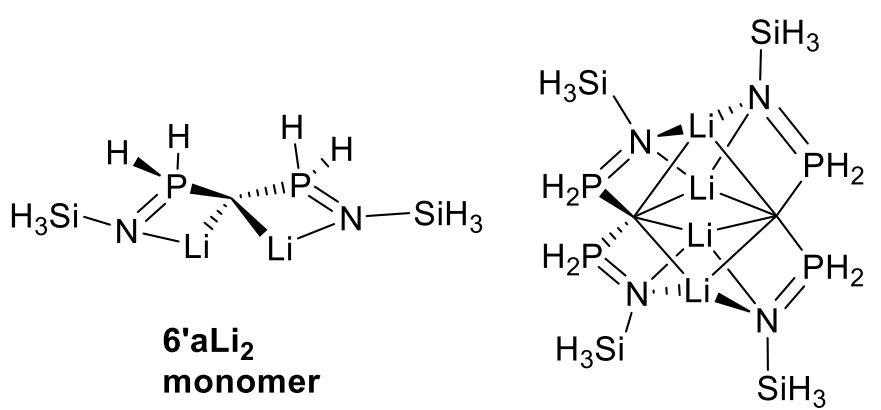

${ }^{6} \mathbf{a L i}_{2}$ dimer<smiles>COP(=O)(OC)C([Al]Cl)P(=O)(OC)OC</smiles>

$9^{\prime} \mathrm{Li}_{2}$

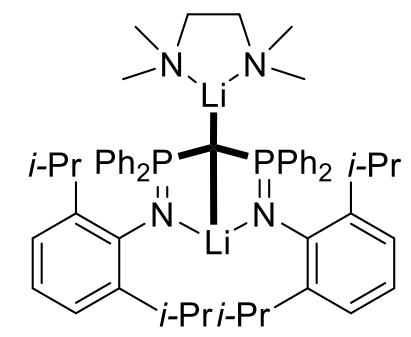

$6 \mathrm{fLi}_{2}$<smiles>[PH2+]1S[Te]=[SH]1</smiles>

$7^{\prime} \mathrm{aLi}_{2}$ monomer<smiles>CO[Al]1O[Si](OC)(c2ccccc2)C([PH](OC)(c2ccccc2)c2ccccc2)[SH](=O)(c2ccccc2)O1</smiles>

$11^{\prime} \mathrm{Li}_{2}$

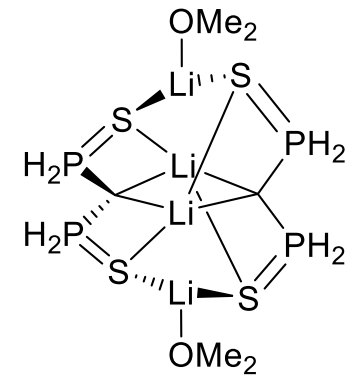

$7^{\prime} \mathrm{aLi}_{2}$ dimer<smiles>[B][PH](OC)(c1ccccc1)C(P(c1ccccc1)c1ccccc1)([Al](OC)(OC)OC)P(=S)(c1ccccc1)c1ccccc1</smiles>

$13{ }^{\prime} \mathrm{Li}_{2}$

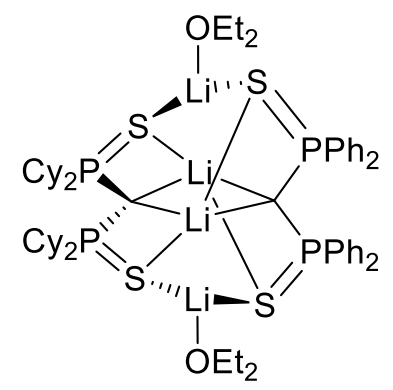

$15 \mathrm{Li}_{2}$

The Kohn-Sham orbitals describing the two lone pairs at $\mathrm{C}$ provided further information. In each case the HOMO described an almost pure p lone pair at C (LP2 in table 1), whereas the second lone pair (LP1), a $\mathrm{sp}^{\mathrm{n}}$ hybrid was lower in energy, as expected. Overall, these data pointed to a Lewis structure 
which involves two lone pairs at $\mathrm{C}$ strongly stabilized by the low lying empty orbitals at the neighboring hypervalent atom $(\mathrm{P}$ or $\mathrm{S})$, i.e. $\sigma^{*}$ orbitals. In the case of $\mathrm{R}_{2} \mathrm{PX}$ moieties, these orbitals are respectively $\sigma^{*}(\mathrm{P}-\mathrm{R})$ and $\sigma^{*}(\mathrm{P}-\mathrm{X})$, and in the case of $\mathrm{SO}_{2} \mathrm{R}$ the $\sigma^{*}(\mathrm{~S}-\mathrm{O})$ and $\sigma^{*}(\mathrm{~S}-\mathrm{R})$. The best Lewis representation of the geminal-dilithio derivatives was thus proposed to involve charged atoms (scheme 16).

\section{Scheme 16: Stabilization of the two lone pairs and "best Lewis representation" of type I} geminal dianions

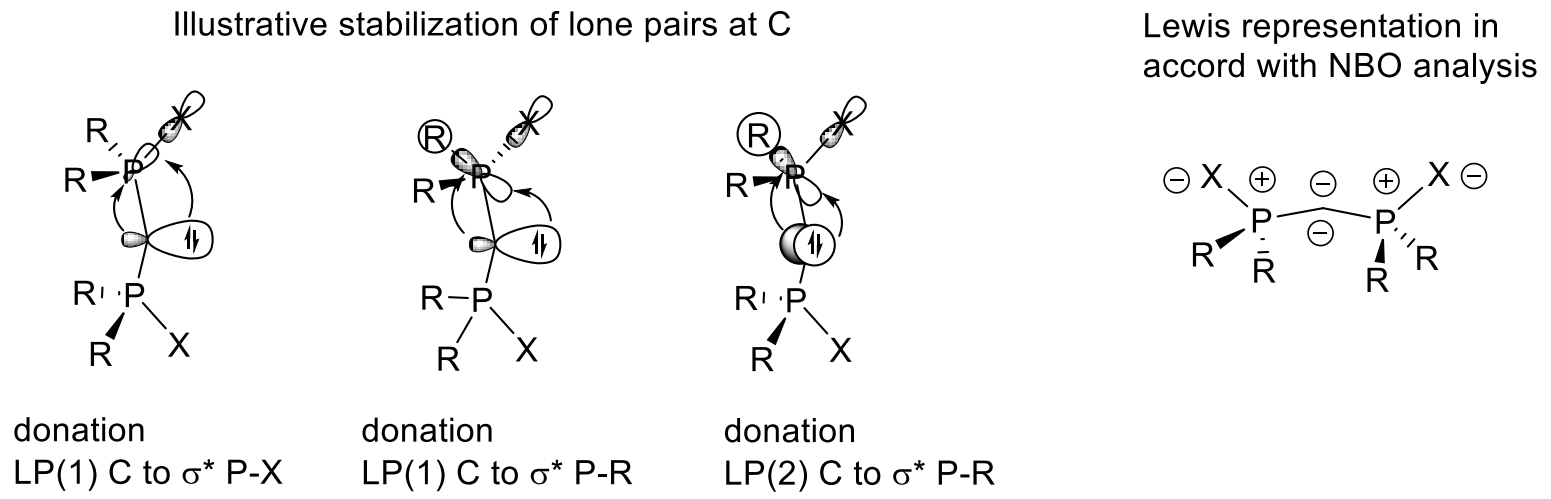

\subsection{Reactivity of geminal-dilithio derivatives}

The vast majority of group 1 geminal dianions have been obtained with $\mathrm{Li}$, and only their reactivity in organic chemistry has been studied. In this section, these developments are presented. In fact, the existence of the two lone pairs at $\mathrm{C}$ was initially probed by the reaction with alkylating agents and proton sources. The formation of two new C-R bonds and $\mathrm{C}-\mathrm{H}$ bonds was taken as a proof of efficient double deprotonation until the same reactivity was observed with QUADAC systems. These two reactions are nonetheless very efficient with geminal dilithio derivatives because of the high charge at the $\mathrm{C}$ center. Reactivity with $\mathrm{C}=\mathrm{O}$ electrophiles was also tested with the aim of synthesizing the corresponding alkene derivative. Unlike what is observed with the metal-carbene complexes generated from the 
dilithio derivatives (vide infra), reaction of the geminal dianions with benzophenone does not occur, likely because the concomitant formation of $\mathrm{Li}_{2} \mathrm{O}$ is not a strong enough driving force. Reactivity toward the stronger electrophile $\mathrm{CS}_{2}$ was observed with both $\mathbf{8} \mathbf{L} \mathbf{i}_{\mathbf{2}}$ and $\mathbf{9} \mathbf{L} \mathbf{i}_{2}$. The kinetics were however drastically different. Indeed, if the reaction occurs within $12 \mathrm{~h}$ at room temperature between $\mathbf{8} \mathbf{L} \mathbf{i}_{\mathbf{2}}$ and a stoichiometric amount of $\mathrm{CS}_{2}$, it required 10 equiv. of $\mathrm{CS}_{2}$ and 10 days under reflux in toluene to react with $\mathbf{9} \mathbf{L} \mathbf{i}_{2}$. The corresponding dianionic alkenes $\left(\mathbf{1 9} \mathbf{L i}_{\mathbf{2}}\right.$ and $\left.\mathbf{2 0} \mathbf{L} \mathbf{i}_{\mathbf{2}}\right)$ were formed in excellent yields $(95$ and $87 \%$ resp.) and subsequently trapped to form electron rich alkenes $\mathbf{2 1}$ and 22 quantitatively (scheme $17) .^{21}$

\section{Scheme 17: Reativity of $8 \mathrm{Li}_{2}$ and $9 \mathrm{Li}_{2}$ with $\mathrm{CS}_{2}$}

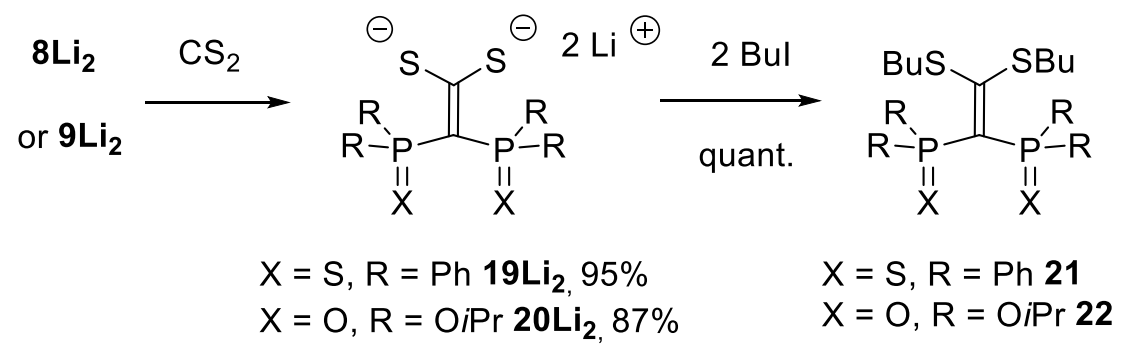

Being intrinsically electron rich, the geminal dianions were envisaged initially by Le Floch and coworkers to be precursors of stable carbene species (scheme 18). In fact, oxidation with $\mathrm{C}_{2} \mathrm{Cl}_{6}$ of $\mathbf{8} \mathbf{L} \mathbf{i}_{2}$ resulted in the formation of the first room temperature stable carbenoid derivative $23{ }^{42}$ In 2008 , oxidation of the same dianion by iodine was performed by Chivers et al., who observed the formation of two compounds in 3:1 ratio: a dimer of the iodo-carbenoid $\mathbf{2 4}$ as well as product $\mathbf{2 5}$ that results from the decomposition of the transient carbene compound. ${ }^{43}$ With these studies, it became apparent that a) the stability of the carbenoid species $\mathbf{2 3}$ and $\mathbf{2 4}$ relied on the separation of LiX; and b) the initially desired carbene species is too electrophilic to be stable and abstracts an $\mathrm{S}$ atom from $\mathrm{PPh}_{2} \mathrm{~S}$ moiety. 


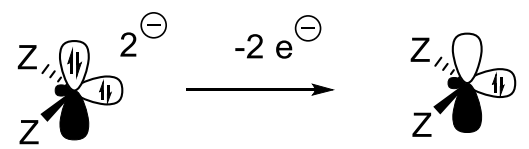

gem dianion carbene

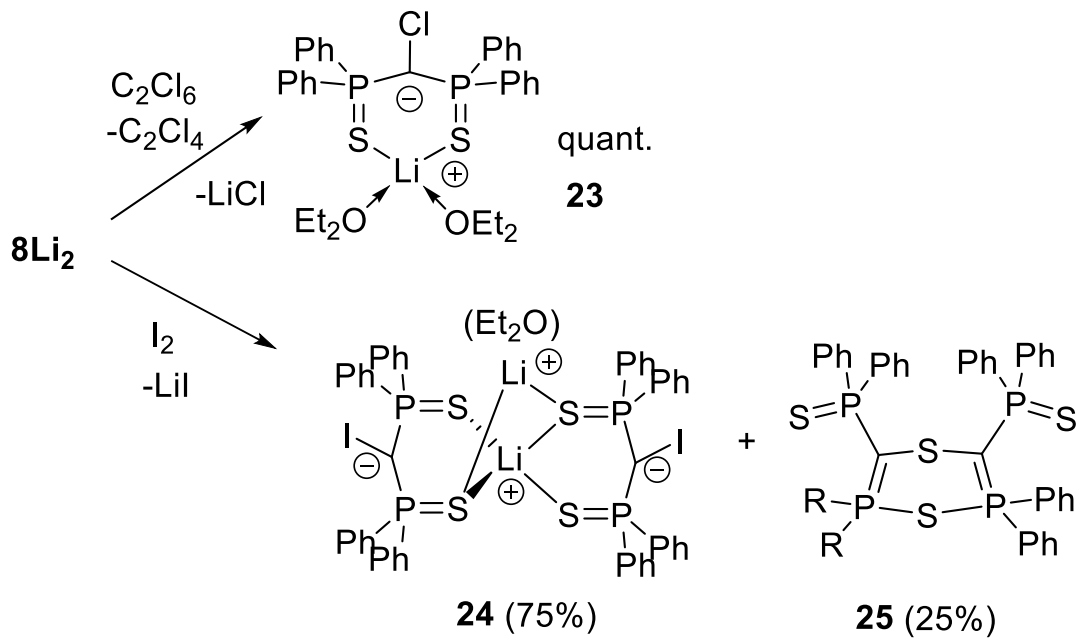

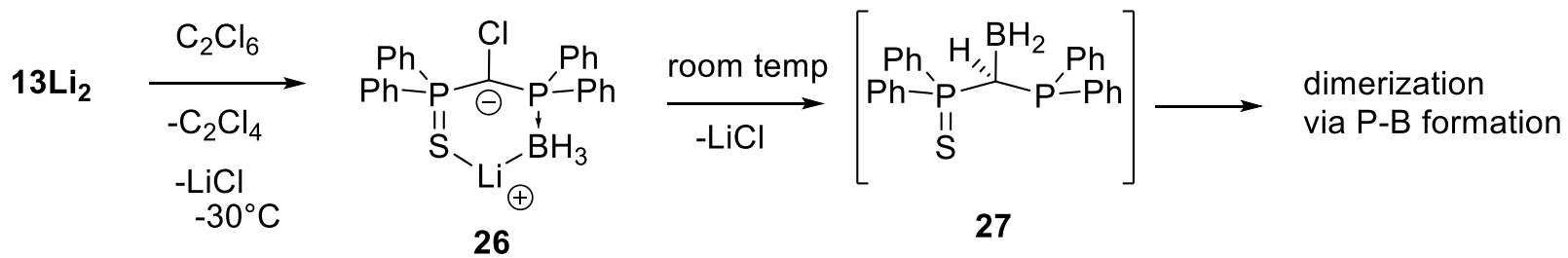

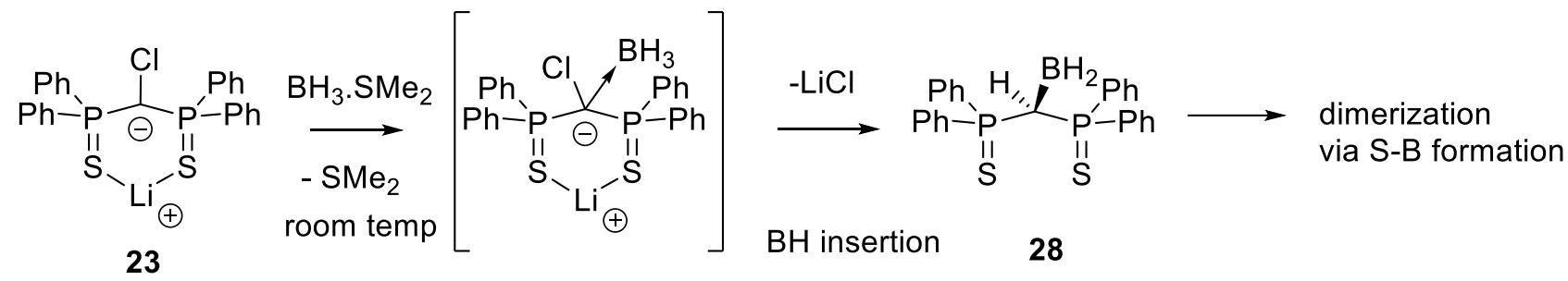

In a following study, in 2013, Mézailles and coworkers attempted the stabilization of a carbenoid starting from dianion $13 \mathbf{L i}_{2}$ featuring $\mathrm{PPh}_{2} \mathrm{~S} \mathrm{PPh}_{2} \mathrm{BH}_{3}$ substituents. The latter substituent did not prove as efficient as $\mathrm{PPh}_{2} \mathrm{~S}$ to coordinate the $\mathrm{Li}^{+}$, and the carbenoid 26 was only stable below $-30^{\circ} \mathrm{C}$ and above, a clean insertion into a $\mathrm{BH}$ bond of $\mathrm{BH}_{3}$ was observed, in line with the strong electrophilic character of 
the carbene, leading to compound 27 which then dimerized. Similar reactivity was seen with carbenoid 23, and the mechanism probed by DFT calculations. The first step involves the nucleophilic character of the carbenoid, which leads to $\mathrm{BH}_{3}$ coordination at the $\mathrm{C}$ center. This coordination results in pyramidalization at $\mathrm{C}$, favoring $\mathrm{LiCl}$ elimination simultaneous to insertion of the electrophilic moiety into the $\mathrm{BH}$ bond to form compound $\mathbf{2 8}$ (which also dimerized). ${ }^{44}$ Carbenoid $\mathbf{2 3}$ was also envisaged as a "carbene transfer agent" to transition metals (vide infra). ${ }^{42}$ It is to be noted here that a related electrophilic carbenoid, although not obtained from the corresponding dianion but rather via a sequence "deprotonation$\mathrm{C}_{2} \mathrm{Cl}_{6}$ oxidation-deprotonation", was shown to react with $\mathrm{BH}_{3}$ to form a lithium borate compound. ${ }^{45}$

In 2014, Gessner and coworkers reported the similar oxidation of the thiophosphinoyl/sulfone derivative 11Li 2 (scheme 19). ${ }^{46}$ In this case, the carbenoid 29 is also stable at room temperature. It features a central structural motif $(\mathrm{S}-\mathrm{O}-\mathrm{Li}-\mathrm{O})_{2}$ eight membered ring which connects two carbenoid molecules. In this case, the Li atoms are only bound to the $\mathrm{O}$ centers. The same compound can be obtained via the "deprotonation-oxidation with $\mathrm{C}_{2} \mathrm{Cl}_{6}$-deprotonation" sequence mentioned above, giving the possibility to obtain carbenoid compounds for which the corresponding geminal dianion are not stable. ${ }^{47}$

The formation of related carbenoids from several stable dianions of bis-iminophosphoranes was attempted. With the bulky alkyl adamantyl group, the carbenoid is not stable. ${ }^{46}$ A formal nitrene transfer occurs to generate the imine derivative 30 from $\mathbf{6 g L i} \mathbf{L i}_{2}$ likely via the generation of the unstable carbene species. In the case of p-tolyl derivative $\mathbf{6} \mathbf{h} \mathbf{L i} \mathbf{2}$, oxidation leads to the expected carbenoid $\mathbf{3 1}$ which is stable in the solid state. The compound however evolves over days in solution to a mixture of compounds. Finally, with the more bulky Mes substituent, the carbenoid 32 becomes stable in solution (scheme 19). 


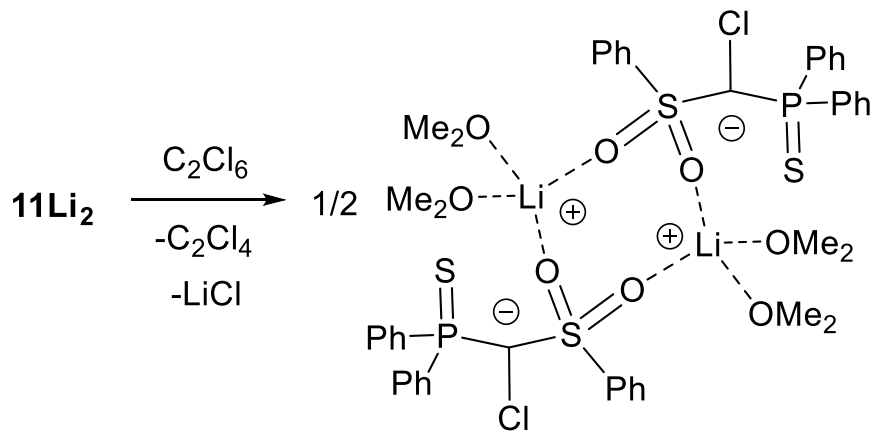

$2982 \%$

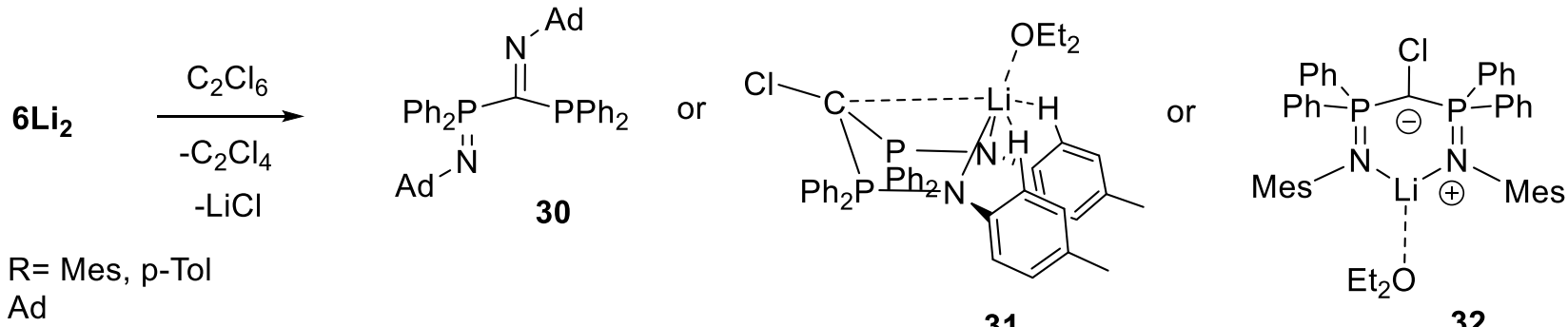

Finally, in 2010, Chivers and coworkers reported the oxidation of $\mathbf{8} \mathrm{Li}_{2}$ by sulfur and selenium (scheme 20). ${ }^{48}$ It lead to the formation of novel dianionic species $\mathbf{3 3}$ and $\mathbf{3 4}$ in excellent isolated yields which have been used subsequently as tridentate "SSS"-" and "SSeS"-» ligands.

Scheme 20: Oxidation of type I geminal dianions $8 \mathrm{Li}_{2}$ with $\mathrm{S}$ or $\mathrm{Se}$

$$
\begin{aligned}
\mathbf{8} \mathrm{Li}_{2} \underset{2 \mathrm{TMEDA}}{\mathrm{E}=\mathrm{S} \text { or Se }} \underset{\mathrm{E}}{\longrightarrow}=\mathrm{S}, \mathbf{3 3}, \mathbf{8 6 \%} \\
\mathrm{E}=\mathrm{Se}, \mathbf{3 4}, \mathbf{9 1 \%}
\end{aligned}
$$




\subsection{Coordination of Type II geminal dianions}

The most developed use of "type I" geminal dianions concerns their coordination chemistry. In fact, these ligands are formally related to ligands found in Schrock type carbene complexes (scheme 21). Indeed, in such complexes, the carbene ligand, also termed alkylidene because the $\mathrm{C}$ center is only substituted by $\mathrm{H}$ or alkyl moieties, is a formal $\mathrm{X}_{2}$ type ligand, i.e. a dianionic $\mathrm{CR}_{2}{ }^{2-}$ ligand. The early works dealing with coordination chemistry of geminal dilitho derivatives were thus dedicated to the synthesis of carbene complexes. The following part will be organized by the group to which belongs the metal center.

\section{Scheme 21: Strategies to Schrock type carbene complexes}

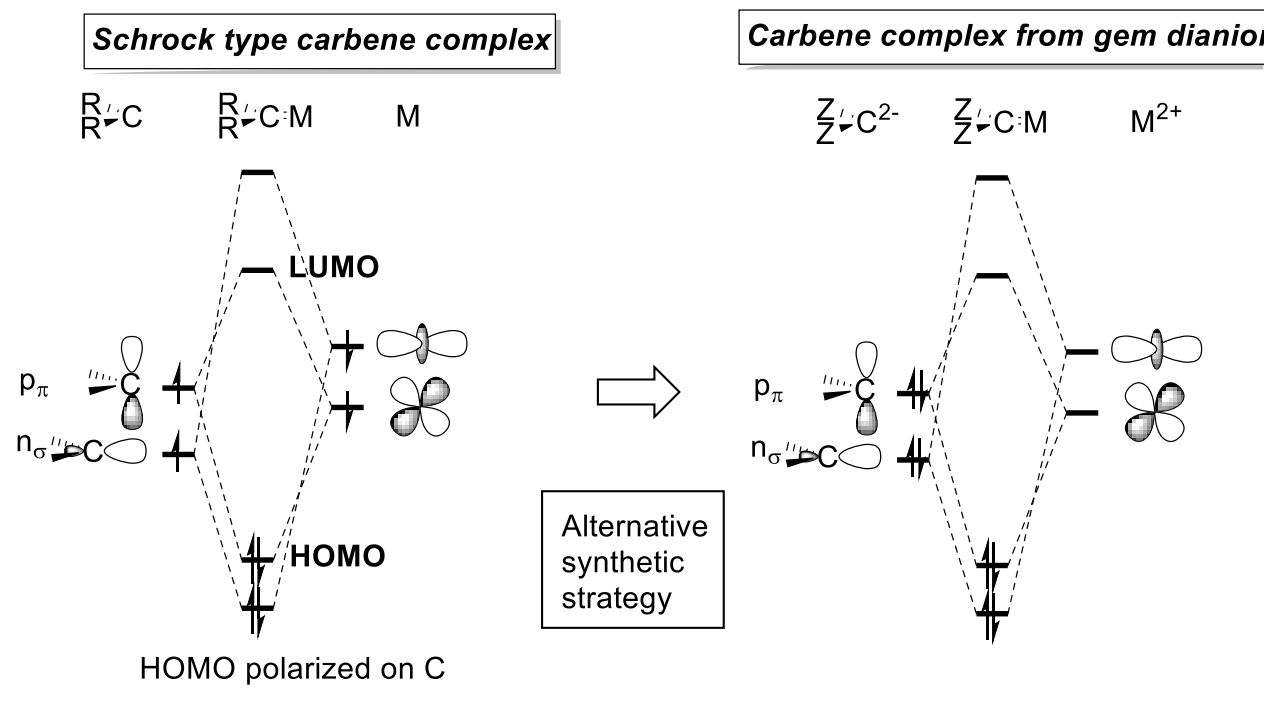

\subsubsection{Group 2: Alkaline-earth metal dianions}

In transition metal carbene complexes, Schrock type (nucleophilic) and Fischer type (electrophilic), a metal-carbon double bond is implied, which requires overlap between d orbitals at the metal 
and orbitals at the carbene fragment. When the energies of valence orbitals at the metal become very high (i.e. for highly electropositive metals), which is the case for group 2 metal centers, orbital overlap is bound to be weak. Two questions were thus addressed using group 2 metal centers: a) can the "carbene complex" be made, i.e. are they stable?; and b) what would be the nature of the metal-carbon interaction, i.e. can they still be named "carbene complexes"?

\subsubsection{Synthesis}

Synthesis of a complex featuring an alkaline-earth (AE) metal/carbon formal double bond is no trivial matter since " $\mathrm{AE}=\mathrm{CH}_{2}$ " species are likely polymeric. The first synthesis of such a molecular complex was reported by Harder and coworkers in $2006 .{ }^{49}$ Very few examples have been reported since then. All of them feature a $\mathrm{C}$ center stabilized by two hypervalent $\mathrm{P}$ centers. Although all but one of the corresponding geminal dilithio derivatives are stable $\left(\mathbf{6} \mathbf{a} \mathbf{L} \mathbf{i}_{\mathbf{2}}, \mathbf{6} \mathbf{\mathbf { L }} \mathbf{i} \mathbf{2}, \mathbf{8} \mathbf{L} \mathbf{i}_{\mathbf{2}}, \mathbf{1 0 L \mathbf { i } _ { 2 } )}\right.$ the synthetic strategy did not rely on the salt metathesis route "Li to group 2 metal". A route that relied on the deprotonation of the neutral ligand in the coordination sphere of the metal was preferred.

\section{Scheme 22: Group 2 complexes}




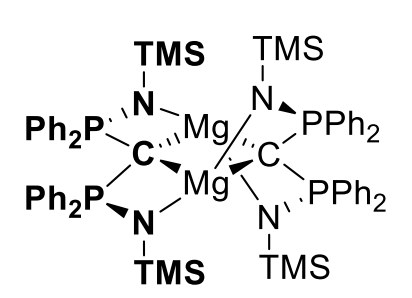

$[(6 \mathbf{a}) \mathrm{Mg}]_{2}$

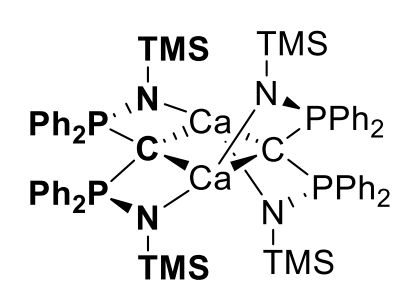

$[(\mathbf{6 a}) \mathrm{Ca}]_{2}$

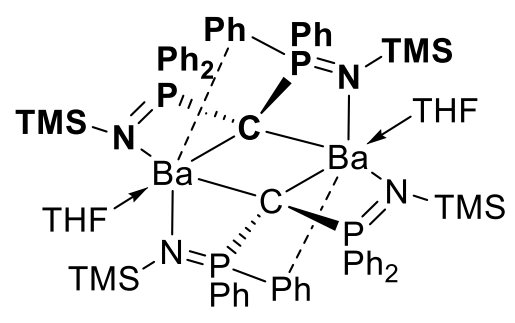

$[(\mathbf{6 a}) \mathrm{Ba}(\mathrm{THF})]_{2}$

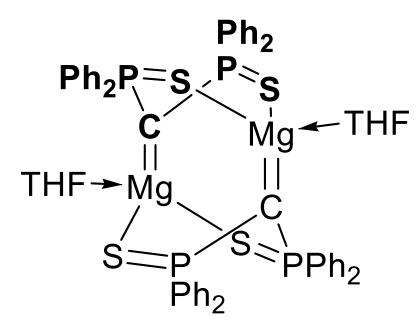

$[(7) \mathrm{Mg}(\mathrm{THF})]_{2}$

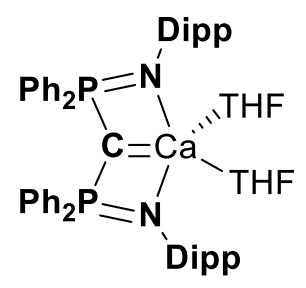

$\left[(\mathbf{6 f}) \mathrm{Ca}(\mathrm{THF})_{2}\right]$

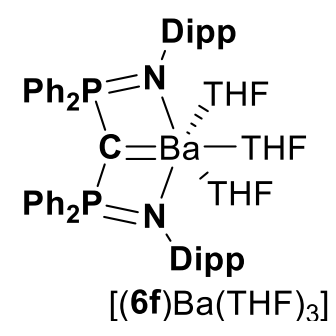

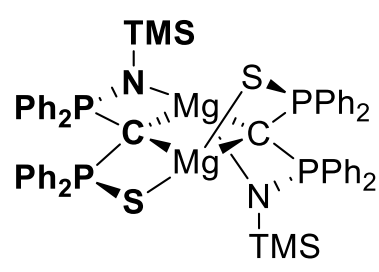

$[(10) \mathrm{Mg}]_{2}$

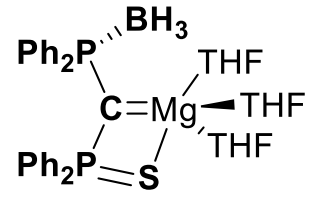

$\left[(14) \mathrm{Mg}(\mathrm{THF})_{3}\right]$

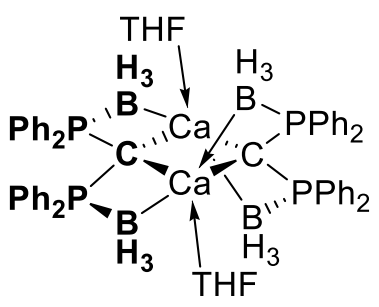

35

It resulted in the successful isolation of a few complexes of magnesium, ${ }^{31},{ }^{50},{ }^{51}$ calcium ${ }^{49}, 52,53$ and even barium, ${ }^{54}$ but to date no example of related complexes of strontium or beryllium are known (scheme 22). In the first report, Harder et al. showed that the use of $\left[\mathrm{Ca}\left(\mathrm{N}(\mathrm{TMS})_{2}\right)_{2}\right]$ did not allow a double deprotonation of $\mathbf{6 H}_{2}$, but stopped at the mono-deprotonated stage. The more basic p-tertbutylbenzyl ligand was required for a successful two-fold deprotonation to yield $[(\mathbf{6 a}) \mathrm{Ca}]_{2}$, in excellent $84 \%$. ${ }^{49}$ The same precursor was subsequently used to obtain complex 35 in more than $95 \%$ yield featuring the dianionic bis-(phosphinoboranyl)methanediide ligand for which the geminal-dilithio derivative is unknown. $^{52}$

Scheme 23: Group 2 complexes, monomer vs dimer formation 


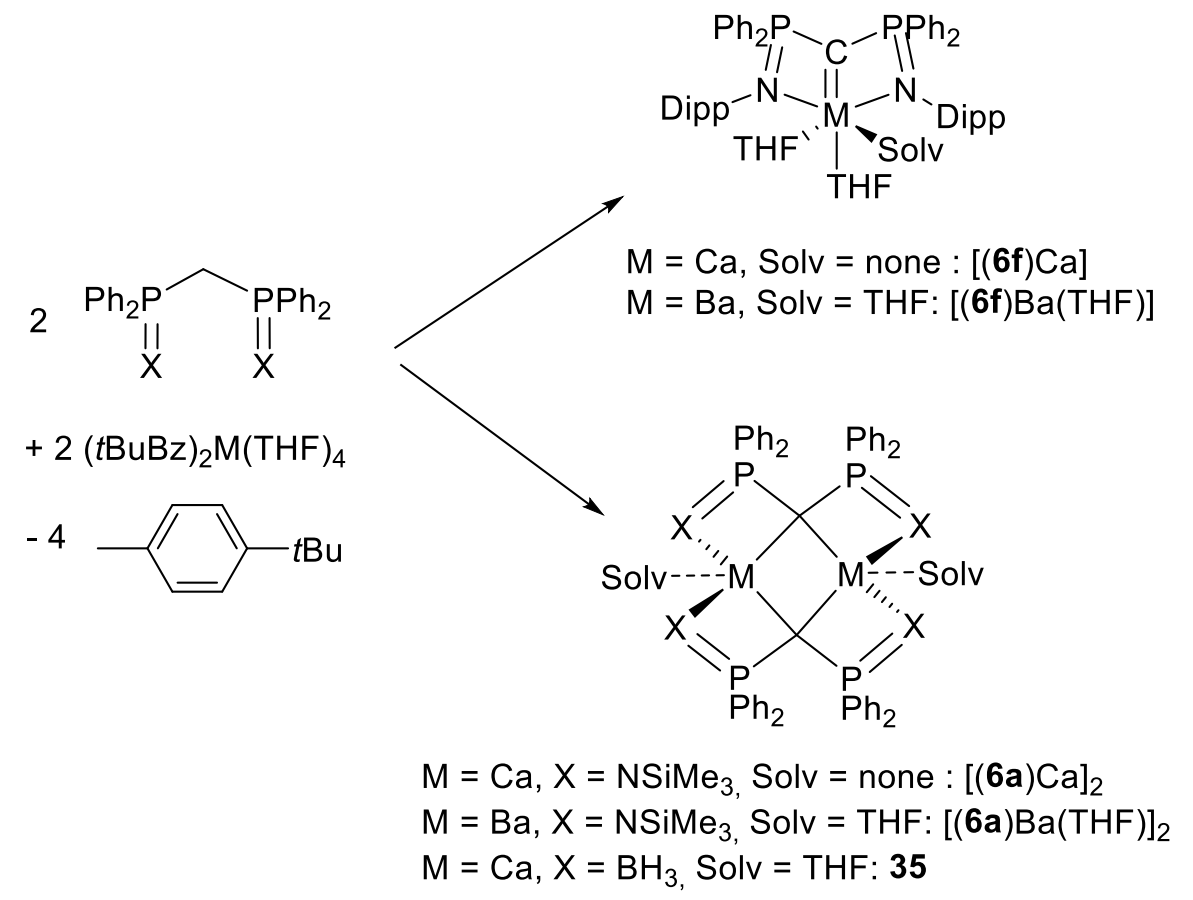

Interestingly, the complexes $[(\mathbf{6 a}) \mathrm{Ca}]_{2}[(\mathbf{6 a}) \mathrm{Ba}(\mathrm{THF})]_{2}$ and $\mathbf{3 5}$ are obtained as dimeric structures with two dianionic carbon bridging two different metallic centers, because of a poor steric hindrance of NTMS and $\mathrm{BH}_{3}$ moieties. In the case of the larger Ba center, an addition molecule of solvent is coordinated to the metal center. $\mathrm{Ph}^{\cdots \cdots} \mathrm{Ba}$ interactions are moreover observed. With an aim at obtaining monomeric $\mathrm{Ca}$ and $\mathrm{Ba}$ complexes, and therefore potentially favor $\sigma+\pi$ interaction rather than two $\sigma$ interactions, the same authors used the much more bulky substituent 2,6-diisopropylphenyl at N. As expected, the monomeric complexes $[(\mathbf{6 f}) \mathrm{Ca}]$ and $[(\mathbf{6 f}) \mathrm{Ba}(\mathrm{THF})]$ were obtained, again in excellent isolated yields ( ca $90 \%)$. NMR studies showed that the dimeric forms $[(\mathbf{6 a}) \mathrm{Ca}]_{2}$ and $[(\mathbf{6 a}) \mathrm{Ba}(\mathrm{THF})]_{2}$ are in equilibrium with monomeric forms $[(\mathbf{6 a}) \mathrm{Ca}]$ and $[(\mathbf{6 a}) \mathrm{Ba}]$ in coordinating solvents.

\section{Scheme 24: Mg complexes}




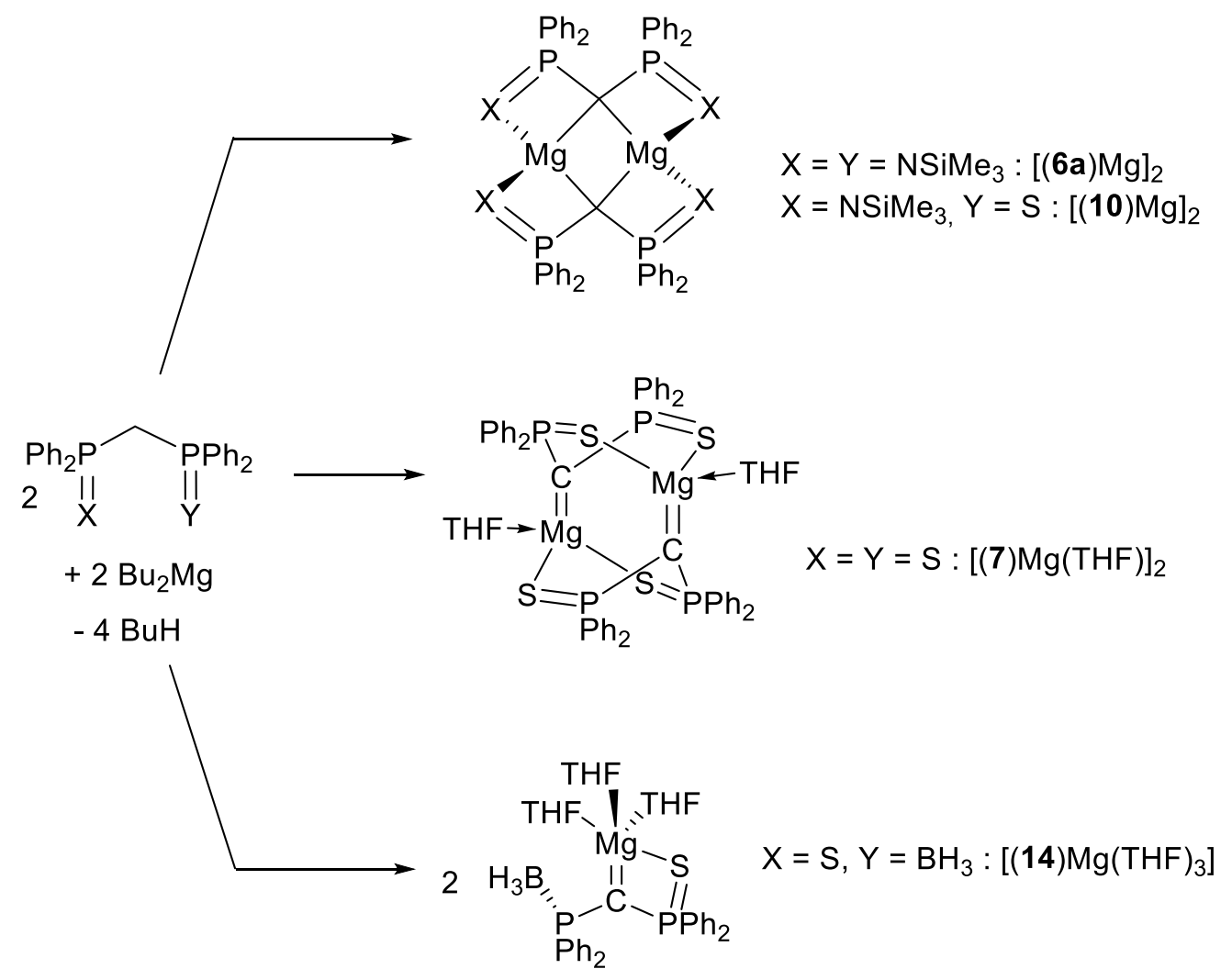

In 2010, the groups of So and Leung reported the first Mg complexes, in moderate to good yields (44 to $65 \%$ ) starting from the same bis-n-butylmagnesium precursor (Scheme 24$) .{ }^{31},{ }^{50}$ From a structural point of view, this alkaline-earth features the most varied coordination scheme, which does not seem to depend on the size of the substituents at P. Indeed, neutral ligand $\mathbf{6} \mathbf{6} \mathbf{H}_{2}$ lead to a complex analogous to the $\mathrm{Ca}$ and $\mathrm{Ba}$ derivatives, i.e. the bridging dimer $[\mathrm{Mg}(\mathbf{6 a})]_{2}$. On the other hand, ligand $\mathbf{7} \mathbf{a H}_{2}$ resulted in the formation of a head to tail dimer. In this complex, the $\mathrm{C}$ center does not act as bridging ligand, and the two $\mathrm{S}$ atoms of one moiety are bound to the $\mathrm{Mg}$ center of the other molecular unit. Finally, the only monomeric $\mathrm{Mg}$ complex of the series, $\left[(\mathbf{1 4}) \mathrm{Mg}(\mathrm{THF})_{3}\right]$, was reported by So, Mézailles et al. with mixed $\mathrm{PPh}_{2} \mathrm{~S} / \mathrm{PPh}_{2} \mathrm{BH}_{3}$ ligand $\mathbf{1 4} \mathbf{H}_{2}{ }^{31}$ The $\mathrm{BH}_{3}$ moiety is not bound to the $\mathrm{Mg}$ center which coordination sphere is completed by three THF molecules, unlike in the Ca complex. A bridging dimer could have been expected from this ligand, because of limited steric constraint of the $\mathrm{P}$ substituents. The $\mathrm{M}-\mathrm{C}$ bond 38 
lengths in complexes $[(7) \mathrm{Mg}(\mathrm{THF})]_{2}$ and $\left[(\mathbf{1 4}) \mathrm{Mg}(\mathrm{THF})_{3}\right]$ at $2.156(5) \AA$ and $2.113(4) \AA$ resp. are as expectedly significantly shorter than the ones measured in the dimers $[(\mathbf{6 a}) \mathrm{Mg}]_{2}$ and $[(\mathbf{1 0}) \mathrm{Mg}]_{2}$ at

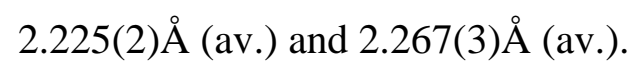

\subsubsection{Electronic structure}

The question of the nature of the bond between the AE metal and $\mathrm{C}$ was addressed. Harder et al. performed a DFT study first on models of $[(\mathbf{6 a}) \mathrm{Ca}]_{2}$ and $[(\mathbf{6 f}) \mathrm{Ca}]$ where $\mathrm{H}$ atoms were considered in place of the real phenyl groups at $\mathrm{P}$ and groups ( $\mathrm{SiMe}_{3}$ and $\mathrm{Ar}$ resp.) at $\mathrm{N} .{ }^{49}$ In the case of the monomeric complex $[(\mathbf{6} \mathbf{f}) \mathrm{Ca}]$, the solvent molecules were not taken into account. Not surprising in light of the difference of electronegativity of the elements, the charge at $\mathrm{C}$ varied between -1.623 (monomer) and 1.847 (dimer) whereas charge at $\mathrm{Ca}$ varied between +1.760 (monomer) and +1.821 (dimer). The $\mathrm{Ca}-\mathrm{C}$ bond was thus described as highly ionic. The calculations with the full dimeric system were carried out, and a slightly reduced charge was calculated at $\mathrm{C}(-1.778)$. The NPA charges were also compared to the ones in neutral $\mathbf{6} \mathbf{a H}$ and the $\left[\mathrm{Ca}(\mathbf{6 a H})_{2}\right]$ complex. Expectedly the charge at $\mathrm{C}$ goes from -1.079 to 1.409 to -1.778 (in $\mathbf{6 a H 2},\left[\mathrm{Ca}(\mathbf{6 a H})_{2}\right],[\mathrm{Ca}(\mathbf{6 a})]_{2}$ resp.). The charge at $\mathrm{N}$ also increases $(-1.474$ to -1.580 to -1.665 resp.) upon deprotonation at $\mathrm{C}$. Conversely, the charge at $\mathrm{P}$ varies but to a small extent $(+1.747$ to +1.727 to +1.716 resp. $)$. These differences in charges underscore the importance of the dipolar resonance form $\mathrm{P}^{+} \mathrm{N}^{-}$. The authors thus proposed a Lewis structure in accord with the one proposed for the geminal-dilithio compounds. They propose however that the stabilization of the high negative charge on the central carbon proceeds via electrostatic interactions with the $\mathrm{Ph}_{2} \mathrm{P}^{+}$moieties.

\subsubsection{Reactivity of AE complexes}


The bonding situation described above point to a high nucleophilic character, and the prototypical reactions involving polar $\mathrm{C}=\mathrm{X}(\mathrm{X}=\mathrm{O}, \mathrm{N})$ bonds in [2+2] reactions to form the corresponding alkene were attempted. The calcium dimer $[\mathrm{Ca}(6 \mathbf{6 a})]_{2}$ did not react at room temperature with AdCN or benzophenone but formed stable adducts. Under more forcing conditions (at $60^{\circ} \mathrm{C}$ ), in the coordinating solvent THF, a very slow reaction with benzophenone lead to several unidentified compounds from which the alcohol $\mathrm{Ph}_{2} \mathrm{C}(\mathrm{OH}) \mathrm{CH}\left(\mathrm{PPh}_{2} \mathrm{NTMS}\right)_{2}$ was identified upon hydrolysis. ${ }^{49}$ This product results from the expected $[2+2]$ reactivity yet did not yield the alkene via $\mathrm{CaO}$ elimination. $[\mathrm{Ca}(\mathbf{6 f})]$ did not prove more reactive despite being monomeric. Stronger electrophiles were thus tested. Complex $[\mathrm{Ca}(\mathbf{6} \mathbf{f})]$ appeared to be a catalyst in a trimerization process of cyclohexyl-isocyanate. ${ }^{52},{ }^{53}$ The stepwise reactivity allowed the isolation and X-ray diffraction analysis of the complex resulting from the double insertion of the isocyanate reagent (scheme 25).

\section{Scheme 25: Reactivity of Ca complexes toward electrophiles}



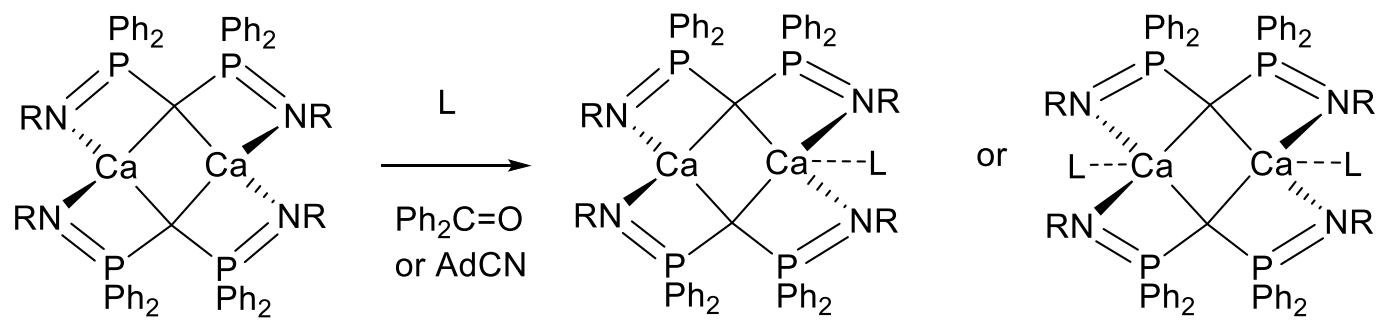

$$
\mathrm{R}=\mathrm{SiMe}_{3}
$$

$$
\mathrm{L}: \mathrm{Ph}_{2} \mathrm{C}=\mathrm{O}
$$

$\mathrm{L}: \mathrm{AdCN}$

THF
1) $\mathrm{Ph}_{2} \mathrm{C}=\mathrm{O}$
2) $\mathrm{H}_{2} \mathrm{O}$

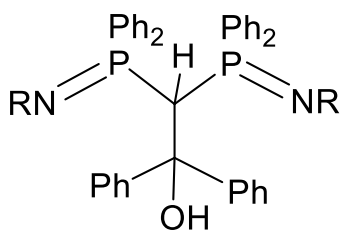
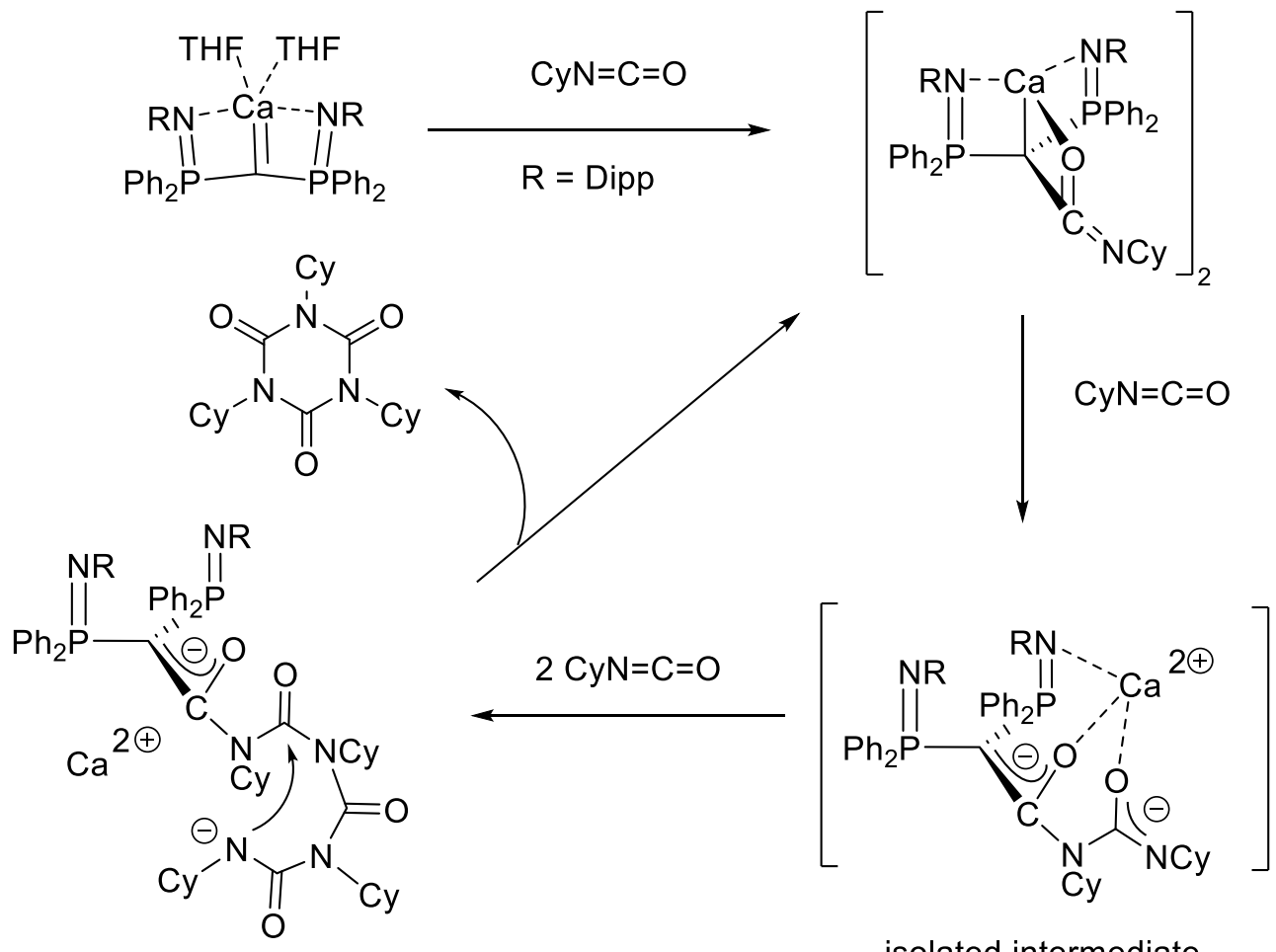

isolated intermediate

The general trend of reactivity down the group was observed with the complexes: $\mathrm{Mg}<\mathrm{Ca}<\mathrm{Ba}$. Accordingly, the $\mathrm{Mg}$ complexes did not react, while the Ba complex $\left[\mathrm{Ba}(\mathbf{6 f})(\mathrm{THF})_{3}\right]$ did also react with cyclohexyl-isocyanate. In this case, the mono insertion product was isolated. ${ }^{54}$ 


\section{Scheme 26: Reactivity of Ba complex toward CyNCO}

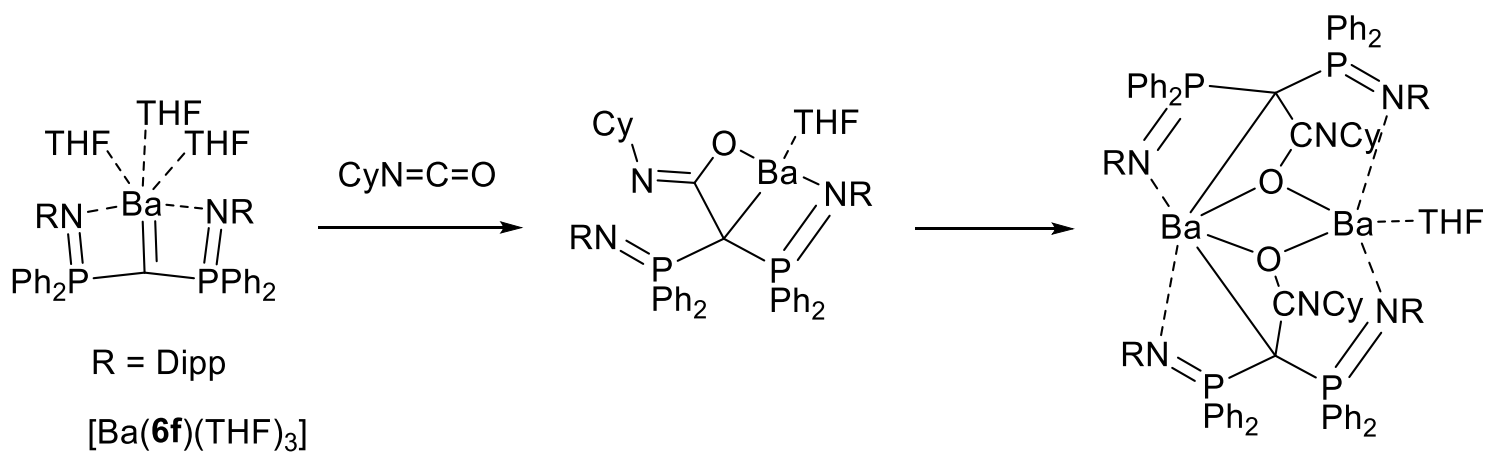

\subsubsection{Rare earths elements: group 3 and lanthanides}

We have gathered here the results for group 3 metals and lanthanides following a common usage. This is justified by the similarities of the main characteristics relevant to their coordination chemistry, i.e. relatively important ionic radius that evolves smoothly amongst the group, quasi-exclusive prevalence of (+III) oxidation state. In addition, the valence orbitals are poorly accessible for metal-ligand interactions because of high energy level or shielding by $4 \mathrm{~d}$ electrons in the case of lanthanides. For all rare earth elements, interactions with any ligands are supposed to be mostly ionic in nature, even if the involvement of $5 \mathrm{~d}$ orbitals ${ }^{55}$ and of $4 \mathrm{f} \mathrm{orbitals}^{56}$ in some cases has been highlighted. In agreement with this, the structurally characterized methylidene complexes of rare-earth all feature a bridging $\mathrm{CH}_{2}{ }^{2-}$ ligand between at least two rare earth ions or main-group metals. ${ }^{57},{ }^{58},{ }^{59},{ }^{60}$ The isolation and characterization of rare earth metal complexes of geminal dianions were thus of interest to further probe the existence and pertinent description of any multiple interactions between rare earth metals and a carbon.

\subsubsection{Synthesis}

Cavell et al. reported the first rare earth metal complex featuring the geminal dianion $\mathbf{6 a}$ as ancillary ligand in $2000 .{ }^{61}$ Although they had shown that $\mathbf{6} \mathbf{a L i} \mathbf{i}_{2}$ is stable a year before, they used an alterna- 
tive route starting with bis(trimethylsilyliminophosphoranyl)methane $\mathbf{6 a H}_{\mathbf{2}}$ as ligand precursor and $\left[\operatorname{Sm}\left(\mathrm{NCy}_{2}\right)_{3}\right]$. The monometallic complex of samarium (III) $\left[\operatorname{Sm}(\mathbf{6 a})\left(\mathrm{NCy}_{2}\right)(\mathrm{THF})\right]$ was obtained. The structure presents two nearly planar, fused four membered rings forming an open book (dihedral angle $37.7^{\circ}$ ). Most importantly, the Sm-C bond distance, at 2.467(4) $\mathrm{A}$, is considerably shorter than average Sm-C bonds (av. $2.743 \AA$ ) indicating a multiple bond character. This complex was hence formulated as a carbene.

After this ground-breaking example, the use of geminal dianion in coordination chemistry of rare earth metals has seen major developments. Several reviews have been published on this topic. ${ }^{62-65}$ In the vast majority two synthetic routes have been used. With the $\mathrm{PPh}_{2} \mathrm{~S}_{\mathrm{PPh}} \mathrm{S}$ ligand, the bis(thiophosphinoyl)methanediide geminal dianion $\mathbf{8} \mathbf{L i}_{2}$ has been exclusively used (route A), while for the $\mathrm{PPh}_{2} \mathrm{NR} / \mathrm{PPh}_{2} \mathrm{NR}$ ligands $\left(\mathbf{6 H}_{2}\right)$, double deprotonation by strongly basic ligands of the RE metal was preferred (route B) (scheme 27).

\section{Scheme 27: Strategies to rare earth carbene complexes}

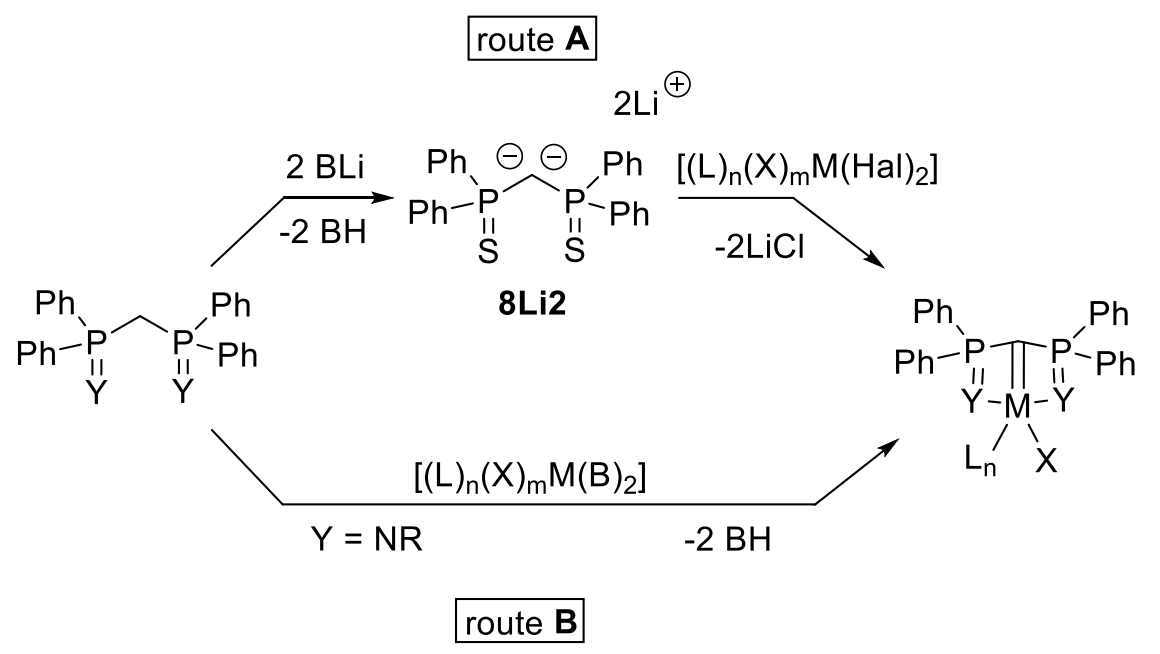

In two cases, deprotonation from coordinated monoanion was reported (scheme 28). ${ }^{66,67}$ 
Scheme 28: Rare earth carbene complexes via deprotonation in the coordination sphere
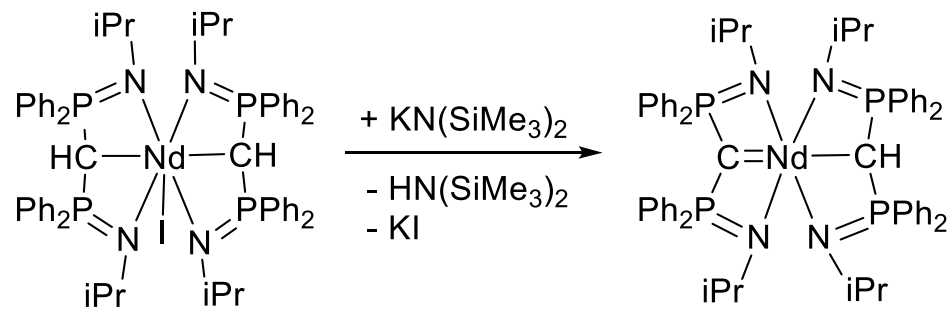

$[(6 \mathrm{c}) \mathrm{Nd}(6 \mathrm{cH})]$

Following one route or the other, numerous complexes have been synthesized which feature different structures: a) monometallic mono-carbenic structure (Scheme 29); b) dimeric in which each metallic centre bears one carbene ligand; c) bis-carbenic, anionic, monometallic structure (Scheme 30). The monometallic, mono-carbenic complexes feature an additional X type ligand (halogen or alkyl), which can be further substituted (vide infra). For example, a complex featuring a rare donor acceptor Y-Ga interaction can be synthesized from the reaction between $\left[\mathrm{Y}(\mathbf{6 a}) \mathrm{I}(\mathrm{THF})_{2}\right]$ and $\mathrm{KGa}\left\{(\mathrm{NArCH})_{2}\right\}$. The latter species is valence isoelectronic to NHC ligand. ${ }^{68}$ Other complexes, such as the alkoxidecoordinated yttrium complex $\left[\mathrm{Y}(\mathbf{6})\left(\mathrm{OCPh}_{2} \mathrm{CH}_{2} \mathrm{Ph}\right)\right]$ can be obtained by transformation of the coordination sphere of these primary complexes.

\section{Scheme 29: Rare earth carbene complexes featuring ligand 6}




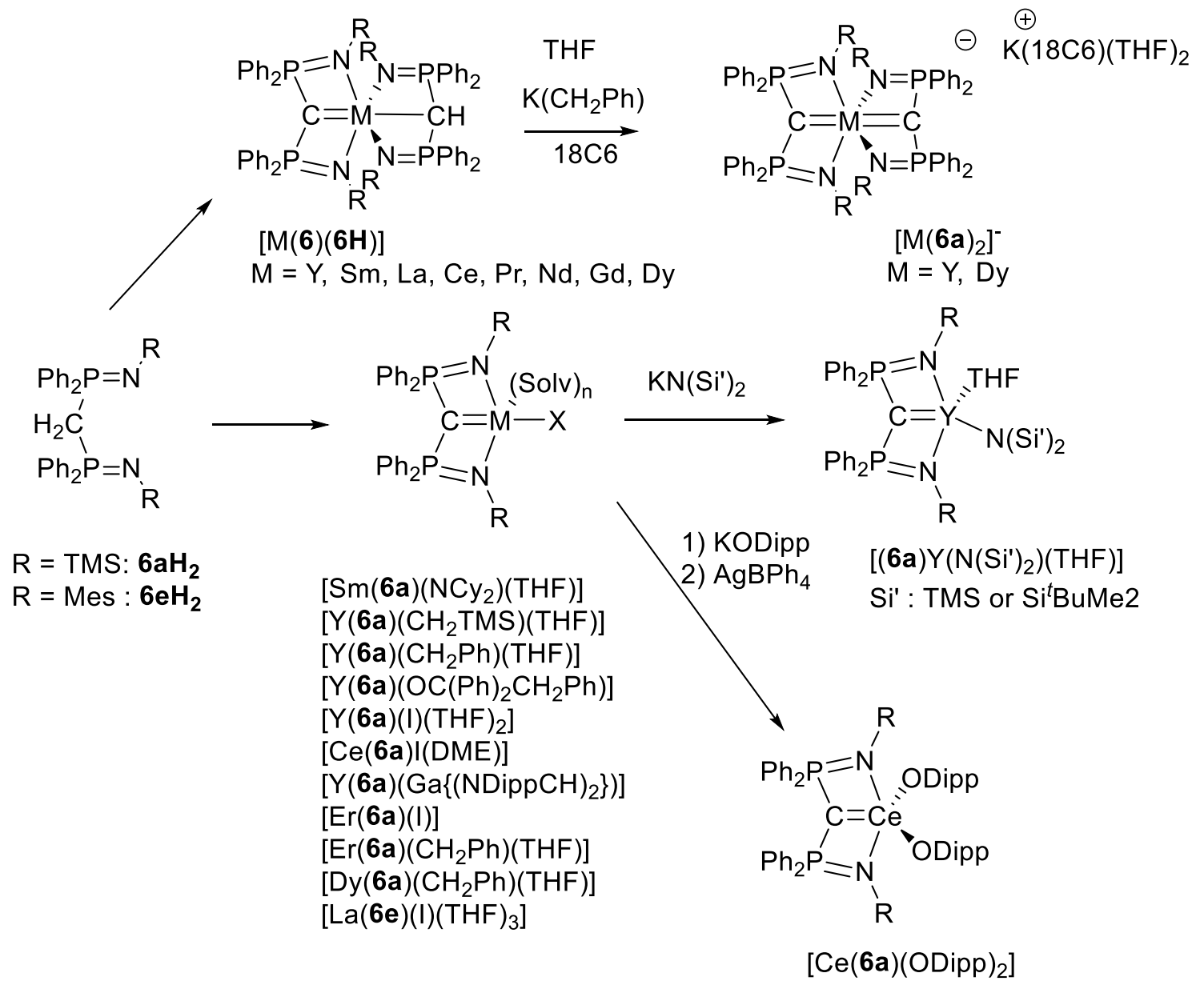

Scheme 30: Rare earth carbene complexes featuring ligand 8 


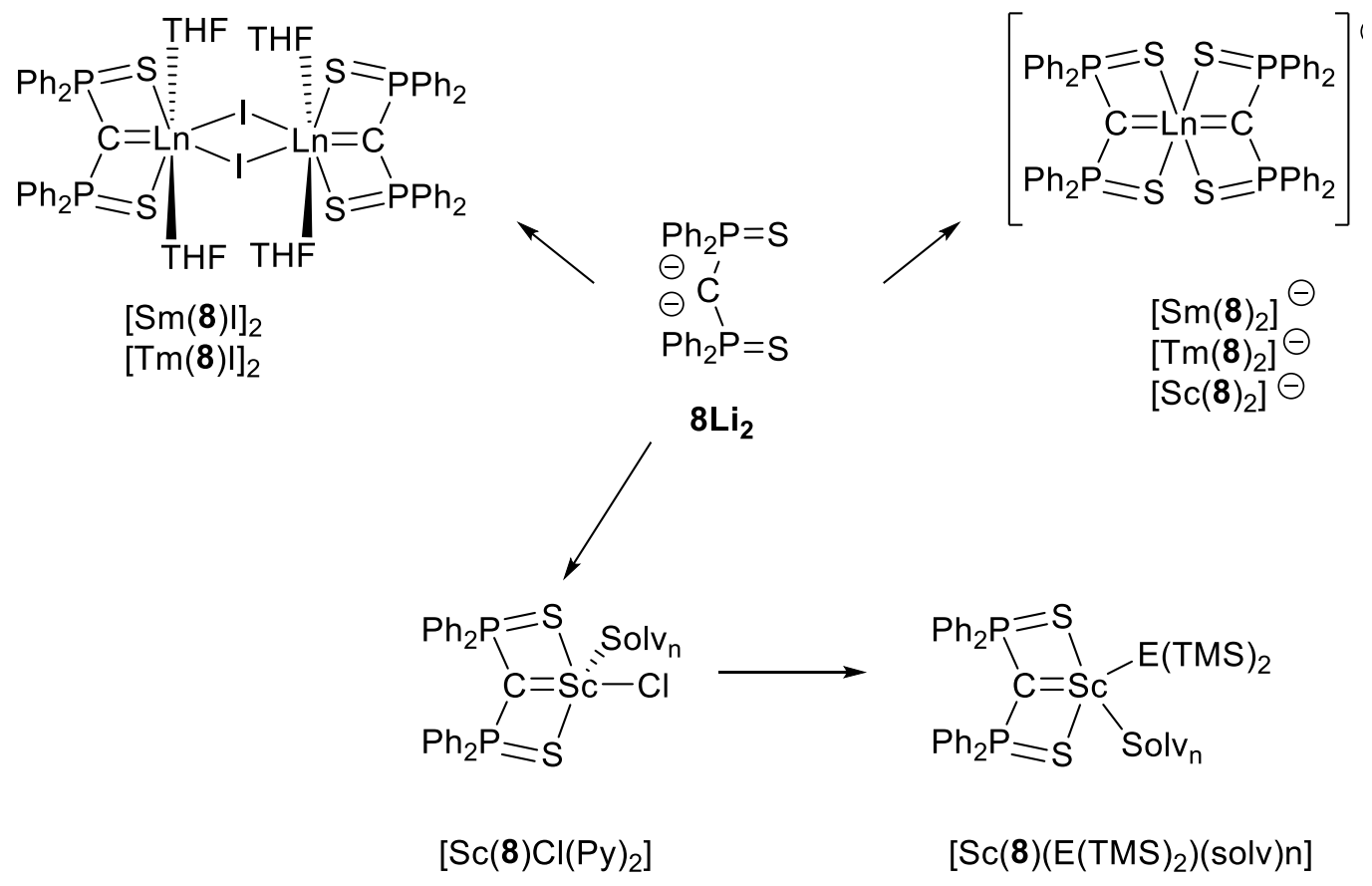

Table 2: Rare earth complexes featuring ligands 6 and 8.

\begin{tabular}{|c|c|c|c|}
\hline Name & $\mathrm{Ln}$ & $\mathrm{X}$ & Ref. \\
\hline$\left[\mathrm{Sm}(\mathbf{6 a})\left(\mathrm{NCy}_{2}\right)(\mathrm{THF})\right]$ & $\mathrm{Sm}$ & $\mathrm{Cy}_{2} \mathrm{~N}^{-}$ & 61 \\
\hline$\left[\mathrm{Y}(\mathbf{6 a})\left(\mathrm{CH}_{2} \mathrm{SiMe}_{3}\right)(\mathrm{THF})\right]$ & $\mathrm{Y}$ & $\mathrm{Me}_{3} \mathrm{SiCH}_{2}^{-}$ & 69 \\
\hline$\left[\mathrm{Y}(\mathbf{6 a})\left(\mathrm{CH}_{2} \mathrm{Ph}\right)(\mathrm{THF})\right]$ & $\mathrm{Y}$ & $\mathrm{PhCH}_{2}^{-}$ & 70 \\
\hline$\left[\mathrm{Y}(\mathbf{6 a})\left(\mathrm{OCPh}_{2} \mathrm{CH}_{2} \mathrm{Ph}\right)(\mathrm{THF})\right]$ & $\mathrm{Y}$ & $\left(\mathrm{PhCH}_{2}\right) \mathrm{Ph}_{2} \mathrm{CO}^{-}$ & 70 \\
\hline$\left[\mathrm{Y}(\mathbf{6 a}) \mathrm{I}(\mathrm{THF})_{2}\right]$ & $\mathrm{Y}$ & $\mathrm{I}^{-}$ & 71 \\
\hline$\left[\mathrm{Y}(\mathbf{6 a})\left(\mathrm{Ga}\left\{(\mathrm{NDippCH})_{2}\right\}\right)(\mathrm{THF})_{2}\right]$ & $\mathrm{Y}$ & {$\left[\mathrm{Ga}\left\{(\mathrm{NDippCH})_{2}\right\}\right]^{-}$} & 68 \\
\hline$\left[\mathrm{Y}_{2}(\mathbf{6 a})_{2}\left(\mathrm{OCPh}_{2} \mathrm{CH}_{2} \mathrm{Ph}\right)_{2}\right]$ & $\mathrm{Y}$ & $\left(\mathrm{CH}_{2} \mathrm{Ph}\right) \mathrm{Ph}_{2} \mathrm{CO}^{-}$ & 70 \\
\hline$[\mathrm{Ce}(\mathbf{6 a}) \mathrm{I}(\mathrm{DME})]$ & $\mathrm{Ce}$ & I & 72 \\
\hline$[\mathrm{Ce}(\mathbf{6 a})(\mathrm{ODipp})(\mathrm{THF})]$ & $\mathrm{Ce}$ & ODipp & 72 \\
\hline$\left[\mathrm{Ce}(\mathbf{6 a})(\mathrm{ODipp})_{2} \mathrm{~K}(\mathrm{THF})\right]$ & $\mathrm{Ce}(\mathrm{III})$ & ODipp & 72 \\
\hline$\left[\mathrm{Ce}(\mathbf{6 a})(\mathrm{ODipp})_{2}\right]$ & $\mathrm{Ce}(\mathrm{IV})$ & ODipp & 72 \\
\hline
\end{tabular}




\begin{tabular}{|c|c|c|c|}
\hline$\left[\mathrm{Er}(\mathbf{6 a}) \mathrm{I}(\mathrm{THF})_{2}\right]$ & Er & $\mathrm{I}^{-}$ & 71 \\
\hline$\left[\mathrm{Er}(\mathbf{6 a})\left(\mathrm{CH}_{2} \mathrm{Ph}\right)(\mathrm{THF})\right]$ & Er & $\mathrm{PhCH}_{2}^{-}$ & 73 \\
\hline$\left[\mathrm{Dy}(\mathbf{6 a})\left(\mathrm{CH}_{2} \mathrm{Ph}\right)(\mathrm{THF})\right]$ & Dy & $\mathrm{PhCH}_{2}^{-}$ & 73 \\
\hline$[\mathrm{La}(\mathbf{6 a})(\mathbf{6 a H})]$ & $\mathrm{La}$ & $\mathbf{6 a H}^{-}$ & 73 \\
\hline$[\mathrm{Ce}(\mathbf{6 a})(\mathbf{6 a H})]$ & $\mathrm{Ce}$ & $\mathbf{6 a H}^{-}$ & 73 \\
\hline$[\operatorname{Pr}(\mathbf{6 a})(\mathbf{6 a H})]$ & $\operatorname{Pr}$ & $\mathbf{6 a H}^{-}$ & 73 \\
\hline$[\mathrm{Nd}(\mathbf{6 a})(\mathbf{6 a H})]$ & $\mathrm{Nd}$ & $6 \mathbf{6 H}^{-}$ & 73 \\
\hline$[\operatorname{Sm}(\mathbf{6 a})(\mathbf{6 a H})]$ & $\mathrm{Sm}$ & $\mathbf{6 a H}^{-}$ & 73 \\
\hline$[\mathrm{Gd}(\mathbf{6 a})(\mathbf{6 a H})]$ & $\mathrm{Gd}$ & $\mathbf{6 a H}^{-}$ & 73 \\
\hline$[\mathrm{Dy}(\mathbf{6 a})(\mathbf{6 a H})]$ & Dy & $\mathbf{6 a H}^{-}$ & 73 \\
\hline$[\mathrm{La}(\mathbf{6 e})(\mathbf{6 e H})]$ & $\mathrm{La}$ & $\mathbf{6 a H}^{-}$ & 74 \\
\hline$[\mathrm{Ce}(\mathbf{6 e})(\mathbf{6 e H})]$ & $\mathrm{Ce}$ & $\mathbf{6 a H}^{-}$ & 74 \\
\hline$[\operatorname{Pr}(\mathbf{6 e})(\mathbf{6 e H})]$ & $\operatorname{Pr}$ & $\mathbf{6 a H}^{-}$ & 74 \\
\hline$[\mathrm{Gd}(\mathbf{6 e})(\mathbf{6 e H})]$ & $\mathrm{Gd}$ & $\mathbf{6 a H}^{-}$ & 74 \\
\hline$[\mathrm{Nd}(\mathbf{6 c})(\mathbf{6 c H})]$ & $\mathrm{Nd}$ & $6 \mathrm{cH}^{-}$ & 66 \\
\hline$\left[\mathrm{Dy}(\mathbf{6 a})_{2}\right]^{-}\left[\mathrm{K}^{+}(18 \mathrm{C} 6)(\mathrm{THF})_{2}\right]$ & Dy & $\mathbf{6 a H}^{-}$ & 75 \\
\hline$\left[\mathrm{Y}(\mathbf{6 a})_{2}\right]^{-}\left[\mathrm{K}^{+}(18 \mathrm{C} 6)(\mathrm{THF})_{2}\right]$ & $\mathrm{Y}$ & $\mathbf{6 a H}^{-}$ & 75 \\
\hline$\left[\mathrm{Y}(\mathbf{6 a})\left(\mathrm{N}\left(\mathrm{Si}^{\prime}\right)_{2}(\mathrm{THF})\right]\right.$ & $\mathrm{Y}$ & $\mathrm{N}\left(\mathrm{Si}^{\prime}\right)_{2}$ & 76 \\
\hline$\left[\mathrm{La}(\mathbf{6 e}) \mathrm{I}(\mathrm{THF})_{3}\right]$ & $\mathrm{La}$ & $\mathrm{I}^{-}$ & 67 \\
\hline$\left[\mathrm{La}_{2}(\mathbf{6 e}) \mathrm{I}_{2}(\mathrm{THF})\right]\left[\mathrm{LiI}(\mathrm{THF})_{2}\right]_{2}$ & $\mathrm{La}$ & $2 \mathrm{I}^{-}$ & \begin{tabular}{|l}
67 \\
\end{tabular} \\
\hline$[\mathrm{Sm}(\mathbf{8}) \mathrm{I}(\mathrm{THF})]_{2}$ & $\mathrm{Sm}$ & $\mathrm{I}^{-}$ & \begin{tabular}{|l}
77 \\
\end{tabular} \\
\hline$\left[\mathrm{Sm}(\mathbf{8})_{2}\right]^{-}$ & $\mathrm{Sm}$ & -- & 77 \\
\hline$[\mathrm{Tm}(\mathbf{8}) \mathrm{I}(\mathrm{THF})]_{2}$ & $\mathrm{Tm}$ & $\mathrm{I}^{-}$ & \begin{tabular}{|l}
78 \\
\end{tabular} \\
\hline$\left[\operatorname{Tm}(\mathbf{8})_{2}\right]^{-}$ & $\mathrm{Tm}$ & -- & 78 \\
\hline$\left[\mathrm{Sc}(\mathbf{8})(\mathrm{Cl})(\mathrm{Py})_{2}\right]$ & Sc & $\mathrm{Cl}^{-}$ & \begin{tabular}{|l}
79 \\
\end{tabular} \\
\hline
\end{tabular}




\begin{tabular}{|l|l|l|l|}
\hline$\left[\mathrm{Sc}(\mathbf{8})\left(\mathrm{P}(\mathrm{TMS})_{2}\right)(\mathrm{Py})_{2}\right]$ & $\mathrm{Sc}$ & $\mathrm{PTMS}_{2}^{-}$ & 80 \\
\hline$\left[\mathrm{Sc}(\mathbf{8})\left(\mathrm{N}(\mathrm{TMS})_{2}\right)(\mathrm{THF})\right]$ & $\mathrm{Sc}$ & $\mathrm{NTMS}_{2}^{-}$ & 80 \\
\hline
\end{tabular}

The series of complexes of ligand $6 \mathbf{a}$ synthesized from the tris-benzyl rare earth metal shows that the structure depends on the ionic radius of the metal. For the bigger ions, complex $[\mathrm{M}(\mathbf{6 a})(\mathbf{6 a H})],(\mathbf{M}=$ $\mathrm{La}, \mathrm{Ce}, \mathrm{Pr}, \mathrm{Nd}, \mathrm{Sm}, \mathrm{Gd}$ ) is obtained despite using a 1:1 stoichiometry between ligand and metal precursors. ${ }^{73}$ On the other hand, with erbium, yttrium ${ }^{70}$ and dysprosium, the benzyl-methanediide complex $\left[\mathrm{M}(\mathbf{6 a})\left(\mathrm{CH}_{2} \mathrm{Ph}\right)(\mathrm{THF})\right]$ was formed.

The complexes shown in table 2 have been structurally characterized which allowed trends to be observed. Thus, the coordination of the dianionic carbon is influenced by the nature of the anionic ligand in $[\mathrm{M}(\mathbf{6 a})(\mathrm{X})]$ complexes. Indeed, an increase of the dianionic carbon-metal bond length is measured when a halogen ligand is changed to an alkyl one. In parallel, the MNPCPN ring changes from a flat geometry to a boat configuration in line with a decrease of the PCP angle (table 3). An exception to this trend is however found with benzyl ligand, which presents an $\eta^{2}$ coordination to yttrium in complex $\left[\mathrm{Y}(\mathbf{6 a})\left(\mathrm{CH}_{2} \mathrm{Ph}\right)(\mathrm{THF})\right] .{ }^{70}$ Liddle and coworkers have used the stable carbene-Ce(III) complex to generate the first carbene complex of Ce(IV) via single electron oxidation. ${ }^{72}$ In this diamagnetic complex, the carbene nature is confirmed by the low field chemical shift (324.6 ppm). The molecular structure revealed one of the shortest Ce-C bond distance $(2.441(5) \AA)$. DFT analysis of the nature this bond was done (vide infra).

The anionic bis carbene complexes $\left[\mathrm{M}(\mathbf{8})_{2}\right]^{-}(\mathrm{M}=\mathrm{Sm}, \mathrm{Tm})^{77,78}$ presented two different X-ray structures depending on the temperature; the low temperature structure revealed two different conformations for the coordination of the ligand $\mathbf{8}$, one being bent while the other is flat. The higher temperature structure presents intermediate geometry of the two both with bond length similar to the one ob48 
served in the halide complex $\left[\mathrm{RE}(\mathbf{8}) \mathrm{I}(\mathrm{THF})_{2}\right]_{2}$. Displacement of the $\mathrm{Cl}-$ in $\left[\mathrm{Sc}(\mathbf{8})(\mathrm{Cl})(\operatorname{solv})_{2}\right]$ by $\mathrm{NTMS}_{2}{ }^{-}$ and $\mathrm{PTMS}_{2}{ }^{-}$provided strikingly different structures for the complexes $\left[\mathrm{Sc}(\mathbf{8})\left(\mathrm{NTMS}_{2}\right)(\mathrm{THF})\right]$ and $\left[\mathrm{Sc}(\mathbf{8})\left(\mathrm{PTMS}_{2}\right)(\mathrm{Py})_{2}\right] .{ }^{80}$ Indeed, in the former the carbene moiety is strongly bent while it is flat in the latter. DFT calculations linked these differences in geometry at $\mathrm{C}$ to the amount of coordinated solvent molecules at the RE center. Indeed, the hypothetical $\left[\operatorname{Sc}(\mathbf{8})\left(\mathrm{PTMS}_{2}\right)(\mathrm{THF})\right]$ complex was calculated to possess similarly bent $\mathrm{C}$ center. Most interestingly, the NBO analysis showed that the magnitude of the $\sigma+\pi$ donation to the RE center is non-sensitive of the geometry at $\mathrm{C}$, although individual $\sigma$ and $\pi$ donations change.

Table 3: Bond lengths and angles for a set of yttrium complexes bearing ligand 6a and various complexes of thulium and samarium bearing ligand 8 .

\begin{tabular}{|c|c|c|c|c|c|c|}
\hline Complex & {$\left[\mathrm{Y}(\mathbf{6 a})\left(\mathrm{CH}_{2} \mathrm{SiMe}_{3}\right)\right]$} & $\begin{array}{l}{\left[\mathrm{Y}(\mathbf{6 a})\left(\mathrm{OCPh}_{2} \mathrm{CH}\right.\right.} \\
\left.\left.{ }_{2} \mathrm{Ph}\right)\right]\end{array}$ & $\begin{array}{l}{\left[\mathrm{Y}(\mathbf{6 a})\left(\mathrm{CH}_{2} \mathrm{P}\right.\right.} \\
\mathrm{h})]\end{array}$ & $\begin{array}{l}{[\mathrm{Y}(\mathbf{6 a})(\mathrm{Ga}\{(\mathrm{NDipp}} \\
\left.\left.\left.\left.\mathrm{CH}_{2}\right)_{2}\right\}\right)\right]\end{array}$ & {$[\mathrm{Y}(\mathbf{6 a}) \mathrm{I}]$} & $6 \mathbf{a L i}_{2}$ \\
\hline C-M bond ( $(\AA)$ & $2.406(3)$ & 2.393 & $2.357(3)$ & $2.348(3)$ & $2.356(3)$ & $\mid--$ \\
\hline P-N bond $(\AA)$ & $\begin{array}{l}1.627(3) \\
1.629(3)\end{array}$ & $\begin{array}{l}1,626(2) \\
1,632(2)\end{array}$ & $1.627(2)$ & $\begin{array}{l}1.629(2) \\
1.630(2)\end{array}$ & $\begin{array}{l}1.620(3) \\
1.623(3)\end{array}$ & $\begin{array}{l}1.630(3) \\
\text { (av) }\end{array}$ \\
\hline P-C bond $(\AA ̊)$ & $\begin{array}{l}1.672(3) \\
1.662(3)\end{array}$ & $\begin{array}{l}1.671(2) \\
1.660(2)\end{array}$ & $1.6521(12)$ & $\begin{array}{l}1.637(3) \\
1.643(3)\end{array}$ & $\begin{array}{l}1.641(3) \\
1.640(3)\end{array}$ & $\begin{array}{l}1.687(3) \\
1.694(3)\end{array}$ \\
\hline P-C-P angle $\left(^{\circ}\right)$ & $138.4(2)$ & $137.58(16)$ & $147.6(2)$ & $171.2(2)$ & $172.5(2)$ & $132.3(2)$ \\
\hline Complex & {$[\operatorname{Sm}(\mathbf{8}) \mathrm{I}]_{2}$} & {$\left[\operatorname{Sm}(\mathbf{8})_{2}\right]$} & {$[\operatorname{Tm}(\mathbf{8}) \mathrm{I}]_{2}$} & {$\left[\operatorname{Tm}(\mathbf{8})_{2}\right]$} & {$\left[\mathrm{Sc}(\mathbf{8}) \mathrm{Cl}(\mathrm{py})_{2}\right]$} & $8 \mathrm{Li}_{2}$ \\
\hline C-M bond ( & $\begin{array}{l}2.371(6) \\
2.352(6)\end{array}$ & $\begin{array}{l}2.491(5) \\
2.507(5)\end{array}$ & $2.325(5)$ & $\begin{array}{l}2.378(9) \\
2.423(9)\end{array}$ & $2.2072(1)$ & -- \\
\hline P-S bond $(\AA)$ & & $\begin{array}{l}2.042(2) \\
2.034(2)\end{array}$ & & & $\begin{array}{l}2.046(1) \\
2.052(1)\end{array}$ & $\begin{array}{l}2.037(1) \\
2.040(1)\end{array}$ \\
\hline P-C bond $(\AA)$ & $\begin{array}{l}1.675(2) \\
1.667(2)\end{array}$ & $\begin{array}{l}1.660(6) \\
1.635(6)\end{array}$ & $\begin{array}{l}1.652(5) 1.668 \\
(4)\end{array}$ & & $\begin{array}{l}1.660(3) \\
1.657(3)\end{array}$ & $\begin{array}{l}1.672(3) \\
1.678(3)\end{array}$ \\
\hline P-C-P angle $\left({ }^{\circ}\right)$ & $146.2(4)$ & $156.4(4)$ & $150.8(3)$ & $158.0(6)$ & $159.3(2)$ & $131.6(2)$ \\
\hline
\end{tabular}




\begin{tabular}{|l|l|l|l|l|l|l|}
\hline & $145.4(4)$ & $136.5(4)$ & & $134.6(6)$ & & \\
\hline
\end{tabular}

\section{Scheme 31: Bridging dianion or carbene complexes featuring ligand 6a}
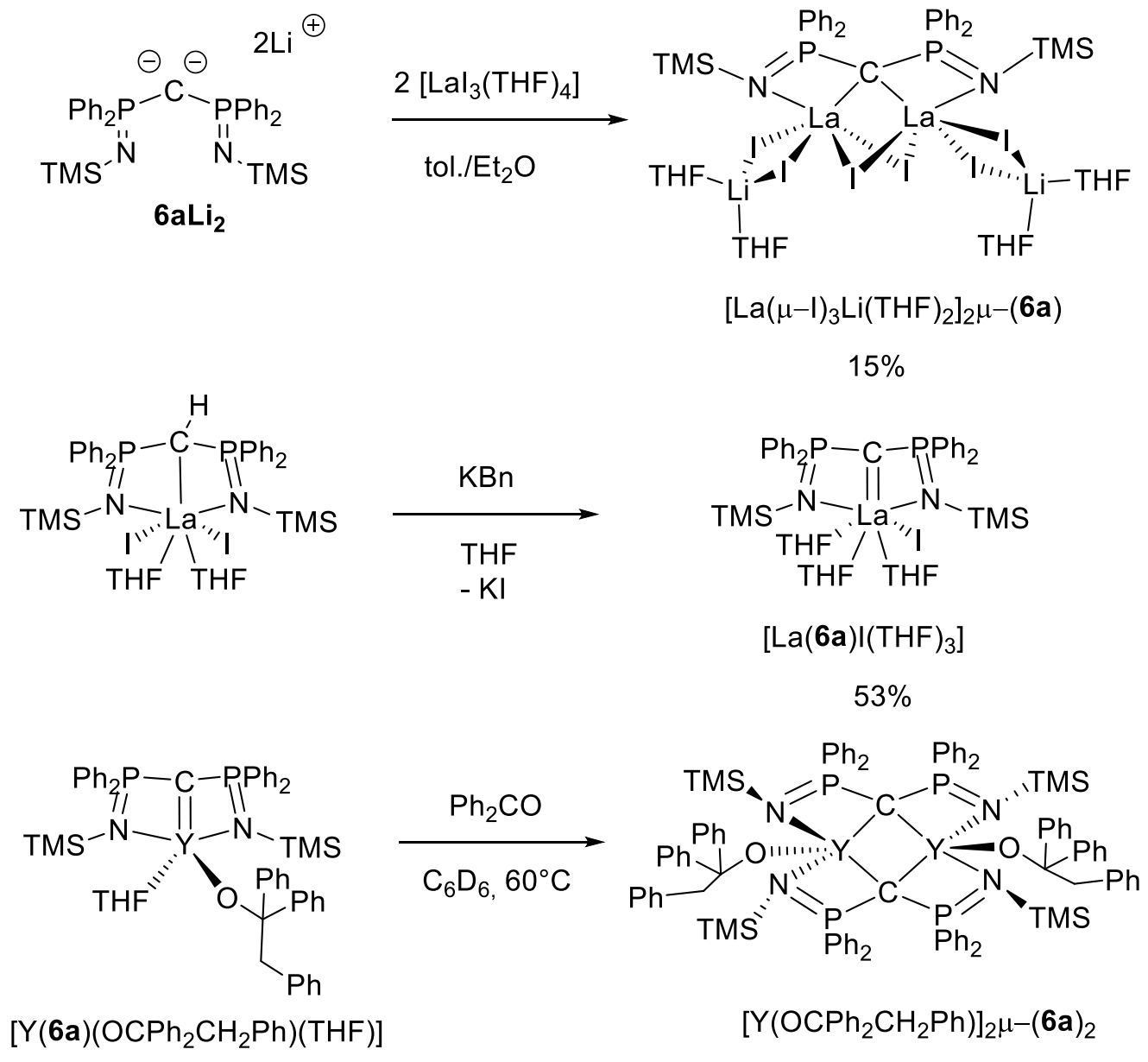

Only two examples of RE complexes featuring a bridging geminal dianion are known, with ligand 6a. It is interesting to note that the first was obtained in a poor $15 \%$ yield from the reaction of the dilithio derivative $\mathbf{6} \mathbf{a L i}_{2}$ with $\left[\mathrm{LaI}_{3}(\mathrm{THF})_{4}\right]$. The authors showed that to obtain the corresponding carbene complex, the deprotonation of the coordinated ligand $\mathbf{6 a H}$ had to be done.$^{67}$ The second example (no yield given) resulted from a thermal rearrangement favoring THF evolution (scheme 31 ). ${ }^{70}$ 
The group of Chen has recently developed a new platform at Sc to generate carbene complexes of Sc featuring mixed $\mathrm{PS} / \mathrm{SiR}_{3}{ }_{3}$ moieties. As presented above, the corresponding geminal dilithio derivative $\mathbf{1 4} \mathbf{a L i}_{2}$ is known but its synthesis not efficient. The authors thus relied on the in situ deprotonation of $\mathbf{1 4 a - b H}$ coordinated to the Sc center by a methyl group. This route appeared very efficient and isolated yields between 58 and $87 \%$ are reported. ${ }^{81}$ Electronic structure and reactivity of these complexes was studied (vide infra). Although the geminal dianion $\left(\mathrm{PPh}_{2} \mathrm{CTMS}\right)^{2-}$ is not known, it was generated in a similar manner in the coordination sphere of Sc. ${ }^{82}$ Mild heating was necessary in this case (scheme 32).

Scheme 32: Sc carbene complexes: generation of the $\mathrm{Sc}=\mathrm{C}$ bond in the coordination sphere

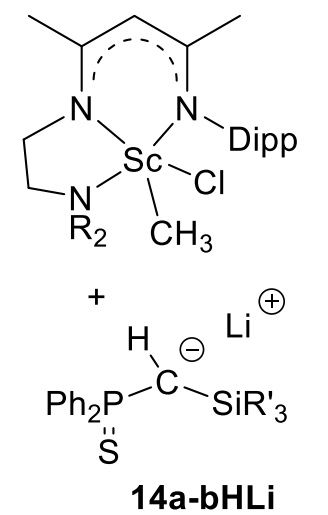

tol. r. t.<smiles>CC(C)(Cl)Cl</smiles>

a: $R^{\prime}=M e$

b: $R^{\prime}=P h$

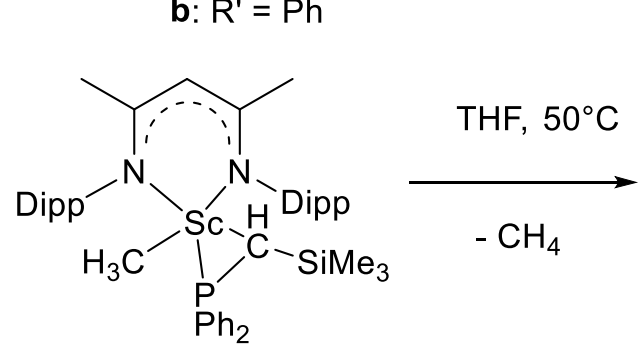

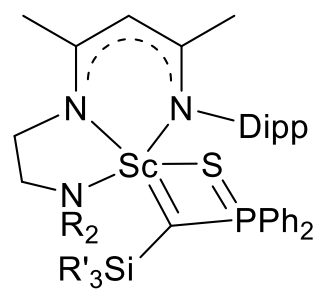

$\mathrm{R}=i \mathrm{Pr}, \mathrm{R}^{\prime}=\mathrm{Me}, 58 \%, 36$

$\mathrm{R}=\mathrm{iPr}, \mathrm{R}^{\prime}=\mathrm{Ph}, 87 \%$

$\mathrm{R}=\mathrm{Me}, \mathrm{R}^{\prime}=\mathrm{Me}, 67 \%, 37$

$\mathrm{R}=\mathrm{Me}, \mathrm{R}^{\prime}=\mathrm{Ph}, 77 \%$

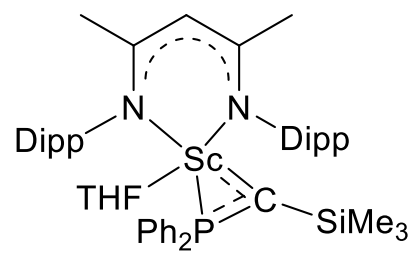

$63 \%, 38$

\subsubsection{2. $M=C(M=$ Rare earth metal $)$ bonding scheme}

Initial theoretical studies have been performed on yttrium and lanthanum complexes with bis(iminophosphoranyl)methanediide ligand $\mathbf{6 a}$ and a scandium complex featuring the 
bis(thiophosphinoyl)methanediide ligand 8. These rare-earths ions possess closed-shell configuration which renders their modelling more straightforward. However, direct comparison between these different studies is not possible due to inhomogeneity of methods, bases and different choices of bonding or charge distribution models.

Stabilization of the double charge at carbon is known to occur by negative hyperconjugation in geminal dilithio compounds $\mathbf{6} \mathbf{L i}_{2}$ and $\mathbf{8} \mathbf{L i}_{2}$. Mézailles et al. have performed theoretical studies on the complexes $\left[\mathrm{Sc}(\mathbf{8})(\mathrm{X})(\mathrm{Py})_{2}\right]\left(\mathrm{X}=\mathrm{Cl}, \mathrm{NTMS}_{2}, \mathrm{PTMS}_{2}\right) \cdot{ }^{80}$ Second order perturbation analysis was used to quantify and compare the way electron density (the two lone pairs) at $\mathrm{C}$ is stabilized, i.e. hyperconjugation vs. donation toward the metallic center. In complex $\left[\mathrm{Sc}(\mathbf{8}) \mathrm{Cl}(\mathrm{Py})_{2}\right]$, donation towards the metal center is about twice as strong as the stabilization via hyperconjugation into the $\mathrm{PPh}_{2} \mathrm{~S}$ moiety (98.4 $\mathrm{kcal} / \mathrm{mol} v s .56 .4 \mathrm{kcal} / \mathrm{mol}$ ) for the $\sigma$ symmetry orbital. For the $\pi$ symmetry orbital, both interactions are of the same order $(39.2 \mathrm{kcal} / \mathrm{mol} v s .55 .4 \mathrm{kcal} / \mathrm{mol})$ yet the stabilization by hyperconjugation is stronger than donation to the Sc center. The scandium-carbon interaction is highly polar, as shown by the moderate $\mathrm{C}-\mathrm{M}$ bond order of $0.6 .{ }^{79}$ The same analysis was later done with the imido and phosphido complexes (scheme 33). ${ }^{80}$ It is interesting to note that the sigma donation is barely affected by the ligand in trans position (stabilization via hyperconjugation of ca $54 \mathrm{kcal} / \mathrm{mol}$ and donation to $\mathrm{Sc}$ of $42 \mathrm{kcal} / \mathrm{mol}$ ). On the other hand, $\pi$ donation of $\mathrm{C}$ to $\mathrm{Sc}$ is stronger in the phosphido complex. It thus appears that the dianion is able to adapt its $\pi$ donation to the trans ligand.

\section{Scheme 33: $\operatorname{Sc}$ carbene complexes $\left[\mathrm{Sc}(8)(\mathrm{X})(\mathrm{Py})_{2}\right]\left(\mathrm{X}=\mathrm{NTMS}_{2}, \mathrm{PTMS}_{2}\right)$ : bonding scheme}




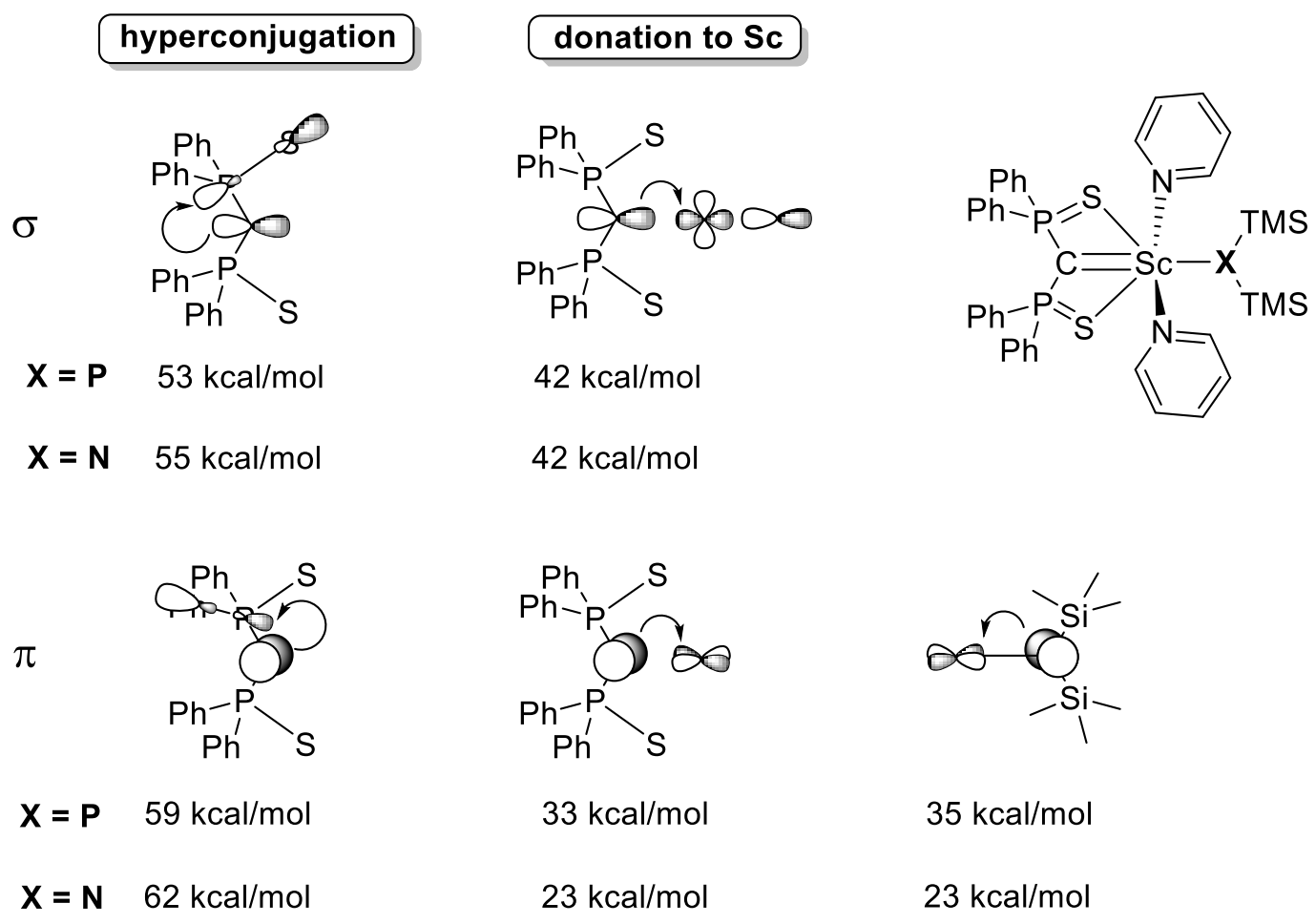

Liddle and co-workers have performed an NBO analysis on a series of $\mathrm{Y}$ complexes featuring ligand $\quad \mathbf{6 a}, \quad\left(\left[\mathrm{Y}(\mathbf{6 a})\left(\mathrm{CH}_{2} \mathrm{SiMe}_{3}\right)(\mathrm{THF})\right],{ }^{69} \quad[\mathrm{Y}(\mathbf{6 a}) \mathrm{I}],{ }^{71} \quad\left[\mathrm{Y}(\mathbf{6 a})\left(\mathrm{Ga}\left\{\left(\mathrm{NDippCH}_{2}\right)_{2}\right\}\right)\right]\right.$, $\left.\left[\mathrm{Y}(\mathbf{6 a})\left(\mathrm{CH}_{2} \mathrm{Ph}\right)(\mathrm{THF})\right]^{68}\right)$, and compared them with the dianion $\mathbf{6} \mathbf{a} \mathbf{L i} \mathbf{i}_{2}$. The Kohn-Sham orbitals of the complexes reflect a strong reminiscence of the dianionic ligand. Indeed, in general, the HOMO presents an almost pure $\mathrm{p}$ orbital whereas the HOMO- 1 shows an $\mathrm{sp}^{\mathrm{n}}$ hybrid orbital character, and thus feature important contributions from carbon. In the complex $\left[\mathrm{Y}(\mathbf{6 a})\left(\mathrm{CH}_{2} \mathrm{Ph}\right)(\mathrm{THF})\right]$ the main contribution to the HOMO comes from the $\mathrm{C}$ atom of the benzyl moiety and the two orbitals developed on the $\mathrm{C}$ of the carbene moiety are thus found as the HOMO-1 and HOMO-2 respectively. In the gallium-yttrium complex, the HOMO-1 also describes the $\pi$ lone pair at $\mathrm{C}$ while the sigma lone pair at carbon is involved in a four electron, three centers interaction with yttrium and gallium. Important contributions at $\mathrm{C}$ (sigma symmetry) are found in two occupied molecular orbitals (HOMO-2 and HOMO-4). Reactivity studies 
with complexes $\left[\mathrm{Y}(\mathbf{6 a})\left(\mathrm{CH}_{2} \mathrm{SiMe}_{3}\right)\right]$ and $\left[\mathrm{Y}(\mathbf{6 a})\left(\mathrm{Ga}\left\{\left(\mathrm{NDippCH}_{2}\right)_{2}\right\}\right)\right]$ were then found in accord with this ordering of the frontier orbitals (see below).

The NBO charge distribution within these complexes highlight the dipolar resonance form of the bis(iminophosphoranyl)methanediide, already found in the free ligand. The NPCPN charges are even moderately increased upon coordination at the Y (cf Table 4). The bond orders within the ligand vary modestly also, and depend on the nature of the other $\mathrm{X}$ type ligand coordinated at $\mathrm{Y}$ (Table 5). A decrease of the involvement of the phosphorus in carbon-centered Kohn-Sham orbitals (above mentioned HOMOs) from dianion $\mathbf{6} \mathbf{a L i} \mathbf{i}_{2}$ to the Y complexes can also be noted. Stabilization by negative hyperconjugation seems thus to be diminished upon coordination to $\mathrm{Y}$ in favor of an increase in ionic interactions.

Table 5: NBO charges, Wiberg bond indices.

\begin{tabular}{|l|l|l|l|l|l|l|}
\hline Complex & qC & qP & $\mathbf{q}_{\mathbf{N}}$ & WBI(PC) & WBI(PN) & WBI(CM) \\
\hline$\left[\mathrm{Y}(\mathbf{6 a})\left(\mathrm{CH}_{2} \mathrm{SiMe}_{3}\right)(\mathrm{THF})\right]$ & -1.49 & +1.59 & -1.61 & $1.31-1.24$ & $1.07-1.08$ & 0.6 \\
\hline$\left[\mathrm{Y}(\mathbf{6 a})\left(\mathrm{Ga}\left\{(\mathrm{NDippCH})_{2}\right\}\right)\right.$ & -1.58 & +1.58 & -1.56 & 1.19 & 0.99 & 0.29 \\
\hline$[\mathrm{Y}(\mathbf{6 a}) \mathrm{I}(\mathrm{THF}) 2]$ & -1.58 & +1.58 & -1.56 & 1.19 & 0.99 & 0.30 \\
\hline $\mathbf{6 a L i} 2$ & -1.37 & +1.61 & -1.48 & 1.29 & 1.04 & - \\
\hline
\end{tabular}

The ground state electronic nature of the $\mathrm{Ce}(\mathrm{IV})$ complex $\left[\mathrm{Ce}(\mathbf{6 a})(\mathrm{ODipp})_{2}\right]$ was computed. ${ }^{72}$ The overlap population density of states suggests that the $\mathrm{Ce}-\mathrm{C}$ interaction is predominantly electrostatic and covalent interactions contribute only modestly. Charges of +1.91 and -1.47 at $\mathrm{Ce}$ and $\mathrm{C}$ were calculated. The Nalewajski-Mrozek bond order of 1.1 is higher than in the more ionic Y carbene complexes of $\mathbf{6 a}$, and compares with more covalent " $\mathrm{U}(\mathbf{6 a})$ " carbene complexes (1.2-1.5, vide infra). The NBO analysis confirmed the large character at $\mathrm{C}(87 \%$ in $\sigma, 88 \%$ in $\pi)$ and small character at $\mathrm{Ce}(13 \%$ in $\sigma, 12 \%$ in $\pi)$. Further analysis using Bader's "atoms in molecules" support the predominantly ionic bonding picture 54 
with a minor covalent component. Nonetheless, the non-zero bond critical path ellipticity supports the double bond formulations for the $\mathrm{M}=\mathrm{C}$ interactions. Finally, an absorption band in the visible spectra resulting from $\mathrm{LMCT}$ from $\mathrm{C}=\mathrm{Ce}$ to $4 \mathrm{f}$ orbitals was also observed.

Recently, a NBO analysis was performed by Maron and Chen on complex $37{ }^{81}$ At the first order, a strongly polarized Sc-C $\sigma$ bond is evidenced, while at the second order the pi lone pair at $\mathrm{C}$ interacts strongly with an empty $3 \mathrm{~d}$ orbital at Sc in a $\pi$ fashion $(82.1 \mathrm{kcal} / \mathrm{mol})$.

In conclusion, DFT calculations showed that both sigma and pi interactions are found between the $\mathrm{C}$ center and the RE metal. The corresponding orbitals are strongly polarized toward the $\mathrm{C}$ center, which clearly point toward a pronounced nucleophilic character of the carbene complexes.

\subsubsection{Reactivity}

In light of the bonding scheme presented above, the reactivity of the RE carbene complexes of geminal dianions with unsaturated, polarized bonds was thus tested. Benzophenone was used as the prototypical reagent, for its unambiguous electrophilic character. Addition of benzophenone to complexes $[\operatorname{Sm}(\mathbf{8}) \mathrm{I}]_{2},{ }^{77}[\operatorname{Tm}(\mathbf{8}) \mathrm{I}]_{2}{ }^{78}\left[\operatorname{Sm}(\mathbf{8})_{2}\right]^{-}$and $\left[\operatorname{Tm}(\mathbf{8})_{2}\right]^{-}$afforded the Wittig-like product $\mathrm{Ph}_{2} \mathrm{C}=\mathrm{C}\left(\mathrm{PPh}_{2}(\mathrm{~S})\right)_{2}$ as single product (scheme 34). In the reaction of the bis-carbene anionic complexes an intermediate in the metala-Wittig process corresponding to the product of [2+2] cycloaddition of two molecules of benzophenone to the two $\mathrm{C}=\mathrm{M}$ bond was isolated. When dissolved in toluene, these complexes form the expected alkene.

\section{Scheme 34: Reactivity of bis carbene complex $\left[\mathrm{M}(8)_{2}\right]^{-}$.}



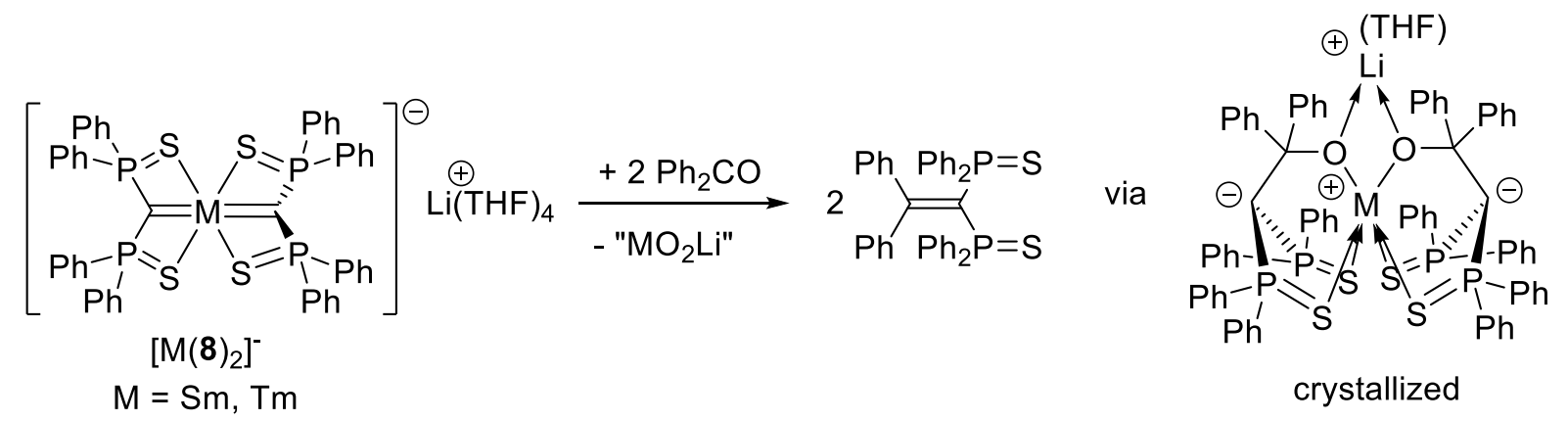

Although slower, a similar reactivity the monocarbene scandium complex $\left[\mathrm{Sc}(\mathbf{8}) \mathrm{Cl}(\mathrm{Py})_{2}\right],{ }^{79}$ was observed. In this case, Mézailles and co-workers could isolate another intermediate, corresponding to the trapping of two equivalents of "ScOCl" produced along with the alkene, by two equivalents of the starting complex $\left[\mathrm{Sc}(\mathbf{8}) \mathrm{Cl}(\mathrm{Py})_{2}\right]$ (scheme 35). It appears that $\left[\mathrm{Sc}(\mathbf{8}) \mathrm{Cl}(\mathrm{Py})_{2}\right]$ is not only nucleophilic via the $\mathrm{C}$ center, but also strongly electrophilic at Sc. Further heating the " $\mathrm{Sc}_{4}(\mathbf{8})_{2}$ " intermediate with two additional equivalents of $\mathrm{Ph}_{2} \mathrm{CO}$ lead to full transformation to the alkene.

\section{Scheme 35: Reactivity of carbene complex $\left[\operatorname{Sc}(8) \mathrm{Cl}(\operatorname{Py})_{2}\right]$ with ketone.}
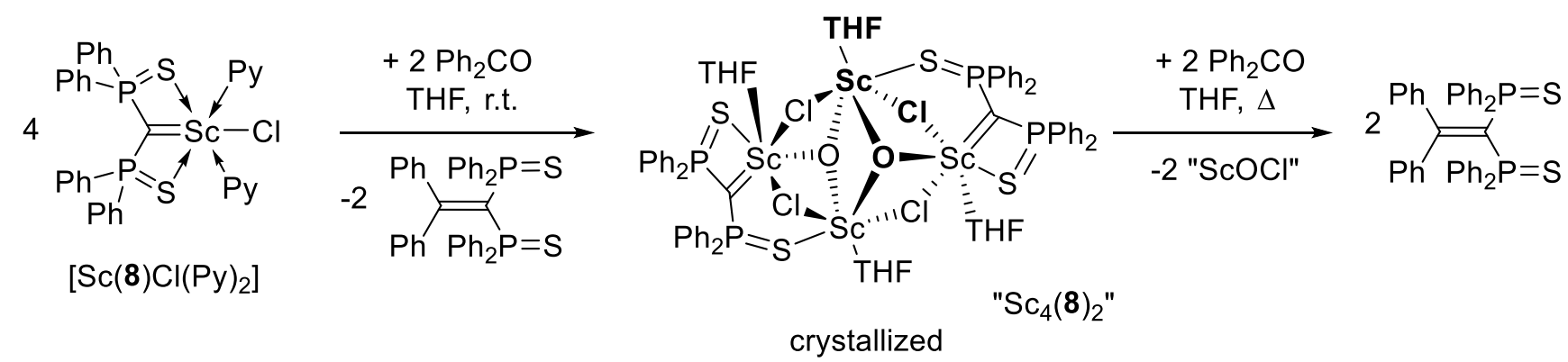

The reactivity of the yttrium complexes of the kind " $\mathrm{Y}(\mathbf{6 a})(\mathrm{X})$ ", where the ligand $\mathrm{X}$ is an alkyl ${ }^{70}$ or an halogen, ${ }^{83}$ toward benzophenone provided radically different outcomes (Scheme 36). In line with a higher energy orbital, an alkyl moiety behaving as a nucleophile will react preferentially to the carbene in a first stage, leading to an alkoxy derivative. In a subsequent step, the carbene moiety acting as a base will deprotonate the aryl in ortho-position followed by subsequent nucleophilic attack of the newly 56 
formed carbanion on another equivalent of benzophenone. On the contrary, when the pendant ligand is a halogen, the dianionic carbon behaves either as a base or as a nucleophile, depending on the substrate.

\section{Scheme 36: Reactivity of $\mathrm{Y}$ carbene complexes with carbonyl derivatives: ketones and}

\section{PhCOF.}
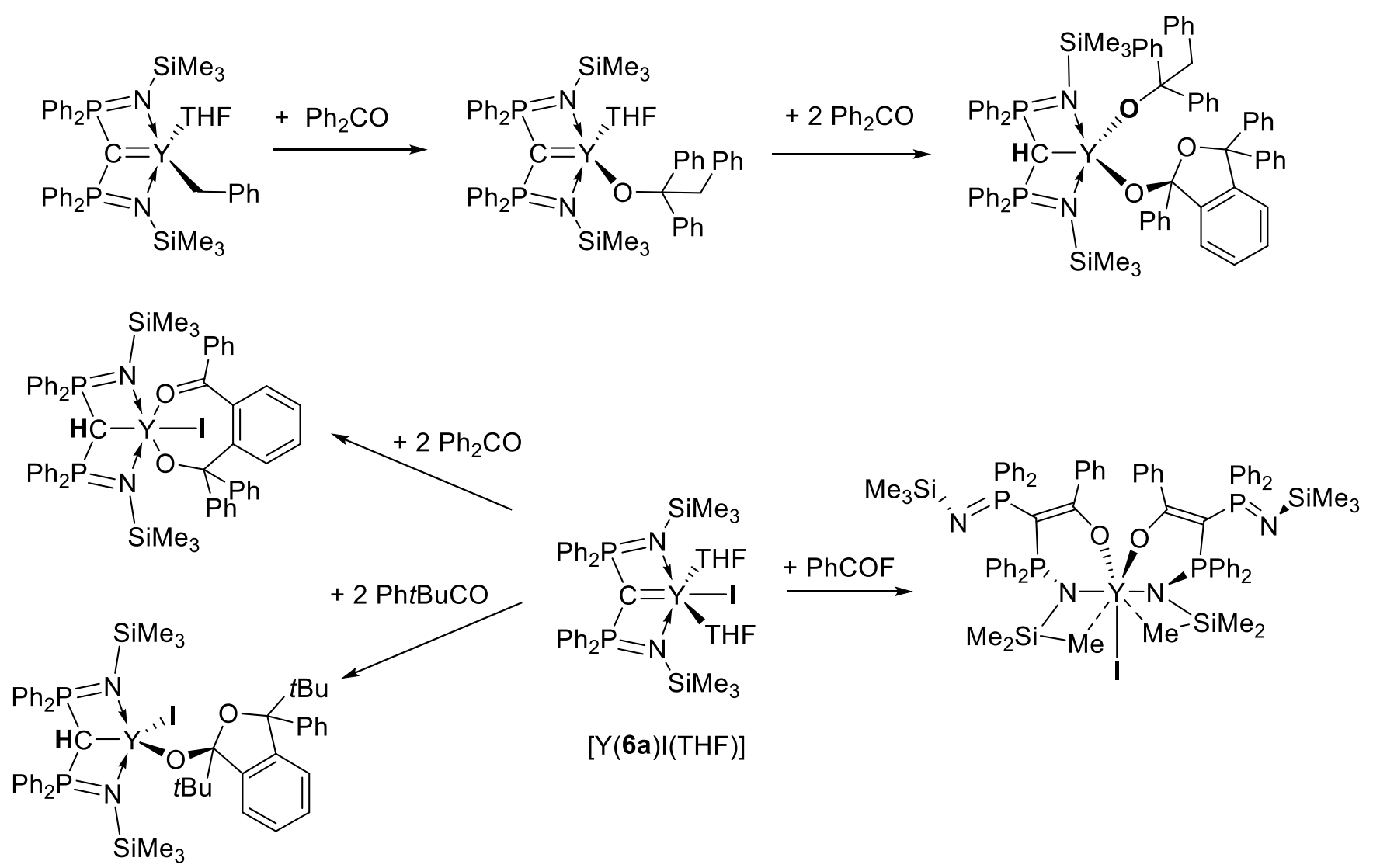

With acyl fluoride or ester derivatives, elimination of Y-F or Y-OR was observed, prior to the coupling with the carbene moiety. Reactivity with thiocyanate or carbodiimide stopped at the [2+2] addition, while the more reactive isothiocyanate formed the keteneimine species following the metala-Wittig process (scheme 37). ${ }^{84}$ When this reagent is added to the alkyl complex $\left[\mathrm{Y}(\mathbf{6 a})\left(\mathrm{CH}_{2} \mathrm{Ph}\right)(\mathrm{THF})\right],{ }^{85}$ a dimeric 
yttrium complex is formed in which the two metallic centers are linked by a tridentate ligand resulting from the addition of a sulphide on the isothiocyanate moiety.

Scheme 37: Reactivity of $Y$ carbene complexes with RNCS, RNCO and $\mathbf{R N}_{3}$.

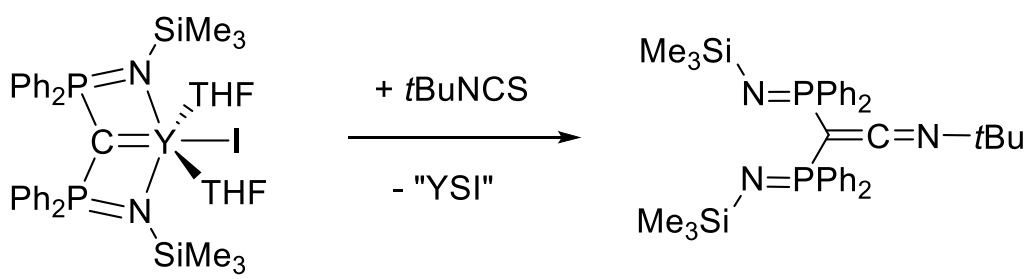

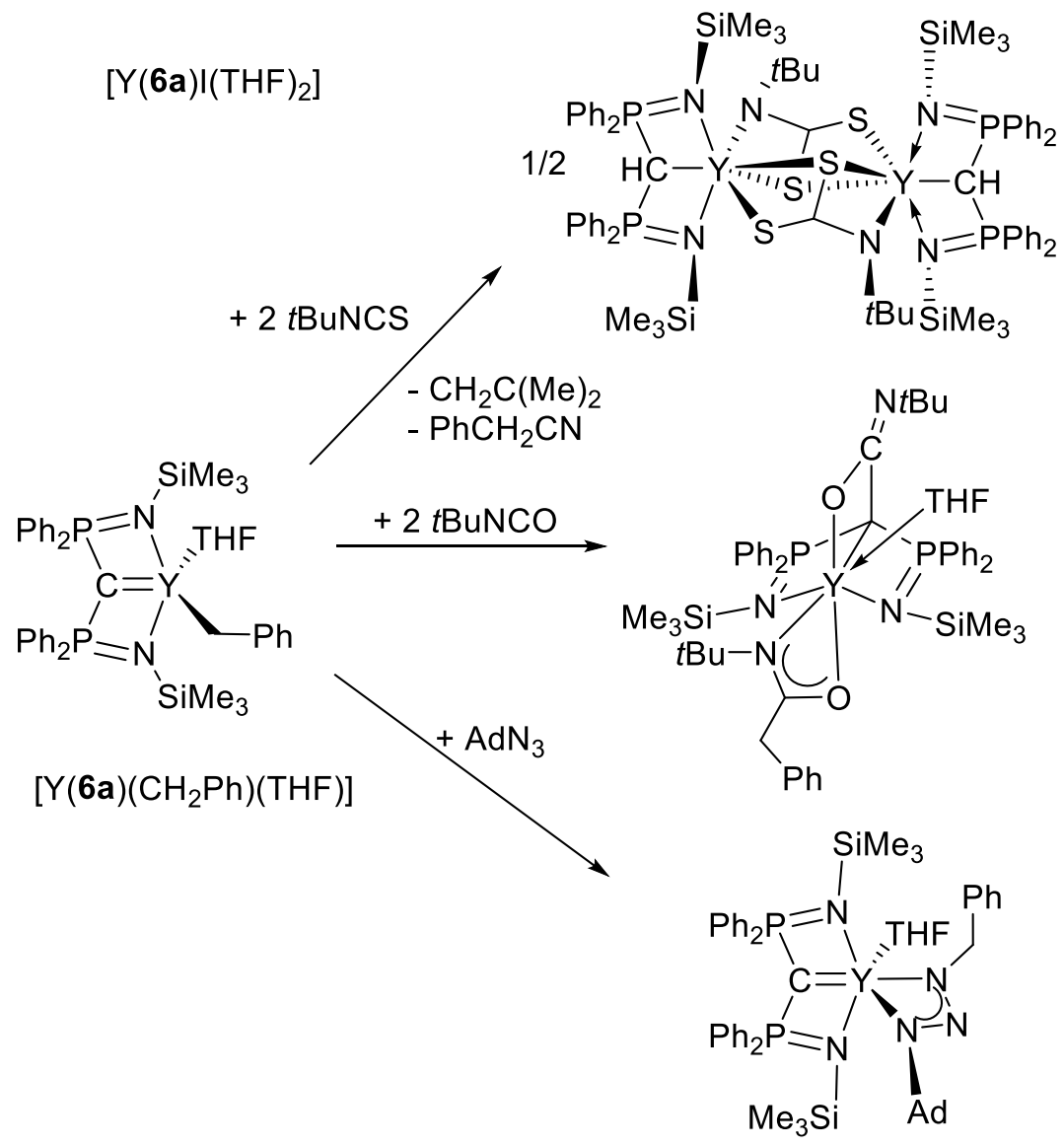

Liddle and coworkers showed that the enhanced covalent character of the $\mathrm{C}=\mathrm{Ce}$ bond in the $\mathrm{Ce}(\mathrm{IV})$ complex $\left[\mathrm{Ce}(\mathbf{6 a})(\mathrm{ODipp})_{2}\right]$ allowed a switch from the $\mathrm{C}-\mathrm{H}$ activations to the metala-Wittig reac- 
tion. Indeed, the use of $\mathrm{RCOH}\left(\mathrm{R}=\mathrm{Ph}\right.$ or anthracene) lead to the synthesis of $\mathrm{RC}(\mathrm{H})=\mathrm{C}\left(\mathrm{PPh}_{2} \mathrm{NTMS}\right)_{2}$ derivatives. $^{72}$

\section{Scheme 38: Reactivity of Sc carbene complex 36.}

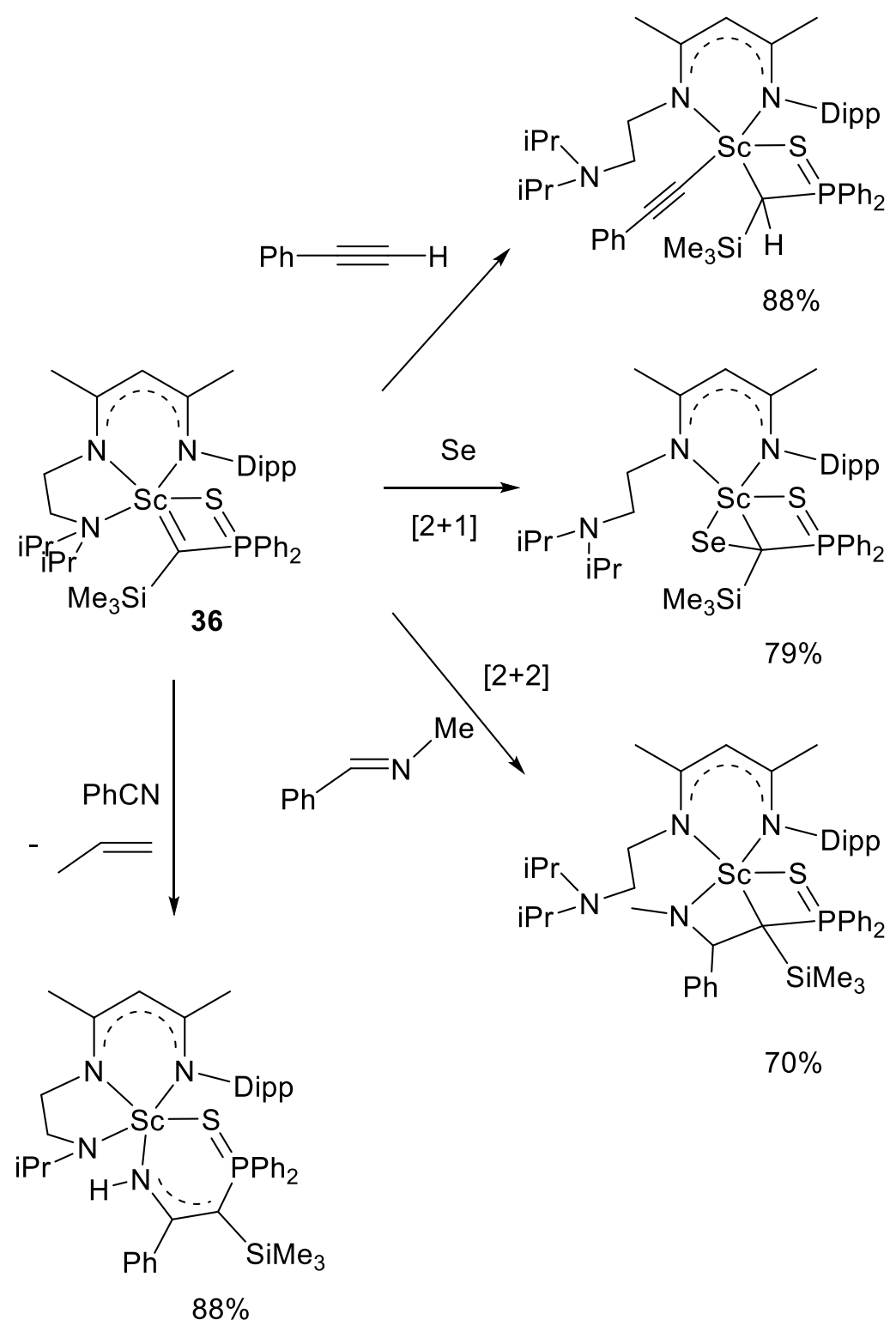

Chen, Maron and co-workers have recently studied the reactivity of the Sc carbene complex 36 (scheme 38). Cycloadditions [2+1] and [2+2] are reported to occur very efficiently, as well as the depro- 
tonation of phenylacetylene by the carbene moiety. ${ }^{81}$ Insertion of the carbene in PhCN was also evidenced. It eventually results in modification of the NNN ligand to an imido moiety. The mechanism of this transformation was corroborated by DFT calculations. ${ }^{86}$

The weak and strongly polarized $\mathrm{C}=\mathrm{Sc}$ bond found in $\mathrm{Scandium}$ carbene complex $\left[\mathrm{Sc}(\mathbf{8}) \mathrm{Cl}(\mathrm{Py})_{2}\right]$ has been used as a formal dianionic ligand transfer reagent by Mézailles in $2012 .{ }^{87}$ Indeed, transmetalation from Sc to several late transition metal centers has been evidenced ( $\mathrm{Ru}, \mathrm{Pd}, \mathrm{Co})$. Notably, the dimetallic iron complex $[\mathrm{Fe}(\mathbf{8})]_{2}$ featuring two bridging methanediide ligands 8 was obtained, while its direct synthesis from $\mathbf{8} \mathbf{L i}_{\mathbf{2}}$ is not reported (Scheme 39). In 2018, a related transfer of the dianionic ligand 14 from the Sc complex 36 to $\mathrm{Cu}$ was reported by Chen and Maron. Interestingly, at room temperature, the heterobimetallic species featuring $\mathbf{1 4}$ as bridging ligand was isolated. Upon heating, with additional $\mathrm{CuI}$, full transfer to the $\mathrm{Cu}$ center was achieved, leading to a " $\mathrm{Cu}_{8}$ " cluster. ${ }^{88 \mathrm{a}}$ They also reported the formation of heterobimetallic Sc-Rh and Sc-Au complexes from the related Sc complex 38. ${ }^{88 b}$

\section{Scheme 39: Reactivity of Sc carbene complexes: transmetallations.}




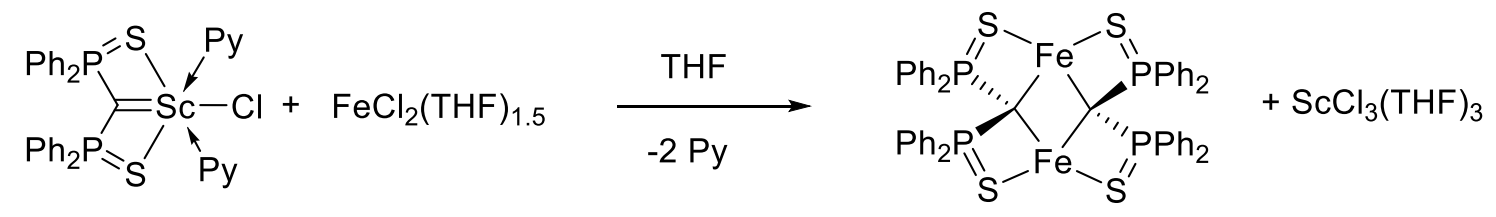

$\left[\mathrm{Sc}(\mathbf{8}) \mathrm{Cl}(\mathrm{Py})_{2}\right]$
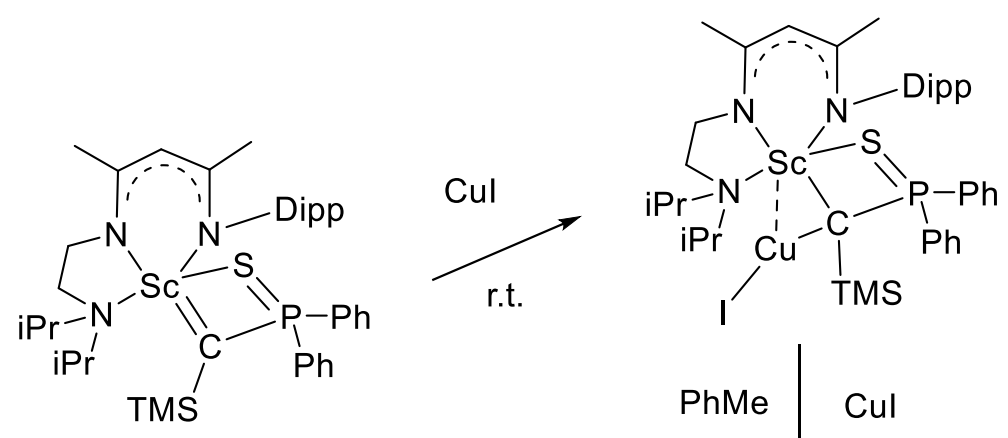

36
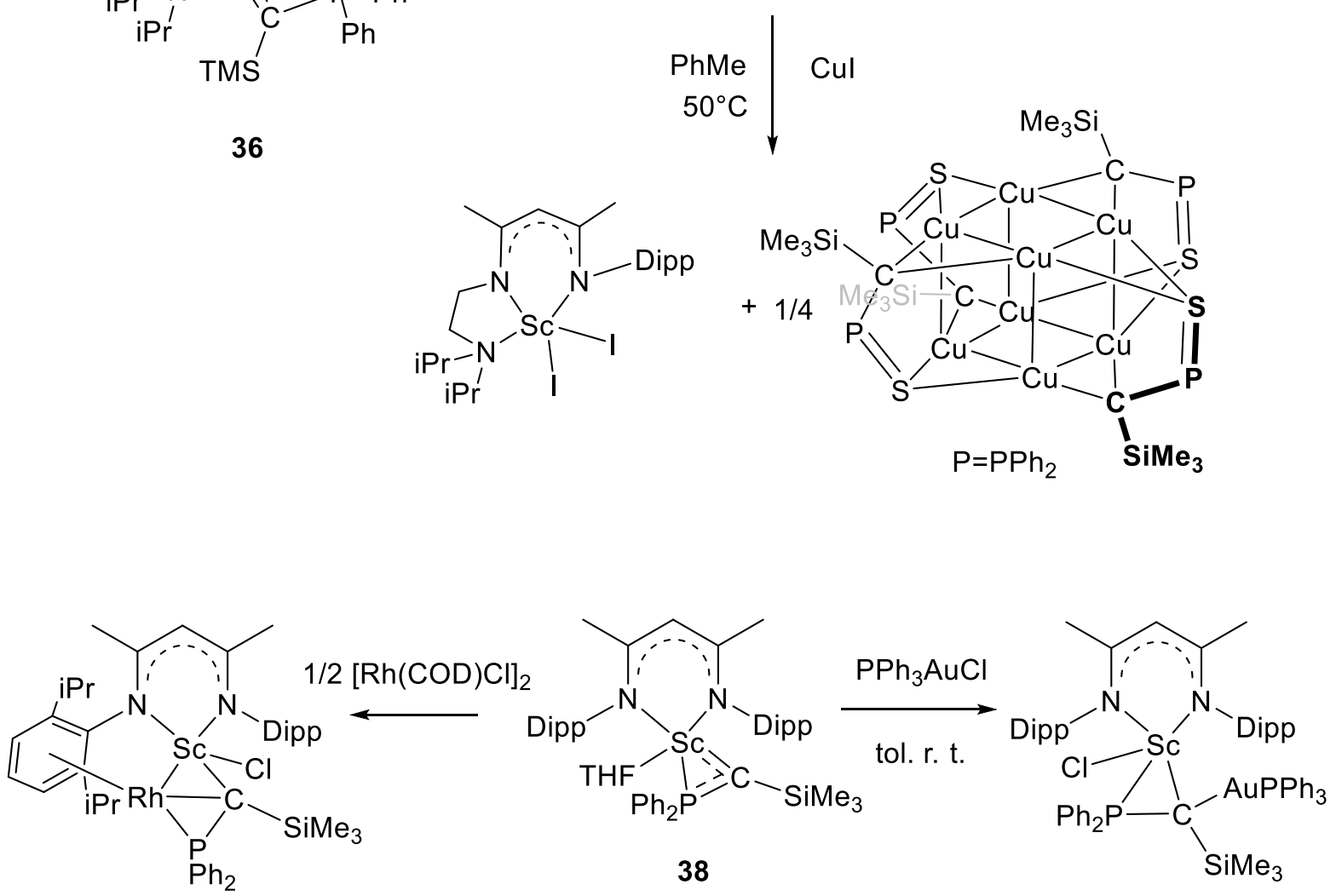
These carbene complexes have been rarely utilized in catalytic processes and it is worth noting that the $\mathrm{Nd}$ complex $[\mathrm{Nd}(\mathbf{6 c})(\mathbf{6 c H})]$ showed some activity in ring-opening polymerization of raclactide. $^{66}$

\subsubsection{Actinide complexes}

\subsubsection{Synthesis}

The fact that actinides possess several accessible oxidation states, increased covalent character of the metal-ligand bond compared to rare earth elements as well as possible involvement of f orbitals, has prompted several groups to investigate the synthesis and reactivity of carbene complexes of these elements. The first example of $\mathrm{U}$ carbene complex $\left[\mathrm{Cp}_{3} \mathrm{U}=\mathrm{CHP}(\mathrm{R}) \mathrm{Me}_{2}\right]$ was reported by Gilje in $1981 .{ }^{89}$ The geminal dilithio derivative $\mathrm{Li}_{2} \mathrm{CHP}(\mathrm{R}) \mathrm{Me}_{2}(\mathrm{R}=\mathrm{Me}$ and $\mathrm{Ph})$ cannot be synthesized and they had to rely on the anionic ylids $\left(\mathrm{CH}_{2}\right) \mathrm{P}(\mathrm{Me})(\mathrm{R})\left(\mathrm{CH}_{2}\right) \mathrm{Li}(\mathrm{R}=\mathrm{Me}$ and $\mathrm{Ph})$ as precursors. Upon reaction with $\left[\mathrm{Cp}_{3} \mathrm{UCl}\right]$, a proton migration to the second $\mathrm{CH}_{2}$ moiety, thereby forming the corresponding $\left[\mathrm{Cp}_{3} \mathrm{U}=\mathrm{CHP}(\mathrm{R}) \mathrm{Me}_{2}\right]$ complexes. The access to geminal dilithio derivatives appeared to the groups of Cavell, Liddle and Mézailles as very promising to expand this chemistry. In 2009, Mézailles, Ephritikhine and co-workers reported the reaction between $\mathrm{U}\left(\mathrm{BH}_{4}\right)_{4}$ precursor and $\mathbf{8} \mathbf{2} \mathbf{i}_{2}$ to yield a trimetallic arrangement featuring a dianionic tris-carbene complexes of U(IV) central fragment stabilized by two

cationic $\mathrm{U}\left(\mathrm{BH}_{4}\right)_{3} \cdot{ }^{90}$ When only $1 / 3$ equiv. of $\mathrm{U}\left(\mathrm{BH}_{4}\right)_{4}$ is used, the same central fragment is stabilized by Li+. Dissolution of the tris-U complex in THF resulted in a major rearrangement to the mono-carbene complex $\left[\mathrm{U}(\mathbf{8})\left(\mathrm{BH}_{4}\right)_{2}(\mathrm{THF})_{2}\right]$. The coordination chemistry of $\mathbf{8} \mathbf{L i} \mathbf{i}_{\mathbf{2}}$ was also performed from the more readily available $\mathrm{UCl}_{4}$ precursor. In this case, both the neutral monocarbene $\left[\mathrm{U}(\mathbf{8}) \mathrm{Cl}_{2}(\mathrm{THF})_{2}\right]$ and bis carbene $\left[\mathrm{U}(\mathbf{8})_{2}(\mathrm{THF})_{2}\right] \mathrm{U}(\mathrm{IV})$ complexes could be obtained. ${ }^{91}$

\section{Scheme 40: Synthesis of U(IV) carbene complexes of ligand 8.}

62 


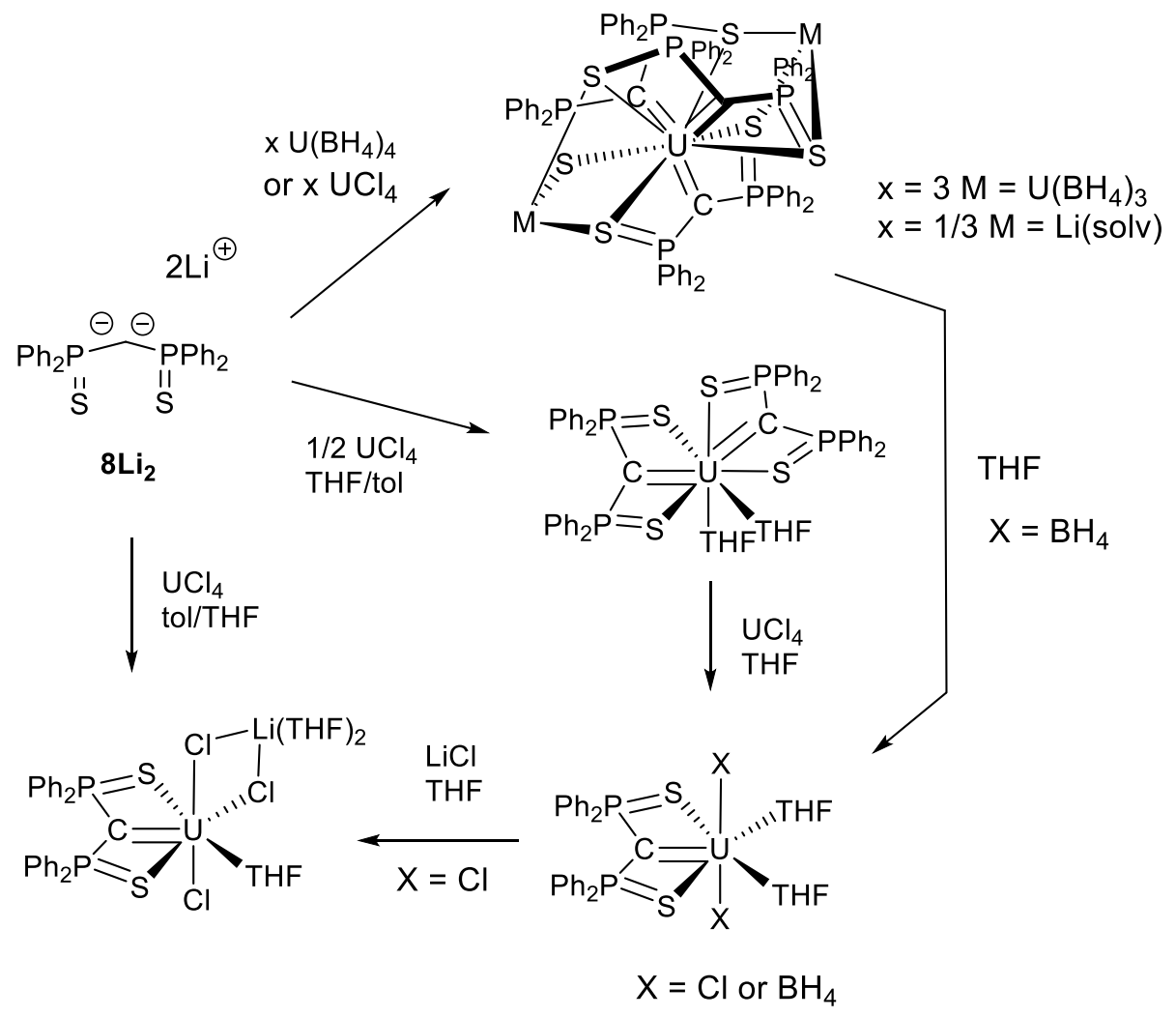

Use of uranium(IV) amide complex [U(Net $\left.)_{4}\right]$ allowed synthesis of mixed carbene/amide complexes via in situ double deprotonation of the neutral ligand. ${ }^{92}$ In 2010 , Liddle et al. reported the first bis carbene of $\mathrm{U}(\mathrm{IV})$ from the reaction of $\mathrm{UI}_{3}(\mathrm{THF})_{4}$ with the dianion $\mathbf{6} \mathbf{e} \mathbf{L i}_{\mathbf{2}}$ via an oxidation of the $\mathrm{U}(\mathrm{III})$ precursor. ${ }^{23}$ On the other hand, reaction of $\mathbf{6} \mathbf{a} \mathbf{L} \mathbf{i}_{2}$ with the tetrachloride yielded the monocarbene $\mathrm{U}$ ate complex $[\mathrm{U}(\mathbf{6 a}) \mathrm{Cl}](\mu-\mathrm{Cl})_{2} \mathrm{Li}(\mathrm{THF})_{2}$ (scheme 4-2). The group of Cavell also developed the chemistry of ligand $6 \mathbf{a L i} i_{2}$ toward actinides. In addition to the similar $\mathrm{U}(\mathrm{IV})\left[\mathrm{U}(\mathbf{6 a}) \mathrm{Cl}_{2}\right]$ complex, the $\mathrm{Th}(\mathrm{IV})$ analogue carbene complex was synthesized. The $\mathrm{Cl}$ ligands in these complexes can be readily substituted by $\mathrm{Cp}$, tris-pyrazolylborate ligands. ${ }^{93}$

Scheme 41: Synthesis of U(IV) carbene complexes of ligands 6. 

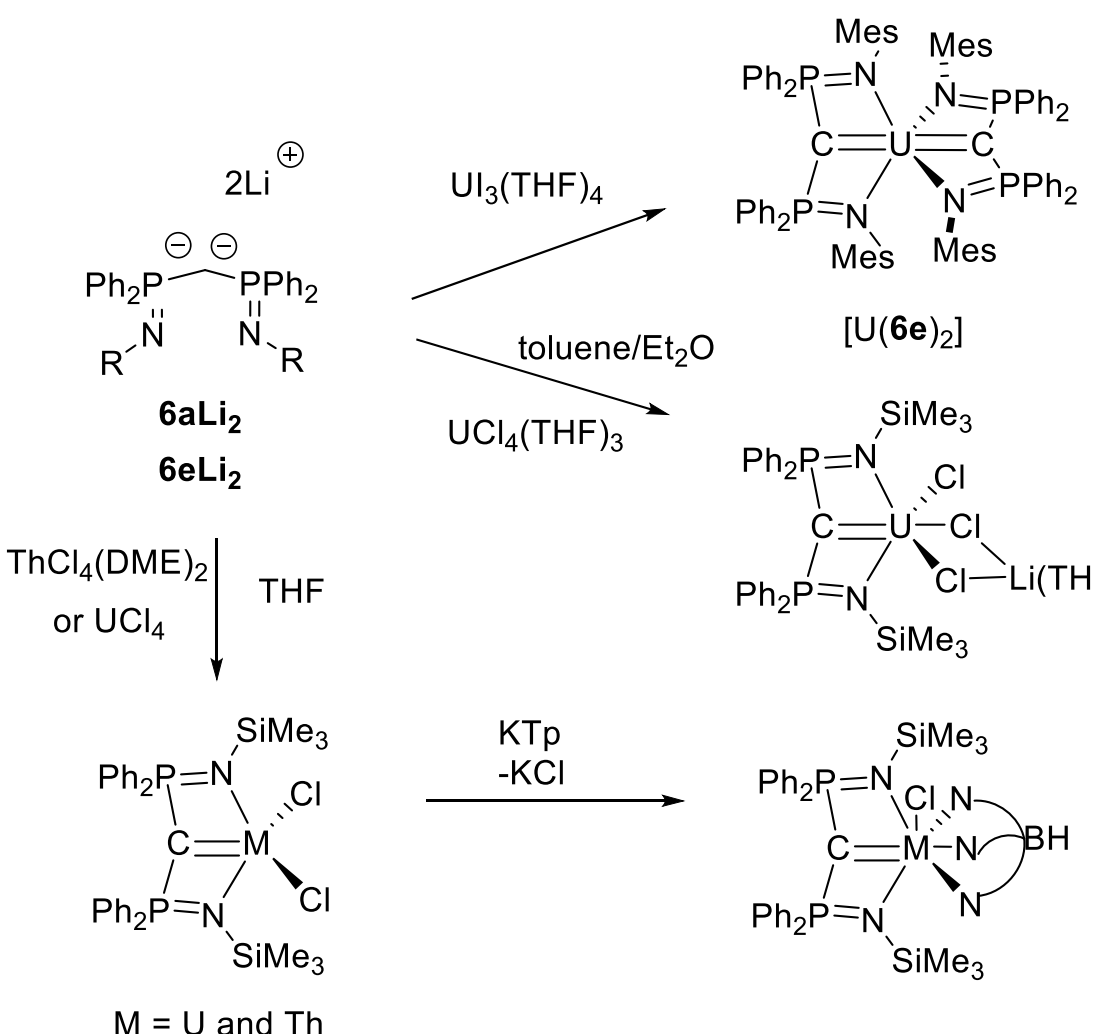

$\mathrm{M}=\mathrm{U}$ and $\mathrm{Th}$

$$
[\mathrm{U}(6 \mathbf{a}) \mathrm{CITp}]
$$

In 2011 , the possibility to use the geminal dianions to stabilize carbene complexes of $\mathrm{U}$ in high oxidation states was studied. Coordination of $\mathbf{8} \mathbf{L i}_{\mathbf{2}}$ to uranyl ion proved successful and no redox process was observed, unlike classical reactivity of uranyl with alkyl nucleophiles. ${ }^{94}$ Alternatively, the complex $\left[\mathrm{U}(\mathbf{8})(\mathrm{O})_{2}(\mathrm{py})_{2}\right]$ could be synthesized using the neutral $\mathbf{8} \mathrm{H}_{2}$ and the appropriate bis amido complex $\left[\mathrm{U}(\mathrm{O})_{2}\left(\mathrm{NTMS}_{2}\right)(\mathrm{THF})_{2}\right]$

Scheme 42: Synthesis of higher oxidation $U$ carbene complexes of ligands $6 a$ and 8. 


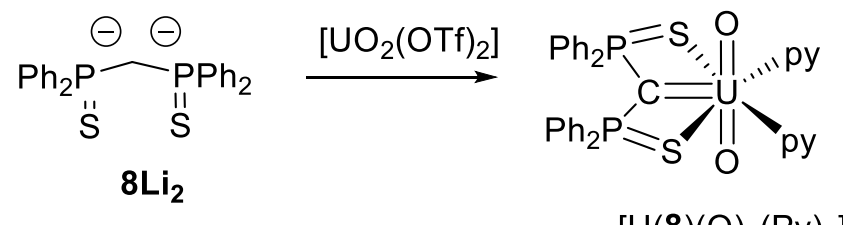

$$
\left[\mathrm{U}(\mathbf{8})(\mathrm{O})_{2}(\mathrm{Py})_{2}\right]
$$

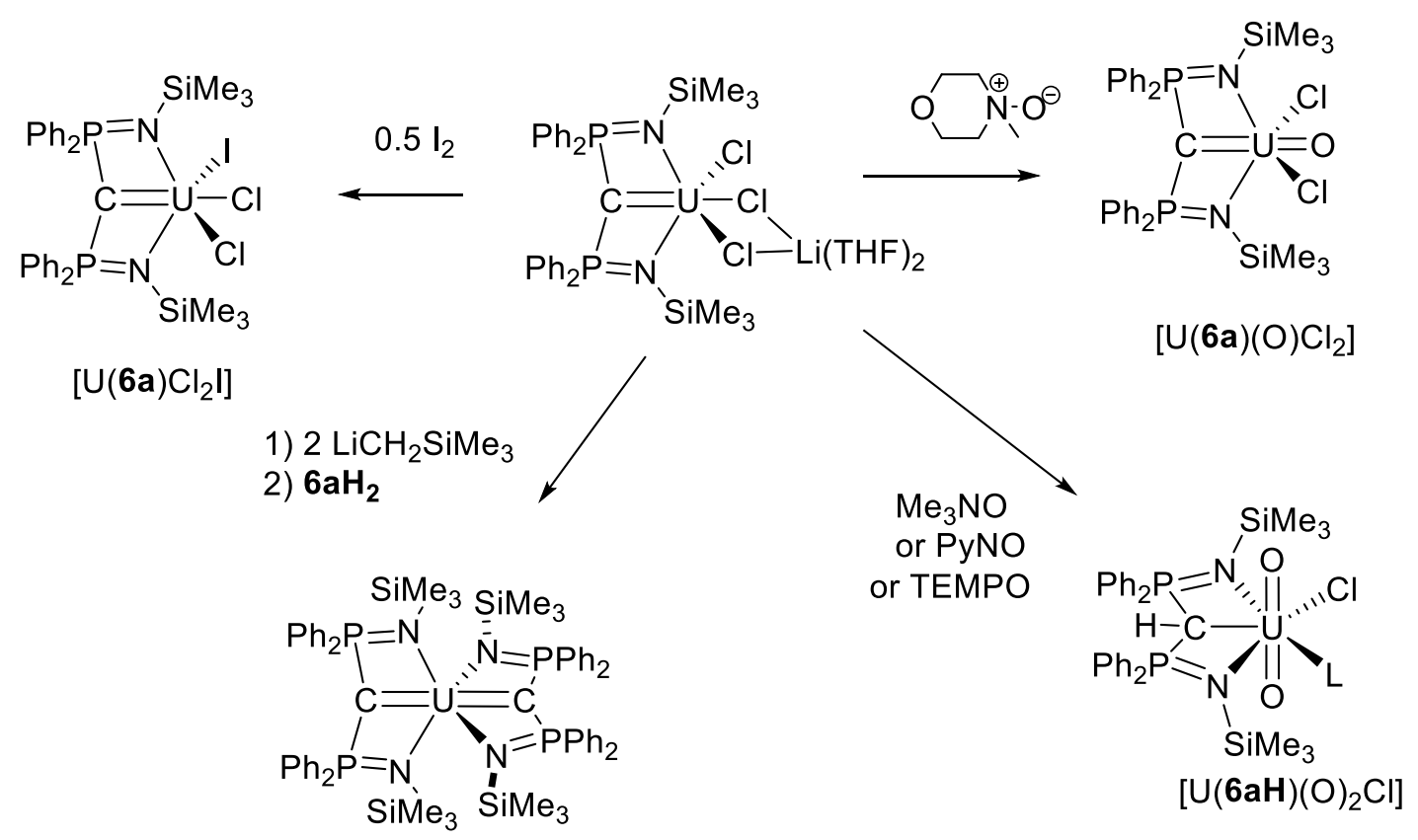

A second strategy relying on controlled oxidation of the $\mathrm{U}(\mathrm{IV})$ ate complex $[\mathrm{U}(\mathbf{6 a}) \mathrm{Cl}](\mu-\mathrm{Cl})_{2} \mathrm{Li}(\mathrm{THF})_{2}$ was pursued by Liddle et al. (scheme 42). Most impressively, they could obtain both U(V) and U(VI) carbene complexes. ${ }^{95}$ Indeed, oxidation with $\mathrm{I}_{2}$ provided the first example of a U(V) carbene complex $\left[\mathrm{U}(\mathbf{6 a}) \mathrm{Cl}_{2} \mathrm{I}\right]$ as proven by magnetic measurements as well as electronic absorption spectra (UV/Vis/NIR) and corroborated by DFT calculations (vide infra). The kinetics of the oxidation with several "O" atom donor compounds proved crucial to the success. When $\mathrm{Me}_{3} \mathrm{NO}$, PyNO or TEMPO were used, an unwanted protonation at the carbene center occurred leading to the known uranyl complex of monoanion 6aH. ${ }^{96}$ On the other hand, the reaction with 4-morpholine-N-oxide resulted in the clean oxidation and formation of $\mathrm{C}=\mathrm{U}=\mathrm{O}$ arrangement, analogous to the ubiquitous $\mathrm{O}=\mathrm{U}=\mathrm{O}$ arrangement found in $\mathrm{U}(\mathrm{VI})$ 65 
chemistry. ${ }^{97}$ In a subsequent study, Liddle and coworkers studied the possibility to stabilize reduced $\mathrm{U}(\mathrm{III})$ carbene complexes. Starting from the chloro bridged dimer $[\mathrm{U}(\mathbf{6 a}) \mathrm{Cl}(\mathrm{THF})(\mu-\mathrm{Cl})]_{2}$, the corresponding iodo bridged, obtained quantitatively after reaction with $\mathrm{TMSI}$, was reduced by $\mathrm{KC}_{8}$ in toluene. The resulting complex is a dimer featuring a mono protonated ligand $\mathbf{6 a H}$ as well as a bridging toluene molecule. Although not being a carbene complex of $U$ any longer, this complex possesses unusual properties as evidenced in the UV/VIS/NIR spectrum. DFT analysis is consistent with complex 30 being formulated as two U(III) center linked by an arene ${ }^{2-}$ moiety through covalent $\delta$ backbonding. Finally, the complex possesses a "Single Molecule Magnet" (SMM) behavior (scheme 43). ${ }^{98}$ Few years later, in 2018, they performed a similar reduction using this time an excess of $\mathrm{KC}_{8}$, which resulted in the formation of an unprecedented hexauranium ring $\left[\{\mathrm{U}(\mathbf{6} \mathbf{a})\}_{6}(\mu-\mathrm{I})_{3}\left(\mu-\eta^{6}: \eta^{6}-\mathrm{C}_{7} \mathrm{H}_{8}\right)_{3}\right]$. The rings formally contain uranium(III)- and uranium(IV)-6a fragments supported by alternating iodide and toluene bridges. ${ }^{\text {natcomm18-2097 }}$ Remarkably, the three toluene ligands could be replaced by benzene. These complexes are the only known complexes of low oxidation state U(III) stabilized by the strongly donor dianions. In 2014, the same group reported the synthesis of a carbene-imido-oxo complex. First, the imido moiety was installed at the U(IV) oxidation state, followed by oxidation to the U(VI) using TEMPO. X-ray structure analysis proved the trans arrangement of the $\mathrm{N}$ and $\mathrm{O}$ atoms, rationalized by the "inverse trans influence" observed in actinides. ${ }^{99,100}$ Bonding analysis and reactivity of this complex was reported in the same article (vide infra). ${ }^{101}$ It is interesting to note that the synthesis of the uranyl derivative "U(6a) $(\mathrm{O})_{2}$ ", analogue of the $\mathrm{U}(\mathbf{8})(\mathrm{O})_{2}$, could not be obtained directly from the $\mathbf{6 a L i _ { 2 }}$ precursor. Complex $\left[\mathrm{U}(\mathbf{6 a})(\mathrm{O})_{2}(\mathrm{DMAP})_{2}\right]$ was successfully synthesized from the selective metathesis reaction between $\left[\mathrm{U}(\mathbf{6 a})(\mathrm{NMes})(\mathrm{O})(\mathrm{DMAP})_{2}\right]$ and $\mathrm{tBuN}=\mathrm{C}=\mathrm{O}$. In 2016, the "missing piece" $\mathrm{C}=\mathrm{U}=\mathrm{NR}$ was reported, in which the $\mathrm{U}$ center is in mid-valence U(IV). In two consecutive studies, Liddle provided examples in 
which the imido moiety can be either cis or trans to the carbene moiety. If the trans arrangement is classical, and explained by the ITI, the cis geometry found in $\left[\mathrm{U}(\mathbf{6 a})\left(\mathrm{NCPh}_{3}\right)(\mathrm{BIPY})\right]$ (angle $\mathrm{C}=\mathrm{U}=\mathrm{N}$ 111.28(18) $)^{\circ}$ is most intriguing. ${ }^{102,103}$ Notably, the cis geometry is also favored when $\mathrm{N}$ and $\mathrm{C}$ are bound to an additional cation in $\left[\mathrm{U}(\mathbf{6 a})\left(\mathrm{NCPh}_{3}\right)\left(\mathrm{NHCPh}_{3}\right)\right]^{-} \mathrm{M}^{+}\left(\mathrm{M}^{+}=\mathrm{Li}^{+}\right.$or $\left.\mathrm{K}^{+}\right)$.

Scheme 43: Reduction of $\mathrm{U}(\mathrm{IV})$ carbene complex and cis vs trans $\mathrm{C}=\mathrm{U}=\mathrm{X}(\mathrm{X}=\mathrm{N}, \mathrm{O})$ in high oxidation $\mathrm{U}$ carbene complexes of ligand $6 \mathrm{a}$. 


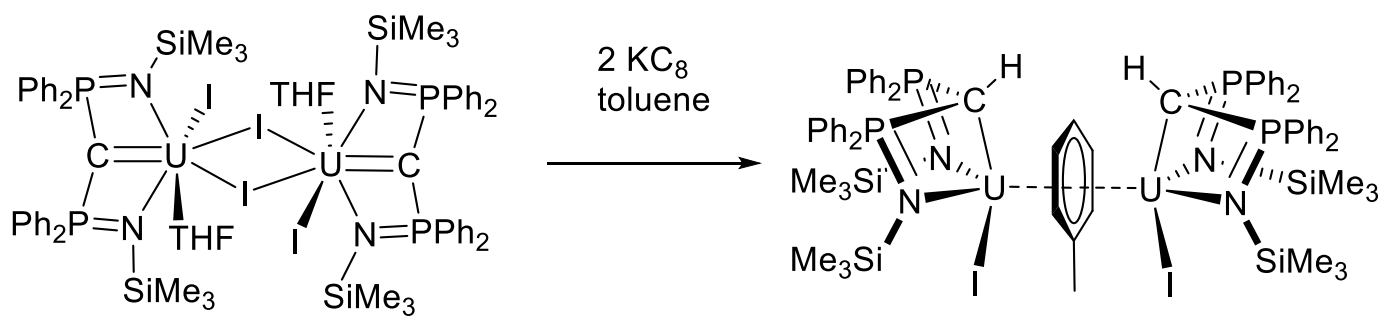

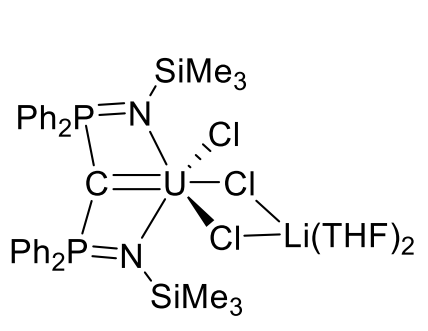
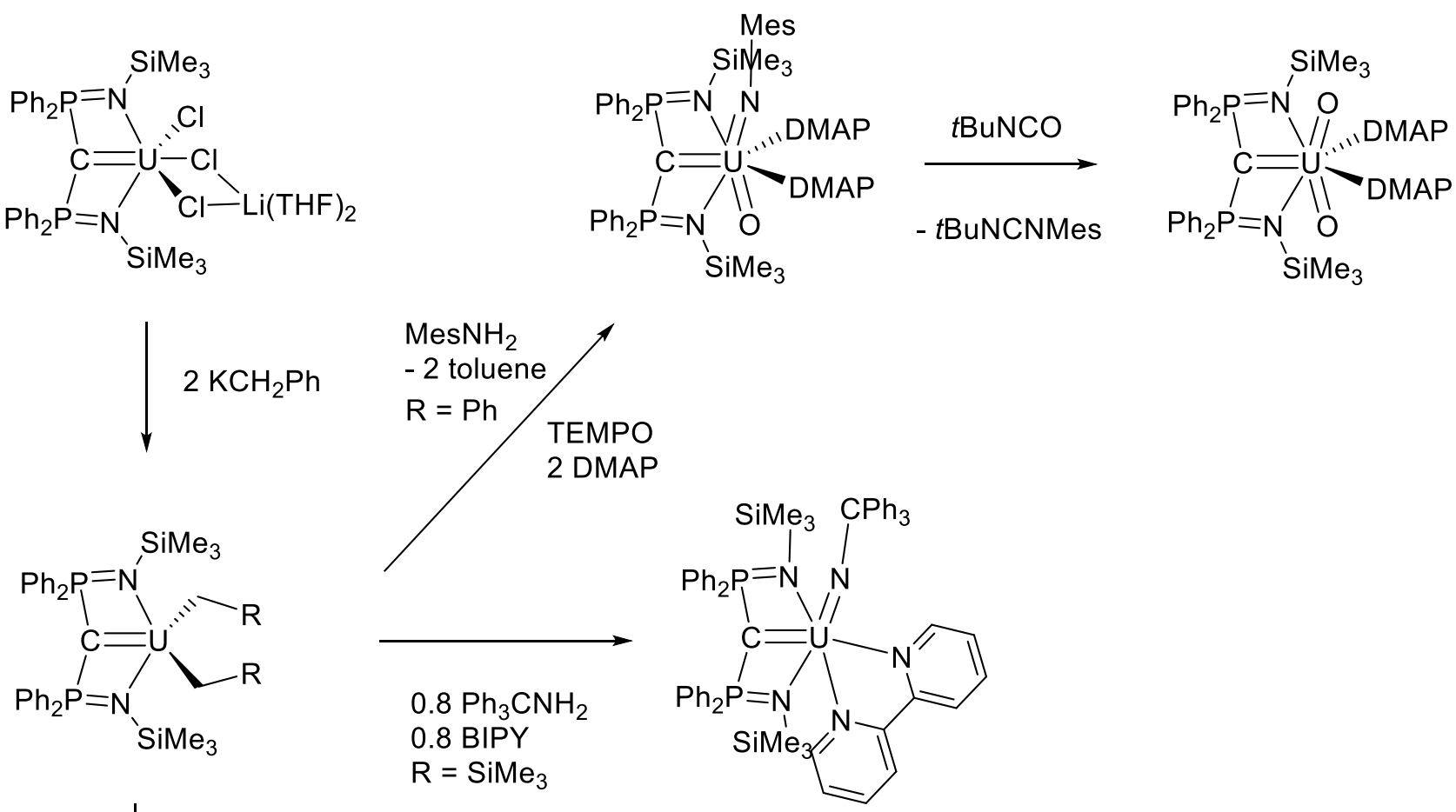

1) $2 \mathrm{Ph}_{3} \mathrm{CNH}_{2}$

- 2 toluene

$\mathrm{R}=\mathrm{Ph}$

2) $\mathrm{KBn}$

- toluene
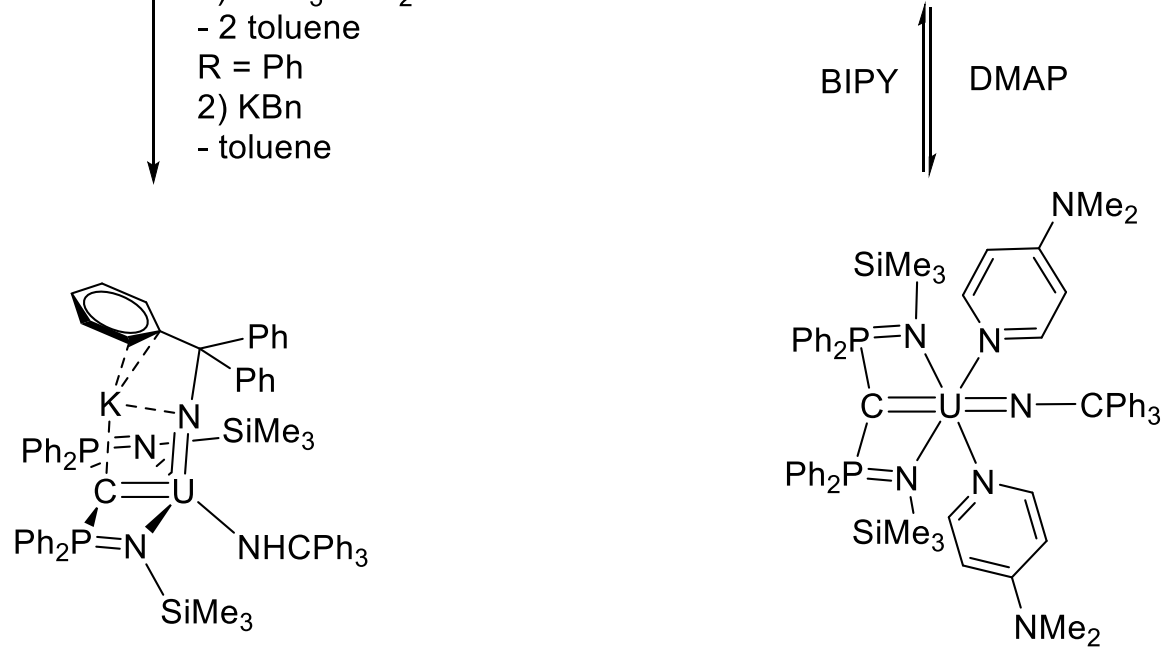
In 2017 the same group reported the synthesis of bis carbene complexes of U, Th and Ce(IV) featuring the stabilized dianion $\mathbf{6 a},{ }^{104}$ to further probe the ITI. Indeed, in these complexes the two carbene ligands are trans to one another and the $\mathrm{M}=\mathrm{C}$ bonds are short, with the $\mathrm{Ce}-\mathrm{C}$ one of the shortest. The characterization data and theoretical data suggest a trend in the covalency of the bond $\mathrm{Ce} \sim \mathrm{U}>\mathrm{Th}$, and that the ITI concept may extend beyond high oxidation state $5 \mathrm{f}$ metals to encompass $4 \mathrm{f}$ lanthanides and mid-range oxidation $5 \mathrm{f}$ actinides. In 2018, they also presented the "mixed" bis carbene complexes with $6 \mathbf{a}$ and the formal coordinated dianion $\left(\mathrm{C}\left(\mathrm{SiMe}_{3}\right)\left(\mathrm{PPh}_{2}\right)\right) .{ }^{105}$ The latter dianion cannot be synthesized as a free geminal dianion, the fragment was constructed in the coordination sphere of the U-carbene complex. It relied on the coordination of the corresponding anion and deprotonation by the carefully optimized basic $\mathrm{CHPh}\left(\mathrm{SiMe}_{3}\right)$ ligand. Three complexes featuring the motif "U(6a) $\left\{\mathrm{C}\left(\mathrm{PPh}_{2}\right)(\mathrm{TMS})\right\}$ " have been obtained which allowed a comparison in the bonding situation for the two kinds of carbene moieties (vide infra). It appears that in these complexes the $\mathrm{U}=\mathrm{C}_{\text {carbene }}$ is the structure-dictating unit (scheme 44 ).

\section{Scheme 44: Synthesis of a mixed bis carbene complex of U(IV) featuring ligand 6a.}
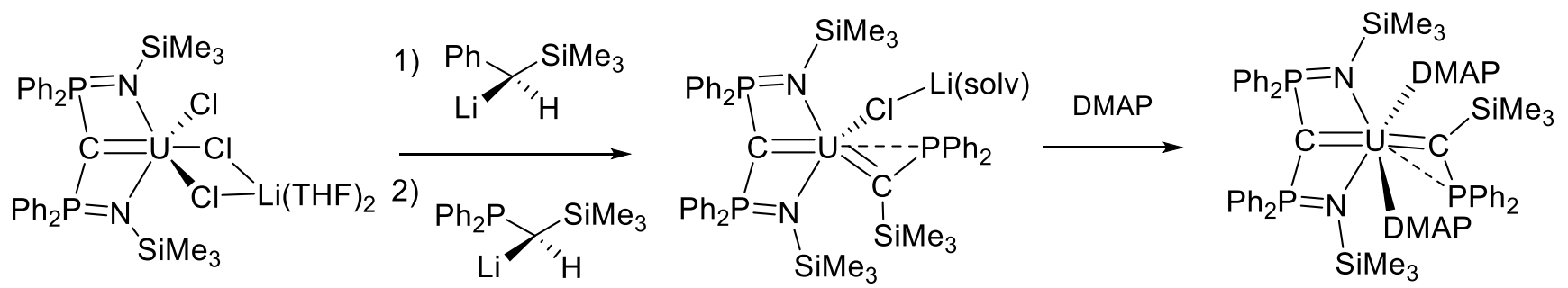

$-\mathrm{PhCH}_{2} \mathrm{SiMe}_{3}$

The coordination chemistry of the more bulky ligand $\mathbf{6 f}$ with $\mathrm{U}$ has been less studied (scheme 45). The $\mathrm{U}(\mathrm{IV})$ complex $[\mathrm{U}(\mathbf{6})](\mu-\mathrm{Cl})_{4} \mathrm{Li}\left(\mathrm{OEt}_{2}\right)(\mathrm{TMEDA})$, synthesized in a straightforward manner, allowed an entry into the higher $\mathrm{U}(\mathrm{VI})$ oxidation state $\left[\mathrm{U}(\mathbf{6 f})(\mathrm{O} t \mathrm{Bu})_{3} \mathrm{I}\right] .{ }^{106}$ In this complex, only one of the bulky PN moieties is bound to the $\mathrm{U}$ center, because of large steric requirements of the three $\mathrm{O} t \mathrm{Bu}$ ligands. 
Scheme 45: Synthesis of U(VI) carbene complex featuring ligand 6 .

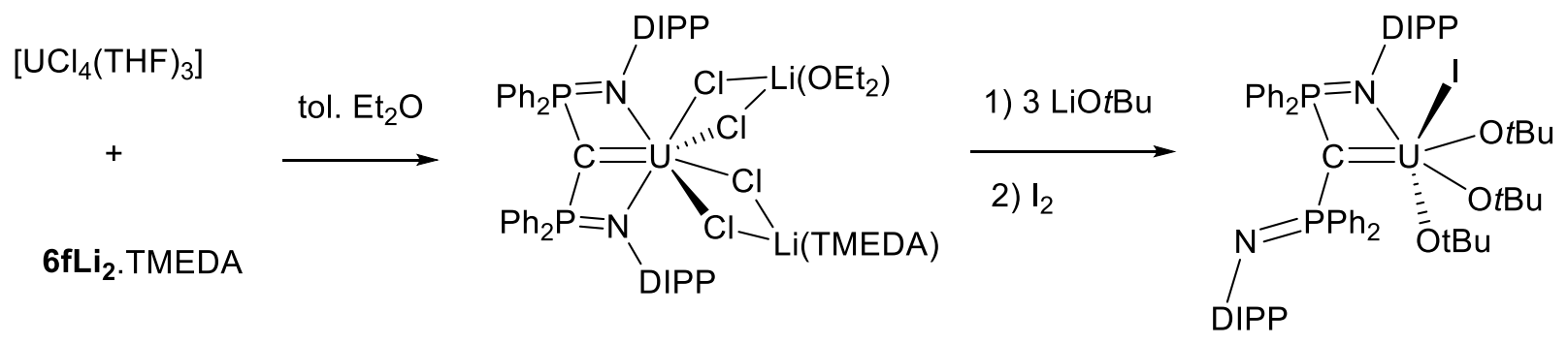

Finally, the $\mathrm{U}$ and $\mathrm{Th}(\mathrm{IV})$ analogues $\left[\mathrm{M}(\mathbf{6 a})(\mathrm{ODiPP})_{2}\right]$ of the Ce complex have been reported with an aim at describing/comparing the nature of the bonding in this series (vide infra) (scheme 45$).{ }^{107}$

\subsubsection{2. $\quad M=C(M=$ actinides $)$ bonding scheme}

As shown above, the stable geminal-dianions of bis-iminophosphorane or bis-thiphosphinoyl $\mathbf{6 a L i}_{2}$ and $\mathbf{8} \mathbf{L} \mathbf{i}_{2}$ allowed a very rich synthetic chemistry of $U$ carbene complexes of various oxidation states (IV, V and VI). It is to be noted that the efficiency of these ligands to stabilize various different oxidation states of a single metal has not been observed so far for any other metal center. Probing the nature of the interaction between the carbon center and the $\mathrm{U}$ center was central to the early works with these ligands. This characterization was done by different experimental techniques (X-ray, UV/Vis/NIR, magnetism) as well as by DFT calculations. The $\mathrm{U}=\mathrm{C}$ bond distances vary to a great extent in the reported complexes, linked to the steric requirements of the ligands, the coordination numbers at $U$ as well as its oxidation state. Similar bond distances were measured in U(IV) monomeric complexes of ligand 6a $\left(2.310(4) \AA\right.$ in $[\mathrm{U}(\mathbf{6 a}) \mathrm{Cl}](\mu-\mathrm{Cl})_{2} \mathrm{Li}(\mathrm{THF})_{2}$ and $2.351(2) \AA$ for $\left.\left[\mathrm{U}(\mathbf{6 a}) \mathrm{Cp}_{2}\right]\right)$ and in $\mathrm{U}(\mathrm{IV})$ complexes of ligand $8\left(2.327(3) \AA\right.$ in $\left[\mathrm{U}(\mathbf{8})\left(\mathrm{BH}_{4}\right)_{2}(\mathrm{THF})_{2}\right]$ to $2.396(4) \AA$ in $\left.\left[\mathrm{U}(\mathbf{8}) \mathrm{Cp}_{2}{ }_{2}\right]\right)$. Interestingly, these U-C bond distances are similar despite a strong geometrical difference within the ligand in the complexes. Indeed, in general the NCN ligand adopts an "open book" conformation whereas the SCS ligand is planar in the 
complexes due to both significant bond distances differences P-N vs P-S (ca $1.6 \AA$ vs 2.0 respectively) as well as U-N vs U-S (ca $2.45 \AA$ vs $3.05 \AA$ ). The C-U bond distances in carbene complexes are shorter than the $\sigma$ alkyl-U bond distances in U(IV) complexes (2.4 to 2.6 $⿱$ A). As mentioned above, greater coordination number can result in increased $\mathrm{U}=\mathrm{C}$ bond distance, such as in the tris-carbene complexes featuring " $\mathrm{U}(\mathbf{8})_{3}{ }^{2-"}$, fragment $\left(2.46(2) \AA\right.$ (av.). On the other hand, one electron oxidation of $\left[\mathrm{U}(\mathbf{6 a}) \mathrm{Cl}_{2}\right]$ to $\left[\mathrm{U}(\mathbf{6 a}) \mathrm{Cl}_{2} \mathrm{I}\right]$ by Liddle showed that the $\mathrm{U}=\mathrm{C}$ bond was almost not affected $(2.268(10) \AA$ in the $\mathrm{U}(\mathrm{V}) v s$ 2.310(4) $\AA$ in the U(IV) complex), reflecting that an electron of essentially nonbonding f character was removed upon oxidation. In the $\mathrm{U}(\mathrm{VI})$ carbene complex $\left[\mathrm{U}(\mathbf{6 a})(\mathrm{O}) \mathrm{Cl}_{2}\right]$, in which the carbene is trans to the oxo, the bond distance is shortened very significantly to $2.183(3) \AA$, ascribed to the inverse trans influence (ITI). On the other hand, in the U(VI) complex $\left[\mathrm{U}(\mathbf{8})(\mathrm{O})_{2}(\mathrm{Py})_{2}\right]$, the U-C bond distance is increased to $2.430(6) \AA$, despite a smaller ionic radius of $\mathrm{U}(\mathrm{VI})$ than $\mathrm{U}(\mathrm{IV})($ ca $0.2 \AA$ ). This was attributed to repulsion between the negatively charged oxo ligands and the dianionic SCS ligand, also evidenced by the strong bending of the $\mathrm{O}=\mathrm{U}=\mathrm{O}$ trans arrangement (angle of $171.8(2)^{\circ}$ ).

In the mixed bis-carbene complexes of $\mathrm{U}(\mathrm{IV})$ featuring the " $\mathrm{U}(\mathbf{6 a})\left\{\mathrm{C}\left(\mathrm{PPh}_{2}\right)(\mathrm{TMS})\right\}$ " central core, the $\mathrm{U}=$ Ccarbene distances are invariant and short $\left(2.28 \AA \mathrm{av}\right.$.) compared to the $\mathrm{U}=\mathrm{C}_{6 \mathrm{a}}$ moiety (between $2.405(9)$ and $2.459(2) \AA)$. The latter bond lengths are up to $0.1 \AA$ longer than in the other $\mathrm{U}(\mathrm{IV})(\mathbf{6 a})$ complexes. A similar bond lengthening was measured in the $\mathrm{U}(\mathbf{6 a})$ (imido) complexes (2.491(6) $\AA$ and 2.500(6) $\AA$ ). Most surprisingly, the same bond length is measure despite the cis and trans geometries of the $\mathrm{C}=\mathrm{U}=\mathrm{N}$ arrangements. Finally, in the carbene-imido-oxo complex $\left[\mathrm{U}(\mathbf{6 a})(\mathrm{NMes})(\mathrm{O})(\mathrm{DMAP})_{2}\right]$ the imido and oxo ligands are mutually trans. It is explained by the more energetically favorable arrangement of the two stronger donor ligands oxo and imido. The U=C bond 
distance in this U(VI) complex at $2.400(3) \AA$ is $0.22 \AA$ longer than in the U(VI) oxo complex with trans arrangement $\left[\mathrm{U}(\mathbf{6 a})(\mathrm{O})(\mathrm{Cl})_{2}\right]$.

DFT calculations were performed mainly to obtain precise information on the nature of the bonding between $\mathrm{C}$ and $\mathrm{U}$ in these complexes (Table 4). The first calculations, reported in 2009 , were done on the U(IV) complex $\left[\mathrm{U}(\mathbf{8})\left(\mathrm{BH}_{4}\right)_{2}(\mathrm{THF})_{2}\right] .^{90}$ The uranium center possesses 2.15 unpaired electrons consistent with a $\mathrm{U}^{\mathrm{IV}}$ metal center (high spin $6 \mathrm{~d}^{0} 5 \mathrm{f}^{2}$ configuration). The HOMO and HOMO-1 are almost pure $5 \mathrm{f}$ AOs $(\% 5 \mathrm{f}>78 \%)$, with a small antibonding interaction with the $\mathrm{S}$ atoms, while the pi interactions are found in the HOMO-2 and less so in the HOMO-5 orbitals. Because of the symmetry of the ligand in the complex, strong mixing of the contributions of $\mathrm{C}$ and $\mathrm{S}$ lone pairs are seen in the MOs. The $\sigma$ and the $\pi$ U-C interactions were analyzed by NBO. They are mainly developed on the C atom ( $\sigma$ symmetry: $80.7 \% \mathrm{C}$ and $19.3 \% \mathrm{U} ; \pi$ interaction: $82.9 \% \mathrm{C}$ and $17.1 \% \mathrm{U})$. In both cases, the U contribution is done via hybrid 5f/6d orbitals, with a major contribution of $5 \mathrm{f} v s$ $6 \mathrm{~d}(52.6 \% 5 \mathrm{f}, 37.0 \% 6 \mathrm{~d}$ in the $\sigma$ bond; $59.0 \% 5 \mathrm{f}, 40.9 \% 6 \mathrm{~d}$ in the $\pi$ bond). The NBO charges at $\mathrm{C},-1.52$, and $\mathrm{U}, 0.98$, finally concur to a bonding scheme featuring a $\mathrm{U}=\mathrm{C}$ double bond polarized toward the carbon atom. DFT calculations on the U(IV) complexes featuring ligands 6 were performed by the groups of Liddle and Cavell. ${ }^{93},{ }^{95}$ The bonding situation in terms of $\mathrm{U}=\mathrm{C}$ bond, is very similar to the one in $\left[\mathrm{U}(\mathbf{8})\left(\mathrm{BH}_{4}\right)_{2}(\mathrm{THF})_{2}\right]$. Indeed, the $\mathrm{NBO}$ analysis performed on complex $\left[(\mathbf{6 a}) \mathrm{UCl}_{2}\right]$, reveals strongly polarized $\mathrm{U}=\mathrm{C}$ bonds with almost identical involvement of $\mathrm{C}$ and $\mathrm{U}$ ( $\sigma$ bond: $82.4 \% \mathrm{C}, 17.6 \% \mathrm{U}$; $\pi$ bond : $82.2 \% \mathrm{C}, 17.8 \% \mathrm{U}$ ). These results have to be compared to DFT calculations performed on $\left[\mathrm{U}\left\{=\mathrm{CH}\left(\mathrm{PPh}_{3}\right)\left(\mathrm{NR}_{2}\right)_{3}\right\}\right]$ and $\left[\mathrm{U}\left\{=\mathrm{CHPMe}_{2} \mathrm{Ph}\right\} \mathrm{Cp}_{3}\right]$ complexes. In these two cases, the formal dianionic $\mathrm{C}$ center in " $\mathrm{CH}\left(\mathrm{PR}_{3}\right)^{- \text {" }}$ is an unstable yldiide compound. The Mulliken population analysis of the $\left[\left(\mathrm{NR}_{2}\right)_{3} \mathrm{U}=\mathrm{CH}\left(\mathrm{PPh}_{3}\right)\right]$ complex showed that the $\sigma$ and $\pi$ interactions (HOMO-6 and HOMO respectively) are also mostly $\mathrm{C}$ centered. 
Furthermore, the $\pi$ interaction possesses $22 \% \mathrm{U}$ character, slightly more than in the above mentioned complexes. The NBO analysis revealed that the $\mathrm{U}-\mathrm{C} \sigma$ bond is made of $88 \% \mathrm{C}$ and $12 \% \mathrm{U}$ character (40\% 5f vs $35 \%$ for $6 \mathrm{~d}$ ) while the $\mathrm{U}-\mathrm{C} \pi$ bond is made of $92 \% \mathrm{C}$ and only $8 \% \mathrm{U}$ character $(17 \% 5 \mathrm{f} v s$ $54 \%$ for $6 \mathrm{~d})$. A very similar picture was obtained for Gilge's complex $\left[\mathrm{Cp}_{3} \mathrm{U}=\mathrm{CHPMe} 2 \mathrm{Ph}\right]$, i.e. $\mathrm{U}-\mathrm{C} \sigma$ bond made of $88 \% \mathrm{C}, 12 \% \mathrm{U}$ and $\pi$ bond made of $93 \% \mathrm{C}$ and $7 \% \mathrm{U}$ characters. Thus, the NBO analysis pointed also in these cases a strongly polarized $\mathrm{U}-\mathrm{C}$ with a modest $\pi$ character. It is interesting to highlight that despite a more efficient stabilization of the two charges in the methanediides by $\operatorname{PPh}_{2} \mathrm{~N}$ or $\mathrm{PPh}_{2} \mathrm{~S}$ moieties (in ligands $6 \mathbf{a}$ and 8) compared to the yldiide " $\mathrm{CH}\left(\mathrm{PPh}_{3}\right)^{-"}$ " moiety, the $\pi$ donation to the metal center is more efficient with the methanediide ligands. ${ }^{106}$

A comparison between the $\mathrm{U}(\mathrm{IV})\left[(\mathbf{6 a}) \mathrm{UCl}_{2}\right]$ and the $\mathrm{U}(\mathrm{V})$ complex $\left[(\mathbf{6 a}) \mathrm{UCl}_{2} \mathrm{I}\right]$ synthesized by Liddle et al., was made. ${ }^{95}$ The oxidation results in the presence of a single electron localized in an essentially pure f-orbital (HOMO) of the U(V) complex. The U-C Nalewajski-Mrozek bond index increased upon oxidation (1.54 vs 1.43). The NBO analysis points a increased participation of $\mathrm{U}$ in both the $\sigma$ and $\pi$ bonds ( $c a 25 \%$ vs $c a 18 \%$ in U(IV) and identical involvement of $\mathrm{C}$ and $\mathrm{U}$ in the polarized $\mathrm{U}=\mathrm{C}$ bonds ( $\sigma$ bond: $74.2 \% \mathrm{C}, 25.8 \% \mathrm{U} ; \pi$ bond $74.3 \% \mathrm{C}, 25.7 \% \mathrm{U}$ ). Strikingly, the involvement of the $5 f$ orbitals is much more important than the $6 \mathrm{~d}$ orbitals ( $c a 90: 10)$ in $\left[(\mathbf{6 a}) \mathrm{UCl}_{2} \mathrm{I}\right]$, compared to the $\mathrm{U}(\mathrm{IV})$ complex (ca 60:40).

Further oxidation results in U(VI) carbene complexes, featuring oxo and/or imido ligands which were also studied by means of DFT. They presented differences dependent on the position of the O/N atoms (cis or trans to $\mathrm{C}$ ) (table). It is however clear that the general picture of the $\mathrm{U}=\mathrm{C}$ interaction remains that of an ionic bond with modest covalent character. Indeed, both the $\mathrm{U}-\mathrm{C} \sigma$ and $\pi$ bonds present mostly C character ( $c$ a 80\%) and $\mathrm{U}$ hybrid orbital ( $c$ a 20\%, with predominance of the $5 f$ over the 6d). 
Finally, complexes featuring two different carbene moieties " $\mathrm{U}(\mathbf{6 a})\left\{\mathrm{C}\left(\mathrm{SiMe}_{3}\right)\left(\mathrm{PPh}_{2}\right)\right\}$ ” reported in 2018 allowed a direct comparison of the two $\mathrm{U}=\mathrm{C}$ interactions. ${ }^{105}$ For all three complexes, the HOMO and HOMO-1 are singly occupied and essentially pure 5f character, in accord with U(IV). HOMO-2 and HOMO-3 are the $\mathrm{U}=\mathrm{C}_{\text {carb }} \pi$ and $\sigma$ bonds respectively, while the $\mathrm{U}=\mathrm{C}_{\mathbf{6}} \boldsymbol{a}$ and $\sigma$ bonds are found slightly lower in energy, as the HOMO-4 and HOMO-8 respectively. Mixing of orbital contributions of $\mathrm{U}=\mathrm{Ccarb}$ and $\mathrm{U}=\mathrm{C}_{\mathbf{6 a}}$ is however present in these molecular orbital, and NBO analysis was thus performed to get a more localized description. The $\mathrm{U}$ character in $\mathrm{U}=\mathrm{C}_{\text {carb }}$ is always larger (4-9\%) than in $\mathrm{U}=\mathrm{C}_{6 \mathbf{a}}$ for both the $\sigma$ and $\pi$ interactions. The Nalewajski-Mrozek bond index corroborate a higher bond order for $\mathrm{U}=\mathrm{C}_{\mathrm{carb}}\left(1.78\right.$ for the neutral complexes) than for $\mathrm{UC}_{\mathbf{6 a}}(1.25$ for the same complexes). It is to be noted that the $\mathrm{UC}_{6 \mathbf{6}}$ bond order is lower than in other $\mathrm{U}(\mathrm{IV})$ complexes featuring $\mathbf{6 a}$ (ca 1.5) which underscores the strongly donating nature of the carbene group. QTAIM analysis further refined the understanding of the $\mathrm{U}=\mathrm{C}$ bonds. Both of them present double bond interactions with polarized covalent U-C chemical bonds.

Table 4: Bonding scheme in carbene complexes of $U$ analyzed by DFT calculations. a: Wiberg bond index. b: Nalewajski-Mrozek bond index. $\mathrm{c}$ : NBO charge. d : MDQ charge

\begin{tabular}{|c|c|c|c|c|c|c|c|c|c|c|}
\hline \multirow{2}{*}{ complex } & \multirow{2}{*}{$\begin{array}{l}\begin{array}{l}\text { bond indi- } \\
\text { ces }\end{array} \\
\text { BI }\end{array}$} & \multicolumn{2}{|c|}{ Atomic charges } & \multicolumn{3}{|c|}{$\mathrm{U}=\mathrm{C} \sigma$-component } & \multicolumn{3}{|c|}{$\mathrm{U}=\mathrm{C} \pi$-component } & \multirow[t]{2}{*}{ ref } \\
\hline & & $\mathbf{q U}$ & $\mathbf{q C}$ & $\mathrm{C} \%$ & U\% & $\begin{array}{l}\text { U } \\
6 \mathrm{~d}: 5 \mathrm{f}\end{array}$ & $\mathrm{C} \%$ & $\mathrm{U} \%$ & $\begin{array}{l}\text { Ud:5f } \\
6 \mathrm{~d}\end{array}$ & \\
\hline $\mathrm{U}(\mathbf{8})\left(\mathrm{BH}_{4}\right)_{2}$ & & $1.52^{\mathrm{c}}$ & $0.98^{\mathrm{c}}$ & 80.7 & 19.3 & $37: 53$ & 82.9 & 17.1 & $\begin{array}{l}40.9: 5 \\
9.0\end{array}$ & 90 \\
\hline $\mathrm{U}(\mathbf{6 a})(\mathrm{Cp})_{2}$ & $0.66^{\mathrm{a}}$ & & & & & & 88.0 & 12.0 & & 93 \\
\hline $\mathrm{U}(\mathbf{6} \mathbf{a}) \mathrm{Cl}_{2}$ & $1.43^{\mathrm{b}}$ & $2.53^{\mathrm{d}}$ & $-2.00^{\mathrm{d}}$ & 82.4 & 17.6 & $20: 79$ & 82.2 & 17.8 & $\begin{array}{l}15.8: 8 \\
4.2\end{array}$ & 95 \\
\hline
\end{tabular}




\begin{tabular}{|c|c|c|c|c|c|c|c|c|c|c|}
\hline $\mathrm{U}\left(\mathrm{CHPR}_{3}\right) \mathrm{Cp}_{3}$ & & & & 88 & 12 & & 93 & 7 & & 106 \\
\hline $\mathrm{U}\left(\mathrm{CHPR}_{3}\right)\left(\mathrm{NR}_{2}\right)_{3}$ & & & & 88 & 12 & $35: 40$ & 92 & 8 & $54: 17$ & 106 \\
\hline $\mathrm{U}(\mathbf{6 a})(\mathrm{ODipp})_{2}$ & & & & 84 & 16 & $12: 87$ & 86 & 14 & $22: 77$ & 107 \\
\hline $\operatorname{Th}(\mathbf{6 a})(\mathrm{ODipp})_{2}$ & & & & & $<5$ & & & $<5$ & & 107 \\
\hline $\mathrm{Ce}(\mathbf{6 a})(\mathrm{ODipp})_{2}$ & & & & 87 & 13 & $21: 76$ & 87 & 13 & 19:80 & 72 \\
\hline $\mathrm{U}(\mathbf{6 a}) \mathrm{Cl}_{2} \mathrm{I}$ & $1.54^{\mathrm{b}}$ & $2.53^{\mathrm{d}}$ & $-1.85^{\mathrm{d}}$ & 74 & 26 & $10: 89$ & 74.3 & 25.7 & 10:90 & 95 \\
\hline $\mathrm{U}(\mathbf{6 a}) \mathrm{OCl}_{2}$ & $1.50^{\mathrm{b}}$ & $3.64^{\mathrm{d}}$ & $-2.01^{\mathrm{d}}$ & 68 & 32 & $5: 95$ & 75.8 & 24.2 & $8: 92$ & 97 \\
\hline $\mathrm{U}(\mathbf{8}) \mathrm{O}_{2}$ & $0.91^{\mathrm{a}}$ & $0.91^{\mathrm{c}}$ & $-1.46^{\mathrm{c}}$ & 81 & 19 & $24: 30$ & 87.3 & 12.7 & 23:68 & 94 \\
\hline $\begin{array}{l}\mathrm{U}(\mathbf{6 a})(\mathrm{NMes})(\mathrm{O})(\mathrm{DMA} \\
\mathrm{P})_{2}\end{array}$ & & & & 85 & 15 & $20: 80$ & 82 & 18 & $5: 94$ & 95 \\
\hline $\mathrm{U}(\mathbf{6 a})\left(\mathrm{NCPh}_{3}\right)(\mathrm{Bipy})$ & & & & 84 & 16 & $20: 80$ & 85 & 15 & $20: 80$ & 103 \\
\hline $\mathrm{U}(\mathbf{6 a})\left(\mathrm{NCPh}_{3}\right)(\mathrm{DMAP})_{2}$ & & & & 86 & 14 & $20: 80$ & 90 & 10 & $20: 80$ & 103 \\
\hline \multirow{2}{*}{$\begin{array}{l}\mathrm{U}(\mathbf{6 a})\left(\mathrm{CSiMe}_{3} \mathrm{PPh}_{2}\right)(\mu- \\
\mathrm{Cl}) \operatorname{Li}(\mathrm{TMEDA})\left(\mathrm{NR}_{3}\right)\end{array}$} & $\mathrm{U}_{-} \mathrm{C}_{6 \mathrm{a}} 1.26$ & $2.87^{\mathrm{d}}$ & $-2.0^{\mathrm{d}}$ & 86 & 14 & $32: 67$ & 89 & 11 & $33: 67$ & \multirow{2}{*}{105} \\
\hline & U-C 1.78 & & $-1.88^{\mathrm{d}}$ & 81 & 19 & $53: 44$ & 80 & 20 & 19:81 & \\
\hline \multirow{2}{*}{$\mathrm{U}(\mathbf{6 a})\left(\mathrm{CSiMe}_{3} \mathrm{PPh}_{2}\right)^{-}$} & U-C $\mathrm{C}_{6 \mathrm{a}} 1.13$ & $2.69^{d}$ & $-1.95^{\mathrm{d}}$ & 89 & 11 & $54: 45$ & 92 & 8 & $21: 79$ & \multirow[t]{2}{*}{105} \\
\hline & U-C 1.71 & & $-1.79^{\mathrm{d}}$ & 85 & 15 & $38: 62$ & 87 & 13 & $31: 67$ & \\
\hline \multirow{2}{*}{$\begin{array}{l}\mathrm{U}(\mathbf{6 a})\left\{\mathrm{C}\left(\mathrm{SiMe}_{3}\right)\left(\mathrm{PPh}_{2}\right)\right\} \\
(\mathrm{DMAP})_{2}\end{array}$} & U-C $\mathrm{C}_{6 \mathrm{a}} 1.25$ & $3.10^{\mathrm{d}}$ & $-2.02^{\mathrm{d}}$ & 85 & 15 & $42: 58$ & 87 & 13 & $35: 65$ & \multirow[t]{2}{*}{105} \\
\hline & U-C 1.78 & & $-1.84^{\mathrm{d}}$ & 81 & 19 & $30: 70$ & 79 & 21 & $36: 64$ & \\
\hline
\end{tabular}

Table 4: a: Wiberg bond index. b: Nalewajski-Mrozek bond index. c : NBO charge. $\mathrm{d}$ : MDQ charge

Overall, although differences can be found for the two ligands $\mathbf{6 a}$ and $\mathbf{8}$, calculations all point strongly polarized $\mathrm{U}=\mathrm{C}$ double bond with significant covalent character. As such, these complexes are predicted to be nucleophilic, which is confirmed by reactivity.

\subsubsection{Reactivity of Actinide complexes}


The results presented above highlight that the main interest in the chemistry of geminal dianionic ligands toward actinides (mostly $\mathrm{U}$ ) resided more in the synthesis of carbene complexes of actinides in different oxidation states than in studying their reactivity. The $\mathrm{U}$-carbene complexes of ligand $\mathbf{8}$ react in a similar fashion as the rare earth metal complexes toward ketones and aldehydes, leading to the expected Wittig-type alkene compounds in excellent yields (scheme 46). ${ }^{90},{ }^{94}$ Similarly, U-carbene complexes (U(IV) to U(VI)) of ligand 6a provide the alkene coupling product with aldehydes and benzophenone, whereas the adduct was observed with the more sterically demanding $t \mathrm{BuCOPh} .^{97}$ It is interesting to note that this reactivity differs sharply with the one of related $\mathrm{Y}(\mathbf{6 a})$, in line with the more covalent character of the $\mathrm{U}=\mathrm{C}$ bond. Cavell studied the reactivity with nitriles and showed that despite the use of an excess, the expected [2+2] reaction with the $\mathrm{U}=\mathrm{C}$ bond stopped at $50 \%$ conversion (scheme 46), likely because of coordination of the nitrile with two U centers preventing further coordination of other nitrile. $^{93}$

Scheme 46: Reactivity of $U$ carbene complexes toward electrophiles. 


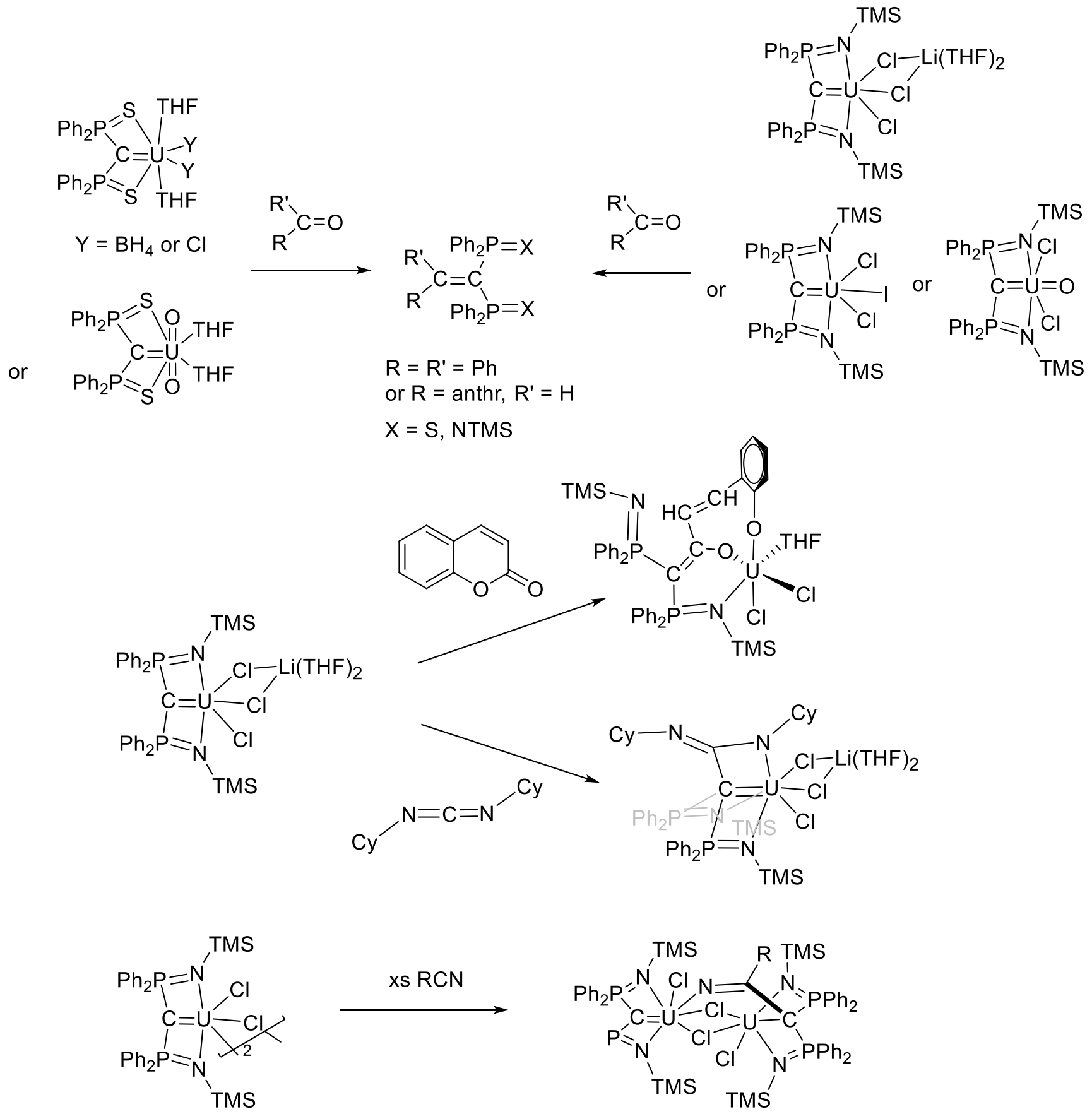

These examples clearly prove the nucleophilic carbene character of the U complexes. It is worth mentioning that complexes featuring the more bulky complexes ligand $\mathbf{6} \mathbf{f}$ did not show reactivity at the carbene center. 
Scheme 47: Divergent reactivities of $U$ carbene complexes featuring ligand $6 a$.
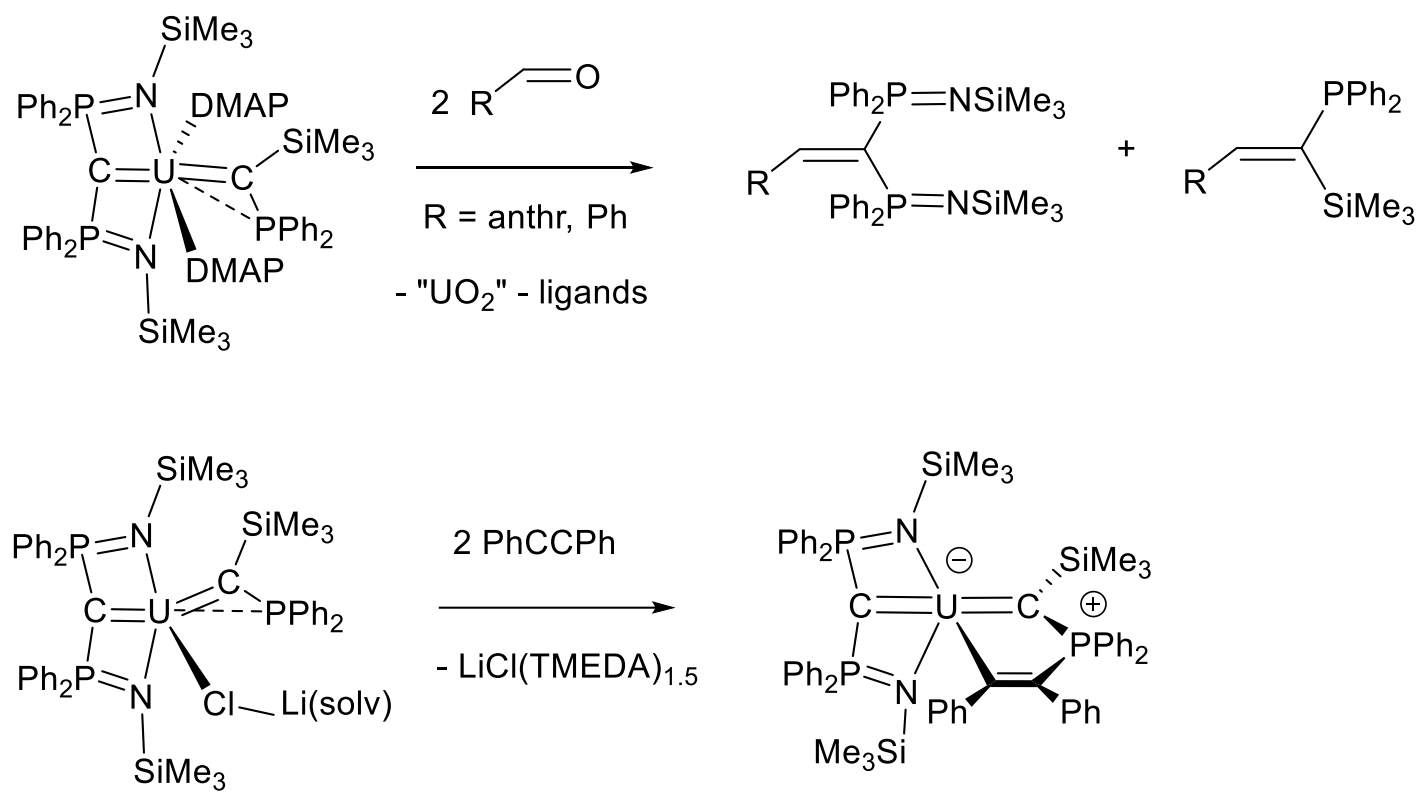

In 2018, Liddle provided the first example of divergent carbene and phosphine reactivities with their bis carbene U(IV) complexes. ${ }^{105}$ With aldehydes, the classical Wittig type chemistry of the U=C bond was observed to form the two expected alkene derivatives (in an unselective manner), whereas the reaction with diphenyl-acetylene yields a complex featuring a metalacycle in which the $\mathrm{U}=\mathrm{C}_{\text {carb }}$ moiety is intact (scheme 47).

\subsubsection{Group 4 complexes}

The group 4 carbene complexes featuring stable geminal dianions, synthesized by Cavell and coworkers in 1999, were the first M-carbene complexes obtained with these ligands. Their seminal works have inspired many groups and truly allowed this chemistry to develop.

\subsubsection{Synthesis}


In their first report, they used the simple metathetical reaction between $\mathbf{6} \mathbf{a L i}_{2}$ and $\mathrm{MCl}_{4} \cdot \mathrm{THF}_{2}$ salts $(\mathrm{M}=\mathrm{Ti}, \mathrm{Zr}){ }^{108}$ They subsequently showed that the alternative route via double deprotonation from strongly basic ligands of the metal could advantageously lead to either the monocarbene $\left[\mathrm{M}(\mathbf{6 a}) \mathrm{X}_{2}\right](\mathrm{X}$ $=\mathrm{Cl}$ or $\left.\mathrm{CH}_{2} \mathrm{Ph}\right)$ complexes. Interestingly, the related bis-carbene $\left[\mathrm{Zr}\left(\mathbf{6}^{\prime} \mathbf{a}\right)_{2}\right]$ complex could only be obtained with the dimethylphosphino derivative, for which the dianion is not known (scheme 48). ${ }^{109}{ }_{-}^{111}$ Roesky and coworkers reported the isolation of the carbene complex $[\mathrm{CpZr}(\mathbf{6 a}) \mathrm{Cl}]$. It resulted from the extrusion of a cyclopentadiene due to the high steric demand of the trimethylsilyl substituted anionic ligand. $^{112}$

Scheme 48: Synthesis of Zr carbene complexes of 6a and 6'a. 


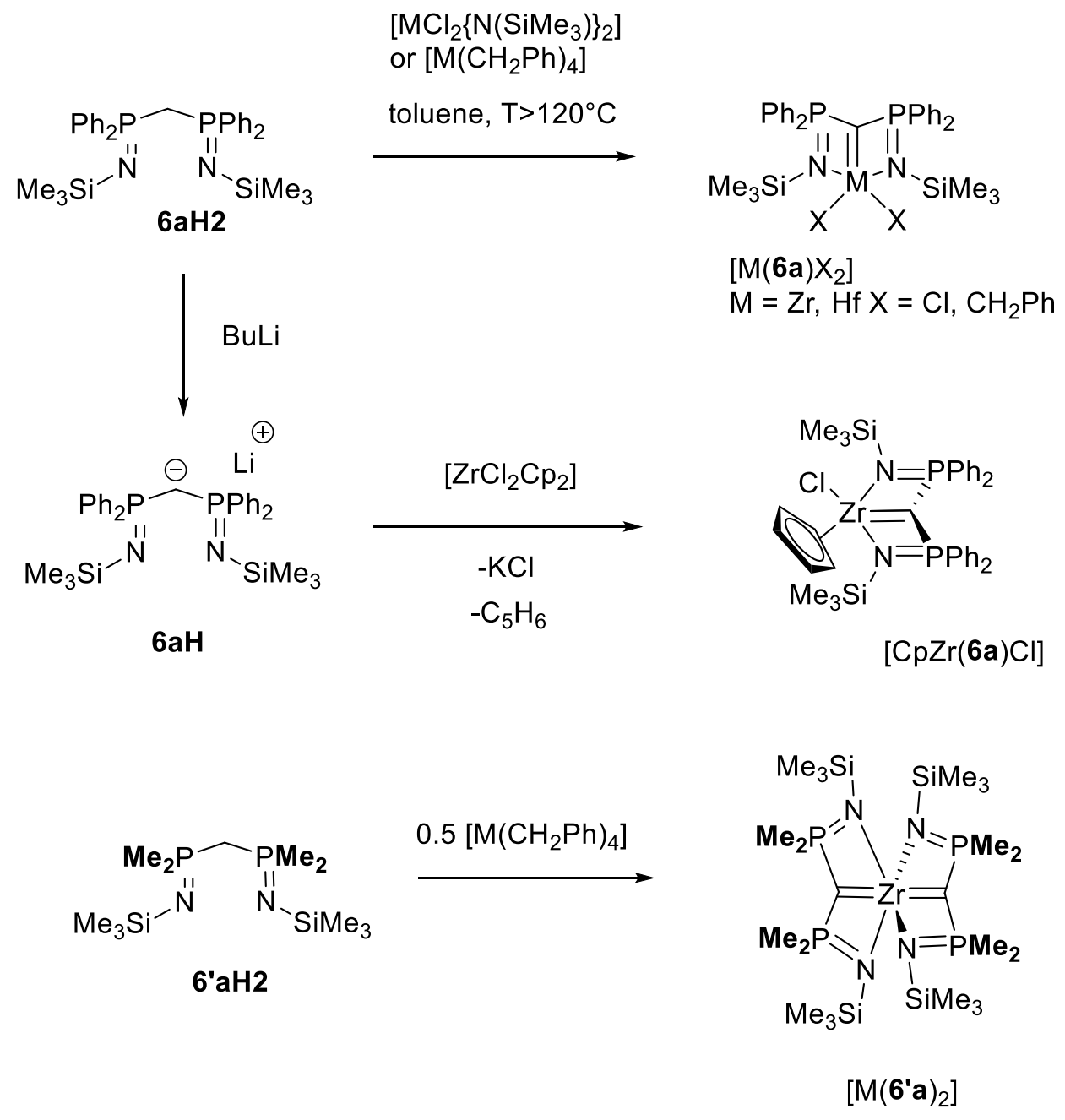

First results pertaining to the coordination of phosphonate stabilized dianions appeared in 2001. Müller et al. studied the coordination of $\mathbf{5} \mathbf{L i}_{2}$, generated in situ, toward $\left[\mathrm{TiCl}(\mathrm{O} i \mathrm{Pr})_{3}\right] .{ }^{113} \mathrm{~A}$ mixed $\mathrm{Ti} / \mathrm{Li}$ cluster 39 was crystallized in $48 \%$ yield. Among notable features of the structure, one can note that both the $\mathrm{P}=\mathrm{O}$ and the $\mathrm{P}-\mathrm{OMe}$ moieties coordinate the $\mathrm{Li}$ atoms, the $\mathrm{P}=\mathrm{O}$ moiety being bridging between one Ti and two Li centers (Scheme 49). Also notable is the partial "destruction" of the ligand as a lithiated methylphosphonate moiety is present in the crystal (as well as $\mathrm{Li}_{2} \mathrm{O}$ ).

\section{Scheme 49: Synthesis of Ti carbene complex of $5 a$.}




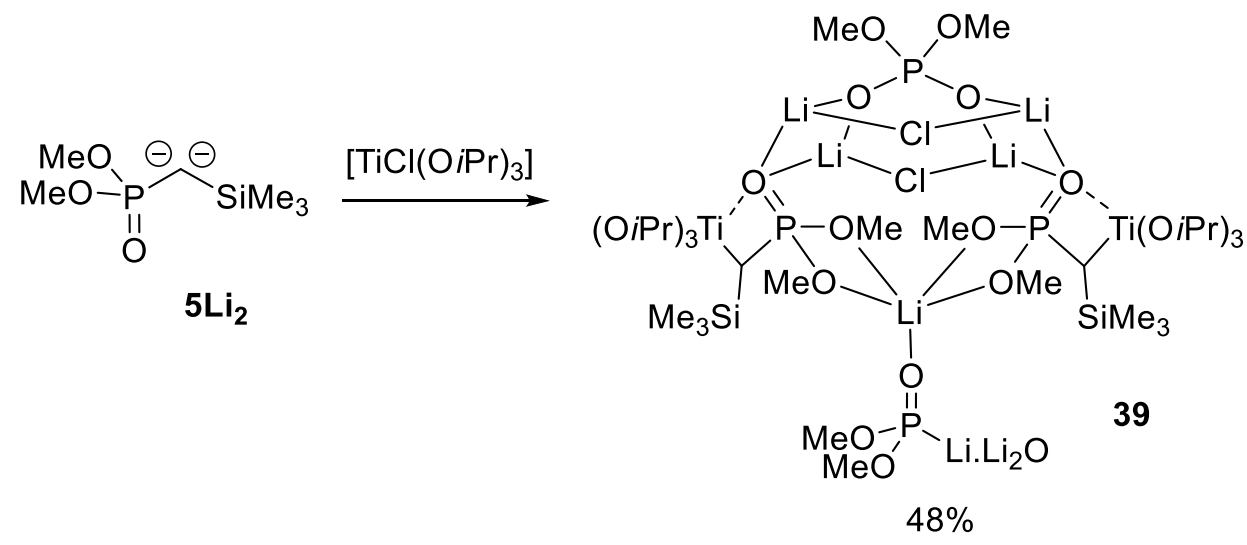

The salt metathesis route from $\mathrm{MCl}_{4}$ salts or $\mathrm{Cp}_{2} \mathrm{ZrCl}_{2}$ is the preferred one for the coordination of bis PS ligand $\mathbf{8} \mathbf{L i}_{2}$. The $\mathrm{Zr}$ complexes were reported in 2006 (Scheme 50). ${ }^{114}$ The reaction goes through an intermediate, $\left[\mathrm{Zr}(\mathbf{8}) \mathrm{Cl}_{2}(\mathrm{THF})_{2}\right]$, which is converted within $2 \mathrm{~h}$ into a chloro bridged dimer if pyridine is not added to the medium. Despite the lack of steric bulk at S, homoleptic bis-carbene complexes of $\mathrm{Zr}$ or $\mathrm{Hf}$ have not been reported. On the other hand, both mono carbene and bis carbene complexes of $\mathrm{Ti}$ could be synthesized readily from $\mathrm{TiCl}_{4} \cdot \mathrm{THF}_{2} \cdot{ }^{115}$

Scheme 50: Synthesis of $\mathrm{Zr}$ carbene complexes of ligand 8.

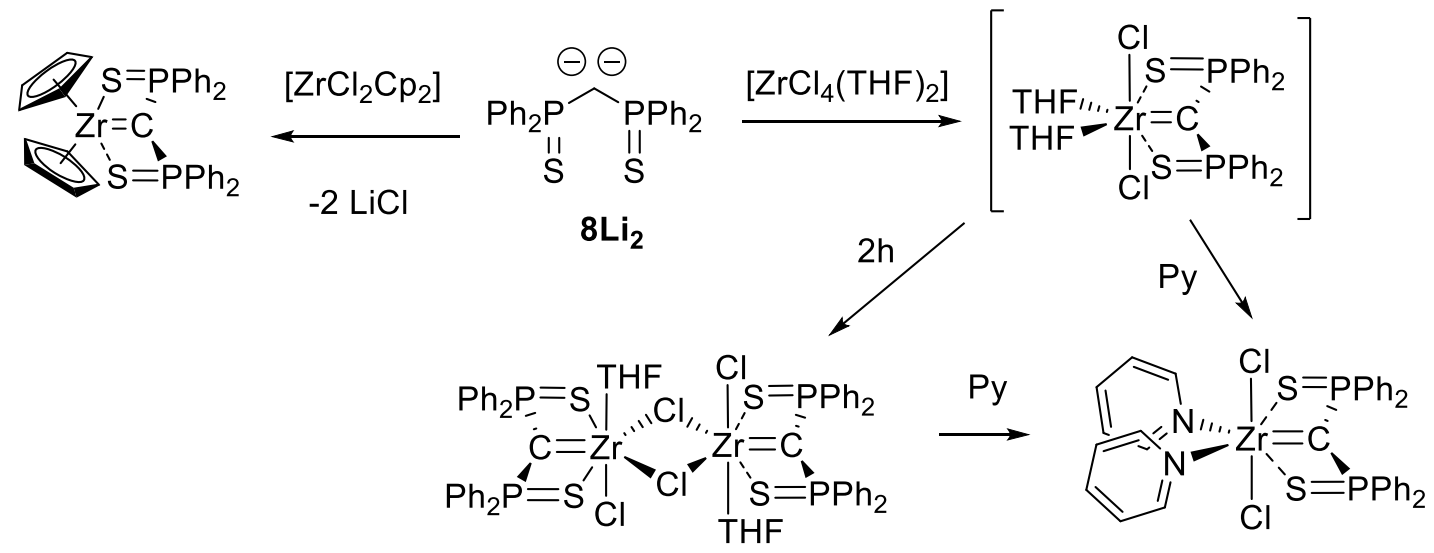


It is worth to mention here a related class of carbene complexes developed by Martin-Vaca, Bourissou et al.. The first example of indenylidene complexes of $\mathrm{Zr}$ were synthesized following in situ coordination/deprotonation of the neutral ligand (under forcing conditions) (scheme 51$).{ }^{116}$ In this case also, the corresponding isolable dianionic ligands are not accessible.

\section{Scheme 51: Synthesis of $\mathrm{Zr}$ indenylidene complexes.}

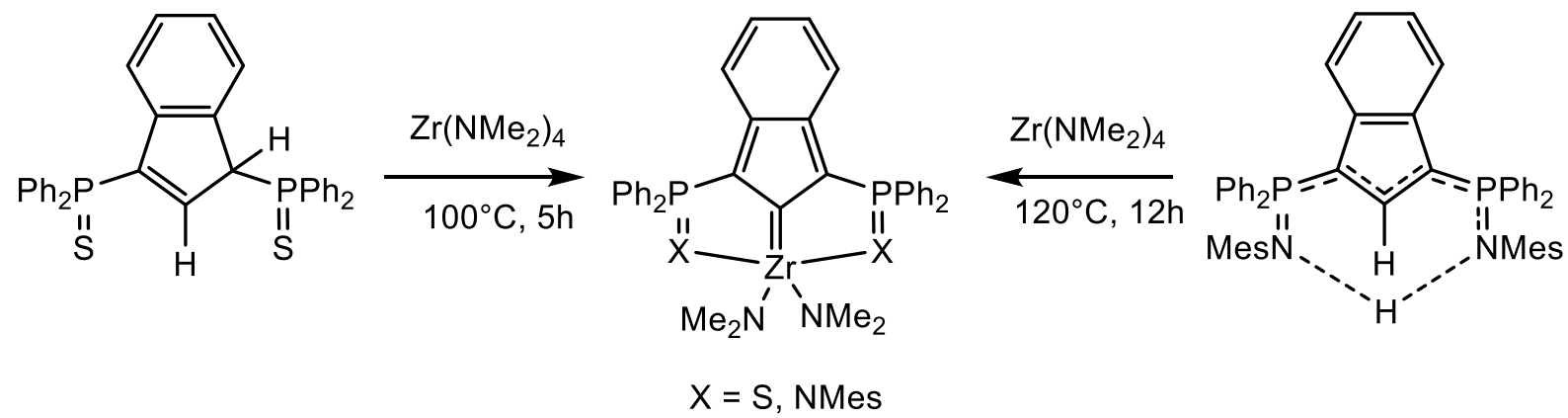

In 2010, the coordination of the bisphosphonate derivative $\mathbf{9} \mathbf{L i}_{2}$ towards $\mathrm{Zr}(\mathrm{IV})$ was studied by Mézailles. ${ }^{117}$ A trimetallic complex was obtained as a kinetic product, isolated in a low yield of $20 \%$. In this complex, a triscarbene dianionic $\mathrm{Zr}$ moiety is found, stabilized by two cationic " $\mathrm{ZrCl}_{3}$ " fragments. More aggregated " $\mathrm{Zr}(\mathbf{9}) \mathrm{Cl}_{2}$ " fragments are likely formed in the medium as addition of coordinating ligand pyridine resulted in major rearrangements leading to a novel bimetallic mono carbene complex (scheme 52). Such as geometry is likely obtained because the $\mathrm{P}=\mathrm{O}$ bond is shorter than the $\mathrm{P}=\mathrm{NR}$ or $\mathrm{P}=\mathrm{S}$ bonds, and thus prevents coordination of the two $\mathrm{P}=\mathrm{O}$ moieties to a single $\mathrm{Zr}$ center. The coordinating properties of the phosphonate are likely responsible for the facile kinetic/thermodynamic product rearrangement via ligands redistribution at room temperature in non-coordinating solvent.

\section{Scheme 52: Synthesis of Zr carbene complexes of ligand 9.}



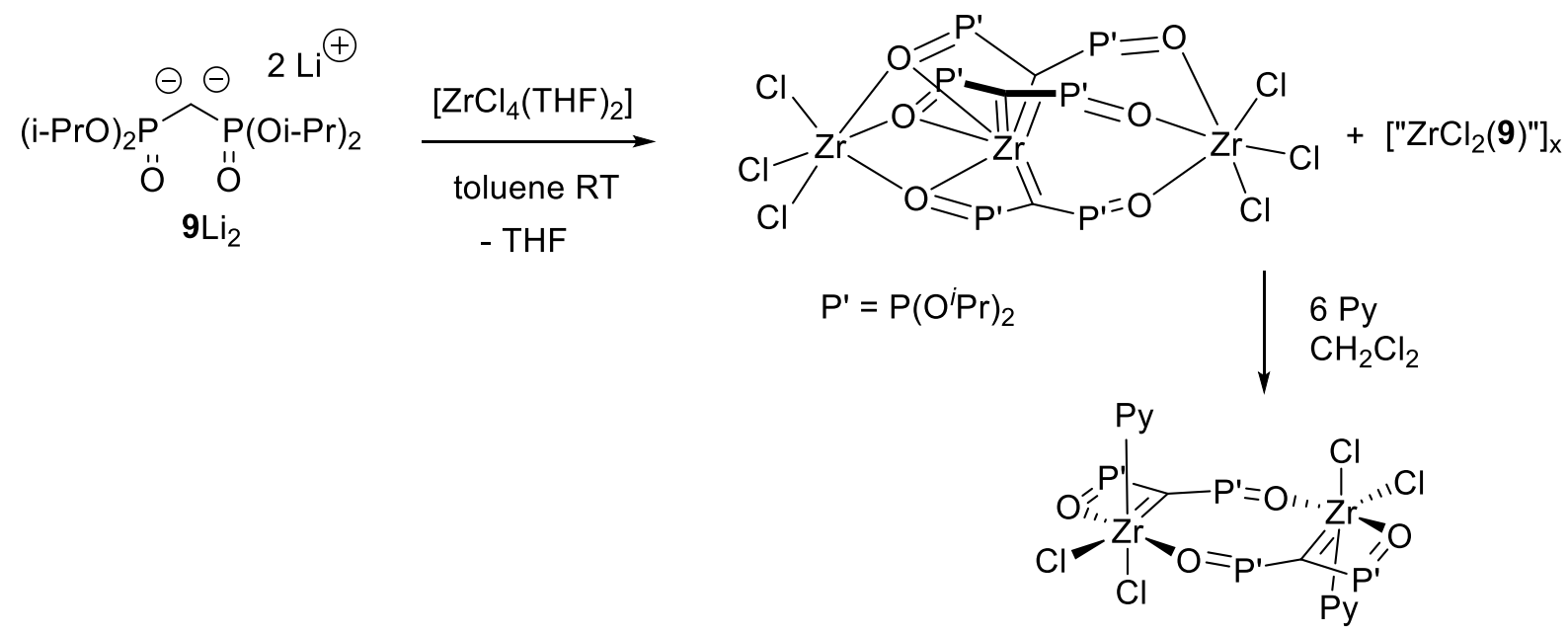

Finally, in 2014, Gessner and co-workers reported the coordination of dianion $11 \mathbf{L i}_{2}$ toward several metal centers, among which $\mathrm{Zr}$ (scheme 53). ${ }^{118}$ In the complex, both the PS and the SO moieties are bound to the $\mathrm{Zr}$ center, leading to the formation of diastereomers. While only the $R_{C} R_{S}$ diastereomer is found in the crystal, a fluxional behavior is observed in solution. Coalescence was seen at $-26^{\circ} \mathrm{C}$ for the signals of the $\mathrm{Cp}$ ligands allowing for an estimation of the rotation barrier, via decoordination, of 52 $\mathrm{kJ} / \mathrm{mol}$. The ${ }^{13} \mathrm{C}\left\{{ }^{1} \mathrm{H}\right\} \mathrm{NMR}$ resonance of the carbene carbon atom appearing at $41 \mathrm{ppm}$ indicate a strong charge at the carbenic carbon.

\section{Scheme 53: Synthesis of $\mathrm{Zr}$ carbene complex of ligand 11.}

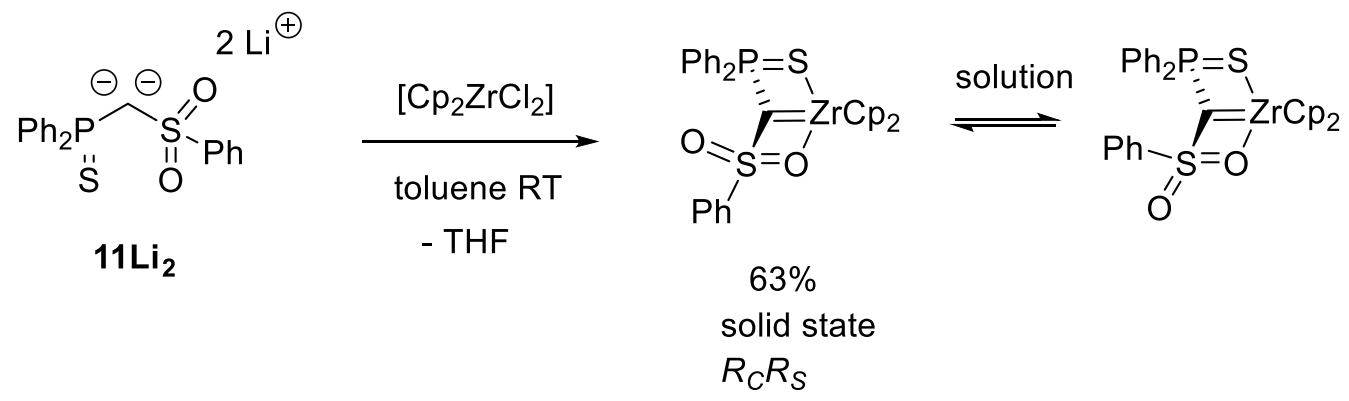

\subsubsection{2. $\quad M=C(M=$ group 4 metal $)$ bonding scheme}


It can be expected that the orbital overlap, and thus the covalency of the $\mathrm{M}=\mathrm{C}$ bond, would be stronger with group 4 metals than with metals of earlier groups. Müller et al. have studied the rotation barrier about the P-C bond in the mixed Ti/Li silyl-phosphonate system. A comparison with the one found in phosphoryl stabilized carbanions revealed a very similar barrier of rotation, showing that the Ti center did not enhance the configurational stability at the $\mathrm{C}$ center. ${ }^{113}$

\section{Scheme 54: Bonding scheme in $\mathrm{Zr}$ carbene complexes of type I ligands.}
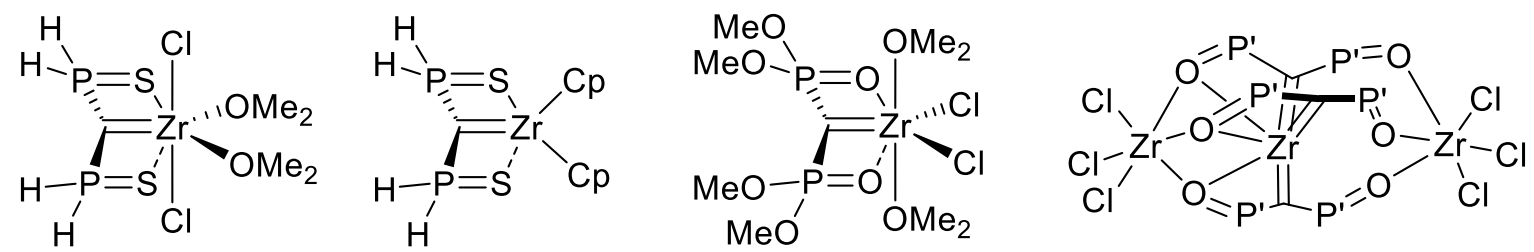

$\mathrm{P}^{\prime}=\mathrm{P}(\mathrm{OMe})_{2}$

An NBO analysis was performed on several $\mathrm{Zr}$ carbene complexes (scheme 54). Notably, the charge calculated at $\mathrm{C}$ is greatly reduced compared to the corresponding geminal dilithio derivatives, which translates to a significant electronic donation to the $\mathrm{Zr}$ center. The nature of the $\mathrm{Zr}$-Carbene interaction was then further probed using AOMIX. In this method, the complex is decomposed into two fragments and the MO diagram describing the $\pi$-interaction was built from the fragment orbitals of the same symmetry. The emerging picture for all complexes is that a significant electron density remains on the carbon center, consistent with the NBO charge. Thus, in these group 4 metal carbene complexes, the orbital overlap increases compared to group 1,2 and 3 metals and the metal/carbon interaction gains in covalency, although the bond stays strongly polarized.

A different picture emerged for the indenylidene complexes (scheme 51). In fact, no significant $\pi$ interaction between $\mathrm{C}$ and $\mathrm{Zr}$ was identified, ${ }^{116}$ and the $\pi$ lone pair at $\mathrm{C}$ is delocalized towards the carbon backbone of the indenyl. 


\subsubsection{Reactivity of Group 4 metal complexes}

Starting from 2000, the reactivity of these group 4 metal complexes has been studied along different directions by Cavell and co-workers. Starting from complex $\left[\mathrm{M}(\mathbf{6 a}) \mathrm{Cl}_{2}\right](\mathrm{M}=\mathrm{Zr}$, Hf), the classical $\mathrm{Cl}^{-}$substitution was observed with nucleophiles such as alkyllithium (Scheme 55$) .{ }^{110}$ The reactions with strong electrophiles such as isocyanates, carbon dioxide or carbodiimide did result in the [2+2] cycloaddition. Obvious basicity of the $\mathrm{C}$ center was evidenced by reactions with aromatic amines, or aliphatic alcohols while nucleophilic character was shown by CC bond formation with methyl iodide, leading to the 1,2 addition product.

Scheme 55: Reactivity of group 4 carbene complexes of ligand 6a.

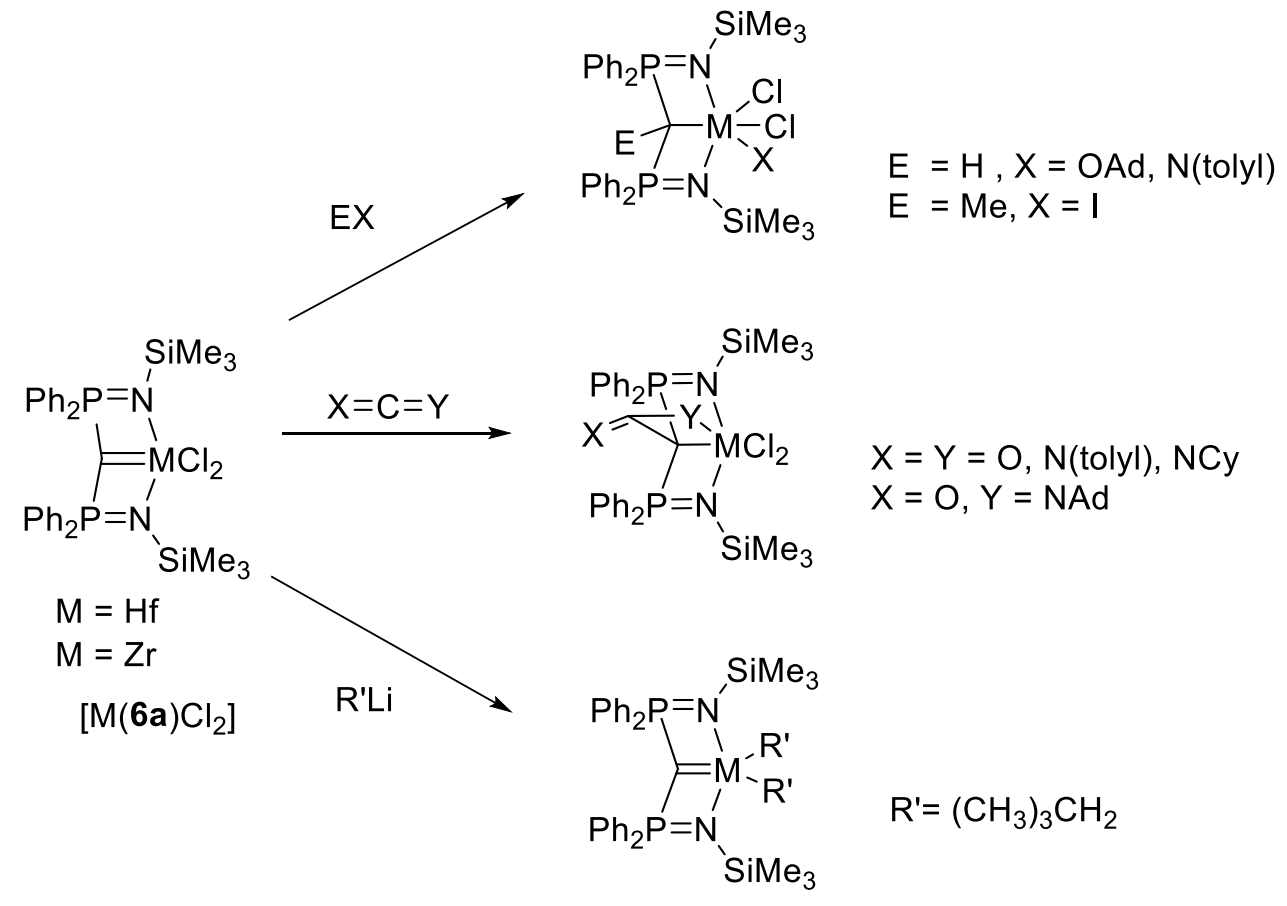

Mézailles and co-workers have studied the reactivity of $\mathrm{Zr}$ carbene complexes featuring ligand $\mathbf{8}$ and 9 in 2006 and 2010 respectively. Complex $\left[\mathrm{Cp}_{2} \operatorname{Zr}(\mathbf{8})\right]$ proved to be unreactive because of its electronic saturation, while the dichloro derivatives $\left[\mathrm{Zr}(\mathbf{8}) \mathrm{Cl}_{2}(\mathrm{THF})\right]_{2}$ and $\left[\mathrm{Zr}(\mathbf{8}) \mathrm{Cl}_{2}(\mathrm{Py})_{2}\right]$ appeared more 
reactive than the related bis PN complexes. ${ }^{114}$ Reaction with weaker electrophiles (aldehydes and ketones) afforded the corresponding geminal bis(diphenylthiophosphinoyl)olefins (scheme 56). $\mathrm{Zr}$ complexes featuring the bis-phosphonate ligand $\mathbf{9}$ were reported to react with aldehydes but not with ketones. ${ }^{117}$

Scheme 56: Reactivity of $\mathrm{Zr}$ carbene complexes of ligand 8.

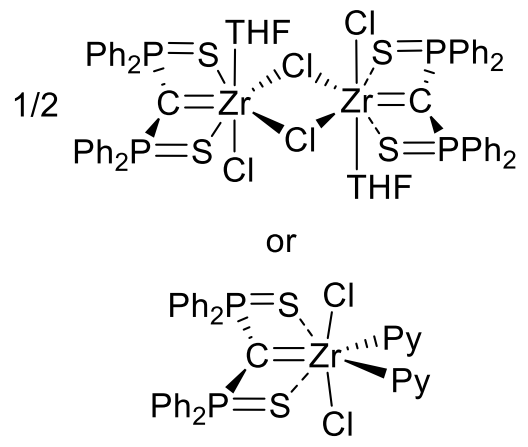

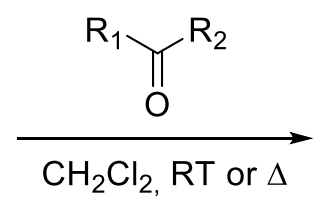

$$
\begin{aligned}
& \mathrm{R}_{1}=\mathrm{H}, \quad \mathrm{R}_{2}=9 \text {-anthracenyl, 2-furyl } \\
& \mathrm{R}_{1}=\mathrm{R}_{2}=\mathrm{Ph}, 2 \text {-pyridyl, 2-thienyl }
\end{aligned}
$$

In 2014 , the reactivity of $\left[\mathrm{Ti}(\mathbf{8}) \mathrm{Cl}_{2}\right.$ (THF)] toward carbodiimide was studied (scheme 57). Unlike what was observed with $\left[\mathrm{Ti}(\mathbf{6 a}) \mathrm{Cl}_{2}(\mathrm{THF})_{2}\right]$, the [2+2] adduct is not the final product. ${ }^{115}$ The keteneimine resulting from the subsequent $\mathrm{C}-\mathrm{N}$ bond breaking and $\mathrm{C}=\mathrm{C}$ bond forming was indeed isolated. The $\mathrm{Ti}$ imido intermediate $\mathbf{I}$ formed during this process was trapped by an excess of dicyclo-carbodiimide and $\mathrm{TiCl}_{4}$, yielding complex $\mathbf{4 0}$ which was crystallized.

Scheme 57: Reactivity of $\left[\mathrm{Ti}(\mathrm{8}) \mathrm{Cl}_{2}(\mathrm{THF})\right]$ toward $\mathrm{CyN}=\mathrm{C}=\mathrm{NCy}$. 

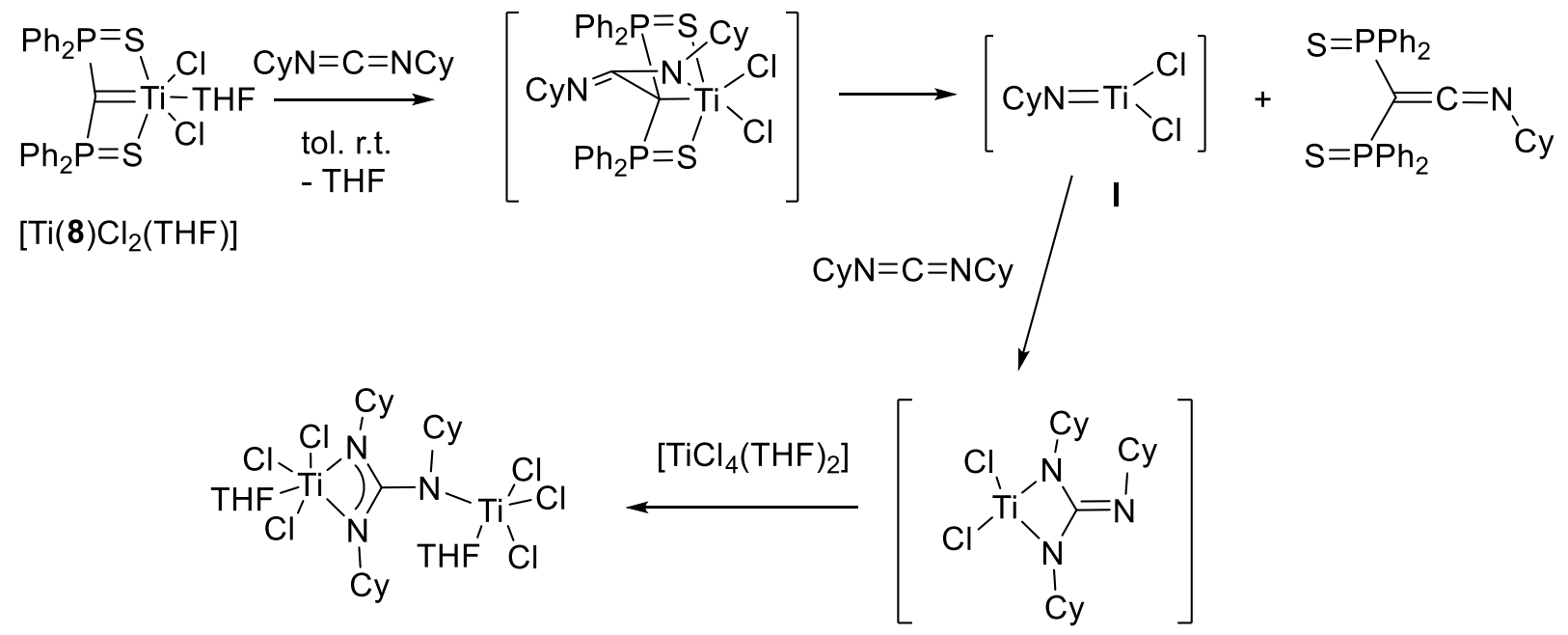

40

Finally, $\mathrm{Zr}$ carbene complex $\left[\mathrm{Zr}(\mathbf{8}) \mathrm{Cl}_{2}(\mathrm{THF})\right]_{2}$ was tested as a carbene transfer agent toward late transition metals. Transmetalation was efficient to generate carbene complexes of $\mathrm{Ru}(\mathrm{II}), \mathrm{Co}(\mathrm{II})$ and Pd(II), but it was not successful to obtain the Fe complex that could be synthesized from the $\left[\mathrm{Sc}(\mathbf{8}) \mathrm{Cl}(\mathrm{Py})_{2}\right]$ complex following the same strategy. It was rationalized by the stronger $\mathrm{Zr}=\mathrm{C}$ bond than the related $\mathrm{Sc}=\mathrm{C}$ bond. ${ }^{87}$

\subsubsection{Group 6 complexes}

There is so far no example of complexes of group 5 with geminal dianions, and only few complexes have been obtained with group 6 . The outcome of the reaction between $\mathbf{6} \mathbf{a} \mathbf{L i}_{2}$ and $\mathrm{CrCl}_{2}(\mathrm{THF})_{2}$ provided the first example in which the ligand acts as a bridging ligand rather than a carbene. It thus appears that the double sigma donation to two metals is preferred to $\sigma+\pi$ donation to one. ${ }^{119}$ Two different complexes were isolated. In a 1:1 metal to ligand ratio, the dimeric complex $[\mathrm{Cr}(\mathbf{6 a})]_{2}$ was obtained. The room temperature magnetic moment of this species is too low to account for the total unpaired electrons for $\mathrm{Cr}(\mathrm{II})$ which points interaction between the $\mathrm{Cr}$ centers. The central core of the complex features four planar four membered rings Cr-N-P-C. A dihedral angle of $45.8^{\circ}$ av. is measured be- 
tween the two planar rings of each ligand. A tetra chromium complex was synthesized when only 0.5 equiv. of $\mathbf{6} \mathbf{a L i}_{2}$ were used. In this case, two different $\mathrm{Cr}$ centers are found (scheme 58).

\section{Scheme 58: Synthesis of bridging Cr complexes from $6 \mathrm{aLi}_{2}$.}

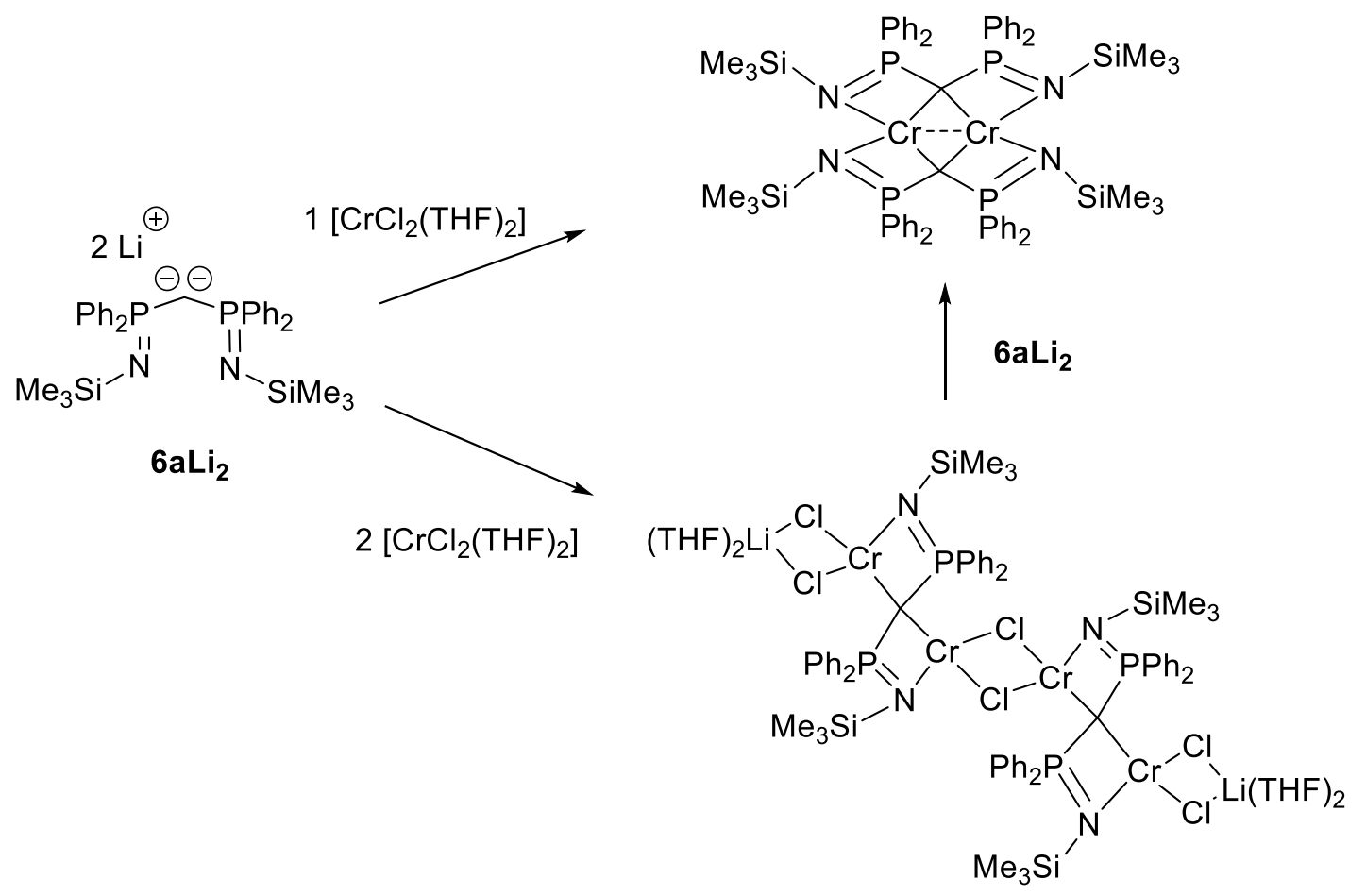

Leung and coworkers did not use the geminal dilithio derivative $\mathbf{6} \mathbf{a L i} \mathbf{i}_{2}$, but a bisgermavinylidene (vide infra) complex as transmetalating reagent. Its reaction with $\mathrm{M}(\mathrm{CO})_{5}(\mathrm{THF})(\mathrm{M}=\mathrm{Cr}, \mathrm{Mo}, \mathrm{W})$ formed the "metallagermacyclopropane" heterobimetallic complexes in moderate yields $(\mathrm{M}=\mathrm{W}, 37 \%, \mathrm{M}=\mathrm{Cr}$, $43 \%$ ), with $6 \mathbf{a}$ being the bridging ligand (scheme 59). ${ }^{120}$ In the case of molybdenum, the reaction required 3 days and the major product $(48 \%)$ was the carbene complex $\left[\mathrm{Mo}(\mathbf{6 a})(\mathrm{CO})_{3}\right]$ as a mixture of $f a c$ and mer isomers in solution. Only the fac derivative crystallized and was characterized by X-ray crystallography.

\section{Scheme 59: Synthesis of Mo complexes by transmetallation from Ge.}



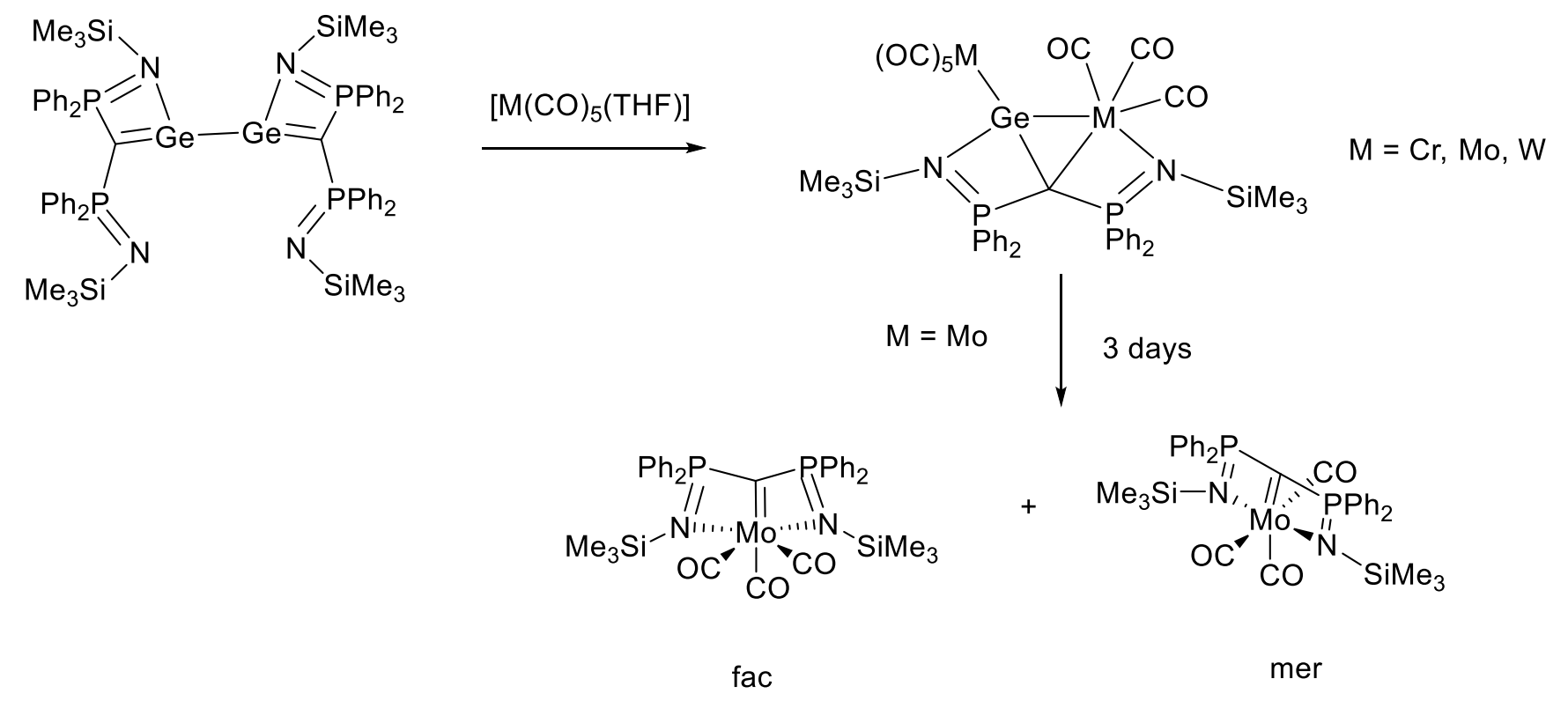

\subsubsection{Group 8 complexes: Syntheses and reactivity}

The first examples of ruthenium carbene complexes featuring bis(iminophosphoranyl) ligands were described by the group of Gimeno and Cadierno in 2004. Although the geminal dilithio derivative of the ligands $\mathrm{CH}_{2}\left(\mathrm{PPh}_{2} \mathrm{NR}\right)_{2}\left(\mathrm{R}=\mathrm{P}\left(\mathrm{OR}{ }^{\prime}\right) \mathrm{X}: \mathrm{R}^{\prime}=\mathrm{Ph}, \mathrm{Et}, \mathrm{X}=\mathrm{S}, \mathrm{O}\right)$ used cannot be obtained, as stated by the authors, the corresponding carbene fragment was generated in the coordination sphere of the Ru center by deprotonation using external base (scheme 60). ${ }^{121},{ }^{122}$ Thus, reaction between phosphorylated and thiophosphorylated bis(iminophosphoranyl)methanide anions to $\left[\mathrm{Ru}\left(\mathrm{p} \text {-cymene) } \mathrm{Cl}_{2}\right]_{2}\right.$ followed by anion exchange yielded cationic complexes, in which tridentate coordination via N,C and X was evidenced. The cationic complexes were easily deprotonated using excess of sodium hydride to give the desired ruthenium carbene. In this case, only one of the PN arm coordinated to the metal center.

\section{Scheme 60: early examples of Ru carbene complexes of type I ligands via in situ deprotona-}

tion. 

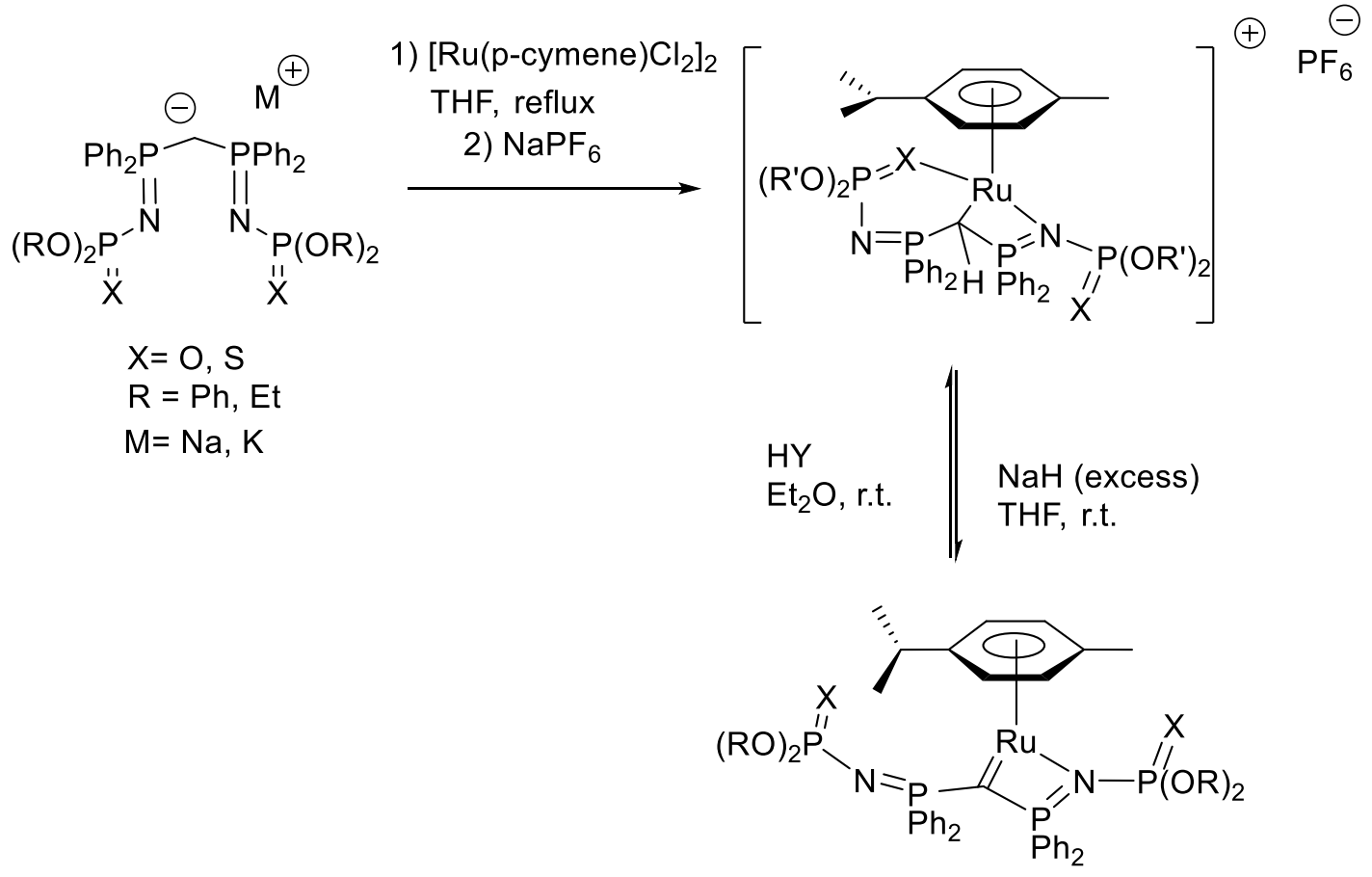

As expected, the carbene moiety retains a basic character and protonation regenerates the intermediate cationic complex. More interestingly, the reaction of phosphorylated carbene complexes with an excess of terminal alkynes resulted in the chemo- and stereoselective formation of complexes 41. Overall, the reaction involves $\mathrm{CC}$ coupling, phenyl orthometalation and $\mathrm{H}$ migration. (Scheme 61$).{ }^{123}$ Deuteration experiments clearly indicate the formation of $\eta^{2}$-alkene complex. When reacted with stoichiometric amount of isocyanide $\mathrm{CNR}$, complexes $\mathrm{X}$ resulting from the $[2+1]$ addition on the $\mathrm{Ru}=\mathrm{C}$ bond are formed. ${ }^{124},{ }^{125},{ }^{126}$ Upon addition of excess of isocyanide, full insertion in the $\mathrm{Ru}=\mathrm{C}$ bond was observed to form the ketenimine derivative, which remains bound to the $\mathrm{Ru}$ center.

\section{Scheme 61: Reactivity of Ru carbene complexes toward alkynes and CNR.}



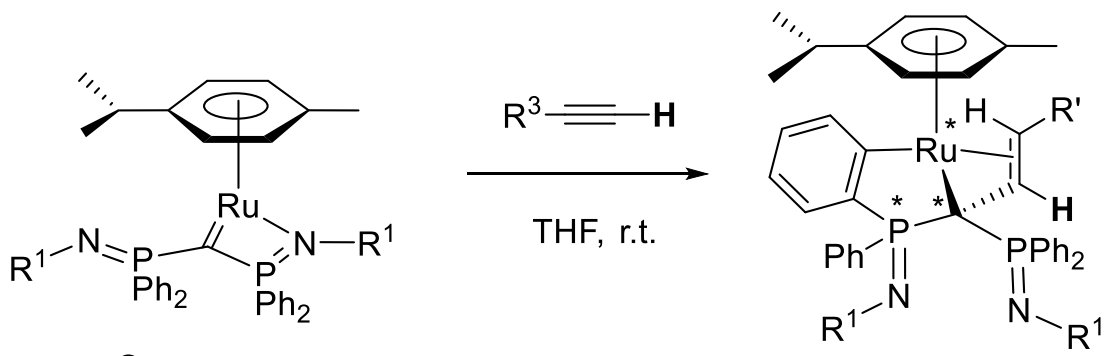

41
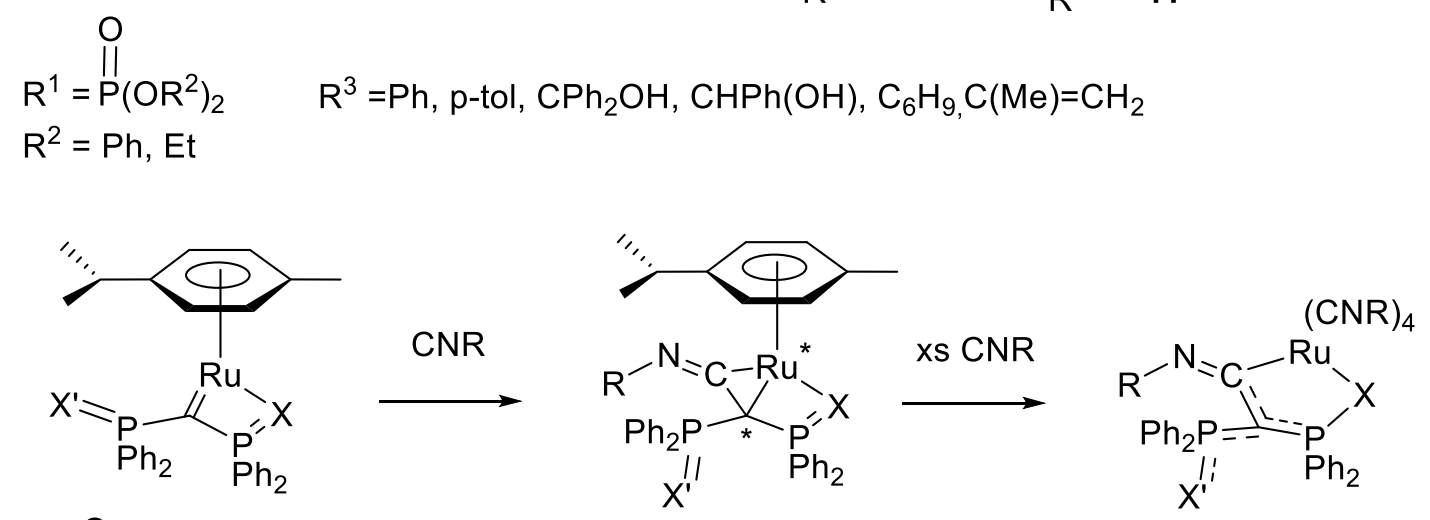

$$
\begin{aligned}
& X=X^{\prime}=N-P\left(O R^{2}\right)_{2} \quad R=C_{2} \mathrm{Ph}, 2,6-C_{6} H_{3} M_{2}, C y \\
& X=N \text { Mes; } X^{\prime}=S \\
& X=S e ; X^{\prime}=N-\stackrel{N}{N}\left(O^{2}\right)_{2} \quad X^{\prime \prime}=S, O ; \\
& \mathrm{R}^{2}=\mathrm{Et}, \mathrm{Ph}
\end{aligned}
$$

Le Floch, Mézailles and co-workers synthesized the first pincer ruthenium carbene complex by the reaction of $\mathbf{8} \mathbf{L i}_{2}$ with the $\left[\mathrm{RuCl}_{2}\left(\mathrm{PPh}_{3}\right)_{4}\right]$ precursor $\left(\right.$ Scheme 62). ${ }^{127}$ Complex $\left[\mathrm{Ru}(\mathbf{8})\left(\mathrm{PPh}_{3}\right)_{2}\right]$ proved to be very resistant and did not react with water, methanol, methyllithium or methyliodide. On the other hand, thermally induced insertion into one $\mathrm{Ph}$ ring of the $\mathrm{PPh}_{2} \mathrm{~S}$ moiety was observed. The final complex results from the protonation of the carbene center. The mechanism was studied by DFT calculations and the rate-determining step consisted in the decoordination of one thiophosphine arm. Oxidative addition of a $\mathrm{C}-\mathrm{H}$ bond proceeds smoothly from the unsaturated intermediate, followed by a ahydride migration and final coordination of the $\mathrm{P}=\mathrm{S}$ arm to form complex 42. With the mixed PS/PO geminal dianion $\mathbf{1 2}_{\mathbf{2}}$, the $\mathrm{CH}$ bond insertion occurred not only at much lower temperature, but also selectively into the 
$\mathrm{PPh}_{2} \mathrm{O}$ group. It was rationalized by the fact that $\mathrm{P}=\mathrm{O}$ bond is shorter than $\mathrm{P}=\mathrm{S}$, resulting in weaker $\mathrm{R}-\mathrm{O}$ bond than $\mathrm{Ru}-\mathrm{S}$, thereby favoring $\mathrm{PO}$ decoordination. Interestingly, this complex, $\mathbf{4 3}$, is the kinetic complex, as if the temperature is raised to boiling toluene the product resulting from the $\mathrm{Ph}$ ring of the $\mathrm{PPh}_{2} \mathrm{~S}$ is obtained selectively, which was also corroborated by DFT calculations.

Scheme 62: Reactivity of Ru carbene complexes: intramolecular $\mathrm{CH}$ insertion.

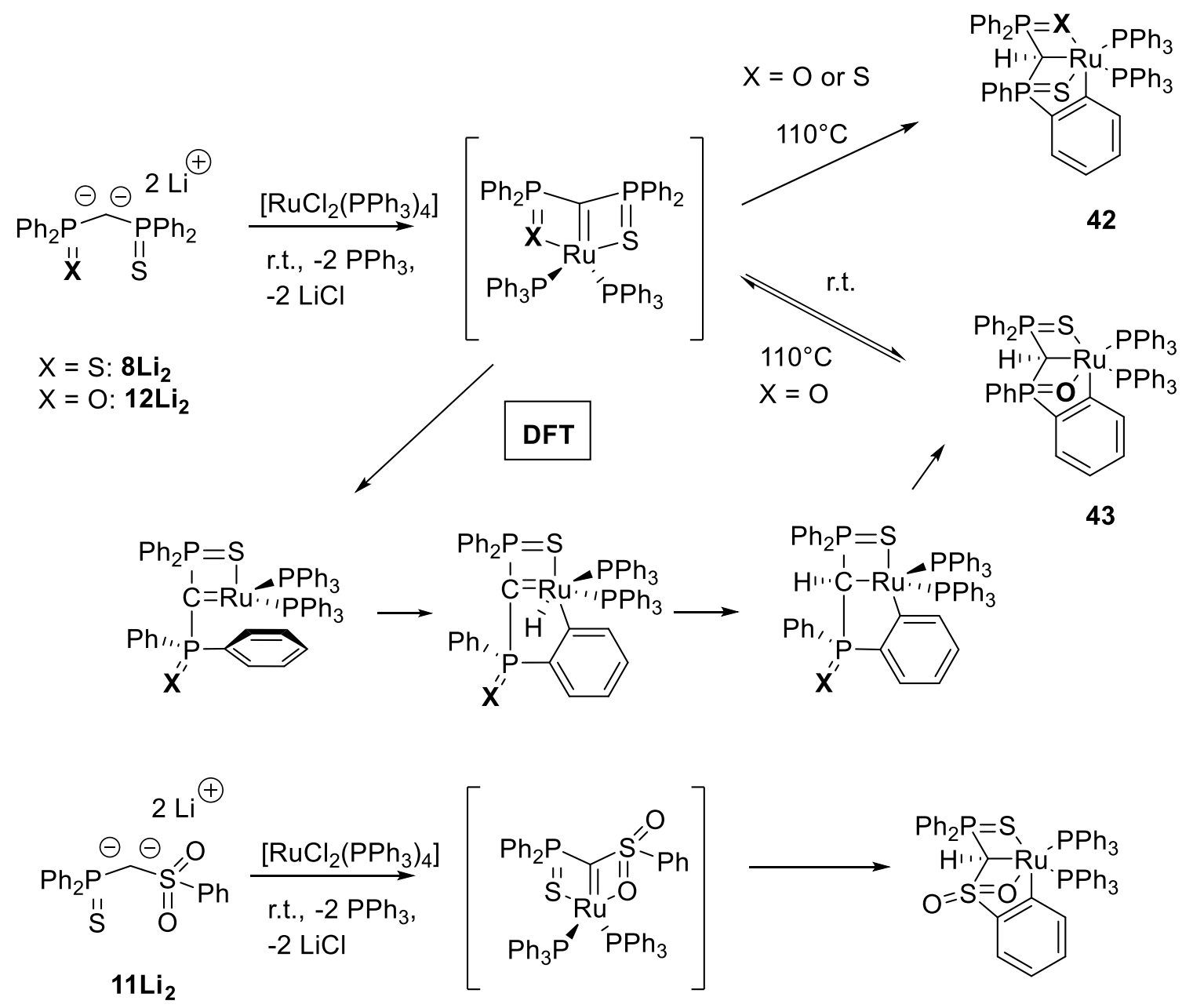

Related chemistry was developed by Gessner in 2014 using dianion 11Li 2 . In this case, the $\left[\mathrm{Ru}\left(\mathbf{1 1 L i} \mathbf{i}_{2}\right)\left(\mathrm{PPh}_{3}\right)_{2}\right]$ is unstable even at low temperature and undergoes cyclometalation selectively in the 
$\mathrm{SO}_{2} \mathrm{Ph}$ moiety. ${ }^{128}$ Replacing the two $\mathrm{PPh}_{3}$ ligands by cymene did result in the isolation of the desired carbene complex $[\mathrm{Ru}(\mathbf{1 1})($ cymene)]. Similar results were reported in 2018 by the same group for the mixed $\mathrm{PN} / \mathrm{SO}_{2}$ dianion $\mathbf{1 7} \mathbf{L i}_{2}$ in the synthesis of the $[\mathrm{Ru}(\mathbf{1 7})($ cymene) $]$ complex (scheme 63). Alternatively, the complex can be obtained from the monoanion coordination followed by deprotonation in the coordination sphere of $\mathrm{Ru} .^{129}$

\section{Scheme 63: Synthesis of Ru carbene complexes of ligands 11 and 17.}
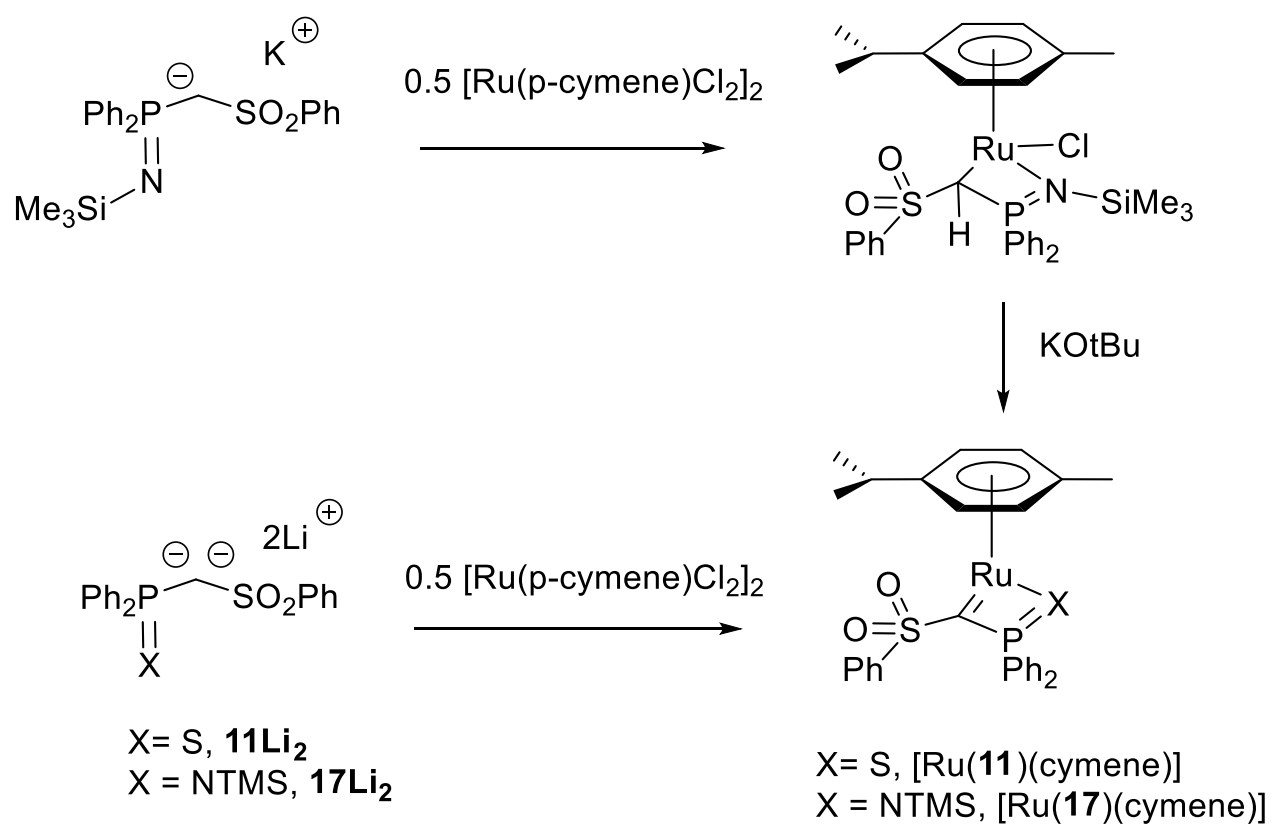

Complexes $[\mathrm{Ru}(\mathbf{1 1})($ cymene) $]$ and $[\mathrm{Ru}(\mathbf{1 7})($ cymene $)]$ present a rich chemistry. Both complexes possess similar electronics of the Ru-C, as shown by almost identical bond lengths (1.955(2) $\AA$ vs 1965(2) $\AA$ respectively), identical ${ }^{13} \mathrm{C}$ NMR shifts of the carbonic carbon (140.8 ppm), as well as DFT calculations. The HOMO and LUMO best describe the bonding and antibonding pi $\mathrm{Ru}-\mathrm{C}$ interactions. The $\mathrm{Ru}-\mathrm{C}$ bond indexes of 1.22 (PN system) vs 1.17 (PS system) and the charge at C (-0.88 and -0.92 in PN and PS systems resp.) are very similar in both complexes. The only small difference lies in the charge at Ru, 
due to the coordination of $\mathrm{N}$ or $\mathrm{S}$, as expected. As a consequence the $\mathrm{Ru}=\mathrm{C}$ bond in $[\mathrm{Ru}(\mathbf{1 7})(\mathrm{cymene})]$ is slightly more polar than in the "PS" complex $[\mathrm{Ru}(\mathbf{1 1})($ cymene) $]$.

The reactivity of complex $[\mathrm{Ru}(\mathbf{1 1})($ cymene)] has been extensively studied (scheme 64$)$. Due to the poorly polarized $\mathrm{Ru}=\mathrm{C}$ bond, the addition of $\mathrm{ArO}-\mathrm{H}$ is almost thermally neutral. With electron poor Ar, the addition is quantitative, whereas for $\mathrm{Ph}$ or more electron rich $\mathrm{Ar}$, an equilibrium is observed. This is of major importance since it showed that the addition of $\mathrm{O}-\mathrm{H}$ bond across the $\mathrm{Ru}=\mathrm{C}$ proceeded via a low energy transition state. The same reactivity was studied with $[\mathrm{Ru}(\mathbf{1 7})(\mathrm{cymene})] .{ }^{129}$ If the first addition of $\mathrm{ArOH}$ on the $\mathrm{Ru}=\mathrm{C}$ bond led to analogous reactivity as for $[\mathrm{Ru}(\mathbf{1 1})($ cymene)], the complex further evolved via $\mathrm{N}-\mathrm{Si}$ bond splitting with additional ArOH. Reaction between complex $[\mathrm{Ru}(\mathbf{1 1})(\mathrm{cymene})]$ and iso-propanol did not result in the alcoholato complex, but rather in the formation of the $\mathrm{Ru}-\mathrm{H}$ species. The $[\mathrm{Ru}(\mathbf{1 1 H})(\mathrm{H})($ cymene $)]$ complex could also be made via the reaction with polar $\mathrm{HCOOH}$ or directly via the activation of non-polar dihydrogen. In the latter case, the addition is fast and irreversible, as corroborated by DFT calculations. Indeed, although a barrier for formal $\mathrm{H}_{2}$ addition of 27 $\mathrm{kcal} / \mathrm{mol}$ is computed, there is a strong thermodynamic preference for the $\mathrm{RuH}-\mathrm{CH}$ complex (by 12 $\mathrm{kcal} / \mathrm{mol})$ over the "carbene $+\mathrm{H}_{2}$ ". ${ }^{128}$ Nonetheless, the formation of $[\mathrm{Ru}(\mathbf{1 1 H})(\mathrm{H})(\mathrm{cymene})]$ from alcohol opened the way for the first catalyzed dehydrogenation of alcohols process with carbene complexes featuring ligands obtained from stable geminal dianions. ${ }^{130}$

Scheme 64: Reversible $\mathrm{ROH}$ addition on $\mathrm{Ru}=\mathrm{C}$ bond: catalytic hydrogenation of ketone. 


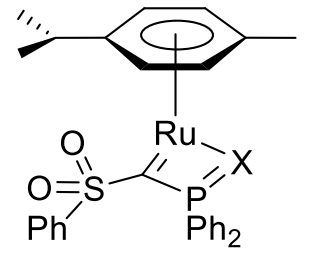

$\mathrm{X}=\mathrm{S},[\mathrm{Ru}(11)$ (cymene)]

$X=$ NTMS, [Ru(17)(cymene)]

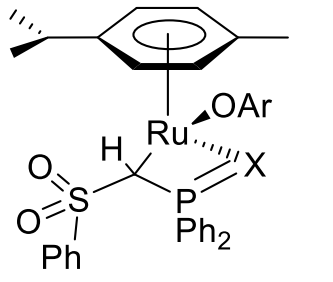

[Ru(11H)(OR)(cymene)] (X = S)

$\mathrm{Ar}=\mathrm{Ph}, \mathrm{p}-\mathrm{C}_{6} \mathrm{H}_{4} \mathrm{OMe}, \mathrm{p}-\mathrm{C}_{6} \mathrm{H}_{4} \mathrm{CF}_{3}$

[Ru(17H)(OR)(cymene)] ( $\left.\mathrm{X}=\mathrm{NSiMe}_{3}\right)$

$\mathrm{Ar}=\mathrm{Ph}, \mathrm{p}-\mathrm{C}_{6} \mathrm{H}_{4} t \mathrm{Bu}, 3,5-\mathrm{C}_{6} \mathrm{H}_{3} \mathrm{Cl}_{2}$
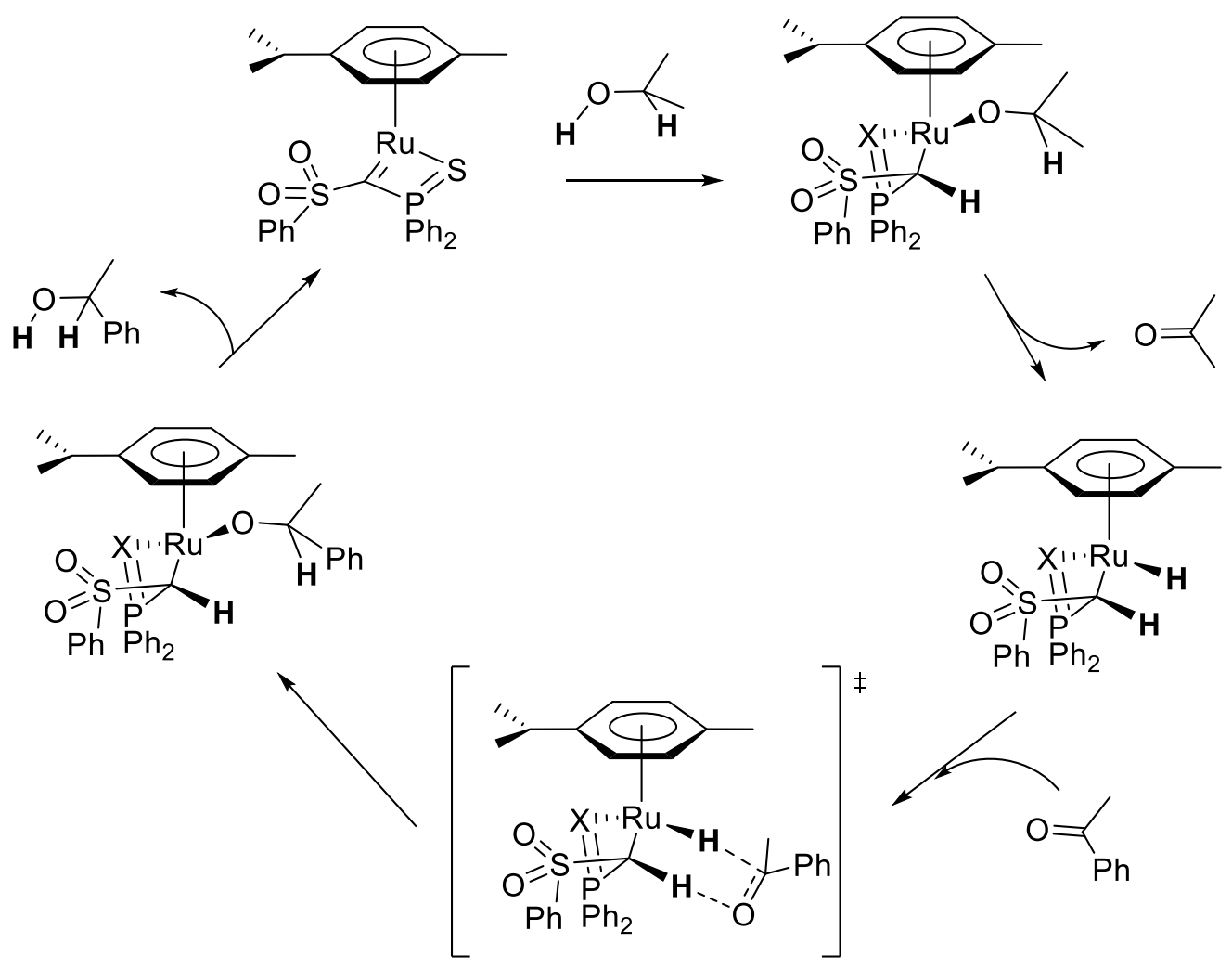

$\mathrm{Ph} \mathrm{Ph}_{2}$

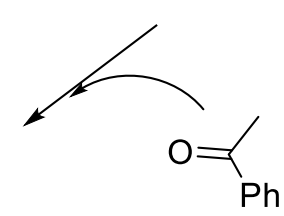

Less polar substrates, such as phosphines, also react in formal 1,2 addition across the $\mathrm{Ru}=\mathrm{C}$ bond of $\left[\mathrm{Ru}(\mathbf{1 1})\left(\right.\right.$ cymene) ${ }^{131}$ Although several complexes have been observed and characterized, the reaction is not selective and side products resulting mainly from cymene displacement by phosphines are always present. On the other hand, secondary phosphine oxides lead cleanly to the desired products in good to 
excellent yields. These 1,2 addition reactions generate chiral $\mathrm{C}$ and $\mathrm{Ru}$ centers and it was demonstrated by Gessner that a chiral sulfoximine $\mathrm{Ru}$ complex $[\mathrm{Ru}(\mathbf{1 6})($ cymene)] could lead to the first diastereoselective S-H bond addition (scheme 65). ${ }^{36}$

\section{Scheme 65: $\mathrm{PH}$ and $\mathrm{SH}$ additions on $\mathrm{Ru}=\mathrm{C}$ bond.}

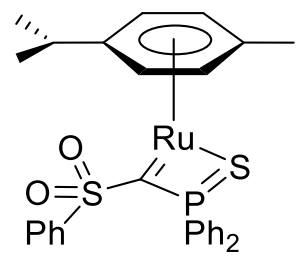

$[\mathrm{Ru}(11)($ cymene)]
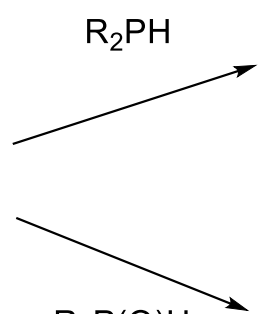

$\mathrm{R}_{2} \mathrm{P}(\mathrm{O}) \mathrm{H}$
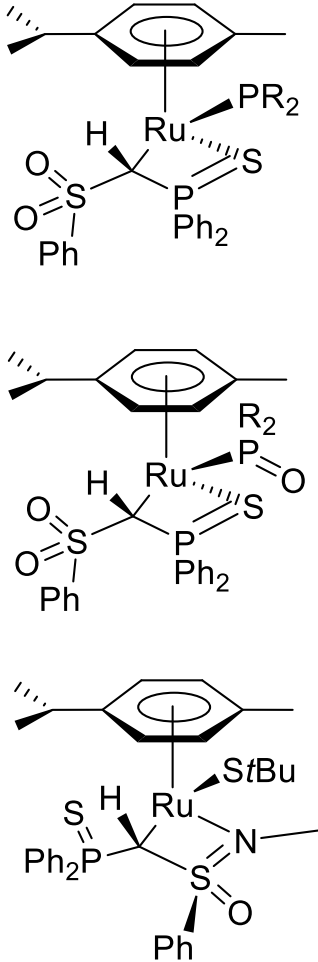

$[\mathrm{Ru}(16 \mathrm{H})(\mathrm{StBu})($ cymene)]

$R_{S}, S_{C}, R_{R u}$
$\mathrm{R}=\mathrm{Ph}, \mathrm{p}-\mathrm{C}_{6} \mathrm{H}_{4} \mathrm{Cl}, 3,5-\mathrm{C}_{6} \mathrm{H}_{3} \mathrm{Cl}_{2}$, $\mathrm{p}-\mathrm{C}_{6} \mathrm{H}_{4} \mathrm{OMe}, \mathrm{p}-\mathrm{C}_{6} \mathrm{H}_{4} \mathrm{NMe}_{2}$, $3,5-\mathrm{C}_{6} \mathrm{H}_{4}\left(\mathrm{CF}_{3}\right)_{2}$

$\mathrm{R}=0-\mathrm{C}_{6} \mathrm{H}_{4} \mathrm{Me}(90 \%)$, $3,5-\mathrm{C}_{6} \mathrm{H}_{3} \mathrm{Cl}_{2}(66 \%)$ $\mathrm{p}-\mathrm{C}_{6} \mathrm{H}_{4} \mathrm{Cl}(77 \%)$

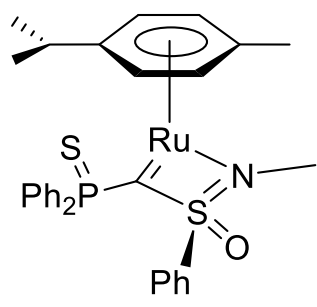

$[R u(16)($ cymene) $]$

$R_{S}$
tBuSH

Finally, addition of hydridic $\mathrm{E}-\mathrm{H}$ bonds to $\mathrm{Ru}=\mathrm{C}$ was studied. In this case the polarity of the $\mathrm{Ru}=\mathrm{C}$ bond should lead to $\mathrm{Ru}-\mathrm{H}$ formation. ${ }^{132}$ However, addition of silanes selectively formed the Ru-Si and C-H bond in a diastereoselective manner ( $\mathrm{Si}$ and $\mathrm{H}$ are in cis position). In the case of $\mathrm{Et}_{3} \mathrm{SiH}$ an equilibrium was observed. This regioselectivity was rationalized by DFT calculations. Interestingly, using Me substituted model, the oxidative addition at Ru was computed as a low energy process ( $c a 19 \mathrm{kcal} / \mathrm{mol})$, 96 
whereas the concerted 1,2-addition across the $\mathrm{Ru}=\mathrm{C}$ bond could not be found. The second transition state, leading to products thus controlled the selectivity of the process (scheme 66). It is $\mathrm{ca} 5 \mathrm{kcal} / \mathrm{mol}$ lower for the $\mathrm{H}$ migration than for the Si migration. Moreover, even if the migration could be reversible, the Ru-Si complex is thermodynamically more stable than the $\mathrm{Ru}-\mathrm{H}$ complex. Overall, despite the initial polarity of the $\mathrm{Ru}=\mathrm{C}$ bond, the ligand enables $\mathrm{Si}-\mathrm{H}$ bond activation by its electronic flexibility.

\section{Scheme 66: $\mathrm{BH}$ and $\mathrm{SiH}$ additions on $\mathrm{Ru}=\mathrm{C}$ bond.}
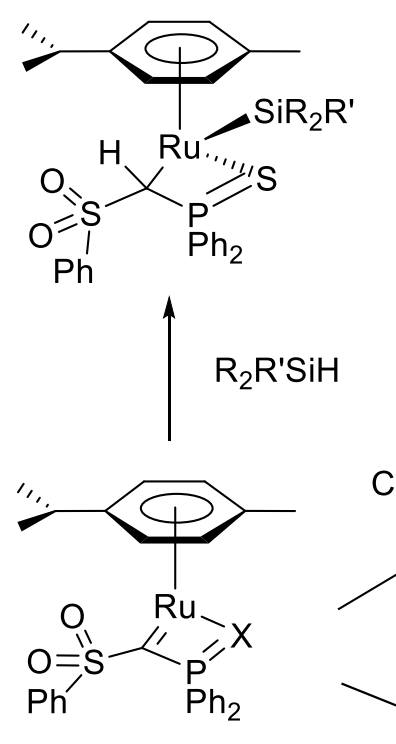

$$
\mathrm{X}=\mathrm{S}, \mathrm{NSiMe}_{3}
$$
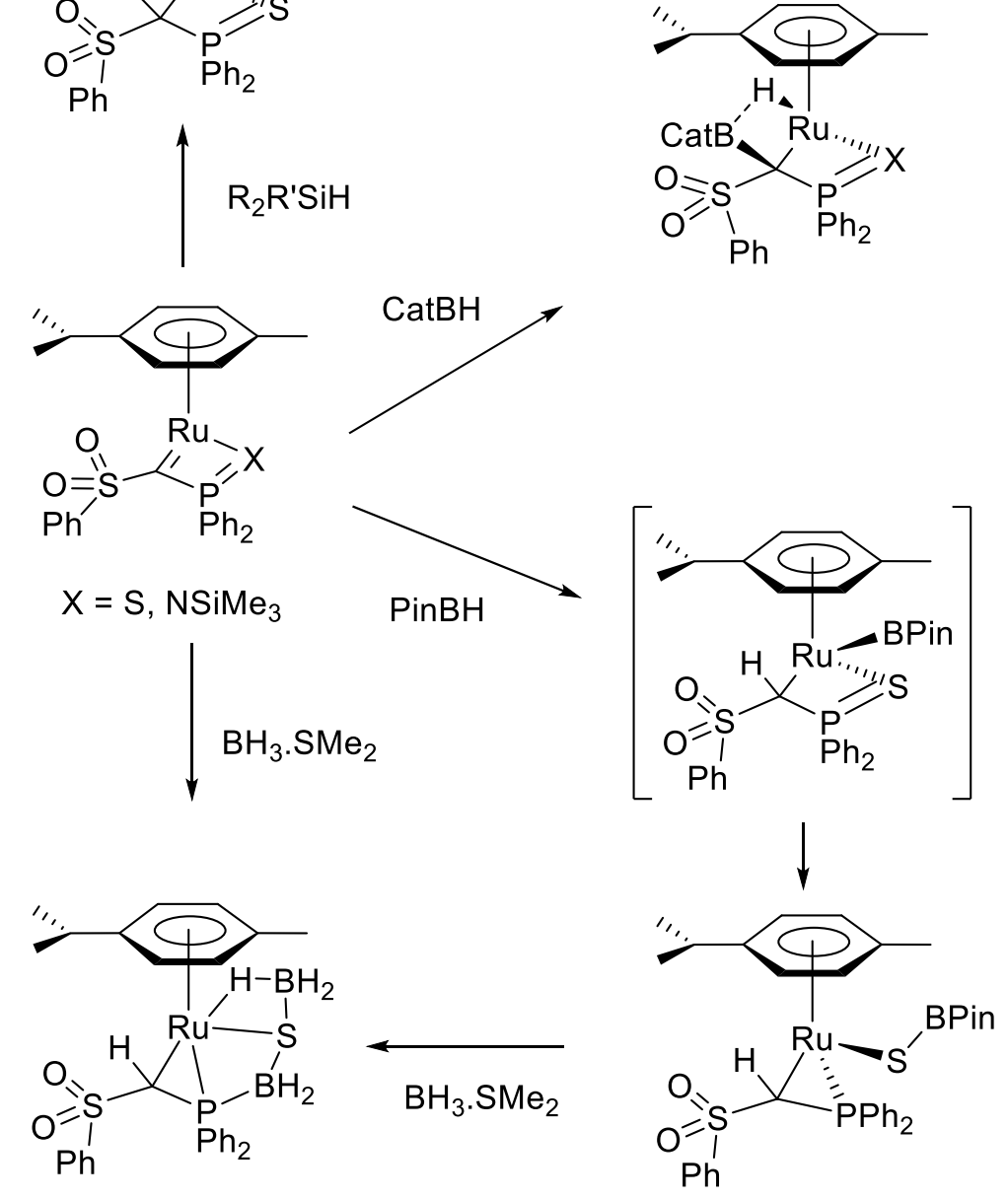
The outcomes of the reaction with boranes depended on the nature of the borane itself but also on the phosphoryl moiety. Indeed, with the $[\mathrm{Ru}(\mathbf{1 1})($ cymene)], the opposite addition of the $\mathrm{BH}$ bond is seen with $\mathrm{CatBH}$ and PinBH. Moreover, with $\mathrm{PinBH}$, the reaction further evolves to formal reduction of the PS moiety, and formation of SBPin. The diverging reactivity was rationalized by DFT calculations. In fact, it results from a kinetic preference for C-Bcat formation over Ru-BCat (ca $7.5 \mathrm{kcal} / \mathrm{mol}$ ). The picture is more complex in the case of PinBH. ${ }^{133}$ Indeed, a negligible difference in the energies of the TS is seen for $\mathrm{C}(\mathrm{BPin})-\mathrm{RuH} v s \mathrm{C}(\mathrm{H})-\mathrm{Ru}(\mathrm{BPin})$ formation. The reaction is further driven by the boryl migration to the $\mathrm{S}$ atom with concomitant PS bond cleavage.

Finally, the reactivity of the $\mathrm{Ru}=\mathrm{C}$ bond of $[\mathrm{Ru}(\mathbf{1 1})$ (cymene)] in $[2+2]$ processes has been studied (scheme 67). In line with the strong metal carbon interaction and the pronounced double bond character, no reaction was observed with ketones even upon prolonged heating. Reaction with more electrophilic substrates, such as cyanates and thiocyanates, lead to the expected $\mathrm{CC}$ bond formation. The regioselectivity of the addition was guided by the HSAB principle, with the softer atom of the heterocumulene binding to the soft Ru center. ${ }^{134}$

\section{Scheme 67: Reactivity of Ru=C bond toward RNCO and RNCS.}




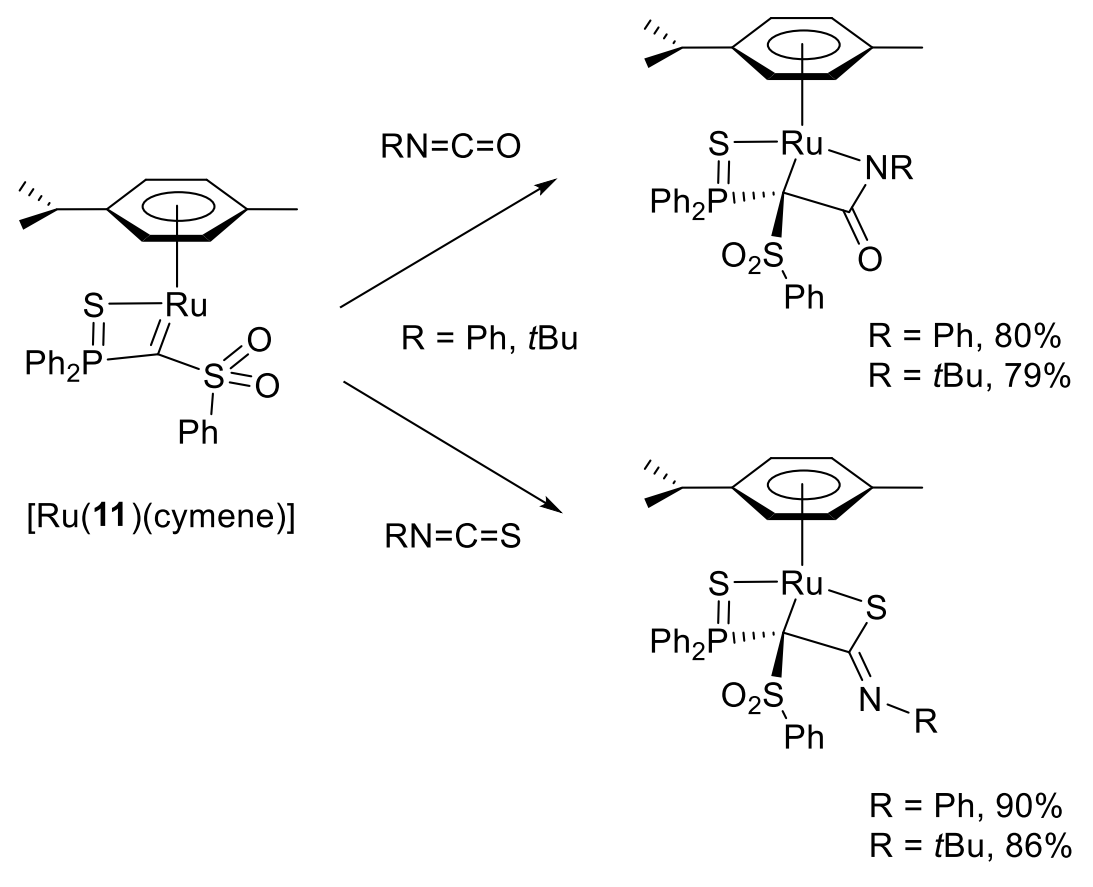

Compared to the chemistry of $\mathrm{Ru}$, the one pertaining to Fe is very limited. In fact, the only example of a Fe complex bearing a geminal dianion has not been made from the corresponding dilithio derivative. Indeed, it appears that redox processes compete with the coordination to $\mathrm{Fe}(\mathrm{II})$, and the complex could only be obtained via a transmetalation process from the $\mathrm{Sc}$ carbene complex $\left[\mathrm{Sc}(\mathbf{8}) \mathrm{Cl}(\mathrm{Py})_{2}\right]$ (scheme 38). ${ }^{79}$ In this complex, the dianion acts as bridging ligand with two Fe-C sigma bonds rather than the more often encountered $\mathrm{M}=\mathrm{C}$ double bond. In terms of reactivity, this complex was rather deceptive as it did not react with various electrophiles such as $\mathrm{Ph}_{2} \mathrm{CO}$ or MeI, or with the Lewis base $\mathrm{CH}_{3} \mathrm{CN}$.

\subsubsection{Group 9 complexes}

Much like the example of Fe presented above, the coordination chemistry of geminal dianion toward the $\mathrm{Rh}(\mathrm{I})$ precursor $[\mathrm{Rh}(\mathrm{COD}) \mathrm{Cl}]_{2}(\mathrm{COD}$ : cyclooctadiene) did not yield a complex featuring a $\mathrm{Rh}=\mathrm{C}$ interaction. Rather, Cavell and coworkers showed that $\mathbf{6} \mathbf{a} \mathbf{L} \mathbf{i}_{2}$ reacted with $[\mathrm{Rh}(\mathrm{COD}) \mathrm{Cl}]_{2}$ to yield spirocyclic bridging-heterobimetallic Rh-Li complex 44, also called bridging carbene (Scheme 68). This 99 
complex is stable up to $-20^{\circ} \mathrm{C}$, but evolves slowly at higher temperature to the orthometalated complex 45. ${ }^{135}$ Under $\mathrm{CO}$ atmosphere, COD was displaced followed by $\mathrm{CO}$ insertion into the $\mathrm{Rh}-\mathrm{C}$ bond, leading to $\mathrm{CC}$ bond formation. The final complex, 46, features a rare bridging ketene ligand. In a subsequent study, the authors showed that the Rh-Li heterobimetallic complex 44 could be used to form $\mathrm{Rh}-\mathrm{Rh}$ homo or Rh-Pd hetero-bimetallic complexes $\mathbf{4 7}$ and $\mathbf{4 8}$ respectively. ${ }^{136}$

Scheme 68: Synthesis of Rh complexes featuring ligand 6a. 


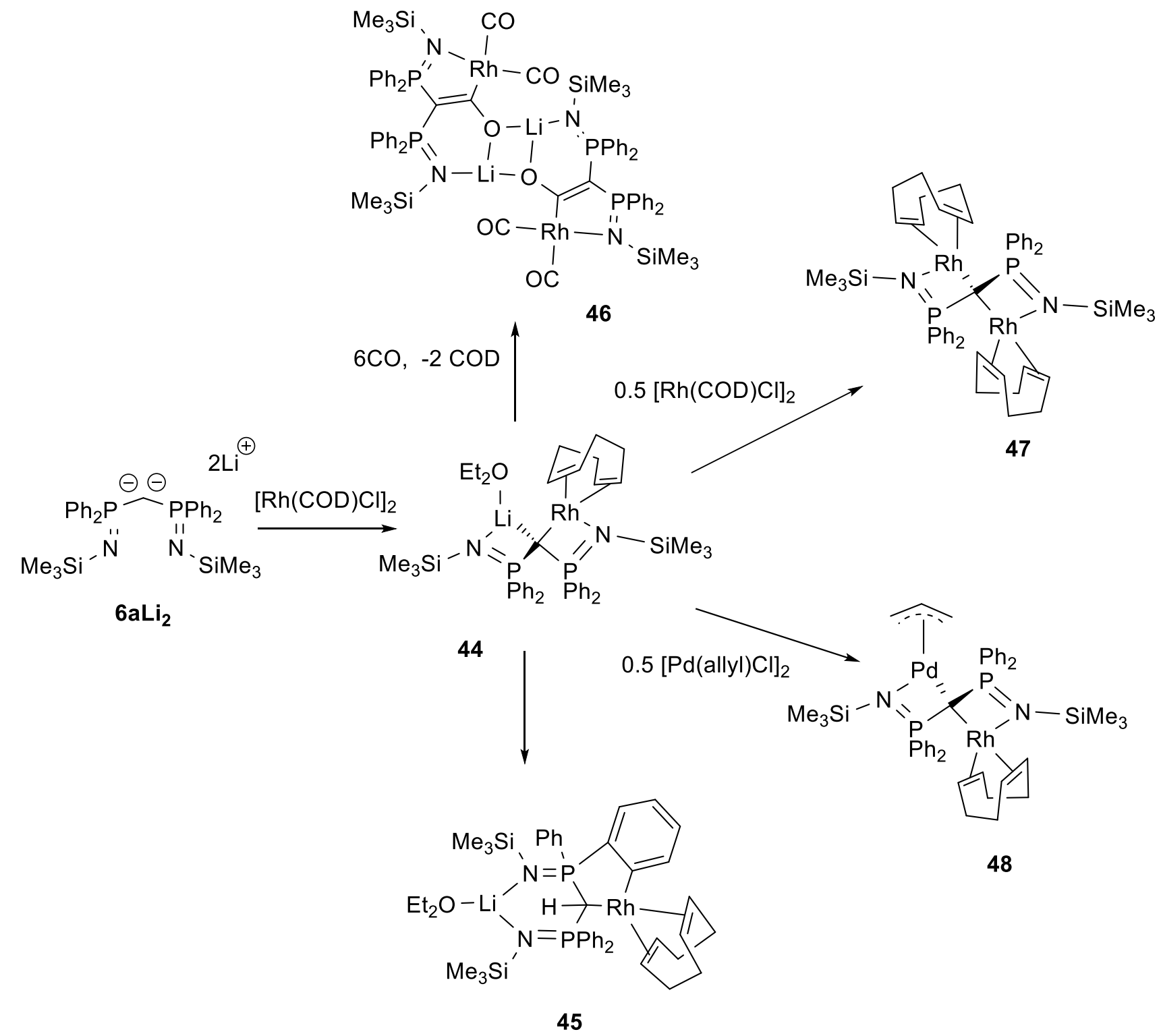

In 2017, Gessner reported the synthesis of the $\operatorname{Ir}(\mathrm{III})$ carbene complex $\left[\operatorname{Ir}(\mathbf{1 1})\left(\mathrm{Cp}^{*}\right)\right]$. Like for the related $\mathrm{Ru}(\mathrm{Cymene})$ complex, the carbene ligand is only bound via the thiophosphoryl moiety. This complex reacts slowly with $\mathrm{H}_{2}$ at room temperature to form the $\mathrm{CH}-\mathrm{IrH}$ addition product, as evidenced by the hydride shift in the ${ }^{1} \mathrm{H}$ NMR spectrum (scheme 69). This complex cannot be isolated as it reacted further via $\mathrm{H}_{2}$ elimination to form complex 49. The same complex could be obtained by reaction with 
$i \mathrm{PrOH}$ at $75^{\circ} \mathrm{C}$. It is interesting to note that direct $\mathrm{CH}$ bond insertion did not occur, even upon heating up to $110^{\circ} \mathrm{C}$. A similar reactivity was observed with various silanes, for which the $\mathrm{CH}-\mathrm{IrSiR}_{3}$ intermediate was evidenced prior to $\mathrm{R}_{3} \mathrm{SiH}$ elimination to form complex $49 .{ }^{137}$ DFT calculations were carried out to understand the mechanism of formation of complex 49 , using a model in which the $\mathrm{Cp}^{*}$ was replaced by $\mathrm{Cp}$. Briefly, the $\mathrm{H}_{2}$ oxidative addition on complex $[\operatorname{Ir}(\mathbf{1 1})(\mathrm{Cp})]$ does generate the $\left[\operatorname{Ir}(\mathbf{1 1})(\mathrm{H})_{2}(\mathrm{Cp})\right]$ intermediate followed by a proton transfer to the methanediide $\mathrm{C}$ leading to $[\operatorname{Ir}(\mathbf{1 1 H})(\mathrm{H})(\mathrm{Cp})]$. This pathway is preferred over the direct 1,2 addition across the $\mathrm{Ir}=\mathrm{C}$ bond. A second oxidative addition then occurs into a $\mathrm{CH}$ bond of a $\mathrm{Ph}$ ring, followed by reductive elimination of $\mathrm{H}_{2}$ forming complex 49 .

\section{Scheme 69: Synthesis and reactivity of $\mathrm{Ir}=\mathrm{C}$ complex featuring ligand 11.}
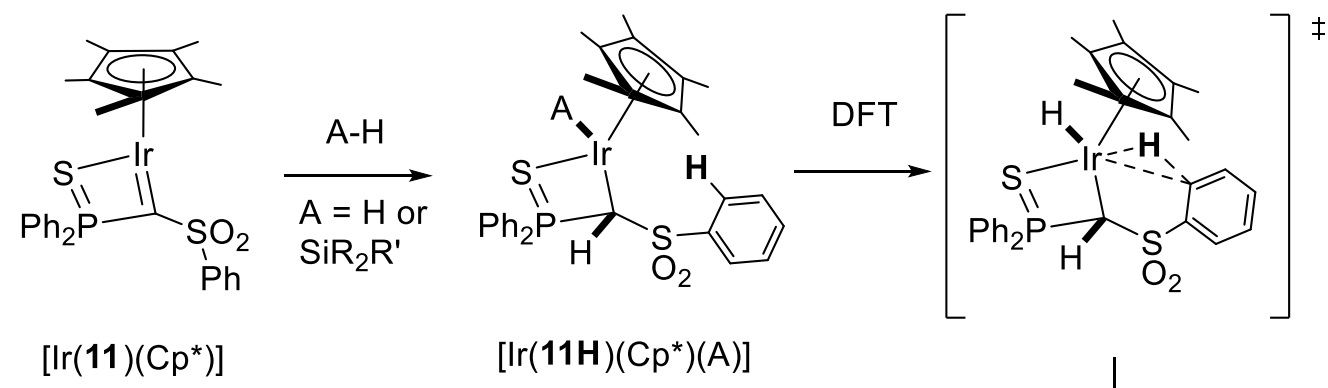

$$
\left[\operatorname{Ir}(11 \mathrm{H})\left(\mathrm{Cp} \mathrm{p}^{*}\right)(\mathrm{A})\right]
$$

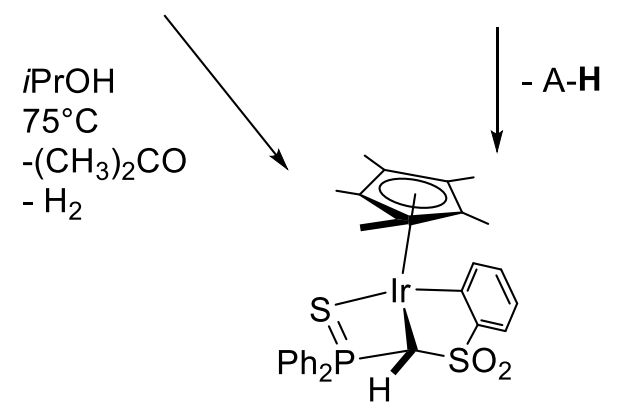

49

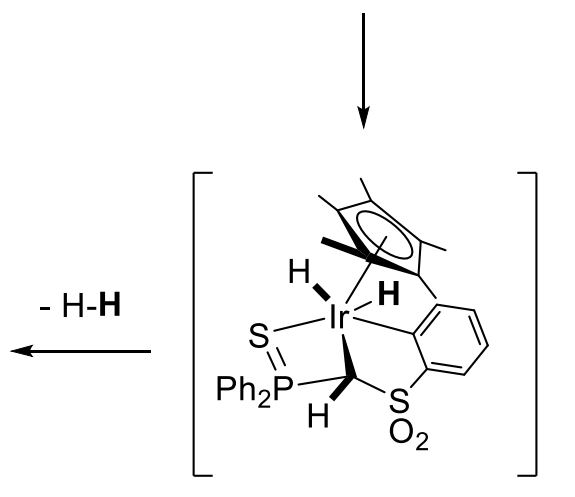

\subsubsection{Group 10 Complexes}


The first example of a group 10 complex featuring a formal stabilized dianion was obtained by Dixon and coworkers in 1989 , with ligand $\mathbf{8}$, more than a decade prior to the isolation of $\mathbf{8} \mathbf{L} \mathbf{i}_{2} .{ }^{138}$ In fact, the authors have studied the coordination of $\mathbf{8} \mathbf{H}_{2}$ toward the $\mathrm{Pt}(\mathrm{II})$ precursor $[\mathrm{Pt}(\mu-\mathrm{Cl})(\mathrm{MeOcod})]_{2}$ $($ MeOcod $=8$-methoxy-cyclooct-4-ene-l-yl), and observed a first deprotonation (although without using a base) leading to coordinated $\mathbf{8 H}$ to Pt(II) (scheme 70). Crystals of a bimetallic Pt(II) complex featuring bridging ligand $\mathbf{8}$ were obtained after several days, but no yield or NMR characterization of the complex are provided given.

\section{Scheme 70: Synthesis of bridging Pt complex featuring ligand 8.}
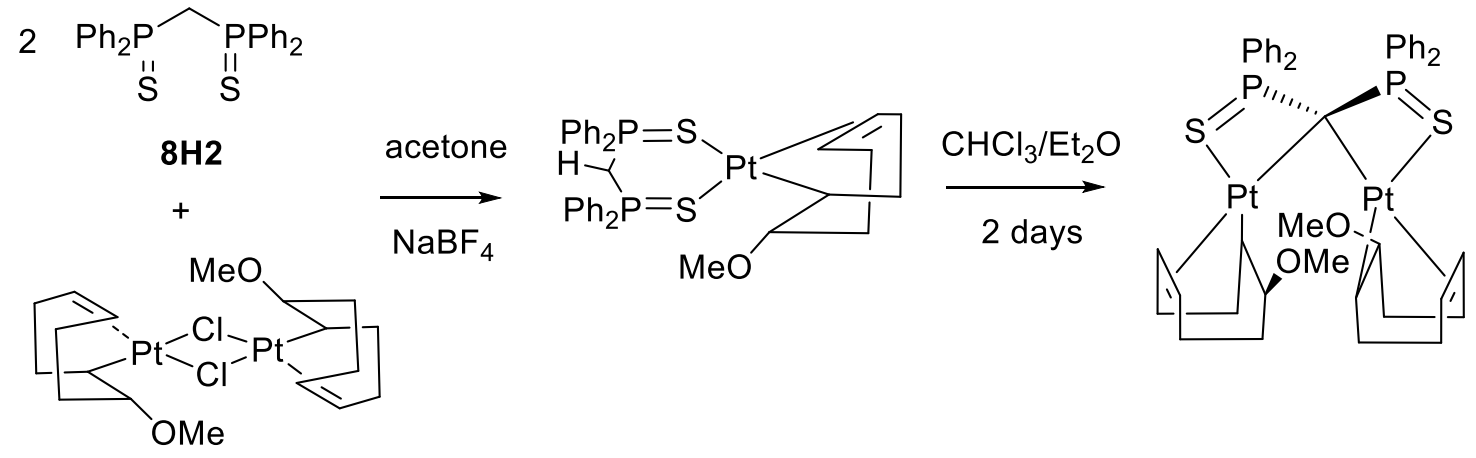

Starting in 2003, Cavell and coworkers reported the coordination $\mathbf{6} \mathbf{a L i} \mathbf{i}_{2}$ toward late transition metals. The first study focused on Pt centers. ${ }^{139}$ Reaction with $\left[\mathrm{PtCl}_{2}(\mathrm{COD})\right]$ lead to complex $[\operatorname{Pt}(\mathrm{COD})(\kappa \mathrm{C}, \kappa \mathrm{N}-6 \mathbf{a})]$ in fair yield $(50 \%)$ (scheme 71$)$. In this complex, ligand $\mathbf{6 a}$ is coordinated only via the carbene and one of the PN moiety. Further proof that COD is a strong ligand was given by the lack of reactivity toward phosphines or pyridine. As expected, the strongly nucleophilic iminophosphorane did react with $\mathrm{CO}_{2}$ followed by silyl migration to the $\mathrm{O}$ atom. Most interestingly, complex $[\mathrm{Pt}(\mathrm{COD})(\kappa \mathrm{C}, \kappa \mathrm{N}-\mathbf{6 a})]$ did react with $\mathrm{CO}$ to yield complex $\mathbf{5 0}$ which features three carbene ligands. ${ }^{140}$ Mechanistically, the reaction is proposed to involve $\mathrm{CO}$ coordination at the Pt center, followed by intramolecular attack of the electrophilic $\mathrm{C}$ center by the free PN moiety, and silyl migration from $\mathrm{N}$ to 103 


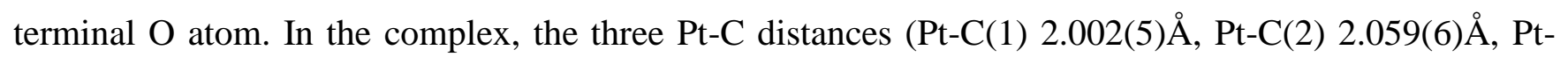

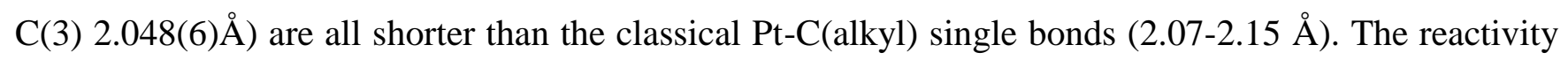
of the carbene center in $[\mathrm{Pt}(\mathrm{COD})(\kappa \mathrm{C}, \kappa \mathrm{N}-6 \mathbf{6})]$ was evidenced upon thermal treatment at $100^{\circ} \mathrm{C}$ for $20 \mathrm{~h}$. It was proposed that the second PN moiety would decoordinate from the Pt center, allowing intramolecular $\mathrm{CH}$ insertion into one of the $\mathrm{Ph}$ rings of the $\mathrm{PPh}_{2} \mathrm{NSiMe}_{3}$ moiety to yield an ortho-metalated complex 51. Hydride migration from Pt to the carbenic carbon is then favorable.

Scheme 71: Synthesis of Pt carbene complex featuring ligand 6a.

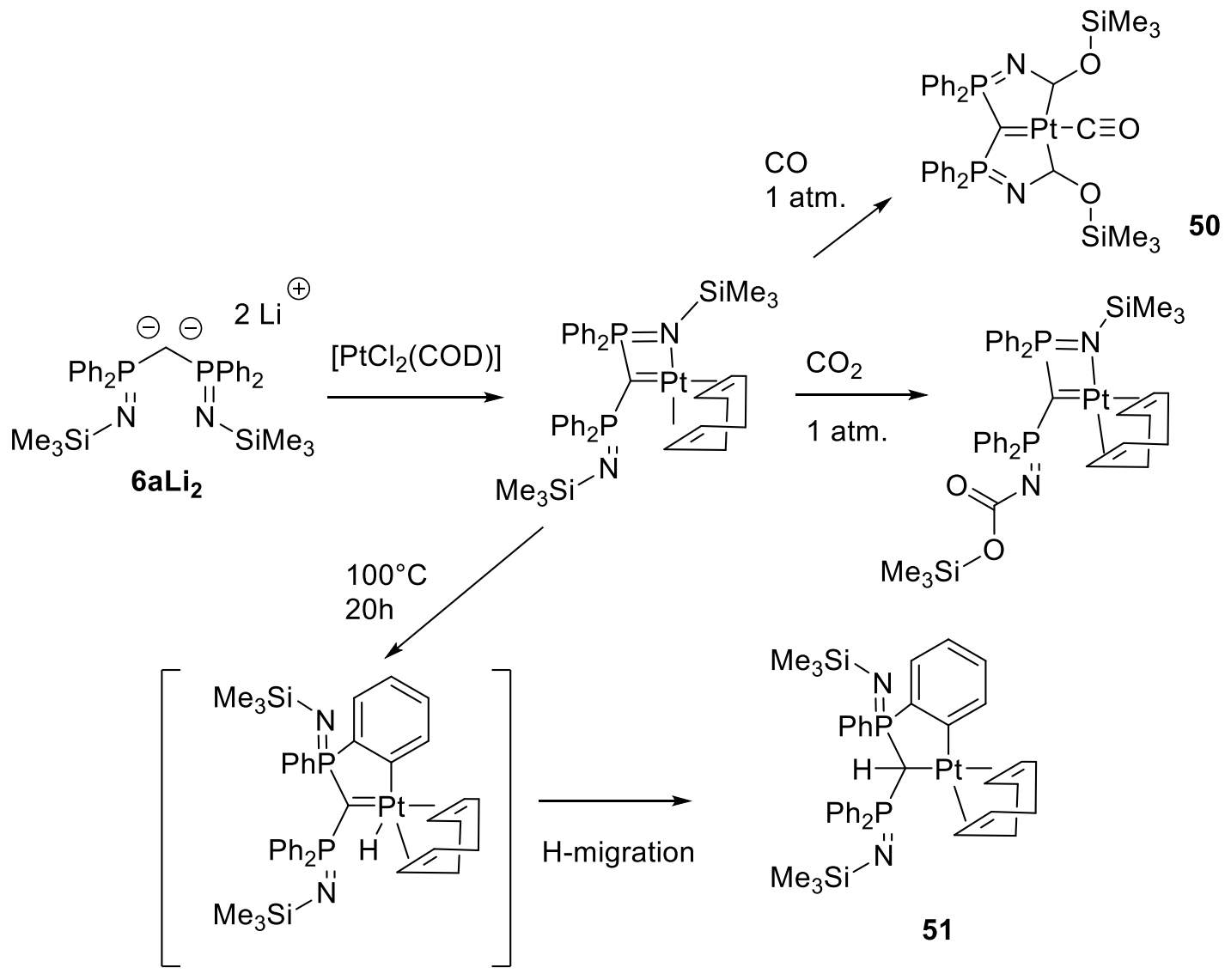

In 2004, Le Floch and coworkers reported the second example of group 10 carbene complexes using ligand $\mathbf{8 L i} \mathbf{2}_{2}{ }^{141}$ Tridentate coordination of ligand $\mathbf{8}$ at $\mathrm{Pd}$ could be achieved in $\left[\mathrm{Pd}(\mathbf{8})\left(\mathrm{PPh}_{3}\right)\right]$ starting with 104 
$\left[\mathrm{PdCl}_{2}\left(\mathrm{PPh}_{3}\right)_{2}\right]$ from which one $\mathrm{PPh}_{3}$ is readily displaced, unlike $\mathrm{COD}$ at $\mathrm{Pt}$ (scheme 72 ). The crystal structure revealed two interesting features. Firstly, a rather long Pd-C distance (2.113(2) Å) was measured, consistent with a single bond, compared to more classical Pd-C double bond (2.005 Å) (Scheme 29). Secondly, the angle between the Pd-C bond and the plane of the PCP ligand of $102.0^{\circ}$ shows that the metal center sits almost perpendicularly to the carbene fragment. Theoretical calculations readily explained the bonding situation in $\left[\operatorname{Pd}(\mathbf{8})\left(\mathrm{PPh}_{3}\right)\right]$. Indeed, unlike in "classical" carbene complexes, in which the $\mathrm{M}=\mathrm{C}$ double bond is constructed from two electrons from the $\mathrm{M}$ center and two from the ligand. A vacant orbital at $\mathrm{C}$ is needed to accept electron density from the $\mathrm{M}$ center. To obtain the present $\operatorname{Pd}$ complex $\left[\mathrm{Pd}(\mathbf{8})\left(\mathrm{PPh}_{3}\right)\right]$, compound $\mathbf{8} \mathbf{L i}_{2}$ is reacted with a $\mathrm{Pd}(\mathrm{II})$ center, and an additional pair of electrons needs to be accommodated ( 4 from the ligand and 2 from the Pd center). Not surprisingly then, the HOMO of the complex involves a $\pi^{*}$ interaction between $\mathrm{C}$ and $\mathrm{Pd}$. It is interesting to note that the same complex could be obtained from the reactivity of carbenoid species $\mathbf{8 L i C l}$ and the $\operatorname{Pd}(0)$ source $\left[\mathrm{Pd}\left(\mathrm{PPh}_{3}\right)_{4}\right] .{ }^{42}$ In this case, the overall six electrons of the $\sigma^{2}-\pi^{2}-\pi^{*^{2}}$ interaction are brought by the ligand (2 electrons) and the metal (4 electrons). This strategy relying on the existence of carbenoid species opened a new synthetic pathway to carbene complexes for which the dianion is not stable (vide infra). The mechanism revealed coordination of the carbenoid to the $\operatorname{Pd}(0)$ center via the $S$ centers, followed by intramolecular nucleophilic substitution at the $\mathrm{C}$ center, leading to $\mathrm{Cl}^{-}$elimination. This pathway is kinetically strongly favored over the oxidative addition in the $\mathrm{C}-\mathrm{Cl}$ bond of the carbenoid $\mathbf{8 L i C l}$. The HOMO of complex $\left[\mathrm{Pd}(\mathbf{8})\left(\mathrm{PPh}_{3}\right)\right]$ being mostly developed at the carbene $\mathrm{C}$ atom, a nucleophilic reactivity was predicted and verified by reaction with MeI which lead to C-C bond formation (complex 52).

Scheme 72: Synthesis of Pd carbene complex featuring ligand 8 from dianion or carbenoid precursors; bonding situation. 


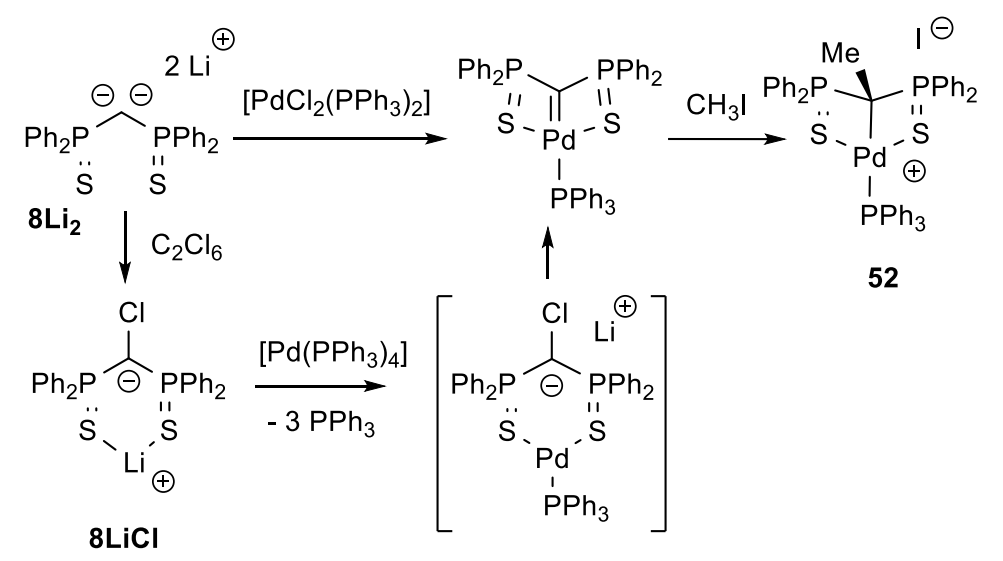

usual bonding mode in carbene complexes

electronic situation in $\left[\mathrm{Pd}(8)\left(\mathrm{PPh}_{3}\right)\right]$

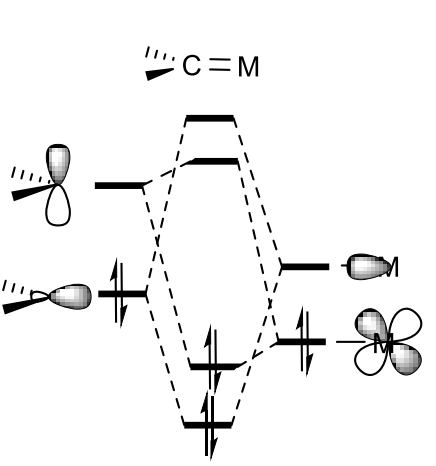
assuming a $\mathrm{d}^{8} \mathrm{PdL}$ fragment and $\mathbf{8}^{2-}$

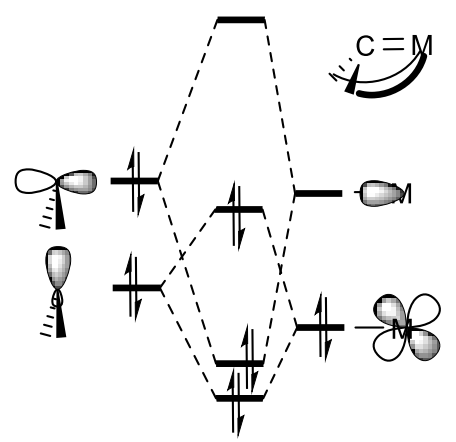

Gessner followed this synthetic strategy in 2011 to obtain Pd carbene complex of ligand $\mathbf{1 4}$ for which the dianion $14 \mathbf{L i}_{2}$ is not readily obtained. Thus, the carbenoid $14 \mathbf{L i C l}$ species being unstable above $30^{\circ} \mathrm{C}$, it was generated in situ and trapped by $\left[\mathrm{Pd}\left(\mathrm{PPh}_{3}\right)_{4}\right] .{ }^{32}$ The outcome of the reaction was unexpected, as the carbene complex was not obtained but rather the thioketone complex, that can be seen as coordination of the $\left(\mathrm{PPh}_{2}\right)\left(\mathrm{SiMe}_{3}\right) \mathrm{C}=\mathrm{S}$ ligand to the $\mathrm{Pd}\left(\mathrm{PPh}_{3}\right)_{2}$ center via the $\mathrm{C}=\mathrm{S}$ bond (scheme 73$)$. This reactivity was rationalized by DFT calculations. Indeed, the unstable intermediate was computed (on models with $\mathrm{PH}_{3}$ in place of $\mathrm{PPh}_{3}$ ) $22 \mathrm{kcal} / \mathrm{mol}$ higher than the final thioketone complex. Moreover, in the HOMO of the intermediate (mainly $\pi^{*} \mathrm{C}-\mathrm{Pd}$ ), a large coefficient at $\mathrm{C}$ is seen, which favors intramolecular nucleophilic attack at S and P-S bond breaking.

Scheme 73: Synthesis of Pd carbene complex featuring ligand 14 from carbenoid precursor. 106 


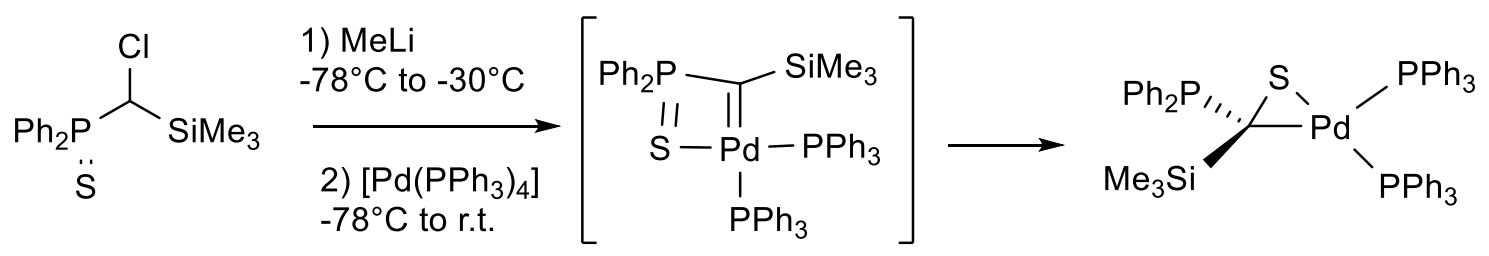

\subsubsection{Group 11 Complexes}

Up until 2017, the only example of group 11 metal carbene featuring a geminal dianion had been

reported by Roesky. ${ }^{142}$ It was obtained from the reaction of two equivalents of $\left[\mathrm{AuCl}\left(\mathrm{PPh}_{3}\right)\right]$ with two equivalents of the bis(iminophosphoranyl)methanide anion 6aHLi. The complex is a dinuclear gold complex 53 in which the carbene ligand is bridging (Scheme 74). Mechanistically, it was proposed that a first equivalent of $\mathbf{6 a H K}$ reacted with one gold precursor to generate $\left[\mathrm{Au}(\mathbf{6 a H})\left(\mathrm{PPh}_{3}\right)\right]$ in which the acidity of the $\mathrm{CH}$ is enhanced upon coordination. The second equivalent of $6 \mathbf{a H K}$ then serves as a base to deprotonate the intermediate mononuclear gold complex, form an anionic $\left[\mathrm{Au}(\mathbf{6 a})\left(\mathrm{PPh}_{3}\right)\right]^{-}$complex that further reacts with the remaining gold precursor to yield the observed dinuclear compound 53. This compound exhibits a strong violet emission at $432 \mathrm{~nm}$.

Scheme 74: Synthesis of bimetallic Au(I) complex featuring bridging ligand 6a.

2

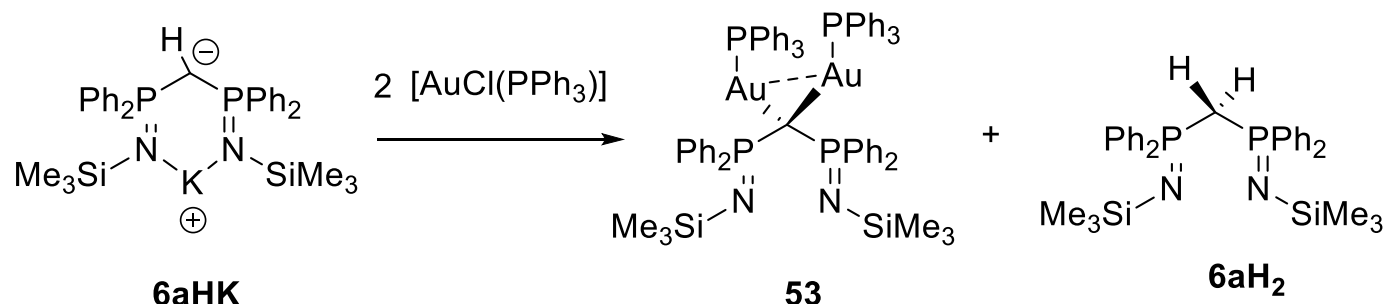


In 2017, Mézailles and co-workers reported the first Au(III) carbene complex. ${ }^{143}$ The successful synthesis relied on the use of a carefully designed $\mathrm{Au}(\mathrm{III})$ precursor together with the geminal dilithio derivative $\mathbf{8} \mathbf{L} \mathbf{i}_{2}$ (scheme 75). A fluxional process renders the two PS moieties equivalent by ${ }^{31} \mathrm{P}$ NMR at room temperature, but inequivalence was seen below $-60^{\circ} \mathrm{C}$. X-ray structure analysis showed the expected trigonal planar at $\mathrm{C}$ and square planar geometry at $\mathrm{Au}$. DFT calculations rationalize the long Au-C bond. Indeed, the HOMO of the complex is described as the antibonding interaction of the $\mathrm{n} \pi$ lone pair at $\mathrm{C}$ and $\mathrm{d}_{\mathrm{xy}}$ at $\mathrm{Au}$. This orbital being mainly developed at the $\mathrm{C}$ center, a nucleophilic character was predicted. The NBO analysis confirmed the qualitative picture, showing that the Au-C bond is polarized toward the carbene center $(72.7 \% \mathrm{C}, 27.3 \%$ at $\mathrm{Au})$. At the second order perturbation level, the p lone pair at $\mathrm{C}$ is shown to interact with low lying orbitals. The result is a strong stabilization of the lone pair by the P substituents (total of $53 \mathrm{kcal} / \mathrm{mol})$ and weak stabilization by the Au center $(6 \mathrm{kcal} / \mathrm{mol})$. The interaction is therefore not a formal $\mathrm{Au}=\mathrm{C}$ double bond, but rather a polarized bond with a high lying HOMO mainly developed at the $\mathrm{C}$ center. Despite this, the complex only reacted with activated electrophiles, such as phenylisothiocyanate or $\mathrm{CS}_{2}$, at $80^{\circ} \mathrm{C}$ overnight. The latter results in formal $\mathrm{CS}_{2}$ insertion into the $\mathrm{AuC}$ bond, while the former forms the expected ketenimine together with a highly reactive putative (PC)Au=S complex II. This complex dimerizes readily to form complexes $\mathbf{5 5}$ and $\mathbf{5 5}$ ' unless an excess of $\mathrm{PhN}=\mathrm{C}=\mathrm{S}$ is present in the medium. In that case, it is efficiently trapped to form complexes $\mathbf{5 4}$ and 54' with corresponding dithiocarbamate ligand.

\section{Scheme 75: Synthesis and reactivity of Au(III) complex featuring ligand 8.}




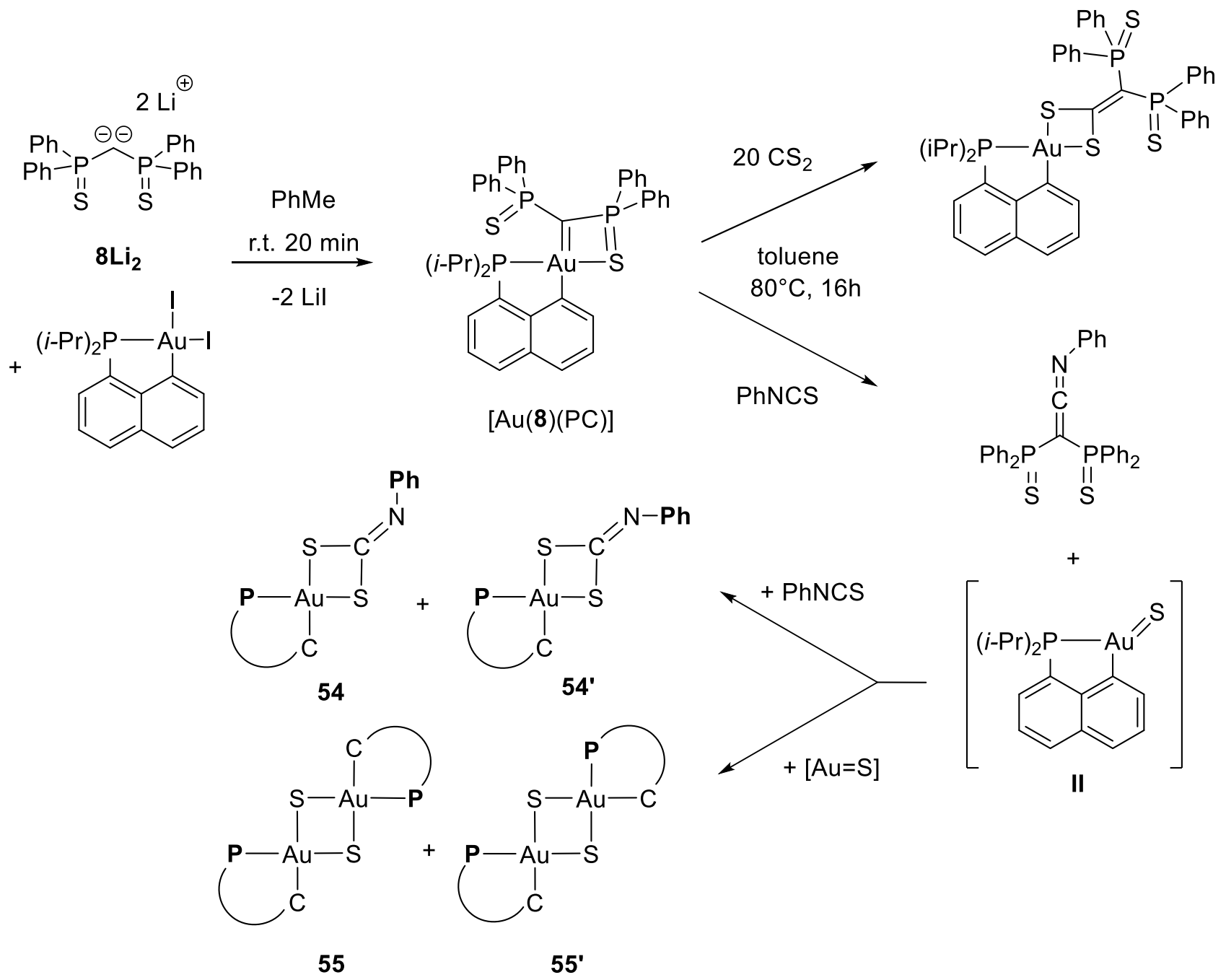

This study thus presented the first Schrock type carbene reactivity of any gold carbene complex.

\subsubsection{Group 12 complexes}

As for group 11, very few examples of carbene complexes involving group 12 metals have been reported. In 2003, Westerhausen et al. reported the synthesis of a trinuclear zinc complex. ${ }^{144}$ Metathesis reaction of bis(iminophosphoranyl)methanediide dianion and zinc chloride gave complex 56 (Scheme 76). 
Scheme 76: Group 12 complex with ligand 6a.

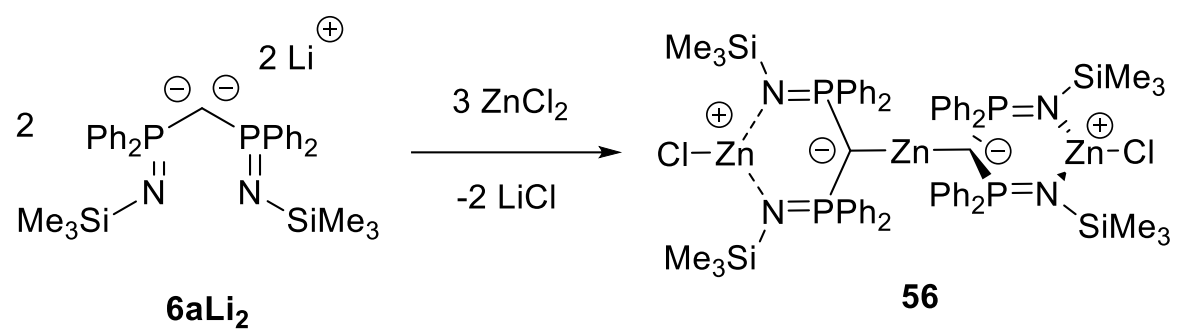

\subsubsection{Group 13 complexes: synthesis and reactivity}

Characterized methylidene-bridged bis-aluminum species have been known for about 30 years, ${ }^{145}$ yet group 13 complexes featuring stabilized methanediide moiety are scarce. Three synthetic pathways have been devised for their synthesis. The first complexes have been reported by Robinson in 1988 with aluminum, and the most common strategy relies on the C-H/Al-Me bond cleavage. ${ }^{146}$ Elimination of methane is a strong driving force and they obtained the dimeric complex $\left[\mathrm{Al}\left(\mathrm{CH}_{3}\right)\right]\left[\mathrm{Ph}_{2} \mathrm{P}(\mathrm{O}) \mathrm{CP}(\mathrm{O}) \mathrm{Ph}_{2}\right]_{2}\left[\mathrm{~A} 1\left(\mathrm{CH}_{3}\right)_{2}\right],{ }^{146}(\mathbf{5 7}$, Scheme 77) from the addition of an excess of trimethylaluminium to the neutral bidentate ligand bis(diphenylphosphinoyl)methane $\mathrm{Ph}_{2} \mathrm{P}(\mathrm{O}) \mathrm{CH}_{2} \mathrm{P}(\mathrm{O}) \mathrm{Ph}_{2}$ in chlorobenzene at $100^{\circ} \mathrm{C}$. It is to be noted that the geminal dianion of the ligand has not been reported so far. The crystallographic structure reveals an unsymmetrical arrangement for the ligand. Indeed, it features two $\mathrm{AlMe}_{2}$ moieties bridging two oxygen atoms of the two ligands, and one central AlMe moiety linked to the two central carbons and the two remaining oxygen of each ligand. The high temperature $\left(160^{\circ} \mathrm{C}\right)$ reaction between ligand $\mathbf{8 H}_{2}$ and 2.5 equivalent of di(isobutyl)aluminium hydride in a mixture of toluene and hexane afforded a complex featuring four $\mathrm{Al}$ centers per dianionic ligand, $\mathbf{5 8}$. In the process, the ligand has been partially reduced, and $\mathrm{S}^{2-}$ acts as bridging ligand between three Al. Double deprotonation of the $\mathrm{CH}_{2}$ moiety results in alkane elimination. ${ }^{147}$

\section{Scheme 77: Al complexes featuring type I geminal dianions}




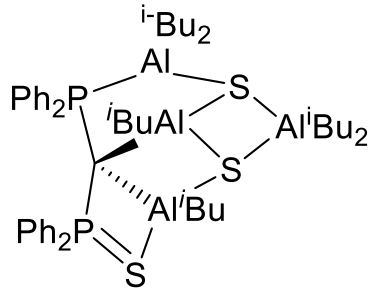

58

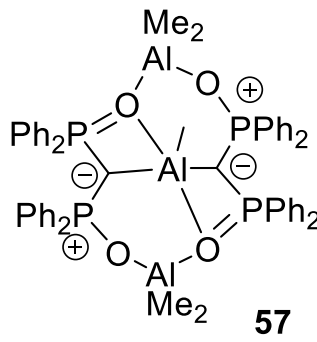

57
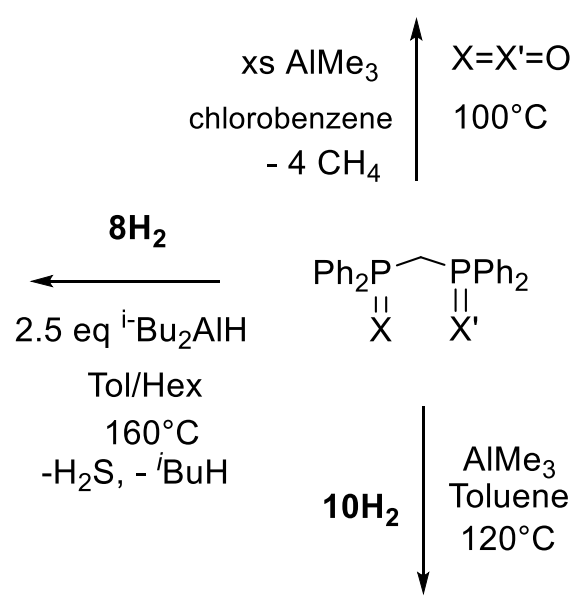

$\mathrm{AlMe}_{3}$

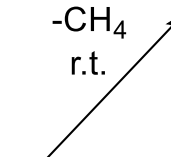

$6 \mathrm{aH}_{2}$

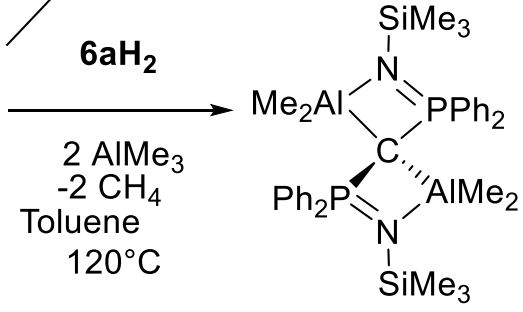

59

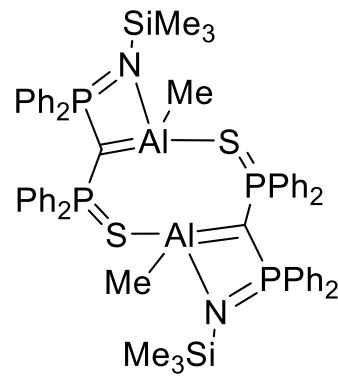

In 2000, roughly at the same time they reported the synthesis of $\mathbf{6} \mathbf{a} \mathbf{L} \mathbf{i}_{2}$, Cavell and coworkers reported the complex $\left[\mathrm{AlMe}_{2}\right] \mu-(\mathbf{6 a}), \mathbf{5 9} .^{148}$ In this case also, methane elimination ensuing deprotonation was chosen as the synthetic strategy. An intermediate can be obtained quantitatively at room temperature while using only one equivalent of trimethylaluminium. It was then further deprotonated at $100^{\circ} \mathrm{C}$ to obtain the final product. In 2010, the unsymmetrical ligand $\mathbf{1 0 H}_{\mathbf{2}}$ has been used to obtain the first carbene aluminum complex with a formal $\mathrm{C}=\mathrm{Al}$ bond. ${ }^{149}$ Here also refluxed toluene was needed to achieve the second deprotonation at $\mathrm{C}$ to afforded complex $[\operatorname{AlMe}(\mathbf{1 0})]_{2}$, complex $\mathbf{6 0}$. This complex is 
dimeric through coordination of the PS moiety to the second aluminum atom. Comparing with the related spiro complex $\left[\mathrm{AlMe}_{2}\right] \mu-(\mathbf{6 a}), \mathbf{5 9} \mathrm{Al}-\mathrm{N}$ bond distances are shortened from 1.933(3) $\AA$ to $1.915(1) \AA$, and very significantly, Al-C bond distances from 2.121(3) $\AA$ to $1.976(1) \AA$ in $\left[\mathrm{AlMe}_{2}\right] \mu-(\mathbf{6 a})$ and $[\mathrm{Al}$ $\mathrm{Me}(\mathbf{1 0})]_{2}$ respectively. The bonding situation in this complex was probed by DFT calculations on a model $\left[\mathrm{AlH}\left\{\mathrm{C}\left(\mathrm{PH}_{2}=\mathrm{NH}\right)\left(\mathrm{PH}_{2}=\mathrm{S}\right)\right\}\right]_{2}$. The NBO analysis showed that the Al-C $\sigma$ and $\pi$ bonds are mainly developed on the $\mathrm{C}$ center (85.7\% in $\sigma$ and 98.2 in $\pi$ interactions), pointing a highly polar interaction ( $16.2 \%$ covalent, $83.8 \%$ ionic character). This is corroborated by the small WBI of 0.474 . Further analysis using Bader's QTAIM (quantum theory of atoms in molecules) confirmed that the Al-C bond is polar and covalent, and similar to $\mathrm{Al}-\mathrm{C}$ bonds in $\left[\mathrm{H}_{3} \mathrm{C}-\mathrm{Al}\left(\mathrm{CH}_{3}\right)(\mathrm{SH})\right]$ and $\left[\mathrm{H}_{2} \mathrm{C}=\mathrm{Al}-\mathrm{CH}_{3}\right]$ models.

In terms of reactivity, Cavell reported the stoichiometric reaction between the spirocyclic dimetallic bis(diphenyliminophosphoranyl)methanediide complexes $\quad\left[(\mathbf{6 a})\left(\mathrm{AlMe}_{2}\right)_{2}\right] \quad \mathbf{5 9}$ and heteroallenes $\mathrm{AdN}=\mathrm{C}=\mathrm{O}$ and $\mathrm{CyN}=\mathrm{C}=\mathrm{NCy}$ to afford the bimetallic bicyclic compounds $\mathbf{6 1}$ and $\mathbf{6 2}($ scheme 78$) .{ }^{150}$

\section{Scheme 78: Reactivity of bridging Al complex of ligand 6a.}

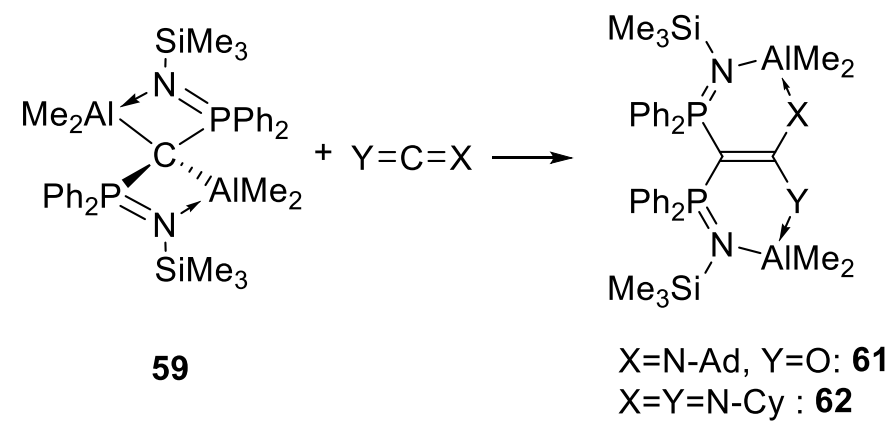

In 2002, they also reported that complexes $\left[(\mathbf{6 a H}) \mathrm{AlR}_{2}\right]$ and $\left[(\mathbf{6 a})\left(\mathrm{AlR}_{2}\right)_{2}\right], \mathrm{R}=\mathrm{Me},{ }^{i-} \mathrm{Pr}$ are also efficient as ethylene polymerization catalysts, with the bimetallic $\left[(\mathbf{6 a})(\mathrm{AlR})_{2}\right]$ species featuring higher activities. ${ }^{151}$ Comparison between Me and ${ }^{i-} \operatorname{Pr}$ bis-aluminum methanediide showed that the bulkier the 
substituent, the higher the molecular weight and the lower the activity. Spirocyclic complex $\left[(\mathbf{6 a})\left(\mathrm{AlMe}_{2}\right)_{2}\right]$ could also be used in the co-polymerization of ethylene and 1-octene.

A milder route toward methanediide aluminum complexes has been reported in 2010 by Leung et al.. ${ }^{51}$ They reacted two equivalents of the monoanionic $8 \mathbf{H L i}$ precursor with $\mathrm{MCl}_{3}(\mathrm{M}=\mathrm{Al}, \mathrm{Ga}, \mathrm{In})$ and obtained a set of homologous group 13 complexes (scheme 79). The second equivalent of the monoanion acts as a base for the deprotonation of the coordinated monoanion, leading to the desired $\mathrm{C}=\mathrm{M}$ bond.

\section{Scheme 79: Synthesis of group 13 carbene complexes of ligand 8.}

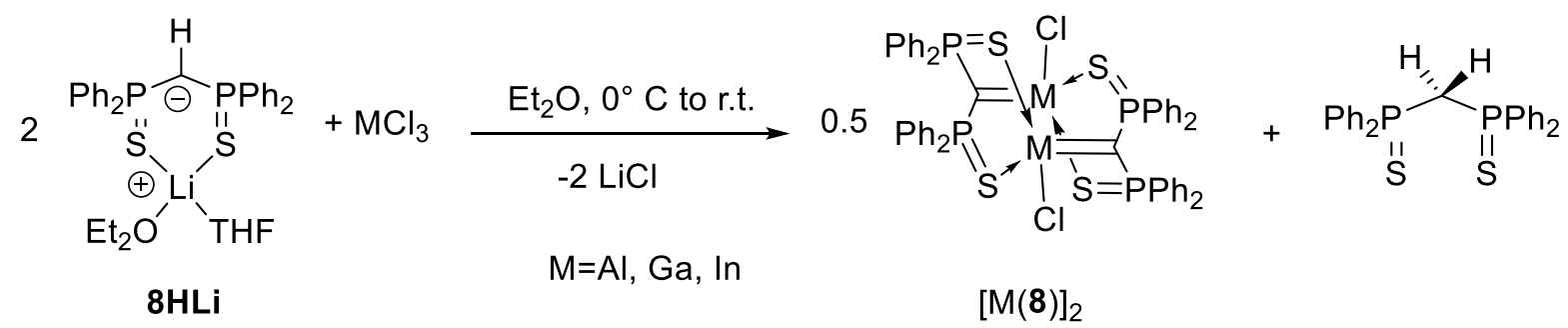

All three complexes are isostructural and the measured values of the P-C-P angles $\left(116.8(1)^{\circ}\right.$ for $[\mathrm{Al}(\mathbf{8})]_{2}, 117.8(3)^{\circ}$ for $[\mathrm{Ga}(8)]_{2}, 121.1(2)^{\circ}$ for $\left.[\operatorname{In}(8)]_{2}\right)$ are in agreement with a $\mathrm{sp}^{2}$-hybridized methanediide carbon. Similarly elongated P-S (between 2.051(2) $\AA$ and 2.062(1) $\AA$ ) and shortened P-C bond lengths $(1.710(5) \AA$ and $1.724(2) \AA)$ compared with the neutral ligand $\left(\mathrm{S}=\mathrm{PPh}_{2}\right)_{2} \mathrm{CH}_{2}(\mathrm{P}-\mathrm{S} 1.95 \AA$ and P-C $1.83 \AA$ ), suggest a similar delocalization of the electronic density from the carbon to the stabilizing $\mathrm{Ph}_{2} \mathrm{P}=\mathrm{S}$ moieties. The In-C bond distance of $2.173(3) \AA ̊$ is much more important in the indium complex than in the very similar gallium and aluminum one (respectively 1.972(4) and 1.975(2) $\AA$ ), as would be anticipated going down a column. It is worth mentioning that these complexes are the first and only indium and gallium methanediide complexes. 
In 2016, Mézailles reported the reactivity between $\mathrm{BH}_{3}$ and geminal dilithio derivative $\mathbf{8 L \mathbf { L }} 2$ (scheme 80). ${ }^{152}$ Unlike the analogous reactivity with $\mathrm{PPh}_{3} \mathrm{CPPh}_{3}$, The mono adduct is not stable and

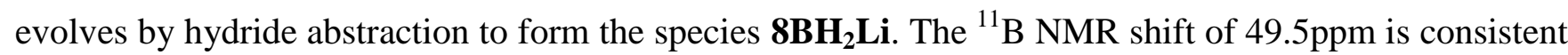
with a stabilized borenium derivative " $\mathrm{BR}_{2}{ }^{+}$". The $\mathrm{C}-\mathrm{B}$ bond is shorter than the analogue borenium stabilized by $\mathrm{PPh}_{3} \mathrm{CPPh}_{3}{ }^{153}$ Both the $\mathrm{C}$ and the $\mathrm{B}$ atoms adopt trigonal planar geometry that favors $\pi$ interaction between the lone pair at $\mathrm{C}$ and the vacant orbital at $\mathrm{B}$. This compound can be seen as the stabilization of parent $\mathrm{BH}_{2}{ }^{+}$by the geminal dianion via $\sigma$ and $\pi$ donation.

\section{Scheme 80: Synthesis of B complex of ligand 8.}

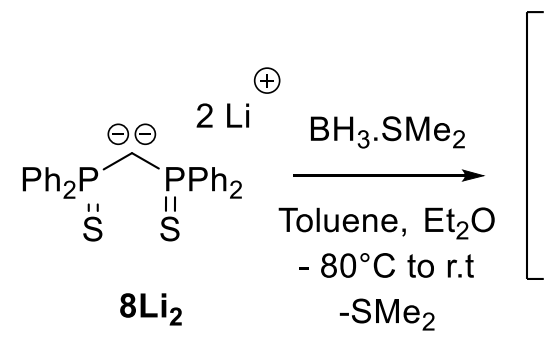

$8 \mathrm{Li}$

$-\mathrm{SMe}_{2}$

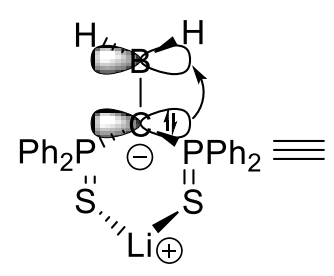

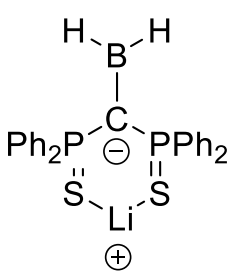

borane

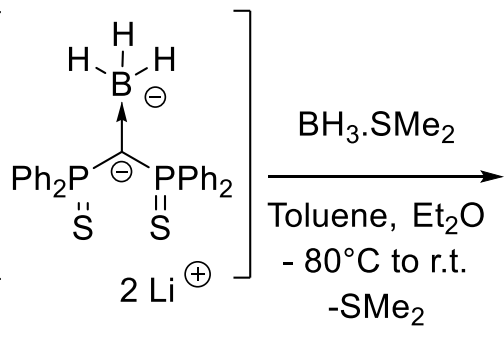

$\mathrm{Me}_{2}$

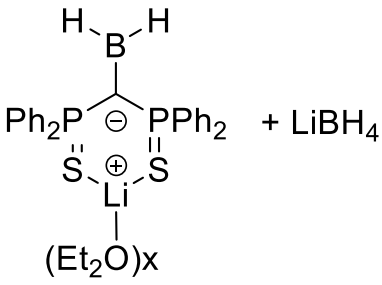

$8 \mathrm{BH}_{2} \mathrm{Li}$

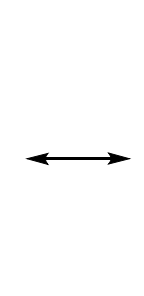

$$
\begin{aligned}
& \text { dihydrido borenium } \\
& \text { stabilized by } \\
& \text { geminal dianion }
\end{aligned}
$$

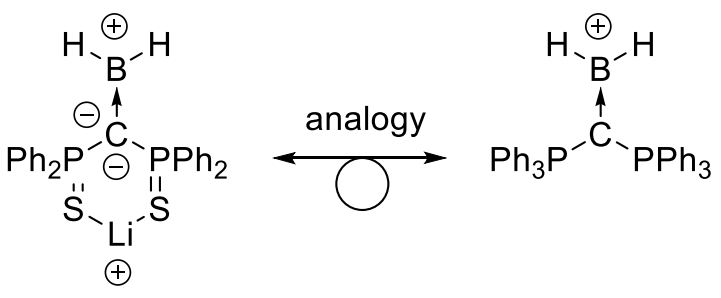

dihydrido borenium stabilized by carbodiphosphorane

The nature of the C-B bond was further evaluated by NBO analysis. The charge at $\mathrm{C}$ in $\mathbf{8 B} \mathbf{H}_{2} \mathbf{L i}$ is almost identical as in $\mathbf{8 H L i}$ (-1.46 vs -1.47), and slightly higher than in $\mathbf{P C P B H}{ }_{2}^{+}(-1.39)$. The charge at $\mathrm{B}$ is identical in $\mathbf{8 B H} \mathbf{2} \mathbf{L i}$ and $\mathbf{P C P B H}+(0.26$ vs 0.25$)$ despite a higher charge at $\mathrm{P}$ in the latter (1.74 
vs 1.53). This analysis corroborates both NMR and metrical data that highlight a very strong analogy between these two species.

In terms of reactivity, $\mathbf{8} \mathbf{B H}_{2} \mathbf{L i}$ expectedly behaved as an ambiphilic species, making adducts with the Lewis base DMAP, and the Lewis acid $\mathrm{BH}_{3}$. The latter compound $\mathbf{8 B}_{2} \mathbf{H}_{5} \mathbf{L i}$ features a rare $\mathrm{B}_{2} \mathrm{H}_{5}{ }^{+}$fragment stabilized by the geminal dianion 8 . Both $\mathbf{8 B H}_{2} \mathbf{L i}$ and $\mathbf{8 B}_{2} \mathbf{H}_{5} \mathbf{L i}$ appeared as excellent catalysts for the $\mathrm{CO}_{2}$ reduction into methanol derivatives by $\mathrm{BH}_{3} \cdot \mathrm{SMe}_{2}$. Indeed, a maximum TOF of $150 \mathrm{~s}^{-1}$ was measured with $0.5 \%$ mol of catalyst, and maximum TON of $c a 2800$ was obtained upon heating at $80^{\circ} \mathrm{C}$ in THF for $22 \mathrm{~h}$.

\subsubsection{Group 14 complexes:}

\subsubsection{Synthesis}

The first isolation of a silene derivative in 1981 led the way for the synthesis and study of species containing a carbon-heavier group 14 element double bonds. ${ }^{154}$ Their peculiar electronic structure confers them a very rich chemistry. ${ }^{155},{ }^{156},{ }^{157}$ Among them, the terminal group 14 metallavinylidene $\mathrm{R}_{2} \mathrm{C}=\mathrm{M}$ : are even more challenging to synthesize because of both decreased steric protection around the group 14 atom and lowered electronic stabilization. Among the strategies envisioned, the use of hypervalent phosphorus-stabilized methanediides proved especially efficient. Although the geminal dilithio derivatives $\mathbf{6} \mathbf{a L i} \mathbf{i}_{\mathbf{2}}$ and $\mathbf{8} \mathbf{L} \mathbf{i}_{\mathbf{2}}$ are known, most compounds of $\operatorname{tin}^{158}$ and lead ${ }^{159}$ in their (+II) oxidation state are usually synthesized either starting from the reaction between the neutral derivative and the corresponding metal-amide precursor or from the mono anion. With the symmetrical ligands, the products are dimeric, cyclic dimetalacyclobutanes (scheme 81).

\section{Scheme 81: Synthesis of low oxidation states group 14 complexes featuring type I geminal}

\section{dianions.}




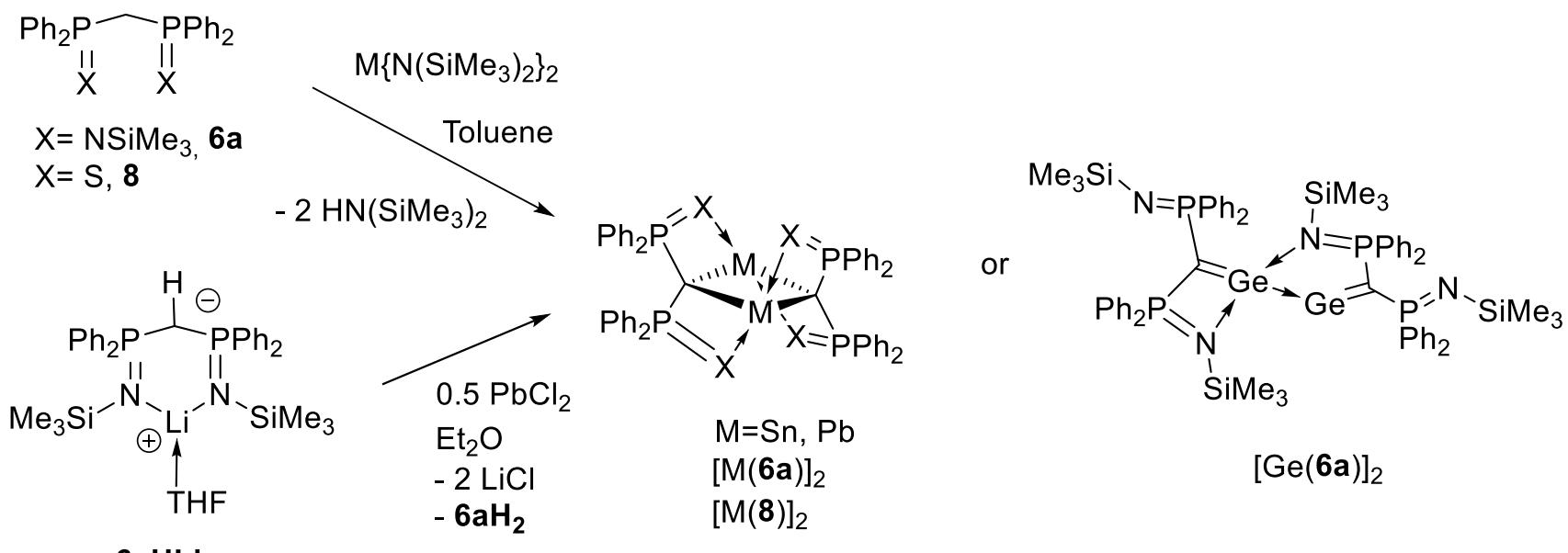

6aHLi

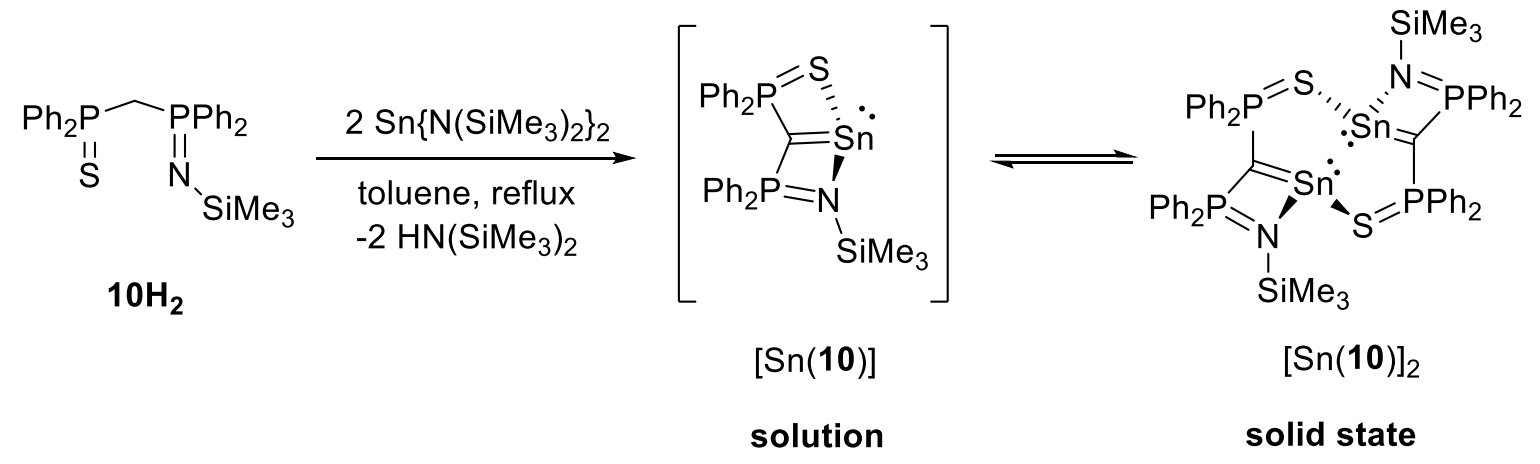

scheme 81

In the case of $\mathrm{Ge}$, Leung showed that the structure did not imply ligand $\mathbf{6 a}$ as bridging, but rather complex $[\mathrm{Ge}(\mathbf{6})]_{2}$ is obtained via a head to head dimerization of two germavinylidenes. ${ }^{158},{ }^{160}$ The Ge-Ge bonding was described as a donor-acceptor interaction. The two carbon-germanium bonds in the two subunits are identical at 1.908(7) $\AA$ and shorter than usual germanium-alkyl or aryl bonds. NMR spectroscopy showed only one single signal for each nucleus at room temperature, suggesting a fluxional coordination of amido groups to the two germanium centers. 
On the other hand, So and coworkers reported in 2010 that using the dissymmetric (thiophosphinoyl)(iminophosphoranyl)methane $\mathbf{1 0 H}_{2} \mathrm{CH}_{2}\left(\mathrm{Ph}_{2} \mathrm{P}=\mathrm{S}\right)\left(\mathrm{Ph}_{2} \mathrm{P}=\mathrm{N}-\mathrm{SiMe}_{3}\right)$ as precursor the first stable monomeric stannavinylidene could be obtained. ${ }^{161}$ Although monomeric in solution, as shown by ${ }^{119} \mathrm{Sn}$ NMR spectroscopy, the species is found as a dimer in the solid state, via coordination of the PS arm to the second Sn center. In this structure, the carbon-tin bond length of 2.2094(9) $\AA$ is much shorter than in the corresponding complex $\left[\operatorname{Sn}(\mathbf{1 0 H})\left(\mathrm{N}\left(\mathrm{SiMe}_{3}\right)_{2}\right)\right]$ featuring the monoanionic ligand $(2.384(4) \AA)$, which suggests an increased C-Sn bond order. It is also shorter than in the spirocyclic complex $[\operatorname{Sn}(\mathbf{6 a})]_{2}(\mathrm{Sn}-\mathrm{C}$ of $2.376 \AA$ in average) .

When it comes to higher oxidation state of group 14 complexes, the use of $\mathbf{8} \mathbf{L} \mathbf{i}_{2}$ proved efficient for isolation of the first 2-germaallene complex $\left[\operatorname{Ge}(\mathbf{8})_{2}\right]$, by So and coworkers in 2009, starting from the highvalent $\mathrm{GeCl}_{4}$ precursor (scheme 82). ${ }^{162}$

\section{Scheme 82: Synthesis of high oxidation state group 14 complexes featuring ligand 8.}

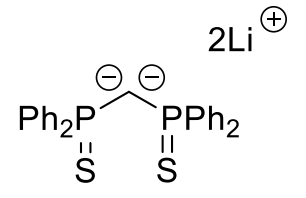

8Li2

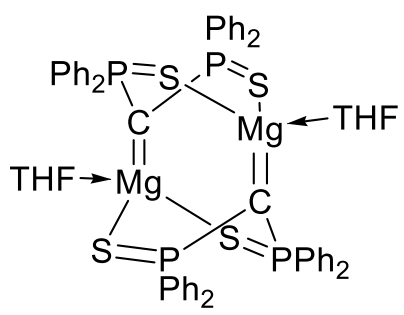

$[\mathrm{Mg}(8)]_{2}$

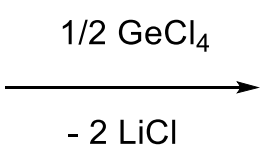

Toluene

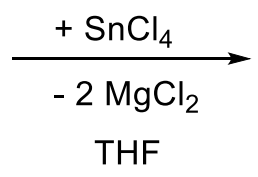

THF

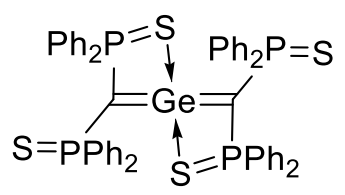

$\left[\mathrm{Ge}(8)_{2}\right]$

$\left[\operatorname{Sn}(8)_{2}\right]$ 
${ }^{31} \mathrm{P}$ NMR characterization of $\left[\mathrm{Ge}(\mathbf{8})_{2}\right]$ showed a single signal for phosphorus in solution even at low temperature, and two signals obtained in the solid state by ${ }^{31} \mathrm{P} \mathrm{CP} / \mathrm{MAS}-\mathrm{NMR}$. These observations suggest a very low energy process for the dynamic coordination of the sulfur atoms to the germanium center in solution. The higher oxidation state of germanium is reflected in the Ge-C bond lengths of $1.882(2) \AA$, slightly shorter than in the in Ge(II) complex $[\mathrm{Ge}(\mathbf{6 a})]_{2}(1.908(7) \AA)$ mentioned above.

In 2011, Leung reported the analogue tin(IV) derivative [Sn(8) $)_{2}$, yet the synthesis relied on transmetallation from magnesium to tin (scheme 82$).{ }^{163}$ In contrast to complex $\left[\mathrm{Ge}(\mathbf{8})_{2}\right]$, the crystal structure of $\left[\operatorname{Sn}(\mathbf{8})_{2}\right]$ showed a coordination of all of four sulfur atoms to the metal center. However, a fluxional behavior of the PS coordination was evidenced by ${ }^{31} \mathrm{P}$ NMR spectroscopy, as for complex $\left[\mathrm{Ge}(\mathbf{8})_{2}\right]$.

It is important to stress here that several related derivatives of group 14 complexes have been obtained with ligands that feature at least one high valent $\mathrm{P}$ moiety, although the corresponding dianions are not known to be stable, or known not to be stable. Their syntheses relied either on the use of the stable monoanion or the double deprotonation using the bis amide precursor. Interestingly, in all but one example, $[(\operatorname{PhosN}) \mathrm{Ge}]_{3}$, the dimetalacyclobutane-type structure is found. Representative examples are given in scheme 83. ${ }^{164 \_} 169$

\section{Scheme 83: Synthesis of related derivatives of group 14 complexes.}




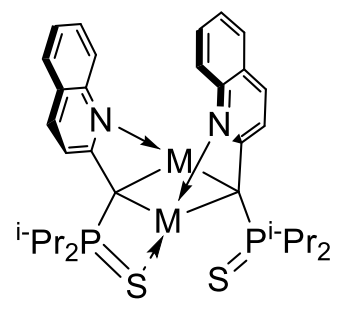

$M=G e, S n, P b$

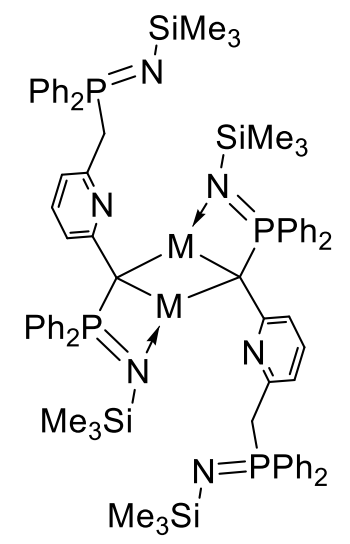

$\mathrm{Me}_{3} \mathrm{Si}$

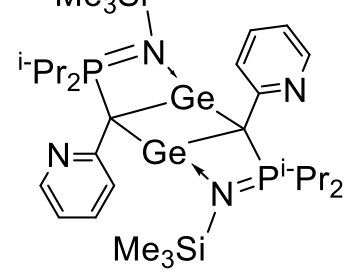

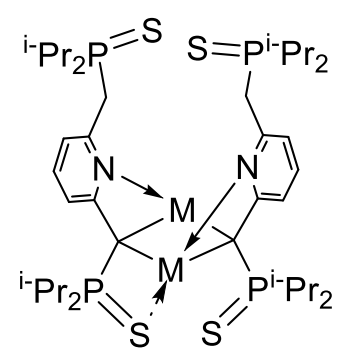

$M=S n, P b$

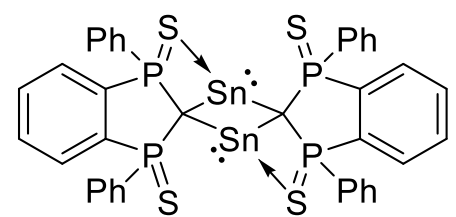

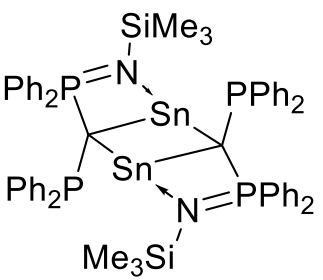

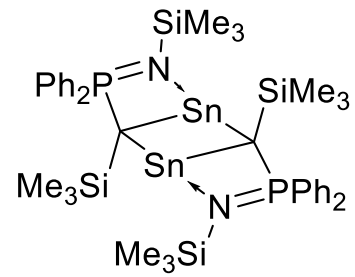

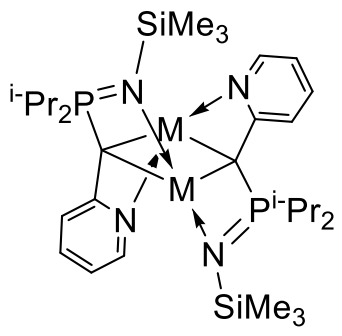

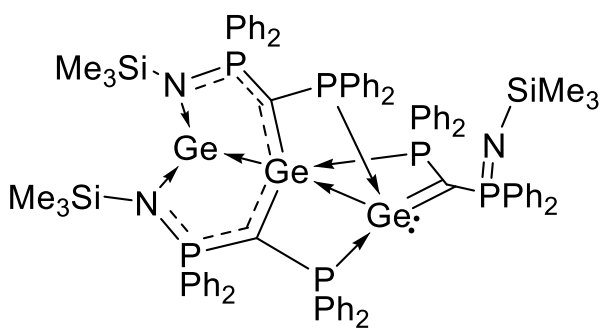

$M=S n, P b$

scheme 83

\subsubsection{2. $\quad \mathrm{MC}(\mathrm{M}=$ group 14$)$ bonding scheme}

In general, the bonding situation between the carbon and the metal is evaluated from the evolution of

bond lengths in 3D structures and comparison with previously described complexes. $\operatorname{In}\left[\operatorname{Ge}(\mathbf{8})_{2}\right],{ }^{162}$ the carbon-germanium bond distance of $1.882(2) \AA$ is significantly longer compared to other Ge(IV) ger- 
mavinylidene ( $c a 1.81 \AA$ A). The corresponding values of C-P an P-S being unusual, a $\pi$-electron delocalization within the Ge-C-P-S ring by conjugation of $\mathrm{P}=\mathrm{S}$ and $\mathrm{C}=\mathrm{Ge}$ bonds was proposed, resulting in a decrease of the bond order between carbon and germanium. It was confirmed by theoretical calculations. ${ }^{162}$ The NBO analysis sustained the description of a polar germanium-carbon bond $(71 \%$ on $\mathrm{C}$, $29 \%$ on $\mathrm{Ge}$ ) consisting of an interaction between a $\mathrm{sp}^{2.2}$ hybridized carbon centered orbital and a $\mathrm{sp}^{1.8}$ hybridized germanium-centered orbital. The influence of the S coordination to Ge on the overall stability and evolution of carbon-germanium bond length was then probed on a simplified model. It was showed that when the S-Ge interaction was removed, the carbon-germanium bond lengths shortens to $1.789 \AA$ and became close to the one predicted for the putative $\mathrm{H}_{2} \mathrm{C}=\mathrm{Ge}=\mathrm{CH}_{2}$ system $(1.745 \AA) .{ }^{170}$ However, it also resulted in a destabilization of $\mathrm{ca} 54 \mathrm{kcal} / \mathrm{mol}$ compared to the system which presents two coordinated sulfur atoms. Finally, a topological analysis of the electronic density using Bader's QTAIM allowed the description of the carbon-germanium bond in $\left[\mathrm{Ge}(\mathbf{8})_{2}\right]$ as being intermediate between an alkyl-germanium bond and a 2-germaallene. A similar analysis was done for the tin complex $\left[\operatorname{Sn}(\mathbf{8})_{2}\right] .{ }^{163}$ In the Tin(II) complexes, an increase in the C-Sn computed bond order is linked to the shortening of the bond distance going from the stannacyclobutane $[\operatorname{Sn}(\mathbf{6 a})]_{2}$ to the stannavinylidene $[\operatorname{Sn}(\mathbf{1 0})]_{2} .{ }^{159}$ A NBO analysis was done on a simplified model (all substituent at phosphorus and nitrogen modeled by $\mathrm{H})$ for the stannavinylidene $[\operatorname{Sn}(\mathbf{1 0})]_{2} \cdot{ }^{161}$ The $\mathrm{C}-\mathrm{Sn}$ bond was described as resulting from $\sigma$ and $\pi$ interactions. The $\sigma$ interaction ( $85 \% \mathrm{C}$ character) is made of an almost pure $\mathrm{p}$, Sn centered orbital $\left(\mathrm{s}^{0.25} \mathrm{p}^{2.00}\right.$-hybridised) and a $\mathrm{sp}^{2.00}$-hybridized carbon-centered orbital, whereas the $\pi$ interaction (97\% C character) is constructed with two pure $\mathrm{p}$, carbon and tin centered orbitals. The overall interaction is again consistent with a highly polarized bond toward carbon. The second-order stabilizing interactions were quantified, i.e. donation from $\mathrm{N}$ and $\mathrm{S}$ moieties to the $\mathrm{Sn}$ center. Second order stabilization 
energy by donation in the carbon-tin $\pi^{*}$ orbital by $\mathrm{N}$ is ca twice as strong as the $\mathrm{S}$ ( $\left.80 \mathrm{vs} 42 \mathrm{kcal} / \mathrm{mol}\right)$. A topological analysis of the carbon-tin bond points a covalent but polar bond which is intermediate between tin alkyl and tin vinylidene, thus similar to the one obtained for $\left[\mathrm{Ge}(\mathbf{8})_{2}\right]$.

\subsubsection{Reactivity}

The bis-germavinylidene complex $[\mathrm{Ge}(\mathbf{6 a})]_{2}$ possesses a very rich chemistry, as proven by Leung and co-workers (scheme 84$).{ }^{171}$ In a first instance, the dimer can be readily broken, which results in availability of lone pair at germanium. Thus, complex $[\mathrm{Ge}(\mathbf{6 a})]$ can act as a two-electron donor ligand (Ge lone pair) towards $\mathrm{Ni}, \mathrm{Pd}, \mathrm{Au}, \mathrm{Ag}^{172} \mathrm{Mn} .{ }^{173}$ Being in low oxidation state, the Ge center can also be engaged in redox chemistry. Indeed it can oxidize chalcogens $(E=S, S e, T e)$ to generate the bridging $E^{2-}$ species via the germaketene $>\mathrm{C}=\mathrm{Ge}=\mathrm{E}$ intermediate. ${ }^{174}$ Alternatively, it can behave as a germene precursor. ${ }^{171}$ The reactivity of the formal $\mathrm{C}=\mathrm{Ge}$ bond can be highlighted in the $[2+2]$-cycloaddition, 1,2 $\operatorname{addition}^{175}$ and [2+3] cycloaddition ${ }^{176}$ reactions. Finally, the weak $\mathrm{C}=\mathrm{Ge}$ pi bond can be used to generate heterobimetallic complexes of $\mathrm{Rh},{ }^{173}$ iron and manganese, ${ }^{176}$ or even to fully transfer the carbene fragment to Mo, which are both $\mathrm{C}$ centered reactions. ${ }^{120}$

\section{Scheme 84: Reactivity of Ge complex $[\operatorname{Ge}(6 a)]_{2}$.}




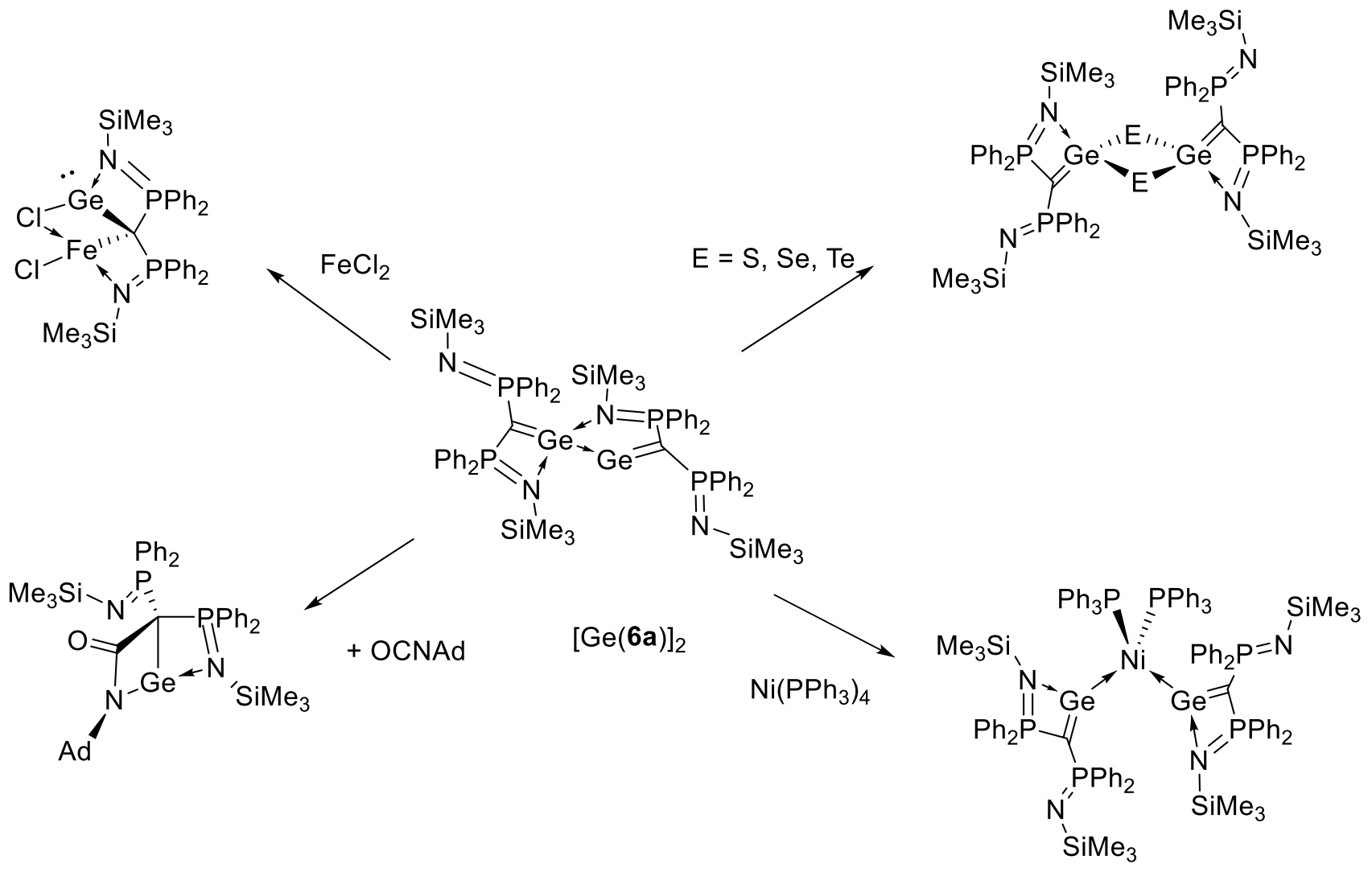

The chemistry of the related tin complex $[\operatorname{Sn}(\mathbf{1 0})]_{2}$ was studied by So and co-workers (scheme 85 ). They evidenced the [2+2] reactivity with various isocyanides consistent with the polarized $\mathrm{C}=\mathrm{Sn}$ bond. Here also, $\mathrm{C}$ centered reactivity to form $\mathrm{Sn}-\mathrm{Rh}$ heterobimetallic complex was shown. ${ }^{177}$ From the reaction with elemental sulfur a low yield $(29 \%)$ of a mixed valence complex was isolated. ${ }^{178}$ In this species, three complexes of tin(IV) sulfide condensed to form a metallacyclohexane structure that stabilize a tin(II) center. Elimination of 0.5 equivalents of the neutral $\mathbf{1 0 \mathbf { H } _ { 2 }}$ ligand is observed in the course of the reaction.

Scheme 85: Reactivity of $\operatorname{Sn}$ complex $[\operatorname{Sn}(10)]_{2}$. 


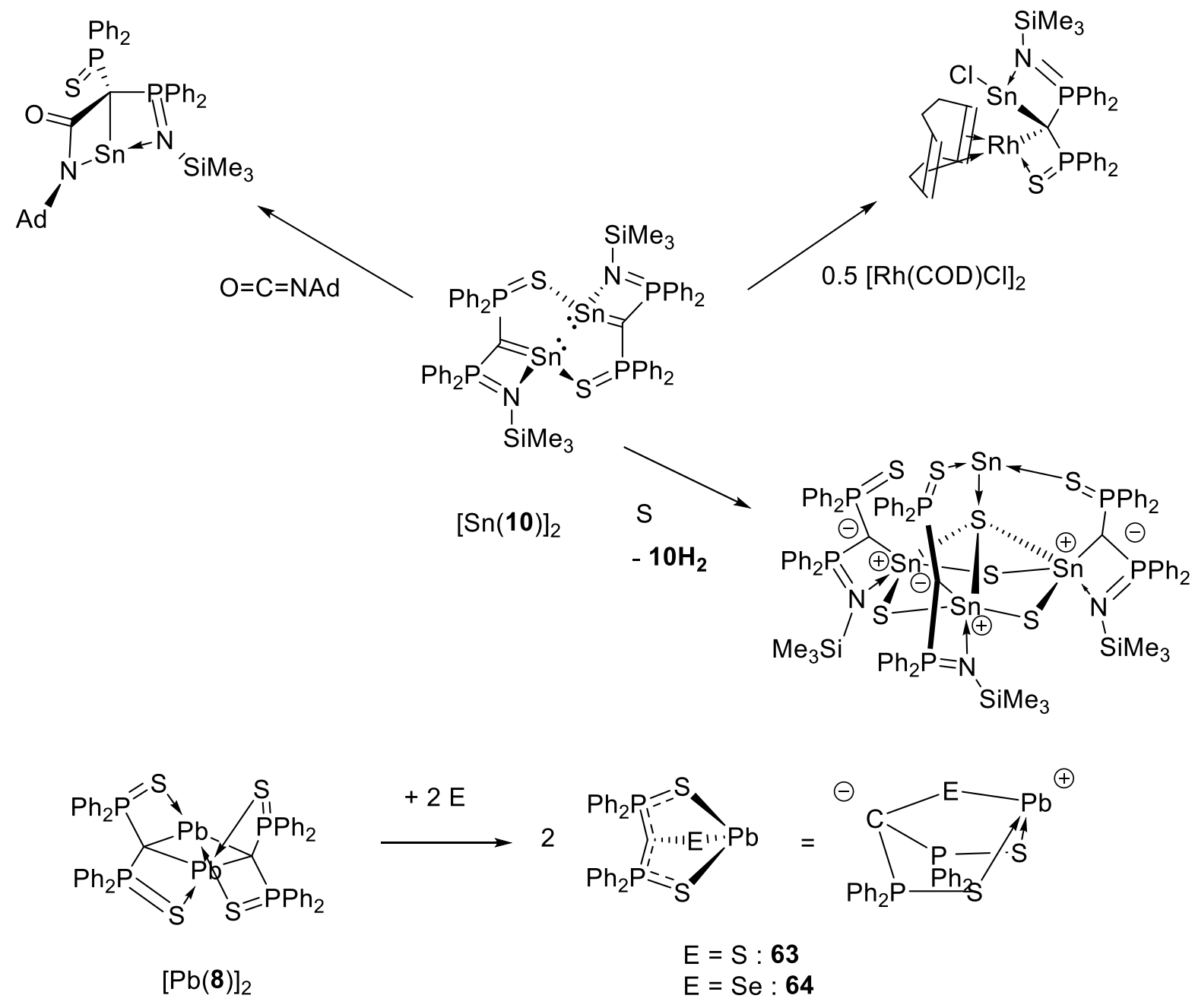

In sharp contrast with the above rich chemistry, the $\mathrm{Sn}$ and $\mathrm{Pb}$ dimers of ligand $\mathbf{8}$, showed only limited reactivity. Indeed, the reaction of the $\mathrm{Pb}$ derivative $[\mathrm{Pb}(\mathbf{8})]_{2}$ with $\mathrm{S}$ or Se resulted in the chalcogen insertion into the $\mathrm{C}-\mathrm{Pb}$ bond. Monomeric species $\mathbf{6 3}$ and $\mathbf{6 4}$ are isolated in poor yield (14 and 25\%, with S and Se respectively). They present a three coordinate $\mathrm{Pb}$ center with a stereochemically active lone pair. The overall geometry of the $\mathrm{PbS}_{2} \mathrm{P}_{2} \mathrm{C}$ metallacycle adopts a boat conformation. ${ }^{159}$ 
Finally, the chemistry of $\mathrm{Sn}(\mathrm{II})$ derivative 65 should be presented here (schemes 86 and 87). As mentioned above, the geminal dilithio derivative is not known so far, but Harder has reported the synthesis of a related diCs derivative of the bis-PN system, 16Cs2. It bears strong geometrical resemblance to complex $[\operatorname{Sn}(\mathbf{8})]_{2}$. Thus, So and coworkers reported its reactivity toward group 12, 13 and 14 Lewis acids. ${ }^{169}$ With $\mathrm{Al}$ derivatives, major rearrangements were observed. Indeed, reaction of the dimer with $\mathrm{AlCl}_{3}$ (2 equivalents) resulted in dimer splitting and formation of the heterobimetallic zwitterionic $\mathrm{Al} / \mathrm{Sn}$ complex 66 in $63 \%$ yield. With one equivalent of $\mathrm{AlCl}_{3}$, a trimetallic " $\mathrm{AlSn}_{2}$ " complex 67 is formed in $56 \%$ yield. A likely common intermediate is proposed. With $\mathrm{AlMe}_{3}$, a sequence of two AlMe transmetallations to Sn was evidenced, with concomitant $\mathrm{SnMe}_{2}$ elimination, to yield the dimeric zwitterionic aluminum complex 68.

\section{Scheme 86: Reactivity of Sn complex 65 toward Lewis acids $\mathrm{AlCl}_{3}, \mathrm{GaCl}_{3}$.}

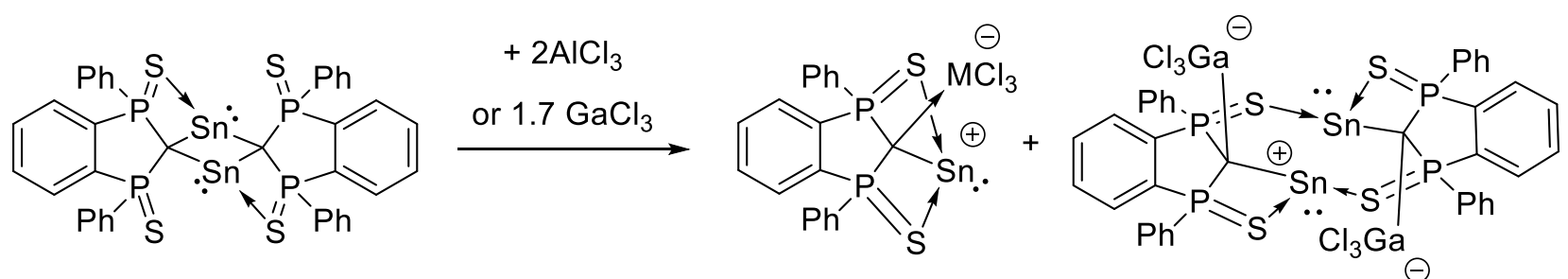

65

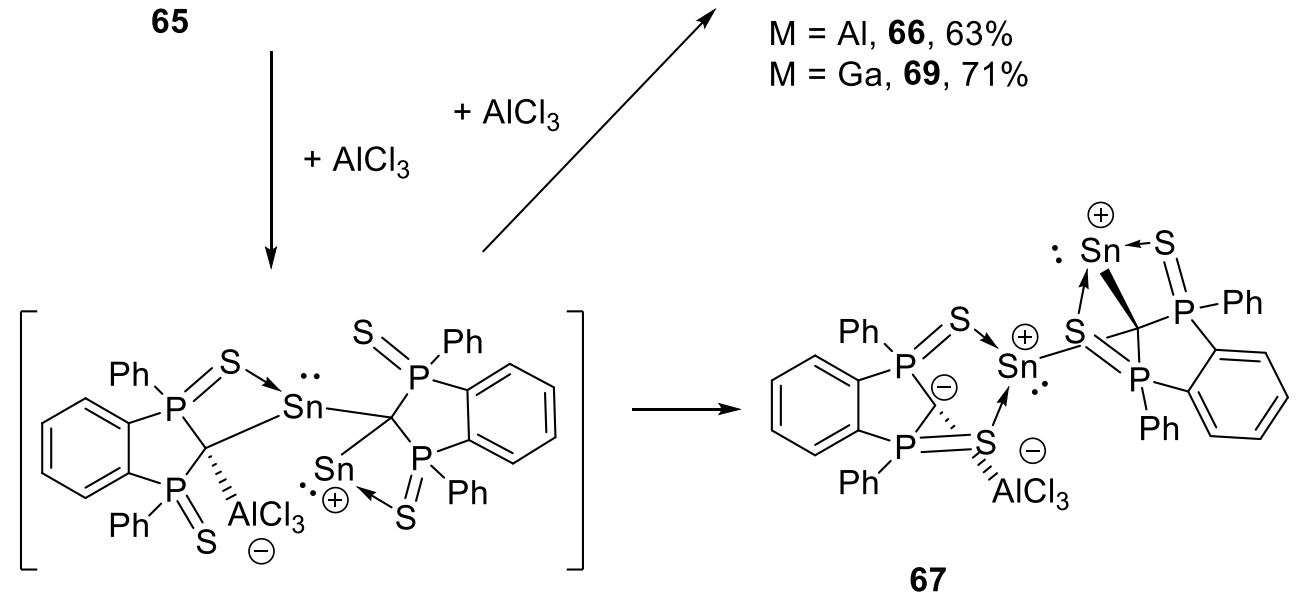

$M=A l, 66,63 \%$ $\mathrm{M}=\mathrm{Ga}, \mathbf{6 9}, 71 \%$ 
The related heterobimetallic zwitterionic $\mathrm{Ga} / \mathrm{Sn}$ complex 69 was obtained in $71 \%$ yield from the reaction with $\mathrm{GaCl}_{3}$ in place of $\mathrm{AlCl}_{3}$ (scheme 87). ${ }^{179}$ Interestingly, the monomer and the dimer cocrystallized from the crude mixture. With $\mathrm{GeCl}_{4}$, a chloride transfer from Ge to $\mathrm{Sn}$ was observed (complex 70). The reactivity toward $\mathrm{ZnEt}_{2}$ proved quite sluggish, and heating to toluene reflux overnight was necessary. A very poor yield (16\%) of complex 71 was crystallized from the mixture. Overall, partial desulfuration of a sacrificial ligand occurred, leading to a $\mathrm{Zn}_{2} \mathrm{~S}_{2}$ central core to which are bound two "LigandSn(Et) $)_{2}$ " moieties via the $\mathrm{S}$ of the $\mathrm{P}=\mathrm{S}$.

Scheme 87: Reactivity of Sn complex 65 toward Lewis acids $\mathrm{AlMe}_{3}, \mathrm{ZnEt}_{2}$ and $\mathrm{GeCl}_{4}$.

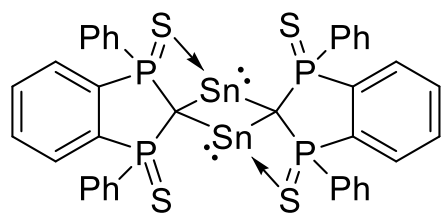

65
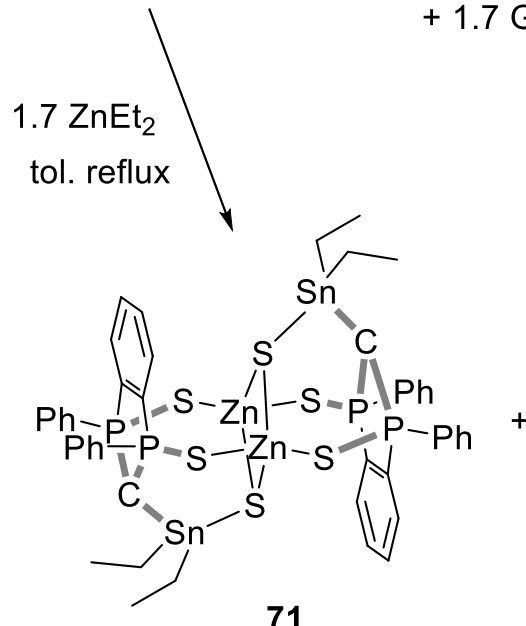

71

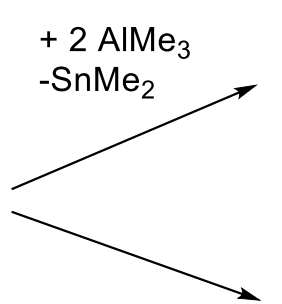

$+1.7 \mathrm{GeCl}_{4}$

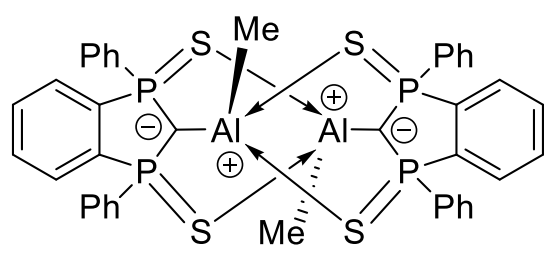

68

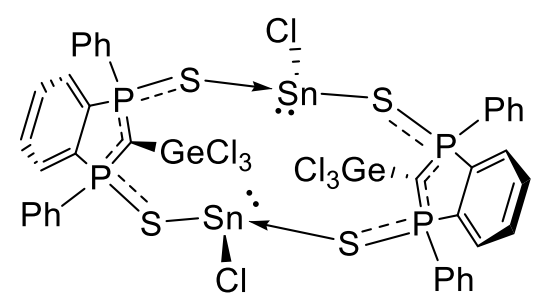

70

\section{Geminal dianions of type II (A neutral fragment, B cationic fragment)}


Amongst the species featuring two lone pairs at carbon, yldiide represent a specific group. The two lone pairs at $\mathrm{C}$ are stabilized on the one hand by a cationic fragment, in all cases by a phosphonium moiety, and on the other hand by a neutral stabilizing group (Scheme 88). Following the common usage in the domain, we will represent the yldiides with a double bond between the charged moiety and the $\mathrm{C}$ center, thus $\mathrm{R}_{3} \mathrm{P}=\mathrm{C}$, and a C-M bond. After early developments in the 1970's, these structures gained renewed interest ${ }^{180}$ with the isolation of stable specimens in the 1990's.

\section{Scheme 88 : From geminal dianion to stabilized geminal dianion of type II : yldiides.}

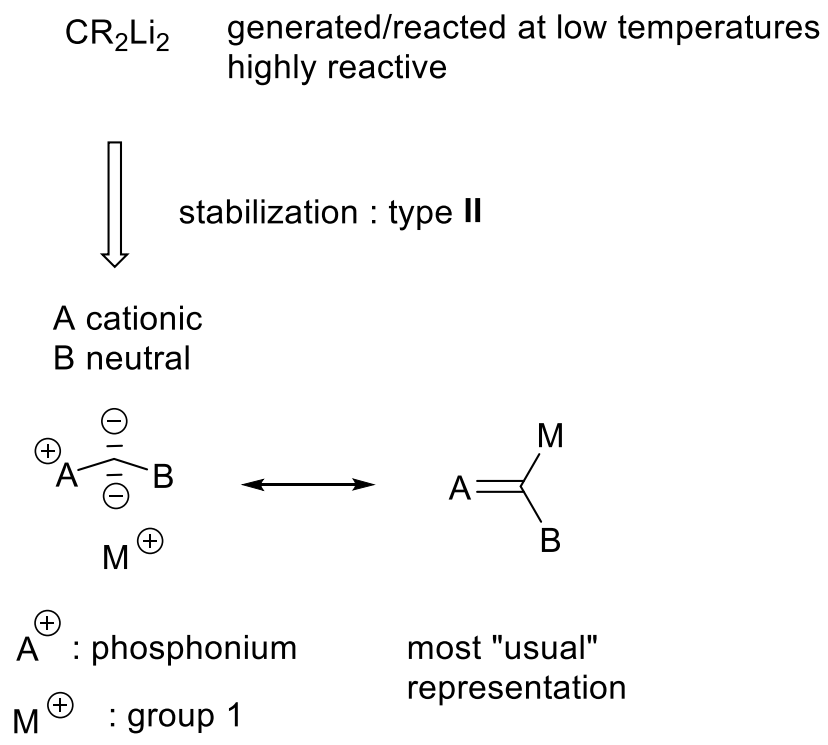

\subsection{Synthesis of geminal dianions of type II}

The quest for metallated ylides, i.e. yldiide, was strongly related to the need to enhance the reactivity of ylides, ${ }^{181}$ or increase the selectivity for a C-centered reactivity in stabilized ylides. ${ }^{182}$ First evidences of the possibility of such a structure was presented by Schlosser as early as in 1966, during his study of nucleophilic substitution at phosphorus. ${ }^{183}$ After addition of an excess of butyllithium to a solution of pentaphenylphosphine, the products of the reaction were trapped by $\mathrm{DBr}$, affording up to $14 \%$ of 126 
([1,1-D 2$]$-butyl)-triphenylphosphonium bromide (scheme 89$)$. The presence of this product suggests the formation of yldiide 72. Later, Corey showed that deprotonation of methylenetriphenylphosphorane by an alkyllithium reagent increased its reactivity toward hindered ketones ${ }^{181,184}$ (vide infra). However, in the absence of any stabilizing group at carbon in addition to the phosphenium moiety, the deprotonated ylide 73 was not isolated and its structure mostly deducted from its subsequent reactivity. ${ }^{185}$ The reaction proved to be quite versatile, deprotonation of the ortho-phenyl position being also observed, ${ }^{186}$ as well as decomposition products over time (scheme 90). Alternatively, the lithium-halogen exchange proved to be a more robust route to obtain the targeted end products with good yields $(63 \%-78 \%$, scheme 89). ${ }^{183,185}$ Finally, a phenyl-substituted compound was mentioned briefly in 1990, with no clear characterization or quantification. ${ }^{187}$

\section{Scheme 89 : Early synthesis of non-isolated yldiides.}

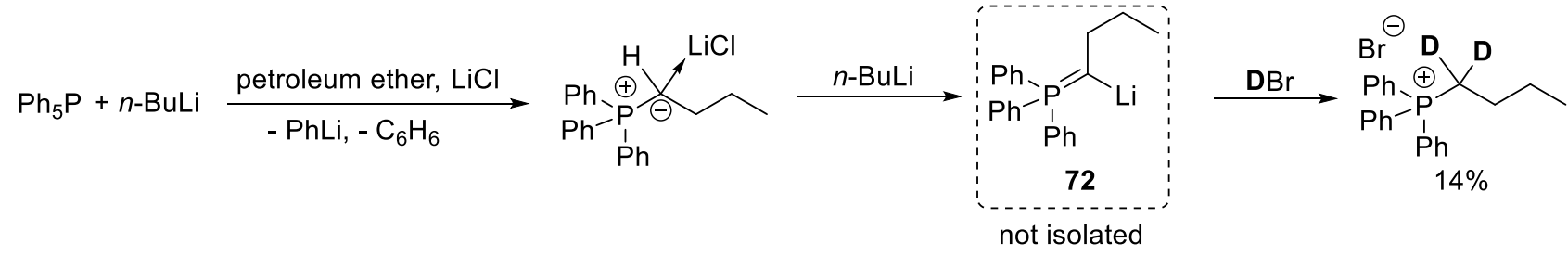

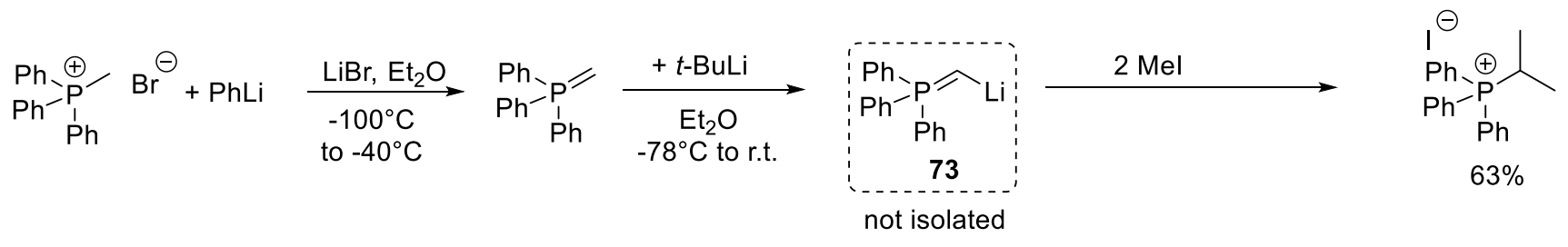

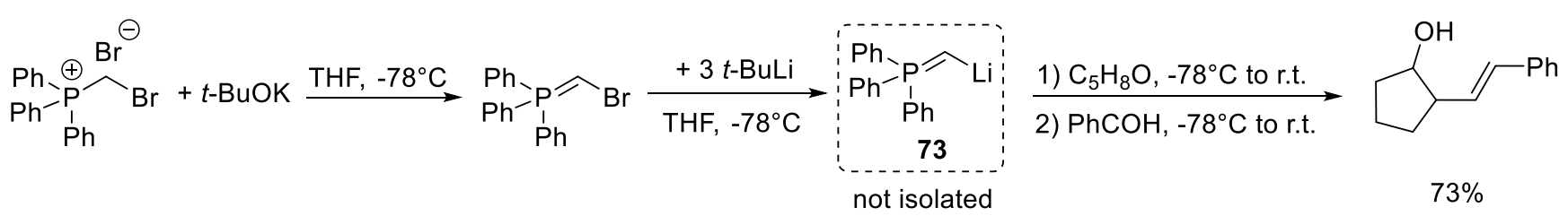

Decomposition was also observed by Bestmann during the deprotonation of ethoxycarbonyl- stabilized methylenetriphenlyphosphorane by various lithiated bases. ${ }^{188}$ Instead of the desired metallated ylide 74, they obtained a cumulene-stabilized ylide by loss of lithium ethanolate. Ligand exchange at phosphorus 127 
was also observed. Any attempt to trap the postulated yldiide intermediate by addition of methyliodide resulted in the isolation of [1-methyl-2,4-dioxo-3-(phosphoranylidene)cyclobutyl]-phosphonium with various substitution schemes at phosphorus, which in fact is the result of the reaction of methyliodide with the cumulene-stabilized ylide, highlighting the short lifetime of the postulated yldiide. Decomposition was even more selective toward the ketenylidene-triphenylphosphorane product with a methoxycarbonyl as stabilizing group and sodium N,N-bis-(trimethylsilyl)amide as base. ${ }^{189}$

Scheme 90 : Undesired side reaction and decomposition mechanism during the preparation of yldiides 73,74 and 75 .
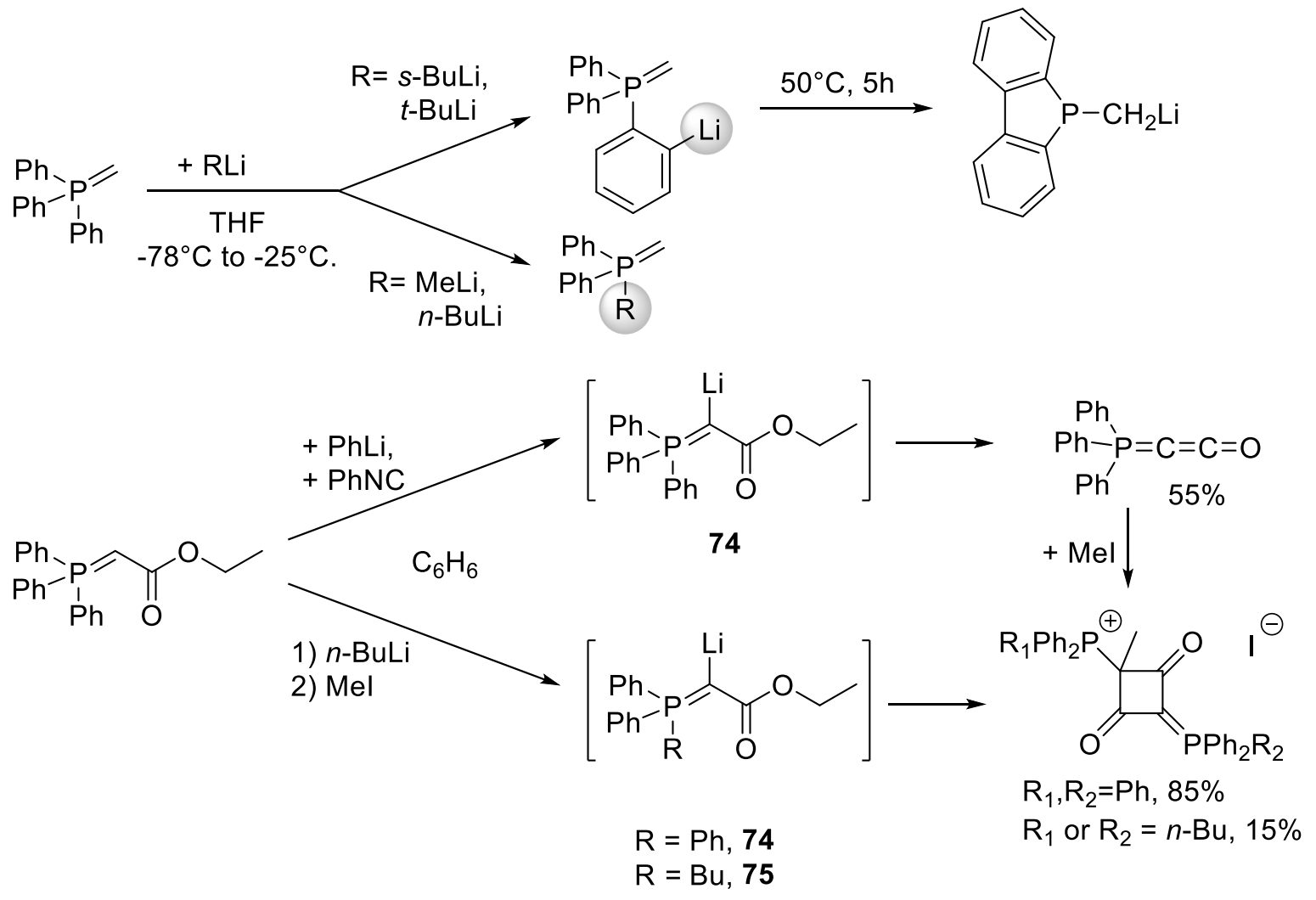

A decade later, Bestmann used a cyano group to increase the stability of the yldiide. ${ }^{190}$ If the metallated species 76 could not be isolated, it proved to be more robust and trapping experiment with various halogenoalkanes confirmed a deprotonation of the methylene carbon (scheme 91). Both IR and NMR 128 
spectroscopy study however suggested a strong conjugation of the charge through the carbonitrile moiety. In the absence of any X-ray structure or more detailed NMR studies, the preferential site of coordination of the cation is still to be deciphered.

\section{Scheme 91 : Synthesis and in situ reactivity of yldiide 76.}

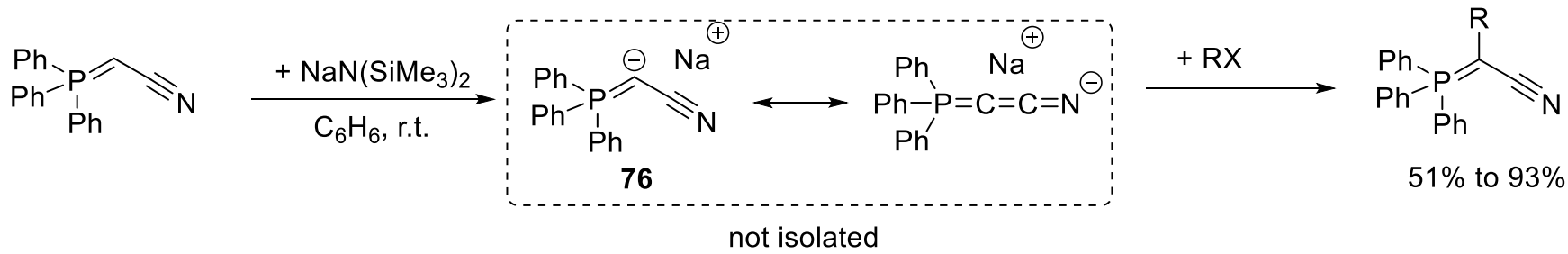

A major breakthrough was made by Niecke who introduced two decisive parameters: ${ }^{191}$ a) stabilization of the charges at $\mathrm{C}$ by $\pi$-conjugation, thanks to the introduction of iminophosphoranyl or methylidenephosphoranyl moieties, and b) steric bulkiness around the yldiide carbon by a judicious choice of substituents. With these parameters, two metallated ylides could be isolated in 78\% (iminophosphoranyl-substitued 77) and 81\% (methylenephosphoranlyl-stubstituted 78) crystalline yield (scheme 92). 
Scheme 92 : Synthesis of yldiides 77 and 78.

first isolated yldiides

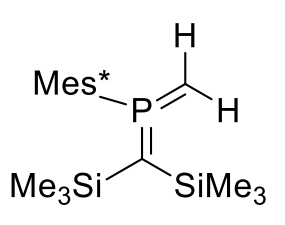

$77_{\mathrm{H}}$<smiles>C[13CH2]/[P+]([14CH3])=N\[14CH3]</smiles>

$\mathbf{7 8}_{\mathrm{H}}$
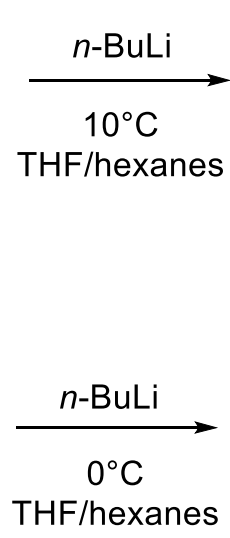

THF/hexanes

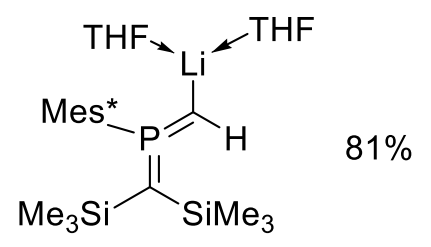

77

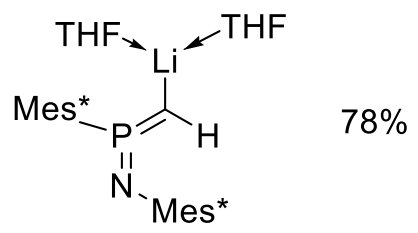

78

A second strategy, envisaged as early as 1972 (sulfoxide), ${ }^{192}$ successfully applied by Bertrand ${ }^{193}$ and pursued by Gessner ${ }^{194}$ and Baceiredo, ${ }^{195}$ consists in the substitution of phosphonium-ylides by a second charge-stabilizing heteroelement. Apart from Bertrand's $\alpha$-lithiomethylenephosphorane 79, obtained by formal 1,2-addition of $n$-butyllithium to an in-situ generated trimethylsilyl-phosphanylcarbene (scheme 93), ${ }^{196}$ all of them are obtained following the previous strategy, i.e. deprotonation of an ylide by $n$ butyllithium $^{195}$ or variously metallated amides. ${ }^{194}$ In the latter cases, X-ray diffraction studies showed the coordination of the alkali metal by both the carbon and one oxygen from the sulfoxide (in 80) or sulfone (in 81) stabilizing moiety. 


\section{Scheme 93 : Synthesis of yldiides 79 to 81.}

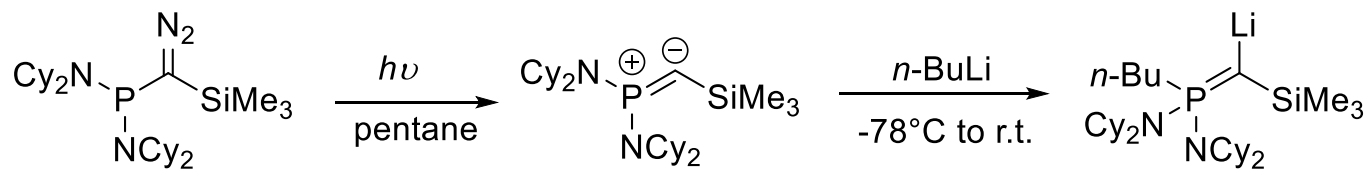

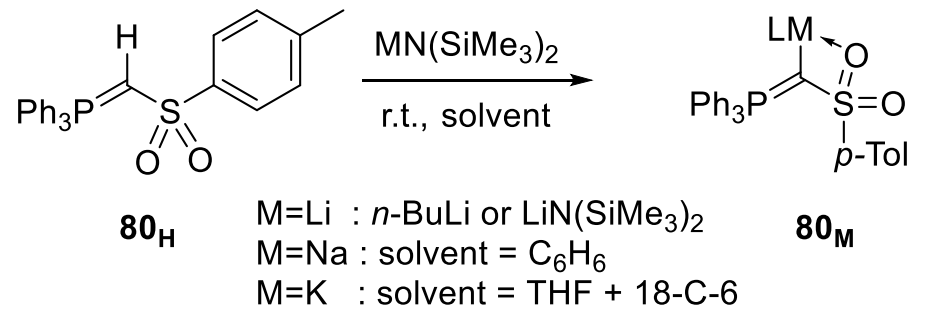

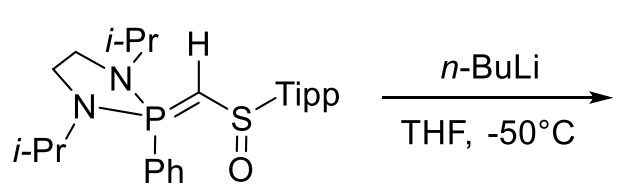

$81_{H}$

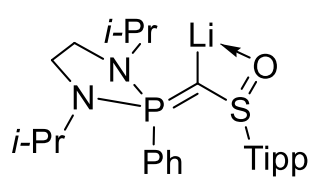

81

\subsection{Structural properties}

As shown above, the handling and isolation of yldiides required specific design highlighting the very peculiar character of the electronic configuration in these species, i.e. the presence of two lone pairs of electron at a same unsaturated carbon. This specificity echoes this of geminal dianions of type I presented above. We will thus try to highlight the eventual differences between these groups along with their common properties.

It appears to be logical to start this analysis by the most completely described yldiides, i.e. those that have been structurally characterized. If the stability of ylide is well described, mostly in terms of electrostatic interactions as well as negative hyperconjugation, the appearance of a second lone pair at car- 
bon, altogether with a negative global charge - and a counter cation - will certainly disturb this depiction. The related ylide will thus be taken as a reference as far as it has been described itself.

\subsubsection{X-ray diffraction}

Figure 1: Structure of yldiide 79, $80_{\mathrm{K}}$ and 81 as determined by $\mathrm{X}$-ray diffraction.

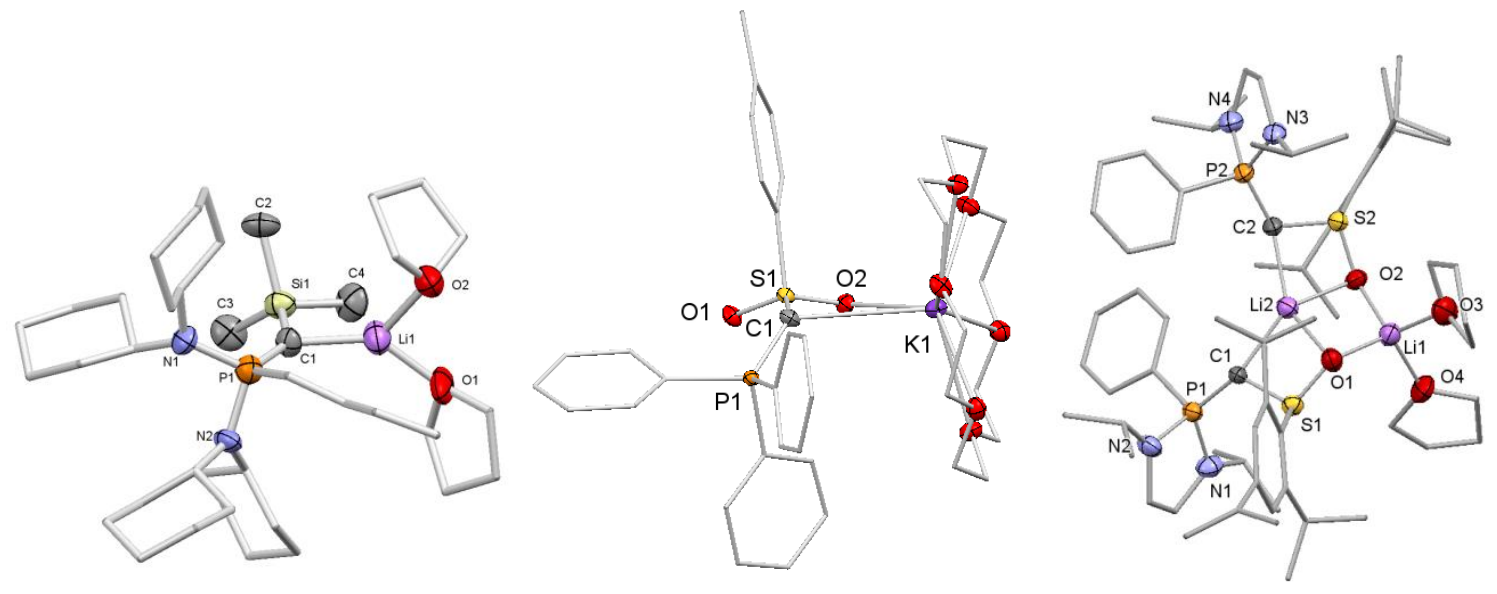

Table 6: Bond distances and angles in yldiides

\begin{tabular}{|c|c|c|c|c|c|c|c|c|}
\hline Species & d C-P $(\AA)$ & $\begin{array}{ll}d & C-X \\
(\AA) & \end{array}$ & $\begin{array}{ll}d & C-M \\
(\AA) & \\
\end{array}$ & $\begin{array}{l}\mathrm{d} \quad \mathrm{C}_{R}-\mathrm{P} \\
(\AA)\end{array}$ & $\begin{array}{ll}\text { d } & \text { Y-P } \\
(\AA) & \end{array}$ & $\alpha(\mathrm{P}-\mathrm{C}-\mathrm{X})^{\circ}$ & $\begin{array}{l}\alpha \quad(\mathrm{P}-\mathrm{C}- \\
\mathrm{M}){ }^{\circ}\end{array}$ & $\begin{array}{l}\alpha(\mathrm{X}-\mathrm{C}- \\
\mathrm{M})^{\circ}\end{array}$ \\
\hline $\mathbf{7 7}_{\mathbf{H}}{ }^{197}$ & $1.612(3)$ & & & $1.803(2)$ & & & & \\
\hline 77 & $1.632(5)$ & & $2.085(11)$ & $1.826(5)$ & & & $140.0(4)$ & \\
\hline 78 & $1.624(5)$ & & $2.081(12)$ & $1.811(6)$ & & & $143.3(5)$ & \\
\hline 79 & $1.64(2)$ & $1.77(1)$ & $2.06(2)$ & $1.87(1)$ & & $139.0(7)$ & $123.7(8)$ & 97.1(8) \\
\hline $80_{H}$ & $1.705(3)$ & $1.681(2)$ & & $\begin{array}{l}1.794(3) \\
- \\
1.815(3)\end{array}$ & & 124.1(2) & & \\
\hline $80_{M}$ & $1.646(2)$ & $1.626(2)$ & $3.154(2)$ & $1.835(3)$ & & $124.3(1)$ & $126.5(1)$ & $85.49(7)$ \\
\hline $81_{H}$ & $1.677(2)$ & $1.736(2)$ & & $1.811(2)$ & $1.816(2)$ & $120.8(1)$ & & \\
\hline 81 & $1.649(3)$ & $\begin{array}{l}1.682(3) \\
- \\
1.693(3)\end{array}$ & $\begin{array}{l}2.158(6)- \\
2.139(7)\end{array}$ & $\begin{array}{l}1.823(3) \\
- \\
1.826(4)\end{array}$ & $\begin{array}{l}1.832(4) \\
- \\
1.833(3)\end{array}$ & $\begin{array}{l}117.5(2)- \\
115.5(2)\end{array}$ & $\begin{array}{l}142.3(3) \\
- \\
142.8(3)\end{array}$ & $\begin{array}{l}85.6(2)- \\
86.0(2)\end{array}$ \\
\hline
\end{tabular}

The most immediate change in X-ray diffraction structures upon metalation of the ylide is a shortening of the bond distances between the yldiic carbon and its stabilizing (Table 6), hypervalent neighbors of about $0.02 \AA$ from $\mathbf{7 7}_{\mathbf{H}}$ to $\mathbf{7 7}$ and from $\mathbf{8 1}_{\mathbf{H}}$ to $\mathbf{8 1}$. This decrease reaches $0.04 \AA$ from $\mathbf{8 0}_{\mathbf{H}}$ to $\mathbf{8 0}_{\mathbf{M}}$. In all 132 
cases, it can be attributed to an increase of the coulombic interaction between $\mathrm{C}$ and its substituents, and thus an increase of the charge density at C. Concomitantly, the bond distances between the heteroatom and its substituents follow an increasing trend, suggesting the population of the $\sigma^{*}$ orbitals of the P-R or S-R bonds by negative hyperconjugation of the lone pairs at carbon. Not surprisingly, C-P bond distances are homogeneous amongst similar substitution pattern, with 1.624(5) $\AA$ and 1.632(5) $\AA$ in $\mathbf{7 8}$ and 77; and 1.64(2) $\AA$ and 1.649(3) $\AA$ in 79 and 81. C-Li bond distance between $2.06 \AA$ and $2.16 \AA$ are also relatively short for organolithium species, ${ }^{197}$ which is in agreement with an increased charge at C. P-C, $\mathrm{P}-\mathrm{C}_{\mathrm{R}}$ and $\mathrm{C}-\mathrm{Li}$ bond distances in $\mathbf{7 8}$ and $\mathbf{7 9}$ are consistent with those measured for $\mathbf{7 7}$ and $\mathbf{8 1}$, suggesting similar stabilization process. The larger C-Li bond distance for $\mathbf{8 1}$ can be understood by the competitive coordination of an oxygen from the sulfoxide substituent. ${ }^{195}$ However, the C-K bond distance is in the normal range for organo-potassium species. ${ }^{198}$ Deprotonation of the ylide does not affect significantly the P-C-X bond angle, which remains characteristic of a $\mathrm{sp}^{2}$ hybridization at carbon for sulfone and sulfoxide-stabilized yldiide 80 and 81. The short S-C-M bond angle $\left(85.49(7)^{\circ}\right.$ and $85.6(2)^{\circ}$ to $86.0(2)^{\circ}$ for $\mathbf{8 0}_{\mathrm{K}}$ and $\mathbf{8 1}$, respectively) can be attributed to the coordination of $\mathrm{M}$ to the $\mathrm{S}=\mathrm{O}$ moiety. Only in the case of 79, a significant deviation from $\mathrm{sp}^{2}$ hybridization is observed, with a P-C-Si angle of $139.0(7)^{\circ}$. This time, no additional coordination of the metal by a substituent of the yldiidic carbon is observed; the $\mathrm{Si}$ $\mathrm{C}$ - $\mathrm{Li}$ angle of $97.1^{\circ}$ is thus the result of the interaction between the charge at $\mathrm{C}$ and $\mathrm{Li}$, forcing an increase of the $\mathrm{p}$ character of the lone pair involved, and thus an increase of the s character of the P-C bond. The geometry around $\mathrm{C}$ remains planar, with a sum of angle of $359^{\circ}$. It is here important to remind that these angles, and thus the carbon hybridization, might vary in solution, since calculation have shown a quite flat energy surface for the bending of the PCS and PCSi angles in model compounds of 80 and 79 in the absence of a counter cation $(3.8 \mathrm{kcal} / \mathrm{mol}$ and $1.8 \mathrm{kcal} / \mathrm{mol}$ respectively to reach an an- 
gle of $150^{\circ}$; see below). ${ }^{199}$ NMR spectroscopy is a tool of choice for a better understanding of the electronic structure in solution.

\subsubsection{NMR Spectroscopy}

Due to the paucity of examples and of the novelty of the subject, yldiides for which a complete NMR characterization $\left({ }^{31} \mathrm{P},{ }^{1} \mathrm{H},{ }^{13} \mathrm{C},{ }^{6} \mathrm{Li}\right.$ for the lithiated species) is available are scarce. Even more scarce are the examples for which a comparison with the NMR characteristics with the ylidic precursor is possible. Some trends can be extracted from the available data. In ${ }^{31} \mathrm{P}$ NMR, lithiation resulted in a shielding of the ${ }^{31} \mathrm{P}$ signal, with similar amplitude for all described structures $(\Delta(\delta)$ between $-20.7 \mathrm{ppm}$ and -30.8 $\mathrm{ppm})$. It is worth to notice here that independently to their substitution patterns, all of the concerned phosphorus atoms are in a tetrahedral geometry, $\mathbf{7 7}$ and $\mathbf{7 8}$ being excluded from this set. On the contrary, two groups can be depicted in ${ }^{13} \mathrm{C}$ NMR. If lithiation results in a deshileding of the yldiidic carbon in all cases, this effect is quite moderate when phosphonium are used as stabilizing moieties $(\Delta(\delta)$ between $+3.2 \mathrm{ppm}$ and $+9 \mathrm{ppm})$; whereas it reaches $+58.4 \mathrm{ppm}$ for $\mathbf{7 7}(+48.7 \mathrm{ppm}$ for $\mathbf{7 8})$. These last shift values are consistent with what was observed in vinyllithium compounds. ${ }^{191}$ Concerning the evolution of ${ }^{1} J_{\mathrm{PC}}$ coupling constants upon lithiation, a strong decrease is observed in all cases, independently from the hybridization of the phosphorus atom $(\Delta \mathrm{J}$ from $-85.3 \mathrm{~Hz}$ to $-98.4 \mathrm{~Hz})$. This was attributed to a decrease of the involvement of $\mathrm{C}$ s orbitals in the P-C bond, and thus an increase of the s character of other Ccentered orbitals ${ }^{191}$, and potentially an increased stabilization of the lone pairs at C. ${ }^{1} \mathrm{H}$ NMR of compound $\mathbf{7 7}$ and $\mathbf{7 8}$ also showed a downfield shift of the proton directly bond to the yldiidic carbon of 1.28 ppm to $2.26 \mathrm{ppm}$, consistent with an increase of the electronic density on the bounded carbon. Finally, ${ }^{6} \mathrm{Li}$ NMR coupling pattern at $-70^{\circ} \mathrm{C}$ were found to be similar to those observed in lithiated vinyl species in compounds 77 and $\mathbf{7 8}$, with ${ }^{1} \mathrm{~J}_{\mathrm{LiC}}$ and ${ }^{2} \mathrm{~J}_{\mathrm{PLi}}$ of $5.1 \mathrm{~Hz}$ and $12.6 \mathrm{~Hz}$ (respectively $7.5 \mathrm{~Hz}$ and $13.2 \mathrm{~Hz}$ ). 134 
Finally, on the ground of a ${ }^{1} \mathrm{~J}_{\mathrm{CH}}$ coupling constant of $108.0 \mathrm{~Hz}$, a planar structure for the yldiidic carbon was postulated for $\mathbf{7 3}$.

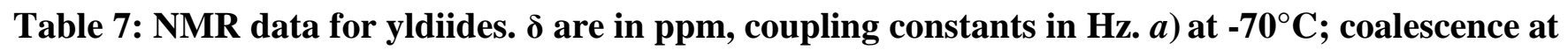
$-30^{\circ} \mathrm{C}$ b) With 18-C-6. $c$ ) in $\mathrm{C}_{6} \mathrm{D}_{6} d$ ) in [D8]-THF $e$ ) in $\mathrm{CD}_{2} \mathrm{Cl}_{2} f$ ) in $\mathrm{CDCl}_{3} g$ ) at $-40^{\circ} \mathrm{C}$.

\begin{tabular}{|l|c|c|c|c|c|c|}
\hline Species & $\delta^{31} \mathrm{P}$ & $\Delta(\mathrm{ppm})$ & $\delta^{13} \mathrm{C}$ & $\boldsymbol{\Delta}(\mathrm{ppm})$ & ${ }^{1} \mathrm{~J}_{\mathrm{PC}}$ & $\Delta(\mathrm{Hz})$ \\
\hline $\mathbf{7 3}^{\mathrm{g}}$ & 9.5 & & 5.3 & & 14.2 & \\
\hline $\mathbf{7 6}_{\mathbf{H}}$ & 23.2 & & & & & \\
\hline $\mathbf{7 6}^{\mathrm{c}}$ & 2.5 & -20.7 & 6.60 & & 94.6 & \\
\hline $\mathbf{7 7}_{\mathbf{H}}{ }^{\mathrm{c}}$ & & & 72.4 & & 126.6 & \\
\hline $\mathbf{7 7}^{\mathrm{a}, \mathrm{d}}$ & 148.3 & & 130.8 & +58.4 & 28.2 & -98.4 \\
\hline $\mathbf{7 8}_{\mathbf{H}}{ }^{\mathrm{c}}$ & & & 73.6 & & 148.0 & \\
\hline $\mathbf{7 8}^{\mathrm{a}, \mathrm{d}}$ & 63.4 & & 122.3 & +48.7 & 50.0 & -98.0 \\
\hline $\mathbf{7 9}_{\mathbf{H}}{ }^{\mathrm{c}}$ & 63.5 & & 8.0 & & 125.7 & \\
\hline $\mathbf{7 9}$ & $41 /(47 ; 32)^{\mathrm{a}}$ & -22.5 & & & & \\
\hline $\mathbf{8 0}_{\mathbf{H}}{ }^{\mathrm{e}}$ & 14.2 & & 34.5 & & 123.3 & \\
\hline $\mathbf{8 0}_{\mathbf{N a}}{ }^{\mathrm{d}}$ & -11.0 & -25.2 & 41.2 & +6.7 & 38.0 & -85.3 \\
\hline $\mathbf{8 0}_{\mathbf{K}}{ }^{\mathrm{c}}$ & -12.3 & -27.7 & 43.5 & +9 & $\mathrm{n} . \mathrm{a}$. & \\
\hline $\mathbf{8 1}_{\mathbf{H}}{ }^{\mathrm{f}}$ & $-16.6^{\mathrm{b}}$ & -30.8 & & & & \\
\hline $\mathbf{8 1}^{\mathrm{d}}$ & 46.8 & & 45.1 & & 151.3 & \\
\hline
\end{tabular}

\subsubsection{Ab initio and DFT modeling}

The instability of the first examples of yldiides and the difficulties encountered to characterize them were responsible for an early interest in their modelling. Calculations were thus performed to answer mostly three questions: what geometry at carbon do they adopt - for those that were not characterized by X-ray diffraction - ; to what extent could their reactivity differ from this of ylides (mostly answered by a depiction of the charge distributions and geometrical parameters), and by which processes is the large charge at $\mathrm{C}$ stabilized. 
The first ab-initio- Molecular orbital study was made on a simplified model of yldiide $\mathbf{7 3}$, for which the phenyl groups are replaced by hydrogen atoms, and at the $3-21+\mathrm{G}+$ level. ${ }^{200} \mathrm{~A} \mathrm{CH}$ fragment population of 8.78 e was found when the lithium cation is modelled with the yldiide, and 8.82 e without the cation. This corresponds to a charge at $\mathrm{C}$ of -1.78 and -1.82 , respectively. The $\mathrm{C}-\mathrm{H}$ bond was found to be coplanar with one of the $\mathrm{P}-\mathrm{H}$ bond, which in addition to the important charge at $\mathrm{C}$ is favorable for an attack on hindered ketones following the Dunitz trajectory. Comments on bond lengths and angles, and their interpretation in terms of $\mathrm{sp}^{2}$ hybridization of the yldiidic carbon and hyperconjugation through phosphorus substituents as main stabilization modes for the electronic density at $\mathrm{C}$ were made later ${ }^{201}$ on the same model and at the same level of theory. Stabilization through negative hyperconjugation was estimated to reach $15.6 \mathrm{kcal} / \mathrm{mol}$ in the model of compound 73.

Table 8: calculated bond distances and angles for model of $79 . \mathbf{R}_{i p}$ : substituent on phosphorus located in the plane formed by P-C and C-X bonds; $R_{o p}$ : substituent located out of the plane formed by P-C and C-X bonds.

\begin{tabular}{|c|c|c|c|c|c|c|c|}
\hline Model & $\begin{array}{ll}d & C-P \\
(\AA) & \end{array}$ & $\begin{array}{l}\mathrm{d}_{\mathrm{O}} \mathrm{R}_{\mathrm{ip}}-\mathrm{P} \\
(\AA)\end{array}$ & $\begin{array}{l}\mathrm{d} \mathrm{R}_{\mathrm{op}} \mathrm{P} \\
(\AA)\end{array}$ & $\begin{array}{l}\text { d C-M } \\
(\AA)\end{array}$ & $\begin{array}{l}\mathrm{d}_{(\AA)} \mathrm{C}-\mathrm{X} \\
(\AA)\end{array}$ & $\begin{array}{ll}\alpha & (\mathrm{P}-\mathrm{C}-\mathrm{X}) \\
0 & \end{array}$ & $\begin{array}{ll}\alpha & (\mathrm{P}-\mathrm{C}-\mathrm{M}) \\
{ }^{2} & \end{array}$ \\
\hline $\begin{array}{l}\text { 79(with } \\
\mathrm{Li})^{200}\end{array}$ & 1.67 & 1.40 & 1.42 & 1.92 & 1.09 & 114.0 & 131.2 \\
\hline $79^{-}$ & 1.64 & 1.40 & 1.46 & & 1.09 & 119.9 & \\
\hline
\end{tabular}

First calculations at the DFT level of theory were performed thirty years later for a depiction of the electronic structure in compound $\mathbf{8 0}$ and for a comparison with $\mathrm{PPh}_{3} \mathrm{CPPh}_{3}$ (scheme 94) and the geminal dilithio derivative $\mathbf{1 1} \mathbf{L i}_{2} \cdot{ }^{194}$ A plot of the two highest occupied Kohn-Sham orbitals of $\mathbf{8 0}^{-}$(the model of 80 with no cation) shows a strong and almost exclusive development of the density on carbon, thus sustaining the presence of two lone pairs at carbon of $\sigma$ and $\pi$ symmetries with respect to the PCS plane. NBO analysis, which aims at proposing the most accurate Lewis structure of a molecule, depicts two orthogonal lone pairs at carbon as well. One of these is of pure p character while the second is close to $\mathrm{sp}^{2}$ hybridization $\left(\mathrm{sp}^{2.1}\right)$. The NBO charge at $\mathrm{C}$ is found to be -1.33 . This scheme is globally unchanged 136 
when sodium or potassium are modelled as well, in agreement with the ionic nature of the C-M interaction. Interestingly, comparison with parent structures $\mathrm{PPh}_{3} \mathrm{CPPh}_{3}$ and $\mathbf{1 1} \mathbf{L} \mathbf{i}_{2}$ showed higher charges at $\mathrm{C}$, -1.50 and -1.40 respectively, which was attributed to the difference in the substituents ability to stabilize negative charges. Hybridization of the $\sigma$ lone pair in $\mathrm{PPh}_{3} \mathrm{CPPh}_{3}$ is close to $\mathrm{sp}^{3}\left(\mathrm{sp}^{2.9}\right.$ ) in contrast with $\mathbf{8 0}^{-}$and $\mathbf{1 1 L i} \mathbf{L}_{2}\left(\mathrm{sp}^{1.2}\right.$ for this last). First and second proton affinities for $\mathbf{8 0}^{-}$appeared to be intermediate between these of $\mathrm{PPh}_{3} \mathrm{CPPh}_{3}$ and $\mathbf{1 1 L i} \mathbf{i}_{2}$, in increasing order.

\section{Scheme 94 : Model compounds used for the discussion on the electronic structure of yldiides in the frame of NBO analysis. ${ }^{194}$}

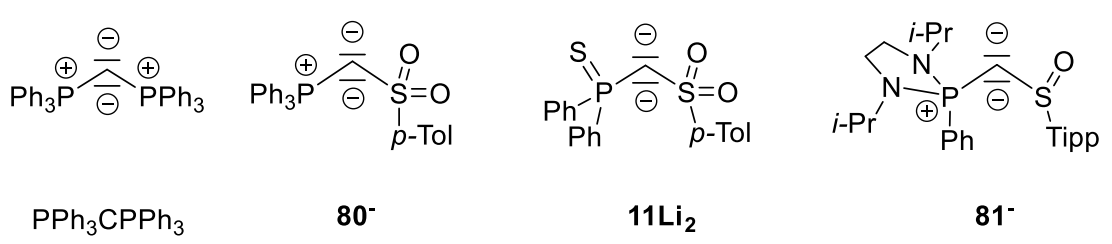

A quite similar situation was described for species 81. ${ }^{195}$ The two highest Kohn-Sham orbital of model anionic species $\mathbf{8 1}^{-}$(without taking into account the Li cation) are also of $\sigma$ and $\pi$ symmetry with respect to the PCS plane, with most of the density developed on carbon. The charge at $\mathrm{C}$ was calculated to be 1.36. When lithium cation is considered, two coordination sites for $\mathrm{Li}$ were found, one at $\mathrm{C}$ and one at $\mathrm{O}$, the first one being favored by $5.9 \mathrm{kcal} / \mathrm{mol}$ in free energy.

In 2017, Gessner and Frenking initiated a systematic DFT study on the influence of the nature of the stabilizing moieties at carbon (anion stabilizing $v s$ electron acceptor, presence of a global charge) on the bonding situation and charge at carbon in yldiide, and the comparison with the situation in carbodiphosphoranes. ${ }^{199}$ This work was summed up in a following publication the same year. ${ }^{202}$ The initial postulate of this work was that the contribution of dative $\mathrm{Ph}_{3} \mathrm{P} \rightarrow \mathrm{C}^{0}$ bonds to the electronic structure in carbodiphosphoranes is significant. 
Table 9: List of $L$ moieties included in the study; charge at $C$ and $P$.

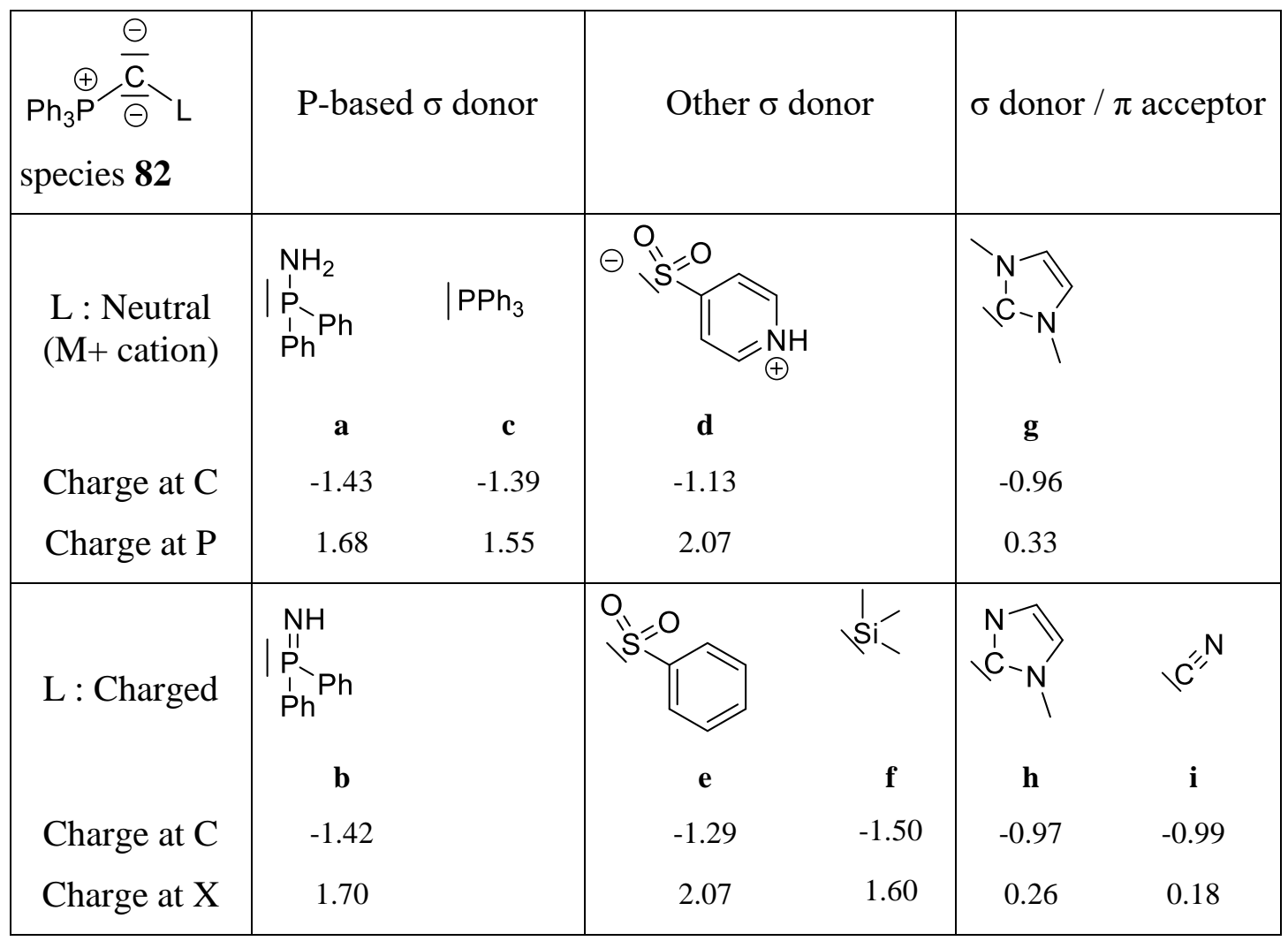

The structural similarities between carbodiphosphoranes and yldiide $\mathbf{8 0}$ (short P-C bonds, two lone pairs at carbon, broad but bent angle around the central carbon) posed the question of a dative bond to describe the bonding situation in metalated ylides. An extensive description of the bonding scheme in various hypothetical yldiide (Table 9) and the related neutral bisylide was proposed to decipher the impact of the charge and the nature of the substituents at $\mathrm{C}$ on the nature of bonds around $\mathrm{C}$. From this study, it appears that introduction of a negative charge leads to a more pronounced ylidic character of the C-X bond $(\mathrm{X}=\mathrm{C}, \mathrm{P}, \mathrm{S}, \mathrm{Si})$, independently of the initial situation in the parent neutral compound. It was also suggested that the P-C-L bond angle is not an appropriate parameter to estimate the bonding scheme around $\mathrm{C}$, since the bending potential surface was found to be mostly flat, and only slightly deepened by 
the introduction of a negative charge. NBO analysis as well as examination of the Kohn-Sham orbitals confirmed the presence of two lone pairs at carbon in all cases, except for $\pi$-acceptor substituents for which a $\mathrm{C}=\mathrm{C}$ double bond was evidenced. The charge at $\mathrm{C}$ is not significantly impacted by the change in global charge; which seems to be reported on the "ligand" backbone, and particularly on the more electronegative atom (nitrogen when present). Altogether, for $\mathrm{Si}, \mathrm{S}$ and $\mathrm{P}$ stabilized lone pairs (species 82a,b,d-f), the large absolute values of the charge on $C$ and $X(X=S i ; S, P)$ pledge for an ylidic structure as well. The $\mathrm{Ph}_{3} \mathrm{P}-\mathrm{C}$ Wiberg bond index (WBI) was found to vary between 1.23 and 1.58 depending on the nature of the ligand $\mathrm{L}$, and increase with the appearance of a charge. $\sigma$ bonds around $\mathrm{C}$ are virtually unaffected by the global charge. Variations in $\sigma \mathrm{C}-\mathrm{X}$ bond polarization mostly depends on the nature of the $\mathrm{X}$ atom: polarization of the $\mathrm{Ph}_{3} \mathrm{P}-\mathrm{C} \sigma$ bond was found to be poorly affected by either the change of substituent at $\mathrm{C}$ or global charge, and the $\mathrm{C}-\mathrm{X}$ bond polarization appeared to be in agreement with the electronegativity of the $\mathrm{X}$ atom. The s-character at $\mathrm{C}$ was also found to be unaffected. As a conclusion, the all-dative configuration has some relevance for carbodiphosphorane only, and introduction of a charge lead to a predominance of a mixed dative-ylidic bond, the dative part concerning exclusively the phosphonium moiety. It is predicted that donor properties can be modulated by the choice of the substituent, and the position of the charge relatively to the central carbon.

\subsection{Reactivity of yldiides}

Due to the limited number of characterized or isolated yldiide, their applications in organic reaction or main group chemistry are still limited, yet quite promising. Some variations in their reactivity have been observed depending on the stabilizing moieties at carbon. If metalated yldiides can obviously perform Wittig reactions even on sterically hindered ketones, their most interesting feature is certainly their strong nucleophilicity. They can thus perform quite readily a nucleophilic addition to a variety of sub139 
strates, resulting in the formation of functionalized ylides (Scheme 95, Path A). These last can be engaged either in a second nucleophilic addition (Scheme 95, Eq (2)) ${ }^{185}$ or in a "classical" Wittig reaction to give original functionalized alkenes (Scheme 95, Eq. (3)). ${ }^{181}$ The whole process is reminiscent of a SCOOPY reaction ${ }^{203}$ (Scheme 95; Eq. (1)), performed without a lithiated base and in one pot, the electrophile being introduced first. When the first electrophilic function engaged in a reaction with a metalated yldiide is a non-enolisable carbonyl (Scheme 95, Path B), the reaction goes through an oxidoylide structure reminiscent of the intermediate species in Wittig reaction under Schlosser modification, selective of the trans product (alkene E) (Scheme 95, Path B, Eq. (5)). When a second equivalent of carbonyl derivative is present, an allylic alcohol is finally obtained (Scheme 95, Path B, Eq. (4)). Trans homoallylic alcohols have been obtained when the first electrophile to be introduced prior to carbonylated substrate is an epoxide (scheme 95, Path A, Eq. (3)). The presence of the metallic cation of the metalated ylide is believed to facilitate the ring-opening process in addition to the nucleophilic character of the yldiide. $^{204}$ 
Scheme 95 : The reactivity of yldiides 73 and 76.

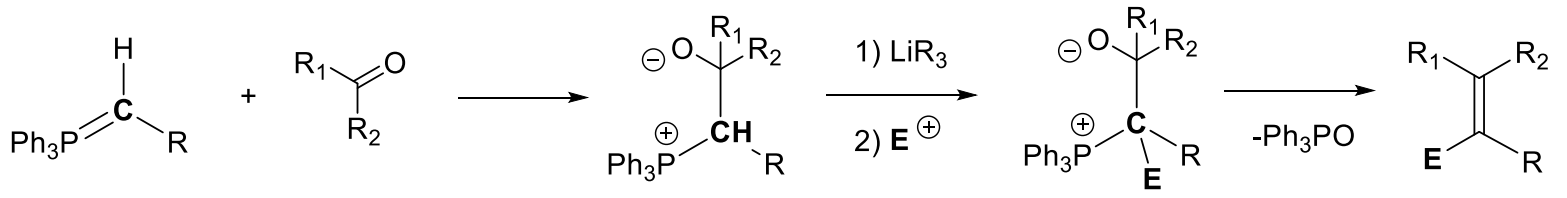

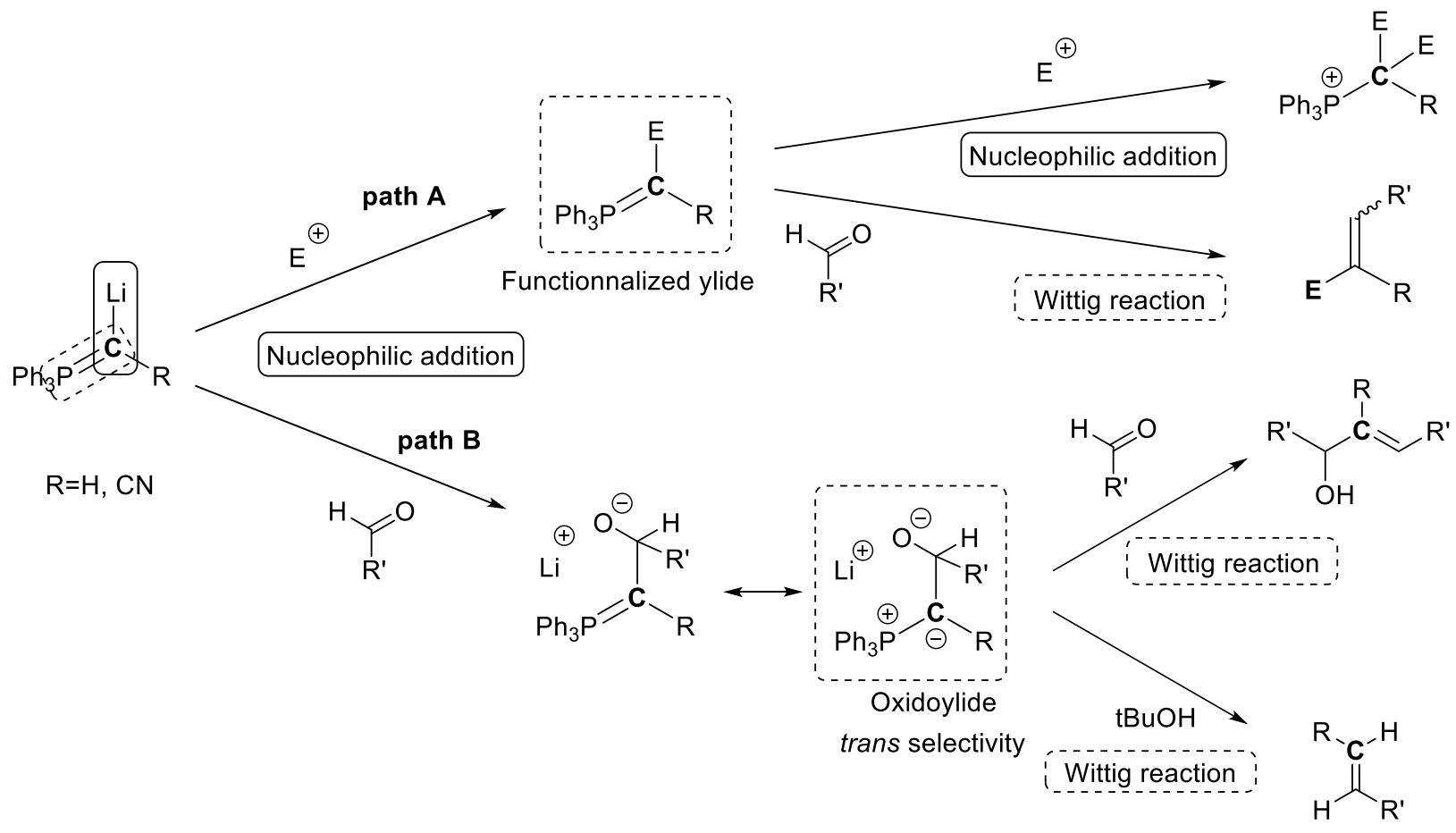

stereoselective trans

Table 10 : Products obtained from compound 73

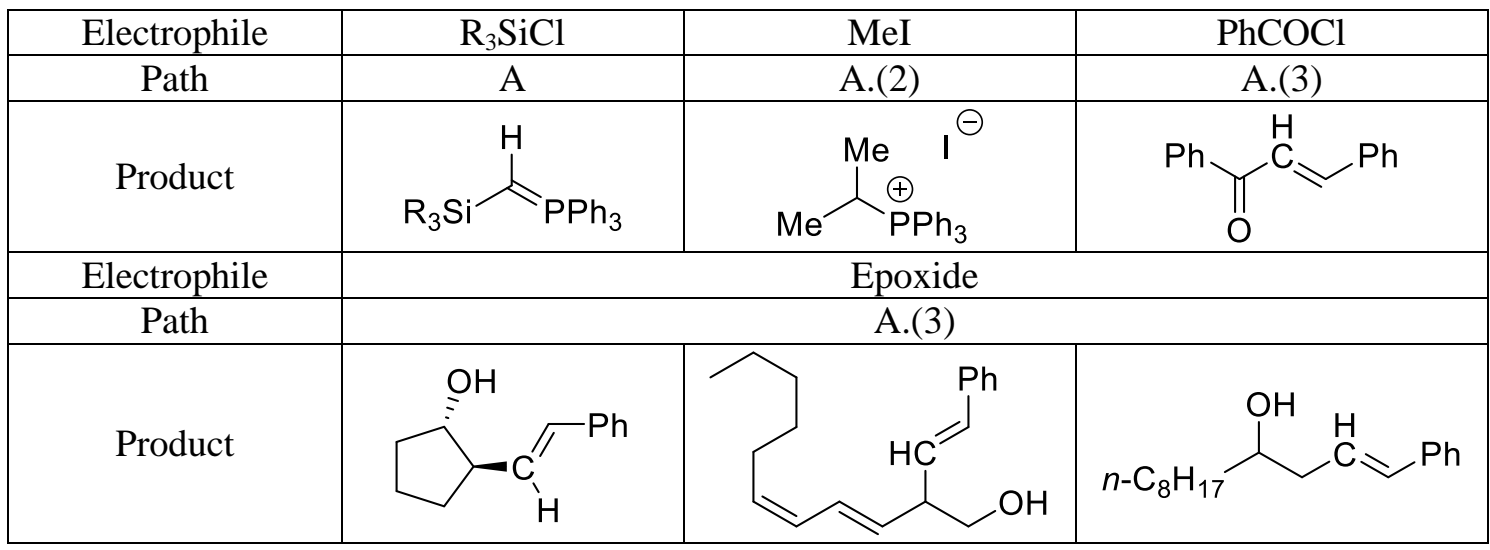




\begin{tabular}{|c|c|c|c|}
\hline Electrophile & $\mathrm{RCHO}$ & Ketone & \\
\hline Path & $\mathrm{B} .(4)$ & B.(5) & \\
\hline \multirow{3}{*}{ Product } & \multirow{\mathrm{OH}}{\mathrm{OH}}{$\widehat{\mathrm{CH}}^{\mathrm{P}} \widehat{\mathrm{P}}_{\mathrm{R}} n-\mathrm{C}_{6} \mathrm{H}_{11}$} &
\end{tabular}

More recently, $\mathbf{7 3}$ was used for the conversion of a cyclic enolester into a cyclopentenone by a tandem Aldol-Wittig reaction in $46 \%$ yield. $^{205}$ In main group chemistry, addition of two equivalent of 73 to phenyldichloroborane afforded phenyl[bis(triphenylphosphanemethylenido)]-borane $\mathbf{8 6}$ in $68 \%$ yield, which was used as a boron containing analogue of allyl ligand for late (Pd) as well as early (Zr) transition metals. ${ }^{206}$ Finally, $\mathbf{7 3}$ was used in the synthesis of triphenylphosphinomethylenyl-methanaminatodiphenylsulfur cation, which is further deprotonated to afford iminosulfane stabilized carbophosphorane 87. ${ }^{207}$ 
Scheme 96: Reactivity of yldiide 73 toward a cyclic enolester, dichlorophenylborane and fluoromethanaminatodiphenylsulfur tetrafluoroborate.
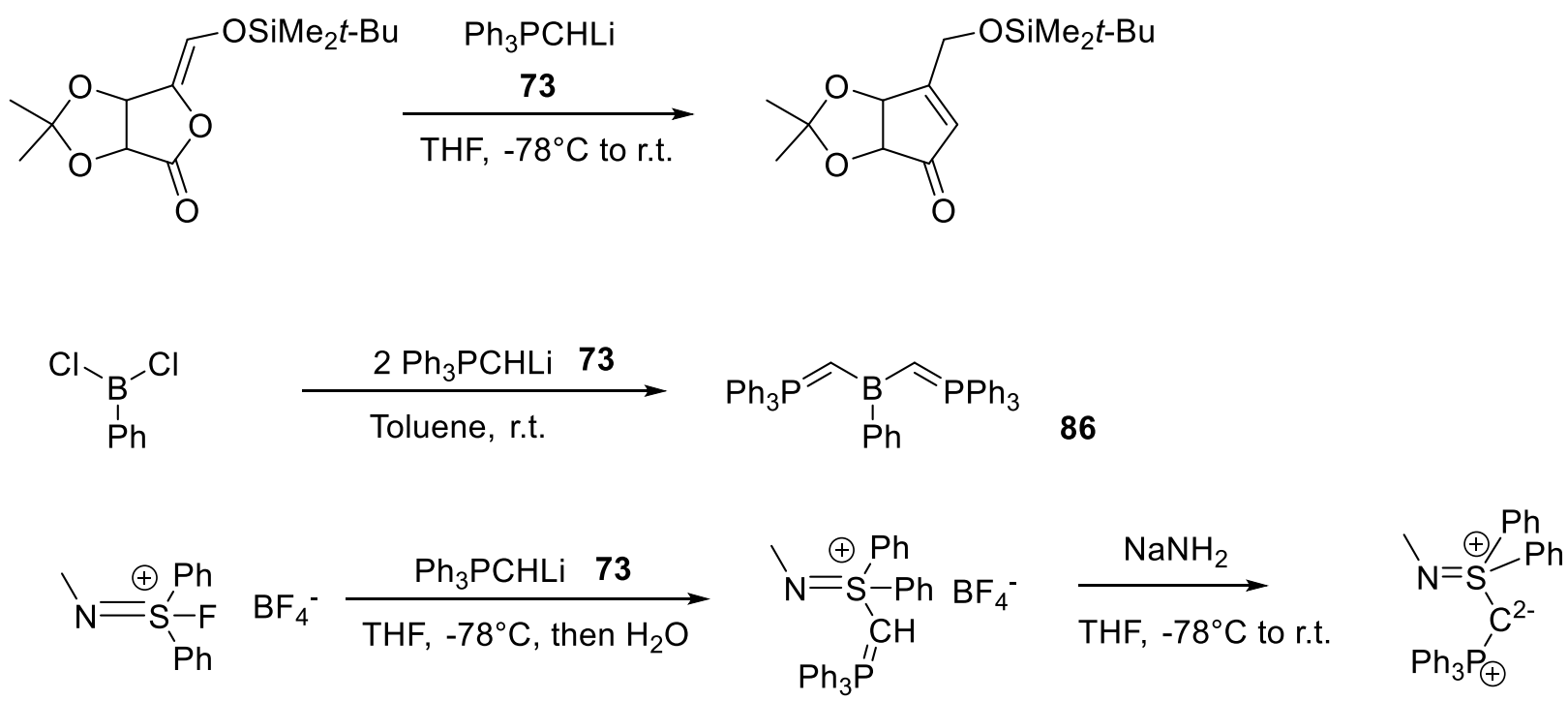

87

With sodium cyanotriphenylphosphoranylidenemethanide $\mathbf{7 6}$, much efforts were made to develop the synthetic potential of its twofold reactivity. ${ }^{190}$ Thus, in addition to the synthesis of a variety of substituted ylides (88-94), strategies to obtain cyclic $\alpha, \beta$-unsaturated nitriles or 2-cyano-1,3-dienes were proposed. In the first case, nucleophilic substitution of $\mathbf{7 6}$ on various acetal-containing halogenoalkanes is followed by hydrolysis of the acetal group to obtain the corresponding aldehyde. Intramolecular Wittig reaction formed the desired cyclic product 95 and $\mathbf{9 6}$. When the first nucleophile to be introduced is an aliphatic aldehyde, followed by treatment with trimethylsilyle chloride, elimination of trimethylsilanol afforded the corresponding $\beta, \gamma$-unsaturated ylid that can be further engaged in a Wittig reaction with aldehyde to give 2-cyano-1,3-dienes 97 and $\mathbf{9 8}$. When the first nucleophile to be introduced is a carbox- 
ylic acid, an intramolecular Wittig reaction on the carbonyl function in $\alpha$ position to the ylidic carbon afforded cyanoacetylene 99-101 in moderate to good yield.

Table 11 : product obtained from 76.

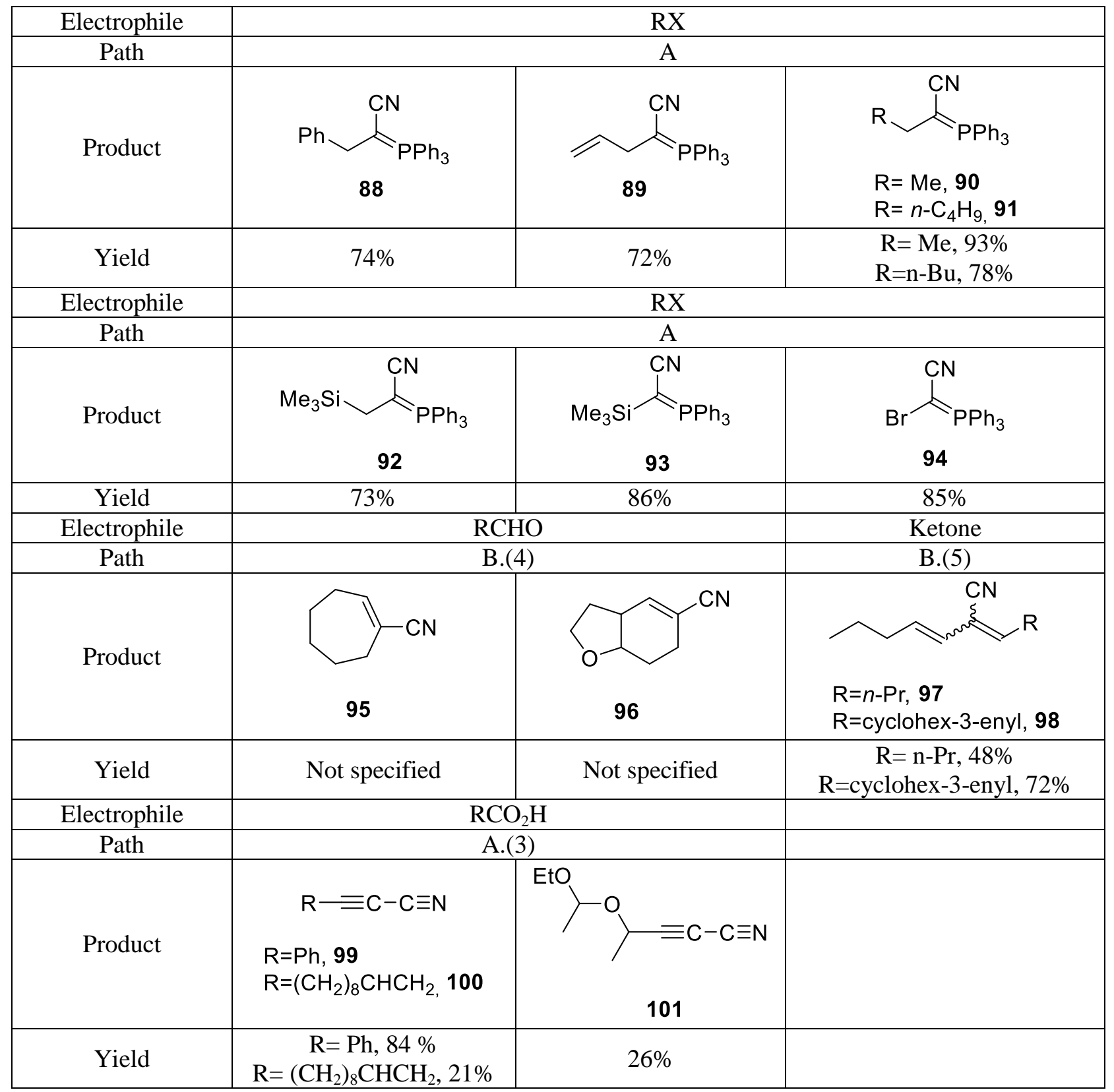


Further efforts were devoted to the valorization of the nitrile function in $\mathbf{7 6}$ (scheme 97). ${ }^{208}$ Nucleophilic addition of yldiide $\mathbf{7 6}$ on epoxide, followed by hydrolysis of the nitrile function to carboxylic acid allowed for the synthesis of various cyclic esters. Alternatively, the alcoolate generated upon opening of the epoxide cycle can be protected by silylation, and the resulting ylide engaged in a Wittig reaction with paraformaldehyde. Hydrolysis under basic conditions of the resulting $\alpha$-methylene- $\gamma$ trimethylsilyloxybutanenitrile followed by intramolecular esterification afforded the corresponding $\alpha$ methylene- $\gamma$-butyrolactones. When the hydrolysis step is made using $p$-toluenesulfonic acid, cyclisation occurred as well going through the corresponding $\alpha$-methyleneiminolactone, which further evolved to the lactone by elimination of p-toluenesulfonamide.

Scheme 97 : Reativity of yldiide 76 toward epoxides and subsequent nitrile-based reactivity.

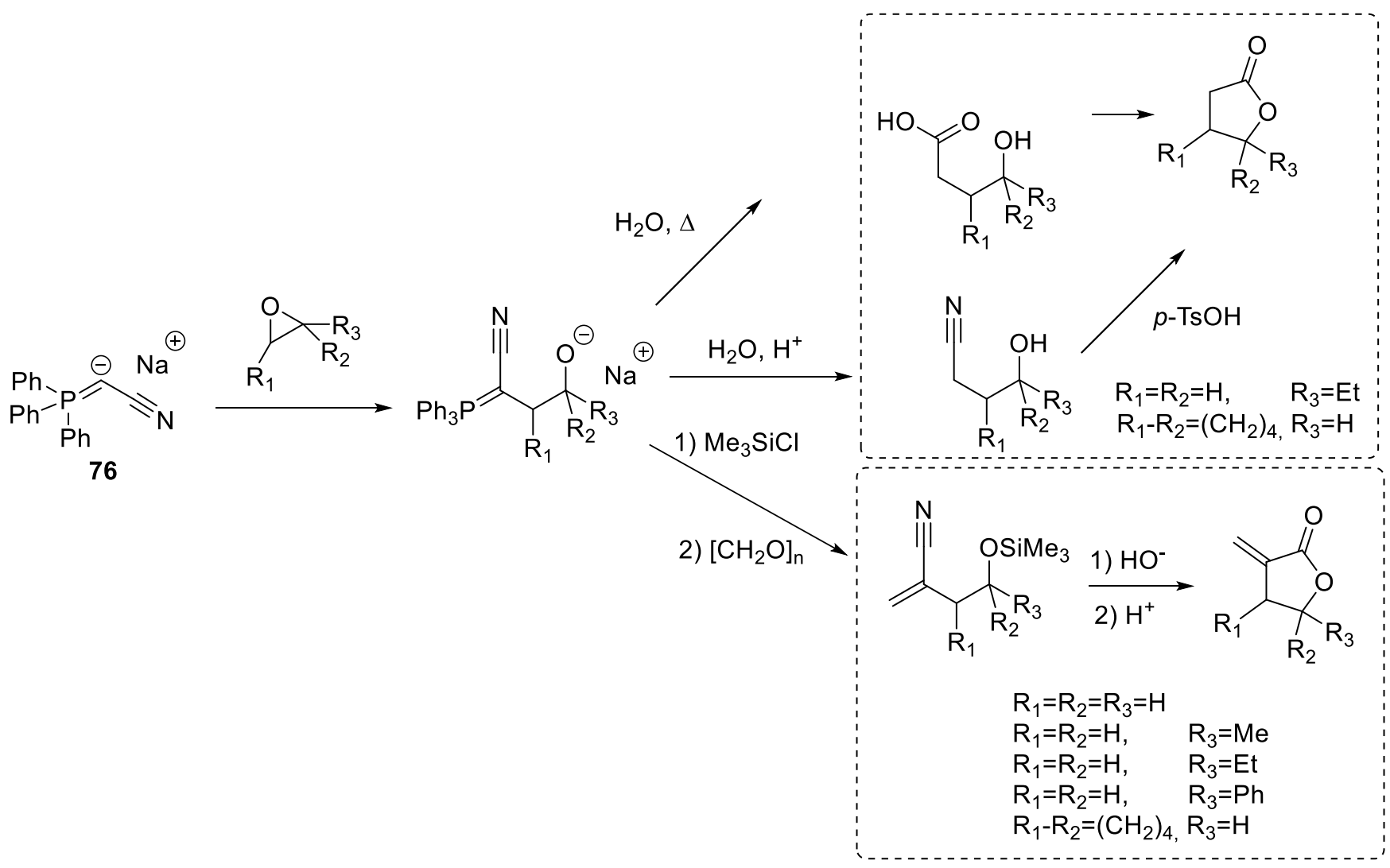


By contrast with species $\mathbf{7 3}$ and $\mathbf{7 6}$, yldiide $80_{\mathrm{Na}}$ did not undergo a Wittig reaction in the presence of benzaldehyde or pentafluorobenzaldehyde (scheme 98). Instead, $\beta$-ketoylides were obtained after elimination of sodium hydride or sodium pentaflorobenzyle respectively. The formal elimination of an hydride from benzaldehyde is reminiscent of what was observed with a (P,S)bis-ylide by Baceiredo et al. ${ }^{209}$ This specific reactivity was attributed to the strong $\pi$-donor ability of the yldiide $\mathbf{8 0}_{\mathbf{N a}}$. In the case of benzaldehyde, traces of the Wittig product were found along with the $\beta$-ketoylides. Nucleophilicity of species $\mathbf{8 0}_{\mathbf{M}}(\mathrm{M}=\mathrm{Na}, \mathrm{K})$ was also probed using various main-group phosphorus and boron electrophiles. It was shown to perform nucleophilic addition on diphenylphosphine chloride, affording a phosphanylsubstituted ylide. Addition of $\mathbf{8 0}_{\mathbf{N a}}$ on borane-tetrahydrofuran adduct resulted in a double addition of yldiide on borane and elimination of sodium borohydride to afford a doubly ylide-substituted borane. Пdonation of the lone pair of one of the ylide toward the boron atom was evidenced by a shorter B-C bond lengths (1.513(4) $\AA$ ) as determined by X-ray diffraction, as well as DFT calculations. Elongation of the corresponding C-P bond (1.743(2) $\AA$ vs 1.731(2) $\AA$ in the second, non $\pi$-interacting ylide and 1.646(2) $\AA$ in free $\mathbf{8 0}_{\mathrm{K}}$ ) was also present, suggesting a lowering of the charge stabilization through hyperconjugation. Abstraction of an hydride from this borane using $\mathrm{Ph}_{3} \mathrm{C}+$ or $\mathrm{B}\left(\mathrm{C}_{6} \mathrm{~F}_{5}\right)_{3}$ allowed for the synthesis of a bis-(ylide)-stabilized borenium with various counter-anions; only with hexafluorophosphonate could the borenium be isolated and an X-ray diffraction structure obtained. B-C bond were found to be even shorter (1.481(7) $\AA$ and .510(9) $\AA$ ) than in the ylid-stabilized borane, and P-C bond are elongated in comparison with $\mathbf{8 0}_{\mathrm{K}}(1.676(8) \AA$ and $1.781(8) \AA)$, highlighting again a decrease of hyperconjugation. 


\section{Scheme 98 : Reactivities of yldiides $80_{M}, M=N a, K$.}
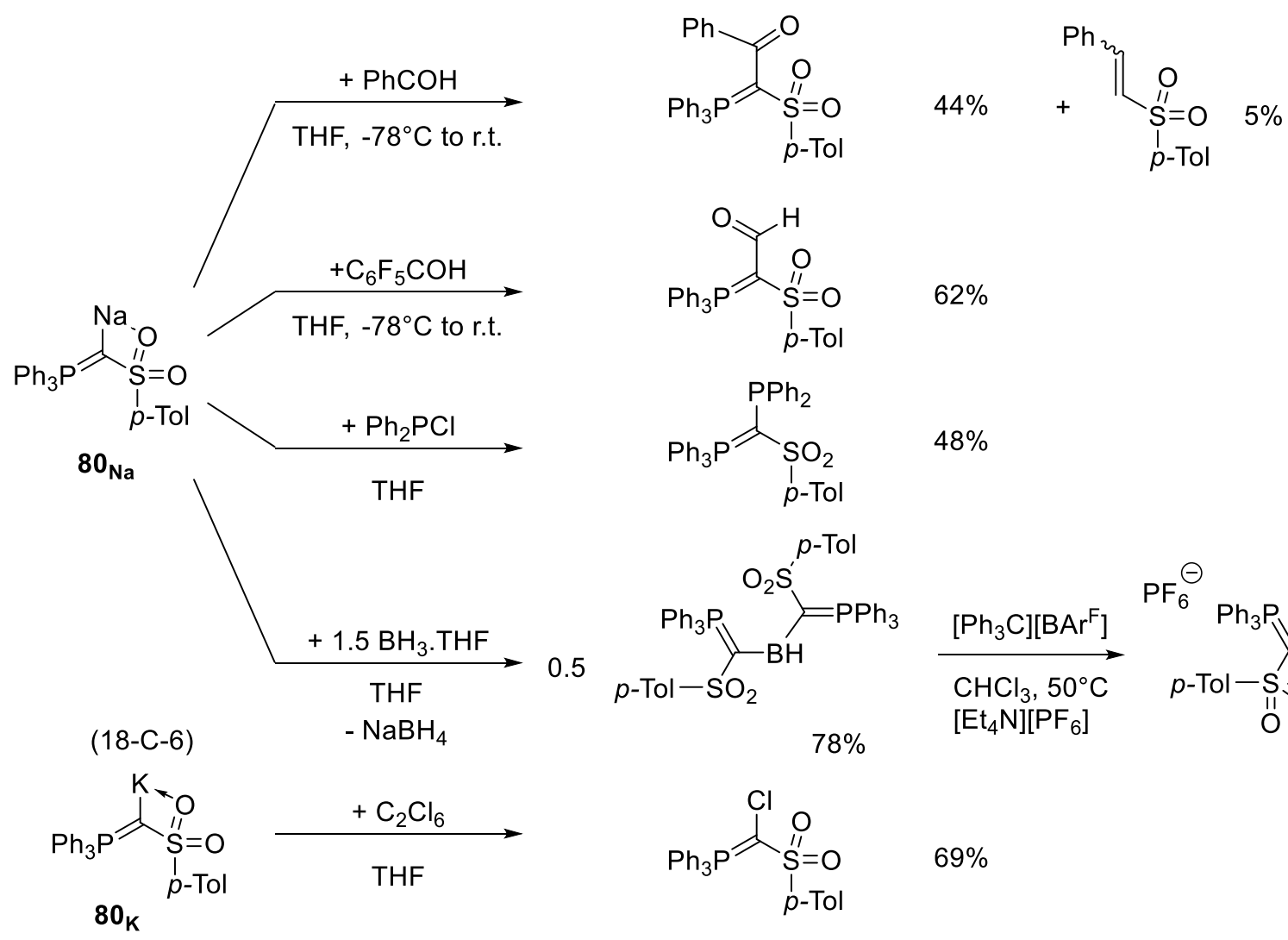

$62 \%$<smiles>[Mg][Mg]</smiles>

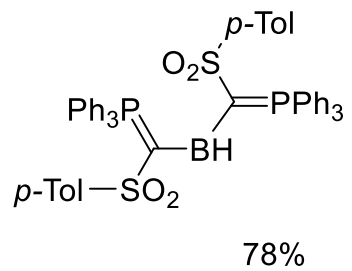

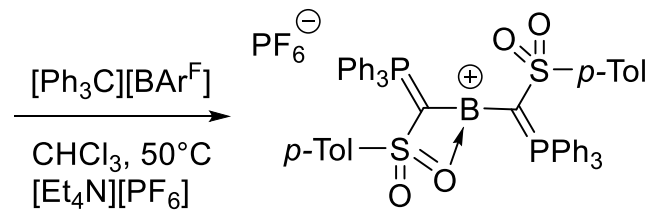<smiles>O=S(=O)([O-])C(=P)Cl</smiles>

$69 \%$

Species $\mathbf{8 1}$ reacts with idodomethane (nucleophilic addition to generate the corresponding ylid, scheme 95, Path A) or trifluoroacetophenone (Wittig reaction to form the corresponding cis-vinylsulfoxide, scheme 95, Path B., eq. (5)), although this last reaction occurs at particularly low temperature due to the assistance of Li cation (scheme 99). ${ }^{195}$ Most interestingly, it was shown that $\mathbf{8 1}$ is a catalyst for the hydroacylation of benzaldehyde. Nucleophilic addition of $\mathbf{8 1}$ to benzaldehyde was supposed to allow for the transfer of a hydride to another equivalent of benzaldehyde, which further reacted with the $\alpha$ carbonylated ylide to regenerate yldiide 81. Such a reactivity was also observed with the related bisylide. $^{209}$ 


\section{Scheme 99 : Reactivity of yldiide 81.}

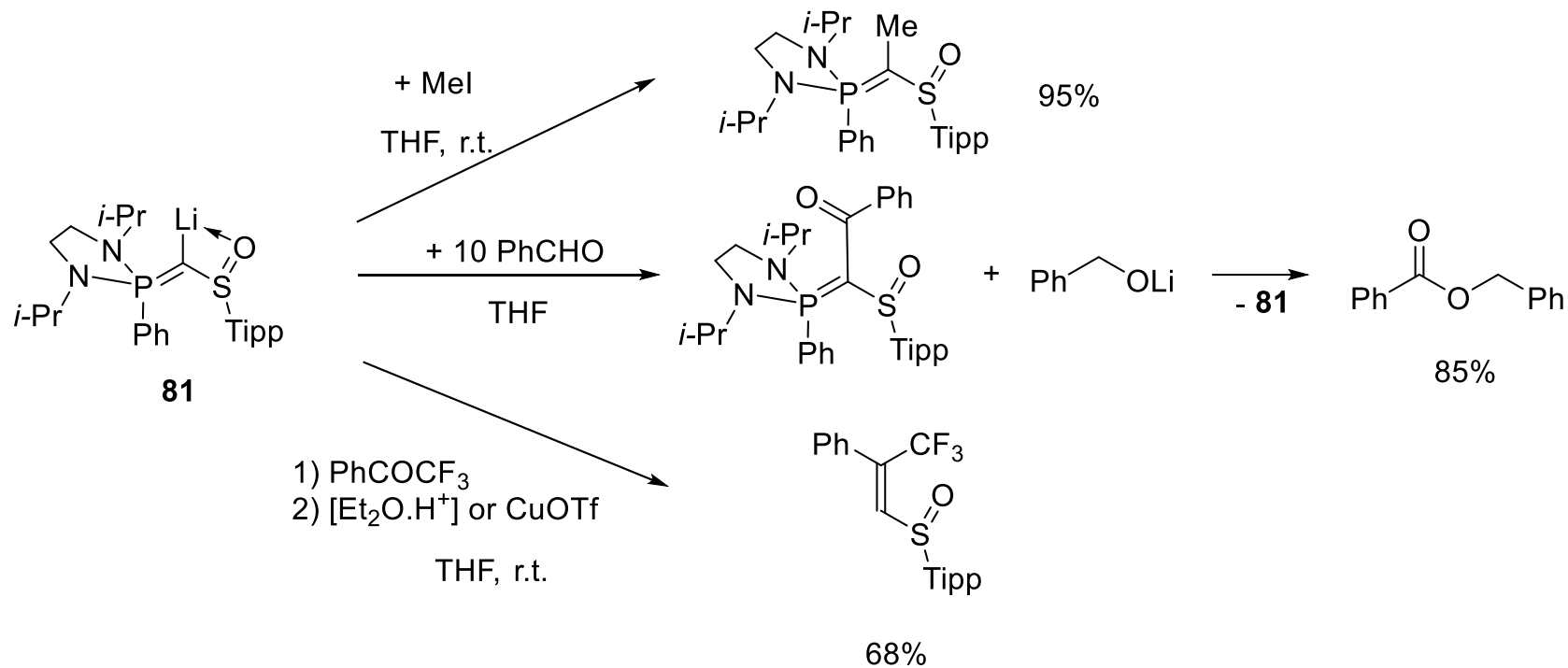

The reactivity of yldiides appears to be particularly rich, thanks to the numerous opportunities offered by the two lone pairs as well as the variety of substitution patterns at carbon. In cyano-stabilized yldiide, the cyano group can be itself the ground for further reactivity. Moving to hypervalent-sulfur stabilizing groups, some new reactions allowed by the strong donor character of yldiides, which are able to induce the elimination of a living group (like a hydride or a stabilized carbanion) from the species generated upon nucleophilic addition on aldehydes or borane. Furthermore, exploration of the reactivity of such species toward main group elements is at its early stage.

\subsection{Coordination chemistry of type II geminal dianions}

The coordination chemistry of yldiide derivatives is quite rich. In fact, the situation is comparable to the chemistry of carbenes, for which carbene complexes were easily obtained far before the isolation of free, stable carbenes. Yldiides can indeed been generated in the coordination sphere of a metal, following various synthetic paths (Scheme 100). Salt metathesis (route 1) which is widely used in the 148 
case of type I geminal dianions, is also possible with yldiide but less frequently used. Route B corresponds to the deprotonation of the parent ylide in the coordination sphere of the metal by a basic ligand, and is also seen with type $\mathbf{I}$ geminal dianions. The related route $\mathbf{C}$ uses the parent ylide itself as a base, the acidity of its proton being increased by initial coordination of the ylide to the metal, and the precipitation of the phosphonium salt participating to the driving force. Route $\mathbf{D}$ consists in the addition of a phosphine to a pre-formed, electrophilic, metal-supported carbon atom.

Scheme 100: Four main paths for the preparation of yldiide complexes.

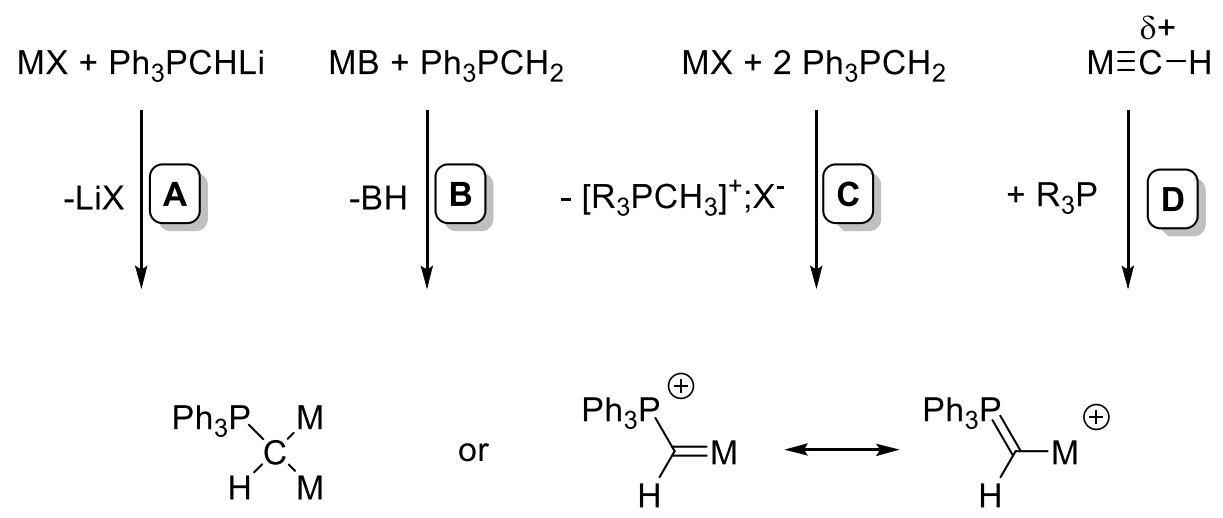

An unusual route (route $\mathbf{E}$ ) is presented scheme 101. Route $\mathbf{E}^{210}$ can be formally seen as a nucleophilic addition of an organotin ylide to a coordinated carbonyl ligand to generate a ketene ylide, subsequent oxidative addition into an aromatic $\mathrm{C}-\mathrm{H}$ bond of the triphenylphosphonium moiety, and migration of the generated hydride to the ketene. A dimetallic iron complex was thus fortuitously generated, where the bridging carbon atom can be seen as a formyl-stabilized yldiide.

Scheme 101: Unusual synthetic path of a gem-dimetallic yldiide from an organotin ylide.
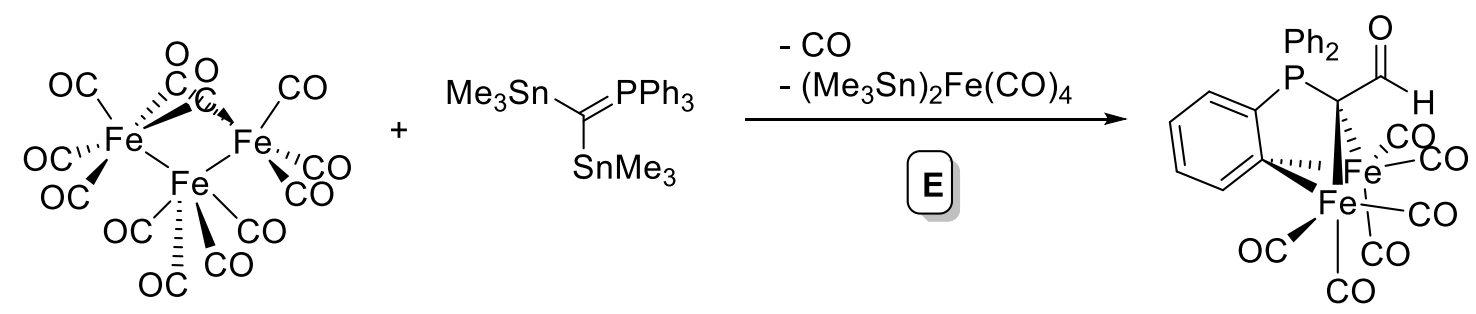
The two lone pairs at carbon can form either two $\sigma$ bonds with two metal centers, or an interaction with a unique metal center. In this last case, and depending on the substitution pattern of the yldiidic carbon, two different coordination schemes are expected: a phosphora-alkenyl - like or phosphonium-alkylidene - like interaction (scheme 100). Reactivity as well as theoretical studies are often necessary to determine which structure is predominant.

\subsubsection{Group 3 and Rare Earths}

The privileged synthetic route for the rare examples of yldiide complexes of the rare earth metals is route $\mathbf{A}$ (scheme 100). However, this route can be in competition with ortho-metalation because of the high reactivity of M-B bonds (where B is a basic ligand). ${ }^{211}$ Only in 2006 could Rufanov and Spannenberg isolate the first example of lutetium and yttrium complexes upon deprotonation of an ylidic position, using the [(2-methoxyphenyl)-methylene]-triphenylphosphorane as a ligand precursor. ${ }^{212}$ However, in addition to the desired reactivity, ortho-metalation was observed. They obtained a dimetallic complex, 102, two phenyl of the phosphorene moiety being deprotonated and bound to two different yttrium centers (scheme 102). The yldiidic carbon is bridging between the two metallic centers. A similar complex was obtained with lutetium, but the crystal structure was not obtained in that case.

Scheme 102 Synthesis of gem-dimetallic yldiide yttrium complex by protonolysis (path B). 


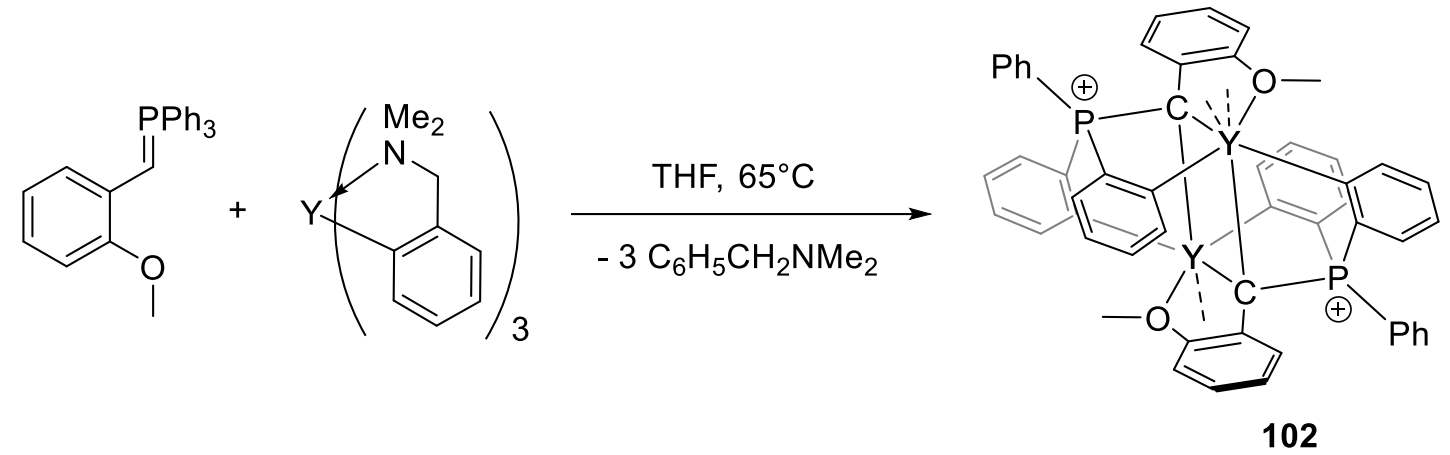

A second example was reported in 2017 with scandium (complex 103) and lutetium (complex 104, scheme 103). ${ }^{213}$ Upon heating, activation of isopropyl C-H bonds as well as ortho-metalation was observed. In the Sc complex 103, the methyl ligand was exchanged for iodide or triflate anion, opening the way to further substitution. Ortho-metalation was also seen for the lutetium complex 104 at room temperature. Interestingly, protonation occurs at the methylidene carbon and not at the alkyl ligand. In a similar way, reactivity toward the electrophile benzylidenemethanamine is made by the yldiide ligand and not the alkyl one. Finally, DFT study highlighted the presence of a three center, $\pi$ bond between P, $\mathrm{C}$ and the metal in both cases.

Scheme 103: Synthesis of scandium and yttrium complexes of yldiide 73.

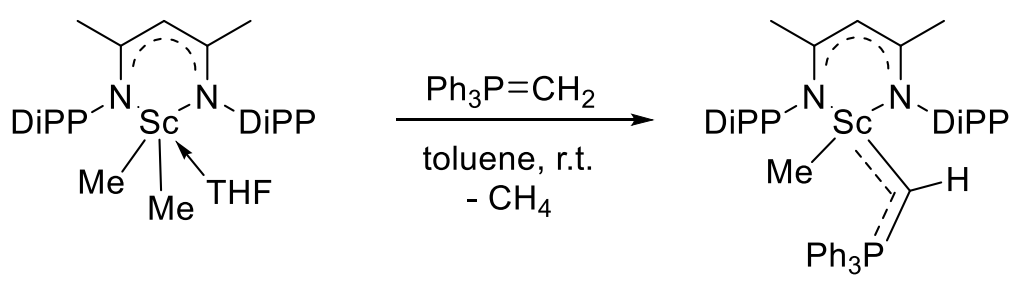

103

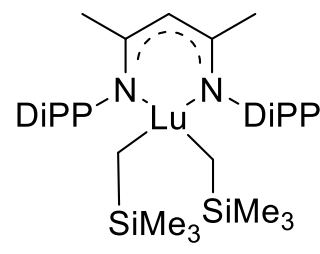

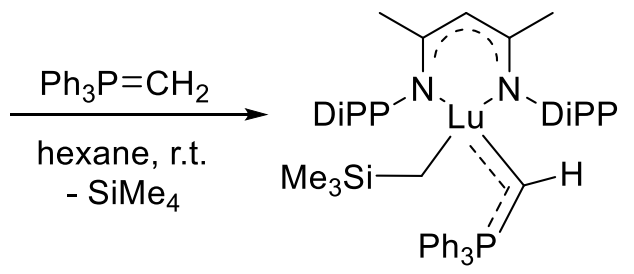




\subsubsection{Complexes of uranium}

The first example of a structurally characterized uranium yldiide was given by Gilje as early as $1978 .^{214}$ Using the bisylide $\mathrm{Ph}_{2} \mathrm{P}\left(\mathrm{CH}_{2}\right)_{2} \mathrm{Li}$ with $\left[\mathrm{Cp}_{3} \mathrm{UCl}\right]$, and after an unexpected transilydation reaction, they obtained complex 105, a dimeric structure where two uranium (IV) atoms were bound by two yldiidic carbon atoms (scheme 104). Very few comments were made on the yldiide structure at this time, focus being made on the unusual coordination number at uranium in this structure. Shortening the reaction time and changing the stoichiometry of the reaction, terminal yldiide complexes $\mathbf{1 0 6}$ could be obtained with various substitution scheme around phosphorus by intramolecular transylidation. ${ }^{215}$

\section{Scheme 104: Synthesis of uranium complexes of yldiide 73 following route A.}

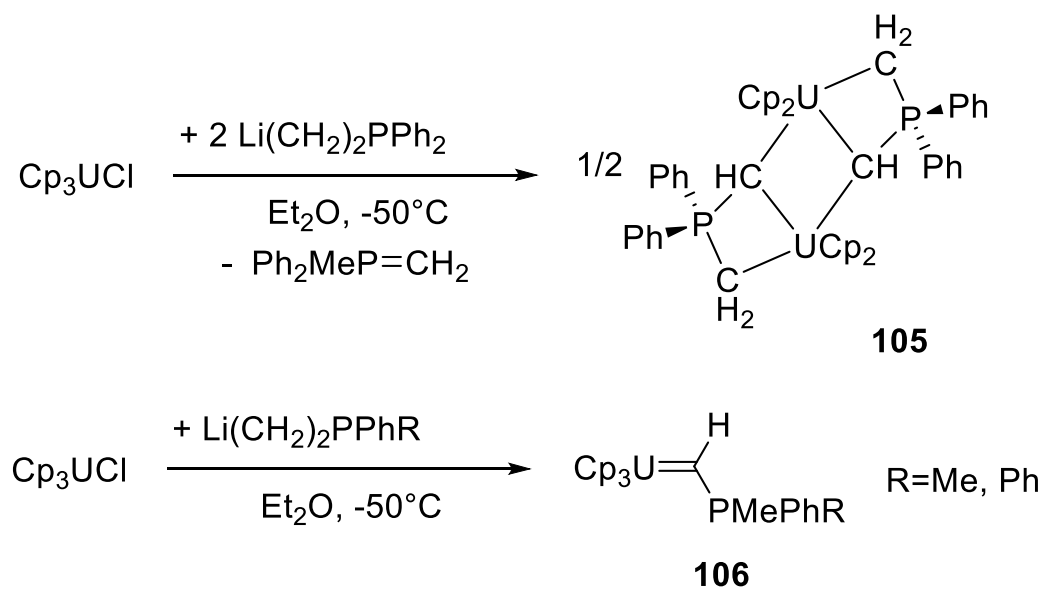

The chemistry of these species was developed quickly enough to be the subject of a short review as early as $1985 .^{216}$ The U-C bond lengths being amongst the shortest known at this time $(2.29 \AA)$, the multiplicity of the $\mathrm{U}-\mathrm{C}$ bond in theses monometallic structures was questioned. Early calculation comparing the bonding scheme in $\mathrm{Cp}_{3} \mathrm{U}-\mathrm{CH}_{3}$ and $\mathrm{Cp}_{3} \mathrm{U}-\mathrm{CHPMePhR}$ showed higher bond order for the latter, with the presence of a small $\pi$ component in the overlap population. These complexes were thus described as phosphonium-alkylidene. Their reactivity was extensively studied, as shown in scheme 105. 
Scheme 105: Reactivity of uranium yldiide complex 106.

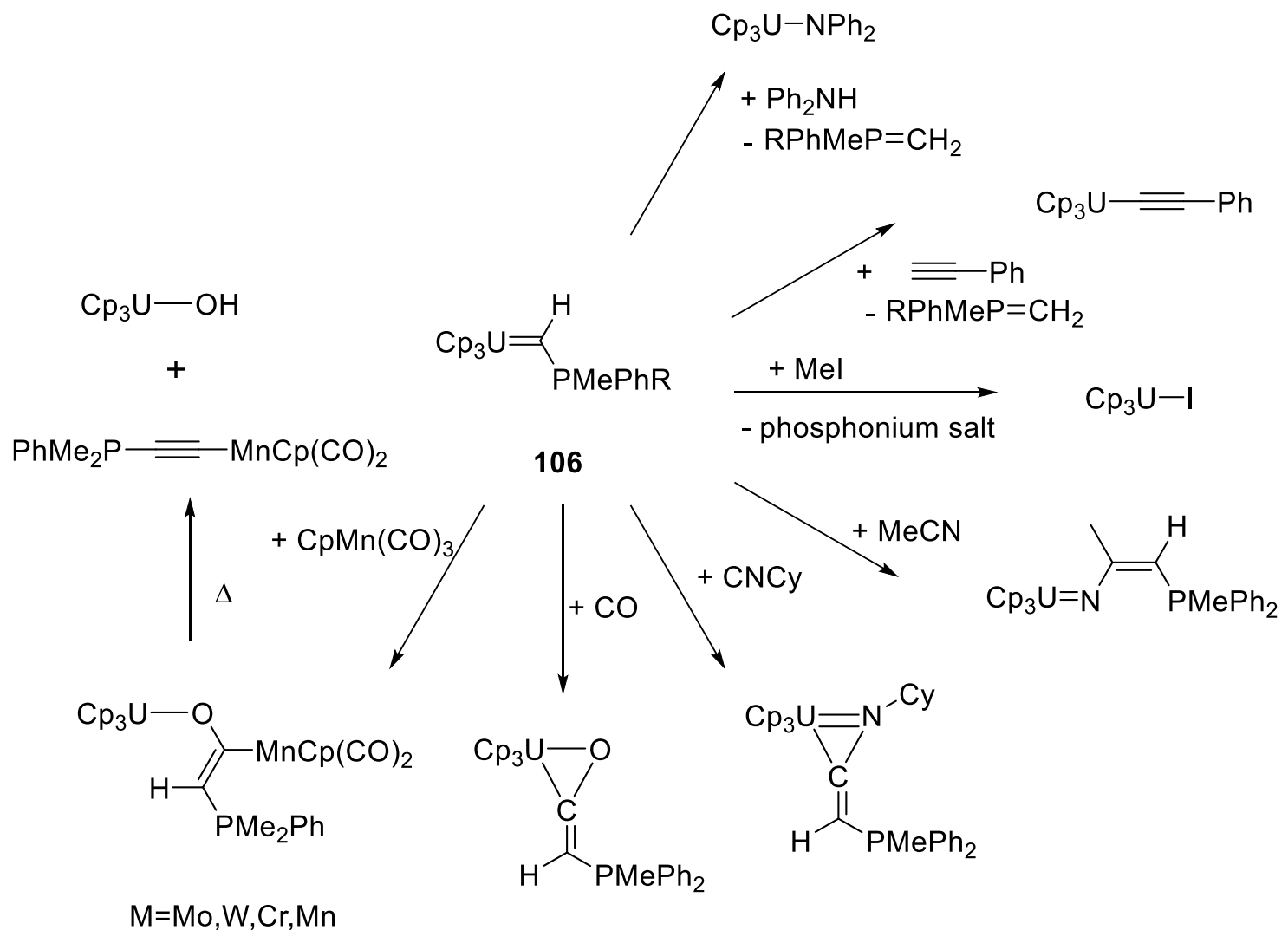

Walensky et al. followed route $\mathbf{C}$ to obtain uranium and thorium complexes featuring triphenylphosphinomethylene ligand $73 .^{217,218}$ Starting from $\left[\mathrm{Cp}_{2}{ }_{2} \mathrm{Th}(\mathrm{Me})_{2}\right]$, a competitive methylenephenyl exchange at phosphorus was observed as a side reaction (scheme 106). ${ }^{217} \mathrm{U}-\mathrm{C}$ bond lengths were found to be the shortest reported to date (2.2428(2) $\AA, \mathrm{X}=\mathrm{Cl}$; 2.252(4) $\AA, \mathrm{X}=\mathrm{Br}$; and 2.2454(2) $\AA$, $\mathrm{X}=\mathrm{I})$. In the case of thorium complexes, it was deduced from ${ }^{13} \mathrm{C}$ NMR data that the Th-C bond had more $\pi$ bond character than the thorium complex featuring a methanediide ligand (vide supra). In the case of paramagnetic uranium, DFT calculation with NBO analysis and QTAIM analysis were the tools used to get insight into the U-C bond structure. It was described as having a $\sigma$ and a $\pi$ component with non negligible contribution from uranium (20\% and $15 \%$, respectively), and a low occupancy (0.9) highlighting 

calculation highlighted a weak covalency.

\section{Scheme 106: synthesis of uranium and thorium compelxes of yldiide 73 follwing route B.}

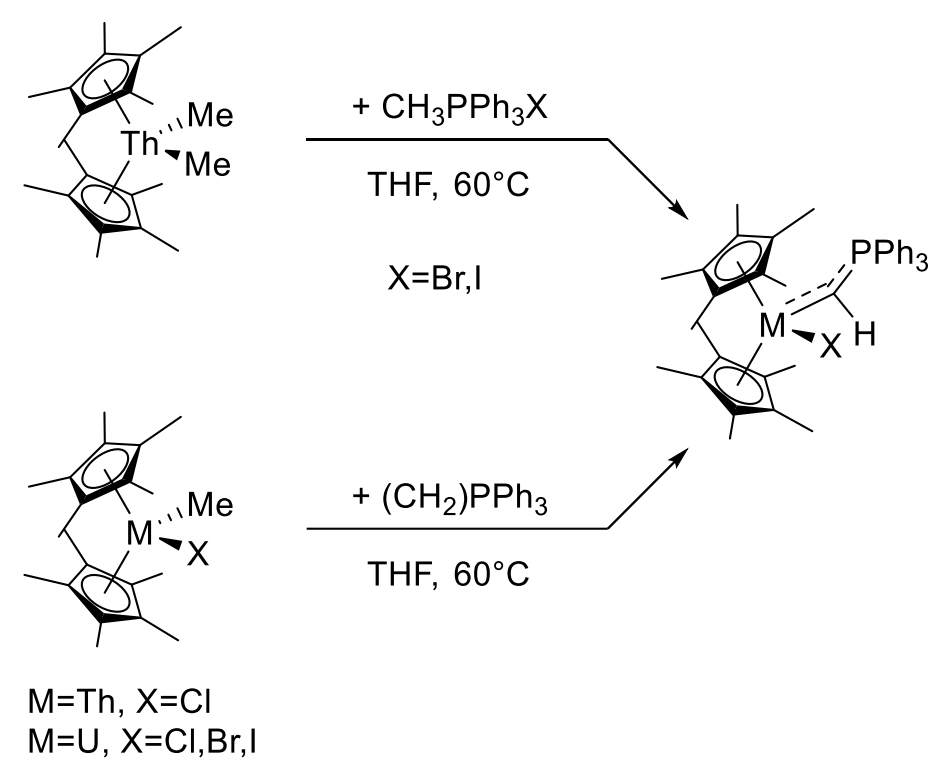

Hayton et al. opened a new synthetic route, starting from Uranium (III) trisamido complex in the presence of methylenetripheniphosphorane $\mathbf{7 3}_{\mathbf{H}}$ (scheme 107). ${ }^{219}$ After preliminary coordination of the ylide at low temperature, increasing the reaction temperature to ambient lead to the one-electron oxidation of uranium (III) to uranium (IV) and generation of a hydrogen radical, which is trapped by an ylide precursor liberating $\mathrm{PPh}_{3}$ and a methyl radical. This methyl radical then reacts with $\mathrm{U}^{\mathrm{III}}$ to generate the complex of uranium (IV). The resulting uranium phosphonium alkylidene complex 107 enters in an equilibrium by deprotonation of a methyl substituent on the bis(trimethylsilyl)amido ligand. The nature of the U-C bond was examined computationally. The HOMO Kohn-Sham orbital is found to be C-U bonding and of $\pi$ symmetry, whereas the $\sigma \mathrm{C}-\mathrm{U}$ bond is found in HOMO-6. NBO analysis showed a strong polarization toward carbon, with $22 \%$ and $13 \%$ of contribution from uranium in $\pi$ and $\sigma \mathrm{U}-\mathrm{C}$ bonds, respectively. 
Scheme 107: Synthesis of uranium and thorium complexes of yldiide 73 by intramolecular protonolysis (route B).

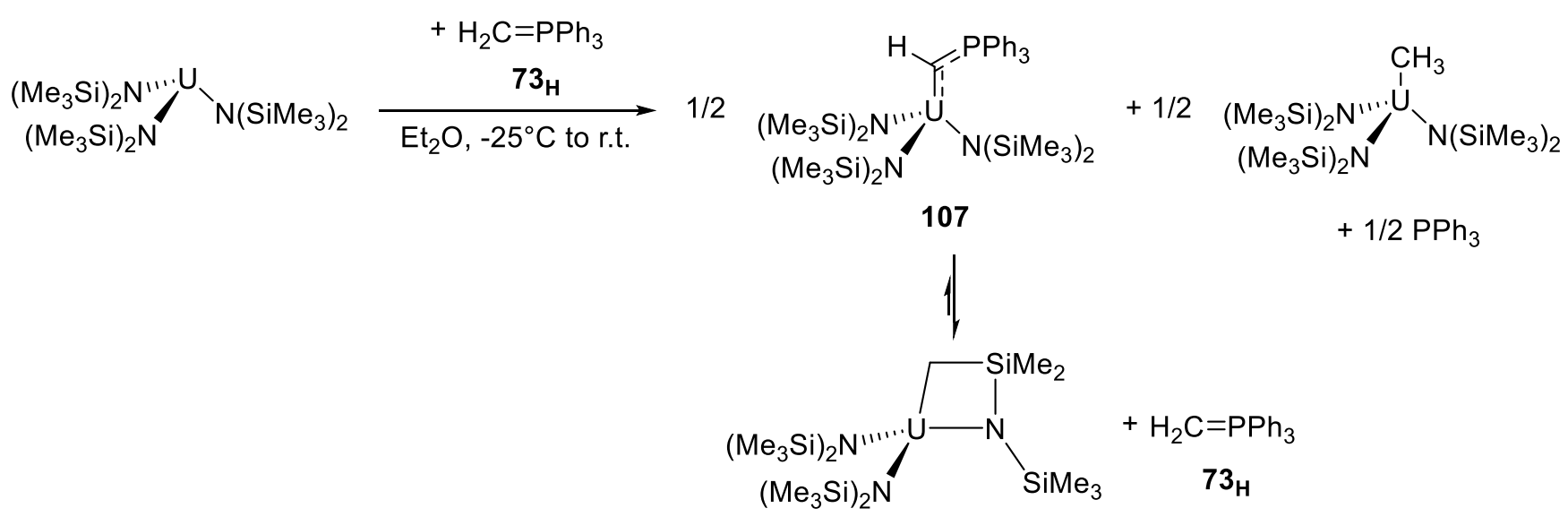

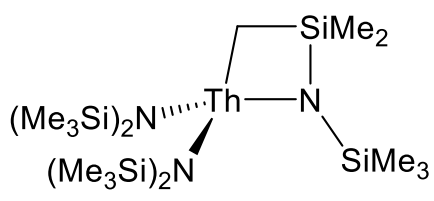
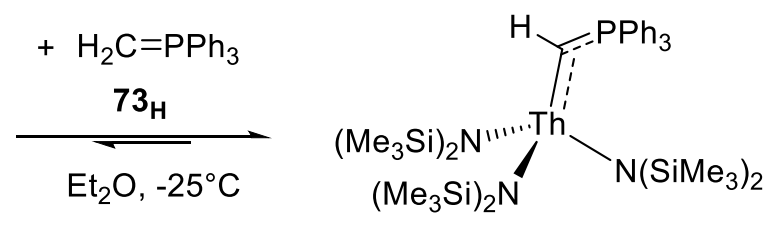

108

Using an analogous Th(IV) metallacycle complex 108 resulting from the $\mathrm{C}-\mathrm{H}$ activation of a bis(trimethylsilyl)amido ligand as a precursor, they obtained an amido-supported phosphonium alkylidene by deprotonation of methylenetriphenylphosphorane. ${ }^{220}$ The cyclometalated form and the phosphonium alkylidene are in equilibrium in solution, this one being in the favor of the alkylidene form.

\subsubsection{Group 4 metal complexes}

Examples of structurally characterized group 4 yldiide complexes are extremely rare. The only structures (complexes 109 and 110) were obtained with zirconocene and hafnocene fragments in 1980, following route $\mathbf{C}$ (scheme 108). ${ }^{221}$ An excess of ylide $\mathbf{7 3}_{\mathbf{H}}$ is necessary for the reaction with zirconium to proceed, whereas a 1:2 stoichiometry is enough for hafnium. Using $\left[\mathrm{Cp}^{*}{ }_{2} \mathrm{ZrCl}_{2}\right]$, the reaction does not 155 
proceed for steric reasons. A $\mathrm{sp}^{2}$ hybridization of the yldiidic carbon in the zirconium complex is supposed based on X-ray structure data as well as ${ }^{1} \mathrm{~J}_{\mathrm{CH}}$ coupling constant of $153 \mathrm{~Hz}$. A rotational barrier of $9.3 \mathrm{kcal} / \mathrm{mol}$ and $8.2 \mathrm{kcal} / \mathrm{mol}$ were found by variable temperature NMR study for the rotation around the M-C bond for $\mathrm{Zr}$ and $\mathrm{Hf}$, respectively.

Scheme 107: Synthesis of uranium and thorium complexes of yldiide 73 by intramolecular protonolysis (route B).

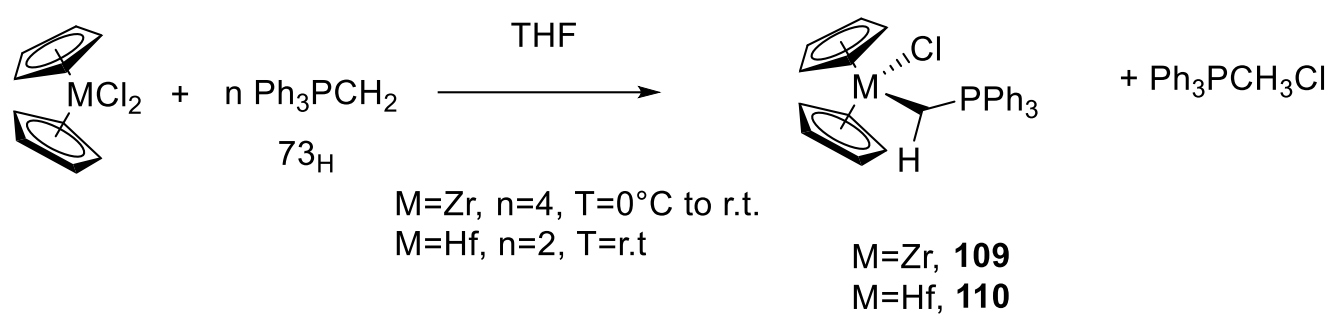

Scheme 108: Synthesis of zirconium and hafnium complexes of yldiide 73 following path $\mathrm{C}$.

\subsubsection{Group 5}

Churchill and Schrock presented the synthesis of a di-tantalum yldiide complex following route $\mathbf{D} .^{222}$ In this reaction, a tantalum hydride was added first to carbon monoxide to generate a supposed bridging formyl ligand; trimethylphosphine was then added, which perform nucleophilic attack on the formyl ligand and induce a C-O bond cleavage, generating complex $\left[\mathrm{Ta}_{2}\left(\eta^{5}-\mathrm{C}_{5} \mathrm{Me}_{4} \mathrm{Et}\right)_{2} \mathrm{Cl}_{4}(\mu-\mathrm{O})(\mu-\mathrm{CHPMe})\right]$ 111 (scheme 109). The P-C(1) distance of $1.750(18) \AA$ is still in the range of ylidic P-C bonds. Position of the hydride was debated elsewhere. ${ }^{223}$ 
ed yldiide.

$\mathrm{Ta}_{2}\left(\eta^{5}-\mathrm{C}_{5} \mathrm{Me}_{4} \mathrm{Et}\right)_{2} \mathrm{Cl}_{4} \mathrm{H}_{2} \stackrel{\text { 1) } \mathrm{CO}}{\stackrel{2}{2} \mathrm{PMe}_{3}}$

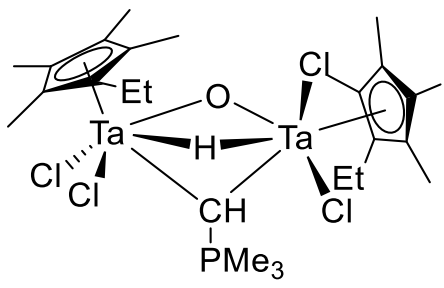

111

Transylidation route $\mathbf{E}$ was also followed to obtain terminal yldiidic complexes of niobium and tantalum with an imido ligand. ${ }^{224}$ It was shown that the reaction can proceed with the two chloride ligands in a presence of an excess of $\mathbf{7 3}_{\mathbf{H}}$; however the mono-chlorinated complex $\mathbf{1 1 2}$ and the bis-yldiidic one 113 are in equilibrium in solution (scheme 110). A phosphonium-alkylidene like structure was assessed from X-ray diffraction study and NMR data.

Scheme 110: Synthesis of niobium complexes of yldiide 73 following route $C$.

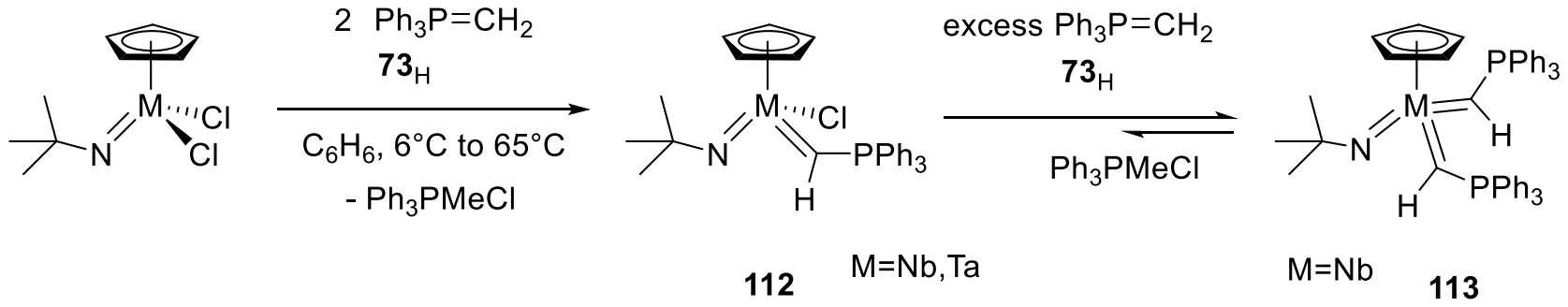

Again by transylildation of methylenetriphenylphosphorane, and starting from $\left[\mathrm{CpTaCl}_{4}\right]$, Sundermeyer et al. could obtain various structures, depending on the amount of added ylide $\mathbf{7 3}_{\mathbf{H}}$ (scheme 111). When one equivalent is added, coordination of the ylide at tantalum occurs with no significant transylidation (59\% isolated yield). When five equivalents were added, complex 114 was obtained. It contains a methylidyne fragment formed after double deprotonation of a coordinated ylide ligand as well as a methylidene ligand generated by a single deprotonation of the ylide ligand. Two more equivalent of ylide can 
be added, to generate an additional methylidene ligand, forming complex 115. Here again, a phosphonium-alkylidene like structure was claimed on the grounds of X-ray diffraction analysis.

\section{Scheme 111: Synthesis of tantalium terminal complexes of yldiide 73 following route C.}

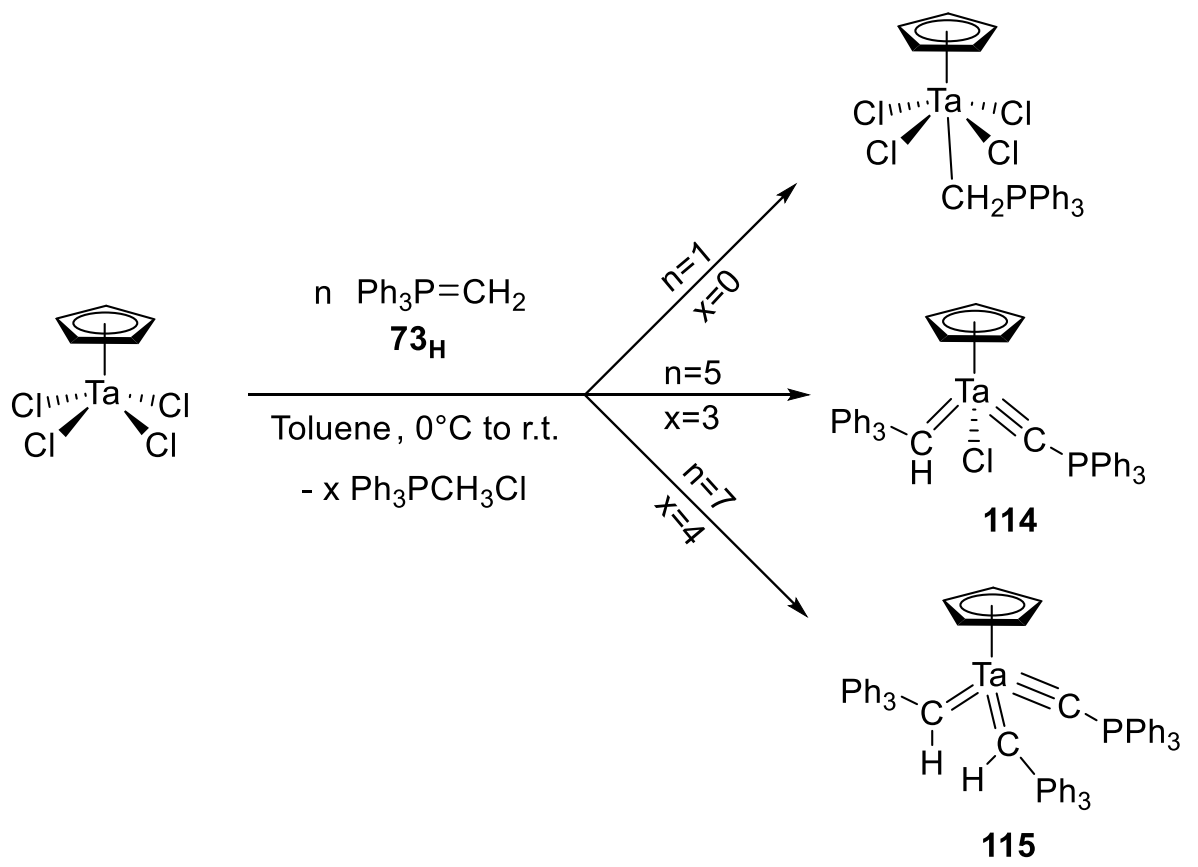

\subsubsection{Group 6}

If the possibility of the synthesis of group 6 complexes featuring a phosphorus-stabilized yldiide ligand was studied as early as 1975 by $\mathrm{Kreiss}^{225}$ on monometallic chromium carbonyl complexes following route $\mathbf{E}$, the first structure to be determined by X-ray diffraction was obtained only in 1981 with a heterobimetalic core. ${ }^{226}$ Addition of trimethylphosphine to $\left[\operatorname{Re}(\mathrm{CO})_{5}-\mathrm{W}(\mathrm{CO})_{4}(\mathrm{C}-p\right.$ tol $\left.)\right]$ featuring an electrophilic alkylidyne ligand lead to the displacement of one equivalent of carbon monoxide and the formation of an yldiide ligand, in a bridging position in place of the expected terminal one (complex 116, scheme 112). A similar reaction with chromium was performed, leading to a similar species according to mass, IR and NMR spectroscopies. A $\mathrm{sp}^{3}$ hybridization is proposed for the bridging carbon. 
Scheme 112: Synthesis of a gem-heterobimetallic tungsten and renium complex of a p-tolylsubstituted yldiide following route $\mathrm{D}$.

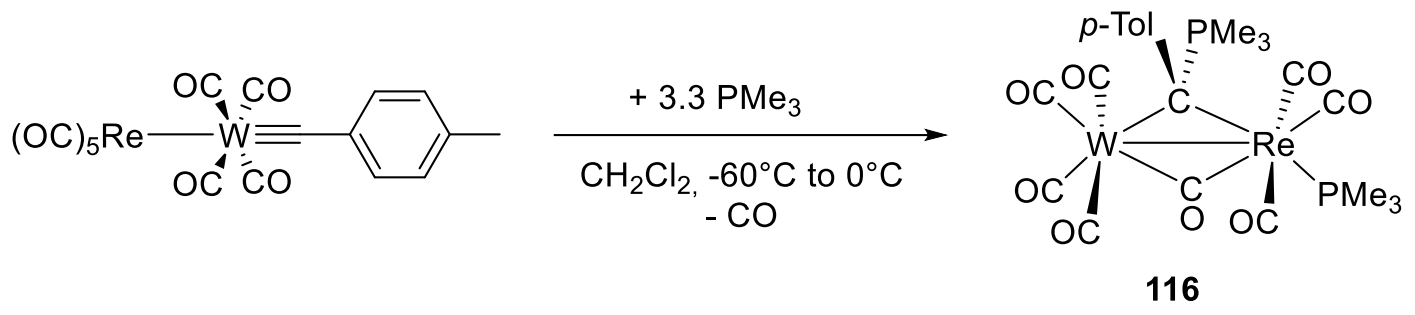

Terminal $\alpha$-phosphinoalkylidenes were obtained with imino complexes of molybdenum and tungsten by Sundermeyer et al. following route D. By stepwise addition of methylenetriphenylphosphorane $\mathbf{7 3}_{\mathbf{H}}$, they could obtain structures containing one or two $\alpha$-phosphinoalkylidenes ligands (scheme 113 ). ${ }^{227}$ Only the doubly substituted tungsten compound $\mathbf{1 1 8}$ could be structurally characterized. Both yldiidic carbons were found to be trigonal planar, and significant $\mathrm{W}-\mathrm{C}$ double bond character was assessed on the basis of W-C bond distance and the staggered geometry of the yldiidic ligand. Competition between $\pi$ donation toward the metal and hyperconjugation was evidenced by the short $\mathrm{P}-\mathrm{C}$ bond lengths

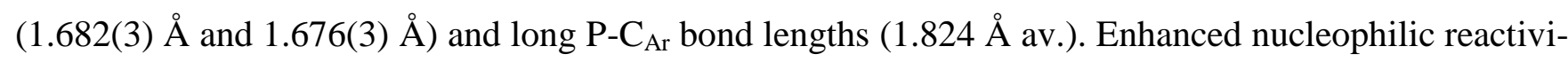
ty compared to Shrock-type carbene complexes was claimed. More details on this reactivity were published later, together with the structure of an analogous mono- $\alpha$-phosphinoalkylidenes chromium complex. $^{228}$ Nucleophilic addition of the yldiidic carbon on unsaturated, polar molecules such as CO and CNR resulted in the formation of 3 membered metallacyclic structure, in which the ylidic P-C bond is still present. When reacted with diphenylketene, a four-membered metallacycle is formed; the ylidic carbon is not coordinated to the metal. Instead, the carbon bearing the two phenyl groups is bound to the metal; the second carbon of the metalacycle is planar, which support delocalization of the positive charge of the phosphonium moiety through the $\mathrm{C}=\mathrm{C}$ double bond. 
Scheme 113: Synthesis of tungsten, molybden and chromium terminal complexes of yldiide 73 and their reactivity.

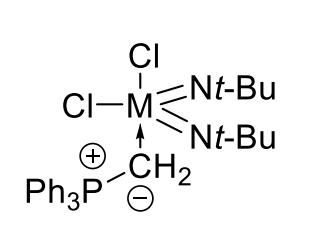

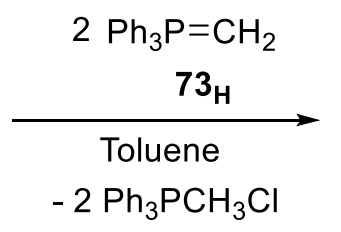

$2 \mathrm{Ph}_{3} \mathrm{PCH}_{3} \mathrm{Cl}$
$\mathrm{M}=\mathrm{Mo}, \mathrm{W}, \mathrm{Cr}$

117
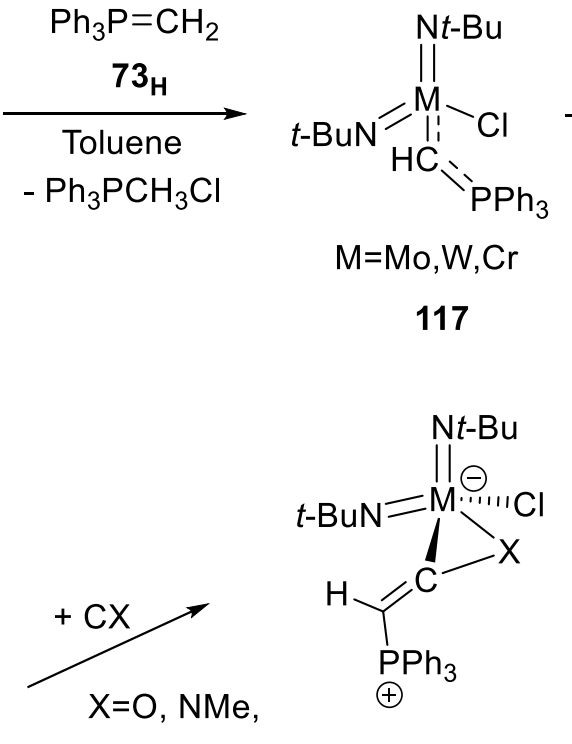

$\mathrm{M}=\mathrm{Mo}, \mathrm{Cr}$
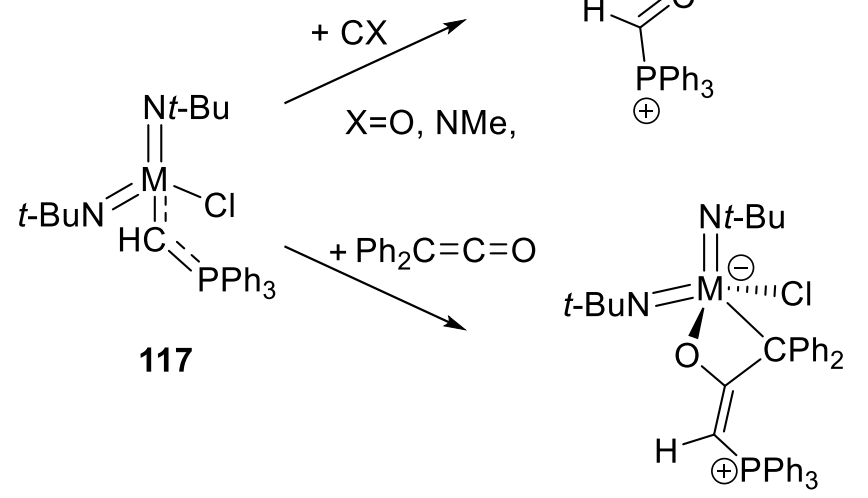

The same group published the synthesis and structure of another high-valent tungsten complex with Hydrotris(3,5-dimethyl-1-pyrazoly1) borate as a supporting ligand, once again by transylidation from methylenetriisopropyl- and methylenetriphenylphosphorane (scheme 114). ${ }^{229}$ On the basis of ${ }^{13} \mathrm{C}$ and ${ }^{1} \mathrm{H}$ NMR, a phosphora-alkenyl like structure depiction of these complexes was given. 
Scheme 114: Synthesis of a tris-pyrazolyl tungsten complex of yldiide 73.
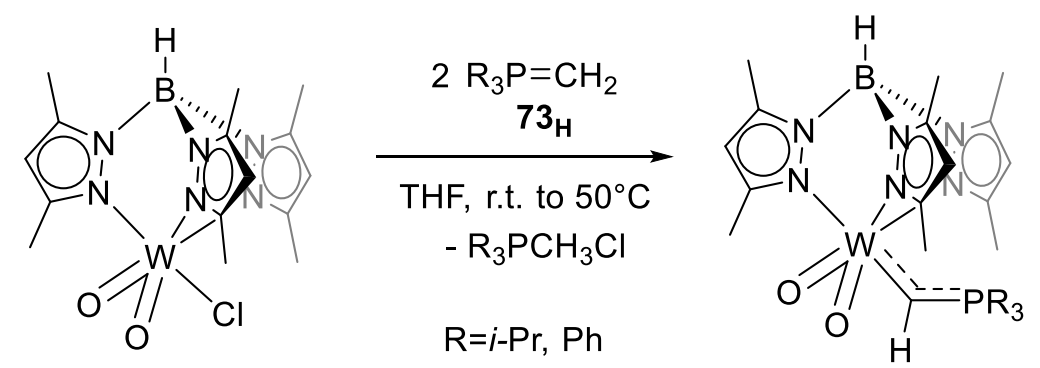

Following route $\mathbf{D}$, Fillipou et al. provided another example of a chromium complex featuring terminal yldiidic ligand. ${ }^{230}$ Addition of $\mathrm{PMe}_{3}$ to a cyclopentadienyl-stabilized carbyne chromium complex afforded, depending on the substitution pattern at cyclopentadienyl, either an $\alpha$-phosphinocarbene complex 119 by addition of the phosphine to the carbyne (non-substituted Cp ligand), or a three-membered metalacycle, complex 120, by coupling between the carbyne and a carbonyle ligand (pentamethylcyclopentadinenyl). Considering both NMR data and X-ray diffraction pattern, the phosphonium-alkylidene structure was preferred to describe the resulting complex (scheme 115).

Scheme 115: Synthesis of chromium yldiide complexes following route $D$.
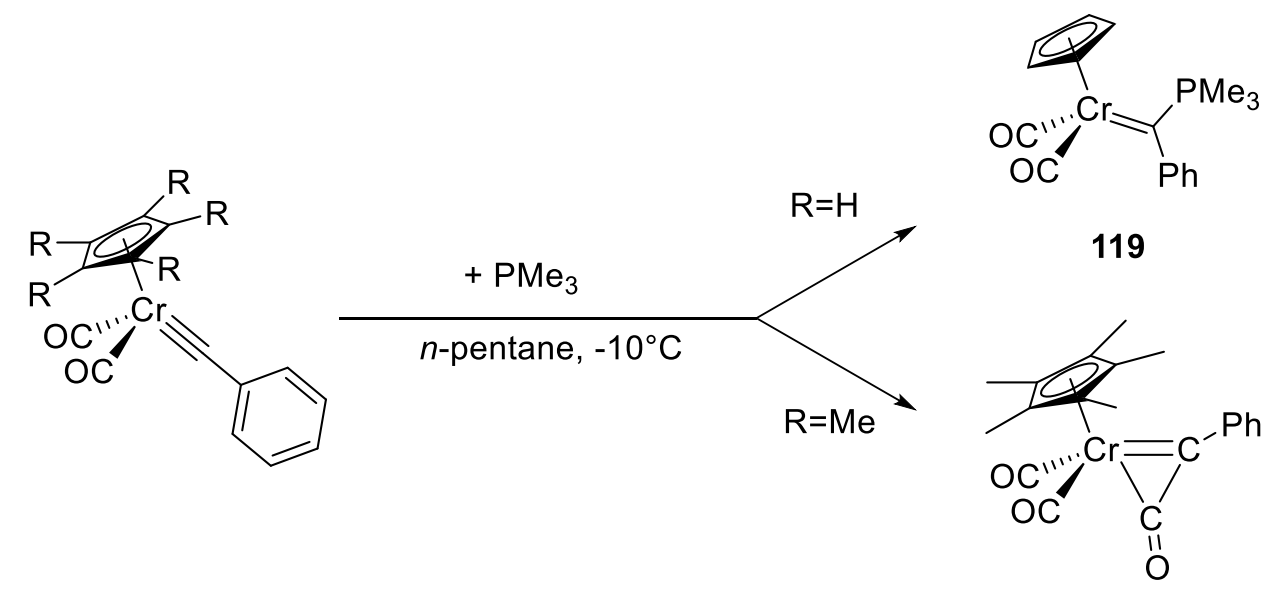

120

Finally, a last example of an imido-stabilized tungsten complex 121 featuring both phosphorusstabilized methylidene and methylidyne was reported by Sundermeyer (scheme 116). ${ }^{231}$ Based on ${ }^{31} \mathrm{P}$ 161 
NMR data, and more specifically on the value of ${ }^{2} J_{P W}$ coupling constants, the metal-yldiide interactions were described as $\sigma$ bonds with additional $\pi$ bonding character - and double bond with triple bond character for the metal-methylidyne interaction. The phosphora-alkenyl structure was still preferred, notably considering that the shorter the W-C bond length is, the longer the C-P bond length, as a result of effective donation toward the metal center.

Scheme 116: Synthesis of terminal tungsten compleses of yldiide 73 following route $C$.

$\underset{\substack{\text { Toluene, }-20^{\circ} \mathrm{C} \text { to r.t. } \\-4 \mathrm{Ph}_{3} \mathrm{PCH}_{3} \mathrm{Cl}}}{\mathrm{NAr}}$ 121

Degradation of a metathesis-competent molybdenum carbene complex containing methyldiphenylphosphine as a ligand in the presence of bipyridine, by reaction with cis-dichloroethylene afforded a phosphoniomethylidene complex 122 of molybdenum by a formal chloride/phosphine exchange at the chlorocarbene generated by olefin metathesis between the alkylidene ligand and cis-dichloroethylene (scheme 117). ${ }^{232}$ This process is reminiscent of what can be observed with a $2^{\text {nd }}$ generation Grubbs catalysts (vide infra).

Scheme 117: Synthesis of a terminal yldiide imino complex of molybdenum by intramolecular chloride/phosphine exchange.
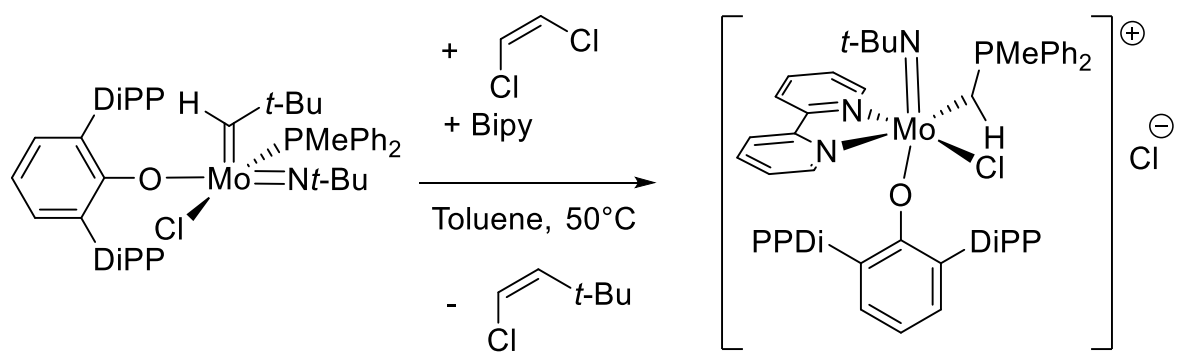

122 


\subsubsection{Group 7}

In addition to the dimetallic tungsten-rhenium complex ${ }^{226}$ cited above, and even if some syntheses are reported, ${ }^{226,227,233,234}$ structurally characterized examples of group 7 yldiide complexes are scarce. Cyclopentadienyl-rhenium and manganese complexes were synthesized as early as 1977 following route $\mathbf{E},{ }^{235}$ and the rhenium complex was structurally characterized shortly after. ${ }^{236}$ The structure at the yldiidic carbon is compatible with a $\mathrm{sp}^{2}$ hybridization, the short $\mathrm{Re}-\mathrm{C}$ bond distance (1.97(1) $\AA$ ) as well as ${ }^{13} \mathrm{C}$ NMR data are consistent with a phosphora-alkenyl like structure. Furthermore, a quite long P-C bond distance was measured $(1.79(1) \AA)$, comparable to the $\mathrm{P}-\mathrm{C}_{\mathrm{Me}}$ bond lengths $(1.76(2) \AA$ to $1.80(2)$. $\AA$ ), showing an absence of hyperconjugation of the electronic density at $\mathrm{C}$ toward the phosphonium moiety (scheme 118).

Scheme 118: Synthesis of terminal yldiide complexes of manganeses and renium following route D.

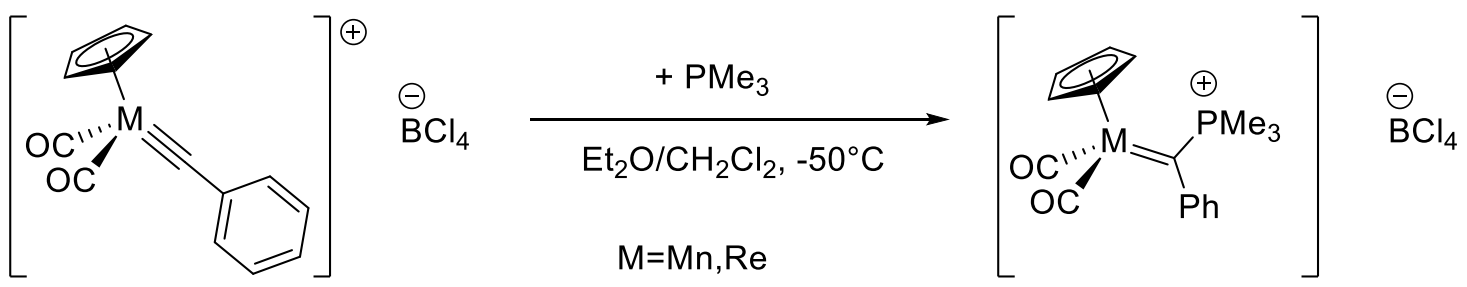

Various heterodimetallic complexes of rhenium and manganese with platinum ${ }^{237}$ were also obtained following route $\mathbf{E}$, i.e. by addition of a phosphine on a bridging alkylidyne ligand (scheme 119). Only for manganese could the X-ray diffraction structure be solved. The substituents at the bridging carbon are in a plane orthogonal to the Pt-C-Mn plane; however a very sharp Pt-C-Mn angle $\left(78.4(2)^{\circ}\right)$ does not sustain a $\mathrm{sp}^{3}$ hybridization. P-C $\mathrm{C}_{\text {yldiide }}$ bond lengths was measured to be 1.791(5) $\AA$, slightly shorter than P- $\mathrm{C}_{\mathrm{Me}}$ bond lengths $(1.803(6) \AA$ to $1.829(7) \AA$ ). Addition of a thiolate to a phosphine-coordinated manganese, alkylidyne-bridged complex also lead to migration of one phosphine ligand to the electrophilic 163 
carbon, the thiolate being coordinated to platinum. The same reaction performed with the rhenium heterobimetallic complex lead to the expected addition of the thiolate onto the alkylidyne ligand.

Scheme 119: Synthesis of gem-heterobimetallic complexes of p-tolyl substituted yldiides following route $\mathbf{D}$.

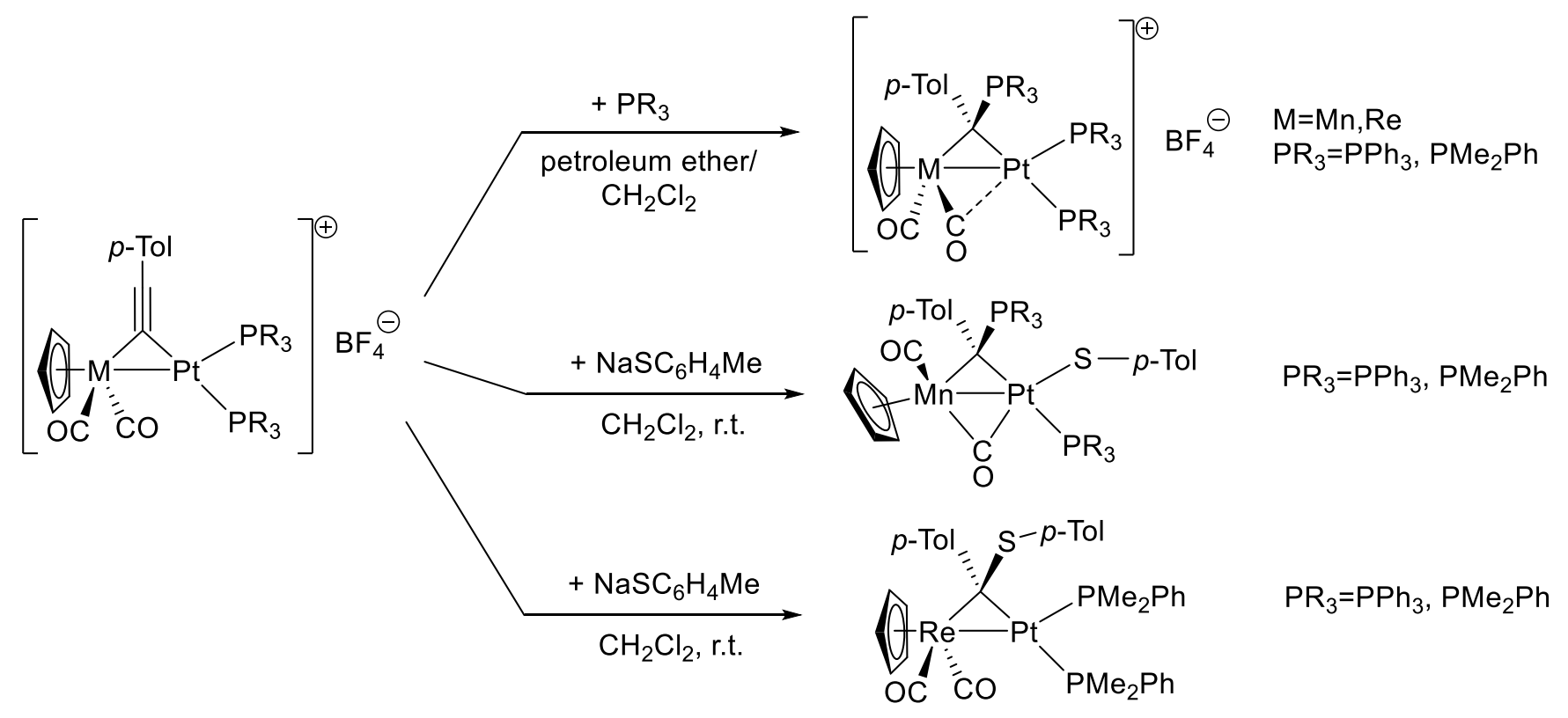

\subsubsection{Group 8}

Diiron structures could be obtained with various substitution scheme and in good yield, from the nucleophilic addition of triphenylphosphine or tris-(n-butyl)phosphine on a methylidyne or ethylidyne bridging between two $\mathrm{CpFeCO}$ moieties (Route $\mathbf{D})($ scheme 120$){ }^{238}$ Only when $\mathrm{BF}_{4}{ }^{-}$counteranion was replace by $\mathrm{PF}_{6}^{-}$could the structure of the $\alpha, \alpha$-diferric methylenetriphenylphosphorane complex be con-

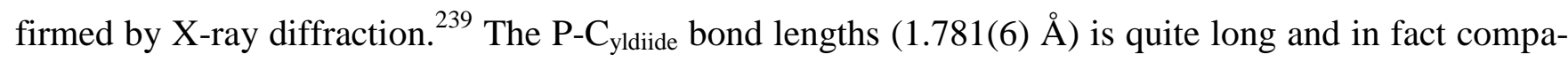
rable to P-C $\mathrm{C}_{\mathrm{Ar}}$ bond lengths $(1.799(7) \AA$ to $1.805(7) \AA$ ). Addition of sodium methoxide resulted in the displacement of the phosphine to produce the corresponding bridging carbene. 
Scheme 120: Synthesis of gem-dimetallated complexes of iron following route $D$, and subsequent reactivity.
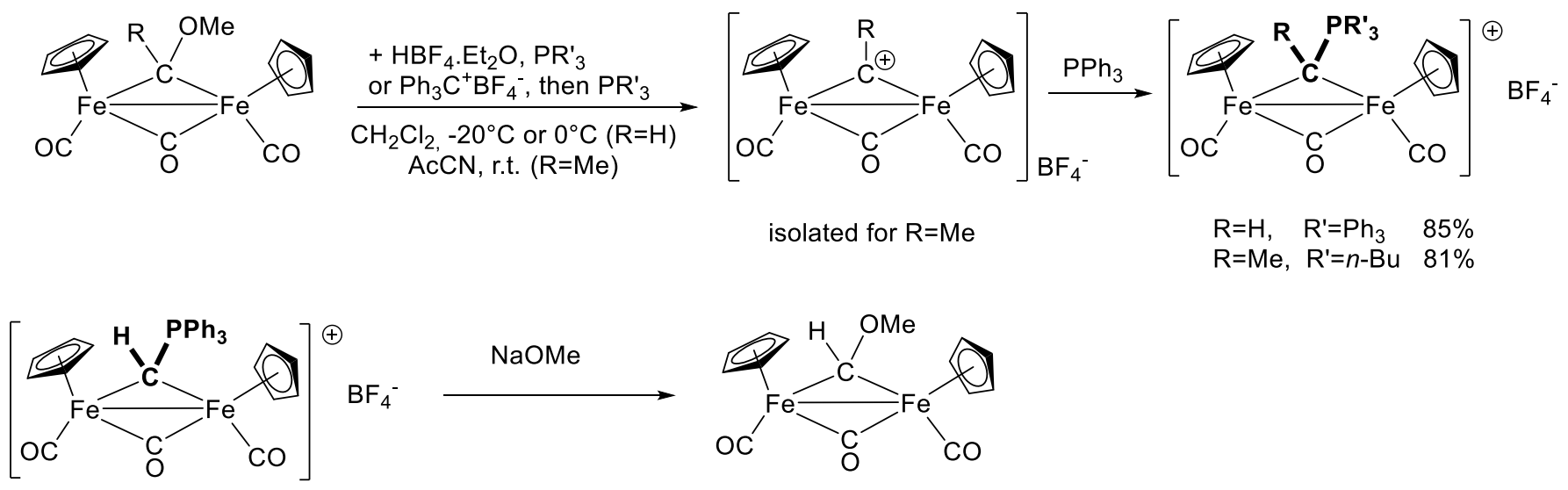

A similar complex, obtained by adding trimethylphosphine instead of triphenylphosphine was synthesized shortly after. X-ray diffraction showed a similar structure, and again, $\mathrm{P}-\mathrm{C}_{\mathrm{yldiide}}$ bond lengths of the same amplitude as P-Me bond lengths (1.760(15) $\AA$ vs $1.747(16) \AA$ to $1.775(18) \AA){ }^{240}$

Rearrangement of the bis(diphenylphosphino)methane ligand at a dimetallacyclopentenone iron complex, namely $\left[\mathrm{Fe}_{2}(\mathrm{CO})_{5}\left\{\mu-\sigma: \eta^{3}-\mathrm{C}(\mathrm{O}) \mathrm{CHCH}\right\}-(\mu-\mathrm{dppm})\right]$ upon thermolysis afforded a structure reminiscent of an yldiide (complex 123, scheme 121). ${ }^{241} \quad \mathrm{P}_{-} \mathrm{C}_{\text {yldiide }} 1.790(2) \AA$ is only slightly shorter than P$\mathrm{C}_{\mathrm{Ph}}$ and $\mathrm{P}-\mathrm{CH}_{2}(1,813(2) \AA$ to $1,821(2) \AA)$.

Scheme 121: Intramolecular formation of a phosphure/yldiide ligand in the coordination sphrere of a diiron carbonyl complex.

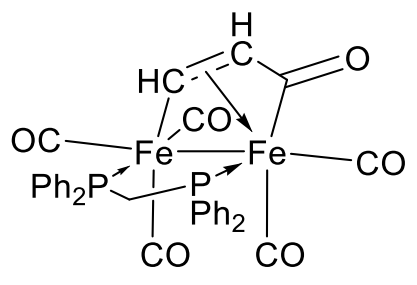

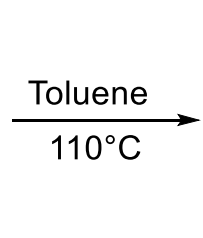

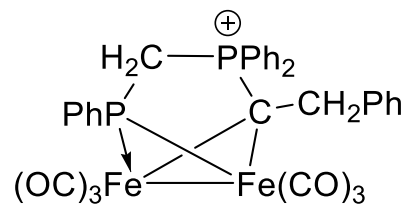


A renewal in group 8 metal yldiidic complexes was brought in 2004 by Piers, ${ }^{242}$ who proposed the generation of a ruthenium phosphonium alkylidene complex following route $\mathbf{E}$ as a way to circumvent the initiation step in Grubbs catalysts for olefin metathesis. The generated complex is found to have increased stability and an activity comparable to this of Schrock catalysts, and to have functional-group tolerance comparable to this of Grubbs catalysts.

\section{Scheme 122: Synthesis of a ruthenium terminal complex of yldiide 73 following route D.}
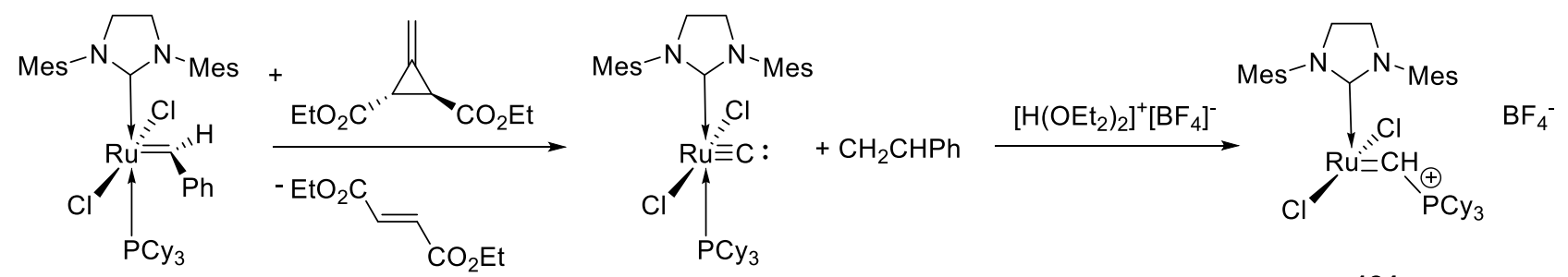

Other complexes with phosphines in place of the carbene ligand were synthesized but not structurally characterized, and their reactivity was not explored further. The yldiide ligand feature a rather long P-C bond of 1.805(2) $\AA$; it has been described as a "dicarbanionic ylid", a description reminiscent of phosphonium-alkylidene like structure. Complex $\mathbf{1 2 4}$ showed remarkable activity at room temperature in ring-closing olefin metathesis for five $(0 ; 1 \%$ catalyst loading), six (1\% catalyst loading and seven membered-rings (5\% catalyst loading), as well as with trisubstituted olefins (1\% catalyst loading). Other

structure with various counter anions were also published and showed similar activities. ${ }^{243}$ Extensive study of the influence of the phosphine substitution pattern was also presented shortly after. ${ }^{244}$ It was shown that triisopropylphosphine presents the best balance between steric bulkiness (to avoid dimerization of the cationic catalyst by sharing of chloride ligands) and a small cone angle (to allow for initiation by ethylene cross metathesis). When the carbene ligand was replaced by a second phosphine ligand, 
dimerization of the generated phosphonium-alkylidene ruthenium complex was observed (scheme 123).

Catalytic activity was still observed at $135^{\circ} \mathrm{C}$, with limited double bond isomerization products. ${ }^{245}$

By contrast, when a $2^{\text {nd }}$ generation Grubbs catalyst was reacted with vinylchloride, formation of a neutral phosphoniomethylidene complex was observed along with a ruthenium carbide complex in a 2-3 to 1 ratio. ${ }^{246}$ Formation of these two complexes in the course of catalysis was hold responsible for the failure of cross-metathesis reactions using vinyl chlorides.

Scheme 123: Dimerization of a phosphonium-alkylidene ruthenium complex upon protonation resulting in the formation of an yldiide ligand (top); generation of a ruthenium yldiide species after carbene metathesis with vinyl chlorides (bottom).
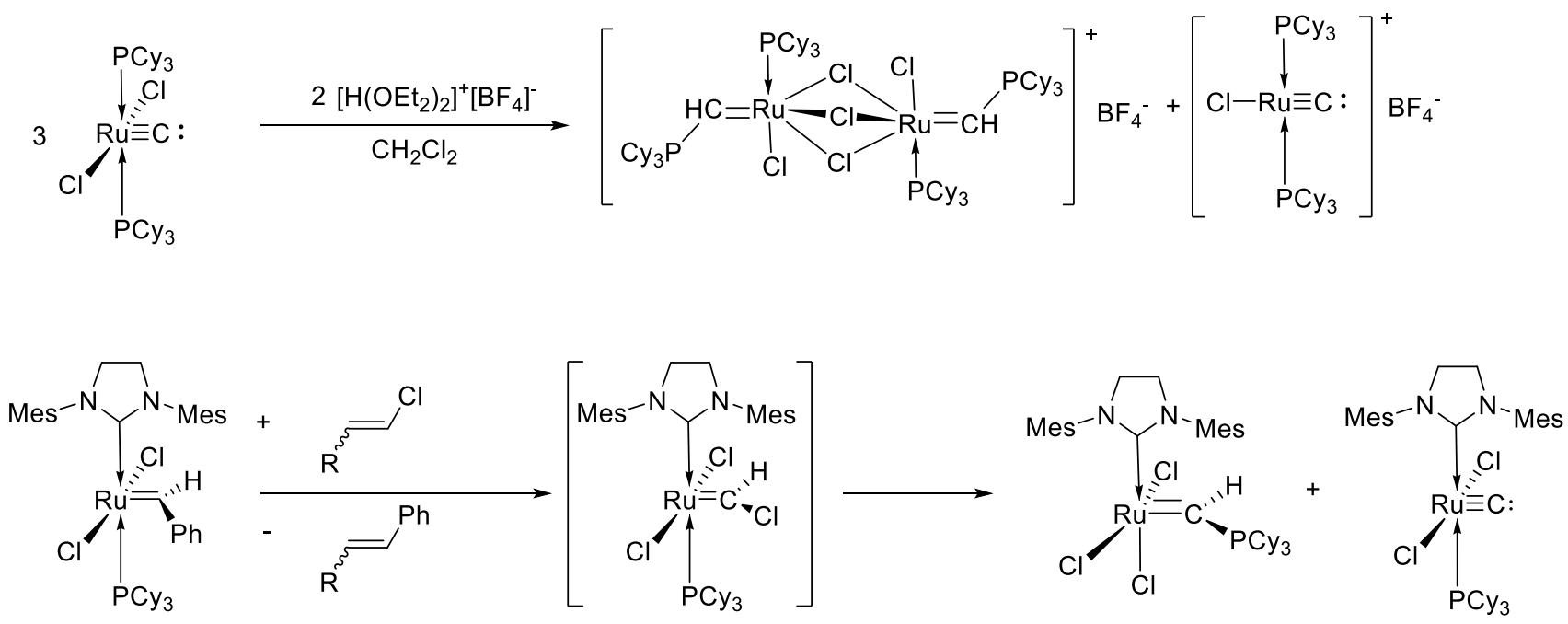

Piers et al. showed that a catalytic activity could be recovered from the phosphinomethylidene complex by abstraction of a chloride ligand using $\mathrm{B}\left(\mathrm{C}_{6} \mathrm{~F}_{5}\right)_{3} \cdot{ }^{244}$

The only characterized complex of osmium with a phosphinomethylidene ligand was reported in 2005 by Lu. ${ }^{247}$ A new synthetic path using hydride addition on N-Isocyanoiminetriphenylphosphorane and subsequent decomposition by release of $\mathrm{N}_{2}$ was proposed for the synthesis of a bridging $\alpha$ phosphinoalkylidenes osmium complex. The phosphinoalkylidene is described as zwitterionic in nature, 167 
with a quite long P-C bond lengths of $1.75(1) \AA$, still shorter than related P-Me ylidic bonds (scheme 124).

Scheme 124: Synthesis of an osmium gem-dimetallic yldiide complex.
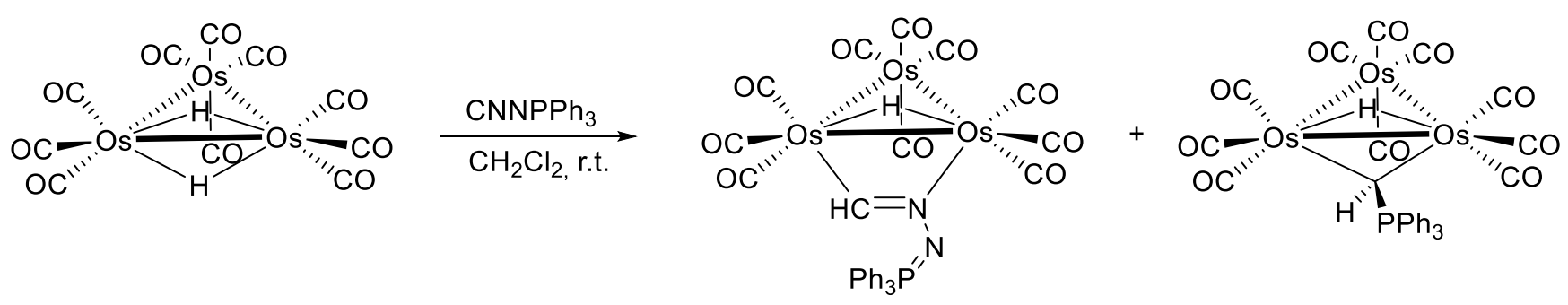

\subsubsection{Group 9.}

In contrast to the abundant literature of geminal dianion coordinated to group 9 elements (vide supra), no structurally characterized complex with an yldiide (or metalated ylide) could be found. Such a structure was however evocated to explain for the epimerization of a rhodium complex featuring a chiral phosphonium ylide ligand in the presence of a base (scheme 125$){ }^{248}$ The intermediate compound was further documented in a later publication, ${ }^{249}$ but the postulated metalated yldiide was not structurally characterized. After stoichiometric deprotonation of the coordinated ylide by sodium hydride, multinuclear NMR spectroscopy showed disappearance of the ylidic proton in ${ }^{1} \mathrm{H}$ NMR; the ylidic carbon is slightly shifted upon deprotonation (38.4 ppm to $41.5 \mathrm{ppm}$ ), and ${ }^{1} \mathrm{~J}_{\mathrm{CRh}}$ coupling constant is increased (23.3 Hz to $37.0 \mathrm{~Hz}$ ). in ${ }^{103} \mathrm{Rh} \mathrm{NMR}$ spectroscopy, the $\mathrm{Rh}$ displacement is shifted at lower field (from $170 \mathrm{ppm}$ to $259 \mathrm{ppm}$ ) which is consistent with increased C-Rh donation. Analysis of the Kohn-Sham orbital calculated in the frame of DFT showed however a poor interaction of the second lone pair at carbon with rhodium, suggestion a phosphora-alkenyl like structure. 
Scheme 125: Synthesis of a rhodium yldiide complex.
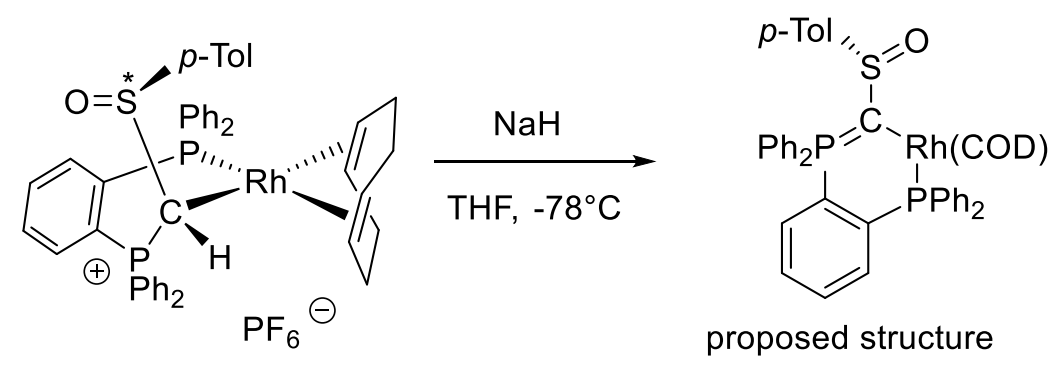

\subsubsection{Group 10}

Only a single structurally characterized yldiide coordinated to a group 10 metal was found. A dimetallic nickel complex 125 was synthesized by Dartiguenave, Dartiguenave and Klein ${ }^{250}$ through $^{2}$ photolysis of a nickel-coordinated diazoalkane and subsequent addition of a phosphine from the coordination sphere of the nickel to the carbyne generated by loss of dinitrogen (scheme 126). This ylidiide is reminiscent of yldiide $\mathbf{7 9}$ isolated by Bertrand et al., even if the mechanism for its generation is totally different. A sp $\mathrm{sp}^{2}$ hybridization of the carbon is expected from the short Ni-C bond lengths (1.906 (4) $\left.\mathrm{A}\right)$ and P-C-Si bond angle $\left(120.0(4)^{\circ}\right)$.

Scheme 126: Synthesis of a gem-dimetallated nickel yldiide complex following route D.
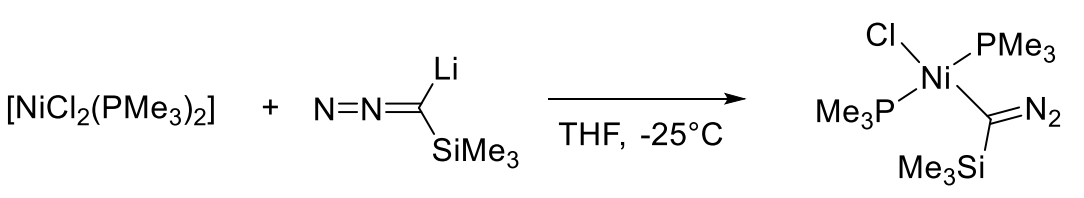
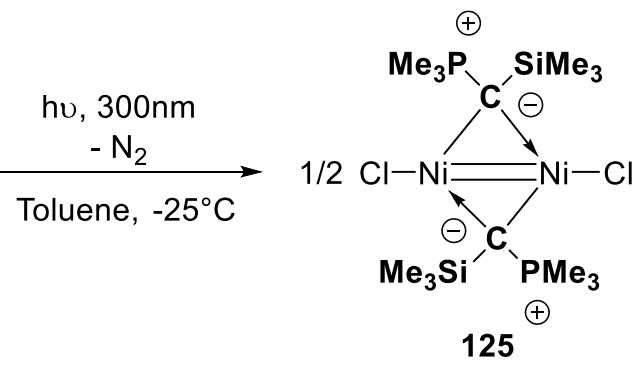

\subsubsection{Group 11}


Yldiidic complexes of group 11 metals are usually synthesized following route $\mathbf{B}$ (deprotonation of a phosphonium or phosphorus ylide by a basic ligand coordinated to the metal) or route $\mathbf{C}$ (transylidation).

Vicente proposed to increase the coordination ability of carbonyl-stabilized ylide by deprotonation of the phosphonium in the coordination sphere of the metal (route B). When two equivalents of gold acetylacetonate complexe were added to the phosphonium, double deprotonation at the ylidic carbon was observed, resulting in the formation of a geminal-diaurated species $\mathbf{1 2 6}$ (scheme 127). Only the ethoxysubstituted yldiide with triphenylphosphine as co-ligand was structurally characterized.

Scheme 127: Synthesis of a gem-diaurated yldiide following route B.

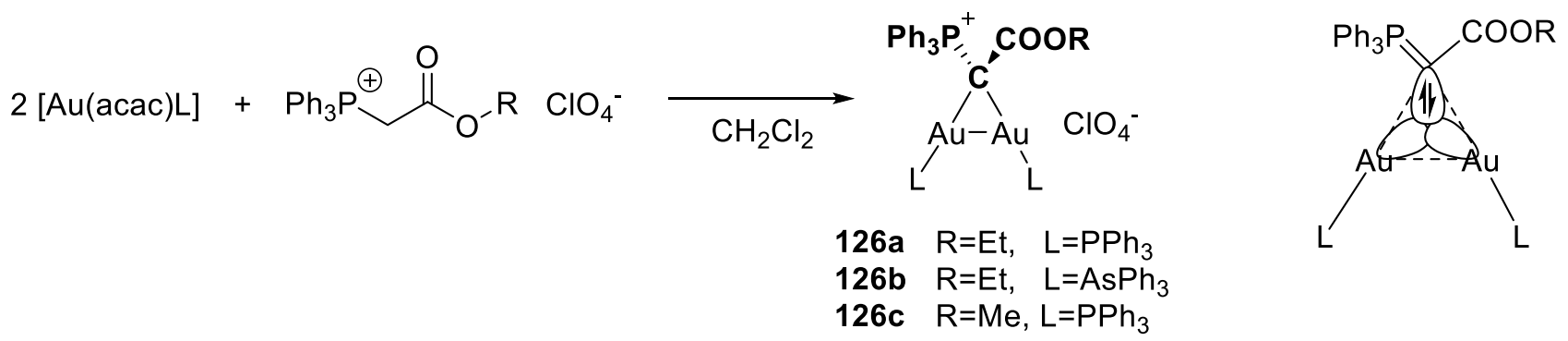

The short P-C $\mathrm{C}_{\text {yldiide }}$ bond distance (1.763(10) $\AA$ ) as well as the low v(CO) suggest some ylidic character, and a mesomeric form with an ylidic bond between $\mathrm{P}$ and $\mathrm{C}$, together with a closed three-center, two electrons interaction between the remaining $\sigma$ lone pair at carbon and relevant empty orbitals at gold was proposed. This corresponds to a phosphora-alkenyl like structure for the ligand.

The same group extended this strategy to an analogous ketone-stabilized diphosphonium salt. Depending on the steric hindrance of the phosphine brought by the gold precursor, tri or tetra auration was observed. A closed three centers, two electron interaction is evocated in both cases to explain for the gold atom arrangements. ${ }^{251}$ Due to low quality of the crystals, P-C bond are not discussed further. 
Using a pyridine-substituted phosphonium salt, and following the same strategy, this same group could provide an example of $\mathrm{Au}_{2}^{\mathrm{I}} \mathrm{Ag}_{1}^{\mathrm{I}}$ cluster 127 (Scheme 128), the silver atom being brought in the proximity of the $\mathrm{Au}_{2} \mathrm{C}$ core by coordination to the nitrogen atom of the pyridine moiety. ${ }^{252}$

Scheme 128: Synthesis of tri- or quadrimetallic structures with group 11 elements.

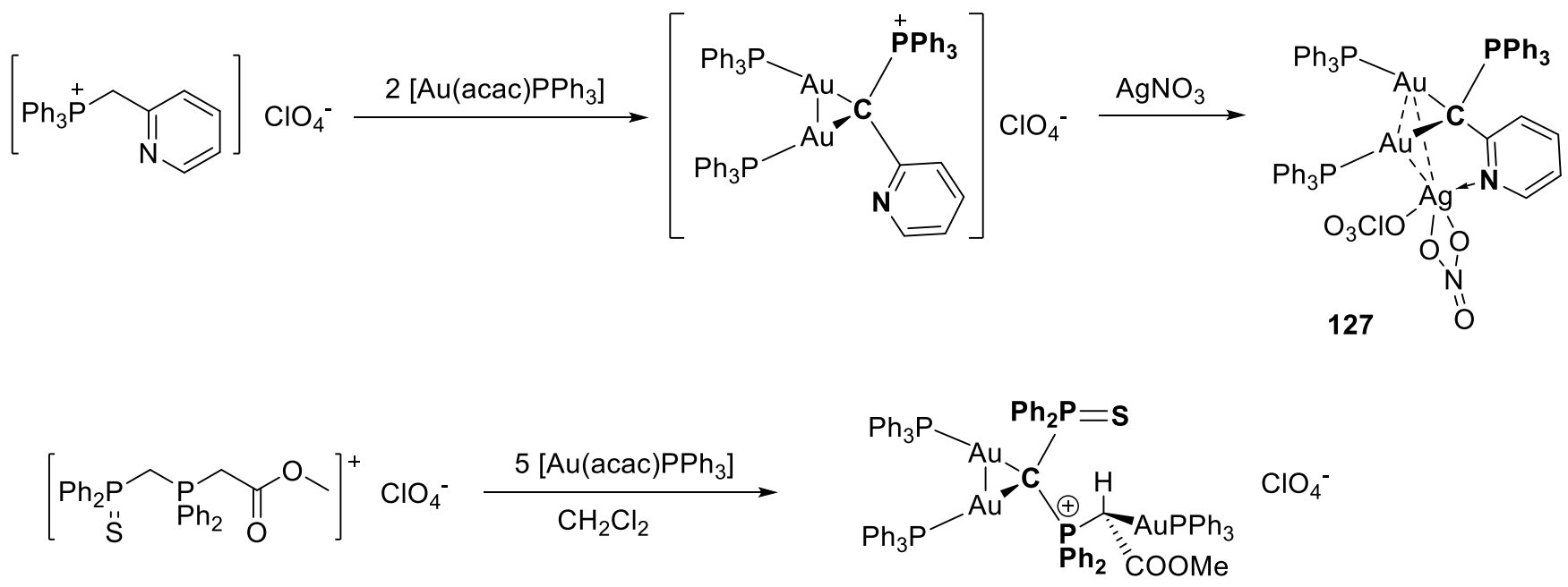

128

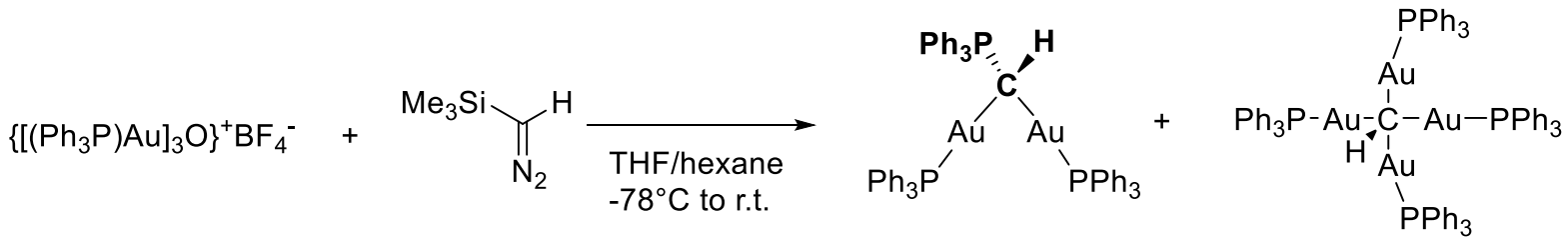

129

Triple deprotonation of [(diphenylphosphinothioyl) methyl] (2-methoxy-2-oxoethyl) diphenylphosphonium perchlorate by acetylacetonate ligands afforded a triply aurated complex, $128{ }^{253}$ An aurophilic interaction is present, which is quite common for geminal-diaurated compounds. $\mathrm{P}-\mathrm{C}_{\mathrm{S}}$ and $\mathrm{P}-\mathrm{C}$ bond lengths of 1.802(10) $\AA$ and 1.742(10) $\AA$ respectively are shorter than average P-C bonds (1.845 $\AA$ ) and the P-C-P bond angle is measured to be $117.1(6)^{\circ}$. Au-C bonds around this yldiidic carbon (2.117(11) $\AA$ and 2.121(9) $\mathrm{A})$ are in the range of gold methanide complexes. 
Finally, synthesis of a geminal-diaurated complex (129, scheme 128) of ligand $\mathbf{7 3}$ methylenetriphenylphosphorane occurred serendipitously as a by-product of the synthesis of a "protonated tetraauriomethane" ${ }^{254}$ It result from the insertion of a phosphine ligand brought by a gold precursor into a methylidynium (CH+) generated by decomposition of trimethylsilyldiazomethane. Being a byproduct, its structure and bonding scheme was not further discussed.

\section{Geminal dianions of type III (A and B: cationic fragments)}

\subsection{Synthesis of carbodiphosphoranes and other related heteroatom-stabilized bis(ylide)s.}

Hexaphenylcarbodiphosphorane, $\mathrm{Ph}_{3} \mathrm{P}=\mathrm{C}=\mathrm{PPh}_{3}(\mathbf{1 3 0})$, was discovered and isolated by Ramirez and co-workers in the early 60's in a three step procedure from tri-phenylphosphine and dibromomethane. ${ }^{255}$ In their pioneering work, $\mathbf{1 3 0}$ was prepared by reduction of the triphenylphosphonium methylenetriphenylphosphorane bromide salt $[\mathbf{1 3 0}-\mathrm{H}][\mathrm{Br}]$ with potassium metal at the boil-ing temperature of dry diglyme during ca. 20-45 min. Once the $\mathrm{H}_{2}$ evolution has ceased, the hot reaction mixture is filtrated under inert atmosphere (removal of $\mathrm{KCl}$ ) and yellow crystals of $\mathbf{1 3 0}$ are formed from the filtrate during the cooling to room temperature. This simple procedure allows for the isolation of $\mathbf{1 3 0}$ in good yields (60-70\%) on multigram scale. The yellow crystals isolated by Ramirez and colleagues were characterized by elemental analysis, ${ }^{31} \mathrm{P}$ NMR (unique signal at $+3.5 \mathrm{ppm}$ which is consistent with a symmetrical structure having two relatively shielded ylidic phosphorus atoms) and absorption spectra, and initially

argued in favour of the proposed structure for $\mathbf{1 3 0} .^{256}$ In order to prove the nature of the isolated material, preliminary studies on the reactivity of $\mathbf{1 3 0}$ were conducted. The isolated crystals are insensitive to dry oxygen, but highly unstable towards moisture. In fact, $\mathbf{1 3 0}$ completely dissolves in water and be- 
comes protonated to yield the diacidic base $\left[\mathrm{Ph}{ }_{3} \mathrm{P}=\mathrm{CH}-\mathrm{PPh}_{3}\right][\mathrm{OH}]$ as shown by its titration with $\mathrm{HCl}$.

Even more remarkable, upon prolonged expo-sure to wet $\mathrm{N}_{2}$-atmosphere, $\mathbf{1 3 0}$ becomes hydrolysed to yield $131\left[\mathrm{Ph}_{3} \mathrm{P}=\mathrm{CH}-\mathrm{PPh}_{2} \mathrm{O}\right]$ quantitatively and benzene. In addition, the oxidation reaction of freshly prepared 130 with one equiv. of bromine in methylene chloride yields the bromomethylidebis(triphenylphosphonium) bromide salt $[\mathbf{1 3 0}-\mathrm{Br}][\mathrm{Br}]$. As a final confirmation on the structure of 130, its reactivity towards $\mathrm{HBr}$ leads to the high-yielding recovery of precursor $[\mathbf{1 3 0}-\mathrm{H}][\mathrm{Br}]$.

Scheme 132. Synthetic approaches to CDP 130 and first reactivity studies accomplished by Ramirez in his original report, and improved synthesis of 130 reported by the Matthews' group.

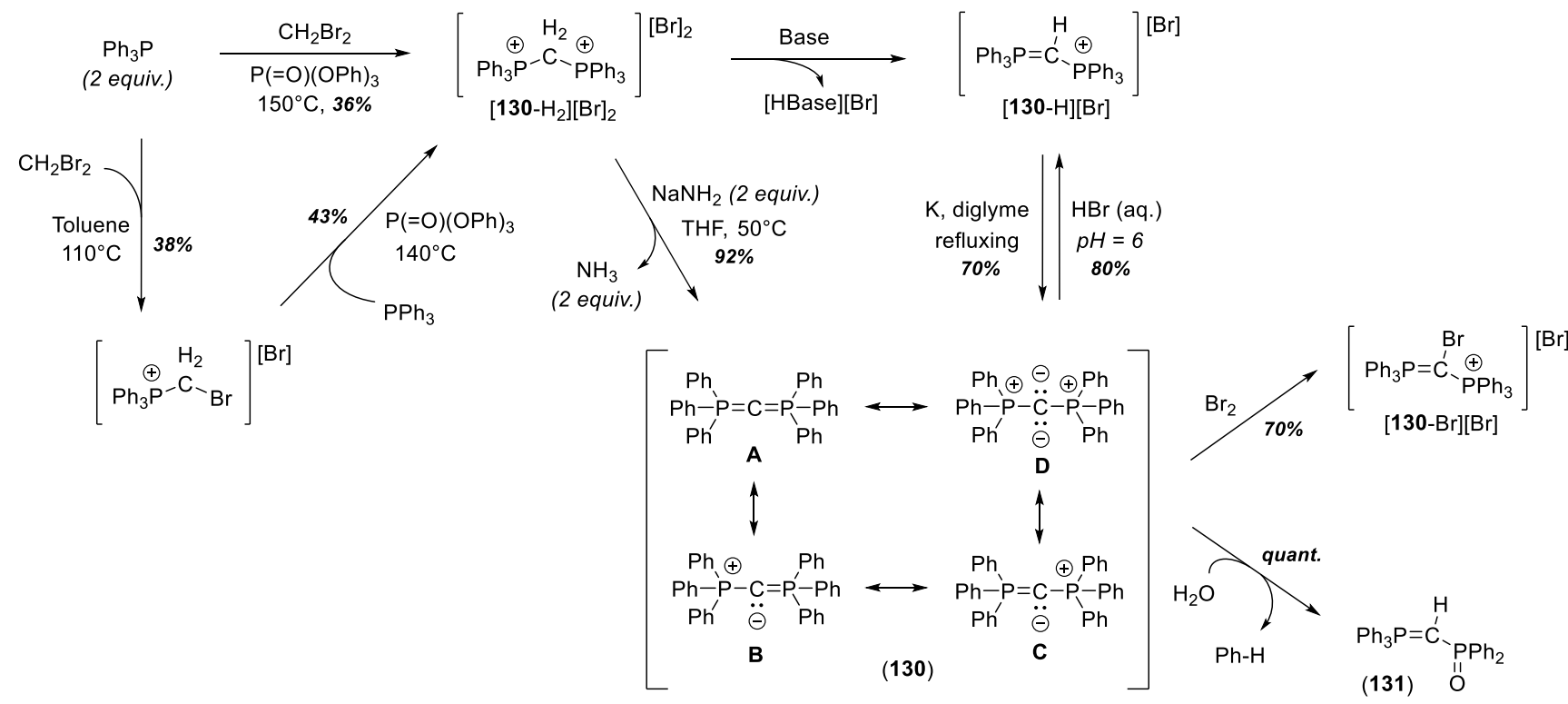

While the reduction of $[\mathbf{1 3 0}-\mathrm{H}][\mathrm{Br}]$ to reach hexaphenylcarbodiphosphorane (130), along with its characterization by both analytical and chemical techniques, was perfectly introduced by Ramirez et al., ${ }^{255}$ the synthesis of the triphenylphosphonium methylenetriphenylphosphorane bromide salt [130$\mathrm{H}][\mathrm{Br}]$ from commercially available triphenylphosphine and dibromomethane was scarcely detailed. Three years later, Matthews revisited the synthesis of $\mathbf{1 3 0} .^{257}$ They reported the monodeprotonation of 
$\left[130-\mathrm{H}_{2}\right][\mathrm{Br}]_{2}$ by $n$-butyl lithium in dry diethyl ether conducting to the isolation of $[\mathbf{1 3 0}-\mathrm{H}][\mathrm{Br}]$ in $65 \%$ yield. Then, the second deprotonation from $[\mathbf{1 3 0}-\mathrm{H}][\mathrm{Br}]$ by a mixture of $\mathrm{NaH}$ in mineral oil/diglyme was carried out. Carbodiphosphorane (CDP) 130 was isolated in moderate $42 \%$ yield. The new proceure allows for the isolation of $\mathbf{1 3 0}$ without the need of strong reducing agents (potassium metal), but the yield has considerably decreased. In a successive report, Matthews and co-workers reported a slightly modified route of access to $\mathbf{1 3 0}$ by using potassium metal allowing to isolate the hexaphenylcarbodiphosphorane in $75 \%$ yield. ${ }^{258}$

Further improvement for the synthesis of $\mathbf{1 3 0}$ was accomplished by Zybill and Müller ${ }^{259}$ a decade later by straightforward double deprotonation of the triphenylphosphonium methylenetriphenylphosphorane bromide salt $[\mathbf{1 3 0}-\mathrm{H}][\mathrm{Br}]$ with $\mathrm{NaNH}_{2}$ in dry THF upon mild heating. This very convenient route of synthesis allowed the isolation of hexaphenylcarbodiphosphorane in excellent $92 \%$ yield. Similar procedure was recently reported by Tykwinski and co-workers, ${ }^{260}$ using higher amounts of $\mathrm{NaNH}_{2}$ to yield crystalline $\mathbf{1 3 0}$ in $90 \%$ from the bis(phosphonium) salt $\left[\mathbf{1 3 0}-\mathrm{H}_{2}\right][\mathrm{Br}]_{2}$. The isolated $\mathbf{1 3 0}$ was fully characterized by IR, exact mass determination and multinuclear NMR including the identification of the central carbon atom in ${ }^{13} \mathrm{C}$ NMR resonating as a triplet at $12.9 \mathrm{ppm}\left({ }^{1} J_{P, C}=125 \mathrm{~Hz}\right)$. In $1983,{ }^{261}$ Bestmann and Oechsner reported the one-pot synthesis of $\mathbf{1 3 0}$ by addition of dibromide salt $\left[\mathbf{1 3 0}-\mathrm{H}_{2}\right][\mathrm{Br}]_{2}$ to a $\mathrm{NaNH}_{2}$ solution in liquid ammonia, that was in situ created from $\mathrm{Fe}\left(\mathrm{NO}_{3}\right)_{3}$ and $\mathrm{Na}$ in liquid ammonia. After removal of $\mathrm{NH}_{3}, \mathbf{1 3 0}$ was extracted in a Soxhlet apparatus with benzene and crystallized in $82 \%$ yield upon cooling at room temperature.

Since the original report by Ramirez et al. the exact nature, along with the most appropriate drawing of 130 among all its plausible Lewis representations, depicted an important discussion forum that still remains active nowadays. Crystal structure determination of $\mathbf{1 3 0}$ has been obtained in three different 174 
crystalline forms. ${ }^{262-265}$ The first structural confirmation of $\mathbf{1 3 0}$ by crystallographic means was accomplished in 1971 by Vincent and Wheatley from a well-concentrated solution of Ramirez's material in diglyme. ${ }^{262,263}$ Under these conditions, two crystallographically independent molecules of $\mathbf{1 3 0}$ are present in the unit cell, each of them possessing a two-fold axis with very distinct $\mathrm{P}-\mathrm{C}-\mathrm{P}$ angles of $143.8^{\circ}$ and $130.1^{\circ}$. A decade after, Zink and co-workers reported a new structure of 130 determined at $-160^{\circ} \mathrm{C}$, giving a $\mathrm{P}-\mathrm{C}-\mathrm{P}$ angle of $131.7(3)^{\circ}$ with $\mathrm{C}-\mathrm{P}-\mathrm{P}-\mathrm{C}$ torsion angles of $25.0-27.5^{\circ}$ vs $5.5-8.3^{\circ}$ in the structure found by Vincent and Wheatley. ${ }^{264}$ These crystallographic data provided a clear picture on the atom connectivity, but the bent nature of $\mathbf{1 3 0}$ suggested the presence of lone pairs at the central $C$-atom, thereby throwing fundamental questions regarding the bonding situation of $\mathbf{1 3 0}$ (vide infra in the Electronic structure of double ylides section). Very recently, Quinlivan and Parkin have demonstrated the flexibility of the P-C-P angle in CDPs and found a linear structure for $\mathbf{1 3 0}\left(\mathrm{C}_{6} \mathrm{H}_{6}\right)_{2}$ obtained from a benzene solution. ${ }^{265}$ Apart from the linearity observed in $\mathbf{1 3 0}\left(\mathrm{C}_{6} \mathrm{H}_{6}\right)_{2}$ that argued in favor of a flexible $\mathrm{P}-\mathrm{C}-\mathrm{P}$ moiety, the new crystal structure exhibits a $\mathrm{C}-\mathrm{P}-\mathrm{P}-\mathrm{C}$ torsion angle of $60.0^{\circ}$. DFT calculations (B3LYP) were carried out by Parkin and co-worker and the NLMO analysis proved the presence of two lone pairs at the central $\mathrm{C}$-atom despite linearity. More interestingly, the modification of the $\mathrm{P}-\mathrm{C}-\mathrm{P}$ angle from $130^{\circ}$ to $180.0^{\circ}$ did not result in a significant difference in energy, thus indicating high flexibility on $\mathbf{1 3 0 .}$

Almost 15 years were required to accomplish the synthesis of the analogous hexamethylcarbodiphosphorane, $\mathrm{Me}_{3} \mathrm{P}=\mathrm{C}=\mathrm{PMe}_{3}$ (135), which was finally achieved by Schmidbaur and co-workers in 1975. ${ }^{266-268}$ As mentioned in their first report, ${ }^{266}$ attempts to obtain $\mathbf{1 3 5}$ by similar procedures to the one employed in the synthesis of $\mathbf{1 3 0}$ were unfruitful. They succeeded to isolate $\mathbf{1 3 5}$ by heating a benzene solution containing $\mathrm{Me}_{3} \mathrm{PF}_{2}$ and the ylide $\mathrm{Me}_{3} \mathrm{P}=\mathrm{CH}-\mathrm{SiMe}_{3}(\mathbf{1 3 3}){ }^{269}$ Deprotonation of 133 with $\mathrm{KH}$ 175 
upon thermal treatment gave the hexamethylcarbodiphosphorane $\mathbf{1 3 5}$ in approximately $60 \%$. An improved yield of $92 \%$ could be obtained by deprotoponation with $n$-butyl lithium $(n \mathrm{BuLi})$ in benzene at $20^{\circ} \mathrm{C} .135$ was characterized by ${ }^{1} \mathrm{H},{ }^{13} \mathrm{C}$ and ${ }^{31} \mathrm{P}$ NMR, MS, IR and EA. Reactivity of $\mathbf{1 3 5}$ vs $\mathrm{HX}$ (with $\mathrm{X}$ being $\mathrm{Cl}$ and $\mathrm{Br})$ and $\left[\mathrm{AuMe}\left(\mathrm{PMe}_{3}\right)\right]$ proved the proposed structure of $\mathbf{1 3 5}$, giving rise to the phosphonium $[135-\mathrm{H}][\mathrm{X}]$ and diphosphonium $\left[135-\mathrm{H}_{2}\right][\mathrm{Cl}]_{2}$ salts depending on the stoichiometry of the reaction, or the gem-diaurated species $\left[\mathbf{1 3 5}-(\mathrm{AuMe})_{2}\right]{ }^{268}$

\section{Scheme 133. Schmidbaur's syntheses of hexamethylcarbodiphosphorane (135) starting from}

$\mathrm{Me}_{3} \mathrm{P}$.

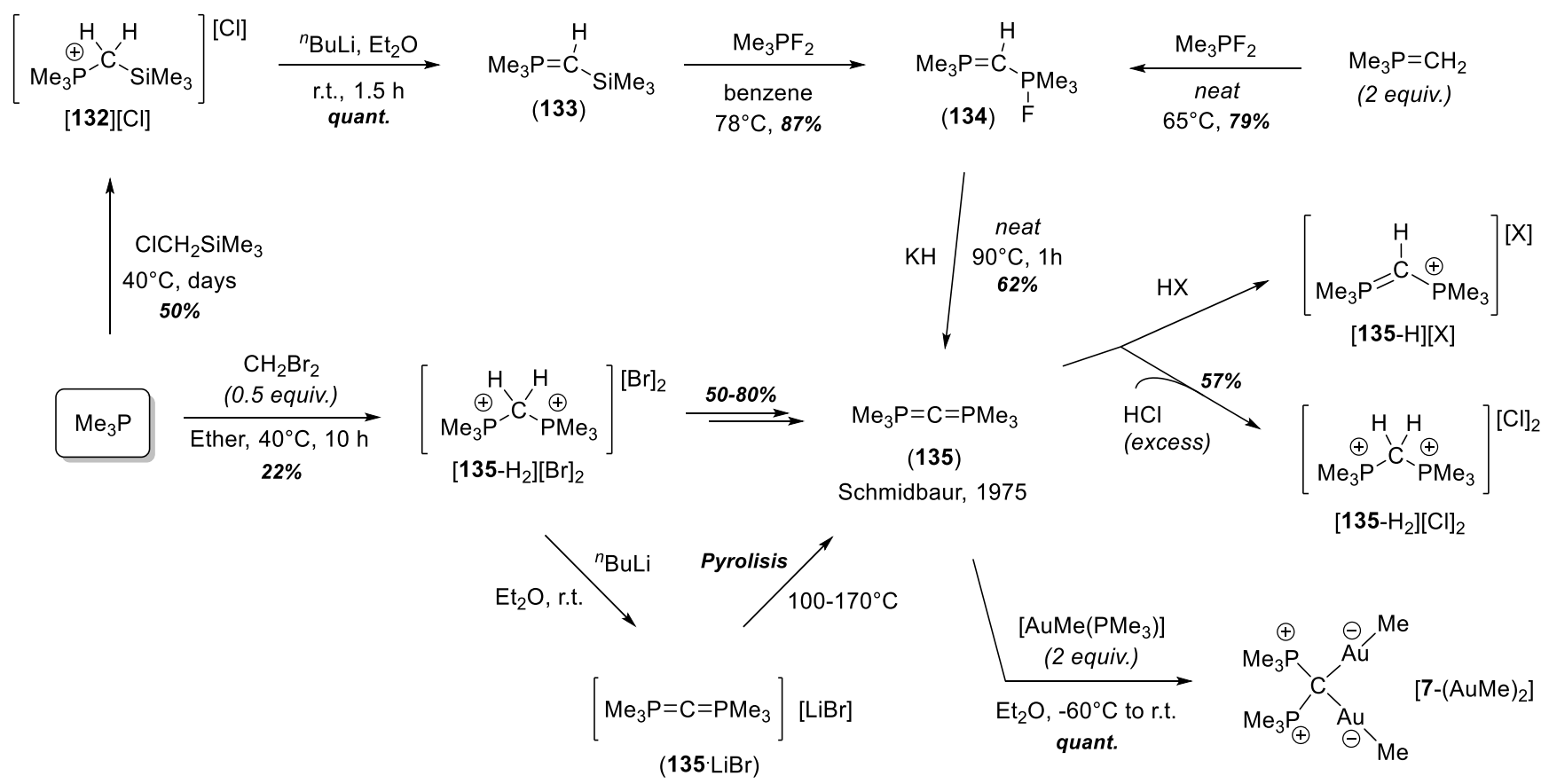

Two years later, ${ }^{267}$ Schmidbaur has finally found a new entry to the CDP 135 starting from $\mathrm{PMe}_{3}$ and $\mathrm{CH}_{2} \mathrm{Br}_{2}$ in a similar fashion to Ramirez's approach (Scheme 133). Deprotonation of methylenebis(trimethylphosphonium) bromide salt $\left[\mathbf{1 3 5}-\mathrm{H}_{2}\right][\mathrm{Br}]_{2}$ with $n$-butyl lithium in diethyl ether, fol176 
lowed by pyrolysis resulted in the isolation of hexamethylcarbodiphosphorane $\mathbf{1 3 5}$ in variable yields ranging from $50 \%$ to $80 \%$. The same group has used identical strategy to reach the synthesis of $\mathrm{Me}_{2} \mathrm{PhP}=\mathrm{C}=\mathrm{PPhMe}_{2}(\mathbf{1 3 6})^{267}$ and the cyclic CDP 137 (Scheme 134). ${ }^{270}$ The synthesis of 136 was carried out by deprotonation of the corresponding dibromide salt of type II with $\mathrm{NaNH}_{2}$ in THF, and was isolated in the form of highly sensitive yellowish crystals that decompose at $0^{\circ} \mathrm{C}$ in solid form (yield not reported). In the case of the cyclic CDP 137, the 1,2-bis(diphenylphosphino)phenyl 145b is reacted with $\mathrm{CH}_{2} \mathrm{Br}_{2}$ upon heating at $100^{\circ} \mathrm{C}$ for 10 days in toluene to yield the cyclic dibromide salt $\left[137-\mathrm{H}_{2}\right][\mathrm{Br}]_{2}$ in 65\% (Scheme 135).

Scheme 134. Synthetic scheme to yield the symmetrical CDPs 136-138 and unsymmetrical CDPs 139-144 via formation of intermediate I through selective monophosphination of dihalomethane.

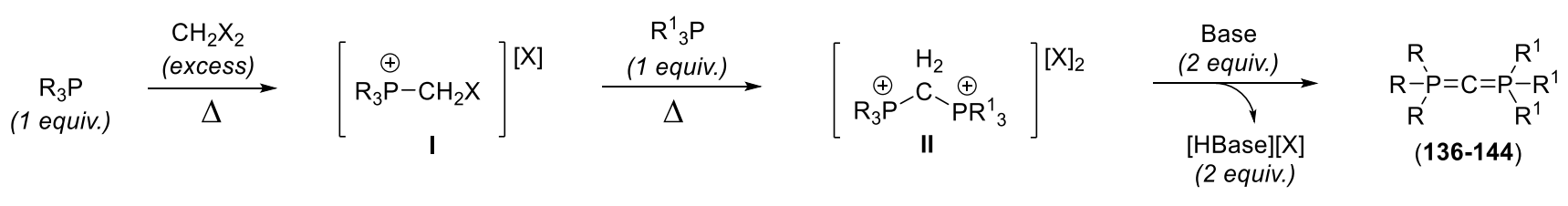

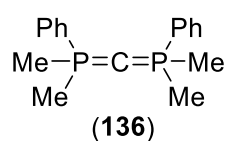

Schmidbaur, 1977

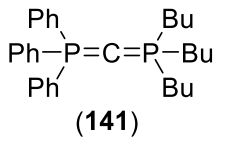

Appel, 1978

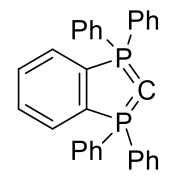

(137)

Schmidbaur, 1983

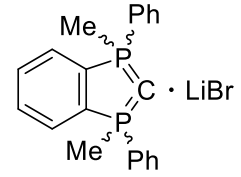

(138. $\mathrm{LiBr}$ ) Schmidbaur, 1983

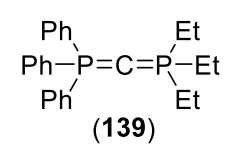

Appel, 1978

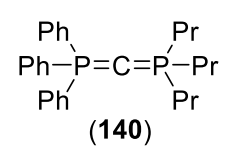

Appel, 1978

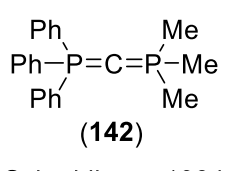

Schmidbaur, 1984

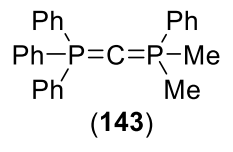

Schmidbaur, 1984

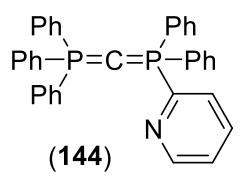

Alcarazo and Fürstner, 2013

A two-step procedure was envisaged by first deprotonation of $\left[137-\mathrm{H}_{2}\right][\mathrm{Br}]_{2}$ in liquid ammonia to yield the semi-ylide phosphonium salt $[137-\mathrm{H}][\mathrm{Br}]$ in $83 \%$, and subsequent transylidation reaction with $\mathrm{Et}_{3} \mathrm{P}=\mathrm{CH}_{2}$ (see below in Scheme 135). The structure of 137 was definitively confirmed by its NMR, the 
FD-MS, and elemental analysis (EA). Reactivity of the isolated material vs HBr leads to the phosphonium salt $[137-\mathrm{H}][\mathrm{Br}]$ or the recovery of the cyclic dibromide salt $\left[137-\mathrm{H}_{2}\right][\mathrm{Br}]_{2}$ depending on the amounts of $\mathrm{HBr}$.

Interestingly, the analogous CDP 138 bearing MePhP-groups was not accessible by transylidation reaction of the corresponding dibromide salt $\left[\mathbf{1 3 8}-\mathrm{H}_{2}\right][\mathrm{Br}]_{2}$ with $\mathrm{Et}_{3} \mathrm{P}=\mathrm{CH}_{2}$. Instead the bis(ylide) 146 is formed by deprotonation of a methyl substituent. Treatment of $\left[\mathbf{1 3 8}-\mathrm{H}_{2}\right][\mathrm{Br}]_{2}$ with ammonia (gas) in dichloromethane at $0^{\circ} \mathrm{C}$ allowed for the instantaneous formation of the semi-ylide phosphonium salt $[\mathbf{1 3 8}-\mathrm{H}][\mathrm{Br}]$, which was isolated as a colourless powder in quantitative yield. The adduct $138 \mathrm{LiBr}$ could be achieved by deprotonation of the cyclic bromide salt $[138-\mathrm{H}][\mathrm{Br}]$ with $n$-butyl lithium in THF at $78^{\circ} \mathrm{C}$. After stirring at this temperature for a day, filtration and evaporation of the solution, $138 \mathrm{LiBr}$ was isolated as a bright yellow solid. ${ }^{270}$ Interestingly, in the absence of LiBr salts, prototropy equilibrium between 138 and 146 takes place preventing isolation of 138. As in the case of 137, the adduct $138 \mathrm{LiBr}$ reacts with anhydrous $\mathrm{HCl}$ to reform the starting cyclic diphosphonium salt. Alternatively, $138 \mathrm{LiBr}$ reacts with MeI to yield the $[\mathbf{1 3 8}-\mathrm{Me}][\mathrm{I}]$ salt that further evolve into dication $[(\mathbf{1 3 8}-\mathrm{H})-\mathrm{Me}]^{2+}$ by protonolysis with $\mathrm{HCl}$. The double protonations performed in cyclic CDPs 137 and $138 \mathrm{LiBr}$, along with the synthesis of $[(\mathbf{1 3 8}-\mathrm{H})-\mathrm{Me}][\mathrm{X}]_{2}$ unequivocally proved the presence of the two lone pairs at the central $C$ atom.

Scheme 135. Syntheses of cyclic CDPs 137 and $138 \cdot \mathbf{L i B r}$. 


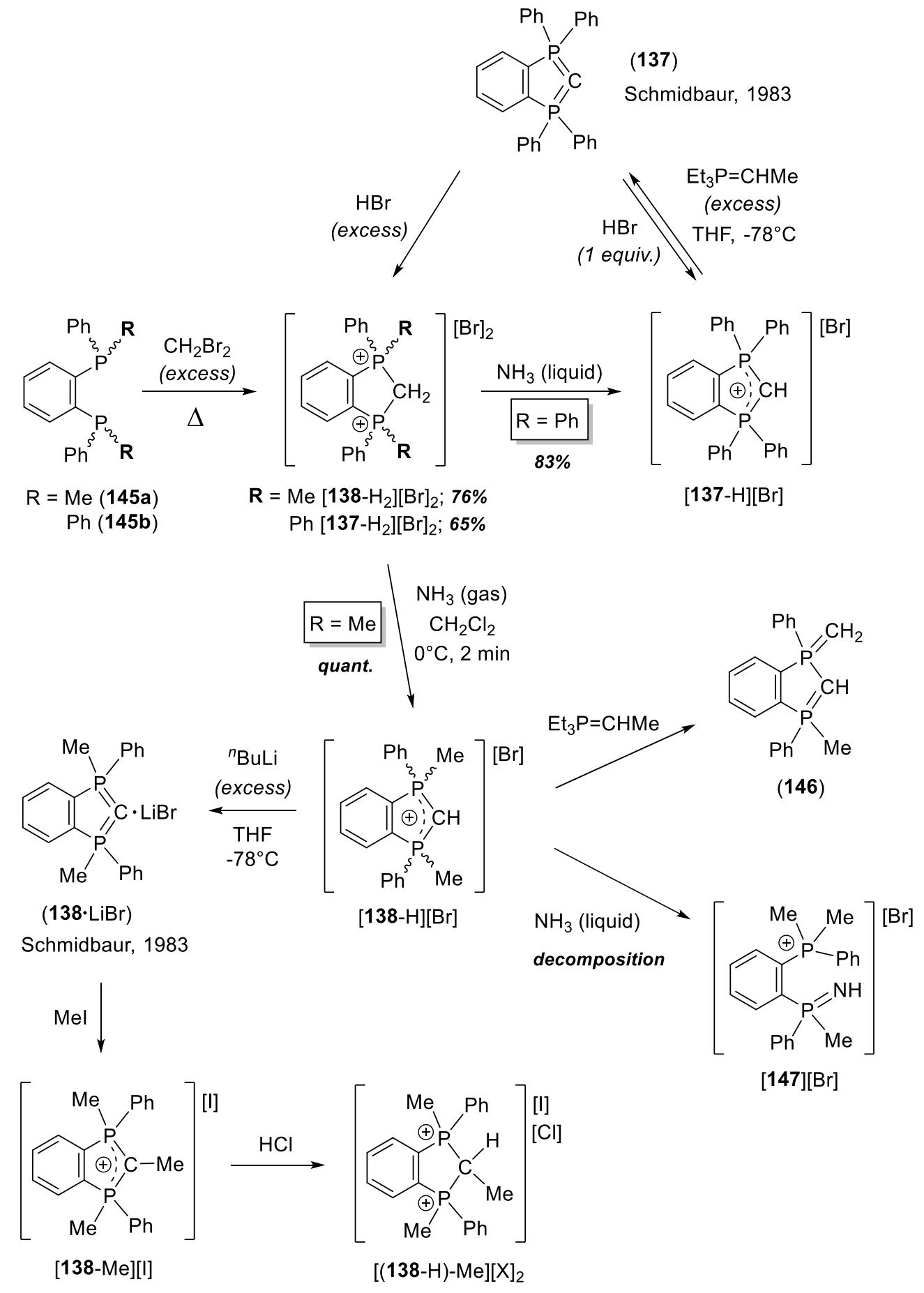

This methodology was further extended to the synthesis of unsymmetrical $\mathrm{CDPs} \mathrm{Ph}_{3} \mathrm{P}=\mathrm{C}=\mathrm{P}\left(\mathrm{CH}_{2} \mathrm{R}\right)_{3}$ $($ 139-141; $\mathrm{R}=\mathrm{Me}, n \mathrm{Et}, n \mathrm{Pr})\left(\right.$ Scheme 136)$,{ }^{271} \mathrm{Ph}_{3} \mathrm{P}=\mathrm{C}=\mathrm{PR}_{3}{ }_{3}\left(\mathbf{1 4 2 - 1 4 3} ; \mathrm{PR}_{3}=\mathrm{PMe}_{3}, \mathrm{PPhMe}_{2}\right),{ }^{272}$ and 
$\mathrm{Ph}_{3} \mathrm{P}=\mathrm{C}=\mathrm{PPh}_{2}(2-\mathrm{Py})(\mathbf{1 4 4})^{273}$ by the groups of Appel, Schmidbaur and Alcarazo, respectively. Carefully chosen reaction conditions allowed for the selective synthesis of the monophosphonium halide salts of type $\mathbf{I}$ by reacting simple phosphines and $\mathrm{CH}_{2} \mathrm{CX}_{2}$. Thus, the monophosphonium halide salts $\mathbf{I}$ can react with a distinct phosphine to afford an unsymmetrical diphosphonium dihalide salt of type II, that represents a suitable entry to the non-symmetric CDPs 139-144. Carbodiphosphoranes 139-141 proved unstable upon warming at $120^{\circ} \mathrm{C}$ driving to the formation of monoylides 139', 140' and 141'. A mechanism for this unexpected rearrangement involving an initial deprotonation of the $\mathrm{CH}_{2}$-unit by the $C$ atom and following phenyl ring migration from the $\mathrm{PPh}_{3}$ motif to the anionic $\mathrm{CHR}$ group was proposed by the authors (the involved H-atom and Ph-ring are highlighted in bold in Scheme 136).

Scheme 136. Access to CDPs 139-141.

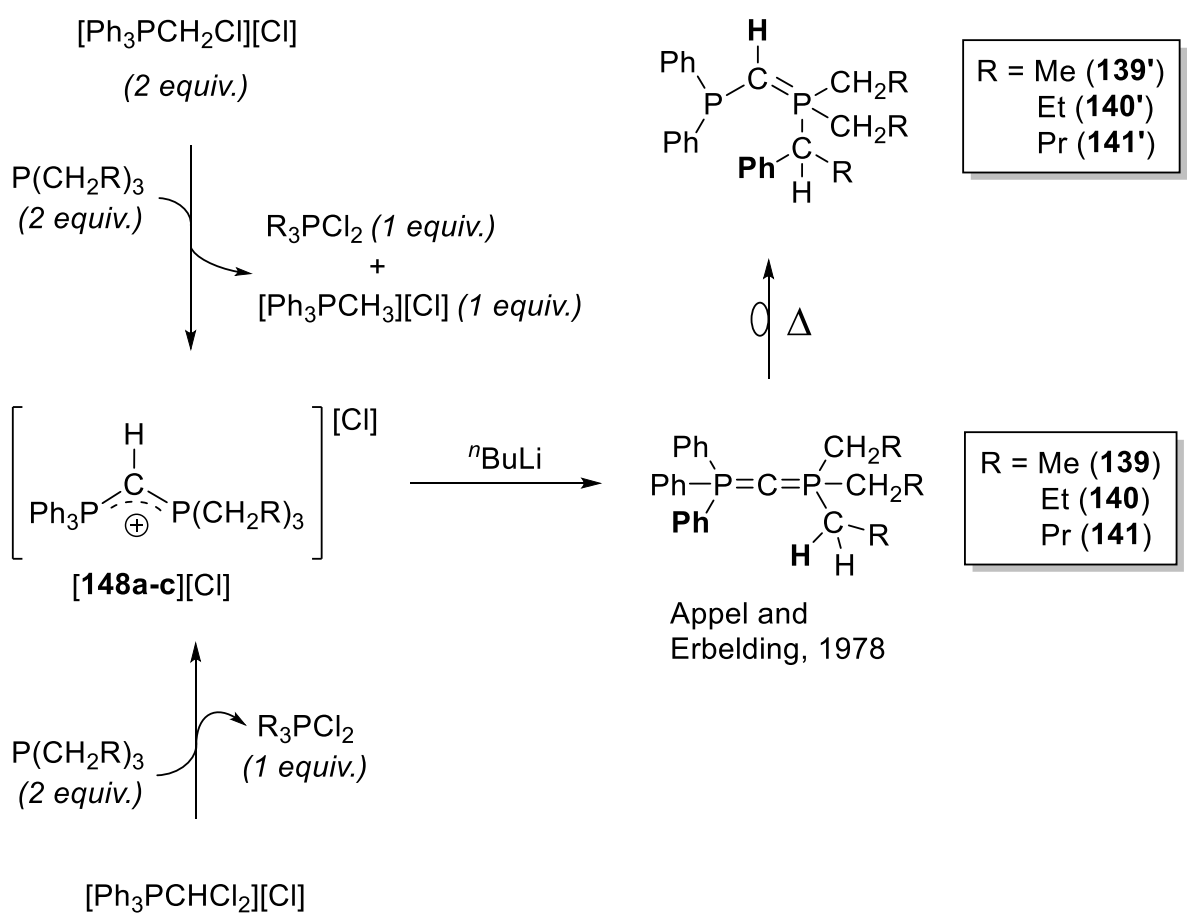


As illustrated in Scheme 137, the bromomethyl triphenylphosphonium bromide resulted a versatile en-

try to the non-symmetrical CDPs $\mathbf{1 4 2 - 1 4 4}$. In 1984, Schmidbaur et al. $^{272}$ reported the synthesis of the diphosphonium salts $\left[\mathbf{1 4 2}-\mathrm{H}_{2}\right]\left[\mathrm{PF}_{6}\right]_{2}$ and $\left[\mathbf{1 4 3}-\mathrm{H}_{2}\right]\left[\mathrm{PF}_{6}\right]_{2}$ in moderate yields by reacting the $\left[\mathrm{PPh}_{3} \mathrm{CH}_{2} \mathrm{Br}\right][\mathrm{Br}]$ salt with one equiv. of $\mathrm{PMe}_{3}$ or $\mathrm{PPhMe}_{2}$ in $\mathrm{THF}$ followed by Br-to-PF $\mathrm{PF}_{6}$ anion exchange. Deprotonation of salt $\left[\mathbf{1 4 2}-\mathrm{H}_{2}\right]\left[\mathrm{PF}_{6}\right]_{2}$ was attained with excess of $\mathrm{NaNH}_{2}$ in liquid ammonia and 142 was isolated in high yield. Heated in refluxing THF in presence of an excess of $\mathrm{NaNH}_{2}$, the bis(phosphonium) salt $\left[\mathbf{1 4 3}-\mathrm{H}_{2}\right]\left[\mathrm{PF}_{6}\right]_{2}$ yields the air-sensitive CDP 143 in $67 \%$.

Scheme 137. Schematic syntheses of non-symmetrical carbodiphosphoranes 142-144 starting from the phosphonium salt $\left[\mathrm{Ph}_{3} \mathrm{PCH} \mathrm{H}_{2} \mathrm{Br}\right][\mathrm{Br}]$.

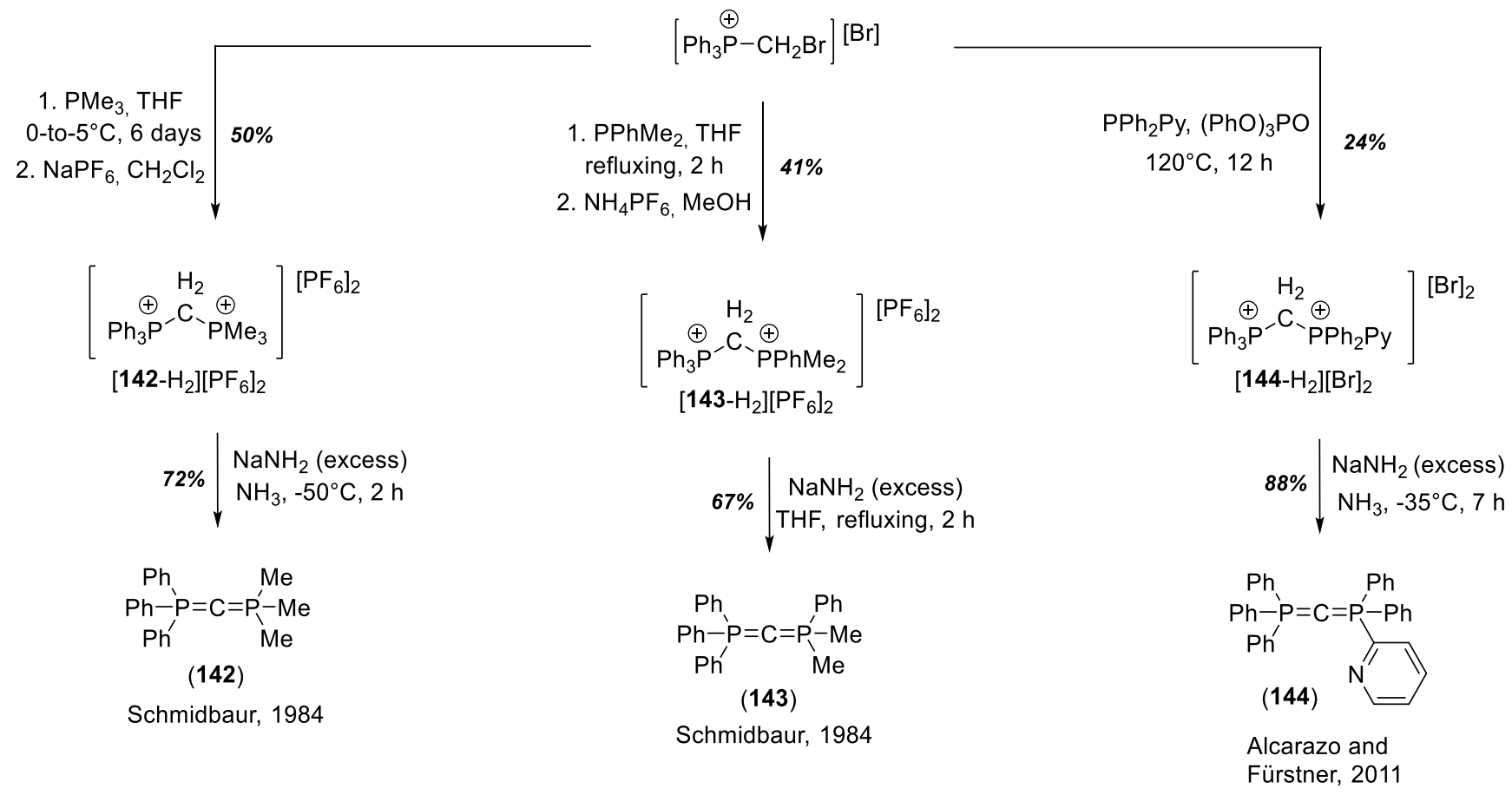

Nearly 30 years later, and aiming to illustrate the ability of CDPs in stabilizing homo- and heterobimetallic species (see Coordination chemistry of double ylides section for further details), the CDP 144 bearing a pyridyl-substituted phosphorus group was designed and prepared by Alcarazo and Fürstner 181 
(Scheme 137). ${ }^{273}$ In strong agreement with a highly electron-rich carbon atom, the carbodiphosphorane nature of 144 was evidenced by its very diagnostic signal displayed in ${ }^{13} \mathrm{C}$ NMR for the central carbon that resonates at high-field $\left(\delta=11.8 \mathrm{ppm},{ }^{1} J_{P, C}=122,119 \mathrm{~Hz}\right)$. In addition to the NMR data, the atom connectivity of 144 was definitively proved by X-ray diffraction analysis of single crystals, and the bent geometry in 144 was confirmed according to its measured $\mathrm{P}-\mathrm{C}-\mathrm{P}$ angle of $133.25(10)^{\circ}$, considerably deviated from linearity.

While working in the discovery of non-CDPs bearing $\mathrm{PPh}_{n} \mathrm{R}_{(3-\mathrm{n})}$ groups (with $\mathrm{R}=\mathrm{Me}$ and $\mathrm{n}=1-3$ ), Schmidbaur and co-workers found the synthesis of $\mathrm{CDP} \mathrm{Ph}_{3} \mathrm{P}=\mathrm{C}=\mathrm{PPhMe}_{2}$ (150) starting from 1,2bis(diphenylphosphino)benzene (Scheme 138). ${ }^{272}$ The quaternization of 1,2bis(diphenylphosphino)benzene with methyl trifluoromethylsulfonate and subsequent transylidation reaction with $\mathrm{Et}_{3} \mathrm{P}=\mathrm{CHMe}$ in $\mathrm{THF}$ at low temperature allowed for the isolation of $\mathbf{1 5 0}$ in modest global yield (22\%). The synthetic pathway to achieve 150 involves the in situ formation of the bis(ylide) III, which rapidly evolves via an unexpected rearrangement. Alternatively, $\mathbf{1 5 0}$ can be prepared by quaternization of the diphenylphosphino-substituted ylide 151 with $\mathrm{MeI}$ in THF, and deprotonation by $\mathrm{NaNH}_{2}$ in liquid ammonia of the resulting phosphonium salt $[\mathbf{1 5 0}-\mathrm{H}][\mathrm{I}]$. Despite its apparent simplicity, this second synthetic approach drove to the isolation of $\mathbf{1 5 0}$ in lower global yield (15\%).

Scheme 138. Alternative route of access to the dissymmetrical $\mathrm{CDP} \mathrm{MePh}_{2} \mathrm{P}=\mathrm{C}=\mathrm{PPh}_{3}(150)$. 


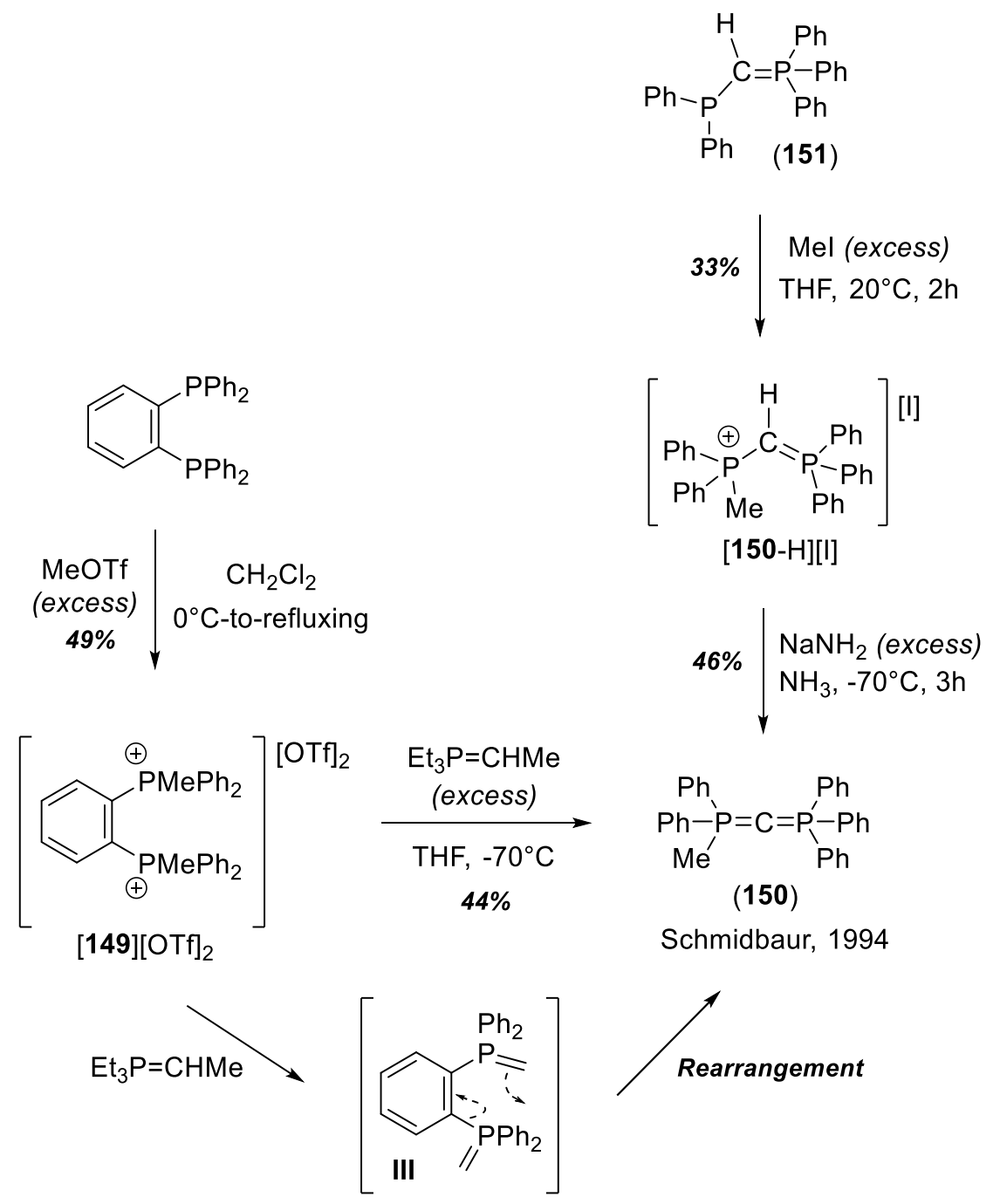

Quantitative formation of $\mathbf{1 5 0}$ was described more recently by Canac, Chauvin and co-workers starting from the bisphosphonium salt $[\mathbf{1 4 9}][\mathrm{OTf}]_{2}$ and $n \mathrm{BuLi}$ (Scheme 139). ${ }^{274}$ As clearly demonstrated in their report, the formation of CDP 150 takes place by rearrangement of the ylide $\mathbf{1 5 3}$. The heterocycle 153 was formed and fully characterized by multinuclear NMR as a mixture of two diastereomers after two consecutive deprotonation steps with $n$ Buli at $-78^{\circ} \mathrm{C}$. Heated at $-10^{\circ} \mathrm{C}$ in a young NMR tube, 153 underwent a quantitative rearrangement to furnish $\mathbf{1 5 0 .}$

Scheme 139. Direct synthesis of CDP 150 from the bis(phosphonium) salt [149][OTf $]_{2}$. 183 

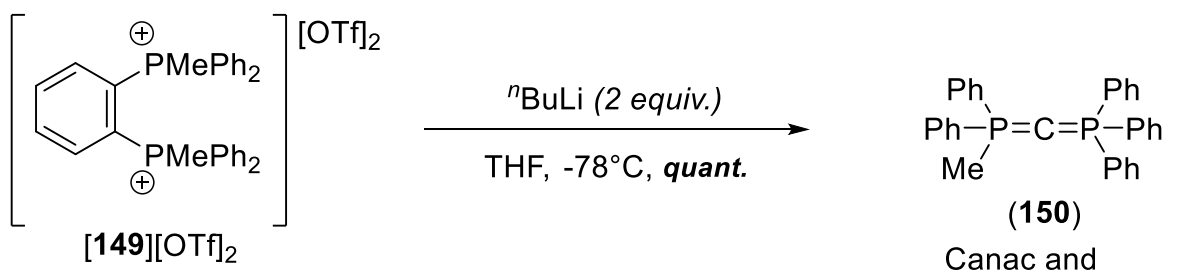

${ }^{n}$ BuLi $\downarrow$ quant.

Chauvin, 2008

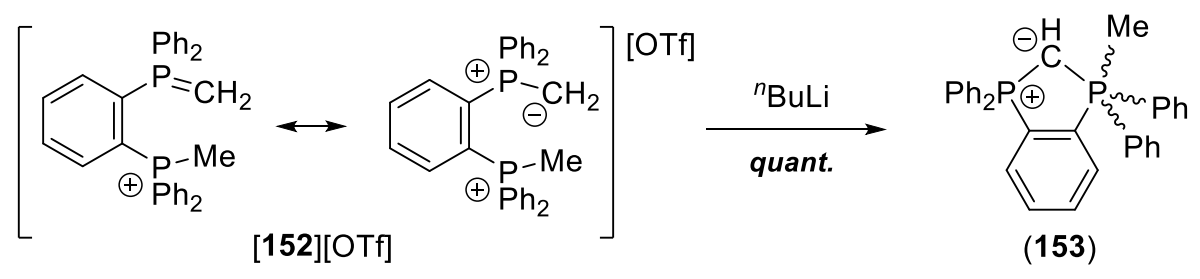

The use of diphosphinomethanes as synthetic intermediates/precursors represents a general and very convenient strategy to build symmetrical CDPs. This approach was deeply employed by Schmidbaur and co-workers 275276277278279280281282283284 due to the high availability of diphosphinomethanes from commercial sources or easily accessible from secondary phosphines and $\mathrm{CH}_{2} \mathrm{X}_{2}$ (with $\mathrm{X}$ being $\mathrm{Cl}, \mathrm{Br}, \mathrm{I}$ ) in the presence of a base (Scheme 140). The double alkylation of the diphosphinomethanes with $\mathrm{R}^{1}-\mathrm{X}$ leads to the formation of the corresponding diphosphonium salts of type IV, thus providing an ideal entry to the desired CDPs 154-162 upon basic treatment.

Scheme 140. Diphosphinomethanes as synthetic intermediates of symmetrical CDPs 154-162. 


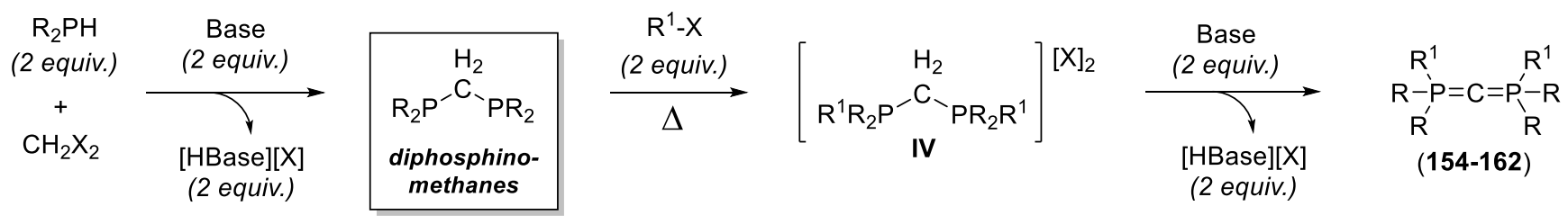

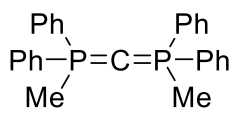

(154)

Schmidbaur, 1976

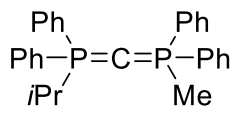

(155)

Schmidbaur, 1977

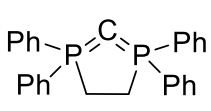

(156)

Schmidbaur and Schubert, 1980

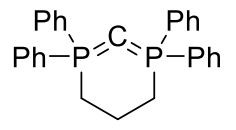

(157)

Schmidbaur and Schubert, 1980

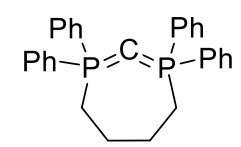

(158)

Schmidbaur and Schubert, 1980

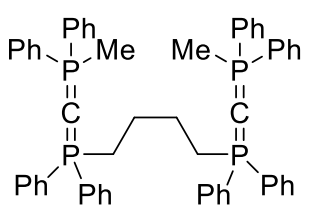

(159)

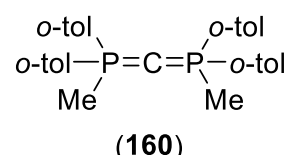

Schmidbaur, 1983

Schmidbaur, 1982

In the course of their studies on the isomerism carbodiphosphorane/bis(phosphoranes), Wohlleben and Schmidbaur reported the synthesis of the CDP 155 through an unexpected rearrangement of diphosphonium salt $\left[\mathbf{1 5 4}-\mathrm{Me}_{2}\right][\mathrm{I}]_{2}$ in presence of a base. ${ }^{278,279}$ Deprotonation of $\left[\mathbf{1 5 4}-\mathrm{Me}_{2}\right][\mathrm{I}]_{2}$ with $\mathrm{NaNH}_{2}$ in $\mathrm{THF}$ did not result in the formation of the desired double ylide, and crystals of $\mathbf{1 5 5}(65 \%$ yield) were isolated instead. The identity of $\mathbf{1 5 5}$ was evidenced by multinuclear NMR characterization, including the identification of the double ylide function in ${ }^{13} \mathrm{C}$ NMR resonating at high field $\left(\delta=1.04 \mathrm{ppm}\right.$; dd, ${ }^{1} J_{P, C}=122$ and $128 \mathrm{~Hz}$ ). The authors suggested a mechanistic pathway involving deprotonation of one PMe group to give an ylidic carbanion that may initiate the rearrangement via nucleophilic substitution on the second phosphorus atom. Thus, the $\mathrm{P}-\mathrm{CMe}_{2}-\mathrm{P}$ bridge would be opened by the high steric demand, and the isopropylidene moiety is liberated with concomitant creation of a $\mathrm{P}-\mathrm{CH}_{2}-\mathrm{P}$ bridge (Scheme 141).

Scheme 141. Synthesis of $\mathrm{MePh}_{2} \mathrm{P}=\mathrm{C}=\mathrm{PPh}_{2} \mathrm{Me}(154)$ and unexpected rearrangement to reach the $\mathrm{CDP} \mathrm{MePh}_{2} \mathrm{P}=\mathrm{C}=\mathrm{PPh}_{2}{ }^{i} \operatorname{Pr}(\mathbf{1 5 5})$. 

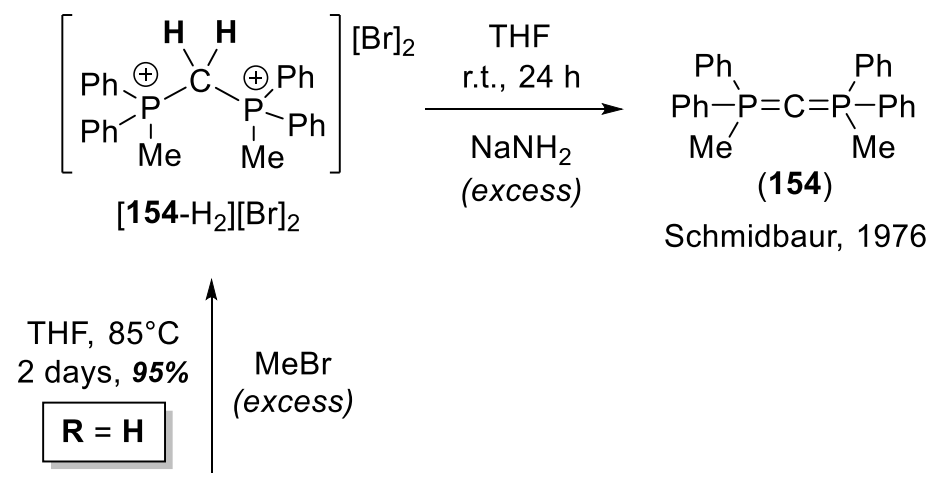

$\mathrm{Ph}_{2} \mathrm{P}-\mathrm{CR}_{\mathbf{2}}-\mathrm{PPh}_{2}$

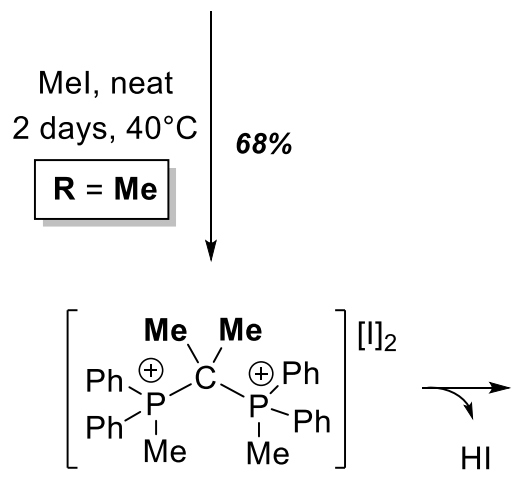

$\left[154-\mathrm{Me}_{2}\right]\left[\mathrm{I}_{2}\right.$
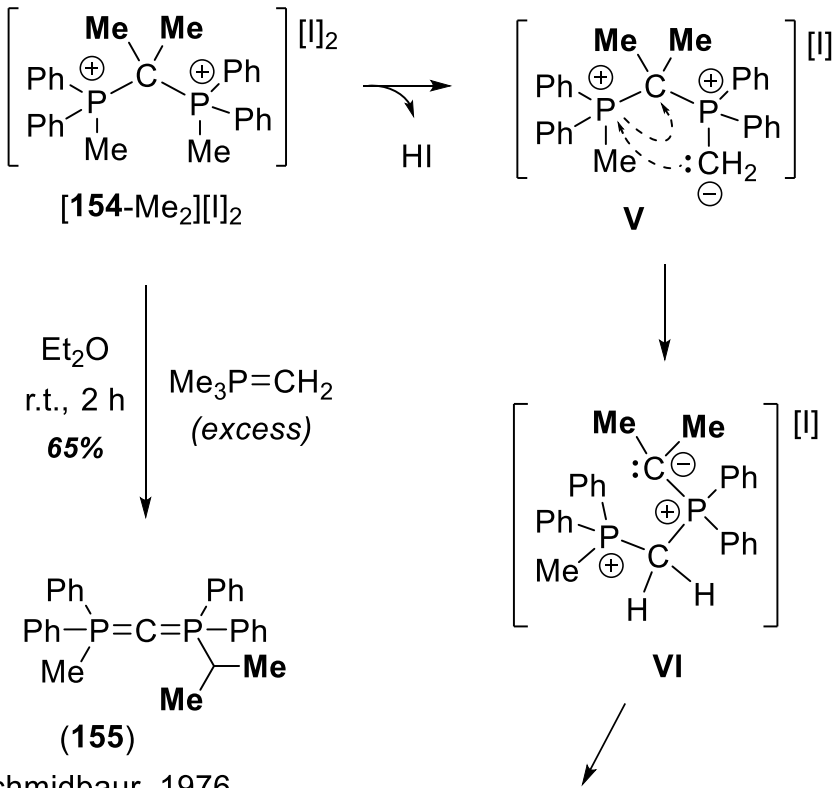

Schmidbaur, 1976

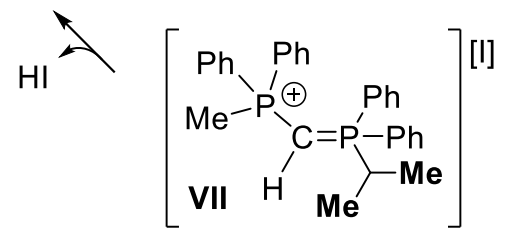

186 
In light of the small $\mathrm{P}-\mathrm{C}-\mathrm{P}$ angle found for the structure of $\mathrm{MePh}_{2} \mathrm{P}=\mathrm{C}=\mathrm{PPh}_{2} \mathrm{Me}, \mathrm{Schmidbaur}$ and Schubert wondered if cyclic CDPs 156-158, expected to have $\mathrm{P}-\mathrm{C}-\mathrm{P}$ angles near to $120^{\circ}$, would be accessible. ${ }^{277,280}$ Using the strategy outlined in Scheme 142, they isolated these compounds and proved their decreasing thermal stability upon diminishing the $\mathrm{P}-\mathrm{C}-\mathrm{P}$ angle. Remarkably, $\mathbf{1 5 7}$ has shown to be thermally unstable and starts to decompose at $35^{\circ} \mathrm{C}$. The proposed structure of CDP 157 was verified by $\mathrm{XRD}$ analysis of single crystals and proved the presence of an exceptionally small $\mathrm{P}-\mathrm{C}-\mathrm{P}$ angle of $121.8(3)^{\circ}$ pointing to the availability of lone pairs at the central. ${ }^{277} 281$

Scheme 142. Synthesis of the 6-membered, cyclic carbodiphosphorane 157 carried out by Schmidbaur and Schubert.

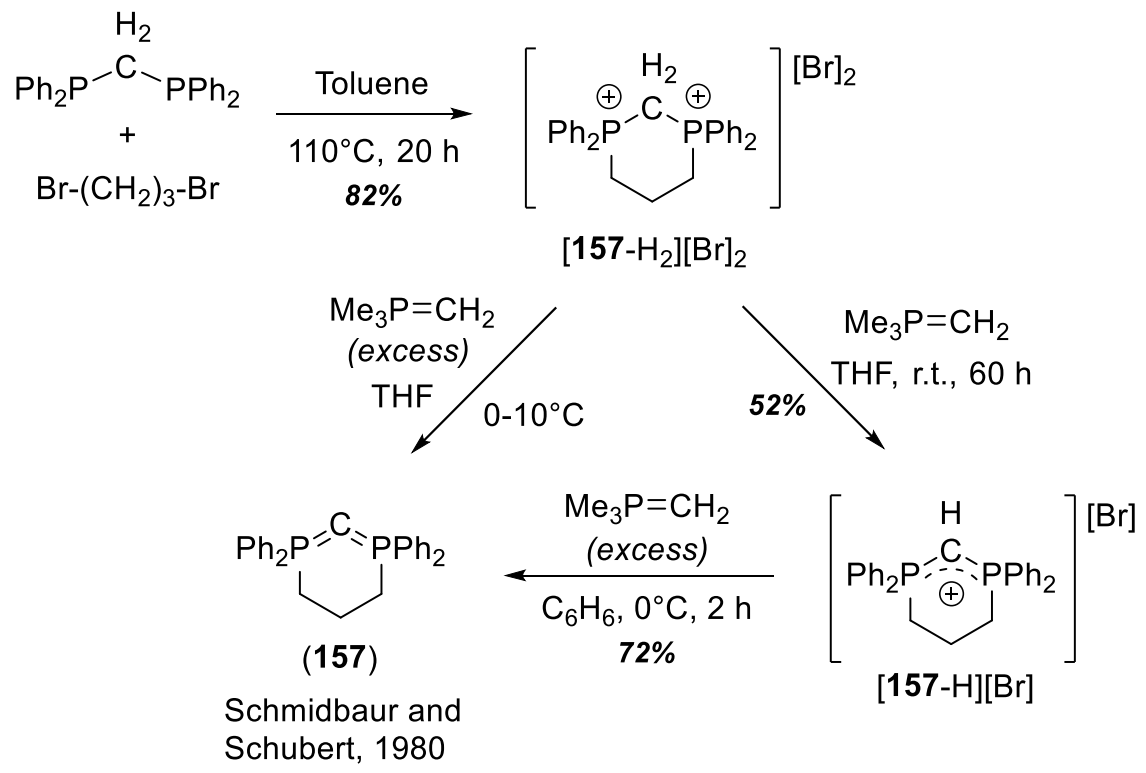

As commented before, the stability of the CDP increases with the size of the cycle. This fact was clearly shown by the observed high stability of $\mathbf{1 5 8}$, which was afforded in $30 \%$ global yield. The longer alkyl chain in 158 vs 157 provided good solubility in organic solvents and $\mathbf{1 5 8}$ was fully characterized by multinuclear NMR, IR, mass spectrum and elemental analysis. The identification of the very distinctive 187 
central carbon atom resonating at high field $\left(\delta=-3.4 \mathrm{ppm} ; \mathrm{t},{ }^{1} J_{P, C}=75.7 \mathrm{~Hz}\right)$ in ${ }^{13} \mathrm{C}$ NMR definitively confirmed the carbodiphosphorane core in $\mathbf{1 5 8}$. On the other hand, $\mathbf{1 5 6}$ was found to be remarkably less stable and rapidly decomposes at room temperature. While working in the synthesis of cyclic CDPs, the same group found the synthesis of the double CDP $159 .{ }^{282}$ Indeed, the main product obtained from the reaction between bis(diphenylphosphino)-methane and 1,4-dibromobutane is the dibromide salt $[158][\mathrm{Br}]_{2}(53 \%$ yield) (Scheme 143). Bis(ylide) 159 has been prepared in a very good yield $(84 \%)$ from a mixture of salts $\left[\mathbf{1 5 8}-\mathrm{H}_{2}\right][\mathrm{Br}]_{2}$ and $[\mathbf{1 6 3}][\mathrm{Br}]_{2}$ (ratio 1:3) by transylidation reaction with $\mathrm{Me}_{3} \mathrm{P}=\mathrm{CH}_{2}$. Finally, the double $\mathrm{CDP} 159$ was then obtained via a classical double alkylation/deprotonation accomplished by fast deprotonation with stoichiometric amounts of ylide $\mathrm{Me}_{3} \mathrm{P}=\mathrm{CH}_{2}$ in benzene at $0^{\circ} \mathrm{C}$. The filtration of the reaction mixture, addition of pentane and cooling to $6^{\circ} \mathrm{C}$ allowed for the growing of yellow crystals of $159 \cdot\left(\mathrm{C}_{6} \mathrm{H}_{6}\right)_{2}(69 \%$ yield $) .159$ was fully characterized by elemental analysis, mass spectrum, and multinuclear NMR experiments (signal attributable to the bis(ylidic) carbon not identified).

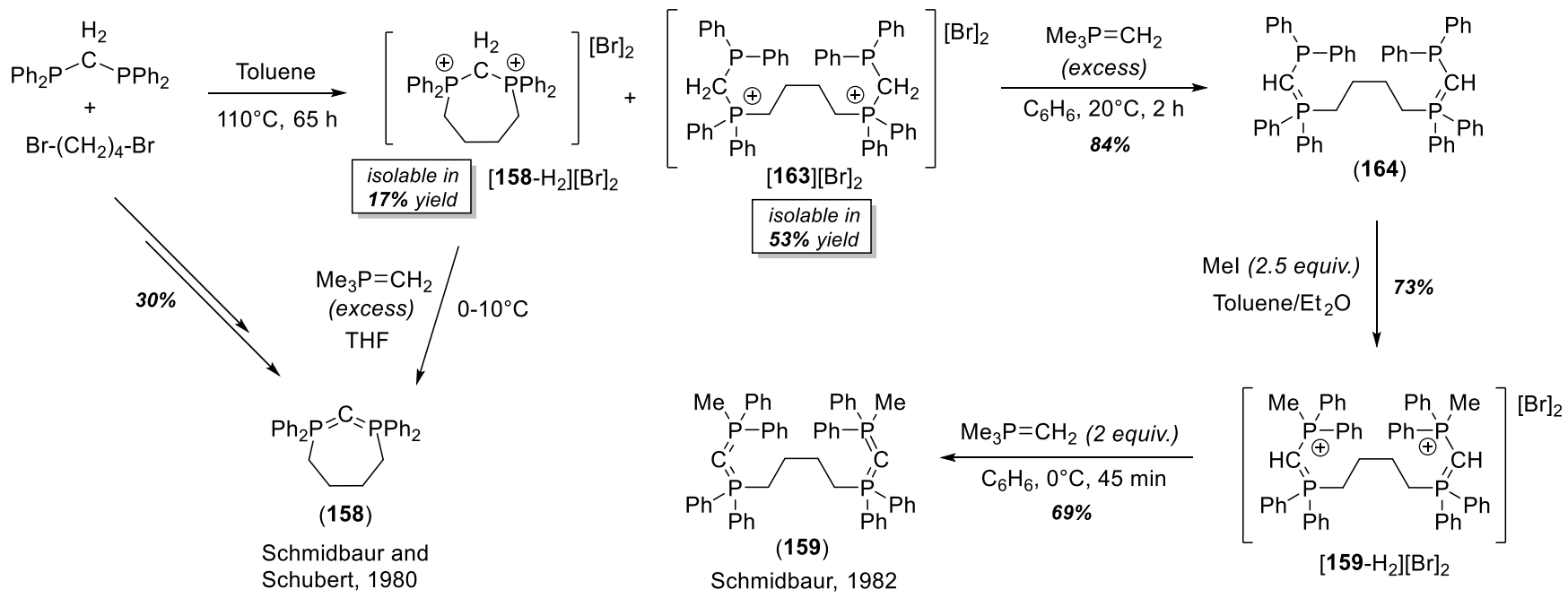

Scheme 143. Divergent access to the cyclic CDP 158 and the bis(CDP) 159 from bis(diphenylphosphino)-methane and 1,4-dibromobutane. 
Schmidbaur and co-worker extended this methodology to diphosphino-methanes bearing 2methylphenyl (ortho-tolyl group) and 2,4,6-timethylphenyl (mesityl group) substituents (represented as Mes and $o$-tol in Scheme 144, respectively). ${ }^{283}$ The quaternization of the diphosphino-methanes in MeI requires several days at room temperature to yield the corresponding diphenylphosphonium salt in almost quantitative yield in the case of $(o \text {-tol })_{2} \mathrm{P}-\mathrm{CH}_{2}-\mathrm{P}(o \text {-tol })_{2}$, whereas the reaction yield considerably decreases for $(\mathrm{Mes})_{2} \mathrm{P}-\mathrm{CH}_{2}-\mathrm{P}(\mathrm{Mes})_{2}$.

The dibromide salts $\left[\mathbf{1 6 0}-\mathrm{H}_{2}\right][\mathrm{Br}]_{2}$ and $[\mathbf{1 6 5}][\mathrm{Br}]_{2}$ were subjected to deprotonation with sodium amide (excess) in tetrahydrofuran with significantly different results. While $\left[\mathbf{1 6 0}-\mathrm{H}_{2}\right][\mathrm{Br}]_{2}$ gave the expected symmetrical CDP 160 in moderate yield, the deprotonation of salt $[\mathbf{1 6 5}][\mathrm{Br}]_{2}$ did not resulted in the formation of the analogous CDP 166. Instead, the cyclic CDP 161 was isolated as a mixture of two diastereoisomers in 54\% via formation of the proposed 2-methylenecyclohexadienylidenephosphorane intermediate VIII, that undergoes a rearrangement into $\mathbf{1 6 1}$ with concomitant elimination of mesitylene.

\section{Scheme 144. Synthesis of the symmetrical CDP 160 and the unexpected cyclic CDP 161.}




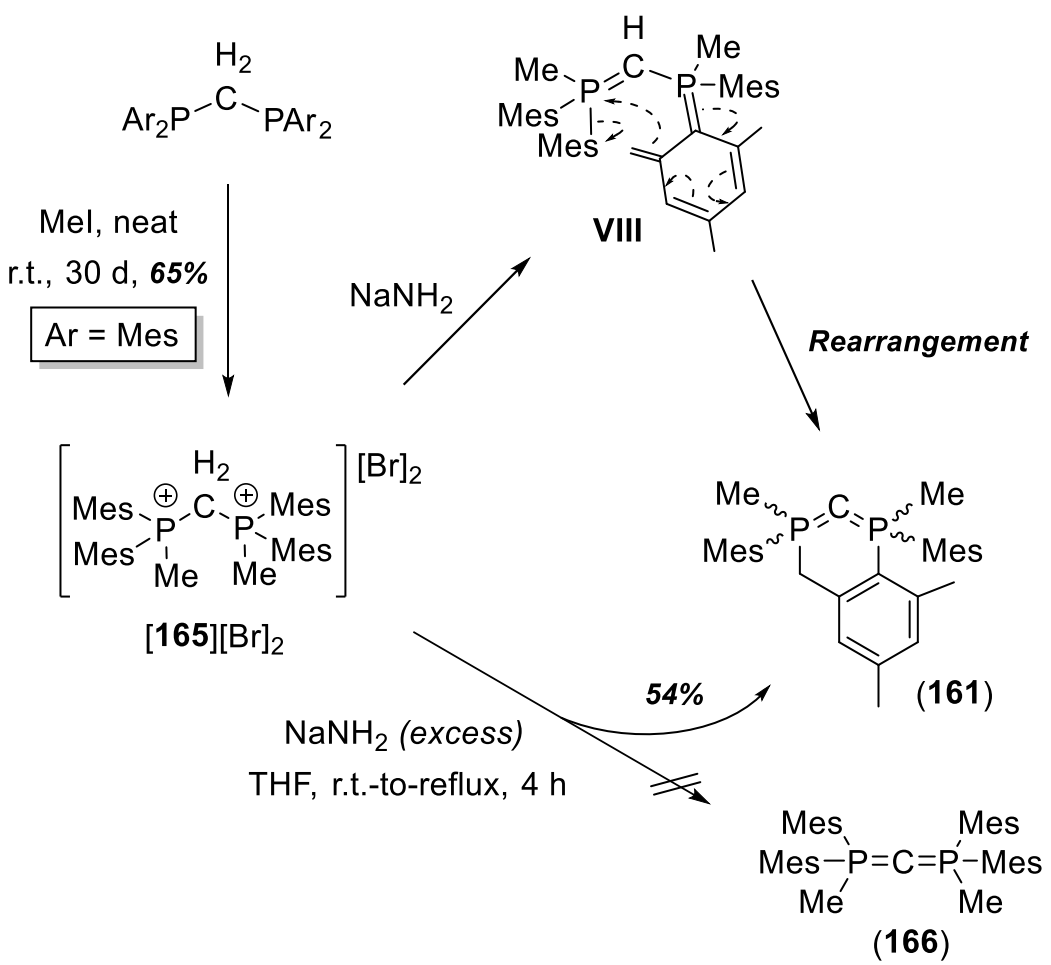

Pursuing in the study of double ylides, Schmidbaur and Pollok designed the diphosphonium salt $[167][\mathrm{I}]_{2}$ as an ideal candidate to exclude unwanted deprotonation at distinct position from the PMe moieties. ${ }^{284}$ The double methylation of 1,1-bis(diphenylphosphino)cyclopropane was efficiently accomplished and the diiodide salt $[\mathbf{1 6 7}][\mathrm{I}]_{2}$ was isolated in excellent 97\% yield (Scheme 145). Deprotonation of $[167][\mathrm{I}]_{2}$ by stoichiometric amounts of $\mathrm{Et}_{3} \mathrm{P}=\mathrm{CHMe}$ at $-70 \mathrm{C}$ surprisingly conducted to the formation of the unsymmetrical compound 162, isolated in 65\% after recrystallization. The mechanistic pathway to achieve the unexpected formation of 162 from $[\mathbf{1 6 7}][\mathrm{I}]_{2}$ involves a first deprotonation step to give 190 
ylide IX that immediately rearranges into $\mathbf{X}$ by nucleophilic attack of the carbanion to the adjacent phosphorus atom and cleavage of the P-cyclopropyl bond. Then, proton migration occurs to access the ylide XI which evolves to CDP $\mathbf{1 6 2}$ upon basic treatment. The structure of $\mathbf{1 6 2}$ was unambiguously attributed by EA and multinuclear NMR, including the observation of the very diagnostic signal belonging to the double ylidic $C$-atom appearing at high field in ${ }^{13} \mathrm{C}$ NMR $\left(\delta=3.6 \mathrm{ppm}\right.$; dd, ${ }^{l} J_{P, C}=109.4$ and $112.3 \mathrm{~Hz})$.

Scheme 145. Synthesis of the unsymmetrical CDP 162 via cyclopropyl group migration.

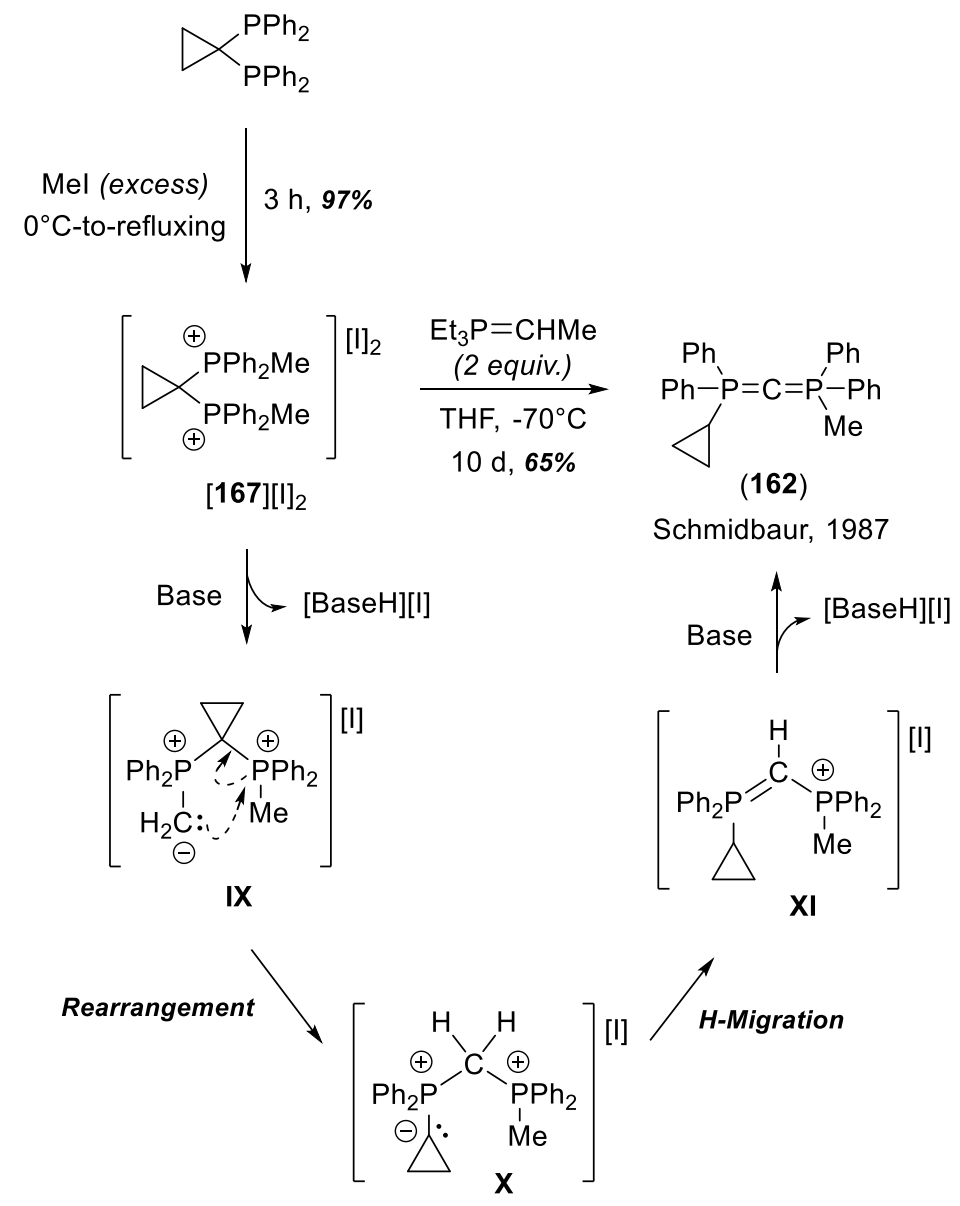


In 1976, Appel and Wihler described an attractive route of access to $\left[\mathrm{Ph}{ }_{3} \mathrm{P}=\mathrm{C}(\mathrm{Cl})-\mathrm{PPh}_{3}\right][\mathrm{Cl}]$ salt $[\mathbf{1 3 0}$ $\mathrm{Cl}][\mathrm{Cl}]$ from readily available $\mathrm{PPh}_{3}$ and $\mathrm{CCl}_{4}$ precursors in very high crystalline yields (Scheme 146). ${ }^{285}$ With $[\mathbf{1 3 0}-\mathrm{Cl}][\mathrm{Cl}]$ in hands, the synthesis of hexaphenylcarbodiphosphorane (130) was carried out by reacting equimolar amounts of $[\mathbf{1 3 0}-\mathrm{Cl}][\mathrm{Cl}]$ and $\left(\mathrm{Me}_{3} \mathrm{~N}\right)_{3} \mathrm{P} .{ }^{268}$ Compound $\mathbf{1 3 0}$ was isolated in $61 \%$ yield as crystalline material. Attempts to prepare the analogous hexamethylcarbodiphosphorane $\mathbf{1 3 5}$ from $\left[\mathrm{Me}_{3} \mathrm{P}=\mathrm{C}(\mathrm{Cl})-\mathrm{PMe}\right][\mathrm{Cl}]$ salt $^{286}$ failed.

Chlorinated CDPs represent an attractive organic synthon that offer structural diversity through reaction with the appropriate nucleophiles such as secondary amines. This appealing strategy was introduced by Appel in 1979 with the synthesis of the bis(chlorodiphenylphosphoranediyl)methane $\left(\mathrm{PPh}_{2} \mathrm{Cl}\right)_{2} \mathrm{C}(\mathbf{1 6 8})$ in nearly quantitative yield $(90 \%)$ from an excess of $\mathrm{CCl}_{4}$ and $\left(\mathrm{Ph}_{2} \mathrm{P}\right)_{2} \mathrm{CH}-\mathrm{SiMe}_{3} \cdot{ }^{287,288} \mathrm{Compound} 168$ was fully characterized by ${ }^{1} \mathrm{H}$ and ${ }^{31} \mathrm{P} \mathrm{NMR}$, mass spectrum and its chemical reactivity $v s \mathrm{HCl}$ and alcohols giving rise to the phosphonium salt $[\mathbf{1 6 8}-\mathrm{H}][\mathrm{Cl}]$ and the dioxide (169), respectively (Scheme 146). The utility of chlorinated CDPs as organic synthons was then demonstrated by Appel and co-workers in $1981,{ }^{289}$ when they reported on the aminolysis reaction of $\mathrm{C}\left(=\mathrm{PPh}_{2} \mathrm{Cl}_{2}\right)_{2}(\mathbf{1 6 8})$ with secondary amines $\mathrm{HNR}_{2}(\mathrm{R}=\mathrm{Me}$, Et, $n \mathrm{Pr}$ and $n \mathrm{Bu})$ leading to the phosphonium salts $\left[\left(\mathrm{R}_{2} \mathrm{~N}\right) \mathrm{Ph}_{2} \mathrm{P}=\mathrm{C}(\mathrm{H})-\mathrm{PPh}_{2} \mathrm{NR}_{2}\right][\mathrm{Cl}]$ ([170a-d $][\mathrm{Cl}]$ in Scheme 146). A more convenient, high yielding (76-85\%), pathway to the same compounds was found by reacting the bis(diphenylphosphino)methane with 3 equiv. of secondary amine $\mathrm{HNR}_{2}$ and 3 equiv. of tetrachloromethane. The dehydrochlorination reaction induced by strong bases such as sodium hydride or $n$-butyl lithium in THF affords the corresponding diaminocarbodiphosphoranes (171a-d) in very good yields (63-82\%). The isolated diaminocarbodiphosphoranes are remarkably stable towards thermal treatment, and the $\mathrm{P}=\mathrm{C}=\mathrm{P}$ structures were established in accord with their ${ }^{31} \mathrm{P}$ 
NMR signature, EA, and the characteristic reactivity $v s$ MeI and $\mathrm{H}_{2} \mathrm{O}$ to yield derivative $[\mathbf{1 7 1 d}-\mathrm{Me}][\mathrm{I}]$ and oxides $172 \mathbf{a}-\mathbf{d}$, respectively.

In $1983,{ }^{290}$ Appel's group has found a three-component, high-yielding route of access to hexakis(bis(dimethylamino)carbodiphosphorane (173) starting from $\mathrm{CCl}_{4}$, dimethylamine and bis[bis(dimethylamino)phosphino]methane. The addition of a solution containing $\mathrm{CCl}_{4}$ and dimethylamine in THF was added to a second flask having the bis[bis(dimethylamino)phosphino]methane dissolved in $\mathrm{THF}$ at $0^{\circ} \mathrm{C}$. After prolonged heating at this temperature, the reaction mixture is warmed to room temperature yielding the pentakis[bis(dimethylamino]phosphonium salt $[\mathbf{1 7 3}-\mathrm{H}][\mathrm{Cl}]$ after removal of solvents. $[\mathbf{1 7 3}-\mathrm{H}][\mathrm{Cl}]$ is then reacted with $\mathrm{NaH}$ in big excess in THF at room temperature. After $\mathrm{H}_{2^{-}}$ evolution has ceased, the solution is filtrated and hexakis(bis(dimethylamino)carbodiphosphorane (173) is furnished in excellent $86 \%$ yield. Its characterization was accomplished by ${ }^{31} \mathrm{P}$ NMR, EA, and the classical reactivity towards $\mathrm{H}_{2} \mathrm{O}, \mathrm{MeI}$ and $\mathrm{CO}_{2}$ that produced the corresponding dioxide $\left[\left(\mathrm{Me}_{2} \mathrm{~N}\right)_{2} \mathrm{P}(=\mathrm{O})-\mathrm{CH}_{2}-(\mathrm{O}=) \mathrm{P}\left(\mathrm{NMe}_{2}\right)_{2}\right](\mathbf{1 7 5})$ with concomitant elimination of dimethylamine, the expected $C$-methylated salt [173-Me][I] and the zwitterion 176.

The structure of $\left[\mathrm{P}\left(\mathrm{NMe}_{2}\right)_{3}\right]_{2} \mathrm{C}$ was determined by $\mathrm{X}$-ray diffraction analysis. The $\mathrm{P}-\mathrm{C}$ distances of 1.584(1) $\AA$ measured in the structure of $\mathbf{1 7 3}$ are remarkably short for a $\mathrm{P}=\mathrm{C}$ double bond. Also interesting is the perfect linearity observed in the $\mathrm{P}-\mathrm{C}-\mathrm{P}$ angle of $\mathbf{1 7 3}$ which represented the first example of a documented linear CDP. This observation was in sharp contrast with previous crystallographically characterized CDPs as reported by Wheatley, ${ }^{262,263}$ Zink, ${ }^{264}$ and Schmidbaur ${ }^{276,277,280}$ having P-C-P angles ranging from $143.8(6)^{\circ 263}$ in $\mathbf{1 3 0}$ to $116.7(7)^{\circ 277}$ in the case of the 6-membered cyclic CDP $\mathbf{1 5 7}$. Over many years, this finding was considered as a rare example in the family of CDPs until the recent discovery made by Parkin and co-worker in $2017,{ }^{265}$ in which new crystallographic data were collected for 193 
$\left[\mathrm{PPh}_{3}=\mathrm{C}=\mathrm{PPh}_{3}\right](\mathbf{1 3 0})$ demonstrating the high fluxionality around the $\mathrm{P}=\mathrm{C}=\mathrm{P}$ angle in this class of compounds.

Scheme 146. Schematic synthesis of 130, and the P-chloro and P-amino substituted CDPs 168, 171a-d and 173 from $\mathrm{CCl}_{4}$.

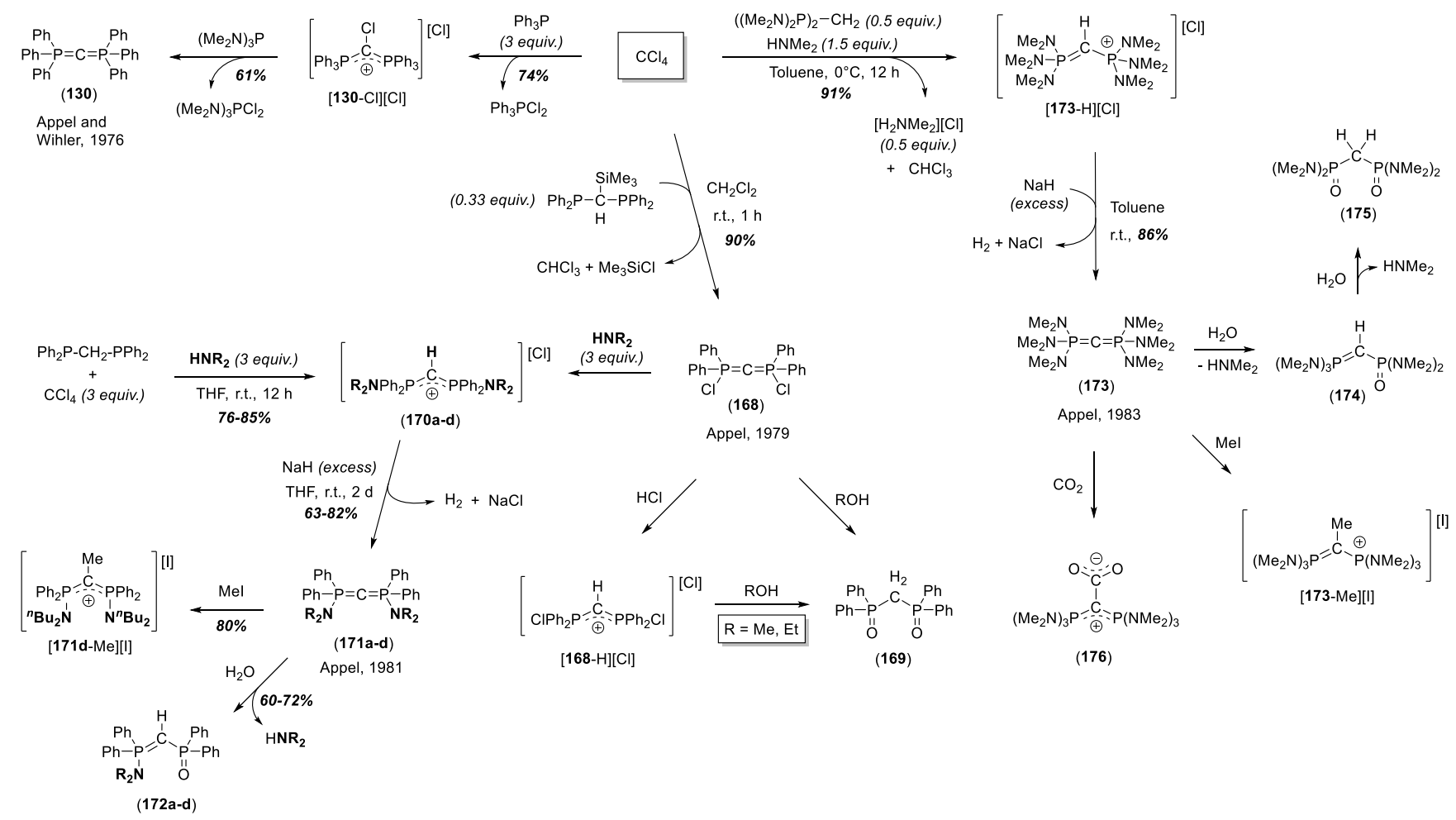

On the continuation of his research program dealing with the synthesis of P-chlorinated and P-amino substituted CDPs made from phosphines and $\mathrm{CCl}_{4}$, Appel and Wihler described the unsymmetrical carbodiphosphorane $\mathrm{Ph}_{3} \mathrm{P}=\mathrm{C}=\mathrm{PPh}_{2} \mathrm{Cl}$ (178 in Scheme 147). ${ }^{291-293}$ Careful temperature control has to be done in the synthesis and isolation of $\mathbf{1 7 8}$ due to its thermal sensibility vs the formation of its dimer structure $1 \lambda^{5}, 3 \lambda^{5}$-diphosphacyclobutadiene $[179][\mathrm{Cl}]_{2}$, that is also obtained in high yield (79\%) from precursor $\left[\mathrm{Ph}_{3} \mathrm{P}-\mathrm{C}(\mathrm{Cl})-\mathrm{PPh}_{2} \mathrm{Cl}\right][\mathrm{Cl}]$ by reduction with $\left(\mathrm{Me}_{2} \mathrm{~N}\right)_{3} \mathrm{P}{ }^{292}$ The structure of the $\mathrm{P}$-chlorinated CDP 178 was confirmed by ${ }^{31} \mathrm{P}$ NMR, EA and its chemical reactivity towards $\mathrm{HCl}$ and $\mathrm{H}_{2} \mathrm{O}$ that led to 194 
the isolation of chloride salts $[\mathbf{1 8 0}][\mathrm{Cl}]$ and $[\mathbf{1 7 8}-\mathrm{H}][\mathrm{Cl}]$ in excellent yields $(92 \%$ and quantitative respectively; see Scheme 147). ${ }^{291}$

The synthetic utility of the P-chlorinated CDP 178 was demonstrated by the same group by reacting it with a variety of secondary amines $\left[\mathrm{HNR}_{2}\right.$ (181a-e); with $\mathrm{R}$ groups being Me, Et, $n \mathrm{Pr}, n \mathrm{Bu}$ and $\left(\mathrm{CH}_{2}\right)_{5}-{ }^{293}$ The corresponding $\left[\mathrm{Ph}_{3} \mathrm{P}-\mathrm{CH}-\mathrm{PPh}_{2}\left(\mathrm{NR}_{2}\right)\right][\mathrm{Cl}][\mathbf{1 8 2 a}-\mathbf{e}-\mathrm{H}][\mathrm{Cl}]$ are obtained in high yields, and their basic treatment with $\mathrm{NaH}$ or $n \mathrm{BuLi}$ resulted in the formation of the $\mathrm{P}$-amino functionalized carbodiphosphoranes $\mathrm{Ph}_{3} \mathrm{P}=\mathrm{C}=\mathrm{PPh}_{2}\left(\mathrm{NR}_{2}\right)$ (182a-e), in 69-82\% yield. The isolated compounds 182a-e were characterized by EA, exact mas determination, ${ }^{31} \mathrm{P}$ and ${ }^{13} \mathrm{C}$ NMR. Again, the double ylidic character at the central carbon was proved by chemical reactivity $v s \mathrm{H}_{2} \mathrm{O}, \mathrm{HCl}$ and $\mathrm{MeI}$ to afford the expected compounds 183, $\left[\mathbf{1 8 2 b}, \mathbf{c}-\mathrm{H}_{2}\right][\mathrm{Cl}]_{2}$ and $[\mathbf{1 8 2 a}, \mathbf{e}-\mathrm{Me}][\mathrm{I}]$ in excellent yields (from $83 \%$ to quantitative; see Scheme 147).

Scheme 147. Schematic synthesis of P-chlorinated and P-amino substituted CDPs 178 and 182 a-e. 


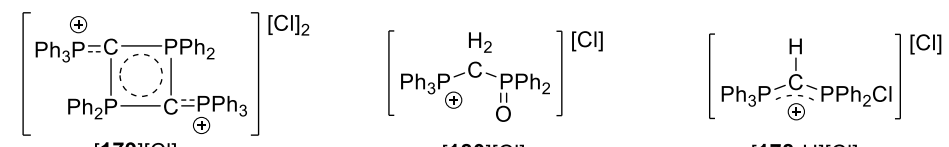

$$
\begin{aligned}
& \left(\mathrm{Me}_{2} \mathrm{~N}\right)_{3} \mathrm{P} \bigcup_{\substack{\mathrm{CH}_{2} \mathrm{Cl}_{2} \text {, r.t. } \\
20 \mathrm{~min}, 79 \%}}^{[179][\mathrm{Cl}]_{2}}
\end{aligned}
$$

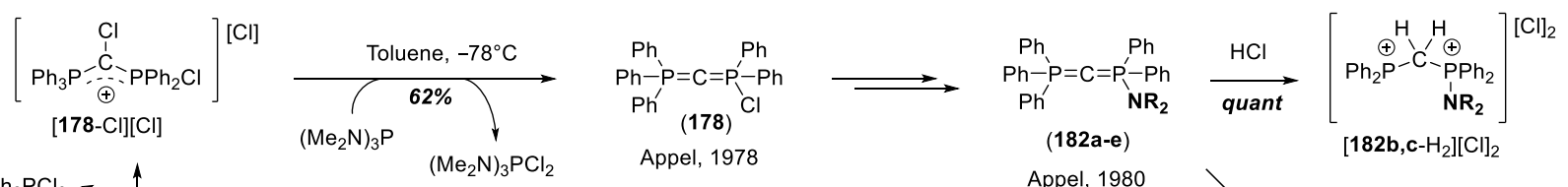

$$
\begin{aligned}
& \underset{\text { (2 equiv.) }}{\mathrm{Ph}_{2} \mathrm{PCl}} \underbrace{\circ} \mathrm{C}, 2 \mathrm{~h}, 71 \% \\
& {\left[\mathrm{Ph}_{3} \stackrel{\oplus}{\mathrm{P}}-\mathrm{CCl}_{3}\right][\mathrm{Cl}]} \\
& \text { [177][Cl] } \\
& \mathrm{Cl}_{2} \text { (2 equiv.) } 91 \%
\end{aligned}
$$

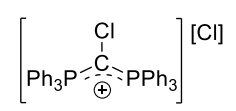

$$
\begin{aligned}
& \text { [130-CI][Cl] }
\end{aligned}
$$

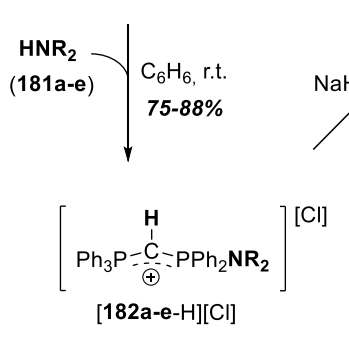

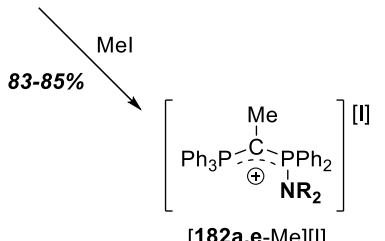

The methodology was further extended to the synthesis of P-amino substituted carbodiphosphoranes

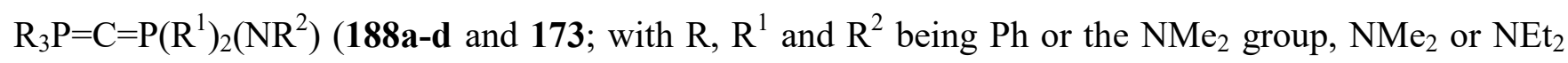
groups and Me or Et, respectively) in good yields by aminolysis of the P-chlorinated carbodiphosphoranes $\mathrm{R}_{3} \mathrm{P}=\mathrm{C}=\mathrm{P}\left(\mathrm{R}^{1}\right)_{2} \mathrm{Cl}\left(\mathbf{1 8 5} \mathrm{a}-\mathrm{c}\right.$ in Scheme 148). ${ }^{290}$

Scheme 148. Synthesis of P-chlorinated CDPs 185a-c and their use as precursors of the analogous P-amino derivatives 188a-d and 173. 


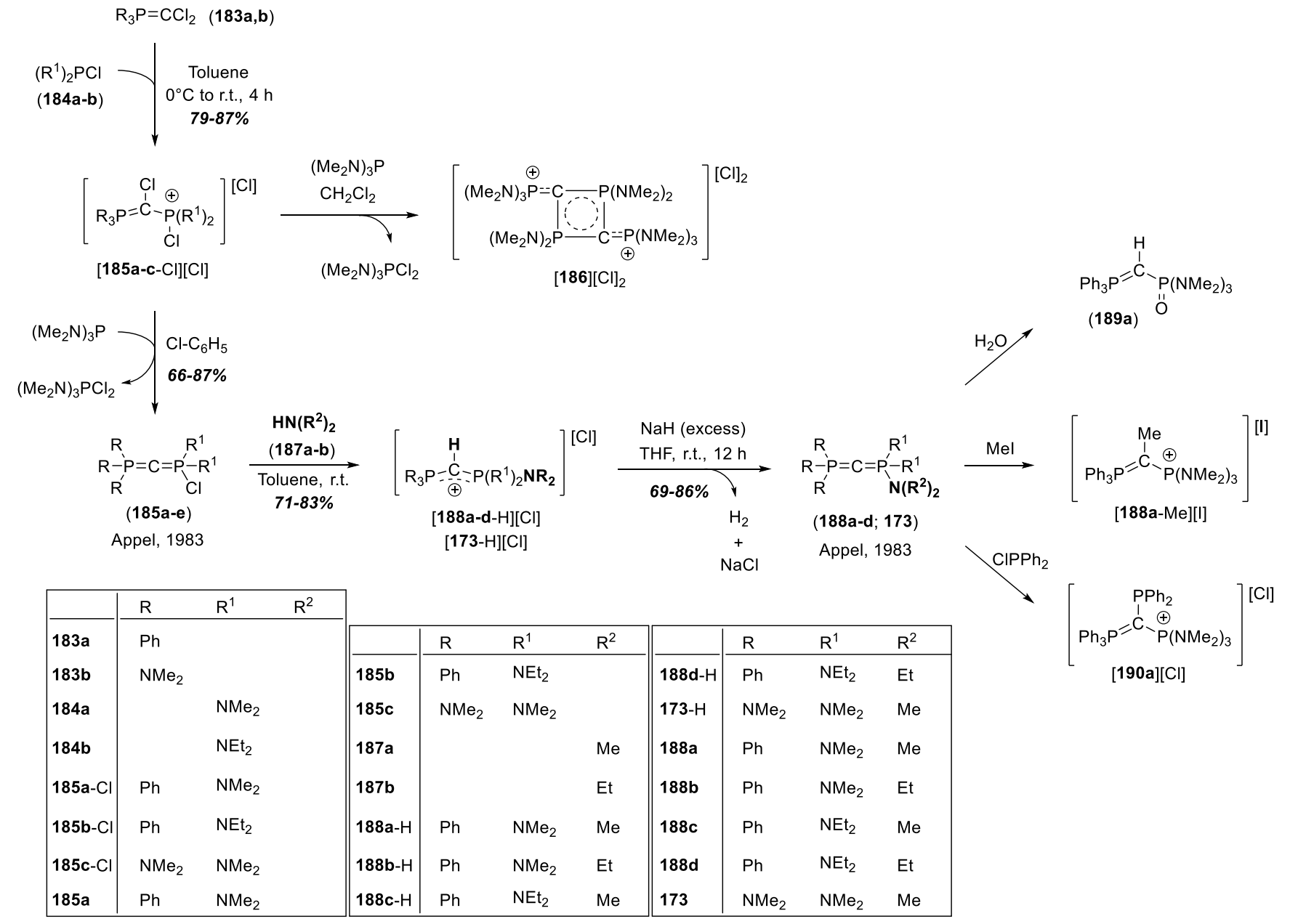

Carbodiphosphorane $\left(\mathrm{NMe}_{2}\right)_{3} \mathrm{P}=\mathrm{C}=\mathrm{P}\left(\mathrm{NMe}_{2}\right)_{2}(\mathrm{Me}) 192$ was synthesized in low yield $(7 \%)$ by the group of Fluck in 1988 (Scheme 149). ${ }^{294}$ Reduction of the P-fluorinated ylide $\left(\mathrm{NMe}_{2}\right)_{2} \mathrm{P}(\mathrm{F})=\mathrm{CH}_{2}(\mathbf{1 9 1})$ with $\mathrm{Li}$ in 1,2-dimethoxyethane leads to impure compound 192.

Scheme 149. Route of access to the CDP 192 by reduction of the P-fluorinated ylide 191. 


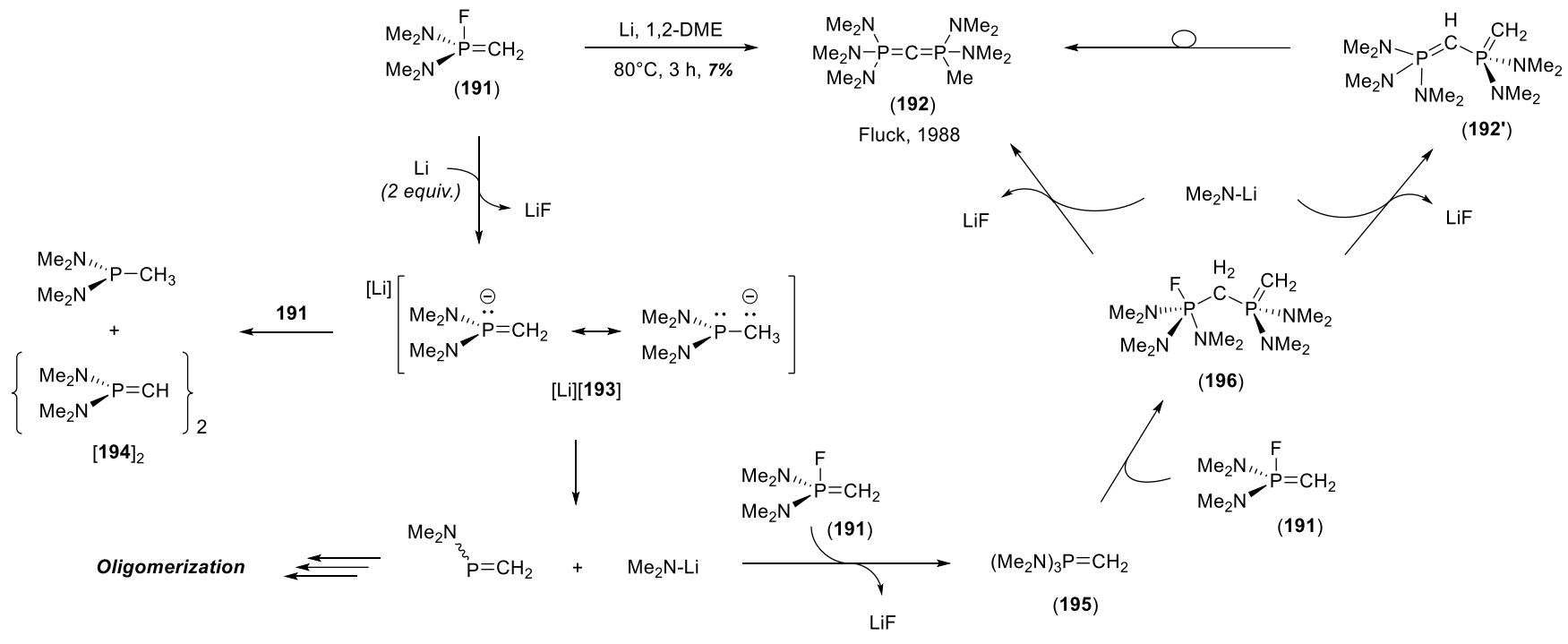

In the same article, the synthesis of difluorinated carbodiphosphoranes $\left(R_{2} F\right) P=C=P\left(R_{2} F\right)$ 198a,b $(R=$ $\mathrm{NMe}_{2}, \mathrm{Ph}$ ) from the corresponding tetrafluorinated precursors $\mathbf{1 9 7 a , b}$ were also reported. ${ }^{295,296}$ In both cases, deprotonation by n-butyl lithium in non-polar solvents ( $n$-pentane and toluene) at low temperatures $\left(-80^{\circ} \mathrm{C}\right.$ and $\left.-55^{\circ} \mathrm{C}\right)$ allowed for the synthesis of the difluorinated CDPs $198 \mathbf{a}, \mathbf{b}$ in $51 \%$ and $36 \%$ yield. The structures of $\mathbf{1 9 8 a}, \mathbf{b}$ were attributed according to the EA, mass spectrometry, IR and multinuclear NMR, as well as X-ray diffraction for 198a. The CDP nature in 198a was evidenced by the very diagnostic signal resonating at high field in ${ }^{13} \mathrm{C}$ NMR for the central carbon $\left(\delta=0.5 \mathrm{ppm} ; \mathrm{t},{ }^{1} J_{P, C}=\right.$ $230.2 \mathrm{~Hz})$.

Scheme 150. Syntheses of P-fluorinated CDPs 198a,b. 

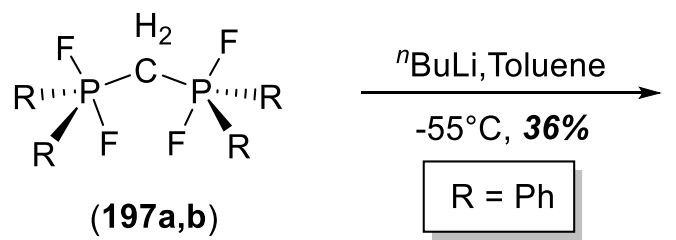

\begin{tabular}{c|c|}
$n_{\text {BuLi, } n \text {-Pentane }}$ & $\mathrm{R}=\mathrm{NMe}_{2}$ \\
$-80^{\circ} \mathrm{C}, 51 \%$ & $\mathrm{R}$
\end{tabular}

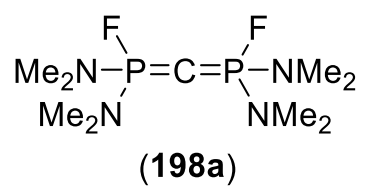

Fluck, 1988

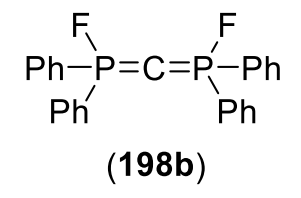

Fluck, 1988

The same group further reported the synthesis of CDPs $\mathbf{2 0 0}$ and $\mathbf{2 0 7 ^ { 2 9 7 }}$ starting from the P-fluorinated phosphaalkene 191 and the difluorinated precursor $\left(\mathrm{Me}_{2} \mathrm{~N}\right)_{2} \mathrm{P}(\mathrm{F})_{2} \mathrm{Me}\left(\mathbf{1 9 9},{ }^{298,299}\right.$ Scheme 151).

Scheme 151. Synthetic approaches to P-aminated CDPs 192, 200 and 207 starting from the difluorinated precursor $\mathrm{F}_{2} \mathrm{P}\left(\mathrm{CH}_{3}\right)\left(\mathrm{NMe}_{2}\right)_{2}$ (199). 


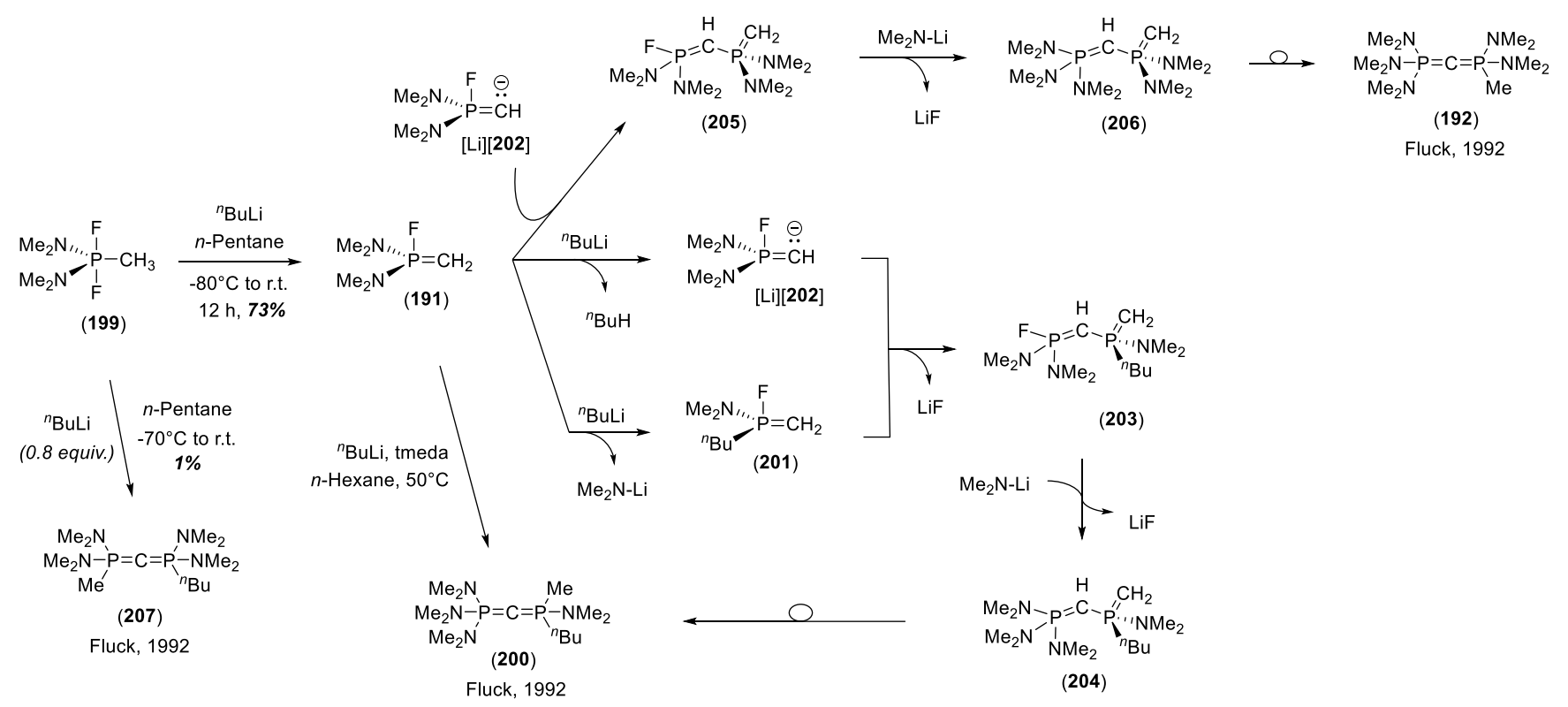

The formation of 192 from 191 can be explained by the direct reaction of anion [Li][202] and 191 to reach the diphosphete 206 that evolves in a similar fashion to diphosphete 204, thus generating 192 . In this article, Fluck also reported the synthesis of CDP 199 although in extremely low 1\% yield as a highly air sensitive, colorless liquid. The new CDPs 200 and 207 were fully characterized by exact mass determination, multinuclear NMR and EA. Remarkable, the double ylide character of the central carbon in CDPs 200 and 207 was demonstrated by their shielded signals in ${ }^{13} \mathrm{C}$ NMR resonating at $1.7 \mathrm{ppm}(\mathrm{dd}$, ${ }^{1} J_{P, C}=207.9$ and $\left.216.9 \mathrm{~Hz}\right)$ and $1.55 \mathrm{ppm}\left(\mathrm{dd},{ }^{1} J_{P, C}=209.4\right.$ and $\left.218.4 \mathrm{~Hz}\right)$, respectively.

According to the classical reactivity of phosphorus ylides, the discovery of CDPs containing $\mathrm{P}-\mathrm{H}$ bonds represented an important synthetic challenge due to plausible equilibrium with the corresponding alkylphosphanes. In 1993 Bertrand and colleagues found the route to these unique class of compounds (Scheme 152). ${ }^{300}$ The synthesis relies on a common precursor, bis[bis(diisopropylamino)phosphanyl]diazomethane $\mathbf{2 0 8} .^{301,302}$ Whereas 210 (isolated as a white powder in 70\% yield) is remarkably stable in solid state, it does rearrange slowly into its isomeric form 211 at 
room temperature. The structure of $\mathbf{2 1 0}$ was unequivocally elucidated according to its multinuclear NMR pattern, and the double ylide character on the central carbon was clear from its diagnostic signal located at $17.9 \mathrm{ppm}$ in ${ }^{13} \mathrm{C}$ NMR which resonates as a doublet of doublet of doublets $\left({ }^{1} J_{P, C}=143.8\right.$ and 195.0 Hz, ${ }^{2} J_{P, F}=24.8 \mathrm{~Hz}$ ). Alternatively, 210 can be reached directly from diphosphinodiazomethane 208 and tetrafluoroboric acid. The addition of $t$-butyl lithium to the phosphanylcarbene [209][OTf] in THF at $-78^{\circ} \mathrm{C}$ gave the highly reactive CDP 212 bearing two $\mathrm{P}-\mathrm{H}$ bonds. Due to its low stability, 212 was exclusively characterized by ${ }^{31} \mathrm{P}$ NMR displaying an AA'XX'M4M4' system $\left({ }^{1} J_{P, H}=465,{ }^{3} J_{P, H}=1\right.$, ${ }^{2} J_{P, P}=158$ and ${ }^{3} J_{P, H}=15 \mathrm{~Hz}$ ), thus unequivocally confirming the structure of 212. At room temperature, 212 undergoes a proton migration to initially afford the phosphaalkene $\mathbf{2 1 3}$ in nearly quantitative yield, which subsequently evolves to the diphosphine $\mathbf{2 1 4}$ that was isolated in $85 \%$ after crystallization.

\section{Scheme 152. Isolation of the $P-H$ bond containing CDPs 210 and 212 from bis[bis(diisopropylamino)phosphanyl]diazomethane (208).}

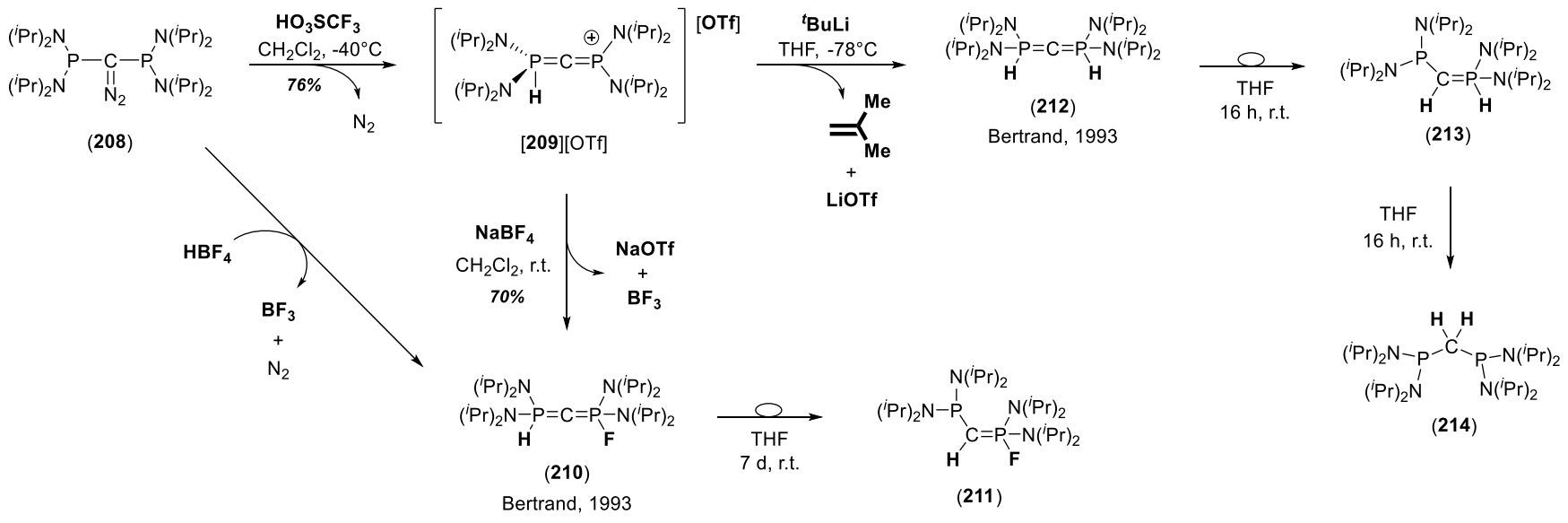

In 1998, Shevchenko reported the oxidation of bis[bis(dialkylamino)phosphinyl]methanes 215a,b with hexafluoroacetone (HFA, Scheme 153) to form CDPs 216a,b that were precipitated from the reaction media and thus easily isolated by filtration. ${ }^{303}$ The formation of those compounds formally involves the 
intermediate formation of mono(ylide)s $217 \mathbf{a}, \mathbf{b}$ by addition of the tautomeric $\mathrm{P}-\mathrm{H}$ ylide form of precursors 215a,b to the carbonyl group from HFA. Despite their high sensitivity to solvent evaporation, CDPs 216a,b are stable for hours in solution and allowed for their characterization by ${ }^{1} \mathrm{H},{ }^{31} \mathrm{P}$ and ${ }^{19} \mathrm{~F}$ NMR. In line with the strong basic character of CDPs, the reactivity studies performed with 216a,b vs Brönsted acids $(\mathrm{HCl}, \mathrm{Py} 2 \mathrm{HF})$ and chlorine gas confirmed the double ylide nature of the central carbon thereby yielding compounds [216a,b-H][Cl] $(\mathrm{HCl}), \mathbf{3 5 9 a}, \mathbf{b}-\mathbf{3 6 1} \mathbf{a}, \mathbf{b}(\mathrm{Py} 2 \mathrm{HF})$, and $[\mathbf{2 1 6 b}-\mathrm{Cl}][\mathrm{Cl}]$ and [216- $\left.\mathrm{Cl}_{2}\right][\mathrm{Cl}]_{2}\left(\mathrm{Cl}_{2}\right.$; see Scheme $\mathbf{1 8 7}$ in the Reactivity of double ylides towards organic compounds section).

In a later report, Shevchenko, Röschenthaler and co-workers used a similar approach to prepare the CDPs 218b,c from diphosphines 215b,c and the hexafluorothioacetone dimer (HFTA; Scheme 153). ${ }^{304}$ Carbodiphosphorane $\mathbf{2 1 8 b}$ was fully characterized by EA, ${ }^{1} \mathrm{H},{ }^{31} \mathrm{P}$ and ${ }^{19} \mathrm{~F}$ NMR experiments. Interestingly, ${ }^{31} \mathrm{P}$ NMR monitoring of the reaction evolution allowed for the confirmation of the mechanistic proposal due to the identification of mono(ylide) $\mathbf{2 1 9 b}$.

Scheme 153. Oxidation reactions of bis[bis(dialkylamino)phosphinyl]methanes 215a,b and bis[bis(diphenyl)phosphinyl]methane 215c with hexafluoroacetone (HFA) and hexafluorothioacetone (HFTA). 


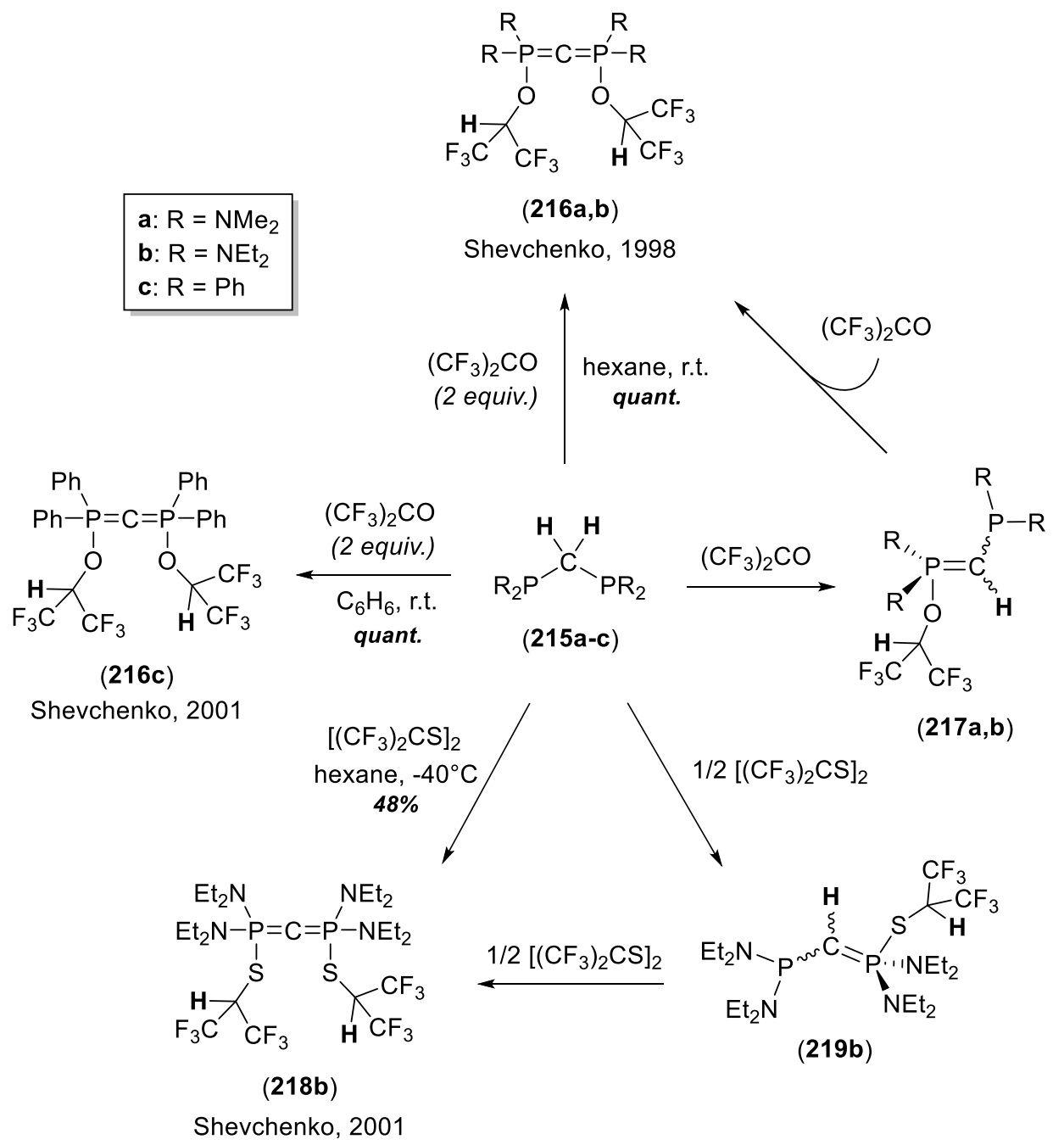

The structure of $\mathbf{2 1 8 b}$ was definitively confirmed by XRD analysis of monocrystals. Most remarkable insights for the structure of $\mathbf{2 1 8 b}$ in the solid state are as follow: i) the $\mathrm{P}-\mathrm{C}-\mathrm{P}$ bond angle is considerably bent as illustrated by the measured angle of $139.5^{\circ}$; ii) the phosphorus atoms have a pseudotetrahedral environment having a $\mathrm{P}-\mathrm{C}$ bond distance of $1.6257 \AA$; and iii) the molecule displays a low symmetry with distinct $\mathrm{CF}_{3}$ and ethyl groups, whereas these groups become equivalent in solution as indicated by multinuclear NMR due to its fluxional behavior. 
Similar CDPs 216c and 218c were prepared by oxidation reactions of bis(diphenylphosphine)methane with HFA and HFTA, respectively. ${ }^{305}$ 216c was cleanly formed in benzene, but its high instability precluded the isolation in solid state. Nevertheless, carbodiphosphorane 216c is stable in solution for hours and was characterized by ${ }^{1} \mathrm{H},{ }^{31} \mathrm{P}$ and ${ }^{19} \mathrm{~F}$ NMR experiments. On the contrary, mixing although CDP 218c can be formed at $-70^{\circ} \mathrm{C}$, it rapidly decomposes at $-40^{\circ} \mathrm{C}$, thus preventing its isolation and full characterization.

Scheme 154. Synthetic scheme of cyclic CDPs 223a,b cis,trans and their interrupted Wittig reactions towards hexafluoroacetone (HFA).

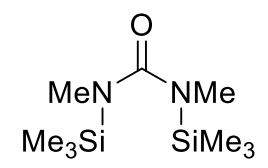

(221)

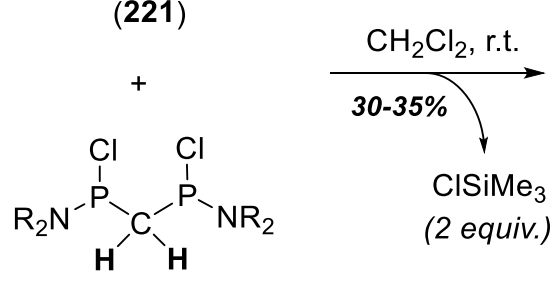

$(220 a, b)$

$$
\text { a: } R=M e
$$$$
\text { b: } R=E t
$$
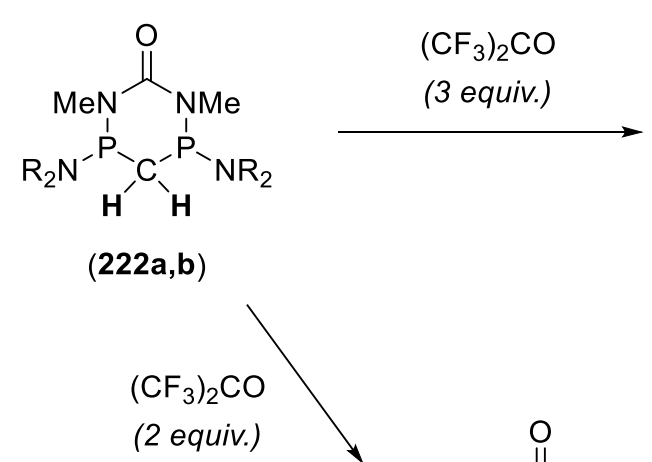
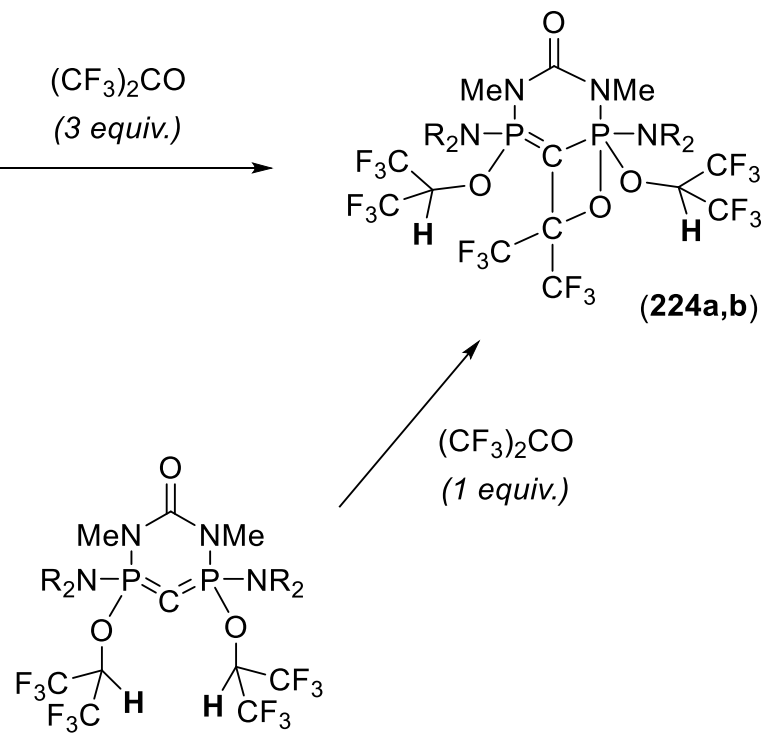

(223a,b; not isolable)

Shevchenko, 2001

The same year, while working in an elegant approach to reach the seemingly accessible cyclic CDPs 223a,b, Shevchenko et al. reported on the synthesis of the oxaphosphetanes $224 \mathbf{a}, \mathbf{b}$, which are key intermediates of the Wittig olefination occurring between 223a,b and the hexafluoroacetone (Scheme 
154). ${ }^{306,307}$ Interestingly, the ratio between the two isomers cis, trans oxaphosphetanes 224a,b can be impacted by the appropriate choice of the reaction solvent (ratio ca 1:1 in $\mathrm{Et}_{2} \mathrm{O} v s$ cis/trans ratio of 1:9 in dichloromethane). Oxaphosphetanes 224a-trans and 224b-trans were fully characterized by multinuclear NMR and EA, and the atom connectivity of 224b-trans was definitively confirmed by X-ray diffraction analysis of single crystals. In spite of the inability of isolating the cyclic CDPs 223a,b, their in situ formation was ascertained by NMR identification and their evolution into bicyclic oxaphosphetanes $224 a, b$.

With exception of Schmidbaur's work (compounds 137 and $138 \cdot \mathrm{LiBr}^{270} \mathbf{1 5 5 - 1 5 7 ,},{ }^{277,280}$ and $\mathbf{1 6 1}$ ), ${ }^{283}$ and despite the knowledge accumulated in the construction of linear CDPs since the pioneering work of Ramirez in 1961, efficient routes of access to cyclic analogs remained scarcely studied until the work of Baceiredo and Kato (Scheme 155). ${ }^{308}$ In 2006, they reported on the synthesis of cyclic CDPs 228a,b starting from bis(diisopropylamino)phosphino diazomethane $\mathbf{2 2 5}$ and bis(dialkylamino)phosphenium salts 226a,b. Deprotonation of the isolated intermediate salts [228a,b-H][OTf] with stoichiometric amount of sodium hexamethyldisilazide in $\mathrm{THF}$ at $-80^{\circ} \mathrm{C}$, and slow warming up to room temperature afforded the corresponding cyclic CDPs 228a,b in high yields (86\% and 76\%, respectively). Both compounds were isolated as crystalline material and were remarkably stable. The identity of cyclic heterocycles 228a,b was confirmed by ${ }^{1} \mathrm{H},{ }^{31} \mathrm{P}$ and ${ }^{13} \mathrm{C}$ NMR. Interestingly, ${ }^{13} \mathrm{C}$ NMR analysis of 228a,b displayed significantly downfield shifted signals and remarkably small ${ }^{1} J_{P, C}$ for the central carbon appearing at $21.5 \mathrm{ppm}\left(\mathrm{dd},{ }^{1} J_{P, C}=10.6\right.$ and $\left.25.6 \mathrm{~Hz} ; \mathbf{2 2 8 a}\right)$ and $15.3 \mathrm{ppm}\left(\mathrm{d},{ }^{1} J_{P, C}=12.1 ; \mathbf{2 2 8 b}\right)$.

\section{Scheme 155. Synthesis of cyclic CDPs 228a,b carried out by Kato and Baceiredo.}



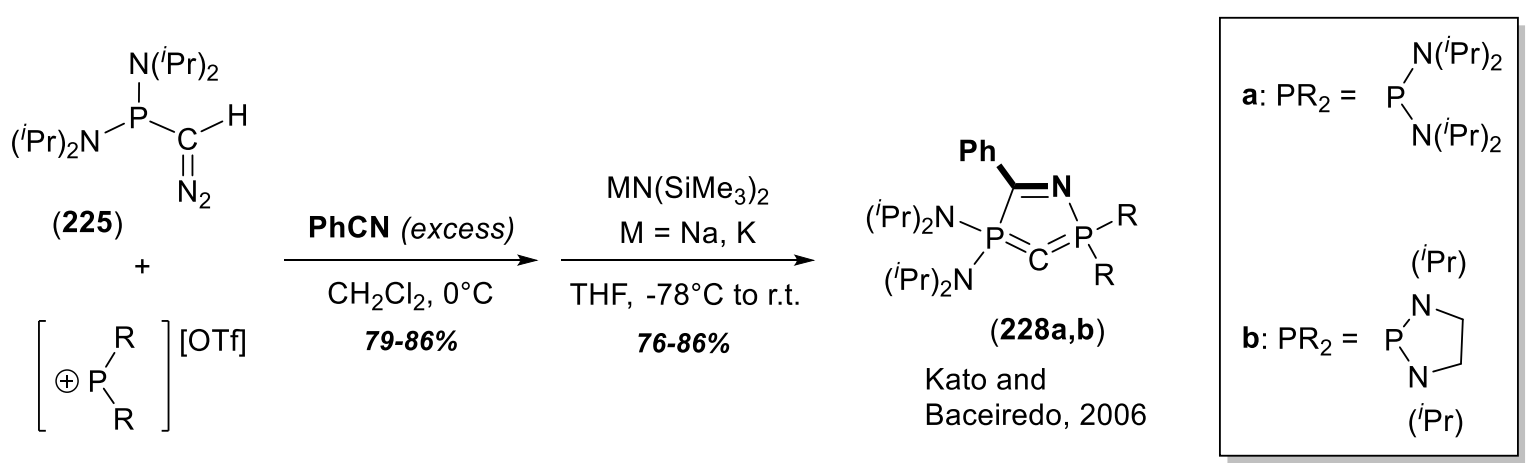

$[226 a, b][O T f]$
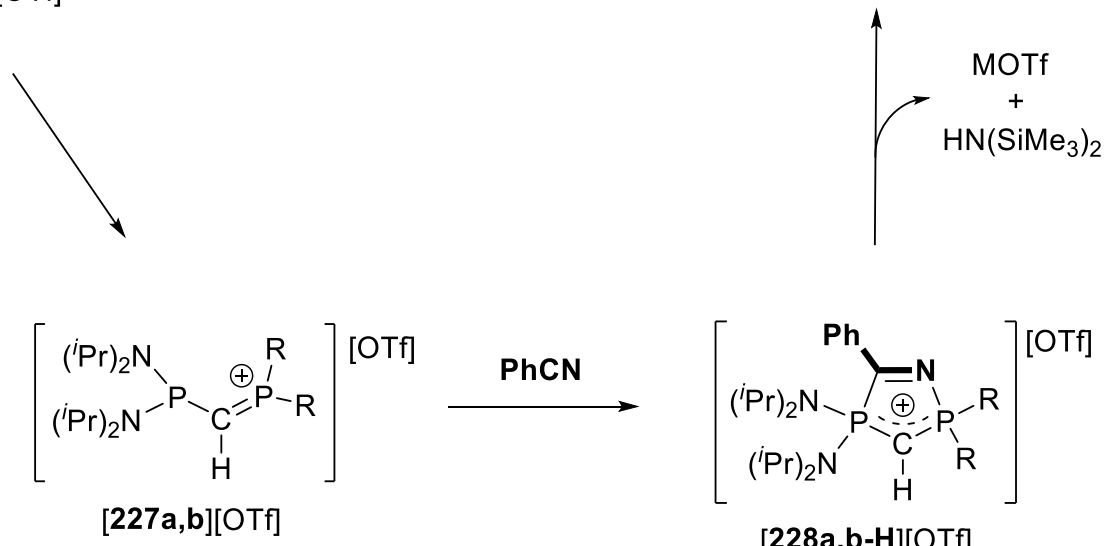

[228a,b-H][OTf]

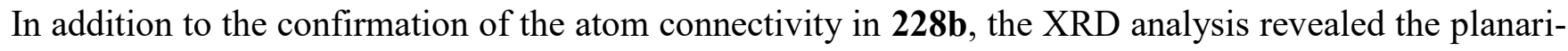
ty of the central 5-member ring, along with its remarkably small $\mathrm{P}-\mathrm{C}-\mathrm{P}$ angle of $104.8^{\circ}$ having the two $\mathrm{P}-\mathrm{C}$ bond distances of 1.64 and $1.66 \AA$ (in accord with the existence of a $\mathrm{P}=\mathrm{C}=\mathrm{P}$ central core).

In spite of the high stability of $\mathbf{2 2 8 b}$ in both solid state and in solution, when heated at $80^{\circ} \mathrm{C}$ in $\mathrm{C}_{6} \mathrm{H}_{6}$ for $60 \mathrm{~h} \mathbf{2 2 8 b}$ rearranged into the $1,2 \lambda^{5}$-azaphosphete $\mathbf{2 2 9 b}$ and allowed for its isolation as white crystals in 76\% yield (Scheme 156). ${ }^{309}$ The observed regioselectivity in $\mathbf{2 2 9 b}$, in which the imine is now directly bonded to the $\mathrm{P}\left(\mathrm{N}^{i} \mathrm{Pr}_{2}\right)_{2}$ fragment (atom connectivity confirmed by NMR and XRD techniques), argued in favor of a [3+2] retrocycloaddition pathway to reach the acyclic diphosphinocarbene $230 \mathbf{b}$ and free benzonitrile, that can further react with each other through a [2+2] cycloaddition to furnish the fourmembered heterocycle $\mathbf{2 2 9 b}$. Altogether, the authors proved very convincingly the intermediacy of the 
acyclic diphosphinocarbene $\mathbf{2 3 0 b}$ in the thermal interconversion of the cyclic CDP $\mathbf{2 2 8 b}$ into heterocycle $229 \mathrm{~b}$, a previously unknown reactivity pattern for this class of compounds.

Scheme 156. Thermal interconversion of the cyclic CDP $228 \mathrm{~b}$ to $1,2 \lambda^{5}$-azaphosphete $229 \mathrm{~b}$, and the trapping of the key intermediate, diphosphinocarbene $230 \mathrm{~b}$.

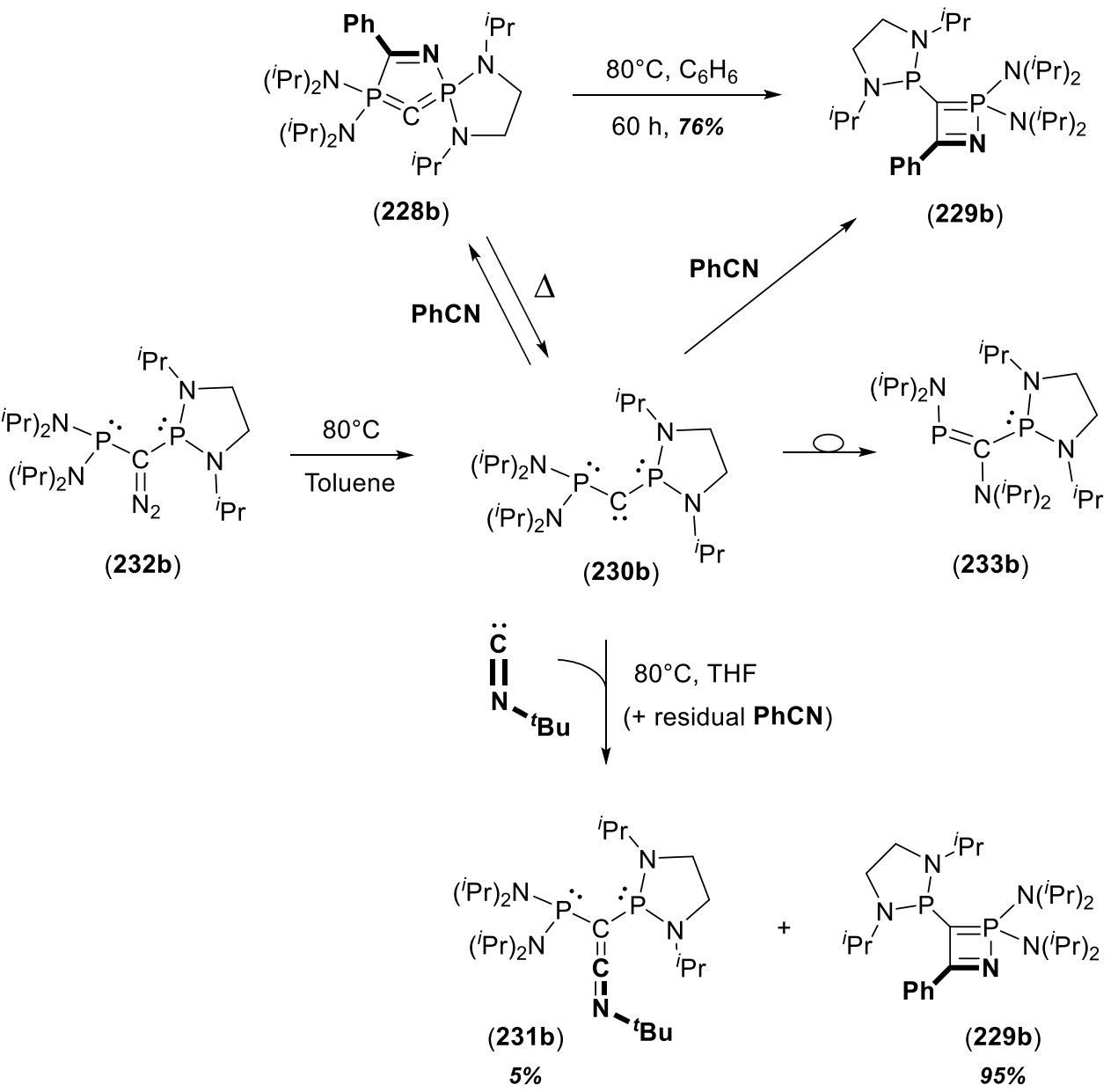

Recently, Weigand reported the $2 e^{-}$reduction of the cyclotri(phosphonio)methanide [234][OTf $]_{2}$ that resulted in the synthesis of the acyclic CDP 235 in $81 \%$ yield via ring opening process. ${ }^{310}$ CDP 235 was fully characterized by common techniques (Raman, IR, EA and multinuclear NMR). In particular, the diagnostic central carbon of the $\mathrm{P}=\mathrm{C}=\mathrm{P}$ core was significantly downfield shifted $\left[v s \delta_{p p m}=12.5\right.$ and ${ }^{1} J_{\mathrm{CP}}$ 207 
$=127.2 \mathrm{~Hz}$ for the known carbodiphosphorane $\mathrm{Ph}_{3} \mathrm{P}=\mathrm{C}=\mathrm{PPh}_{3}(\mathbf{1 3 0})$ in ${ }^{13} \mathrm{C} \mathrm{NMR}$ and was found at 18.1 ppm $\left(\mathrm{ddd},{ }^{1} J_{\mathrm{CP}}=135.7 \mathrm{~Hz},{ }^{1} J_{\mathrm{CP}}=134.4 \mathrm{~Hz}\right.$ and $\left.{ }^{4} J_{\mathrm{CP}}=16.3 \mathrm{~Hz}\right]$. The significant shift observed in ${ }^{13} \mathrm{C}$ NMR for the central carbon atom was attributed by the authors to the donor-acceptor interaction of one lone pair of electrons and the $\sigma^{*}(\mathrm{P}-\mathrm{C})$ orbital. The structure of 235 was definitively confirmed by X-ray diffraction of single crystals. In addition, the $\mathrm{P}-\mathrm{C}-\mathrm{P}$ angle of $140.74(8)^{\circ}$ is remarkably large in comparison with its analogous compound $\mathrm{Ph}_{3} \mathrm{P}=\mathrm{C}=\mathrm{PPh}_{3}\left[130\right.$; angle of $\left.131.7(3)^{\circ}\right]$, and the short $\mathrm{P}-\mathrm{C}$ bonds $\left[\mathrm{d}_{\mathrm{C}^{-}}\right.$ $\mathrm{P}=1.636(1) \AA$ and $\left.\mathrm{d}_{\mathrm{C}-\mathrm{P}}=1.642(2) \AA\right]$ are fully consistent with a double bond character across the $\mathrm{P}-\mathrm{C}-$ P core.

Scheme 157. Weigand's synthesis of CDP 235 through a $2 e^{-}$reduction of cyclotri(phosphonio)methanide $[234][\text { OTf }]_{2}$. 


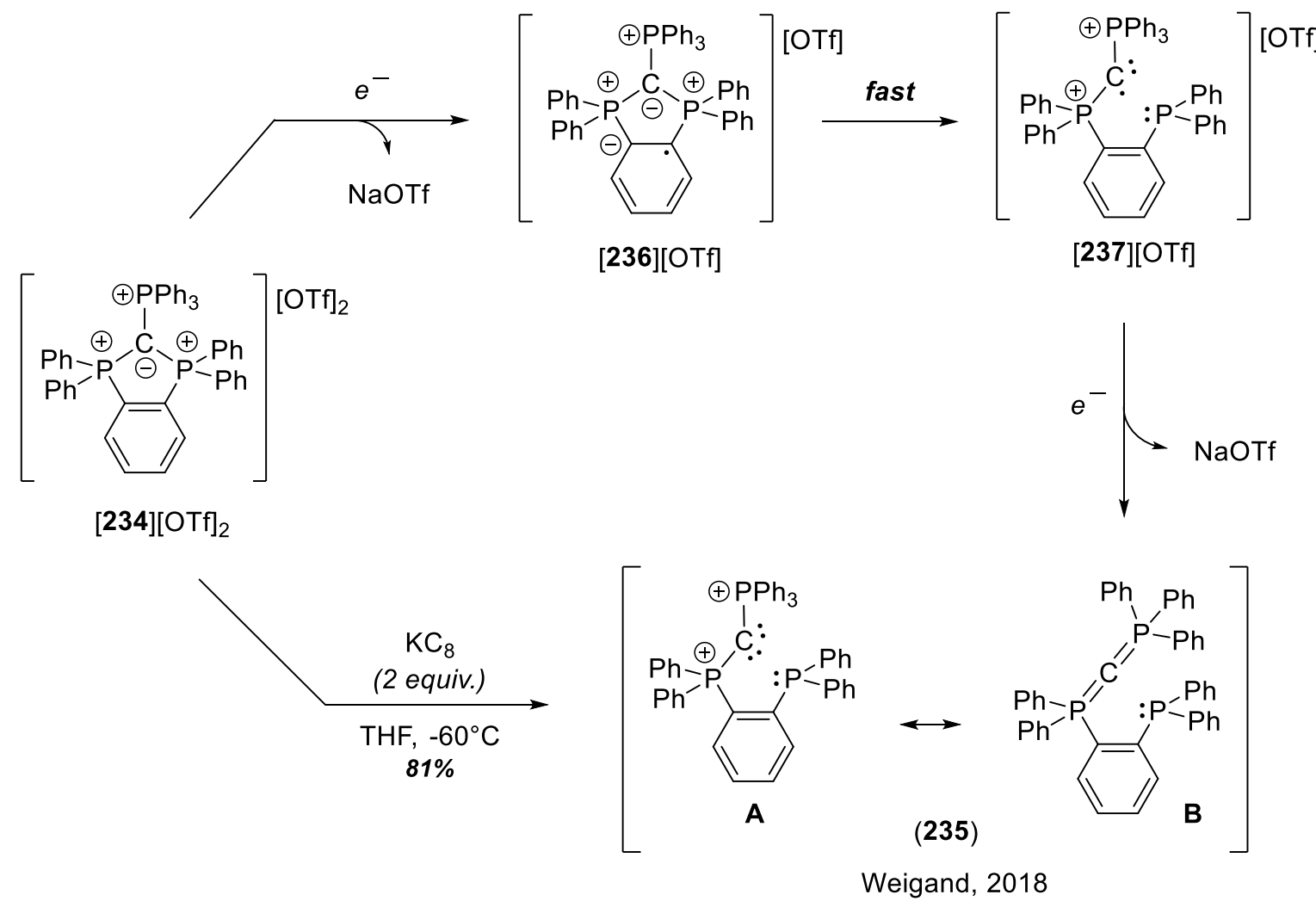

A particular contribution to the synthesis of CDP derivatives was made by Peringer and co-workers in 2007. ${ }^{311}$ Indeed, they reported on the template synthesis of the unprecedented CDP-Pd complex $[\mathbf{2 3 8}][\mathrm{Cl}]$, which bears two additional phosphine sidearms allowing for the isolation of a palladium $P, C, P$-pincer complex (Scheme 158). Complex $[238][\mathrm{Cl}]$ is obtained from a reaction mixture containing $\operatorname{Pd}(\mathrm{II})$ chloride, bis(diphenylphosphino)methane (dppm) and carbon disulfide in 1:4:8 ratio giving rise to the pincer complex in more than $60 \%$ yield. $[238][\mathrm{Cl}]$ was characterized by ${ }^{31} \mathrm{P} \mathrm{NMR}$, and elemental analysis. First indication on the bis(ylidic) nature of the ligand in [238][Cl] was provided by its reaction with $\mathrm{HCl}$ that resulted in the selective protonation at the central $C$-atom.

Scheme 158. Synthesis of the palladium $P, C, P$-pincer complex $[238][C]$ bearing a carbodiphosphorane framework. 


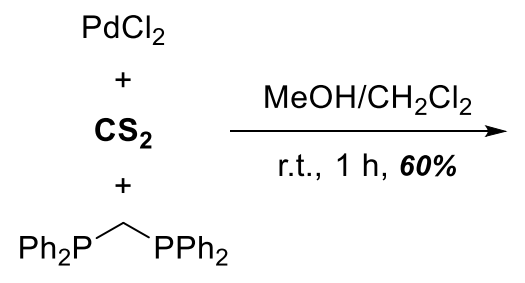

(4 equiv.)
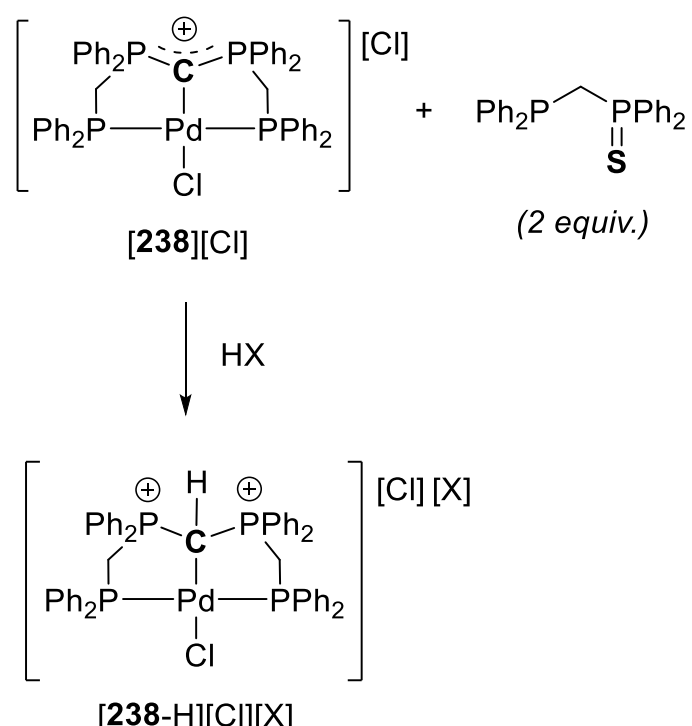

In 2007, Baceiredo and colleagues carried out the synthesis and in situ NMR characterization of the first persistent mixed P,S $S^{\text {II }}$-bis(ylide) 241a. ${ }^{312}$ Their strategy relied on the deprotonation of the corresponding conjugated acid [241a-H][OTf] that already contains the desired P-C-S skeleton (Scheme 159). Basic treatment with KHMDS in $\mathrm{C}_{6} \mathrm{D}_{6}$ allowed for the quantitative deprotonation and formation of CDP 241a. Due to its high reactivity, 241a was characterized in situ by multinuclear NMR $\left({ }^{31} \mathrm{P}\right.$ NMR: $\delta_{\mathrm{ppm}}=44.0$; ${ }^{13} \mathrm{C}$ NMR: $\delta_{\mathrm{ppm}}=36.0$, doublet, ${ }^{1} \mathrm{~J}_{\mathrm{P}, \mathrm{C}}=86.4 \mathrm{~Hz}$ ). Confirmation of the identity of 241a was provided by its chemical reactivity $v s$ methyl iodide leading to the isolation and full characterization (including XRD analysis) of the $C$-methylated salt [241a-Me][I].

Scheme 159. Synthesis of mixed $\mathrm{P}, \mathrm{S}^{\mathrm{II}}{ }^{-}$and $\mathrm{P}, \mathrm{Si}^{\mathrm{II}}-$-bis(ylide)s $241 \mathrm{a}, \mathrm{b}$ and $243 \mathrm{a}-\mathrm{c}$, respectively. Conditions: i) stirring a mixture of [241a-H][OTf] and KHMDS in $\mathrm{C}_{6} \mathrm{D}_{6}$ at $0^{\circ} \mathrm{C}$; ii) mixing [241b$\mathrm{H}][\mathrm{OTf}]$ and $\mathrm{KHMDS}$ in THF at $-50^{\circ} \mathrm{C}$ and subsequent warming up to room temperature; iii) stirring overnight a mixture of $242 \mathrm{c}$ and bis(ylide) $241 \mathrm{~b}$ in THF at room temperature; and $i v$ ) stirring overnight a mixture of $242 \mathrm{~d}, \mathrm{e}$ and bis(ylide) $241 \mathrm{~b}$ in toluene at room temperature. 


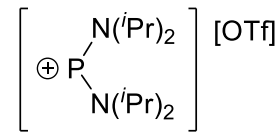

[226a][OTf]

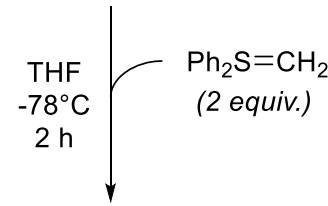

$[\overbrace{\mathrm{N}^{i} \mathrm{Pr}^{\prime} \mathrm{Ph}^{\prime}-\mathrm{Pr}}^{\mathrm{N}^{\prime}}]^{[\mathrm{Cl}]}$

[240b][Cl]

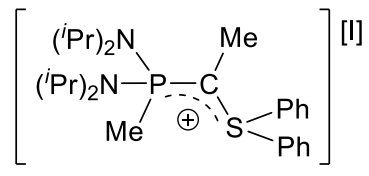

[241a-Me][I]

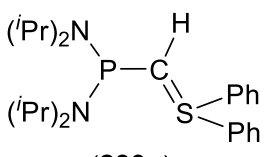

(239a)

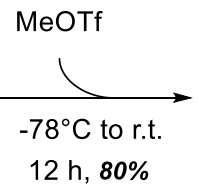

12 h, $80 \%$
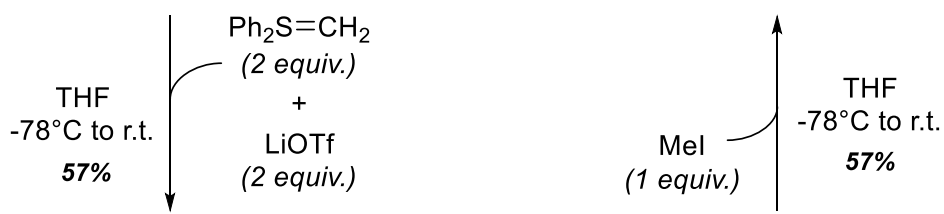

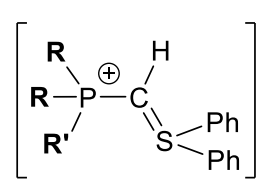

[241a,b-H][OTf]
[OTf]

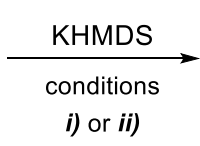

i) or ii)

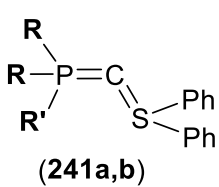

(241a,b)

Kato and Baceiredo, 2007 and 2010

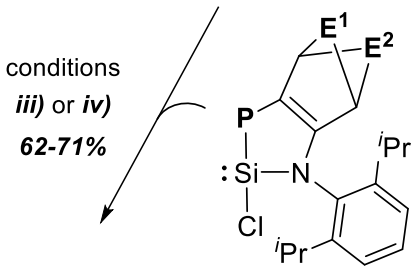

(242c-e)

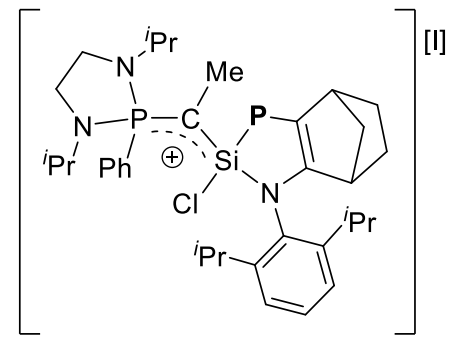

[243c-Me][I]

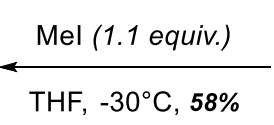

$\mathrm{THF},-30^{\circ} \mathrm{C}, \mathbf{5 8} \%$

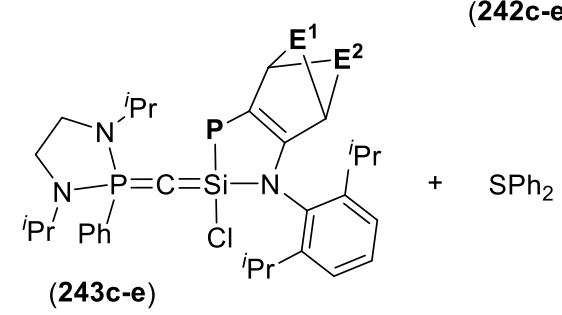

Kato, 2017

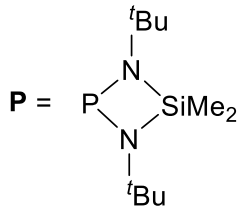


The same approach was later carried out by Kato and Baceiredo to achieve the synthesis of the mixed $\mathrm{P}, \mathrm{S}^{\mathrm{II}}$-bis(ylide) 241b (in good isolated yield 72\%) via basic treatment of intermediate [241b-H][OTf]. ${ }^{313}$ Bis(ylide) 241b was characterized by multinuclear NMR $\left({ }^{31} \mathrm{P}\right.$ NMR: $\delta_{\mathrm{ppm}}=39.6 ;{ }^{13} \mathrm{C} \mathrm{NMR}: \delta_{\mathrm{ppm}}=16.6$, doublet, ${ }^{1} \mathrm{~J}_{\mathrm{P}, \mathrm{C}}=22.0 \mathrm{~Hz}$ ) as well as by X-ray diffraction analysis of single crystals. Main features on the structure of $\mathbf{2 4 1 b}$ are: $i)$ the $\mathrm{P}-\mathrm{C}-\mathrm{S}$ angle of $109.8^{\circ}$ was found to be considerably smaller than the $\mathrm{P}-\mathrm{C}-$ $\mathrm{S}$ angle in salt $[\mathbf{2 4 1 b}-\mathrm{H}][\mathrm{OTf}]\left(116.6^{\circ}\right)$. This observation is in contrast with the general trend observed in CDPs, in which the $\mathrm{P}-\mathrm{C}-\mathrm{P}$ angle increases upon deprotonation of the corresponding conjugated acids; ii) the remarkably short $\mathrm{P}-\mathrm{C}-\mathrm{S}$ angle of $109.8^{\circ}$ is close to the $\mathrm{P}-\mathrm{C}-\mathrm{P}$ angle of $105^{\circ}$ found in the cyclic carbodiphosphorane $\mathbf{2 2 8 b}$; and iii) the $\mathrm{P}-\mathrm{C}$ bond distance in $\mathbf{2 4 1 b}(1.667 \AA)$ slightly decreases upon deprotonation $\left(\mathrm{d}_{\mathrm{P}-\mathrm{C}}=1.690 \AA\right.$ for $\left.241 \mathrm{~b}-\mathrm{H}\right)$. NBO calculations were carried out and suggested that

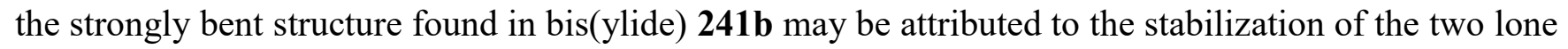
pairs located at the central carbon through interactions with $\sigma^{*}(\mathrm{~S}-\mathrm{C}), \sigma^{*}(\mathrm{P}-\mathrm{C})$ and $\sigma^{*}(\mathrm{P}-\mathrm{N})$ orbitals.

Even more interesting, bis(ylide) $\mathbf{2 4 1 b}$ proved to be an excellent precursor to obtain the challenging P,Si ${ }^{\mathrm{II}}$-bis(ylides) 243c-d via $\mathrm{C}=\mathrm{SPh}_{2}$ to $\mathrm{C}=\mathrm{Si}(\mathrm{Cl})(\mathrm{P}-\mathrm{N})$ conversion through a likely cross-metathesis step with donor-stabilized silylenes 242c-d ${ }^{314,315}$ (Scheme 159). ${ }^{316}$ The 1-silavinylidene phosphoranes 243c-e featuring the desired $\mathrm{P}=\mathrm{C}=\mathrm{Si}$ motif were isolated in good yields (62-71\%). The $\mathrm{P}, \mathrm{Si}^{\mathrm{II}}$-bis(ylide)s 243c-d were fully characterized by multinuclear $\left({ }^{1} \mathrm{H},{ }^{31} \mathrm{P},{ }^{29} \mathrm{Si}\right.$, and $\left.{ }^{13} \mathrm{C}\right) \mathrm{NMR}$. The most significant NMR data obtained are: $i)$ the significant high-field signals observed in ${ }^{29} \mathrm{Si}$ NMR $\left[\delta_{\mathrm{ppm}}=-60.3(\mathrm{dd}\right.$, ${ }^{1} J_{\mathrm{Si}, \mathrm{P}}=162.5$ and $\left.{ }^{2} J_{\mathrm{Si}, \mathrm{P}}=59.1 \mathrm{~Hz}, 243 \mathrm{c}\right) ; \delta_{\mathrm{ppm}}=-59.6\left(\mathrm{dd},{ }^{1} J_{\mathrm{Si}, \mathrm{P}}=82.0\right.$ and ${ }^{2} J_{\mathrm{Si}, \mathrm{P}}=57.1 \mathrm{~Hz}, \mathbf{2 4 3 d}$; and $\delta_{\mathrm{ppm}}=-64.7\left(\mathrm{dd},{ }^{1} J_{\mathrm{Si}, \mathrm{P}}=155.4\right.$ and $\left.\left.{ }^{2} J_{\mathrm{Si}, \mathrm{P}}=62.0 \mathrm{~Hz}, \mathbf{2 4 3 e}\right)\right]$ in comparison with the silylene precursors 242c-e, thereby suggesting strong $\sigma$-donation from the Si-fragment to the central carbon atom; and ii) the signals for the central carbon in ${ }^{13} \mathrm{C}$ NMR resonating at $\delta_{\mathrm{ppm}}=27.5\left(\mathrm{dd},{ }^{1} J_{\mathrm{C}, \mathrm{P}}=97.7\right.$ and ${ }^{2} J_{\mathrm{C}, \mathrm{P}}=51.5$ 212 
$\mathrm{Hz}, 243 \mathrm{c}), 28.0\left(\mathrm{dd},{ }^{1} J_{\mathrm{C}, \mathrm{P}}=98.6\right.$ and $\left.{ }^{2} J_{\mathrm{C}, \mathrm{P}}=59.3 \mathrm{~Hz}, \mathbf{2 4 3 d}\right)$, and $25.6\left(\mathrm{dd},{ }^{1} J_{\mathrm{C}, \mathrm{P}}=103.0\right.$ and ${ }^{2} J_{\mathrm{C}, \mathrm{P}}=51.9$ $\mathrm{Hz}, \mathbf{2 4 3 e )}$.

The structures of the 1-silavinylidene phosphoranes $243 \mathrm{c}-\mathrm{e}$ were definitively confirmed by X-ray diffraction analysis of single crystals. Interestingly, the structure of the $\mathrm{P}, \mathrm{Si}^{\mathrm{II}}$-bis(ylide)s $\mathbf{2 4 3 c}$-e are considerably bent with $\mathrm{P}-\mathrm{C}-\mathrm{Si}$ angles ranging from $128.69(9)^{\circ}$ in $\mathbf{2 4 3 c}$ to $140.07(3)^{\circ}$ in $\mathbf{2 4 3 d}$, having $\mathrm{P}-\mathrm{C}$ bond distances $(1.6226(4)-1.6279(11) \AA)$ fully consistent with a double $\mathrm{P}=\mathrm{C}$ bond character. Remarkably, very short C-Si bond distances $(1.683(1)-1.6968(10) \AA)$ were found in 243c-e, that are similar to the $\mathrm{Si}=\mathrm{C}$ bond distance $(1.674 \AA$ A). This fact, along with the elongated $\mathrm{Si}-\mathrm{Cl}$ bond distances observed in 243c-e $(2.121(1)-2.1276(2) \AA) v s$ the classical Si-Cl bond distances $(2.06 \AA)$ argued in favor of an important negative hyperconjugation of the $n_{\sigma}$-lone pair orbital located at the central carbon across the $\sigma^{*}(\mathrm{Si}-\mathrm{Cl})$ orbital.

DFT calculations were carried out for the model compound 243d at the M06-2x/6-31G(d) level of theory. The NBO analysis have corroborated the strong electron density around the central carbon atom (two high lying lone pairs: HOMO and HOMO-1), attributed by the authors to the strong $\sigma$-donation of the silylene moiety. The HOMO corresponds to the out of plane lone pair orbital $\left(\mathrm{n}_{\pi \mathrm{C}}\right)$ displaying $\pi$ delocalization to both $\mathrm{Si}$ and $\mathrm{P}$ atoms. The HOMO-1 corresponds to the in plane $\sigma$-lone pair orbital $\left(\mathrm{n}_{\sigma \mathrm{C}}\right)$ which spreads to the Si-atom suggesting a $\pi$-interaction of the $\mathrm{n}_{\sigma \mathrm{C}}$ and Si by negative hyperconjugation.

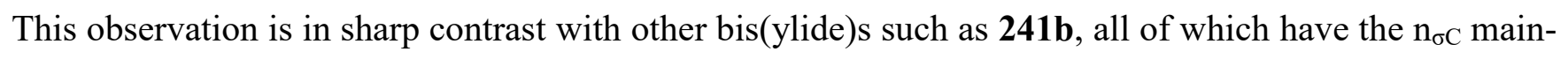
ly located at the central carbon atom. Experimental electron density distribution analysis was performed on the $\mathrm{P}, \mathrm{Si}^{\mathrm{II}}$-bis(ylide) 243d and the $\mathrm{P}, \mathrm{S}^{\mathrm{II}}$-bis(ylide) 241b revealing insightful information regarding their bonding situation. These measurements clearly provided a proof on the 3-center-2-electron interac-

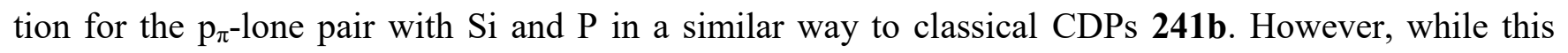
213 
analysis has revealed the presence of the $\sigma$-lone pair at the central carbon for $\mathbf{2 4 1 b}$, in the case of $\mathbf{2 4 3 d}$ the $\sigma$-lone pair density is directional toward the adjacent Si-atom, thus illustrating the delocalization of $\mathrm{n}_{\sigma \mathrm{C}}$ between $\mathrm{C}$ and $\mathrm{Si}$. In addition, Kato and Baceiredo have attributed the observed strong $\pi$-back donation from the $C$-atom to $\mathrm{Si}$ to the high electron density around the $C$-atom resulting from the strong $\sigma$ donating character of the Si-fragment, along with enhanced $\pi$-accepting properties of donor-stabilized silylenes vs phosphines.

The electron density at the central carbon on the $\mathrm{P}=\mathrm{C}=\mathrm{Si}$ fragment of $\mathrm{P}, \mathrm{Si}{ }^{\mathrm{II}}$-bis(ylide)s 243c-e was experimentally proved by the reactivity of $243 \mathrm{c}$ towards methyl iodide to form the $C$-methylated salt $[\mathbf{2 4 3 c}-\mathrm{Me}][\mathrm{I}]$ as a mixture of two diastereoisomers.

The first bis(ylide) exclusively stabilized by $S^{\mathrm{IV}}$ moieties $(\mathbf{2 4 8}$, Scheme $\mathbf{1 6 0})$ was synthesized and fully characterized by Yoshimura in 2002..$^{317-319}$ A multistep, low yield, synthesis of the acidic precursor $[148]\left[\mathrm{ClO}_{4}\right]$ was devised. The subsequent deprotonation was accomplished nearly quantitatively to yield the targeted carbobis(iminosulfane) $\mathbf{2 4 8}$, exclusively stabilized by $\mathrm{S}^{\mathrm{IV}}$-based fragments. [248- $\left.\mathrm{H}\right]\left[\mathrm{ClO}_{4}\right]$ and 248 were characterized by IR, EA, ${ }^{1} \mathrm{H}$ and ${ }^{13} \mathrm{C}$ NMR experiments and XRD analysis of single crystals. The $\mathrm{S}-\mathrm{C}-\mathrm{S}$ angle in $\mathbf{2 4 8}$ and $[\mathbf{2 4 8}-\mathrm{H}]\left[\mathrm{ClO}_{4}\right]$ are quite similar $\left(116.8(2)^{\circ}\right.$ and $118.0(1)^{\circ}$, respective1y). However, the $\mathrm{d}_{\mathrm{S}(\mathrm{IV})-\mathrm{C}}$ of $1.635(4)$ and 1.632(2) $\AA$ in $\mathbf{2 4 8}$ are shorter than the ones found in precursor $[248-\mathrm{H}]\left[\mathrm{ClO}_{4}\right](1.695(2)$ and $1.691(2) \AA)$, whereas the measured $\mathrm{d}_{\mathrm{S}(\mathrm{II})-\mathrm{N}}$ of $1.553(10)$ and $1.550(8) \AA$ in 248 are longer than those observed in $[248-\mathrm{H}]\left[\mathrm{ClO}_{4}\right](1.526(2)$ and $1.531 \AA$ ). All these crystallographic data pointed to the double ylidic character along the $\mathrm{S}-\mathrm{C}-\mathrm{S}$ core, with the presence of two lone pair $\left(\mathrm{n}_{\sigma \mathrm{C}}\right.$ $\left.+\mathrm{n}_{\pi \mathrm{C}}\right)$ located at the central carbon that are delocalized by orbital interactions with the $\sigma^{*}(\mathrm{~S}-\mathrm{C})$ and $\sigma^{*}(\mathrm{~S}-\mathrm{C})$ orbitals. Natural population analysis (NPA) and natural bond orbital (NBO) analyses were carried out for the analogous bis(ylide) $(\mathrm{MeN}=) \mathrm{Me}_{2} \mathrm{~S}=\mathrm{C}=\mathrm{SMe}_{2}(=\mathrm{NMe}) \quad(\mathbf{2 4 8}$ ') at the $\mathrm{B} 3 \mathrm{LYP} / 6$ 214 
$311+\mathrm{G}(2 \mathrm{~d}, \mathrm{p})$ level of theory, and showed that the canonical structure B (Scheme 160) displays the best Lewis representation for $\mathbf{2 4 8}$ (see Electronic structure of double ylides section for further details).

Scheme 160. Route of access to the carbobis(iminosulfane) $(\mathrm{MeN}=) \mathrm{Ph} \mathrm{h}_{2} \mathrm{~S}=\mathrm{C}=\mathrm{SPh}_{2}(=\mathrm{NMe})(248)$ carried out by Yoshimura.
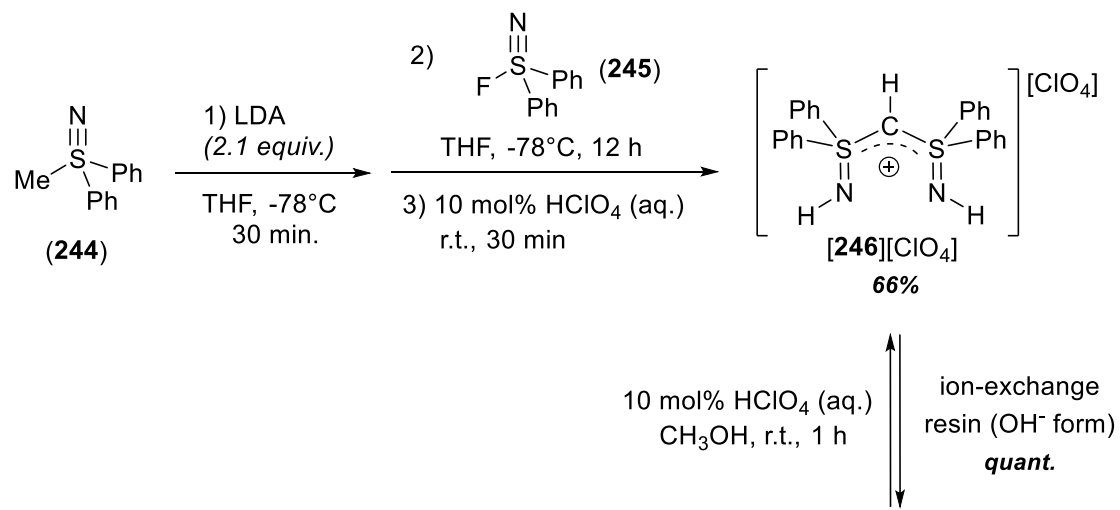

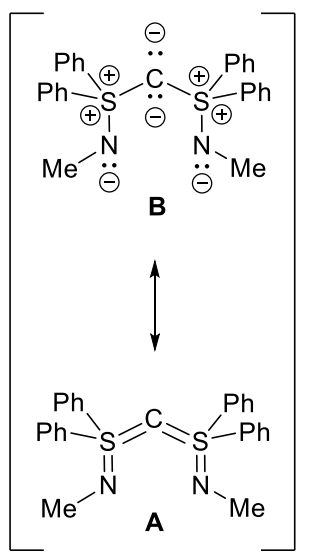

(248)
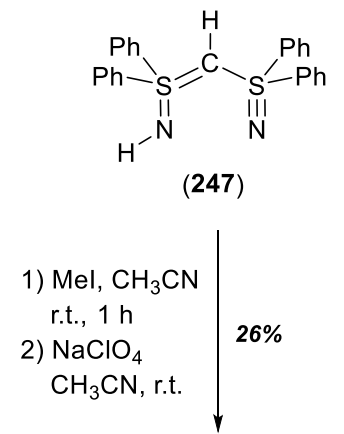

ion-exchange resin $\underset{10 \mathrm{~mol}_{\%} \mathrm{HClO}_{4} \text { (aq.) }}{\stackrel{\left(\mathrm{OH}^{-} \text {form }\right), 98 \%}{\longrightarrow}}$ $\mathrm{CH}_{3} \mathrm{OH}$, r.t., $1 \mathrm{~h}$

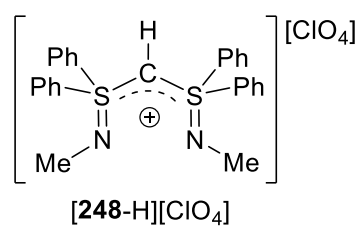

Yoshimura, 2002

More recently, Fujii's group used a similar strategy to access the bis(ylide)s 251a,b. ${ }^{320}$ One-pot deprotonation of precursors $[\mathbf{2 4 9} \mathbf{a}, \mathbf{b}]\left[\mathrm{BF}_{4}\right]$ in presence of the fluorinated iminosulfonium electrophilic salt $[\mathbf{2 5 0}]\left[\mathrm{BF}_{4}\right]$ takes place to reach precursors $[\mathbf{2 5 1 a}, \mathbf{b}-\mathrm{H}]\left[\mathrm{BF}_{4}\right]$ in moderate to good isolated yields (49215 
70\%; Scheme 161). The near quantitative synthesis of carbodichalcogenures $\mathbf{2 5 1 a , b}$ (97\% yields) was achieved by subsequent deprotonation of precursors $[\mathbf{2 5 1} \mathbf{a}, \mathbf{b}-\mathrm{H}]\left[\mathrm{BF}_{4}\right]$ with sodium amide. Carbodichalcogenures 251a,b are the first examples of a bis(ylide) exclusively stabilized by two different chalcogen-donating groups such as an iminosulfane and an $\mathrm{E}^{\mathrm{II}}$-bearing moiety (with $\mathrm{E}^{\mathrm{II}}$ being $\mathrm{S}^{\mathrm{II}}$ or $\mathrm{Se}^{\mathrm{II}}$ ), with 251b representing the unique Se-stabilized bis(ylide) known to date. 251a,b were characterized by multinuclear $\left({ }^{1} \mathrm{H},{ }^{13} \mathrm{C}\right.$ and $\left.{ }^{77} \mathrm{Se}\right) \mathrm{NMR}$ in $\mathrm{CD}_{3} \mathrm{CN}$ and $\mathrm{C}_{6} \mathrm{D}_{6}$. The XRD analysis provided definitive proof on their structures and showed unexpectedly large $d_{E(I I)-C}$ of 1.707 and $1.876 \AA$ for $\mathbf{2 5 1 a}$ and $251 \mathbf{b}$ respectively slightly longer than the measured $\mathrm{d}_{\mathrm{E}(\mathrm{II})-\mathrm{C}}$ in precursors $[\mathbf{2 5 1 a}-\mathrm{H}]\left[\mathrm{BF}_{4}\right]$ and $[\mathbf{2 5 1 b}-\mathrm{H}][\mathrm{OTf}](1.672$ and $1.846 \AA$ ), along with decreasing of the $\mathrm{E}^{\mathrm{II}}-\mathrm{C}-\mathrm{S}^{\mathrm{IV}}$ angles $\left(106.7^{\circ}\right.$ in $\mathbf{2 5 1 \mathbf { a }}$ and $105.5^{\circ}$ in $\mathbf{2 5 1 b}$. The shortening in the $\mathrm{d}_{\mathrm{E}(\mathrm{II})-\mathrm{C}}$ upon deprotonation is in contrast with the general tendencies in carbodiphosphoranes and carbobis(iminosulfane)s. This observations pointed to important electronic repulsions between the lone pair at the $S^{I I}$ or $\mathrm{Se}^{\mathrm{II}}$ atom and the two lone pair $\left(\mathrm{n}_{\sigma \mathrm{C}}+\mathrm{n}_{\pi \mathrm{C}}\right)$ at the central carbon in carbodichalcogenures 251a,b that impose them to be in antiperiplanar disposition.

Scheme 161. Synthesis of the $E^{I I}, S^{I V}$-bis(ylide)s 251a,b, double protonation to afford [251b$\left.\mathrm{H}_{2}\right][\mathrm{OTF}]_{2}$ and unexpected entry to bis(ylide) 252 reported by Fujii (a: $\left.\mathbf{E}=\mathrm{S}^{\mathrm{II}} ; \mathrm{b}: \mathrm{E}=\mathrm{Se}^{\mathrm{II}}\right)$.

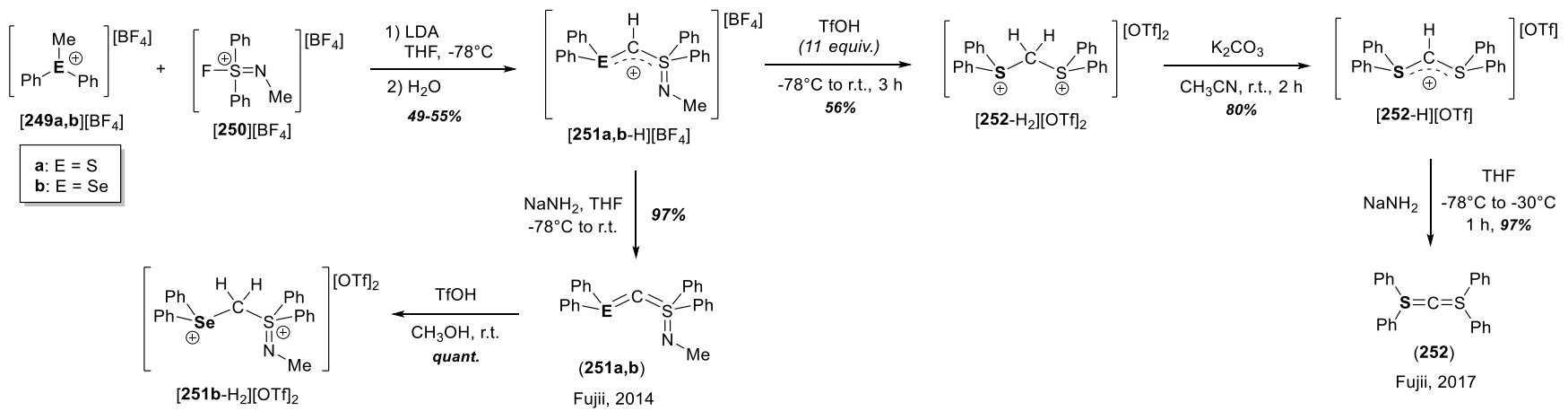

Cyclic voltammetry was carried out for carbodichalcogenures 251a,b and carbobis(iminosulfane) 248 proved their irreversible oxidation at $-0.73,-0.92$ and $-0.45 \mathrm{~V}\left(v s \mathrm{Fc} / \mathrm{Fc}^{+}\right)$, respectively. These experi216 
mental values are translated to their estimated HOMO energy levels of $-4.07,-3.88$ and $-4.36 \mathrm{eV}$, respectively and clearly illustrates the decreasing order of electron donor capacity as follow: 251b $>$ 251a $>248$.

Treatment of carbodichalcogenure $\mathbf{2 5 1 b}$ with $\mathrm{TfOH}$ quantitatively afforded the double protonated dication $\left[\mathbf{2 5 1 b}-\mathrm{H}_{2}\right][\mathrm{OTf}]_{2}$, which provides unequivocal proof for the existence of the two lone pairs at the central C-atom.

While exploring the reactivity of the salt $[251 \mathbf{a}-\mathrm{H}]\left[\mathrm{BF}_{4}\right]$ towards $\mathrm{TfOH}$, Fujii and colleagues discovered an unexpected deamination reaction to form the previously inaccessible $\left[\mathrm{Ph}_{2} \mathrm{~S}^{\mathrm{II}}-\mathrm{CH}_{2}-\mathrm{S}^{\mathrm{II}} \mathrm{Ph}_{2}\right]^{2+}$ motif $\left[\mathbf{2 5 2}-\mathrm{H}_{2}\right][\mathrm{OTf}]_{2}$ that represented an excellent entry to bis(ylide) 252, the first stabilized by two $\mathrm{S}^{\mathrm{II}}-$ donating groups (Scheme 161). ${ }^{321}$ Carbodisulfane 252 is an air, moisture and thermally sensitive compound and was therefore only characterized by ${ }^{1} \mathrm{H}$ and ${ }^{13} \mathrm{C}$ NMR [with the bis(ylidic) $\mathrm{C}$-atom resonating at $\delta_{\mathrm{ppm}}=41.8\left(\mathrm{~S}^{\mathrm{II}} C \mathrm{~S}^{\mathrm{II}}\right)$ in $\mathrm{THF}-\mathrm{d}_{8} v s \delta_{\mathrm{ppm}}=39.5\left(\mathrm{~S}^{\mathrm{IV}} C \mathrm{~S}^{\mathrm{IV}}\right)$ and $35.3\left(\mathrm{~S}^{\mathrm{II}} C \mathrm{~S}^{\mathrm{IV}}\right)$ for 248 and $251 \mathrm{a}$ in $\mathrm{THF}-$ $\mathrm{d}_{8}$, respectively]. However, it was used as ligand toward $\mathrm{Au}(\mathrm{I})$ precursor (see the Coordination chemistry of double ylides section for further details).

The low stability of $\mathbf{2 5 2}$ was attributed by the authors to the limited $\pi$-acceptor character of the $\mathrm{SPh}_{2}$ groups as a consequence of the lone pair at the $\mathrm{S}^{\mathrm{II}}$-atoms. NBO analyses revealed the presence of two lone pairs at the central carbon for the HOMO $\left(\mathrm{n}_{\sigma \mathrm{C}},-8.49 \mathrm{eV}\right)$ and HOMO-1 $\left(\mathrm{n}_{\pi \mathrm{C}} ;-5.02 \mathrm{eV}\right)$ arguing in favor of a strong donor capacity of 252. The second order perturbation analysis confirmed that almost no backbonding from the $\mathrm{n}_{\sigma \mathrm{C}}$ to the $\sigma^{*}\left(\mathrm{~S}^{\mathrm{II}}-\mathrm{C}_{\mathrm{Ph}}\right)$ is present in $\mathbf{2 5 2}$ and proved the increase in electron density at the central $C$-atom upon the $\mathrm{S}^{\mathrm{IV}}$-to- $\mathrm{S}^{\mathrm{II}}$ substitution in carbodisulfanes resulting in its low stability. 
The group of Fujii targeted the isolation of mixed $\mathrm{P}, \mathrm{S}^{\mathrm{IV}}$-bis(ylide)s $\mathbf{2 5 5 a - c}$ by increasing the C-S bond strength through the favoring of the $n-\sigma^{*}$ interactions compared to the corresponding $P, S^{\text {II }}$ derivatives. ${ }^{322}$ Thus, bis(ylide)s 255a-c were prepared in a two-step procedure from the corresponding $\left[\mathrm{MePAr}_{3}\right][\mathrm{X}]$ salts 254a-c (with $\mathrm{X}$ being $\mathrm{Br}^{-}$or $\mathrm{BF}_{4}^{-}$) and the fluorinated iminosulfonium salt $[\mathbf{2 5 0}]\left[\mathrm{BF}_{4}\right]$ via multiple deprotonations (Scheme 162). Interestingly, whereas bis(ylide) 255a decomposes at room temperature in presence of air to give $\mathrm{Ph}_{3} \mathrm{P}(=\mathrm{O})$ after a day, 255c is more robust (thermally, air and moisture stable compound for at least three months), and represents the first stable P,S $\mathrm{S}^{\mathrm{IV}}$ bis(ylide). The remarkably high stability shown by $\mathbf{2 5 5 c}$ brings new life to the chemistry of bis(ylide)s, and may create new research opportunities in related fields such as catalysis development. The isolated bis(ylide)s 255a-c were fully characterized by ${ }^{1} \mathrm{H},{ }^{31} \mathrm{P}$ and ${ }^{13} \mathrm{C}$ NMR experiments, including the signals attributed to the bis(ylidic) $C$-atom in ${ }^{13} \mathrm{C}$ NMR resonating at $\delta_{\mathrm{ppm}}=23.1\left(\mathrm{~d},{ }^{1} J_{\mathrm{C}, \mathrm{P}}=61.6 \mathrm{~Hz}, \mathbf{2 5 5 a}\right), 23.0$ $\left(\mathrm{d},{ }^{1} J_{\mathrm{C}, \mathrm{P}}=57.9 \mathrm{~Hz}, \mathbf{2 5 5 b}\right)$ and $23.6\left(\mathrm{~d},{ }^{1} J_{\mathrm{C}, \mathrm{P}}=61.9 \mathrm{~Hz}, \mathbf{2 5 5}\right)$. In addition, a comparative study of the electron donating ability of these mixed $\mathrm{P}, \mathrm{S}^{\mathrm{IV}}$-bis(ylide)s $\mathbf{2 5 5 a - c}$ was performed by cyclic voltammetry measurements. 255a-c exhibit irreversible oxidation processes with experimentally determined onset oxidation potentials $\left(E_{\text {ox }}^{\text {onset }}\right)$ of -0.84 (255a), -0.97 (255b) and $-1.04 \mathrm{~V}(\mathbf{2 5 5 c})\left(v s \mathrm{Fc} / \mathrm{Fc}^{+}\right)$clearly demonstrated the decreasing energy of the HOMOs on the series 255c $>255 \mathbf{b}>255 \mathbf{a}$, and the $E_{\text {ox. }}^{\text {onset }}$ alues of $\mathbf{2 5 5 b}, \mathbf{c}$ are more negative than the ones found for bis(ylide)s $248(-0.45 \mathrm{~V}), \mathbf{2 5 1 a}(-$ $0.73 \mathrm{~V})$ and $251 \mathrm{~b}(-0.92 \mathrm{~V})$. As illustrated in Scheme 162, the identity of 255c was further investigated by chemical reactivity towards methyl iodide and trifluoromethanesulfonic acid (TfOH). Thus, 255c reacts with methyl iodide to afford the expected $C$-methylated salt $[\mathbf{2 5 5} \mathbf{c}-\mathrm{Me}][\mathrm{I}]$ in nearly quantitative yield, and further evolves upon acid treatment to give the vinylphosphonium salt [256][OTf] in 92\% global yield. Proof of concept for the four-electron donation capacity of bis(ylide)s 255a,c was provided 
upon coordination to $\left[\mathrm{AuCl}\left(\mathrm{PPh}_{3}\right)\right]$ (further details are shown in the Coordination chemistry of double ylides to metallic species section).

The structure of $\mathbf{2 5 5} \mathbf{c}$ was additionally characterized by EA and definitively confirmed by X-ray diffraction analysis of single crystals. The measured $d_{P-C}$ of $1.663 \AA$ in $\mathbf{2 5 5} \mathbf{c}$ is longer than the $d_{P-C}$ of $1.635 \AA$ found in hexaphenylcarbodiphosphorane $(\mathbf{1 3 0}),{ }^{264}$ but close to the $\mathrm{d}_{\mathrm{P}-\mathrm{C}}$ of $1.667 \AA$ reported for the mixed P, $\mathrm{S}^{\mathrm{II}}$-bis(ylide) $\mathbf{2 4 1 \mathbf { b }}$. $^{312}$ Of special interest was the $\mathrm{d}_{\mathrm{S}(\mathrm{IV})-\mathrm{C}}$ of $1.602 \AA$ found in $\mathbf{2 5 5}$, being the shortest $\mathrm{S}-\mathrm{C}$ bond distance known in any bis(ylide). In addition, the $\mathrm{P}-\mathrm{C}-\mathrm{S}^{\mathrm{IV}}$ angle of $125.6^{\circ}$ in $\mathbf{2 5 5 c}$ is included in between the $\mathrm{P}-\mathrm{C}-\mathrm{P}$ angles observed in acyclic $\mathrm{CDPs}$ (from $130.1^{\circ}$ to $180^{\circ}$ ) and the $\mathrm{P}-\mathrm{C}-\mathrm{S}^{\mathrm{IV}}$ angle of $116.8^{\circ}$ determined for carbobis(iminosulfane) 248. All these crystallographic data points to the efficient stabilization of the electron pair $\left(\mathrm{n}_{\sigma \mathrm{C}}+\mathrm{n}_{\pi \mathrm{C}}\right)$ by negative hyperconjugation with the $\sigma^{*}\left(\mathrm{~S}-\mathrm{C}_{\mathrm{Ph}}\right)$ orbitals (n- $\sigma^{*}$ interaction).

Scheme 162. Isolation of the mixte $P, S^{I V}$-bis(ylide)s $255 a-c$ and their chemical behavior towards methyl iodide, trifluoromethanesulfonic acid and moisture.

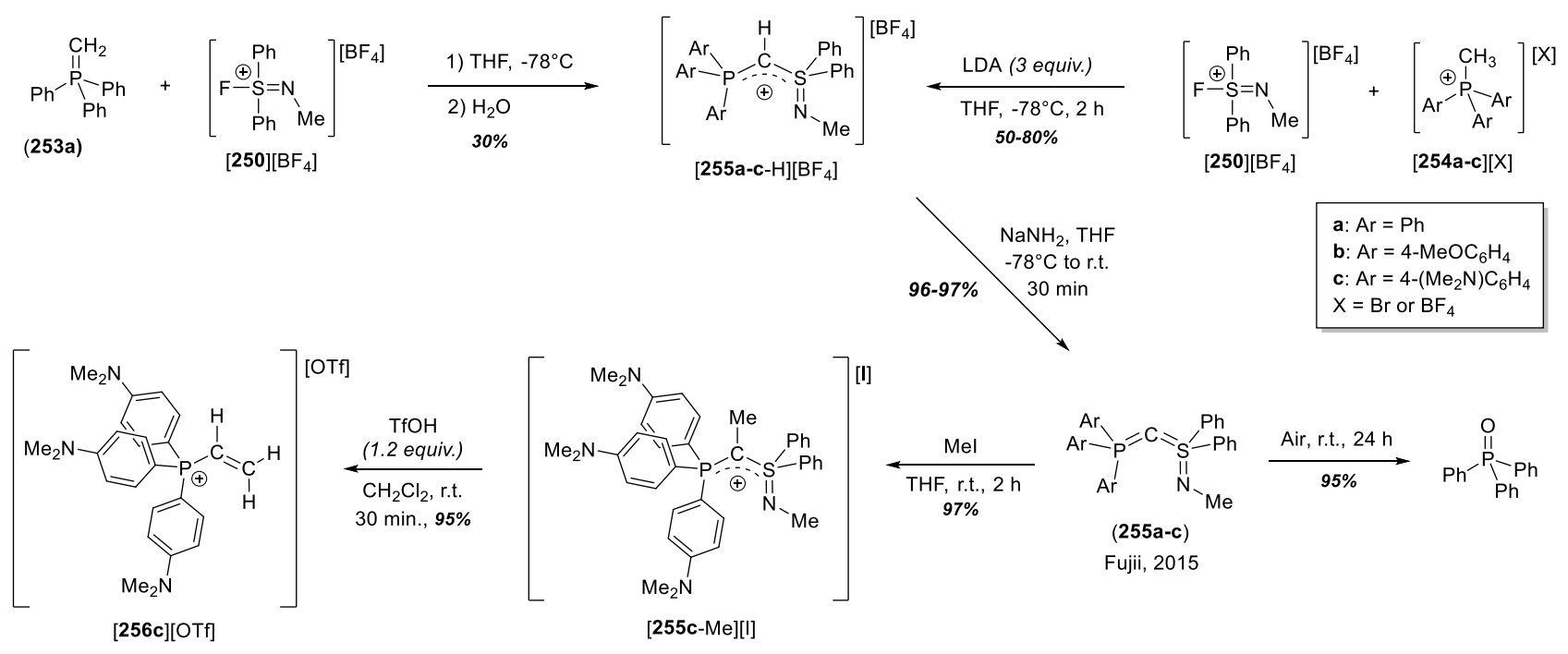


In 2018, Maerten and Baceiredo have accomplished the two-step synthesis of the mixed P, $\mathrm{S}^{\mathrm{IV}}$-bis(ylide) 258 starting from chlorophosphonium salt $[\mathbf{2 4 0 b}][\mathrm{Cl}]$ and the methyldiphenylsulfoxonium salt [257][OTf]. ${ }^{323}$ The ylide [258-H][OTf] was prepared by addition of LDA (2 equiv.) to a mixture of salts [240b][Cl] and [257][OTf] and subsequently transformed to bis(ylide) 258 upon deprotonation. After isolation (76\%), 258 was fully characterized by HRMS analysis and multinuclear NMR experiments. Interestingly, the bis(ylidic) $C$-atom was clearly identified in ${ }^{13} \mathrm{C} N \mathrm{NR}$ resonating as a doublet signal at a very diagnostic upfield chemical shift $\left(\delta_{\mathrm{ppm}}=31.2, \mathrm{~d},{ }^{1} J_{\mathrm{C}, \mathrm{P}}=84.9 \mathrm{~Hz}\right)$.

Single-crystals of $\mathbf{2 5 8}$ were grown and the XRD analysis confirmed its atom connectivity. Remarkably, the value of $1.5929(14) \AA$ measured for the $\mathrm{d}_{\mathrm{S}(\mathrm{IV})-\mathrm{C}}$ in $\mathbf{2 5 8}$ represents the shorted $\mathrm{S}-\mathrm{C}$ bond distance reported to date in the family of bis(ylides) (typically ranging from 1.602 to $1.713 \AA$ ). In addition, the $\mathrm{S}^{\mathrm{IV}}-\mathrm{O}$ and the $\mathrm{S}^{\mathrm{IV}}-\mathrm{C}_{\mathrm{Ph}}$ bond distances are slightly increased $v s$ those found in [258-H][OTf] while the $\mathrm{P}-\mathrm{C}-\mathrm{S}$ angle remained almost constant $\left\{120.74(8)^{\circ}\right.$ in 258 vs $120.98(9)^{\circ}$ in $\left.[\mathbf{2 5 8}-\mathrm{H}][\mathrm{OTf}]\right\}$. All these crystallographic features clearly indicate the delocalization of the two lone pair at the $C$-atom across the sulfoxide moiety.

Scheme 163. Synthesis of the mixed $P, S^{I V}$-bis(ylide) 258 and its nucleophilic reactivity towards methyl iodide. 
$[\overbrace{\mathrm{N}-\mathrm{P}^{\prime}-\mathrm{i} P \mathrm{Cl}}^{\mathrm{N}}]_{\mathrm{Ph}}^{\prime}$

$[240 \mathrm{~b}][\mathrm{Cl}]$

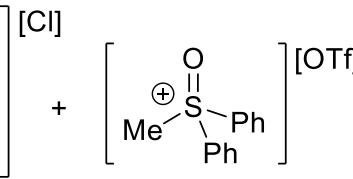

[257][OTf]

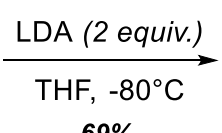

$69 \%$

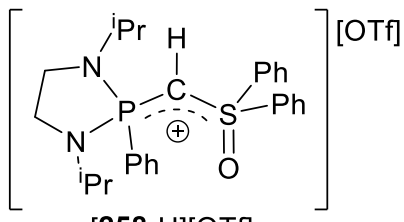

[258-H][OTf]

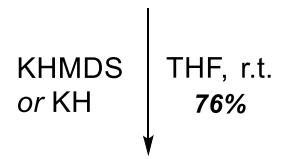

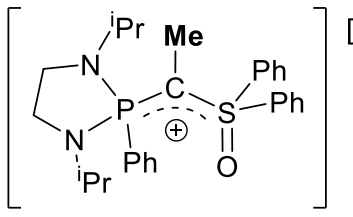

[258-Me][l]

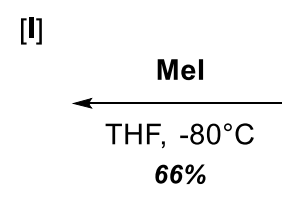

$66 \%$

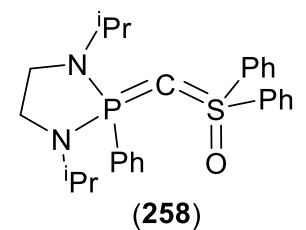

Maerten and Baceiredo, 2018

The reactivity of bis(ylide) $\mathbf{2 5 8}$ towards methyl iodide and transition metals was explored and confirmed the strong nucleophilicity of the central carbon. Evaluation of the electron-donating ability of the mixed $\mathrm{P}, \mathrm{S}^{\mathrm{IV}}$-bis(ylide) 258 toward transition metals was carried out by coordination to the $\left[\mathrm{AuCl}\left(\mathrm{SMe}_{2}\right)\right]$ precursor (proof for the four electron donor capacity), as well as by preparing the complex $\left[(\mathbf{2 5 8}) \mathrm{RhCl}(\mathrm{CO})_{2}\right]$. The average $\mathrm{CO}$-stretching frequency of $2016 \mathrm{~cm}^{-1}$ measured in complex $\left[(\mathbf{2 5 8}) \mathrm{RhCl}(\mathrm{CO})_{2}\right]$ was compared to NHCs $\left(2060-2036 \mathrm{~cm}^{-1}\right)$, parent bent-allenes and carbodicarbenes $\left(2018-2014 \mathrm{~cm}^{-1}\right)$ and the cyclic CDP $\mathbf{2 2 8 b}\left(2001 \mathrm{~cm}^{-1}\right){ }^{308}$ This comparative study proved bis(ylide) 258 to be higher electron-donating ligand than NHCs, albeit weaker than cyclic carbodiphosphorane 228b (the coordination chemistry of $\mathbf{2 5 8}$ to $\mathrm{Au}$ and $\mathrm{Rh}$ precursors will be deeply disseminated in the Coordination chemistry of double ylides to metallic species section).

In 2009, Fürstner prepared a family of phosphacumulenes of the type $\mathrm{Ph}_{3} \mathrm{P}=\mathrm{C}=\mathrm{CR}_{2}(\mathbf{2 6 0}, \mathbf{2 6 2 a}, \mathbf{b}$ and $\mathbf{2 6 4 a , b})$ to evaluate their chemical behavior and four-electron donor capacity towards $\left[\mathrm{AuCl}\left(\mathrm{SMe}_{2}\right)\right]$ and $\mathrm{GaCl}_{3}$ Lewis acids (Scheme 164). ${ }^{324-329}$ Compound 260 was obtained in a two-step procedure from $\mathrm{PPh}_{3}$ 221 
and 9-bromomethylene-9H-fluorene (259). It was found to be highly instable and was characterized by low-temperature ${ }^{1} \mathrm{H},{ }^{31} \mathrm{P}$ and ${ }^{13} \mathrm{C}$ NMR experiments. As reported by Bestmann, ${ }^{325} \mathbf{2 6 2 b}$ can be synthesized in $85 \%$ yield from a one-pot reaction between $\mathrm{Ph}_{3} \mathrm{P}=\mathrm{CH}_{2}$ and $\mathbf{2 6 1 b}$, whereas the isolation of $\mathbf{2 6 4 b}$ requires the synthesis of intermediate $[\mathbf{2 6 4 b}-\mathrm{H}]\left[\mathrm{BF}_{4}\right]$ and subsequent deprotonation with $\mathrm{NaNH}_{2} / \mathrm{NH}_{3}$. A similar synthetic scheme was described by Fürstner ${ }^{324}$ for the synthesis of phosphacumulene 264a starting from the analogous precursor (dimethylaminocarbonylmethylene)triphenylphosphorane (263a). ${ }^{329}$ Phosphacumulenes 262b, 264a and 264b were characterized by multinuclear NMR, accompanied by IR and HRMS analysis in the case of 264a. More interesting was the observed reactivity towards the $\left[\mathrm{AuCl}\left(\mathrm{SMe}_{2}\right)\right]$ precursor, providing a clear picture of the donation ability of the abovementioned phosphacumulenes. Interestingly, it was shown that ligands 260, 262a,b and $264 \mathbf{a}$ are able to coordinate to one $\mathrm{Au}(\mathrm{I})$-center, whereas phosphallene $\mathbf{2 6 4 b}$ allowed to reach the geminal diaurated complex [264b-(AuCl $)_{2}$ ] (the bonding of phosphacumulenes 260, 262a,b and 264a to Lewis metals will be discussed below in the Coordination chemistry of double ylides to metallic species section). The geminal diaurated complex $\left[\mathbf{2 6 4 b}-(\mathrm{AuCl})_{2}\right]$ was characterized by multinuclear NMR, IR, EA and its identity was unequivocally proved by XRD analysis of single crystals. The isolation and full characterization of this geminal diaurated species $\left[\mathbf{2 6 4 b}-(\mathrm{AuCl})_{2}\right]$ illustrates the excellent coordination capacity of 264b, and represents a definitive proof on the presence of two lone pair $\left(\mathrm{n}_{\sigma \mathrm{C}}+\mathrm{n}_{\pi \mathrm{C}}\right)$ at the bis $(\mathrm{ylide}) \mathrm{C}$ atom. Bisylure 264b was alternatively described as a $\mathrm{C}^{0}$-coordination complex stabilized by the triphenylphosphine and the dialcoxycarbene ligands, thereby having two lone pair located at the $\mathrm{C}^{0}$-center (i.e. carbone compounds; the particular bonding situation of this class of compounds is disseminated in the Electronic structure of double ylides section). 
Scheme 164. Syntheses of heterocumulenes 260, 262a,b and 264a,b and formation of the geminal diaurated compound $\left[264 \mathrm{~b}-(\mathrm{AuCl})_{2}\right]$. Proof of concept for the four-electron donation in phosphaallenes.<smiles></smiles>

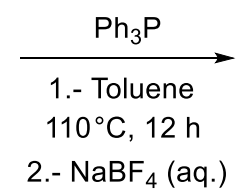

$48 \%$<smiles>CC(Cc1ccccc1-c1ccccc1)C(Br)Br</smiles>

$[260-\mathrm{H}]\left[\mathrm{BF}_{4}\right]$

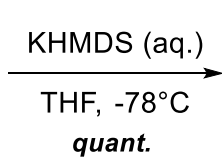

quant.<smiles>O=C(C=C1c2ccccc2-c2ccccc21)P(c1ccccc1)c1ccccc1</smiles>

Fürstner, 2009

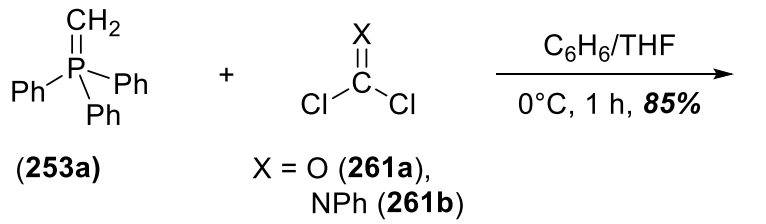<smiles>O=C=C=P(c1ccccc1)(c1ccccc1)c1ccccc1</smiles>

(262a)

now commercially available (eq.1)<smiles>[O]</smiles><smiles>C=C(C=C=Nc1ccccc1)[PH](c1ccccc1)(c1ccccc1)c1ccccc1</smiles>

(262b)

Bestmann, 1980

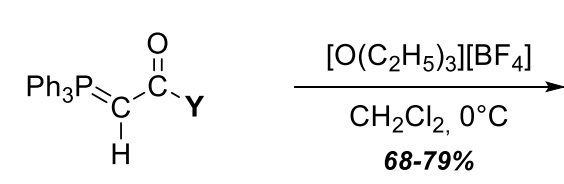

$\mathrm{Y}=\mathrm{NMe}_{2}$ (263a),

OEt (263b)

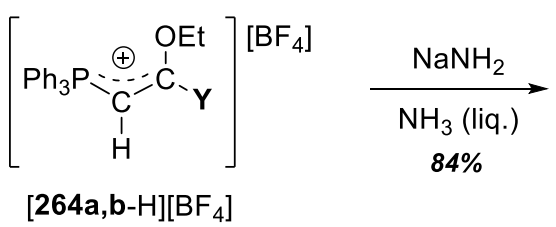

48\% $\downarrow \begin{gathered}\mathrm{NaNH}_{2} \\ \mathrm{NH}_{3} \text { (liq.) }\end{gathered}$<smiles>CCOC(=C=P(c1ccccc1)(c1ccccc1)c1ccccc1)OCC</smiles>

Bestmann, 1973

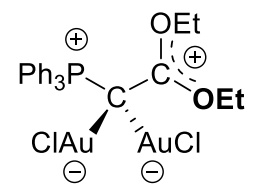

[264b-(AuCl $)_{2}$ ] 
In 1985, Schmidbaur and Nusstein carried out the synthesis of the unique, very sensitive carbodiarsane $\mathrm{MePh}_{2} \mathrm{As}=\mathrm{C}=\mathrm{AsPh}_{2} \mathrm{Me}\left(\mathbf{2 6 5} ;\right.$ Scheme 165). ${ }^{330}$ In analogy with its analogue carbodiphosphorane $\mathrm{MePh}_{2} \mathrm{P}=\mathrm{C}=\mathrm{PPh}_{2} \mathrm{Me}(\mathbf{1 5 4}$; see Scheme 140), the carbodiarsane 265 was prepared in $32 \%$ global yield following a two-step procedure involving the double quaternization of bis(diphenylarsino)methane with methyl fluorosulfate, and its subsequent deprotonation with $\mathrm{NaNH}_{2}$ in liquid ammonia.

Scheme 165. Synthesis of $\mathrm{MePh}_{2} \mathrm{As}=\mathrm{C}=\mathrm{AsPh}_{2} \mathrm{Me}(265)$ and its protonolysis to yield salt [265$\mathbf{H}][\mathbf{C l}]$.<smiles>c1ccc([AsH2]c2ccccc2)cc1</smiles>

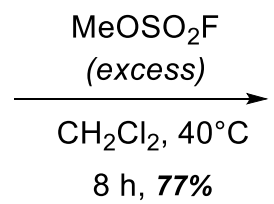

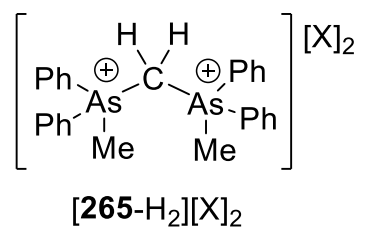
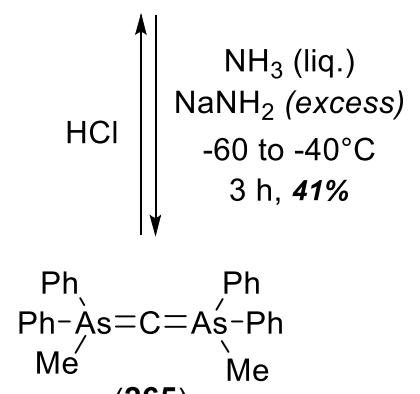
(265)

Schmidbaur, 1985

\subsection{Electronic strucutre of carbodiphosphoranes and other related heteroatom-stabilized bis(ylide)s.}

The electronic structure of carbodiphosphoranes CDPs $\mathrm{R}_{3} \mathrm{P}=\mathrm{C}=\mathrm{PR}_{3}$ was the subject of early interest after their synthesis. This discussion was fed by the contemporary considerations on the electronic structure of phosphorus ylides. ${ }^{331}$ A model that could explain altogether the short P-C bond length, the long 
P-R bond lengths as well as the nucleophilic reactivity at carbon was to be established. In the case of carbodiphosphoranes, the values of the P-C-P angle was an additional point to discuss, with linear P-CP bond angle being reminiscent of allenic structure (Scheme 1, left), and acute one of a zwitterionic structure (Scheme 1, middle). It was however recognized quite early that the bending potential surface of carbodiphosphoranes might be quite flat at least in the case of hexaphenylcarbodiphosphorane, 3, since a variety of bond angles were measured in different crystalline forms, ${ }^{262,264}$ one of them featuring even two very different bond angles in a same unit cell. ${ }^{263}$ Coming back to the seminal question of the electronic structure of ylides: a) the exclusion of the possibility of a $C=P$ double bond via $p$ - $d$ overlap; b) the presence of a strong negative charge at $\mathrm{C}$ (stabilized by $\pi$-accepting substituents) responsible for its reactivity and coordinative properties; c) the possibility of negative hyperconjugation in the adjacent P-R $\sigma^{*}$ orbitals, were progressively established and pledged for the predominance of a zwitterionic structure. ${ }^{332}$ A more unconventional description of ylides was also proposed, in agreement with the synthesis by addition of a phosphine to a carbene in the 1960 's. ${ }^{333}$ According to this description, phosphorus ylides can be envisaged as phosphine-stabilized carbenes, and this description of the P-C bond as a dative interaction between a phosphorus and a carbon was extended to carbodiphosphorane $\mathrm{e}^{334,335}$ (Scheme 166, right).

Scheme 166. Mesomeric forms used for the description of the binding situation in carbodiphosphoranes.

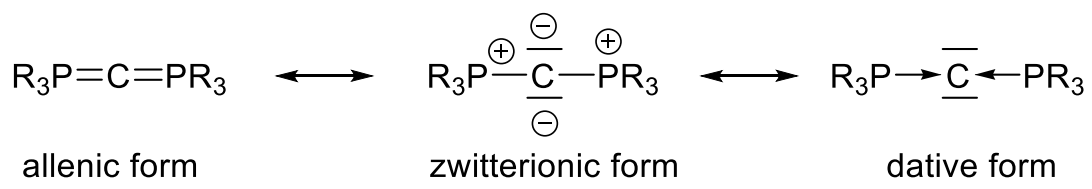


In fact, this last description corresponds to a methodology that was widely used in theoretical chemistry in the 1970's for the building of molecular orbitals; made via fragment orbitals interaction diagram. In this frame, the molecular orbitals of ylides and carbodiphosphoranes were initially built through stepwise combination of the well-known $\mathrm{PH}_{3}$ fragment orbitals with those of a non-hybridized, neutral carbon bearing 4 electrons (Scheme 167). ${ }^{336}$ Note that in this description, the bond between phosphorus and carbon is considered as covalent, in the same way as interacting two $\mathrm{CH}_{3}$ fragments leads to the building of $\mathrm{C}_{2} \mathrm{H}_{6}$ with a covalent $\mathrm{C}-\mathrm{C}$ bond.

Scheme 167. Building of the molecular orbitals of model compound $\mathrm{H}_{3} \mathrm{PCPH}_{3}(266)$ by successive interactions between fragment orbitals, on the basis of a linear geometry.

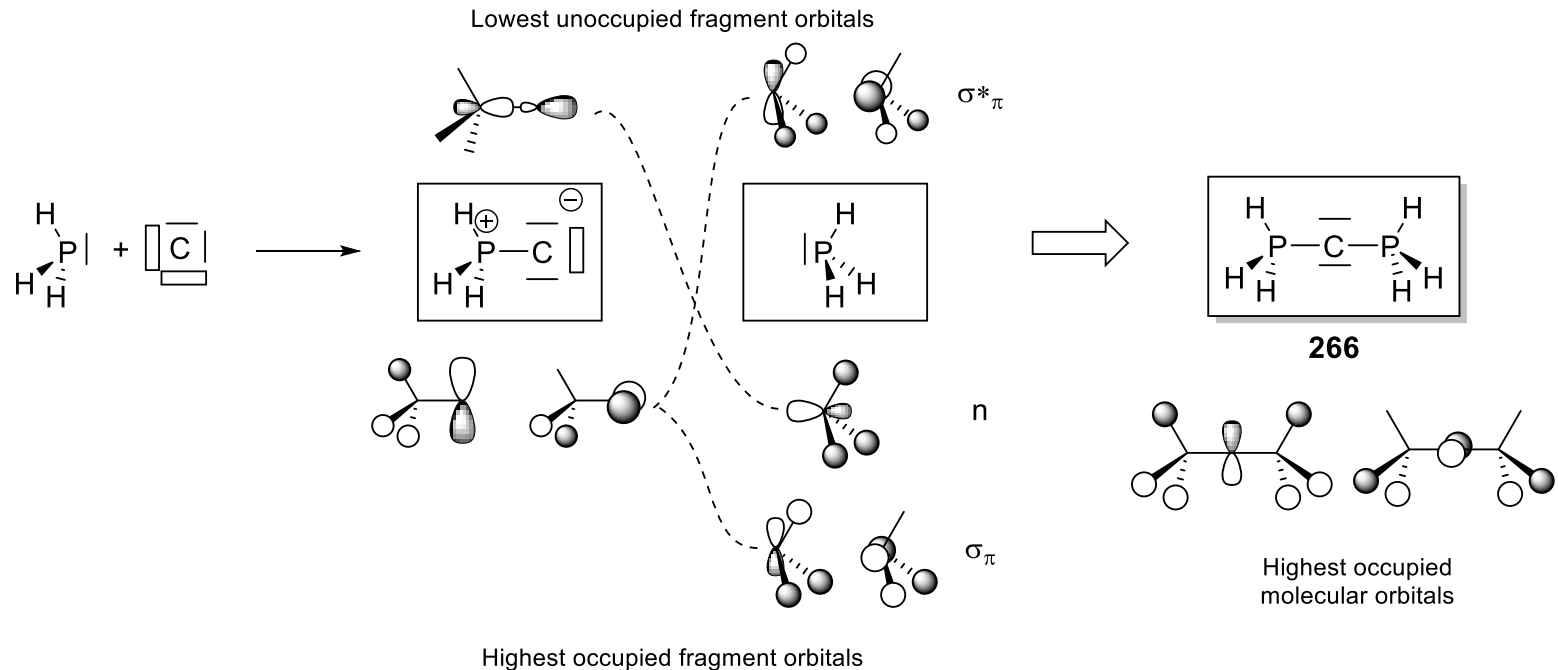

In this model, the presence of two lone pairs at carbon was illustrated by the important coefficients at carbon in the two degenerate highest occupied molecular orbitals. The influence of substituents at carbon on bending was discussed in the light of the energy level of $\pi$ donor and $\pi^{*}$ acceptor orbitals of the substituent at $\mathrm{C}-\sigma_{\pi}$ and $\sigma^{*}{ }_{\pi}$ orbitals in the case of carbodiphosphoranes, which refers to negative hyperconjugation. Linear structures are predicted to be observed with strong $\pi$-accepting substituent, con226 
sistent with the increase of the double bond character of the carbon-substituent interaction, going toward an allenic structure. In this model, carbodiphosphoranes should be bent, $\sigma^{*}{ }_{\pi}$ orbitals being poor acceptors. The author highlight the small energetic cost of the bending of the PCP bond angle to explain the large P-C-P bond measured in the solid state.

A different approach was proposed by Glidewell who considered second-order Jahn-Teller effect to be central to the determination of the bond angle in hexasubstituted triatomic structures. ${ }^{337}$ According to this model, the difference in bonding energies of the valence electrons of the three atoms is determining the equilibrium geometry of the molecule and the amplitude of its bending vibration. This difference in bonding energies is conditioning the amplitude of the gap between the frontier orbitals of the triatomic, eight valence-electrons system in its linear conformation, i.e. two degenerated and occupied $\pi_{\mathrm{u}}$ orbitals and one empty $\sigma_{\mathrm{g}}$ orbital (Scheme 168). Note that the two occupied $\pi_{\mathrm{u}}$ orbitals correspond to two lone pairs at the central atom. A small gap is expected if the central atom has a higher bonding energy than the terminal ones (for example, if it is more electronegative than the two others); a large gap is expected in the opposite situation. According to second-order Jahn-Teller effect, if this gap is small, then an efficient overlap between $\sigma$ orbitals of the terminal atoms and p orbitals of the central atom is created upon bending, and the bent conformation is more stable; if this gap is large, then the linear structure is preferred with a weak amplitude for the bending vibration. If the three atoms have similar bonding energies, then large amplitude bending vibration occurs and the structure is very fluxional. Carbodiphosphoranes belongs to this last category, binding energies of $\mathrm{P}(3 \mathrm{p})$ and $\mathrm{C}(2 \mathrm{p})$ being comparable. 

small energy gap on the equilibrium geometry.

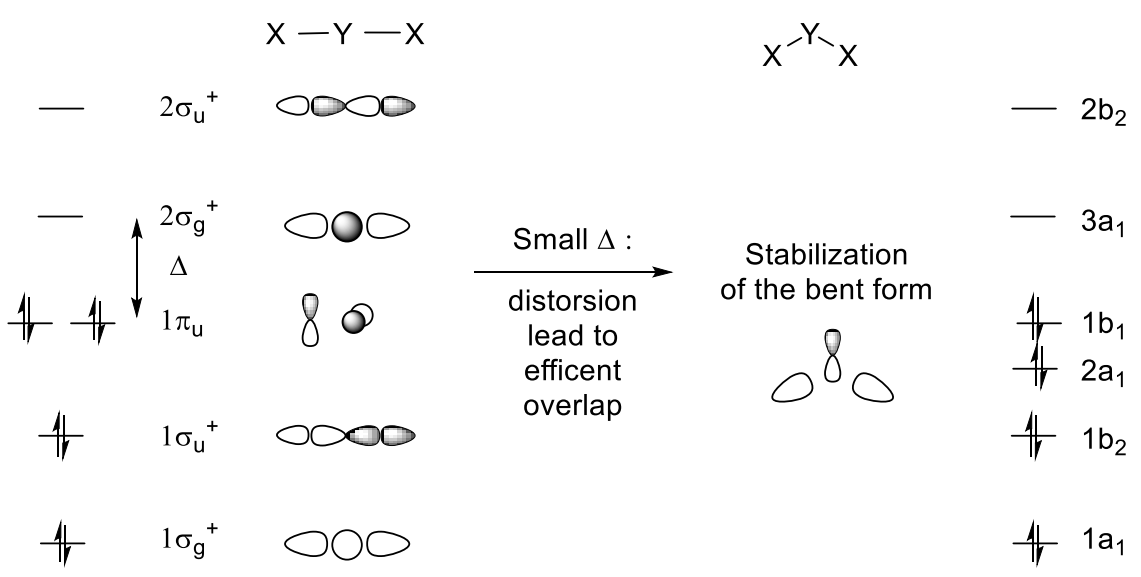

This discussion of the equilibrium geometry in terms of correlation diagram was recently completed in a study highlighting the balance between stabilization of the bent geometry through improved overlap between $\sigma_{\mathrm{P}}$ and $\mathrm{p}_{\mathrm{C}}$ (or $\pi_{\mathrm{u}}$ with the previous notation) and destabilization of the adjacent filled P-R $\sigma_{\pi}$ orbital of the phosphorus substituents by interaction with this same filled $\mathrm{p}_{\mathrm{C}}$ orbital. ${ }^{265}$ These competing interactions result in a very shallow bending potential for hexaphenylcarbodiphophorane 130, which appears to be even more shallow than this of the isoelectronic $\mathrm{Ph}_{3} \mathrm{SiOSiPh}_{3}$ and $\mathrm{Ph}_{3} \mathrm{PNPPh}_{3}{ }^{+}$.

The description of the electronic structure of carbodiphosphoranes was brought up to date in 2006 by Frenking with a first paper using Natural Bond Orbital (NBO) analysis to describe the electronic structure of hexamethylcarbodiphosphorane $\mathbf{1 3 5} .^{338,339}$ Two lone pairs at carbon were found, as well as two P-C $\sigma$-bonding orbitals, which were interpreted as a donor-acceptor interaction between the phosphorus lone-pairs (which were not otherwise described amongst the natural orbitals) and the carbon atom, its two lone pairs being interpreted as its four valence electrons. This was the ground of the renewal of the "divalent Carbon (0)" denomination for the description of the electronic configuration of carbon in car228 
bodiphosphoranes and related molecules. The central carbon was found to retain an important negative charge even through successive protonations (from $-1.43 \mathrm{e}$ in the neutral molecule to $-1.07 \mathrm{e}$ in the dicationic, doubly protonated one). Proton affinities and bond dissociation energies between variously substituted carbodiphosphoranes and a set of Lewis acids were also calculated, showing a strong first protonation affinity comparable to this of $\mathrm{N}$-heterocyclic carbenes and predicting the double coordination of $\mathrm{BH}_{3}, \mathrm{BCl}_{3}$ and $\mathrm{AlCl}_{3}$ to $\mathrm{H}_{3} \mathrm{PCPH}_{3}(\mathbf{2 6 6})$ and $\mathrm{Me}_{3} \mathrm{PCPMe}_{3}(\mathbf{1 3 5})$, but only $\mathrm{BH}_{3}$ would make a double adduct with $\mathrm{Ph}_{3} \mathrm{PCPPh}_{3}$.

Considering the similarities between phosphine and N-heterocyclic carbenes in coordination chemistry, this study was extended to molecules where the $\mathrm{Ph}_{3} \mathrm{P}$ moiety of hexaphenylcarbodiphosphorane has been replaced by proton (267) or methyl (268) substituted N-heterocyclic carbene (Scheme 169) to form a "carbodicarbene". ${ }^{340}$ Here again, the bending potential was found to be very shallow, with little energy changes upon bending of the C-C-C angle and twisting the NHCs plane. Both HOMO and HOMO-1 featured a strong coefficient at the central carbon with $\sigma$ and $\pi$ symmetry respectively, in agreement with the presence of two lone pairs at carbon. A delocalization of the $\pi$ lone pair toward the two vacant C-centered orbitals of the adjacent carbene fragments is also seen in HOMO-1, as reflected by the allenic structure in Scheme 169, and making this molecule a relative to electron-rich allenes, and more specifically to tetraaminoallenes (see below). First and second proton affinities were calculated. First proton affinity was found to be higher in carbodicarbenes CDCs than in carbodiphosphoranes CDPs. Second proton affinity is sensitive to the nature of substituents but is comparable and slightly lower to this of carbodiphosphoranes. Tetraaminoallene $\mathbf{2 6 9}$ was included in this study and was found to have similar properties, with a shallow bending potential and first and second proton affinities of intermediate 
values. From the higher value of the first proton affinity of carbodicarbenes, they were predicted as being stronger nucleophiles than both carbodiphosphoranes and tetraaminoallenes.

Scheme 169 : From phosphine to carbene for the building of novel yldiide and relation to electronrich allenes.<smiles>[PbH]P([PbH2]P[PbH2])c1ccccc1</smiles><smiles>[O-][Pb]C[Pb]</smiles>

130
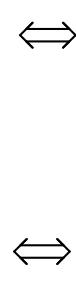<smiles>[R]N1C=CN([R])[IH]1</smiles><smiles>[R]n1ccnc1C=[C-]C(C)C</smiles>

$267 \mathrm{R}=\mathrm{H}$

$268 \mathrm{R}=\mathrm{Me}$

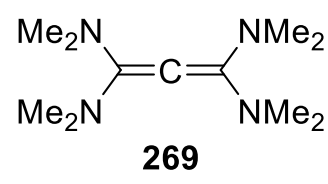

$\Uparrow$<smiles>[R]N1C=CNC1=C=C1NC=CN1[R]</smiles>

Shortly after, the same group proposed another approach to this topic, using bond dissociation energies and energy decomposition analysis (EDA) in addition to NBO and AIM analysis to support the dative bonding scheme in carbodiphosphoranes and carbodicarbenes. ${ }^{341}$ Both NBO and AIM analysis support the presence of two lone pairs at carbon for carbodiphosphoranes. A more ambiguous situation was depicted by NBO analysis for carbodicarbenes, with strongly polarized C-C double bonds, the $\pi$ bond being mostly developed on the central carbon. Charges at $\mathrm{C}$ were also found to be greater in the case of carbodiphosphorane compared to carbodicarbenes (-1.32 e to -1.43 e compared to -0.50$)$. Bond dissociation energy of L-C bonds (L being a phosphine, a N-heterocyclic carbene and other related fragment relevant to carbon (0) molecules) were compared to this of $\mathrm{L}-\mathrm{BH}_{3}$. $\mathrm{L}-\mathrm{C}$ bond dissociation energy appeared to be twice ( $\mathrm{L}=$ phosphine) to three times $\left(\mathrm{L}=\mathrm{N}\right.$-Heterocyclic Carbene) greater than for $\mathrm{L}-\mathrm{BH}_{3}$ ranging from $64.9 \mathrm{kcal} / \mathrm{mol}$ for $\mathrm{PH}_{3}$ (vs $22.7 \mathrm{kcal} / \mathrm{mol}$ for the $\mathrm{BH}_{3}$ adduct) to $99.7 \mathrm{kcal} / \mathrm{mol}$ for the me- 
thyl-substituted N-heterocyclic carbene (vs $54.7 \mathrm{kcal} / \mathrm{mol}$ for the $\mathrm{BH}_{3}$ adduct) at the SCS-MP2 level of theory. To study the carbon-phosphorus interaction through EDA, the C-P bonds are artificially broken to give three fragments (two $\mathrm{R}_{3} \mathrm{P}$, one $\mathrm{C}$ ) according to the following procedure. The geometry of each fragment is the same as in the final molecule; the electronic configuration of each fragment is at the appreciation of the operator and is to be discussed in the light of the calculation results. Here the authors have chosen uncharged fragments obtained by heterolytic cleavage, i.e. attributing four valence electrons to carbon and the two electrons of the $\mathrm{P}-\mathrm{C}$ bond to the phosphine fragment. Within this frame they have restricted their study to closed-shell electronic configurations for all fragments. The molecule is then assembled in three steps, each step requiring a certain amount of energy. Schematically, the first energy $\mathrm{E}_{\text {elec }}$ correspond to the electrostatic interaction between the fragments. The second energy $E_{\text {Pauli }}$ correspond to the anti-symmetrization and renormalization of the global wavefunction including all the electrons of all fragments, i.e. the interaction of electrons of all fragments prior to any overlap or charge transfer. The third one $\mathrm{E}_{\text {orb }}$ is the energy gained through orbital interaction and charge transfer. Bond dissociation energy is obtained by adding the energy required to bring each fragment from its ground state to the chosen electronic configuration. Comparing the results obtained with different electronic configurations of the fragments, the smallest value of $E_{\text {orb }}$ is indicative of the most pertinent fragments configuration. The most pertinent description amongst the electronic configurations envisaged was found to be $\mathrm{s}^{0} \mathrm{p}_{\sigma} 2 \mathrm{p}_{\pi}{ }^{2} \mathrm{p}_{\pi}{ }^{0}$ for $\mathrm{C}$ in carbodiphosphoranes and carbodicarbenes with $\mathrm{E}_{\text {orb }}$ between -527.7 $\mathrm{kcal} / \mathrm{mol}$ and $-600.3 \mathrm{kcal} / \mathrm{mol}$, sustaining the dative bond scheme amongst these molecules. The authors however highlight that the orbital energy calculated for a "carbene-like" or divalent carbon (II) configuration of the $\mathrm{C}$ fragment, i.e. a s $\mathrm{p}_{\sigma} 2 \mathrm{p}_{\pi}{ }^{0} \mathrm{p}_{\pi}{ }^{0}$ configuration, was not much higher than this calculated for a carbon (0). They state that "It is important to realize that the two bonding models are qualitative descrip- 
tions which should not be confused with physical reality. The value of the distinction between the two bonding models and the classification of the two compounds in different categories lies in the explanation of the chemical behavior and the predictions which can be made."

The Lewis base character of carbodiphosphoranes and carbodicarbenes was explored further in a following paper. ${ }^{342}$ Bond dissociation energies of carbodicarbenes- $\mathrm{BH}_{3}$ adducts were found to be higher than carbodiphosphoranes adducts $(-61.4 \mathrm{kcal} / \mathrm{mol}$ for unsubstituted N-heterocyclic carbodicarbenes $\mathbf{2 6 7}$ vs $-34.8 \mathrm{kcal} / \mathrm{mol}$ for $\mathrm{H}_{3} \mathrm{PCPH}_{3}$ (266)). Addition of a second $\mathrm{BH}_{3}$ was found to be less energetic than the first one in the case of carbodicarbenes $(28.4 \mathrm{kcal} / \mathrm{mol}$ for the less favorable one), and of similar magnitude in the case of carbodiphosphoranes. $\mathrm{CO}_{2}$ was found to be added once only, with relatively low bond dissociation energies (from $7.8 \mathrm{kcal} / \mathrm{mol}$ for the synthetically isolated hexaphenylcarbodiphosphorane- $\mathrm{CO}_{2}$ adduct to $17.3 \mathrm{kcal} / \mathrm{mol}$ for the methylated $\mathrm{N}$-heterocyclic carbodicarbenes 268 ). EDA analysis was also performed to investigate the dative interaction between the carbon(0) molecules and $\mathrm{BH}_{3}$ or $\mathrm{CO}_{2}$. $\mathrm{E}_{\text {orb }}$ was found to range from $-93.6 \mathrm{kcal} / \mathrm{mol}$ for the model $\mathrm{H}_{3} \mathrm{PCPH}_{3}(\mathbf{2 6 6})$ to $-131.7 \mathrm{kcal} / \mathrm{mol}$ for methylated N-heterocyclic carbodicarbenes (268), the trend being in agreement with bond dissociation energies. Adding a second $\mathrm{BH}_{3}$ molecules roughly double these values. Calculation were also made on carbodiphosphoranes and carbodicarbenes coordinated to pentacarbonyl tungsten, triscarbonyl and dicarbonyl nickel. Bond dissociation energies were found to be similar to those of the $\mathrm{BH}_{3}$ adducts, the strongest interactions being found again for unsubstituted N-heterocyclic carbodicarbenes 267 (from $55.8 \mathrm{kcal} / \mathrm{mol}$ in the case of $\mathrm{W}(\mathrm{CO})_{5}$ accepting fragment to $38.6 \mathrm{kcal} / \mathrm{mol}$ for $\left.\mathrm{Ni}(\mathrm{CO})_{3}\right)$. Interactions with $\mathrm{Ni}(\mathrm{CO})_{3}$ fragment were found to be weaker, and those with $\mathrm{Ni}(\mathrm{CO})_{2}$ of similar magnitude $(50.2$ $\mathrm{kcal} / \mathrm{mol}$ for the same ligand). This trend was observed for all substitution patterns at NHC and for $\mathrm{H}_{3} \mathrm{PCPH}_{3}$, but substituted carbodiphosphoranes showed higher dissociation energies with $\mathrm{Ni}(\mathrm{CO})_{2}$. In 232 
any case, the bond dissociation energies with tetraaminoallene 269 as a ligand was found to be weaker of about half of this of carbodicarbenes, but followed the same trend. The weaker interactions in $\mathrm{Ni}(\mathrm{CO})_{3}$ compared to $\mathrm{Ni}(\mathrm{CO})_{2}$, correlated with longer $\mathrm{C}-\mathrm{Ni}$ bond lengths, support the idea that carbodiphosphoranes and carbodicarbenes are four electron-donors, leading to a 18 electrons complex in the case of $\mathrm{Ni}(\mathrm{CO})_{2}$. In all cases, an important residual charge was found on carbon, ranging from -1.41 e to -1.55 e for carbodiphosphoranes and -0.53 to -0.64 for carbodicarbenes. Examination of $E_{\text {orb }}$ divided into $\sigma$ and $\pi$ contribution revealed an exclusively $\sigma$ orbital contribution to the bonding in the case of 16 electrons fragments $\mathrm{W}(\mathrm{CO})_{5}$ and $\mathrm{Ni}(\mathrm{CO})_{3}$, whereas an additionnal strong $\pi$ contribution was found for the 14 electrons fragment $\mathrm{Ni}(\mathrm{CO})_{2}$. Altogether, carbodicarbenes as well as carbodiphosphoranes are predicted to be reasonably good $\sigma$ donor ligands, with the possibility of additional $\pi$ donation through the second lone pair at carbon.

If this dative description of the bonding situation in carbodiphosphorane and its extrapolation to other systems ${ }^{343}$ was subject to controversy amongst the chemists community, ${ }^{339,344,345}$ it has the merit to have brought back in the light the family of carbodiphosphoranes and other unconventional structures, ${ }^{324,}$ 346,347 and paved the way to the vivid field of carbodicarbenes ${ }^{348}$ which have found numerous original applications in not more than ten years (see below).

\subsection{Reactivity of double ylides towards organic compounds.}

As already mentioned in the previous section of this review, hexaphenylcarbodiphosphorane (130) was first isolated by the Ramirez's group in 1961. However, its atom connectivity was not definitively established until 1971 when Vincent and Wheatley reported its X-ray diffraction analysis. During this decade, amongst other techniques, indirect chemical methods were carried out in order to confirm the pro- 
posed structure for $\mathbf{1 3 0}$ based on its behaviour towards simple organic reagents such as Brönsted acids, alkyl (pseudo)halides, organic oxidants $\left(\mathrm{Br}_{2}\right)$ and moisture (Scheme 170). ${ }^{349-351}$

Scheme 170. Reactivity of CDP 130 vs water, hydrochloric acid, bromine and organic electrophiles.

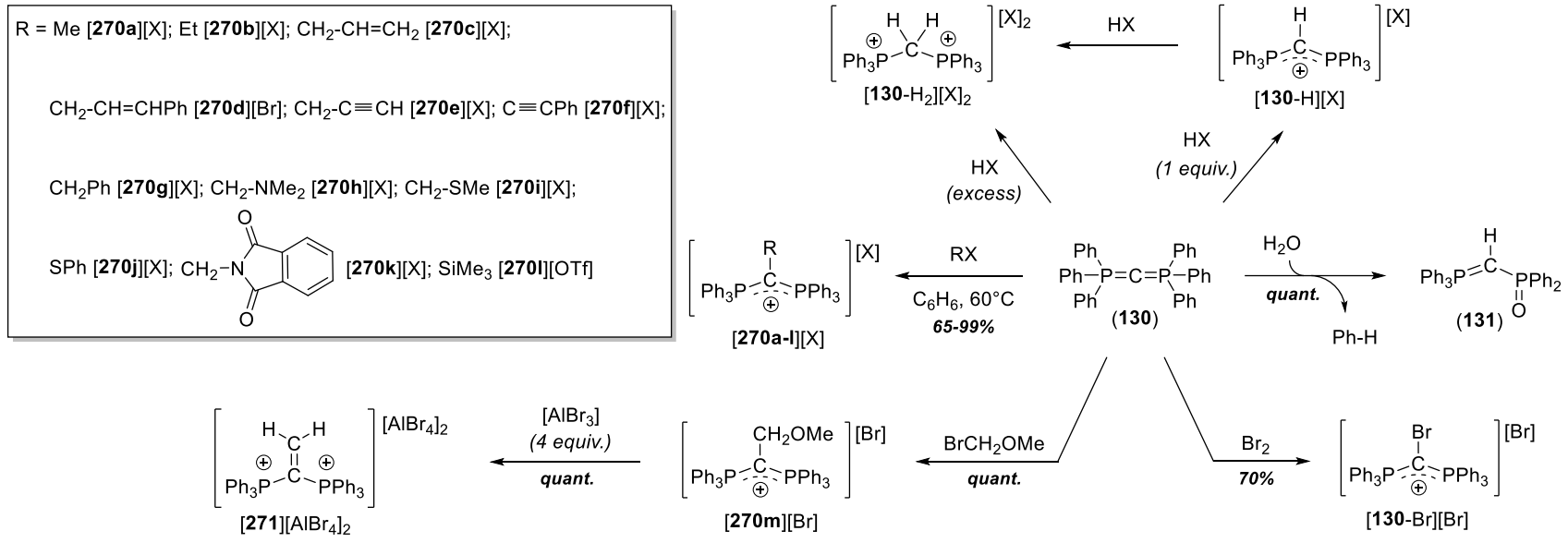

Exposing 130 to moisture in diglyme allows for the releasing of benzene to afford the ylide $\mathrm{Ph}_{3} \mathrm{P}=\mathrm{CH}$ $\mathrm{P}(=\mathrm{O}) \mathrm{Ph}_{2}$ (131). The synthesis of ylide 131 was revisited in 2010 by Petz and Neumüller, and was fully characterized by multinuclear NMR, IR and XRD analysis of single crystals. ${ }^{349,350}$

As might be expected, addition of equimolar amounts of a Brönsted acid to $\mathbf{1 3 0}$ gives the $C$-protonated salt $[\mathbf{1 3 0}-\mathrm{H}][\mathrm{X}]$ whereas an excess of HX leads to bis(phosphonium) salt $\left[\mathbf{1 3 0}-\mathrm{H}_{2}\right][\mathrm{X}]_{2}$. Similar results are obtained when mixing 130 with organic electrophiles RX leading to the corresponding monoalkylated salts $[\mathbf{2 7 0 a - k}][X]$ and $[\mathbf{2 7 0 m}][X]$ in moderate to excellent yields $(65-95 \%) .130$ does also react quantitatively with TMS-OTf and [2701][OTf] was fully characterized by common techniques (EA, Raman, NMR, HR-MS). It is to be noted that the double alkylation of the bis(ylidic) $C$-atom of $\mathbf{1 3 0}$ was never achieved even when performing the $C$-methylation reaction in neat MeI. 
Over the following decades to the discovery of hexaphenylcarbodiphosphorane (130), Bestmann and colleagues have dedicated important efforts to depict its utility in organic synthesis. In $1983,{ }^{261}$ they reported the highly selective synthesis of cyclopropane 273 in $65 \%$ yield (Scheme 171). In the same article, the authors described the reaction of $\mathbf{1 3 0}$ and isothiocyanatoacetic acid ester (274) to isolate heterocycle $\mathbf{2 7 5}$ in $65 \%$ yield upon selective crystallization.

Scheme 171. Reactivity studies of CDP 130 conducting to the isolation of cyclopropane 175 and heterocycle 177 reported by Bestmann and Oechsner.

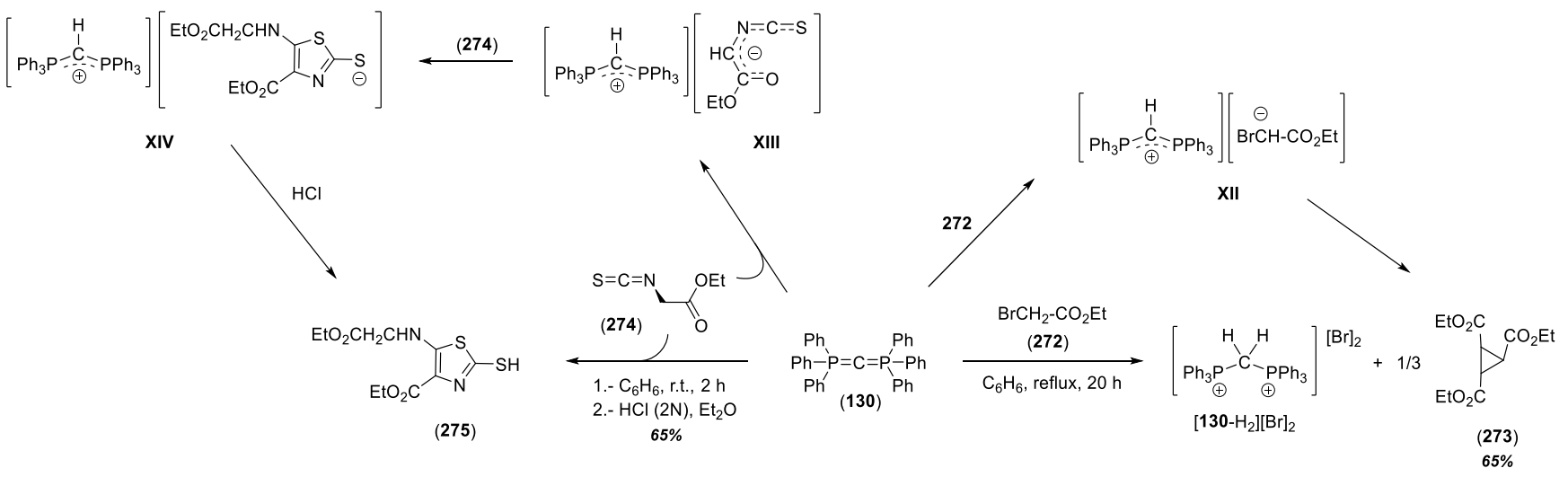

Appel and Veltmann used the strong nucleophilic and basic character $\mathbf{1 3 0}$ to generate derivatives of methylenephosphoranes 184a, 253a and 279 (Scheme 172). ${ }^{352}$ It is to be noted that (dichloromethylene)triphenylphosphorane (184a), is a typically short-lived intermediate whose synthesis was previously achieved in situ from triphenylphosphine and dichlorocarbene s53,354 $^{\text {or carbon tetrachloride }}$ c55-357 $^{350}$ but never isolated. Interestingly, the work of Appel and Veltmann brings an excellent entry to this organic synthon as they succeeded to isolate 184a in 55\% yield by carefully choosing an apolar solvent (mixture chlorobenzene and toluene) to precipitate the respective salts $[\mathbf{1 3 0}-\mathrm{Cl}][\mathrm{Cl}]$ or $[\mathbf{1 3 0}-\mathrm{H}][\mathrm{Cl}]$ happened.

Scheme 172. Synthesis of triphenylphosphoranes 184a, 279 and 253a starting from CDP 130. 235 


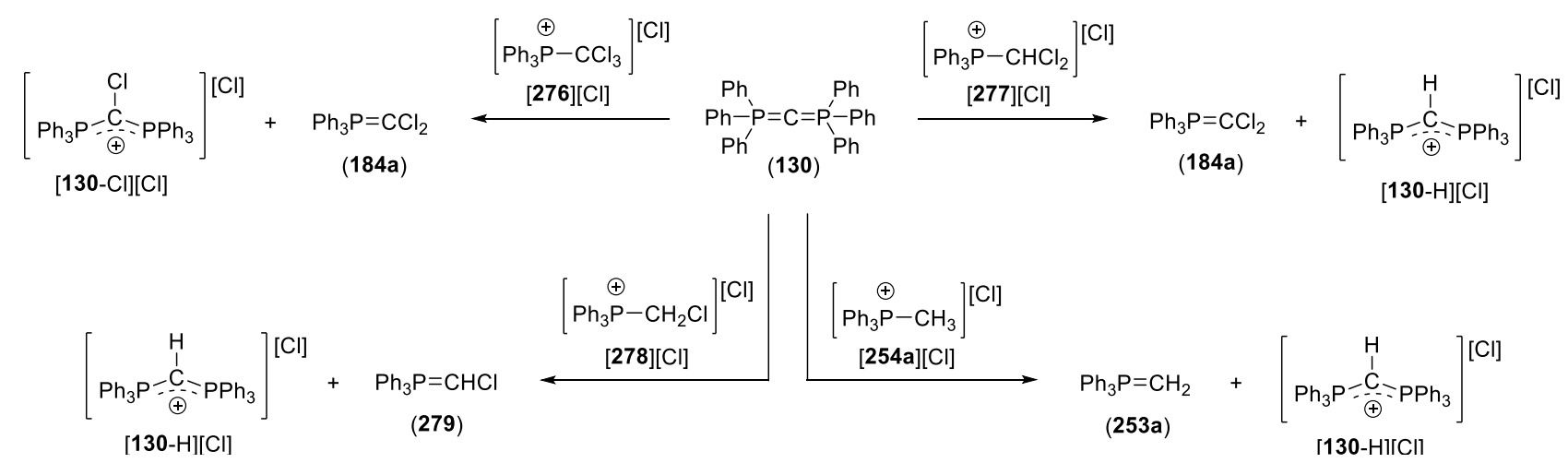

In 1966, ${ }^{358}$ Matthews and co-workers published the adduct formation of $\mathbf{1 3 0}$ with carbon dioxide, carbon disulphide and carbonyl sulphide (Scheme 173) to yield the mesomeric phosphonium inner salts 280, 281 and 282, respectively as highly insoluble species, thus precluding their complete characterization by NMR or IR. Chemical reactivity tests starting from the isolated material were thereby revealed as crucial experiments in order to discern the structure of $\mathbf{2 8 0}$. The reaction with trifluoroacetic or fluoroboric acids produced salt $[\mathbf{2 8 0}-\mathrm{H}][\mathrm{X}]$ that undergoes fast decarboxylation reaction to yield $[\mathbf{1 3 0}$ $\left.\mathrm{H}_{2}\right][\mathrm{X}]_{2}$. In contrast, addition of MeI to $\mathbf{2 8 0}$ yielded [280-Me][I]. ${ }^{358}$

Scheme 173. Synthesis of mesomeric phosphonium inner salts 182,183 and 184 and reactivity of 182 towards MeI and Brönsted acids. 


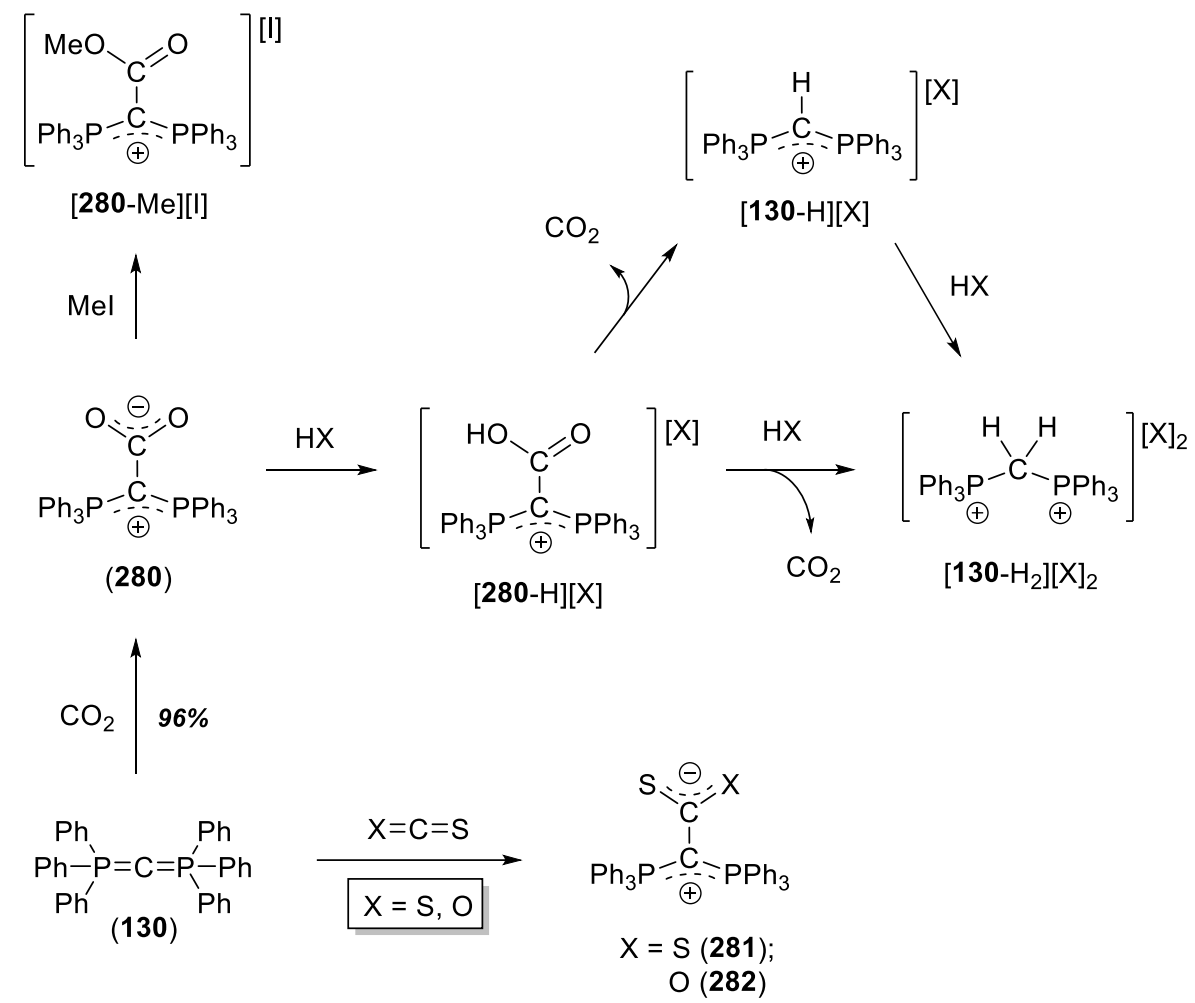

Warming the adduct 280 at $145^{\circ} \mathrm{C}$ in diglyme provided insightful information about its structure since $\mathrm{Ph}_{3} \mathrm{P}=\mathrm{O}$ elimination takes place at this temperature achieving triphenylphosphoranylideneketene, 262a (Scheme 174). ${ }^{359}$ Full characterization of 262a was accomplished by IR, EA, NMR and XRD of single crystals. Interestingly the bond lengths across the phosphacumulene $\left[\mathrm{Ph}{ }_{3} \mathrm{P}=\mathrm{C}=\mathrm{C}=\mathrm{O}\right]$ are remarkably short and the $\mathrm{P}=\mathrm{C}=\mathrm{C}$ bond is unexpectedly bent (measured angle of $145.5^{\circ}$ ), whereas the $\mathrm{C}=\mathrm{C}=\mathrm{O}$ angle is almost linear $\left(175.6^{\circ}\right)$. Same procedure allows for the preparation of the mesomeric inner salts 281 and 282 when using carbon disulphide and carbonyl sulphide instead carbon monoxide. ${ }^{358}$

In a following article ${ }^{360}$ the same group has demonstrated the richness and synthetic value of phosphacumulene 262a. Treatment with carbon disulphide gave the analogous triphenylphosphoranylidenethioketene (283) which was presumably reached via formation of the four-membered cyclic intermediate 284, and subsequent $\mathrm{O}=\mathrm{C}=\mathrm{S}$ gas extrusion (Scheme 174). ${ }^{360}$ Alternatively, the inner salt 281 undergoes 237 
thermal cleavage to build the phosphacumulene $\mathrm{Ph}_{3} \mathrm{P}=\mathrm{C}=\mathrm{C}=\mathrm{S}$ (283) by $\mathrm{Ph}_{3} \mathrm{P}=\mathrm{S}$ elimination reaction. ${ }^{358,360}$ On the one hand, the ylidic character of 262a was proved by its reaction with MeI that produces the salt $[\mathbf{2 8 5}][\mathrm{I}]$ containing the $C$-methylated four-membered cation bearing the triphenylphosphonium moiety. On the other hand, 262a undergoes Wittig reactions with a family of ketones and aldehydes (286a-f) to generate the transient cumulenes $\mathbf{2 8 7 a - f}$. These transient species further react with a second equivalent of 262a, and the four-membered rings 288a-f bearing an ylide function were thus isolated and fully characterized by NMR, EA and mass spectra. The authors noted that this reaction did not proceed when using unactivated ketones such as acetone or fluorenone. Of particular interest to argue in favor of the structures proposed for ylides 288a-f was the observed fragmentations in mass spectra that are consistently similar to the ones found in the cyclic ylides $\mathbf{2 9 0 g , h}$ formed from 262a and ketenes 289g,h (see below in Scheme 174).

Scheme 174. Synthesis of triphenylphosphoranylideneketene (185) and its synthetic value. 


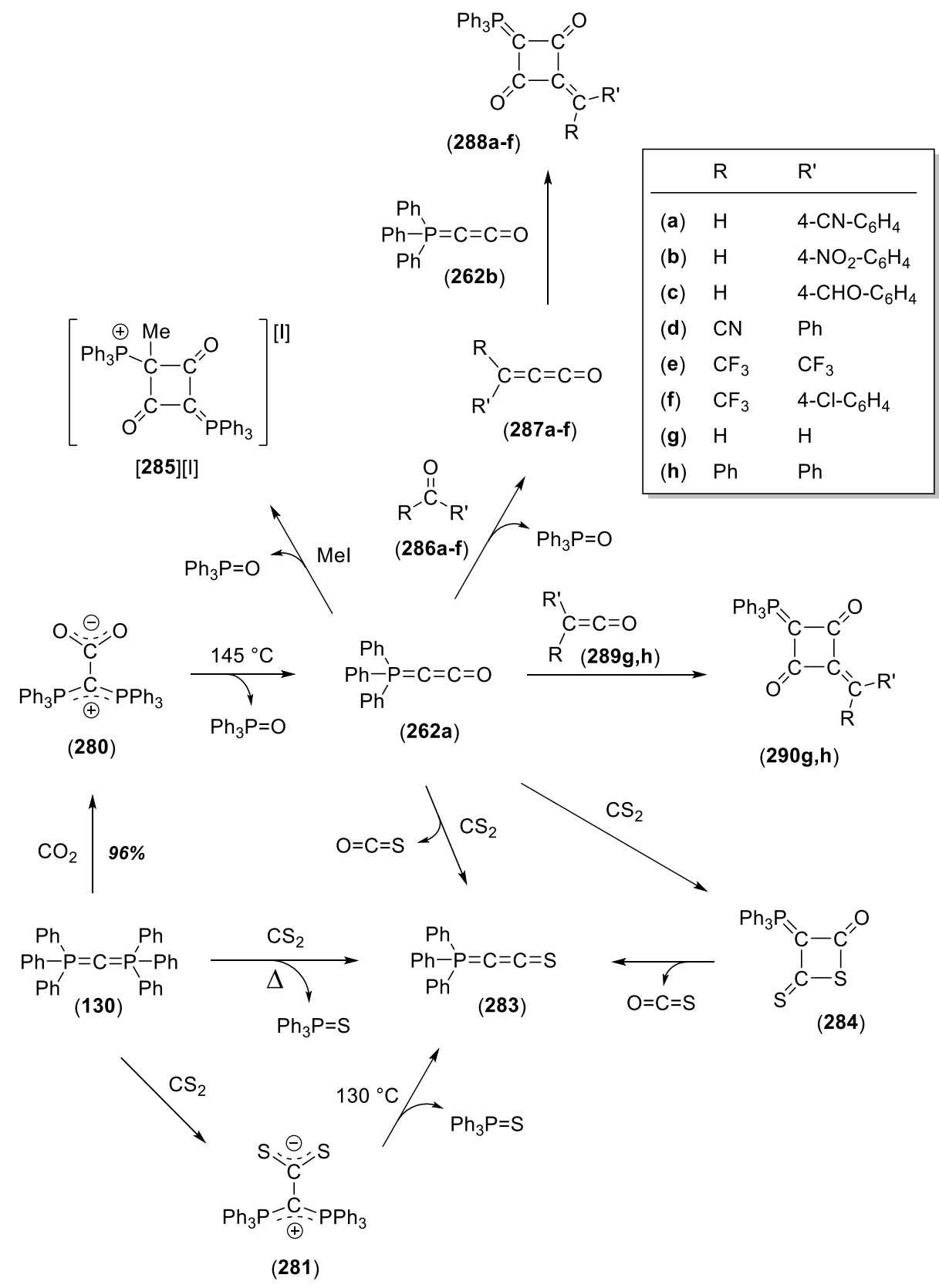

The structures of the mesomeric phosphonium inner salts $\mathbf{2 8 0}$ and $\mathbf{2 8 1}$ were not definitively confirmed until very recently ${ }^{361}$ when Petz et al. revisited the synthesis of the inner salt 281, its DFT analysis and coordination chemistry towards Group 6 metals to afford complexes of the type $\left\{(\mathrm{CO})_{4} \mathrm{M}\left[\mathrm{S}_{2} \mathrm{CC}\left(\mathrm{PPh}_{3}\right)_{2}\right]\right\}(\mathrm{M}=\mathrm{Cr}, \mathrm{Mo}, \mathrm{W})$. They were characterized by X-ray diffraction analysis of 
single crystals. Their most interesting features are: $i)$ the remarkably short $\mathrm{C}-\mathrm{C}$ bond distances of 149.4(3) $\AA$ (280) and 146.9(6) $\AA$ (281), even shorter than a single C-C bond; and ii) the sp ${ }^{2}$ hybridation in both carbon atoms as indicated by the sum of angles of $360^{\circ}$.

By analogy to the synthesis of the zwitterionic compounds $\mathbf{2 8 0 - 2 8 2},{ }^{358-360}$ Ramirez reported the formation of 292a,b and 295a-d by treatment of hexaphenylcarbodiphosphorane (130) with diarylcarbodiimides 291a,b or aryl isocyanates 294a-d in high very yields (85-99\%, Scheme 175). ${ }^{256}$ These zwitterionic compounds were characterized by melting point, EA and IR and unless X-ray diffraction analysis for 292a. ${ }^{362}$

Scheme 175. Synthesis and reactivity of adducts $292 \mathbf{a}, \mathbf{b}, \mathbf{2 9 5 a - d}$ and $297 \mathbf{a}-\mathbf{c}$ by treating hexaphenylcarbodiphosphorane (130) with diarylcarbodiimides 291a,b, aryl isocyanates 294a-d and aryl isothiocyanates 297a-c. 


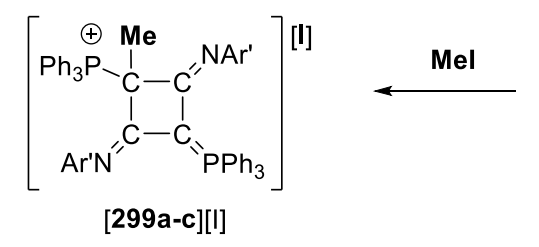

$$
\begin{aligned}
& \underset{(298 \mathrm{a}-\mathrm{c})}{\mathrm{Ph}-\mathrm{Ph}=\mathrm{C}=\mathrm{C}=\mathrm{N}} \mathrm{N}^{\mathrm{Ph}} \mathrm{Ph}^{\prime} \\
& \Delta \uparrow \mathrm{Ph}_{3} \mathrm{P}=\mathrm{S}
\end{aligned}
$$

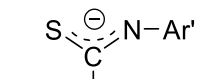

$$
\begin{aligned}
& \mathrm{Ph}_{3} \mathrm{P}=\stackrel{\mathrm{I}}{\mathrm{C}} \underset{\mathrm{C}}{\oplus} \mathrm{PPh}_{3} \\
& \text { (297a-c) }
\end{aligned}
$$
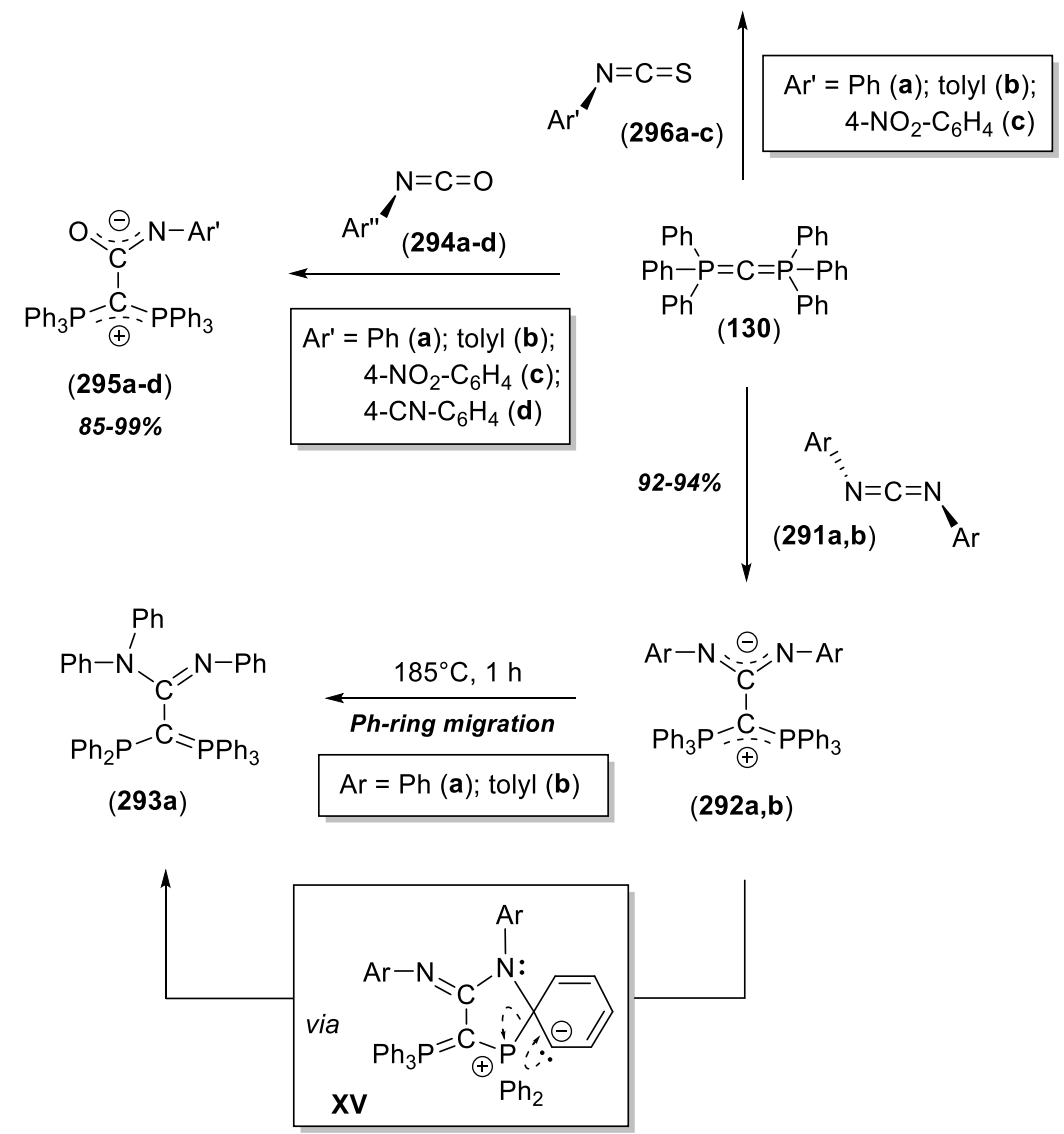

Pyrolysis of ethylene-1,1-bis(triphenylphosphonium)-2,2-bis(phenylamide) (292a) conducted to the formation of ethylene-1-(diphenylphosphino)-1-(triphenylphosphonium)-2-(diphenylamino)-2(phenylamide) (293a). ${ }^{363}$ The formation of 293a requires the phenyl ring migration from the initial $\mathrm{PPh}_{3}$ 
group to create a $\mathrm{NPh}_{2}$ function. According to the author's proposal, this unprecedented Ph-ring migration takes place via cyclic intermediate $\mathbf{X V}$ through a nucleophilic aromatic substitution of the amide to the triphenylphosphonium group.

The zwitterions 297a-c were synthesized by Mathews and co-workers in excellent yields, and proved to be prone to undergo thermal cleavage yielding the aryl-substituted phosphaketeneimines $\mathrm{Ph}_{3} \mathrm{P}=\mathrm{C}=\mathrm{C}=\mathrm{NAr}$ 298a-c with concomitant elimination of $\mathrm{Ph}_{3} \mathrm{P}=\mathrm{S}$. ${ }^{360,364}$ Addition of methyl iodide to the freshly prepared keteneimines 298a-c allowed for the isolation of the salts [299a-c][I] in moderate yields, that gave similar NMR patterns to the 1,3-cyclobutanedione [285][I].

The ylide-type reactivity of CDP $\mathbf{1 3 0}$ was also demonstrated through its reactivity towards ketones and aromatic acid chlorides (Scheme 176). Matthews and co-workers reported in 1967 the isolation of the first stable oxaphosphetane $\mathbf{3 0 0}$ upon reaction with hexafluoroacetone, ${ }^{365}$ instead of the zwitterionic noncyclic structure of the type XVI, which was commonly accepted as an intermediate in the Wittig reaction, at the time.

Scheme 176. Reactivity of hexaphenylcarbodiphosphorane (130) vs hexafluoroacetone and benzoyl chlorides 302a-c. 


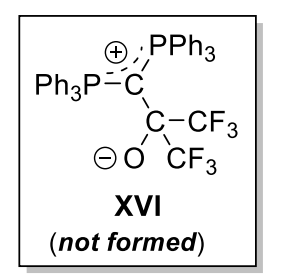

$\mathrm{Ph}_{3} \mathrm{P}-\mathrm{C}^{\prime \prime} \mathrm{PPh}_{3}$
$\mathrm{I} \quad \mathrm{l}$
$\mathrm{O}-\mathrm{C}-\mathrm{CF}_{3}$
$\mathrm{l} \mathrm{CF}_{3}$
$(\mathbf{3 0 0})$

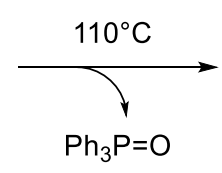

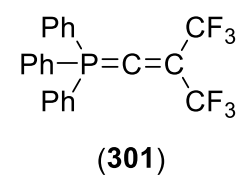
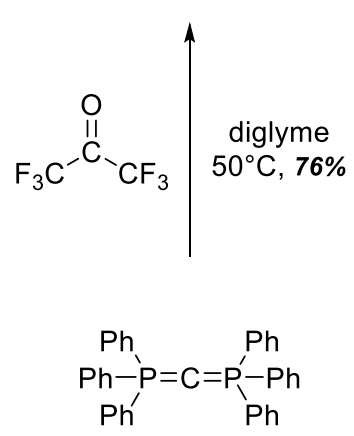

(130)

$\left[\begin{array}{c}\stackrel{\oplus}{\mathrm{PPh}_{3}} \\ \mathrm{Ph}_{3} \mathrm{P}-\mathrm{C}^{\prime} \\ \mathrm{HO} \mathrm{CF}_{3}-\mathrm{CF}_{3}\end{array}\right]^{[\mathrm{X}]}$

$[300-H][1]$

$\mathrm{X}=\mathrm{PF}_{6} ; \mathrm{BF}_{4}$

$\left\{\left[\mathrm{CF}_{3} \mathrm{CO}_{2}\right]_{2} \mathrm{H}\right\}$

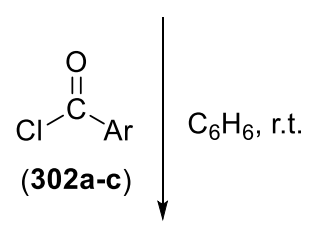

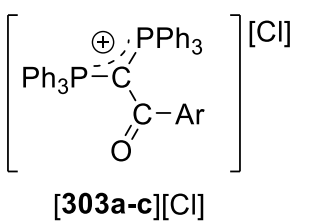

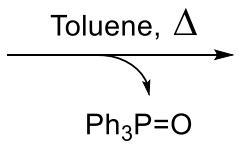

$\mathrm{Ar}=\mathrm{Ph}(\mathbf{a}) ;$

4-MeO- $\mathrm{C}_{6} \mathrm{H}_{4}$ (b)

2-Naphthyl (c)

Oxaphosphetane $\mathbf{3 0 0}$ was isolated in good yield and its structure was elucidated by multinuclear NMR, X-ray crystallography, ${ }^{365,366}$ and by its associated reactivity. Interestingly, the involvement of the oxaphosphetane $\mathbf{3 0 0}$ in Wittig olefination was demonstrated by thermal treatment, leading to a nonseparable mixture of $\mathrm{Ph}_{3} \mathrm{P}=\mathrm{O}$ and the triphenyl-2,2-bis(trifluoromethyl)vinylidenephosphorane (301).

Scheme 177. Reactions of CDP 130 with salicylaldehyde and phthalic anhydride. 


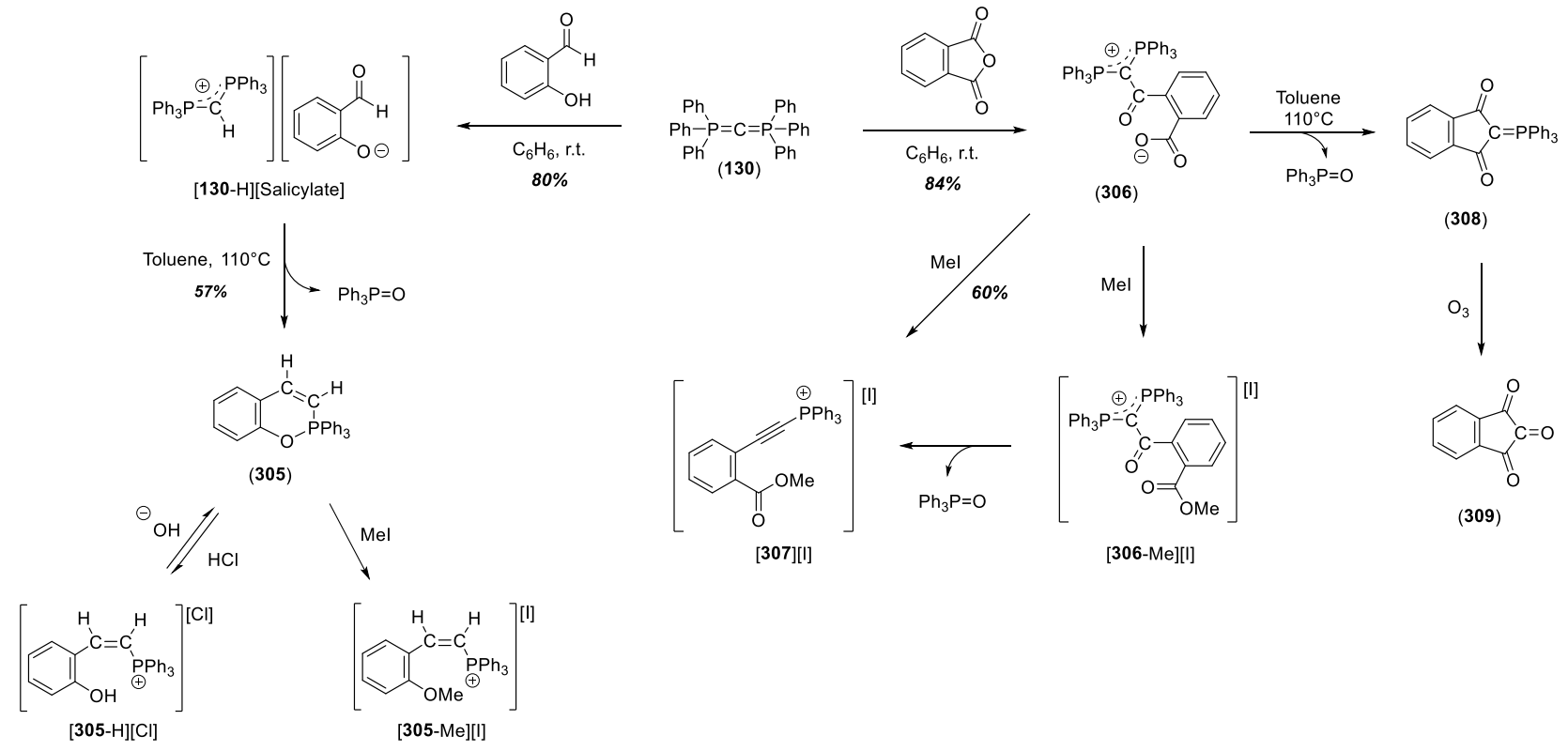

In 1977, Bestmann and Kloeters described a useful entry to (arylethynyl)triphenylphosphonium salts $[\mathbf{3 0 4 a - c}][\mathrm{Cl}]$, which are important building blocks, starting from 130 and benzoyl chlorides 302a-c (Scheme 179). ${ }^{367}$ The same authors also reported the reaction of 130 with salicylaldehyde under similar conditions to get the six-membered, P-containing heterocycle 305 (Scheme 177). ${ }^{368,369}$ One year later, they carried out the reaction between $\mathbf{1 3 0}$ and phthalic anhydride promoting the ring opening and yielding the inner salt $\mathbf{3 0 6}$ in $80 \%$. Subsequent transformations of $\mathbf{3 0 6}$ are reported.

The very rich chemistry of hexaphenylcarbodiphosphorane (130) towards carbonyl compounds shown mainly by Mathews and Bestmann has stimulated the group of Soliman to investigate in depth the reactivity of 130 with highly functionalized organic scaffolds. In $2008,{ }^{370}$ they studied the feasibility of the Wittig reaction between 130 and the carbonyl derivatives 310-316 (Scheme 178). 

room temperature $(6 \mathrm{~h})$.
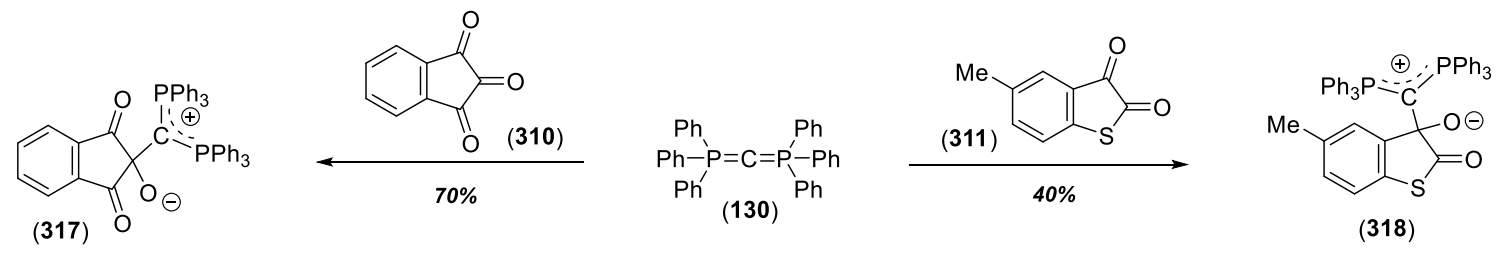

(eq. 1)
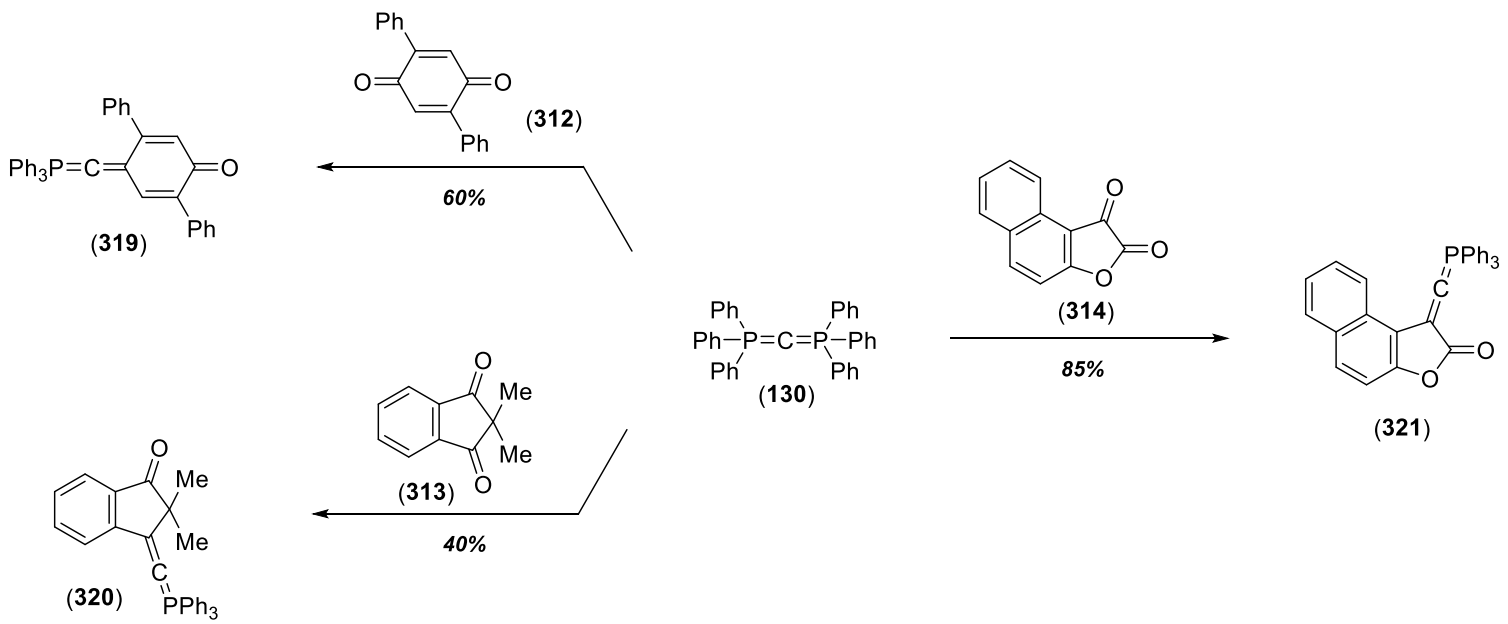

(eq. 2)
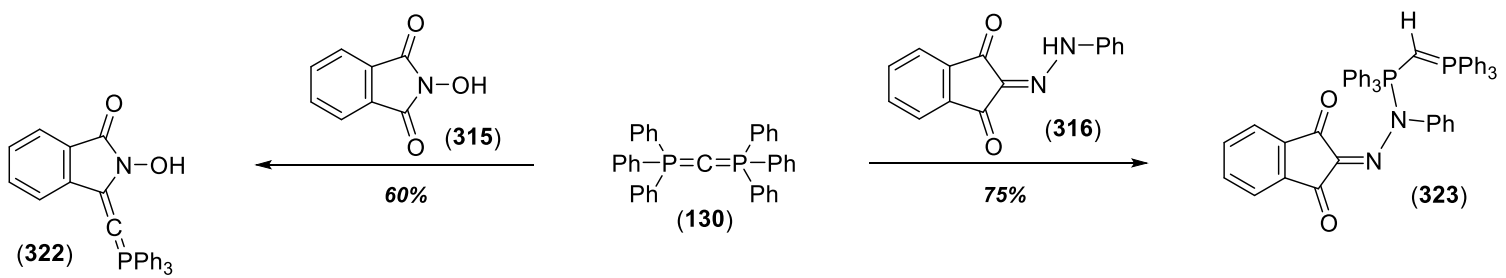

(eq. 3)

In the same article, ${ }^{370}$ Soliman reported the reactivity of $\mathbf{1 3 0}$ with biologically relevant niclosamide derivatives 324a,b and 229a. They could obtain oxaphosphinines 326 and 327 in good yields upon an unprecedented cyclization reaction (Scheme 179).

Pyrolysis of $\mathbf{3 2 6}$ and $\mathbf{3 2 7}$ underwent Hoffmann degradations liberating $\mathrm{Ph}_{3} \mathrm{P}$ and producing the corresponding phosphaheterocycles $\mathbf{3 2 8}$ and $\mathbf{3 3 0}$ in moderate yields. Compounds $\mathbf{3 2 6}$ and $\mathbf{3 2 7}$ were also sub- 
jected to Wittig reaction conditions with 4-nitroacetaldehyde to form the exocyclic olefins $\mathbf{3 2 9}$ and $\mathbf{3 3 1}$ with identical yield (65\%).

Scheme 179. O-H bond activation of phenols mediated by 130 to build niclosamide-based oxaphosphinines 326 and 327, along with their reactivity upon pyrolysis and Wittig reaction conditions. 


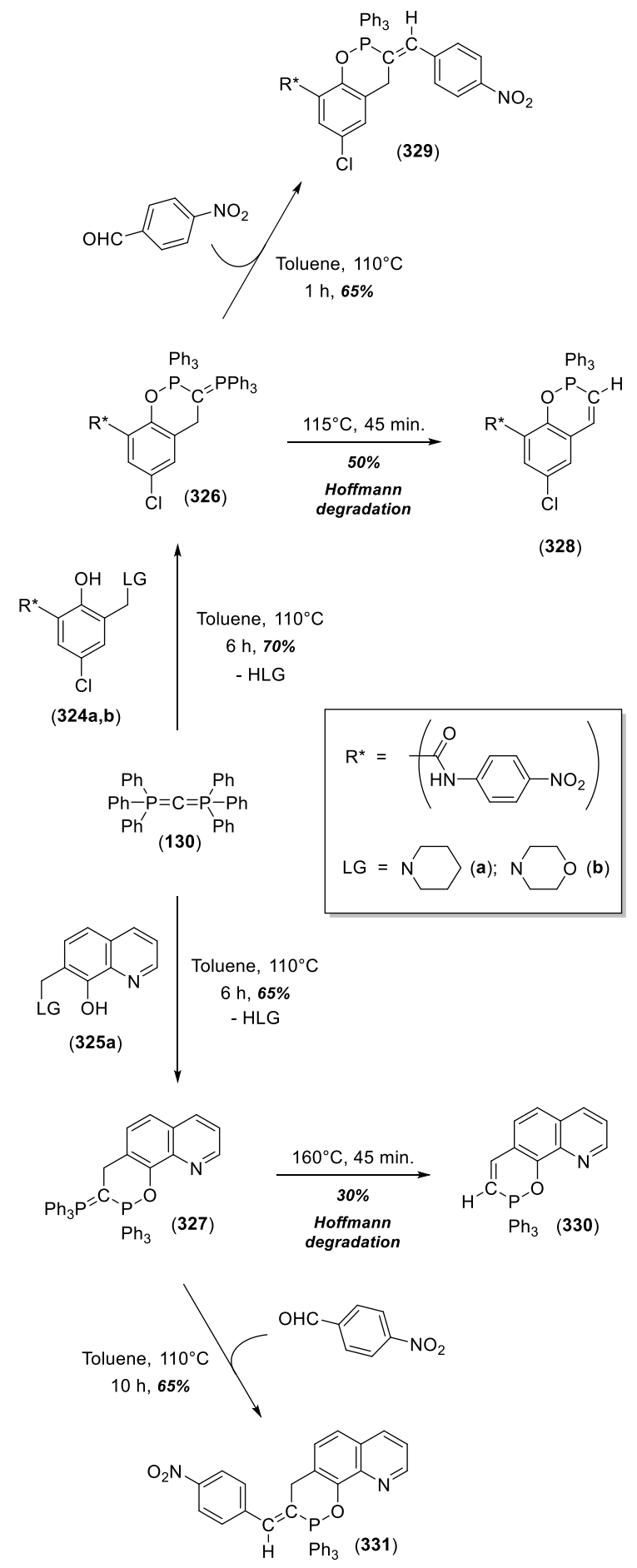

The same group explored the synthetic value of CDP 130 in organic synthesis starting from other biologically active heterocycles such as the 3-acetyl-4-hydroxy- $H$-chromen-2-one (332) and 3247 
acetylchromenone 333 (Scheme 180), to form 334 and $335 .{ }^{371}$ In a later report, ${ }^{372}$ Soliman reacted the azidocoumarin 336 with 130 resulting in the [3+2] cycloaddition reaction to yield a mixture of triazinone $\mathbf{3 3 7}$ and azetone $\mathbf{3 3 8}$ that were separated and isolated by $\mathrm{SiO}_{2}$-chromatography in $40 \%$ and $30 \%$ yield, respectively. By analogy to the observed reactivity of CDP 130 with the imine 316 bearing a NH functional group, Soliman's group has reported the 1,2-addition of the O-H bond of monoximes 339a-d across the $\mathrm{P}=\mathrm{C}$ bond of $\mathbf{1 3 0}$ rather than the Wittig reaction with the carbonyl moieties (Scheme 180). ${ }^{372}$ This selective transformation forms ylides 340a-d isolated with 40-80\% yields. Noticeably, ylides 340ad are remarkably stable and do not promote intramolecular cyclizations via Wittig reactions.

\section{Scheme 180. 1,2-addition of O-H bonds of monoximes 339a-d to CDP 130 and cyclization reactions} of 130 with the functionalized chromenone scaffolds 332,333 and 337.

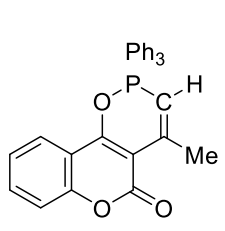

(334)

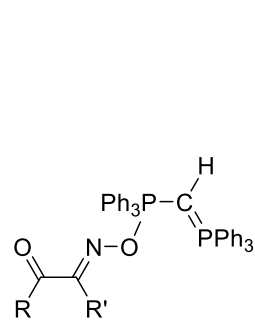

(340a-d)

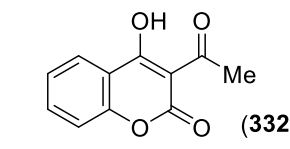

THF, reflux, $12 \mathrm{~h}$ $75 \%$

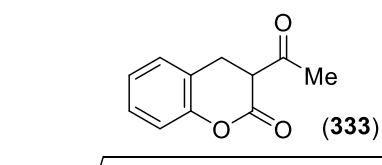

THF, reflux, $12 \mathrm{~h}$ $70 \%$

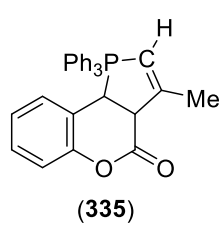

$$
\begin{gathered}
\mathrm{Ph}^{-} \\
\mathrm{Ph}^{-} \mathrm{P}=\mathrm{C}=\mathrm{P}_{-}^{\prime}-\mathrm{Ph} \\
\mathrm{Ph}^{\prime}{ }_{\text {(130) }} \mathrm{Ph}
\end{gathered}
$$

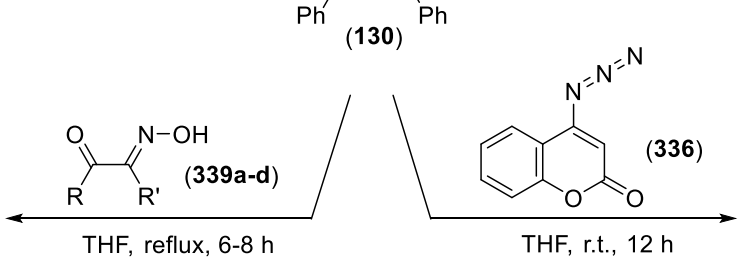

$40-80 \%$

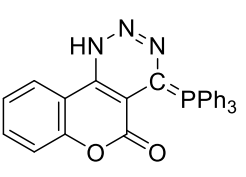

(337; 40\%)

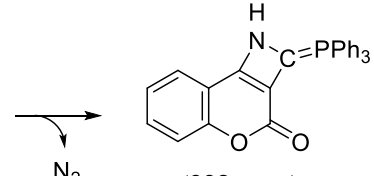

(338; $30 \%)$

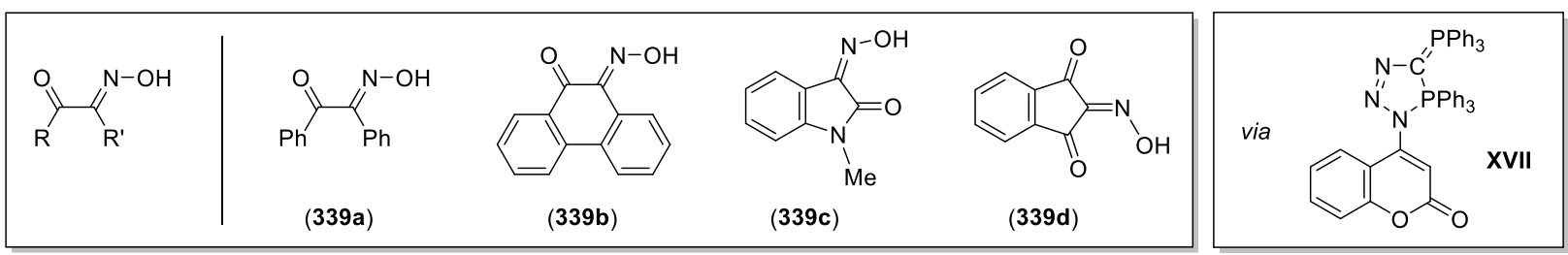


In 2014, Soliman has shown similar reactivity patterns between CDP 130 and the carbonyl derivatives 341, 342 and 345a,b (Scheme 181). ${ }^{373-375} 130$ was treated with anthracenedione 341 at room temperature to yield the stable oxaphosphetane 343 in 55\% yield, whereas the addition of $\alpha$-ketoimine 342 to 130 efficiently afforded the [2+2]-cycloaddition reaction with the imine instead the carbonyl group. Reaction with indene-1,3-diones 345a,b favored a [4+2]-cycloaddition reaction that led to the pyranring skeletons 346a,b. Interestingly, the anticancer activity of heterocycles 343, 344 and 347a, possess a stronger cytotoxicity than the reference drug Doxorubicin. Pursuing on their research program focusing on the synthesis of potentially bioactive P-containing heterocycles, Soliman and co-workers reported the formation of the spirocyclic ylides 349a-d and 351a,b from 348a-d and 350a,b (Scheme 181).

Scheme 181 Treatment of 130 with carbonyl derivatives 341, 342, 345a,b, 348a-d and 350a,b. 


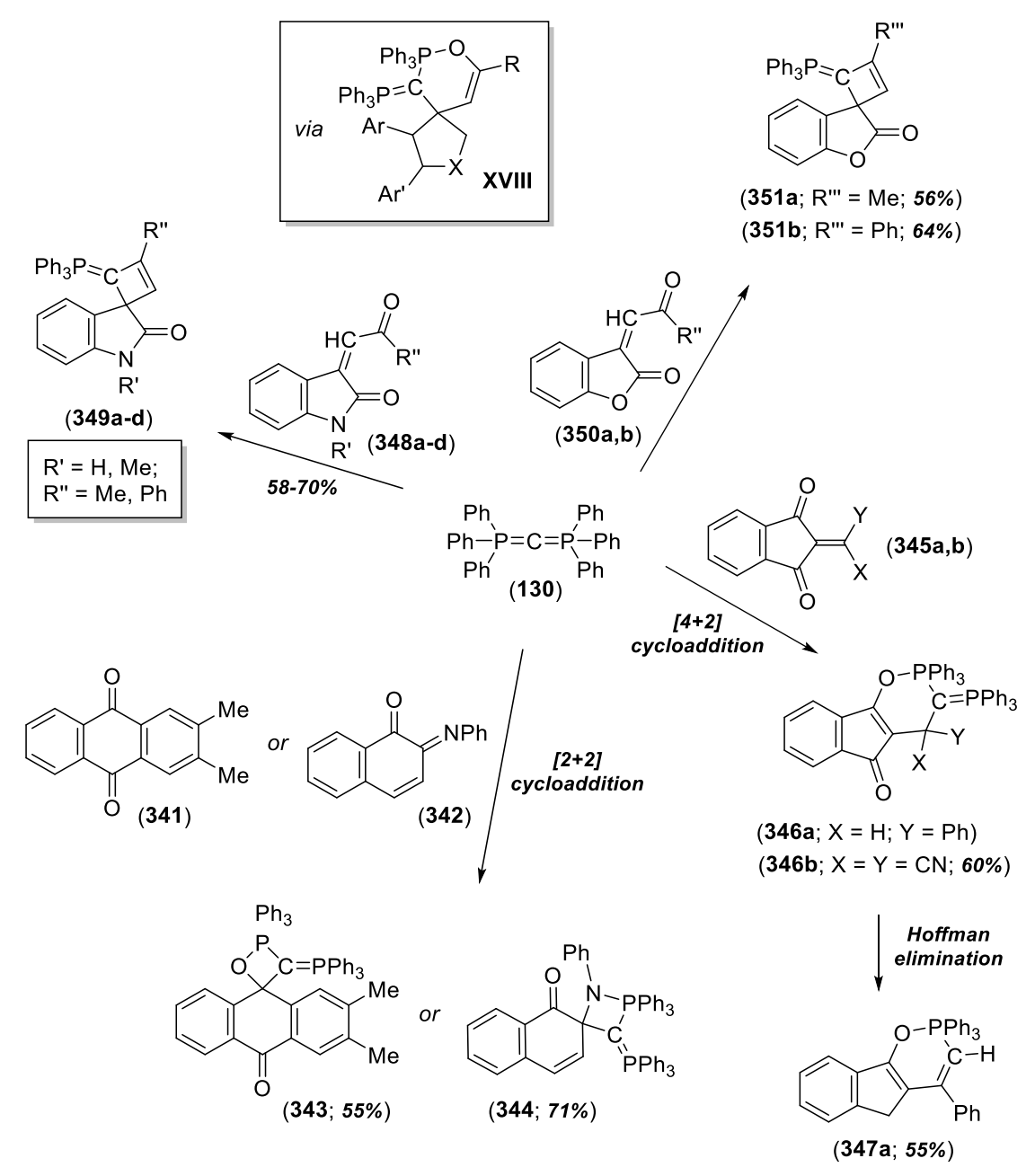

The spirocyclic ylide 351b was evaluated against colon and liver types of cancer providing comparable $\mathrm{IC}_{50}$ values $v s$ the ones given by the reference drug (Doxorubicin).

Very recently, Alcarazo's team studied the reactivity of the tetrakis(trifluoromethyl)cyclopentadienone (352) towards strong $C$-based Lewis bases such as the carbodiphosphorane 130, $N$-heterocyclic carbenes (NHCs) and isonitriles. ${ }^{376}$ Wilkinson has demonstrated in 1970 that cyclopentadienone 352 reacts with phosphines giving rise to the zwitterionic Lewis adducts of type XX (Scheme 182). ${ }^{377}$ This surprising transformation can be attributed to the significant contribution of the canonical representation 352B which is favored by the aromatization of the cyclopentadienyl ring and the simultaneous stabilization of 250 
the negative charge by the presence of the $\mathrm{CF}_{3}$-substituents (Scheme 182) ${ }^{377}$ Later, Burk et al. revisited this chemistry and proved the intermediacy of compounds of the type XIX (kinetic product) that underwent the phosphine-group migration upon thermal treatment to afford the thermodynamic zwitterion XX. ${ }^{378}$ The comparative studies carried out by Alcarazo and co-workers have demonstrated that using the more sterically hindered $\mathbf{1 3 0}$ allows for the clean and high yielding entry to the $O$-bridged Lewis adduct 353, whereas less bulkier (NHCs) nucleophiles conducted to the kinetic adducts through nucleophilic attack to the $C$-atom located in $\alpha$-position to the carbonyl group. Zwitterion $\mathbf{3 5 3}$ was isolated in excellent $91 \%$ yield and appropriately characterized by multinuclear NMR, IR, HRMS and XRD analysis of single crystals.

\section{Scheme 182. Adduct formation between CDP 130 and tetrakis(trifluoromethyl)cyclopentadienone} (352).
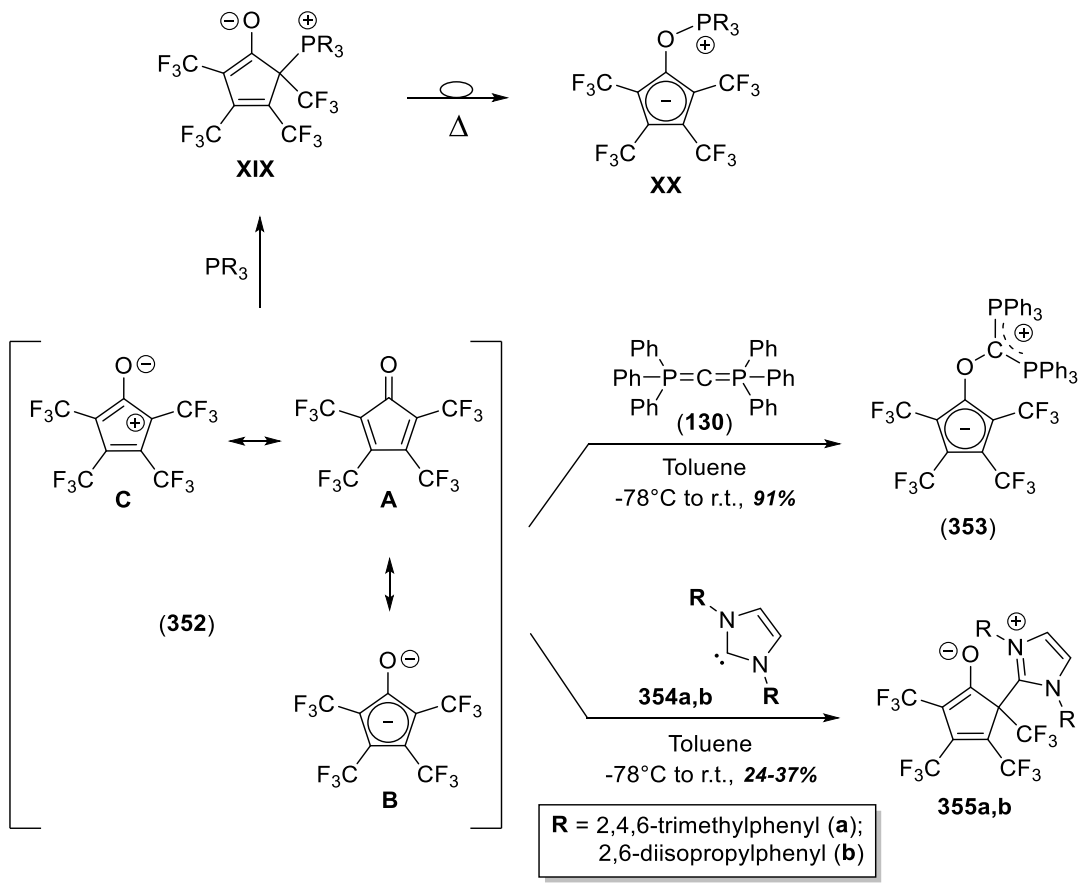
As presented above for CDP 130, classical reactivity tests towards moisture, Brönsted acids and organic electrophiles were commonly selected as additional proof for the bis(ylide) nature of other CDPs. For instance, Schmidbaur carried out the synthesis of monophosphonium and diphosphonium salts [135$\mathrm{H}][\mathrm{X}]$ and $\left[\mathbf{1 3 5}-\mathrm{H}_{2}\right][\mathrm{Cl}]_{2}$ by selective addition of $\mathrm{HCl}$ to hexamethylcarbodiphosphorane $(\mathbf{1 3 5}){ }^{266,267}$ Aqueous treatment initially produced $\mathrm{Me}_{3} \mathrm{P}=\mathrm{O}$ and $\left[\mathrm{Me}_{4} \mathrm{P}\right][\mathrm{OH}]$ that is converted into methane and 2 equiv. of $\mathrm{Me}_{3} \mathrm{P}=\mathrm{O}$ upon addition of a second equivalent of water (Scheme 183). The same group evidenced the clean hydrolysis of the symmetric CDP 154 to give ylide 356 and benzene, ${ }^{266}$ and proved the nucleophilic character of bis(ylide) 154 versus $\mathrm{Cl}-\mathrm{SiMe}_{3}$, reaching the $C$-substituted salt [154$\left.\mathrm{SiMe}_{3}\right][\mathrm{Cl}]{ }^{266}$

Scheme 183. Reactivity of P-chloro and P-amino CDPs 135 and 154 towards organic electrophiles and moisture.

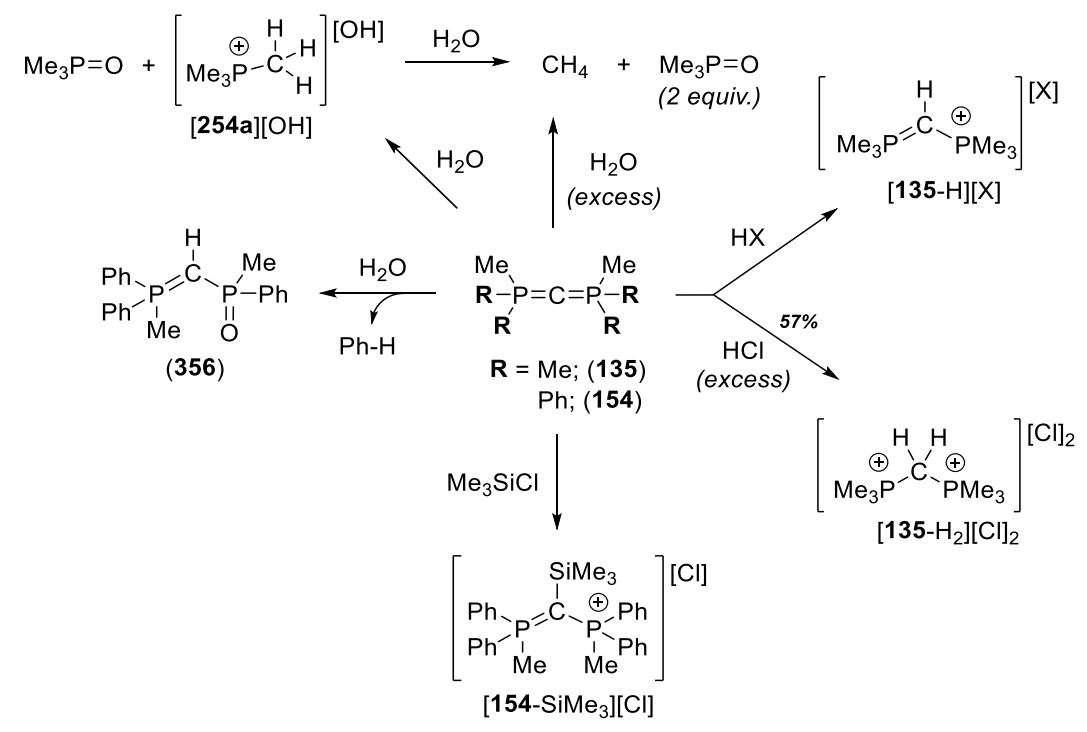

Similar set of experiments were carried out by Appel and co-workers for the $P$-chloro and $P$-amino substituted carbodiphosphoranes $\mathrm{XPh}_{2} \mathrm{P}=\mathrm{C}=\mathrm{PPh}_{2} \mathbf{X}$ [with $\mathbf{X}$ being $\mathrm{Cl}(\mathbf{1 6 8})^{287}$ or $\mathrm{NR}_{2}(\mathbf{1 7 1 a - d}){ }^{289}$ and 
$\mathrm{Ph}_{3} \mathrm{P}=\mathrm{C}=\mathrm{PPh}_{2} \mathbf{X}$ [with $\mathbf{X}$ being $\mathrm{Cl}(\mathbf{1 7 8})^{291}$ or $\left.\mathrm{NR}_{2}(\mathbf{1 8 2 a}-\mathbf{e})\right] .{ }^{293}$ Addition of two equivalents of alcohols (methanol or ethanol) to bis(ylide) $\mathbf{1 6 8}$ produced the diphenylphosphinomethane dioxide derivative (dppmO; 169) and concomitant liberation of $\mathrm{R}$ '-Cl (see Scheme 184). The $P$-amino substituted 171a-d have shown clean transformations towards moisture and methyl iodide. As expected, $C$-methylated salt [171d-Me][I] was isolated in $80 \%$ yield by reaction of $\mathrm{Ph}_{2}\left({ }^{n} \mathrm{Bu}_{2} \mathrm{~N}\right) \mathrm{P}=\mathrm{C}=\mathrm{P}\left(\mathrm{N}^{n} \mathrm{Bu}_{2}\right) \mathrm{Ph}_{2}(\mathbf{1 7 1 d})$ and $\mathrm{MeI}$ (excess). More surprising was the selectivity achieved for the hydrolysis of bis(ylides) 171a-d yielding ylides 172a-d through the removal of an amino group $\left(\mathrm{HNR}_{2}\right)$.

Scheme 184. Reactivity of P-chloro and P-amino CDPs 186 and 171a-d towards organic electrophiles and moisture.

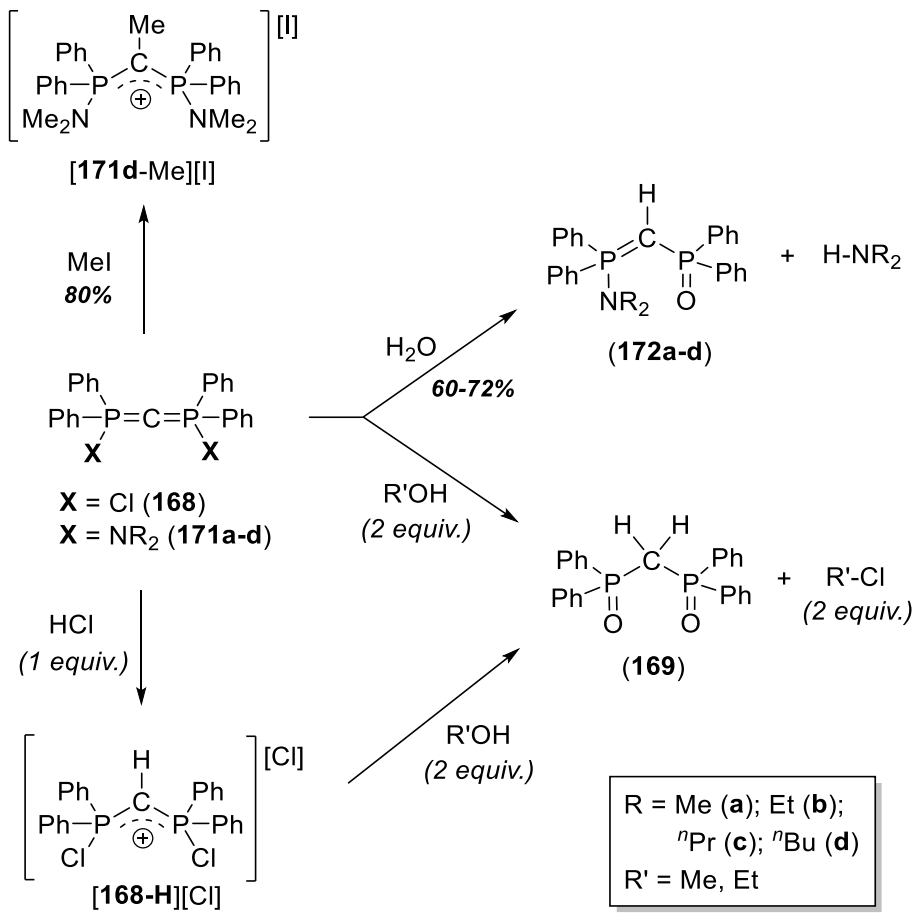

Exposed to $\mathrm{HCl}$, a toluene solution containing the analogous bis(ylide) $\mathrm{Ph}{ }_{3} \mathrm{P}=\mathrm{C}=\mathrm{PPh}_{2} \mathrm{Cl}(\mathbf{1 7 8})$ quantitatively yielded the corresponding chloride salt $[\mathbf{1 7 8}-\mathrm{H}][\mathrm{Cl}]$ that efficiently underwent $\mathrm{PMe}_{3}$ chlorination 
to give the diphenylphosphinoylide 357 in $93 \%$ isolated yield, accompanied by the formation of $\mathrm{Cl}_{2} \mathrm{PMe}_{3}$ as side-product (Scheme 185). 178 proved sensitive to moisture and gave the chloride salt $\left[\mathbf{1 7 8}-\mathrm{H}_{2}\right][\mathrm{Cl}]$. Its $P$-amino derivatives 182a-e were reacted versus $\mathrm{HCl}, \mathrm{MeI}$ and moisture too. While bis(ylide)s 182b,c were protonated twice by $\mathrm{HCl}$ providing salts $\left[\mathbf{1 8 2 b}-\mathrm{H}_{2}\right][\mathrm{Cl}]_{2}$ and $\left[\mathbf{1 8 2} \mathbf{c}-\mathrm{H}_{2}\right][\mathrm{Cl}]_{2}$ in quantitative yields, the addition of methyl iodide conducted to the exclusive formation of the iodide salts [182a,e-Me][I] in good yields. As shown above for bis(ylides) 171a-d, hydrolysis of the $P$-amino substituted CDPs 182a-e allowed for the quantitative isolation of ylide $\mathbf{1 8 3}$ via amine group releasing.

Scheme 185. Reactivity of P-chloro and P-amino substituted CDPs 178 and 182a-e towards hydrochloric acid, methyl iodide and moisture.

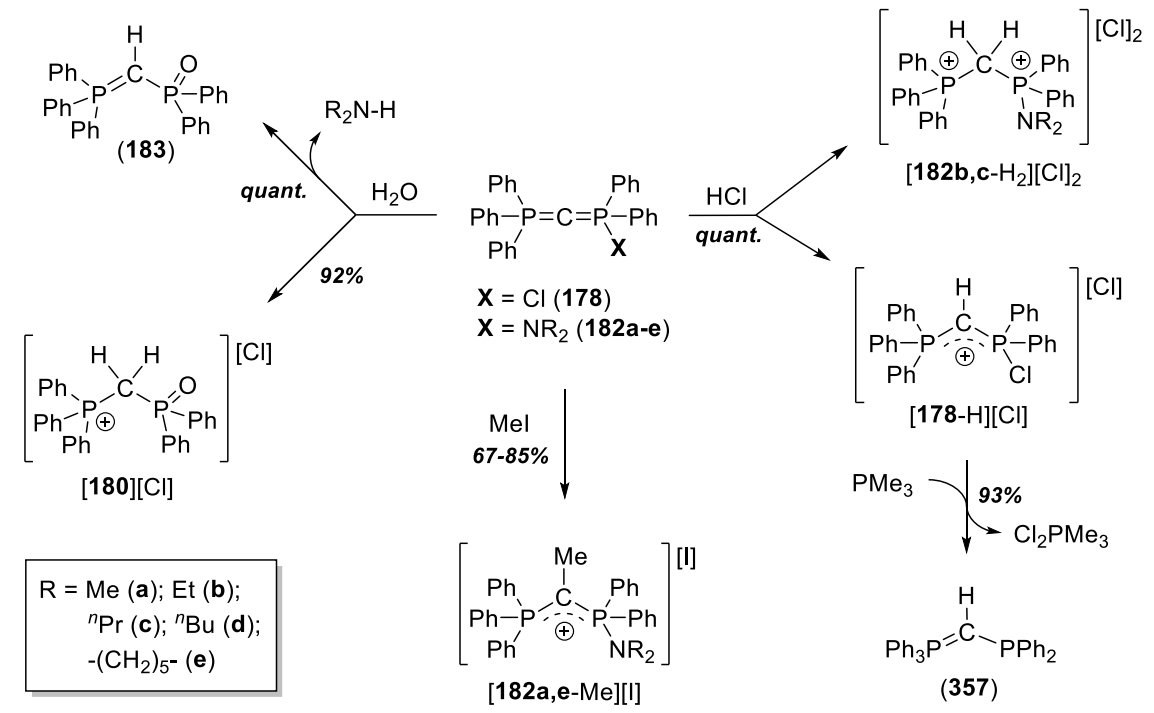

Appel pursued with the reactivity studies of $P$-amino substituted CDPs 185c, 173 and 189a-d. ${ }^{290-293}$ The results are summarized in Schemes 186-188.

Scheme 186. The reactivity of the P-chlorinated CDP $185 \mathrm{c}$ vs organic electrophiles, moisture and dimethylamine. 


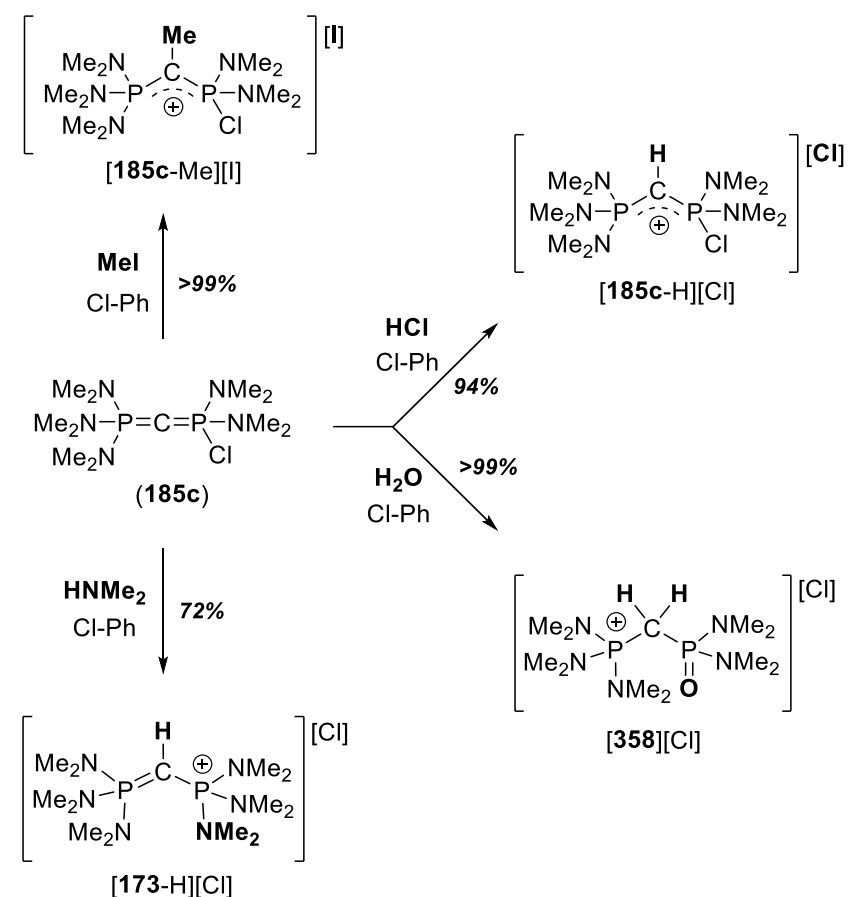

Scheme 187. The reactivity of CDP 173 towards organic reagents.
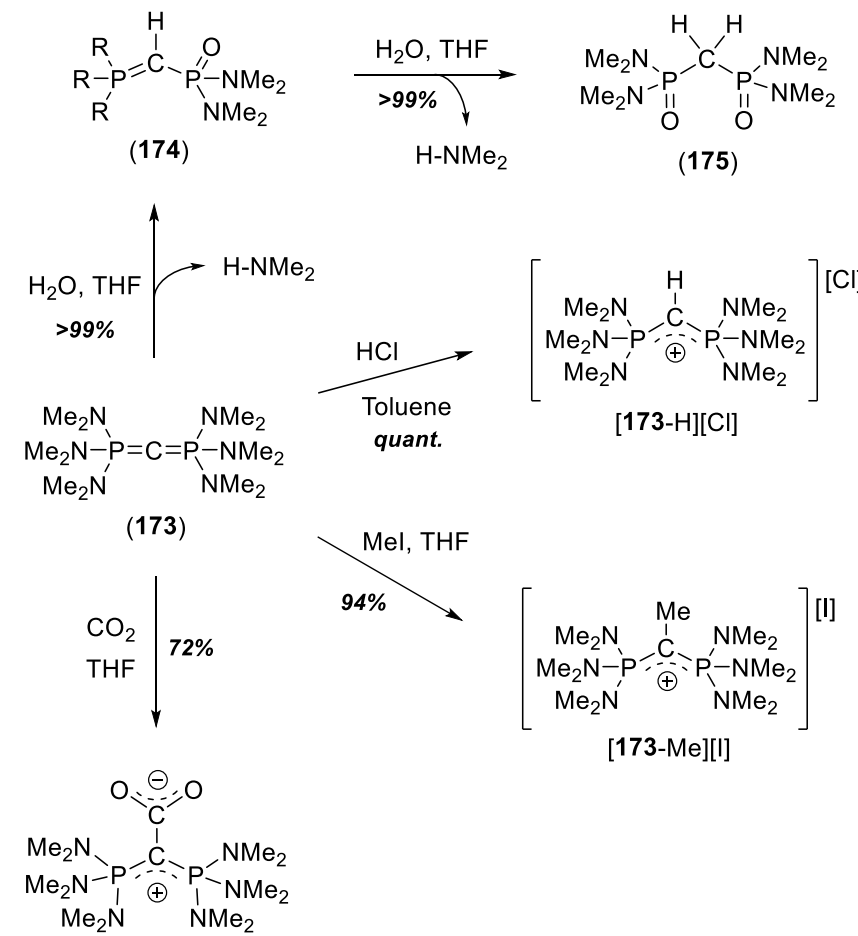

(176) 
Scheme 188. The reactivity of CDPs 189a-d towards organic reagents.

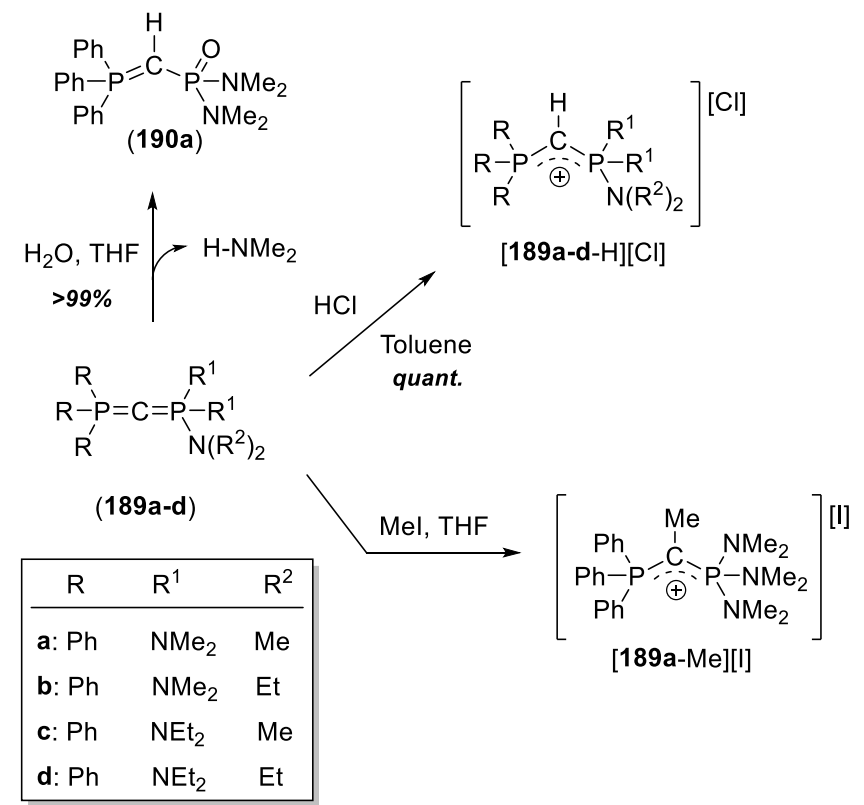

The reactivity of cyclic CDPs 137 and $138 \mathrm{LiBr}$ towards electrophiles was explored by Schmidbaur. ${ }^{270}$ The addition of ethereal $\mathrm{HBr}$ proved the presence of the two lone pair at the central carbon and quantita-

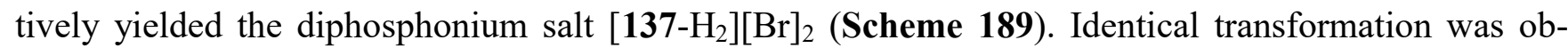
served for $138 \mathrm{LiBr}$ leading to the dichloride salt $\left[138-\mathrm{H}_{2}\right][\mathrm{Cl}]_{2}$. In contrast, its reaction toward an excess of MeI exclusively led to the formation of the $C$-methylated salt [138-Me][I], subsequently protonated to $[(\mathbf{1 3 8}-\mathrm{H})-\mathrm{Me}][\mathrm{I}][\mathrm{Cl}]$. The same group carried out the reactivity studies on $\mathbf{1 5 7 ,}{ }^{281}$ with similar outcomes (Scheme 189).

Scheme 189. Experimental proof for the double ylide function at the central $C$-atom in the cyclic CDPs 137, 138: LiBr and 157. 

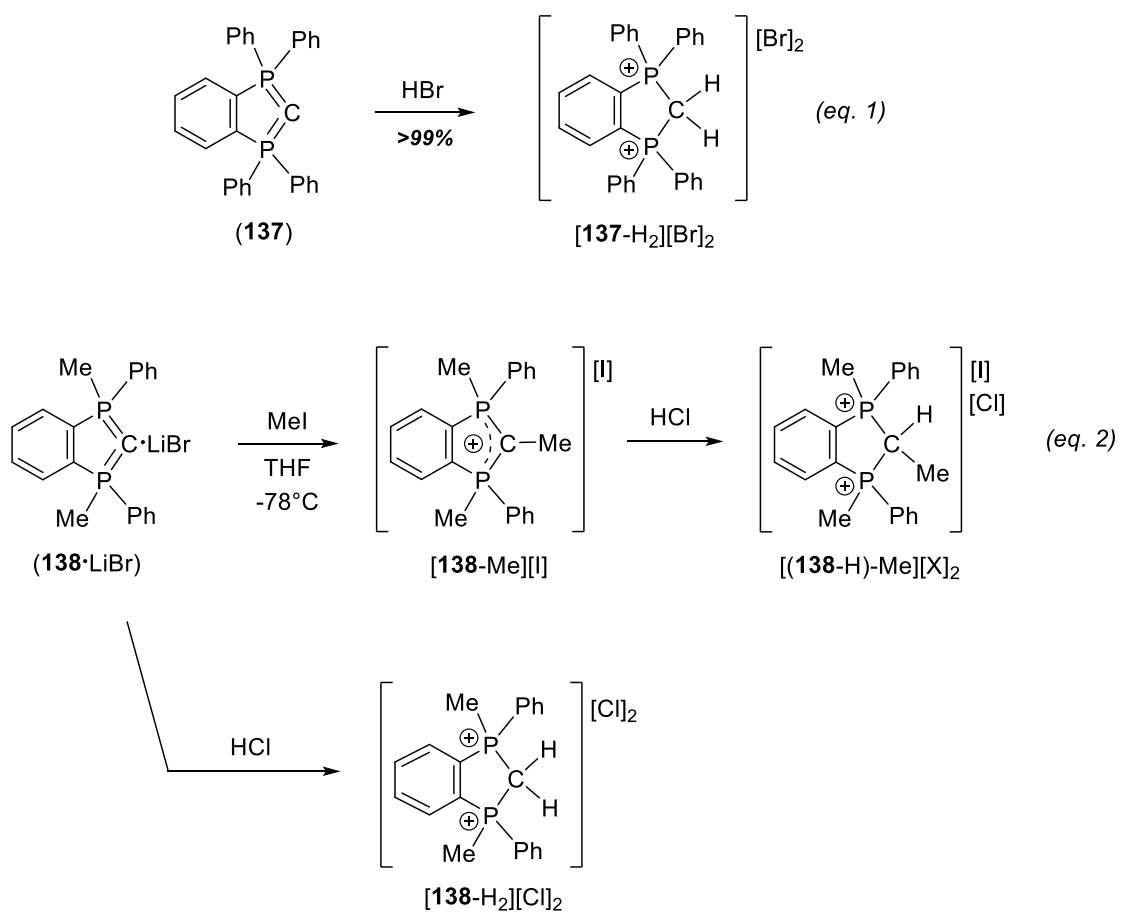

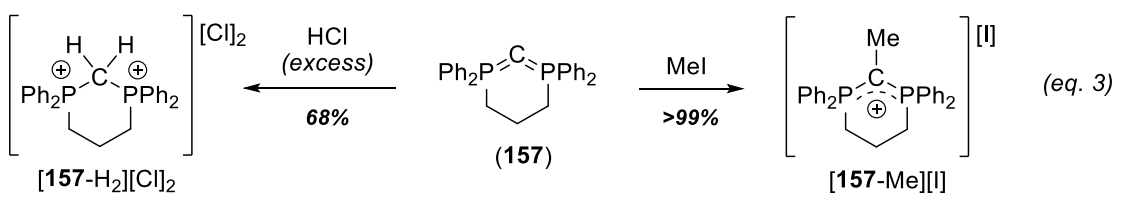

With the aim of proving the ylide-type reactivity on the bis(ylide)s $\mathbf{2 1 6 a - c}$ and $\mathbf{2 1 8 b , c}$, Shevchenko has evaluated their reactivity towards Brönsted acids, oxidants, and (thio)carbonyl compounds (see below in Schemes 190 and 191). The bis(ylide)s 216a,b were reacted with one equiv. of $\mathrm{HCl}$ in ether to deliver the remarkably stable chloride salts $[\mathbf{2 1 6 a}, \mathbf{b}-\mathrm{H}][\mathrm{Cl}]$ isolated in $63 \%$ and $52 \%{ }^{303}$ In fact, attempts to achieve a second protonation at the ylidic carbon in salts $[\mathbf{2 1 6} \mathbf{6}, \mathbf{b}-\mathrm{H}][\mathrm{Cl}]$ with $\mathrm{HCl}$ were unfruitful. ${ }^{303}$ The CDP 216b was exposed to oxidative conditions (chlorine gas) to achieve the tetrachloride derivative $\left[\mathbf{2 1 6}-\mathrm{Cl}_{2}\right][\mathrm{Cl}]_{2}$ at room temperature, thereby testifying for the double ylidic character of $\mathbf{2 1 6 \mathbf { b }} .^{304}$ Isolation of the $C$-chlorinated salt $[\mathbf{2 1 6 b}-\mathrm{Cl}][\mathrm{Cl}]$ was only possible by dechlorination of the dichloride salt $\left[\right.$ 216- $\left.-\mathrm{Cl}_{2}\right][\mathrm{Cl}]_{2}$ with $\mathrm{SnCl}_{2}$, or more conveniently by its comproportionation reaction with $\mathbf{2 1 6 b}$. ${ }^{304}$ 
Scheme 190. Reactivity of CDPs 216a-c carried out by Shevchenko and co-workers.
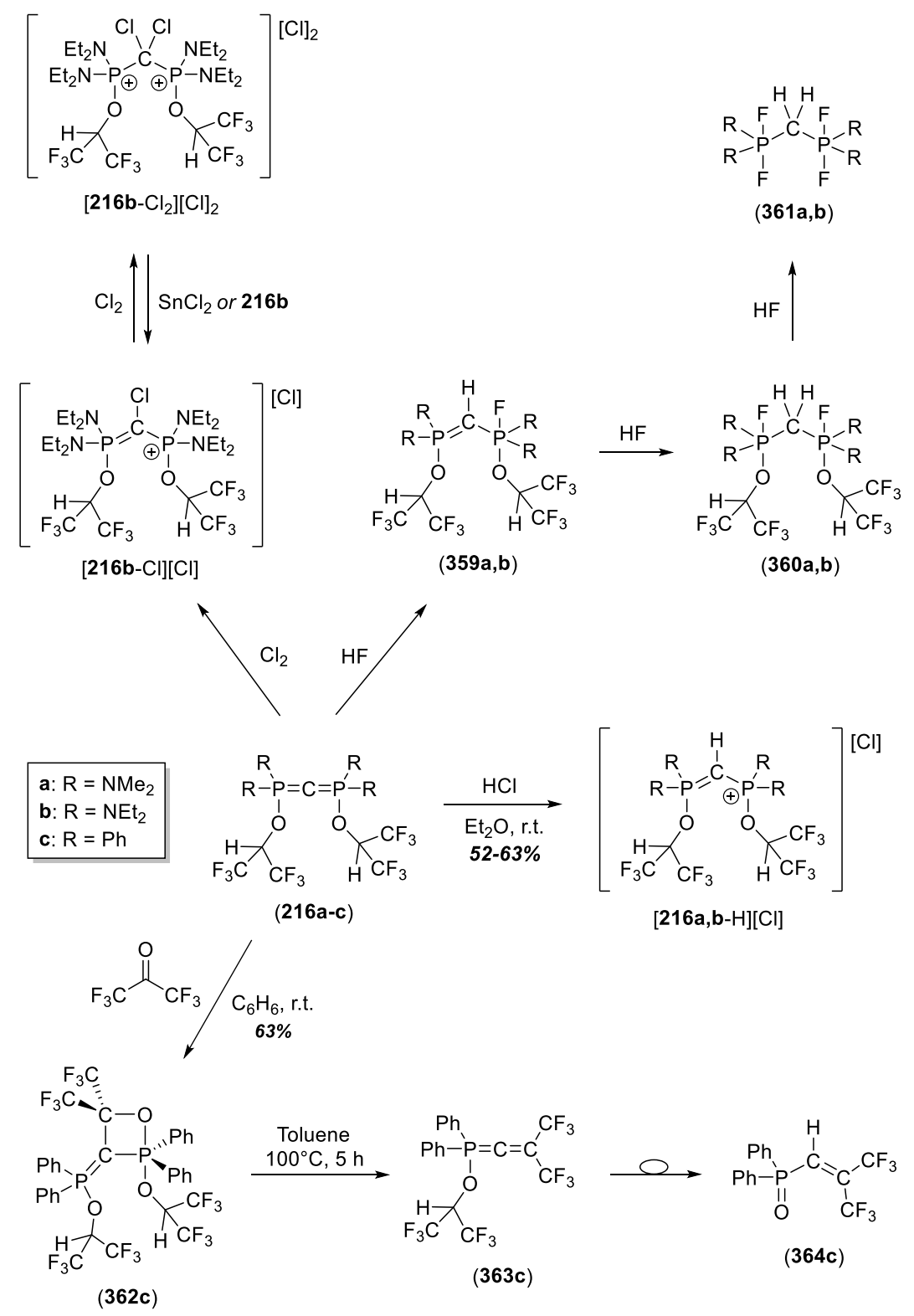

Double protonation at the ylidic $C$-atom was achieved upon addition of $\mathrm{Et}_{3} \mathrm{~N} \cdot 2 \mathrm{HF}$ or $\mathrm{HF}$ (2.2 equiv.) in hexanes (Scheme 190). ${ }^{304}$ A mixture containing 360a,b and 361a,b was obtained, from which derivatives $\mathbf{3 6 0 a}, \mathbf{b}$ were isolated as light yellow oils due to their complete insolubility in hexanes. ${ }^{304}$ Increasing the amount of $\mathrm{Et}_{3} \mathrm{~N} \cdot 2 \mathrm{HF}$ up to 2.5 equiv. drove to the formation of the tetrafluoride derivatives 258 
361a,b that were isolated in $c a .30 \%$ yield. ${ }^{304}$ The phenyl-substituted CDP $216 \mathbf{c}$ was able to react with an equiv. of hexafluoroacetone providing a direct entry to the oxaphosphetane derivative $362 \mathrm{c}$ isolated in $63 \%$ yield and fully characterized by multinuclear NMR, EA and X-ray diffraction analysis of single crystals. ${ }^{305}$ Heated to $100^{\circ} \mathrm{C}$ for 5 hours, the oxaphosphetane $362 \mathrm{c}$ underwent the Wittig olefination to reach the phosphallene 363c with elimination of the corresponding phosphine oxide. ${ }^{305}$ Despite the fact that phosphallene 363c proved unstable and evolved into the phosphine oxide $364 \mathbf{c}$ upon heating, the ${ }^{31} \mathrm{P}$ NMR identification of $363 \mathrm{c}$ confirmed the intermediacy of the oxaphosphetane $362 \mathrm{c}$ in the Wittig reaction. Scheme 191 collects a similar set of experiments carried out by Shevchenko and co-workers with the isolated CDPs $\mathbf{2 1 8 b}$, c. $^{305}$

Scheme 191. Reactivity of carbodiphosphoranes $218 \mathrm{~b}, \mathrm{c}$. 


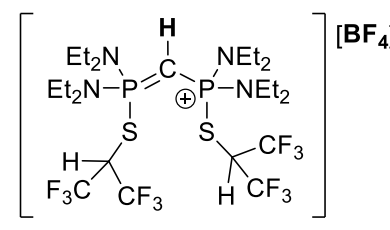

[218b-H] $\left[\mathrm{BF}_{4}\right]$
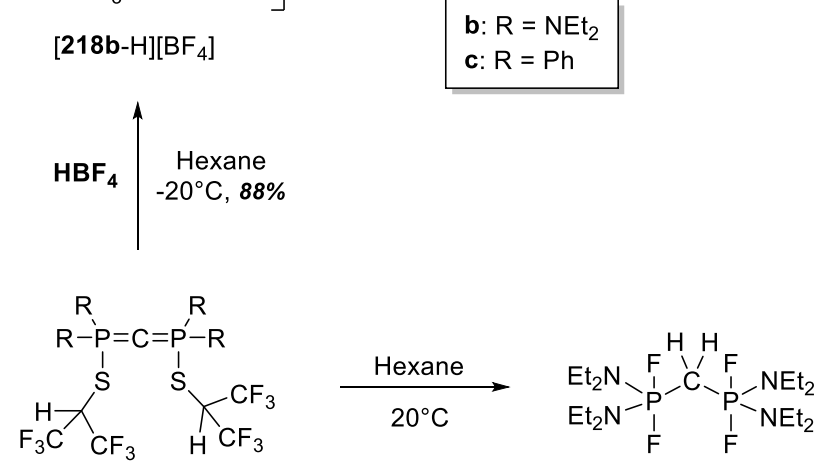

$(218 b, c)$

(361b)
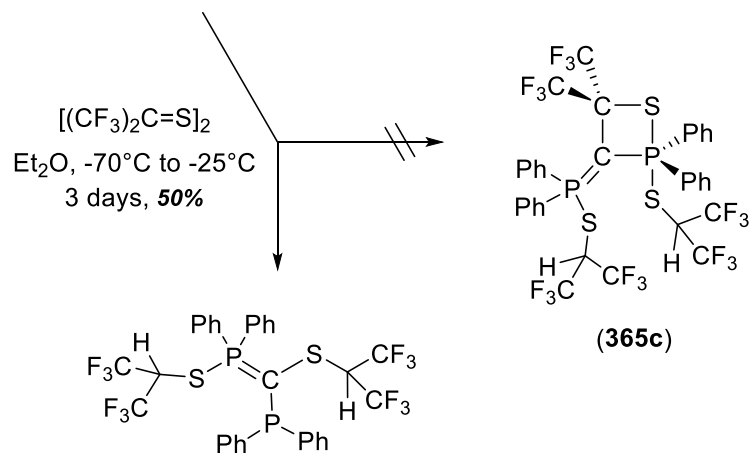

(365c)

(366c)

As already observed in the case of $\mathbf{2 1 6} \mathbf{a}, \mathbf{b}$, the CDP $\mathbf{2 1 8 b}$ is only stable in hexane at $-20^{\circ} \mathrm{C}$ and a decomposition pathway was found upon warming up to room temperature with the tetrafluoride derivative 361b being identified as the main decomposition product. $\mathbf{2 1 8 b}$ was also reacted with Brönsted acids such as $\mathrm{HCl}$ or $\mathrm{HBF}_{4}$ to yield the corresponding cationic mono(ylide)s. The highly reactive CDP 218c reacted with hexafluorothioacetone (HFTA) at very low temperature $\left(-70^{\circ} \mathrm{C}\right)$ yielding the mono(ylide) 366c.

As already mentioned, the nucleophilic character on the mixed bis(ylide)s 241a, 243c, 258 and 255c was illustrated by their reactivity towards methyl iodide leading to the respective $C$-methylated ylides 260 
$[241 \mathrm{a}-\mathrm{Me}][\mathrm{I}],{ }^{312}[\mathbf{2 4 3 c}-\mathrm{Me}][\mathrm{I}],{ }^{316}[\mathbf{2 5 8}-\mathrm{Me}][\mathrm{I}]^{323}$ and $[\mathbf{2 5 5 c}-\mathrm{Me}][\mathrm{I}]^{322}$ (Scheme 192). The double ylide character on the mixed $\mathrm{P}, \mathrm{S}^{\mathrm{IV}}$-bis(ylide) $255 \mathrm{c}$ was proved by the subsequent addition of trifluoromethanesulfonic acid to the monomethylated ylide [255c-Me][I] that produced the vinyl-substituted phosphonium salt [256c][OTf] (Scheme 192). The formation of [256c][OTf] can be rationalized on the basis of a first protonation step of ylide [255c-Me][I] to form the dicationic intermediate XXI followed by an intermolecular deprotonation of the methyl group and concomitant elimination of the $\mathrm{Me}_{2} \mathrm{~S}=\mathrm{NH}(\mathrm{Me})$ fragment. ${ }^{322}$ In the case of the mixed $\mathrm{Se}^{\mathrm{II}}, \mathrm{S}^{\mathrm{IV}}$-bis(ylide) $251 \mathbf{b}$ reported by Fujii, ${ }^{318}$ the double ylide function at the central $C$-atom was demonstrated by protonolysis with of trifluoromethanesulfonic acid yielding the dicationic salt $\left[\mathbf{2 5 1 b}-\mathrm{H}_{2}\right][\mathrm{OTf}]_{2}$.

Scheme 192. Methylation experiments carried out on the mixed bis(ylide)s 241a $\left(P, S^{I I}\right), 243 c$ $\left(\mathrm{P}, \mathrm{Si}^{\mathrm{II}}\right)$ and $258\left(\mathrm{P}, \mathrm{S}^{\mathrm{IV}}\right)$ by the group of Kato, Maerten and Baceiredo, and similar methylation and protonolysis reactions explored by Fujii and coworkers on the bis(ylide)s $255 \mathrm{c}\left(\mathrm{P}, \mathrm{S}^{\mathrm{IV}}\right)$ and $251 \mathrm{~b}$ $\left(\mathrm{Se}^{\mathrm{II}}, \mathrm{S}^{\mathrm{IV}}\right)$. 

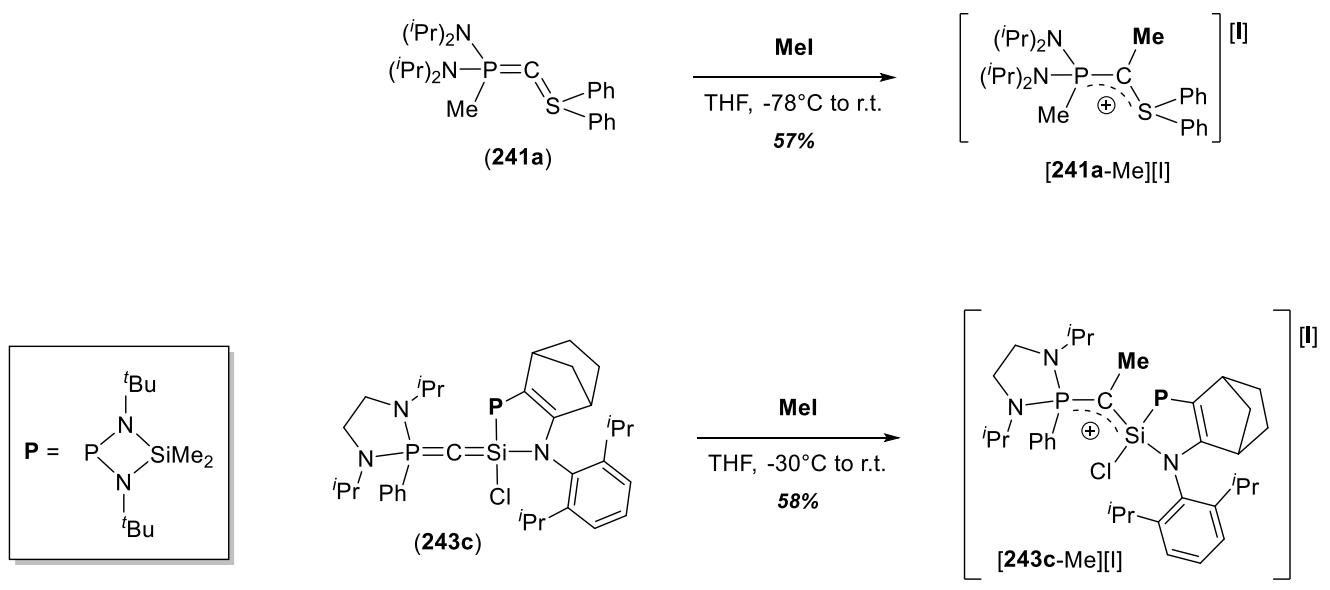

(eq. 2)
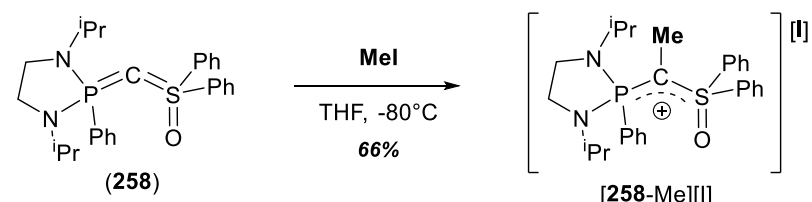

(eq. 3)
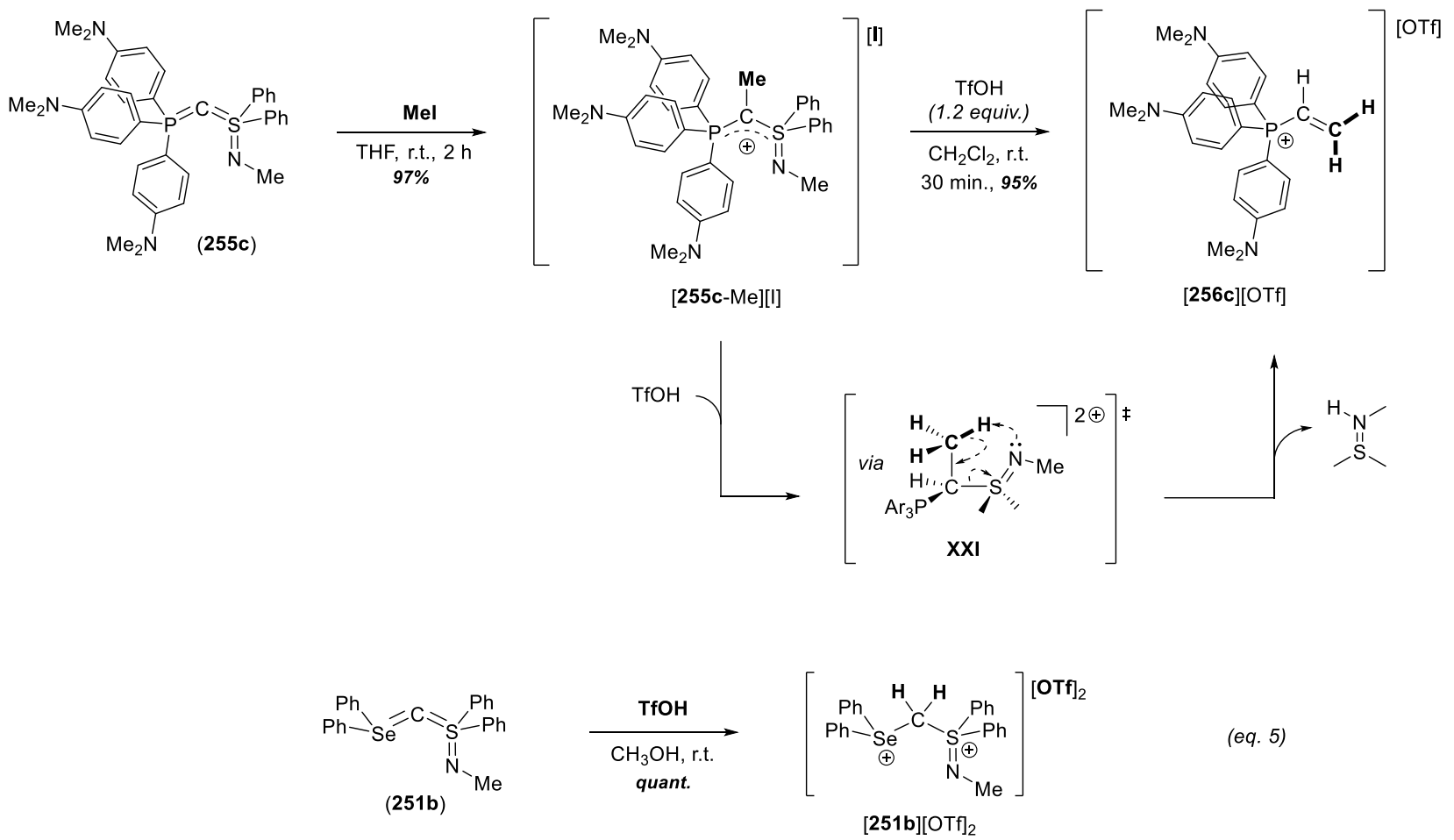

(eq. 5) 
Kato and Baceiredo studied the reactivity of the mixed P,S ${ }^{\mathrm{II}}$-bis(ylide) $241 \mathbf{b}$ towards carbonyl derivatives, ie. benzaldehyde and 1,1,1-trifluoroacetophenone (Scheme 193). ${ }^{313}$ The bis(ylide) $241 \mathbf{b}$ reacts with equimolar amounts of benzaldehyde to yield the oxaphosphetane $\mathbf{3 6 7 b}$ which slowly evolves in presence of additional benzaldehyde to provide benzyl benzoate $\mathbf{3 6 8}$. The unexpected reactivity shown by oxaphosphetane $\mathbf{3 6 7 b}$ versus the benzaldehyde was attributed by the authors as the main reason for the absence of Wittig-type reactions involving aldehydes and carbodiphosphoranes. The four-membered cycle $\mathbf{3 6 7 b}$ also reacts with two equivalents of thiophenol at room temperature to yield the $\alpha, \beta$-disulfide 369 in $63 \%$ yield.

Scheme 193. Synthesis of oxaphosphetanes 267b and 370b from bis(ylide) 241 b and carbonyl compounds along with their further reactivity with carbonyl derivatives, thiols and amides. Proof of concept for the use of bis(ylide)s as an "atomic carbon source" in organic synthesis.

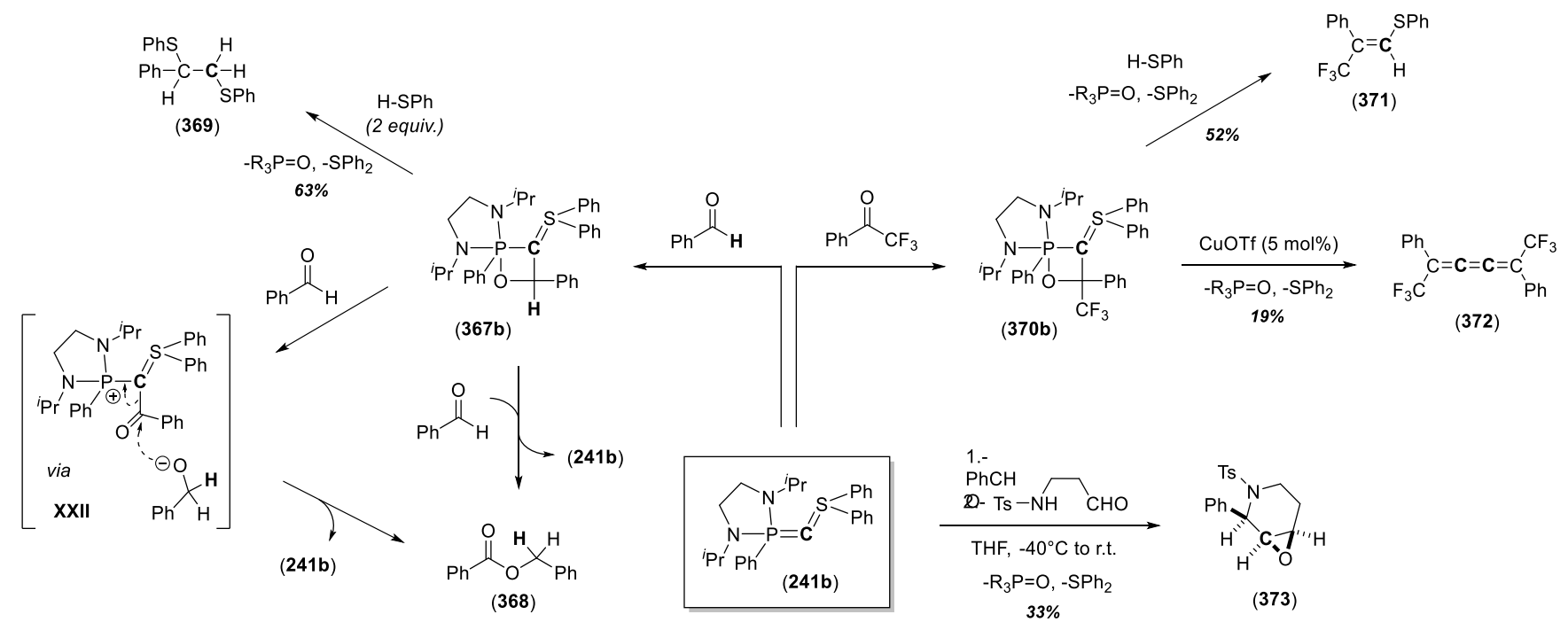

The reactivity of bis(ylide) $\mathbf{2 4 1 b}$ was decisively impacted by the electronic properties of the carbonyl compounds. Treatment of $\mathbf{2 4 1 b}$ with 1,1,1-trifluoroacetophenone allowed for the efficient stabilization 
of the oxaphosphetane $\mathbf{3 7 0 b}$ which was isolated as white crystals (83\% yield), and fully characterized by NMR and XRD analysis of single crystals. The crystallographic study of oxaphosphetane $\mathbf{3 7 0 b}$ revealed remarkably short $\mathrm{P}-\mathrm{C}$ and abnormally long $\mathrm{P}-\mathrm{O}$ bond distances of 1.758 and $1.837 \AA$, respectively. These observations were attributed to the increasing negative charge at the ylide carbon atom that is efficiently delocalized towards the phosphorane moiety. Oxaphosphetane $\mathbf{3 7 0 b}$ is highly stable, and did not evolve cleanly upon heating. The authors rationalized that the addition of a Lewis acid (CuOTf) should decrease the negative charge at the ylide function and would increase the reactivity of oxaphosphetane 370b. In fact, the addition of copper triflate in catalytic amounts to $\mathbf{3 7 0 b}$ at room temperature presumably leads to the formation of the corresponding copper vinylidene complex $\left[\mathrm{Cu}^{+}=\mathrm{C}=\mathrm{C}(\mathrm{Ph})\left(\mathrm{CF}_{3}\right)\right]$ that further evolves via dimerization reaction into the cumulene $\mathbf{3 7 2}$ isolated in $c a$. 20\% yield as a mixture 1:1 of both $Z$ and $E$ isomers (Scheme 193). Finally, Kato and Baceiredo per-

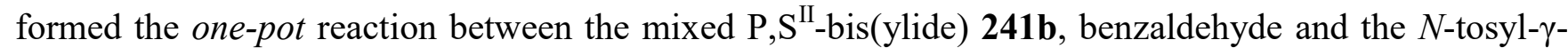
aminoaldehyde $\left[\mathrm{TsNH}\left(\mathrm{CH}_{2}\right)_{2} \mathrm{CHO}\right]$ and isolated the cis-fused bicyclic epoxide $\mathbf{3 7 3}$ in $33 \%$ yield. The route of access to bicyclic epoxide $\mathbf{3 7 3}$ encompasses four distinct steps, namely: $i$ ) oxaphosphetane 367b formation; ii) $\mathrm{Ph}_{3} \mathrm{P}=\mathrm{O}$ elimination to afford the sulfonium ylide $(\mathrm{Ph}) \mathrm{HC}=\mathrm{C}=\mathrm{SPh}_{2} ;$ iii) $\mathrm{N}-\mathrm{H}$ bond addition across the $\mathrm{C}=\mathrm{C}$ bond; and $i v) \mathrm{SPh}_{2}$ releasing and concomitant formation of epoxide 373. This work represented the first reaction of one bis(ylide) behaving as an atomic carbon source, and could bring new opportunities for the creation of enantiopure quaternary carbon centers.

\subsection{Coordination chemistry of double ylides to metallic species.}

\subsubsection{Coordination to Group 2 Metals.}


Based on an appropriate choice of apolar solvent, Petz et al. succeeded to isolate the zwiterionic complex 130 $\rightarrow \mathrm{BeCl}_{2}(\mathbf{2 7 8})$ in high yield (Scheme 194). ${ }^{379}$ The crystallographic data confirmed the structure of 374, in which both the ylidic carbon and the Be-atom are in trigonal planar geometry with a $\mathrm{C}-\mathrm{Be}$ bond distance of 1.742(9) $\AA$ and a dihedral angle of $44^{\circ}$ formed by the $\mathrm{CP}_{2}$ and $\mathrm{BeCl}_{2}$ planes. Theoretical studies at the BP86/SVP level indicated the $\sigma$ lone pair donation from carbon to the Be-center in the $\mathrm{C} \rightarrow \mathrm{BeCl}_{2}$ complex $\mathbf{3 7 4}$, as well as a weak $\pi$ contribution.

\section{Scheme 194. Coordination of 130 to $\mathrm{BeCl}_{2}$.}

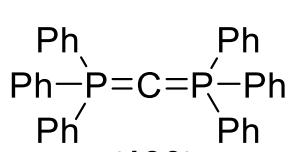

(130)

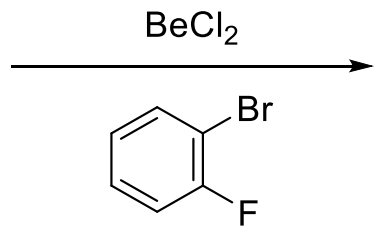

(solvent)

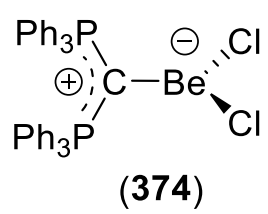

(374)

\subsubsection{Coordination to Actinides: Uranium Complexes}

A cutting edge article has been reported last year by Zhao, Frenking and Zhu covering the coordination of in situ prepared CDPs 130, 375 and 376 to $\mathrm{UCl}_{4}$ to afford the corresponding double dative bond adducts 377-379 with moderate isolated yields (Scheme 195). ${ }^{380}$ Suitable crystals for XRD analysis of the U-complexes 377-379 could be achieved and the crystallographic data confirmed the proposed atom connectivity. Magnetic measurements, the FT-IR spectra, and the remarkably short measured C-U bond distances of 1.411(3) $\AA$ (377), 2.461(5) $\AA$ (378) and 2.471(7) $\AA$ (379) pointed to the presence of a $\mathrm{C}=\mathrm{U}^{\mathrm{IV}}$ double bond. ${ }^{90,92}$ The double $\mathrm{C}=\mathrm{U}$ dative bonds were substantiated by DFT calculations. BDE analysis indicated the presence of strong $\mathrm{U} \leftleftarrows \mathrm{C}$ double donor bond, with significant improvement of the bond strength upon introduction of Py sidearms $\left[\mathrm{D}_{e}=70.8 \mathrm{kcal} \mathrm{mol}^{-1}(\mathbf{3 7 7}), 82.8 \mathrm{kcal} \mathrm{mol}^{-1}(\mathbf{3 7 8})\right.$ and 
$91.5 \mathrm{kcal} \mathrm{mol}^{-1}$ (379)]. In addition, the EDA-NOCV calculations for complexes 377-379 verified the double $\sigma+\pi$ lone pairs donation from the C-atom to uranium, and NBO analysis revealed a strong polarization of the $\sigma$ and $\pi$ bonds towards carbon, with the acceptor orbitals at uranium located mainly at the $5 \mathrm{f}$ and $6 \mathrm{~d}$ atomic orbitals.

Scheme 195. Synthesis of CDP-UCl ${ }_{4}$ complexes 377-379 from CDPs 130, 375 and 376.

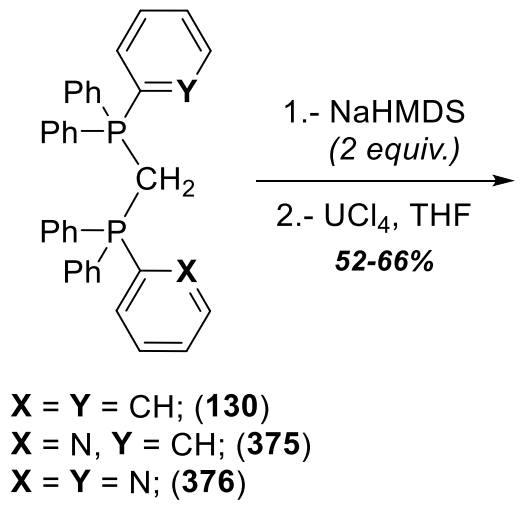

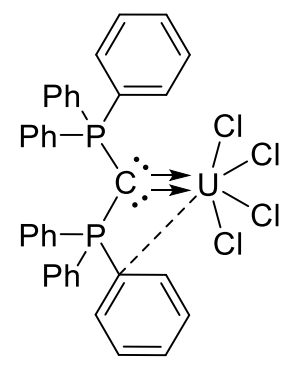

(377)

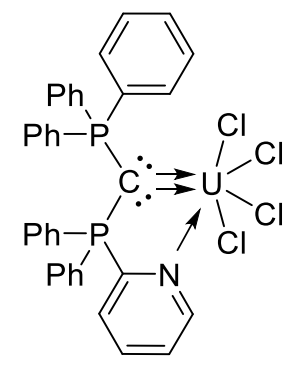

(378)

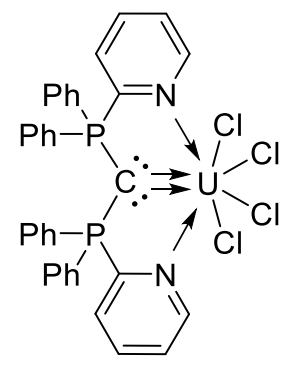

(379)

\subsubsection{Coordination to Group 4 Metals: Zirconium Complexes}

The unique organometallic complex of a group 4 metal bearing a "PCP" moiety was reported in1993 by Karsch et al. starting from the Zr-complex $\mathbf{3 8 0}$ that already contains the $\left[\mathrm{Me}_{2} \mathrm{P}-\mathrm{CH}-\mathrm{PMe}\right]^{-}$motif coordinated to the metal center (Scheme 196). ${ }^{381}$ Deprotonation by $t$ BuLi results in the formation of the $\mathrm{Zr}$ dimer complex 381 in excellent yield (87\%). The structure was established by XRD analysis and confirmed the bridging nature of the two $\mathrm{Me}_{2} \mathrm{P}-\mathrm{C}^{2-}-\mathrm{PMe}_{2}$ units that become reminiscent of the carbodiphosphorane ligands upon phosphine coordination to the $\mathrm{Zr}^{\mathrm{IV}}$.

Scheme 196. Synthesis of the Zr-dimer complex 381 decorated with two bridging carbodiphosphorane motifs. 


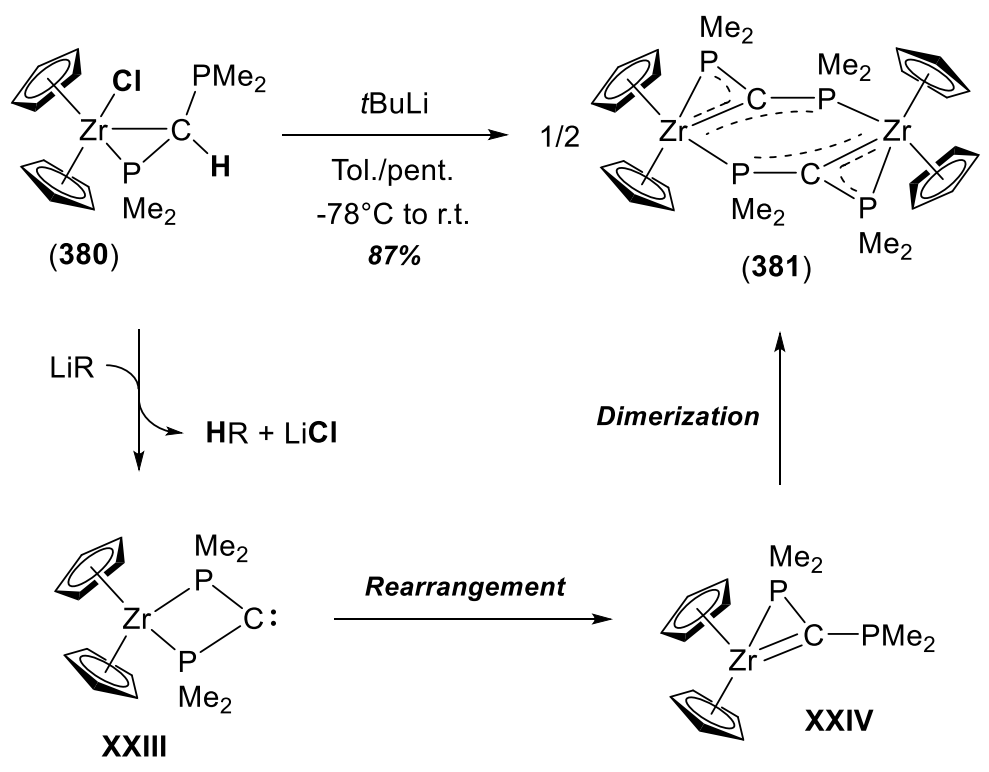

\subsubsection{Coordination to Group 6 Metals: Tungsten Complexes}

The coordination chemistry of CDPs to group 6 metals has been scarcely studied, and only tungsten complexes were envisaged. Kaska et al. evidenced in the early 70's two distinct reactivity patterns (paths i) and ii) in Scheme 197). ${ }^{382}$ In the first type of reactivity, 130 behaves as a strong Lewis base able to replace a $\mathrm{CO}$ ligand. Accordingly, mixing equimolar amounts of $\mathbf{1 3 0}$ and $\left[\mathrm{W}(\mathrm{CO})_{5}(\right.$ thf $\left.)\right]$ in tetrahydrofuran allowed for the isolation of complex 382, which was very sensitive to moisture. In contrast, the alternative path ii) took place when reacting 130 and $\left[\mathrm{W}(\mathrm{CO})_{6}\right]$ in benzene under photolytic conditions. $\mathrm{C}-\mathrm{P}$ bond splitting was observed, leading to mixtures of complex $\mathbf{3 8 3}$ and $\mathrm{Ph}_{3} \mathrm{P}=\mathrm{O}$. The formation of the phosphonioacetylide W-complex $\mathbf{3 8 3}$ occurs through a Wittig type reactivity initiated by $\mathbf{1 3 0}$ via nucleophilic attack to the electrophilic CO. Almost 40 years later, Petz et al. revisited this chemistry and isolated complex $\mathbf{3 8 3}$ in crystalline form. ${ }^{383}$

Scheme 197. Reactivity of hexaphenylcarbodiphosphorane (130) vs LW(CO) 5 precursors. 

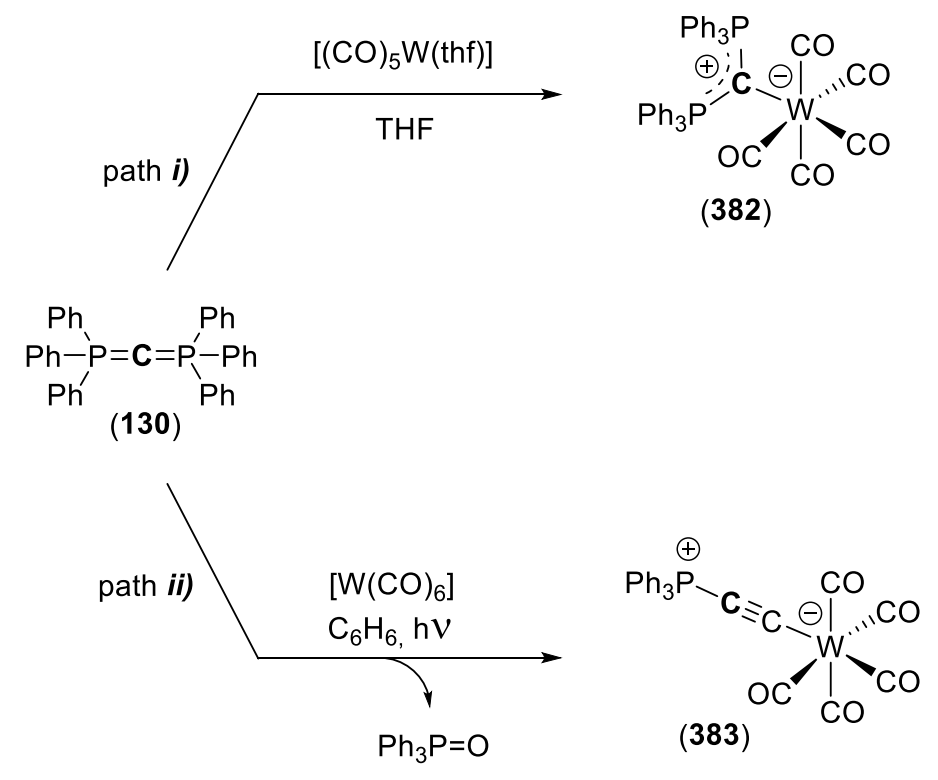

Alternative and very elegant entry to CDP-tungsten complexes was described by Templeton in 1987 through the synthesis of the carbodiphosphorane scaffold in the coordination sphere of the W-center (see Scheme 198). ${ }^{384}$ Starting from the tungsten carbyne 384, the CDP derivative $[\mathbf{3 8 5}]\left[\mathrm{PF}_{6}\right]$ was isolated in excellent $93 \%$ yield upon addition of $\mathrm{PMe}_{3}$ in excess. The structure of [385][ $\left.\mathrm{PF}_{6}\right]$ was definitively established by XRD analysis displaying a short W-C bond distance of 2.11(1) $\AA$ which is representative of a double $\mathrm{W}=\mathrm{C}$ bond. The authors proposed a two-step pathway involving the intermediate formation of the phosphonium carbyne $\mathbf{X X V}$ and the subsequent addition of a second $\mathrm{PMe}_{3}$ to forge the carbodiphosporane skeleton.

Scheme 198. Route of access to the hexamethylcarbodiphosphorane-containing tungsten complex $[289]\left[\mathrm{PF}_{6}\right] \cdot$ 


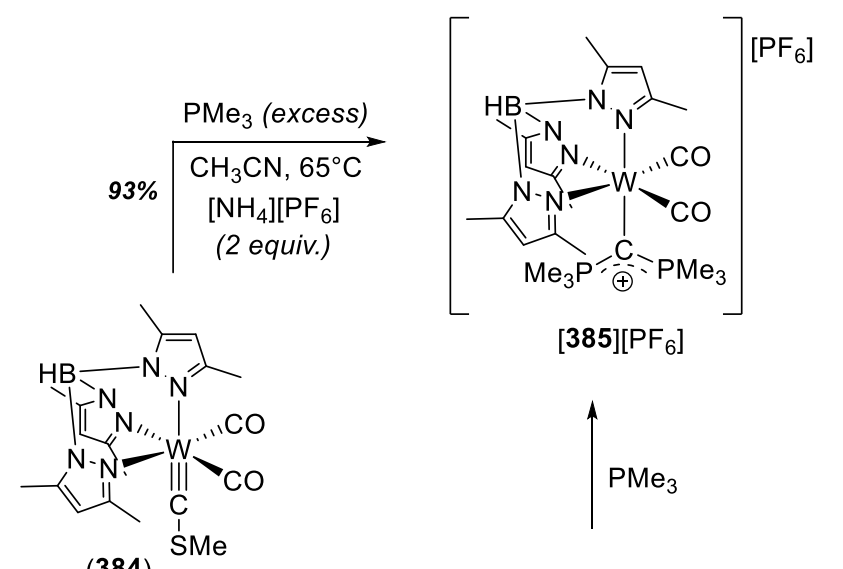

(384)

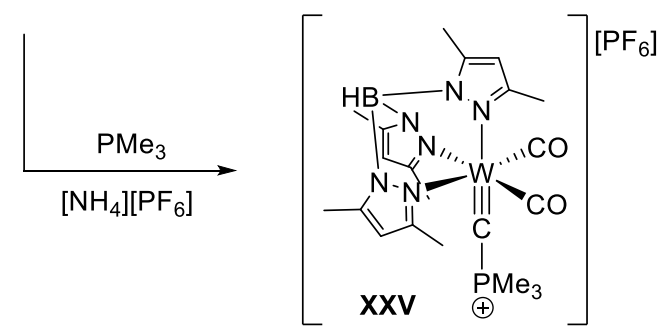

\subsubsection{Coordination to Group 7 Metals: Manganese and Rhenium Complexes}

The coordination of CDP $\mathbf{1 3 0}$ to group 7 metals was also addressed by Kaska and co-workers in 1974. ${ }^{385,386}$ As in the case of the tungsten complex $\mathbf{3 8 3}$, manganese and rhenium acetylide complexes 386 and 387 were obtained. Creation of the $\mathrm{C} \equiv \mathrm{CPh}$ fragment and the cis-conformation was verified by IR and mass spectrometry. ${ }^{385}$ Definitive proof for the structure of $\mathbf{3 8 6}$ was reported by others. ${ }^{387}$ Similar experiences by Petz et al. starting from $\left[\mathrm{Mn}_{2}(\mathrm{CO})_{10}\right]$ demonstrated the easy, unwanted protonation of 130. ${ }^{388}$ However, when using DME or benzene as solvent small quantities of an unexpected secondary compound $[\mathbf{3 8 8}]\left[\mathrm{Mn}(\mathrm{CO})_{5}\right]_{2}$ were obtained in crystalline form. XRD analysis proved the structure of cation 388 and revealed the presence of two $\mathrm{Ph}_{3} \mathrm{P}=\mathrm{O}$ ligands coordinated in cis-fashion. The complete characterization of $[\mathbf{3 8 8}]\left[\mathrm{Mn}(\mathrm{CO})_{5}\right]_{2}$ bearing two $\mathrm{Ph}{ }_{3} \mathrm{P}=\mathrm{O}$ and two $\left(\mathrm{Ph}_{3} \mathrm{P}\right)_{2} \mathrm{C}-\mathrm{CO}_{2}{ }^{-}$ligands in cation 388 pointed to the side reactivity of $\mathbf{1 3 0}$ and $\left[\mathrm{Mn}_{2}(\mathrm{CO})_{10}\right]$ via Wittig olefination. 
Scheme 199. Reactivity of hexaphenylcarbodiphosphorane (130) vs $\left[\mathrm{M}(\mathrm{CO})_{5} \mathrm{Br}\right]$ precursors $(\mathrm{M}=$ $\mathrm{Mn}, \mathrm{Re}),\left[\mathrm{Mn}_{2}(\mathrm{CO})_{10}\right]$ and $\left[\operatorname{Re}_{2} \mathrm{O}_{7}\right]$.

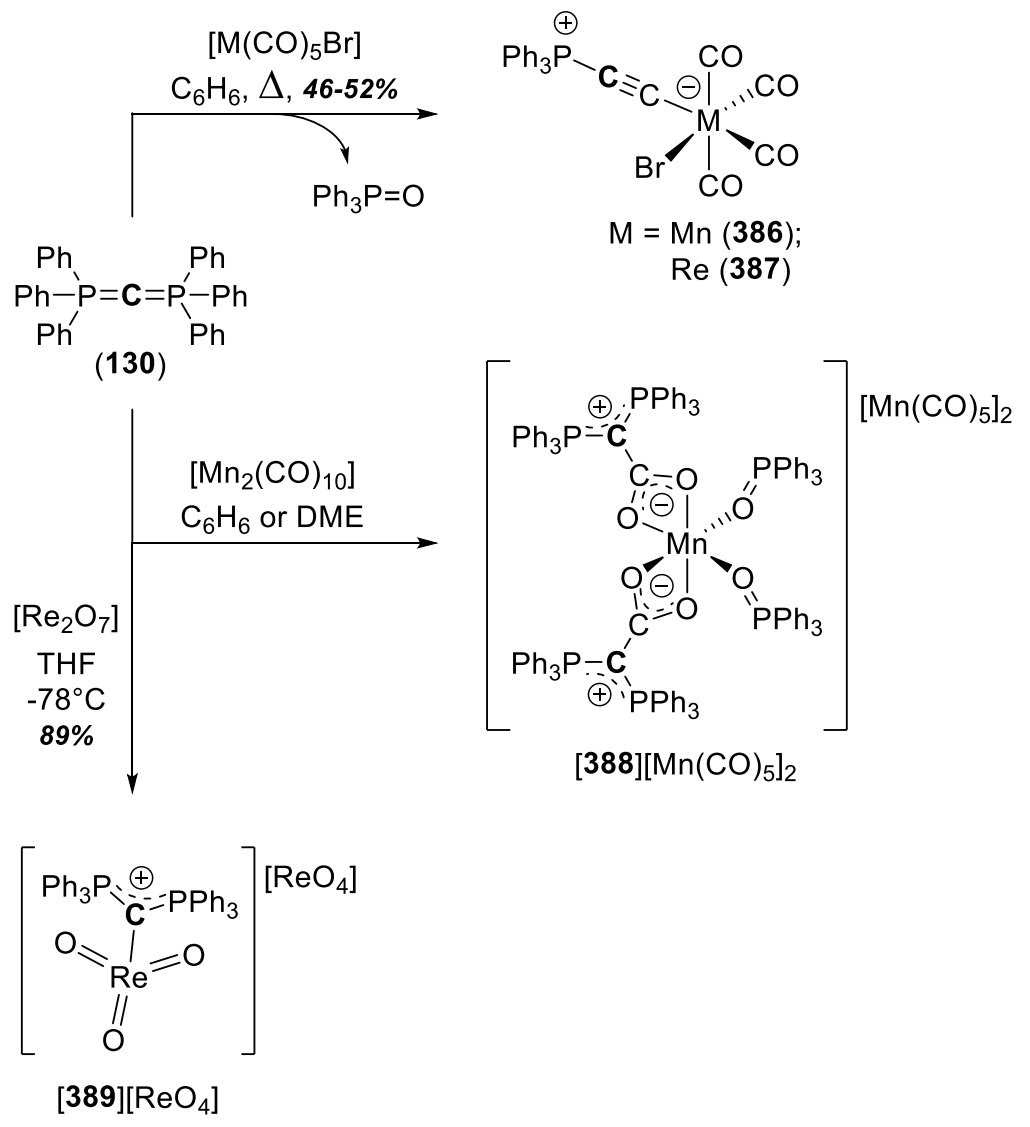

Guided by the possible double $\sigma+\pi$ donation capacity of 130, Sundermeyer et al. succeeded in synthesizing the organorhenyl perrhenate complex $[389]\left[\mathrm{ReO}_{4}\right]$ in high yield (Scheme 199). ${ }^{389}$ Crystallographic studies exhibit a tetracoordinated trioxorhenium cation with a $C_{3 v}$ symmetry containing the CDP 130 that shows a trigonal planar geometry around the ylidic carbon. The C-Re bond distance of 1.991(7) $\AA$ indicates partial $\pi$-donation from 130 to the Re-center.

\subsubsection{Coordination to Group 8 Metals: Iron Complexes}


Since the pioneering discovery of $\mathbf{1 3 0}$ in 1961, a single work has met success in the synthesis of Fe complexes. $^{390}$ This 2016 work by Stephan and coworkers includes a novel and safer synthetic approach for 130, isolated in ca. $90 \%$ yield at gram scale from the corresponding methylene diphosphonium salt and KHMDS. Combining 130 and $\mathrm{FeCl}_{2}$ in tetrahydrofuran allowed isolation of a tricoordinate monomer 390 along with its dimeric version (391 in Scheme 200). Crystallographic studies from a $\mathrm{CH}_{2} \mathrm{Cl}_{2} / \mathrm{Et}_{2} \mathrm{O}$ mixture of solvents showed both compounds in the same asymmetric unit, while replacement of $\mathrm{Et}_{2} \mathrm{O}$ by pentane allowed for the selective crystallization of dimer 391. These paramagnetic materials were characterized by ${ }^{1} \mathrm{H}$ NMR displaying signals between 10.0 and -1.3 ppm for the phenyl rings, and by ${ }^{57} \mathrm{Fe}$ Mössbauer spectroscopy that demonstrated the presence of tetracoordinate Fe(II) species 391, thereby proving the preference of the dimeric form in solid state. The utility of complexes 390/391 as an organoiron synthon was evaluated towards $\mathrm{BnMgCl}$ to give the tricoordinate dibenzylic iron complex 382, whereas two successive chloride replacements were achieved by selective anion metathesis reactions with LiHMDS and TMSOTf to give the Fe(II) complexes 393 and 394. These unprecedented Fe(II) complexes were fully characterized, including by XRD analysis for the case of $\mathbf{3 9 2}$ and 394 that represent two rare examples of Fe(II) centers in rare trigonal planar geometry probably mediated by the exceptional donor capacity of $\mathbf{1 3 0 .}$

\section{Scheme 200. Synthesis CDP-Fe complexes 390-394 bearing the CDP130 reported by Stephan.}




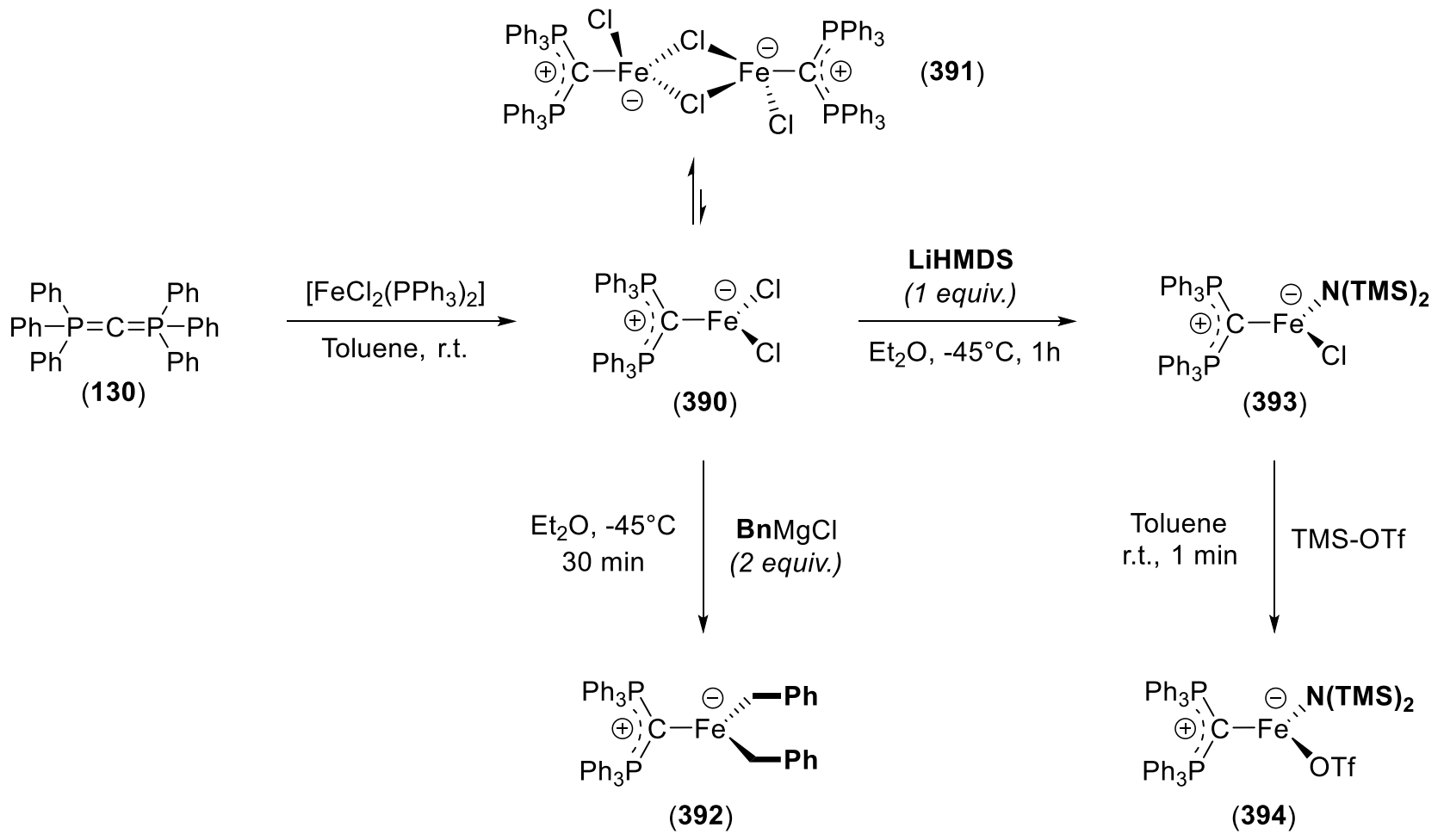

Two decades before, Petz and co-worker tested the coordination chemistry of $\mathbf{1 3 0}$ towards different iron carbonyl complexes without success. ${ }^{391}$ Instead, the authors observed the Wittig type reactivity to create the cumullene $\left[(\mathrm{CO})_{4} \mathrm{Fe}=\mathrm{C}=\mathrm{C}=\mathrm{PPh}_{3}\right](\mathbf{3 9 5})$ and the iron cluster $\left[\mathrm{Fe}_{3}(\mathrm{CO})_{9}\left(\mu^{3}-\eta^{2}-\mathrm{C} \equiv \mathrm{CPPh}_{3}\right)\right](\mathbf{3 9 6})$ from $\left[\mathrm{Fe}(\mathrm{CO})_{5}\right]$ or $\left[\mathrm{Fe}_{2}(\mathrm{CO})_{9}\right]$ and $\mathbf{1 3 0}$ (synthetic schemes and structures of complexes $\mathbf{3 9 5}$ and $\mathbf{3 9 6}$ are shown in Scheme 201).

Scheme 201. Reactivity of CDP 130 vs $\left[\mathrm{Fe}(\mathrm{CO})_{5}\right]$ and $\left[\mathrm{Fe}_{2}(\mathrm{CO})_{9}\right]$ reported by Petz. 


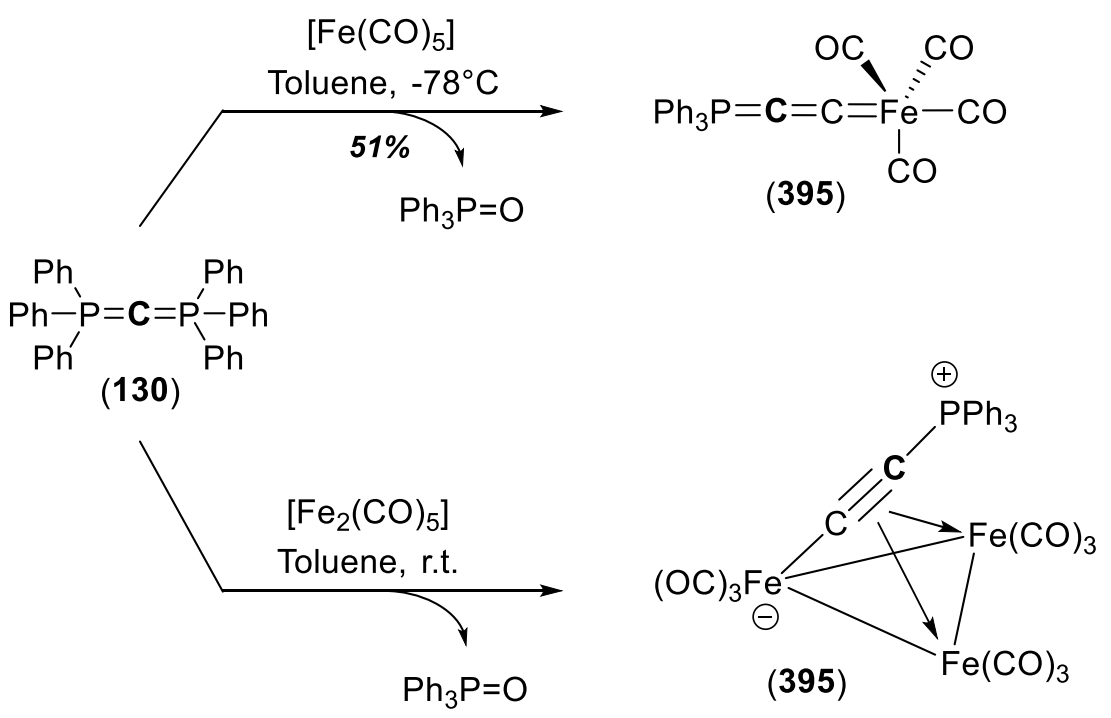

\subsubsection{Coordination to Group 9 Metals: Rhodium and Iridium Complexes}

Continuing with his pioneering work in transition metal complexes bearing CDP 130, Kaska et al. studied its coordination to cationic iridium complexes (Scheme 202). ${ }^{392}$ Despite being identified, the isolation of the Ir-complex [397] $\left[\mathrm{PF}_{6}\right]$ in pure form was impossible, due to its high sensitivity. Formation of [397] $\left[\mathrm{PF}_{6}\right]$ was accompanied by the allylic $\mathrm{C}-\mathrm{H}$ bond activation of the $\mathrm{COD}$ ligand to bring the unwanted species 398 and the phosphonium salt $[\mathbf{1 3 0}-\mathrm{H}]\left[\mathrm{PF}_{6}\right]$.

Very recently, Cavell took advantage of the basic character of $\mathbf{1 3 0}$ to get access to the cyclometallated Rh-complex 399 via $\mathrm{C}-\mathrm{H}_{\text {ortho }}$ bond activation of one phenyl ring (Scheme 202). ${ }^{393}$ Based on the identification of the salt $[\mathbf{1 3 0}-\mathrm{H}][\mathrm{Cl}]$, the authors proposed a mechanism involving a first $\mathrm{C}-\mathrm{H}$ bond activation step of the aromatic ring to yield a $\mathrm{Cl}-\mathrm{Rh}(\mathrm{III})-\mathrm{H}$ intermediate that undergoes $\mathrm{HCl}$ elimination induced by 130. The structure of $\mathbf{3 9 9}$ was determined crystallographically confirming the atom connectivity and proving the $\mathrm{sp}^{2}$ hybridation of the donating $C$-atom, as indicated by its trigonal planar geometry. However, the measured $\mathrm{C}-\mathrm{Rh}$ bond distance of 2.165(2) $\AA$ argued in favor of a single bond. Interestingly, 
the addition of two equiv. of strong $\sigma$-donationg $\mathrm{PMe}_{3}$ ligands mediates the second orthometallation reaction and leads to the formation of the $C, C, C$-pincer $\mathrm{Rh}(\mathrm{III})-\mathrm{H}$ complex $\mathbf{4 0 0}$. The structure of $\mathbf{4 0 0}$ was established by XRD analysis as well and confirmed the distorted octahedral geometry retaining the $\mathrm{sp}^{2}$ hydridation at the ylicic carbon. The $\mathrm{C}-\mathrm{Rh}$ bond distance of $2.202(3) \AA$ is slightly longer than the one found in complex 399, being in accordance with a single $\mathrm{C}-\mathrm{Rh}$ bond. The electronic structure in complex 400 was studied by DFT calculations that indicated the presence of a single $\sigma$-bonding contribution, which is described as an efficient orbital overlapping between the $\mathrm{sp}^{2}$ hybridized orbital at the donating $C$-atom and a d-orbital from $\mathrm{Rh}$, with the HOMO mainly located at the $\mathrm{p}_{\mathrm{z}}$-orbital of the $C$ atom.

Scheme 202. Synthesis of CDP-Ir complex $[397]\left[\mathrm{PF}_{6}\right]$ and double orthometallation of the phenyl rings of hexaphenylcarbodiphosphorane (130) to forge the $C$-only pincer $\mathrm{Rh}(\mathrm{III})$ complex 399.

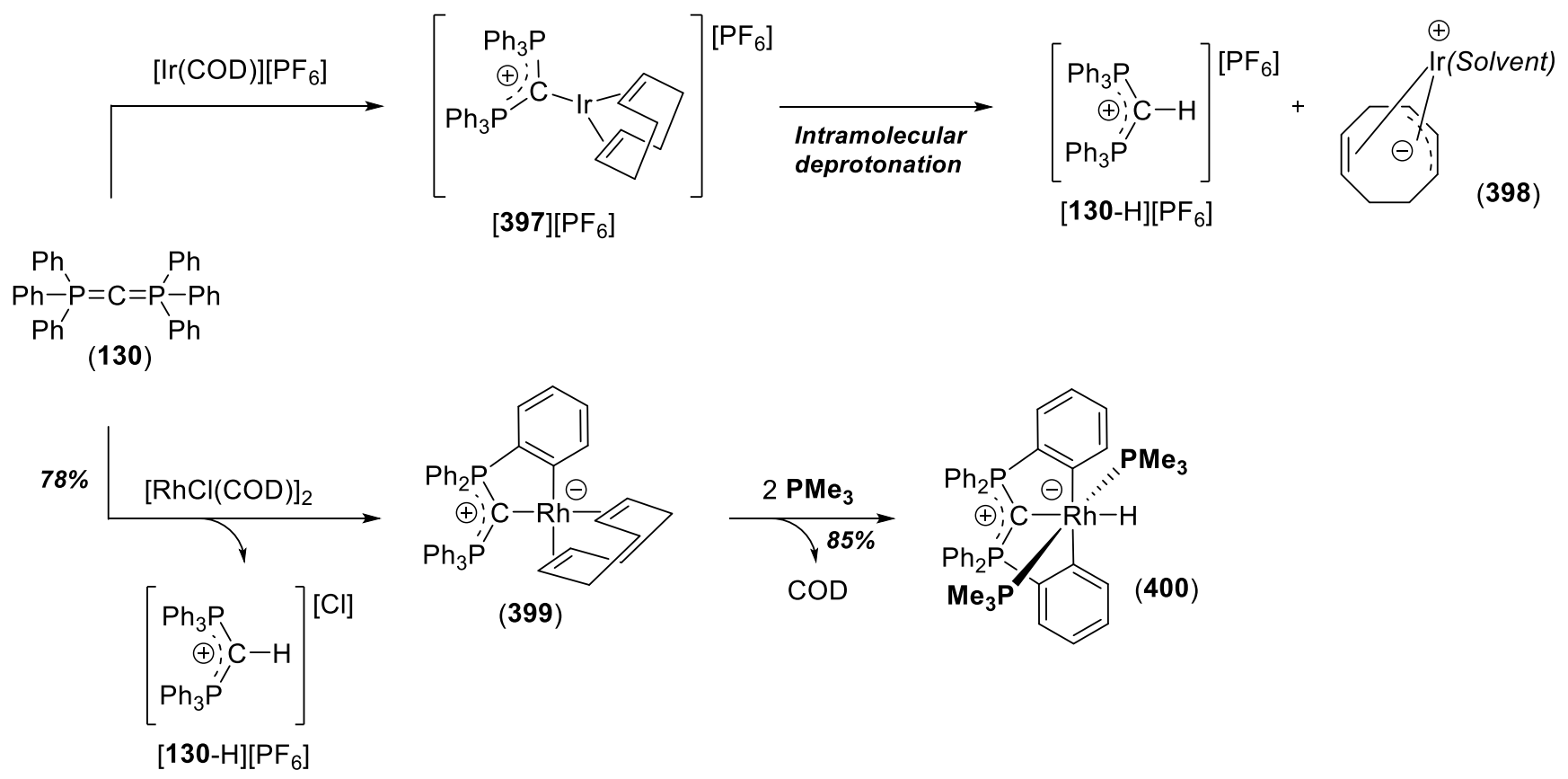


Measurement of the carbonyl stretching frequencies of the $c i s-\left[(\mathbf{L}) \mathrm{RhCl}(\mathrm{CO})_{2}\right]$ complexes are generally carried out to rank/compare the donating capacity of ligands $\mathbf{L}$ (Scheme 203). This method was applied to acquire some insight on the electron donor ability of the P,C-bis(ylide) $\mathbf{2 6 4 b},{ }^{[324]}$ and the P,Sbis(ylide)s $\mathbf{2 2 8 b ^ { [ 3 0 8 ] }}$ and $\mathbf{2 5 8} .^{[323]}$ The complexes were synthesized according to two alternative routes. As indicated in Scheme 203, the carbonyl rhodium complexes 403, 404 and 405 gave an average $v_{\mathrm{CO}}$ of 2001, 2016 and $2007 \mathrm{~cm}^{-1}$ respectively, which pointed to the higher donation ability of the cyclic CDP 228b $v s$ the acyclic homologues 258 and $\mathbf{2 6 4 b}$.

Scheme 203. Two alternative routes for accessing the cis-[(L)RhCl(CO) $\left.)_{2}\right]$ complexes $403-405$ bearing the bis(ylide)s $228 \mathrm{~b}, 258$ and $264 \mathrm{~b}$. 

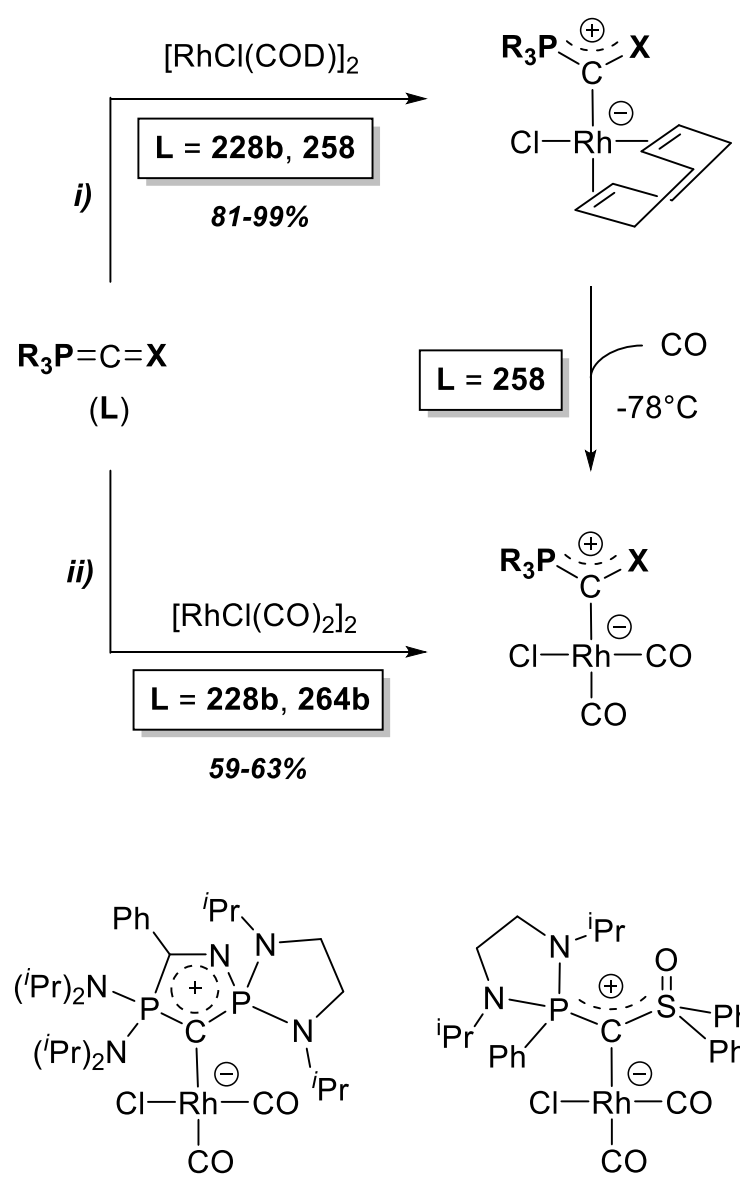

Complex $\quad 403$

$v_{\mathrm{CO}}\left(\mathrm{cm}^{-1}\right) \quad 2001$

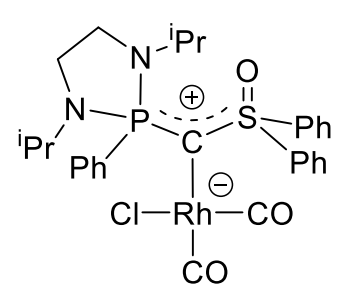

404

2016

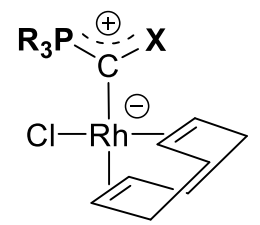

$L=228 b ;(401)$

258; (402)
$\mathrm{L}=\mathbf{2 2 8 b},(403)$

258, (404);

264b, (405)

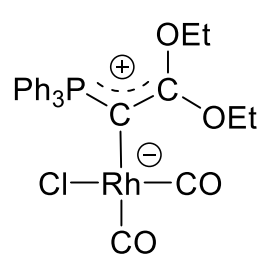

405

\subsubsection{Coordination to Group 10 Metals}

First approaches to group 10 metals containing a CDP ligand were done in 1973 by Kaska et al who coordinated CDP 130 to precursor $\left[\left(\mathrm{PPh}_{3}\right)_{2} \mathrm{Pt}\left(\mathrm{C}_{2} \mathrm{H}_{4}\right)\right]$ in benzene at r.t. ${ }^{382}$ The authors observed the formation of a new compound by NMR, that was characterized by IR, EA and by its decomposition reaction into the phosphonium salt $[\mathbf{1 3 0}-\mathrm{H}][\mathrm{Cl}]$ upon protonolysis with hydrogen chloride. Based on these data, the authors proposed the isolated material to be $\mathbf{4 0 6}$ (Scheme 204), containing the carbodiphosphorane $\mathbf{1 3 0}$ coordinated in $\eta^{2}$-fashion in place of the ethylene molecule. However, in 2005, ${ }^{394}$ Petz, 276 
Neumüller and co-worker demonstrated that no reaction occurs under the conditions reported by Kaska et $a l$., and that the isolated compound was most likely the hydrolysis compound $\mathrm{Ph}_{3} \mathrm{P}(\mathrm{O})-\mathrm{CHPPh}$ derived from 130. They also proved that 130 does not react with $\left[\left(\mathrm{PPh}_{3}\right)_{2} \mathrm{Pt}\left(\mathrm{C}_{2} \mathrm{H}_{4}\right)\right]$ even under refluxing of toluene, instead giving the dimer Pt-complex 407 without participation of the CDP. In the same article, the authors succeeded to make the orthometallated $\mathrm{Pt}(\mathrm{II})$-complex 408 from 130 and $\left[\mathrm{Pt}(\mathrm{COD}) \mathrm{I}_{2}\right]$, which was isolated in nearly quantitative yield and requires a sacrificial stoichiometric amount of $\mathbf{1 3 0}$ in order to trap the released Brönsted acid (HI). The structure of $\mathbf{4 0 8}$ was determined by XRD analysis and revealed the ortho phenyl ring cyclometallation of $\mathbf{1 3 0}$ upon coordination to the Pt-center along with the $\eta^{3}$-coordination of the $\mathrm{C}_{8} \mathrm{H}_{11}$ fragment via a double bond and a $\sigma$ bond (Scheme 204). ${ }^{394}$

In subsequent articles, ${ }^{395,396}$ Petz et al. studied the reactivity of the orthometallated complex $\mathbf{4 0 8}^{395}$ Thus the addition of hydrogen chloride to $\mathbf{4 0 8}$ favored COD dissociation and the formation of the $C, C, C$-pincer $\mathrm{Pt}(\mathrm{IV})$-complex 409 through a second $\mathrm{C}-\mathrm{H}_{\text {ortho }}$ bond activation and $\mathrm{H}$ migration to the ylide carbon. Attempts to achieve the chloride substitution by $\mathrm{PPh}_{3}$ in $\mathrm{CHCl}_{3}$ allowed to crystallize the unexpected carbonyl Pt(II) complex 410, whose unexpected formation can be only rationalized by the intermediate formation of an electrophilic $\mathrm{Pt}=\mathrm{CCl}_{2}$ carbene complex and its subsequent hydrolysis with adventitious water to create the CO ligand. ${ }^{395}$ The stirring of a 1:1 mixture of 130 and $\left[\mathrm{Pt}(\mathrm{COD}) \mathrm{I}_{2}\right]$, followed by recrystallization from a chlorinated solvent allowed for the isolation of the very rare, octahedral Pt(IV)-complex 411 which was isolated in excellent yield. ${ }^{396}$ The crystallographic data for 411 proved the formation of the $\left(\mathrm{Ph}_{3} \mathrm{P}\right)_{2} \mathrm{C}-\mathrm{CH}_{2}{ }^{-}$unit which is $\eta^{2}$-coordinated to the Pt-atom with $\mathrm{C}-\mathrm{Pt}$ bond distances of $2.12 \AA$ and $2.09 \AA$ via two $\sigma$ bonds. The bonding situation in 411 was analyzed by DFT calculations. The calculated diagram of the Laplacian distribution $\nabla 2 \rho(r)$ of $\mathbf{4 1 1}$ in the $\boldsymbol{P t}-\boldsymbol{C}-\boldsymbol{C H} \mathrm{H}_{2}$ plane displayed two areas of charge concentration located at the ylide carbon and the methylenic carbon point277 
ing towards the Pt-atom. This indicates the donation of both electron pairs at the $C$-atoms to the metal center. NBO calculations were carried out as well and showed the presence of negative charge at both donor $C$-atoms and Wiberg bond indexes of $0.40\left(\mathrm{Pt}-\mathrm{C}_{\text {ylide }}\right), 0.56\left(\mathrm{Pt}-\mathrm{C}_{\text {methylenic }}\right)$ and $1.15\left(\mathrm{C}_{\text {ylide- }}\right.$ $\mathrm{C}_{\text {methylenic }}$ ) that fits nicely with the interpretation of the unprecedented $C_{2}$-fragment behaving as a fourelectron $\sigma$ donor ligand. The $\left(\mathrm{Ph}_{3} \mathrm{P}\right)_{2} \mathrm{C}-\mathrm{CH}_{2}{ }^{-}$ligand in 411 was presumably formed by in situ reaction of the expected intermediate $\mathbf{4 0 8}$ and dichloromethane. However, treatment of the isolated Pt(II)-complex 408 with pure $\mathrm{CH}_{2} \mathrm{Cl}_{2}$ resulted in the formation of the $C, C, C$-pincer complex $412 .{ }^{396}$

Similar reactivity was observed by the group of Cavell for the coordination of $\mathbf{1 3 0}$ to precursor $\left[\mathrm{Me}_{2} \mathrm{Pt}\left(\mathrm{SMe}_{2}\right)_{2}\right]$. The $C, C, C$-pincer $\mathrm{Pt}(\mathrm{IV})$ complex 413 was formed by double orthometallation of two phenyl rings of the carbodiphosphorane core with the concomitant releasing of two equiv. of methane (Scheme 204). ${ }^{393}$

Kaska studied the coordination chemistry of $\mathbf{1 3 0}$ towards cationic Pt(IV) complexes. ${ }^{397}$ Thus, the rigorous control of the $\mathrm{Pt} / \mathbf{1 3 0}$ stoichiometry allowed for the selective isolation of the Pt(II)-complex 414 in moderate yield, or quantitative formation of complex 415. One should note that most of these reactions are dominated by the formation of the sideproduct $[130-H][X]$ which seems to be the driving force for the orthometallation reactions observed at Pt-centers.

Scheme 204. Synthesis of Pt-complexes bearing the hexaphenylcarbodiphosphorane ligand (130). 


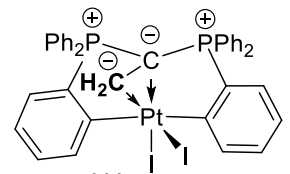

(411)
$\left[\begin{array}{c}\mathrm{Ph}_{3} \mathrm{P} \\ \Theta_{i} \mathrm{C}-\mathrm{H} \\ \mathrm{Ph}_{3} \mathrm{P}\end{array}\right]$

$[130-\mathrm{H}][1]$
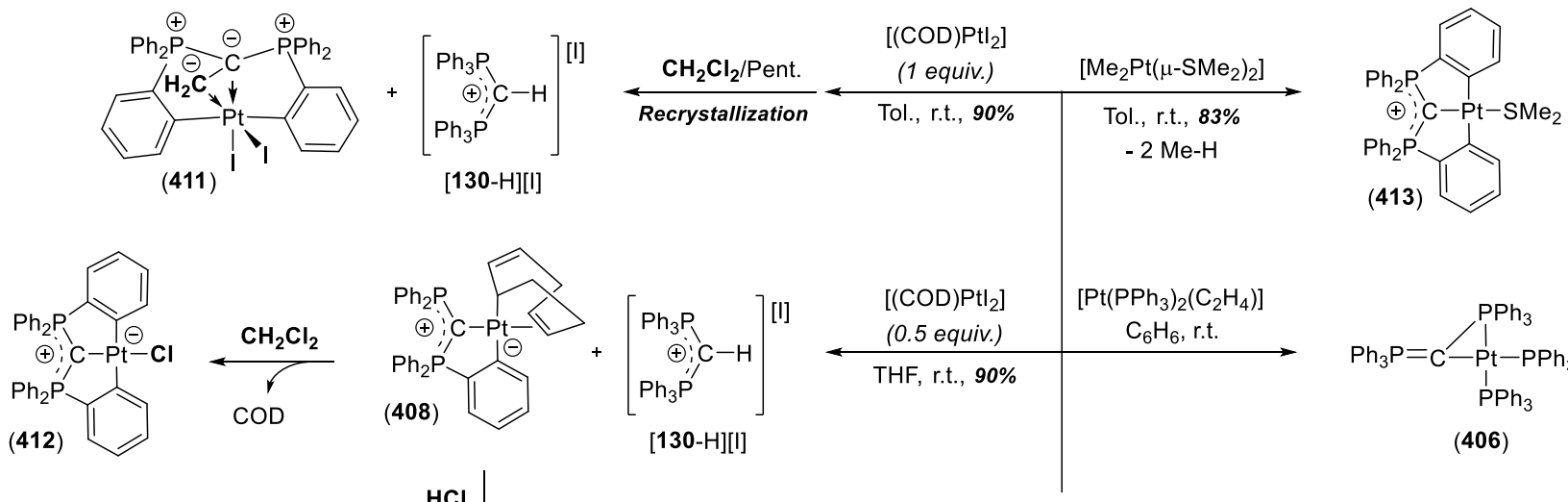

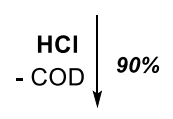

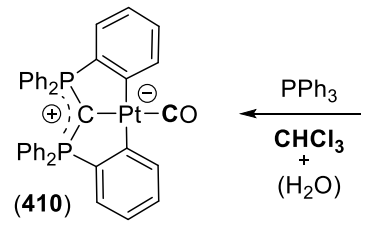

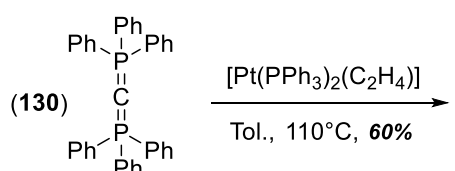

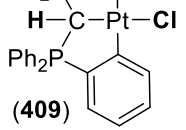

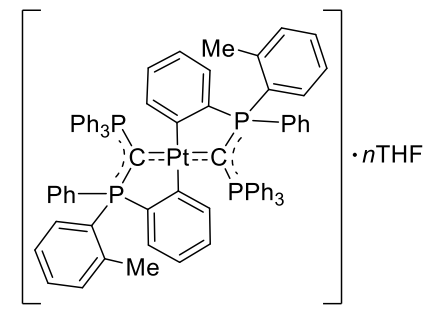

$(315) \cdot n$ THF

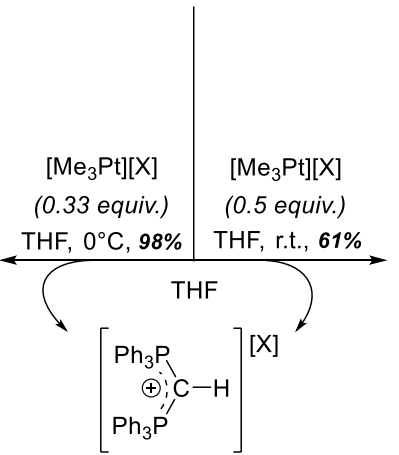

[130-H][X]

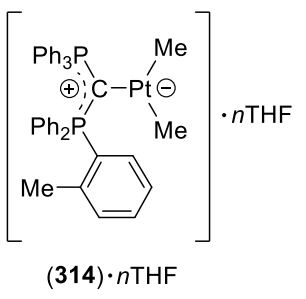

$(314) \cdot n T H F$

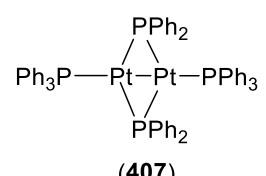

(407)

The chloride ligand in $P, C, P$-pincer $\mathrm{Pt}(\mathrm{II})$-complex 413, was readily displaced by $\mathrm{PEt}_{3}$ to yield quantitatively complex 416. XRD analysis of $\mathbf{4 1 6}$ evidenced the pyramidalization of the donating carbon that is rationalized by the partial change of the hydridation at the $C$-atom from $\mathrm{sp}^{2}$ to $\mathrm{sp}^{3}$, thus enhancing the lone pair availability. The $P, C, P$-pincer complex 416 was thus found to be an excellent organometallic synthon to access unprecedented $\mathrm{Pt}^{\mathrm{II}} \bullet \bullet \mathrm{Ag}^{\mathrm{I}}$ heterobimetallic species $417-419$ (Scheme 205). ${ }^{398}$ Indeed, 416 reacts cleanly with AgOTf to form cluster $[417][\mathrm{OTf}]_{2}$ in very high yield. The full characterization of cluster 417 in solution by NMR techniques was precluded owing to the broadening of the NMR signals indicating fast fluxionality of the tetrametallic species. The solid state structure of [417][OTf $]_{2}$ 279 
shows an antiparallel sandwich structure for the tetrametallic unit with a ladder-shaped $\mathrm{PtC} / \mathrm{AgAg} / \mathrm{CPt}$ core having $\mathrm{Pt}-\mathrm{Ag}$ bond distances that are included within the range of analogous $\mathrm{Ag}_{2} \mathrm{Pt}_{2}$ clusters being consistent with the presence of $\mathrm{Pt}^{\mathrm{II}} \bullet \bullet \mathrm{Ag}^{\mathrm{I}}$ donor-aceptor interactions. The $\mathrm{Ag}-\mathrm{Ag}$ bond distance of $2.7346(7) \AA$ is remarkably short and points to the presence of significant $\mathrm{d}^{10} \bullet \bullet \mathrm{d}^{10}$ closed-shell interactions. In fact, the formation of the dicationic cluster $\mathbf{4 1 7}$ is proposed to happen through the formation of the heterobimetallic intermediate XXVI that quickly undergoes dimerization, the strong argentophilic interactions seemingly being the driving force for cluster formation. The key role of these argentophilic interactions in the stabilization of the cluster core was further evidenced by the cluster opening and forming of heterobimetallic species [418][OTf] and [419][OTf] upon addition of $\mathrm{P}(\mathrm{OPh})_{3}$ or $\mathrm{PPh}_{3}$, respectively. These two new compound were fully characterized by multinuclear NMR, EA and crystallographic studies structural parameters typical from $\mathrm{Pt}^{\mathrm{II}} \bullet \bullet \mathrm{Ag}^{\mathrm{I}}$ closed-shell interactions. Alternatively, the heterobimetallic species [419][OTf] was obtained in an improved yield by direct reaction of 416 and $\left[\mathrm{Ag}\left(\mathrm{PPh}_{3}\right)\right][\mathrm{OTf}]$

Scheme 205. Synthesis of $\mathrm{Pt}^{\mathrm{II}}-\mathrm{Ag}^{\mathrm{I}}$ heterobimetallic complexes supported by a CDP framework published by Kubo and Mizuta. 


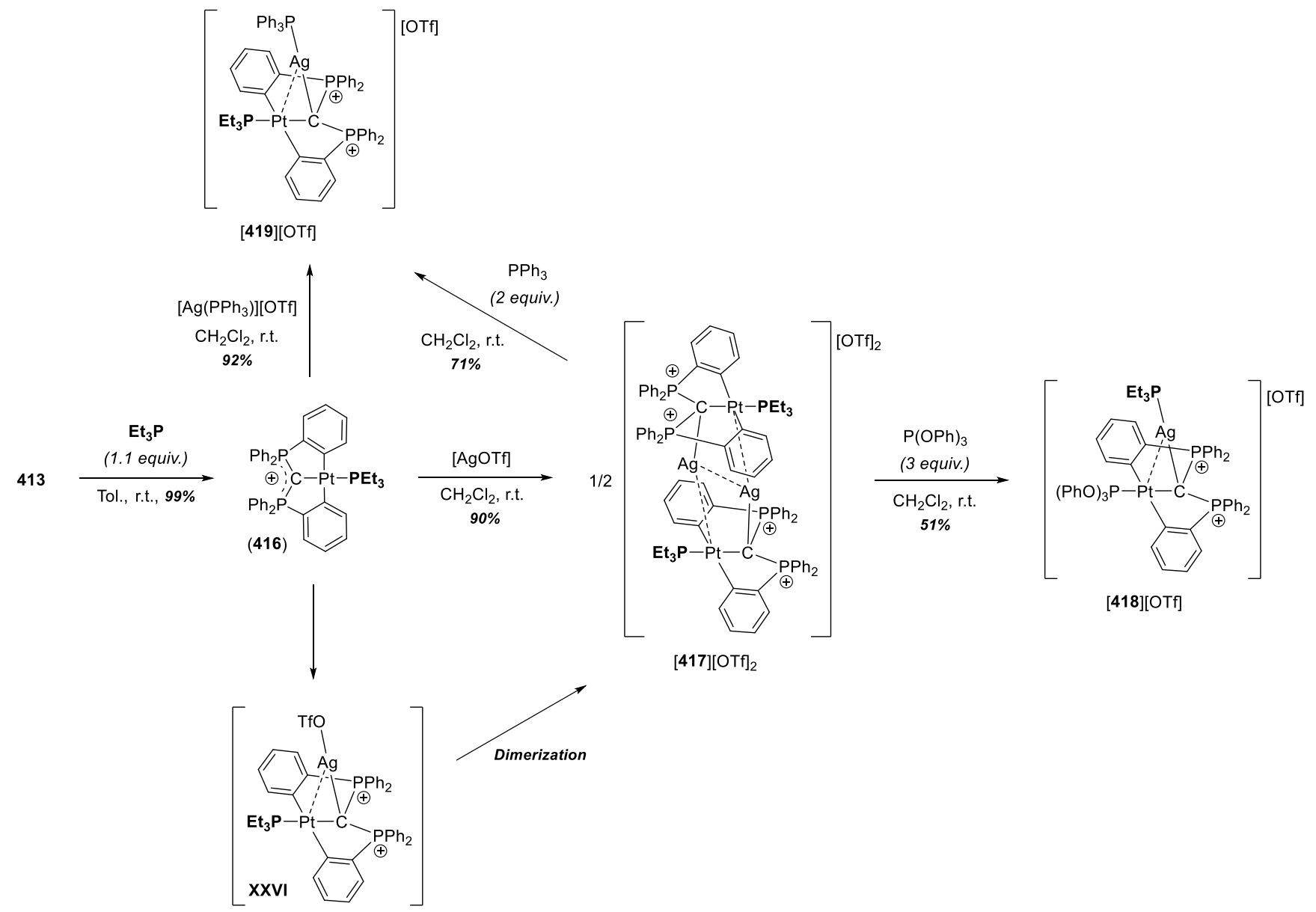

The first organopalladium complex stabilized by a carbodiphosphorane ligand was reported in 2006 by Kato and Baceiredo. (Scheme 206). ${ }^{308}$ The allyl palladium complex 420 was formed upon coordination of the cyclic, strongly donor CDP $\mathbf{2 2 8 b}$ to the $[\mathrm{PdCl}(\text { allyl })]_{2}$ dimer. The solid state structure revealed the trigonal planar geometry around the donating $C$-atom ( $\mathrm{sp}^{2}$ hybridation at carbon) with $\mathrm{C}-\mathrm{Pd}$ bond distance of 2.120(2) $\AA$ (indicative of single $\sigma$ bond), and $\mathrm{P}-\mathrm{C}_{\text {ylide }}$ distances of 1.673(2) $\AA$ and 1.694(2) $\AA$ that are comprised in the range between single and double $\mathrm{C}-\mathrm{P}$ bond. These structural features pointed to a bonding situation having a $\mathrm{Pd}-\mathrm{C} \sigma$ interaction with the $\pi$ lone pair at the donor carbon being delocalized though the two phosphonium groups. 


\section{Kato and Baceiredo.}
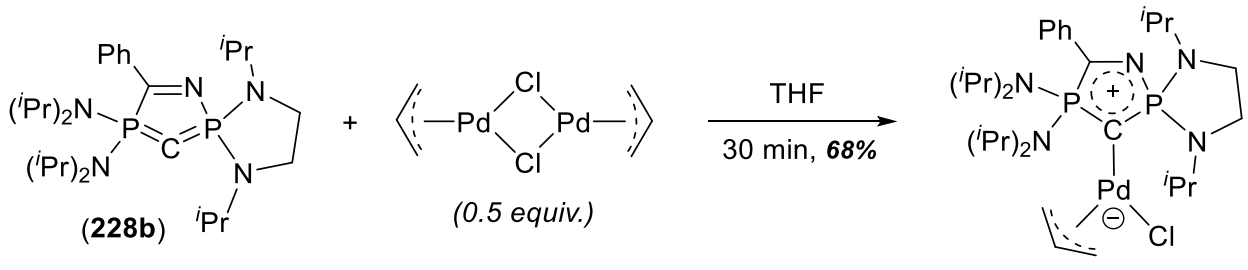

(420)

As already presented in the Synthesis of carbodiphosphoranes and other related heteroatom-stabilized bis(ylide)s section, an original strategy to get access into CDP-Pd complexes was discovered by Peringer and co-workers in 2007..$^{311}$ They devised a one-pot formation of the carbodiphosphorane $(\mathrm{dppm})_{2} \mathrm{C}$ ligand within the coordination sphere of a group 10 metal, forming the $\mathrm{M}$ (II) $P, C, P$-pincer complexes $[\mathbf{4 2 1}][\mathrm{Cl}],[\mathbf{2 3 8}][\mathrm{Cl}]$ and $[\mathbf{4 2 2}][\mathrm{Cl}](\mathrm{M}=\mathrm{Pt}, \mathrm{Pd}, \mathrm{Ni}$, resp. $)$ in $33 \%, 78 \%$ and $92 \%$ yield, respectively (Scheme 207). ${ }^{399}$ The new complexes were fully characterized by multinuclear NMR, and the $\mathrm{Ni}(\mathrm{II})$-complex $[\mathbf{4 2 2}][\mathrm{Cl}]$ was additionally characterized by cyclic voltammetry that proved both

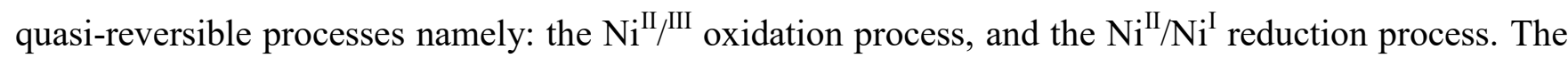
$P, C, P-\mathrm{Pt}(\mathrm{II})$ and $\mathrm{Pd}(\mathrm{II})$ pincer complexes $[\mathbf{4 2 1}][\mathrm{Cl}]$ and $[\mathbf{2 3 8}][\mathrm{Cl}]$ react selectively with hydrochloric acid resulting in the protonation at the ylidic carbon atom to give the dicationic complexes $[421-\mathrm{H}][\mathrm{Cl}]_{2}$ and $[\mathbf{2 3 8}-\mathrm{H}][\mathrm{Cl}]_{2}$. This transformation proved reversible upon addition of water and this protonation/deprotonation reversibility might open novel metal-ligand cooperative pathways in catalysis. In sharp contrast, the protonolysis of the $P, C, P$-pincer Ni(II)-complex [422][Cl] and subsequent treatment with ammonia resulted in ligand release and protonation at the ylidic position, the salt $[\mathbf{4 2 3}][\mathrm{Cl}]$ being isolated in nearly quantitative yield. The synthetic utility of $[\mathbf{4 2 3}][\mathrm{Cl}]$ in organometallic synthesis was 
demonstrated by the formation of the $P, C, P$-pincer complexes $[\mathbf{4 2 1}][\mathrm{Cl}]$ and $[\mathbf{2 3 8}][\mathrm{Cl}]$ in quantitative yield.

Scheme 207. Template synthesis of $P, C, P$-pincer complexes of group 10 metals $(\mathrm{Ni}, \mathrm{Pd}, \mathrm{Pt})$ bearing the carbodiphosphorane ligand $(\mathrm{dppm})_{2} \mathrm{C}$ and their original reactivity (Peringer).

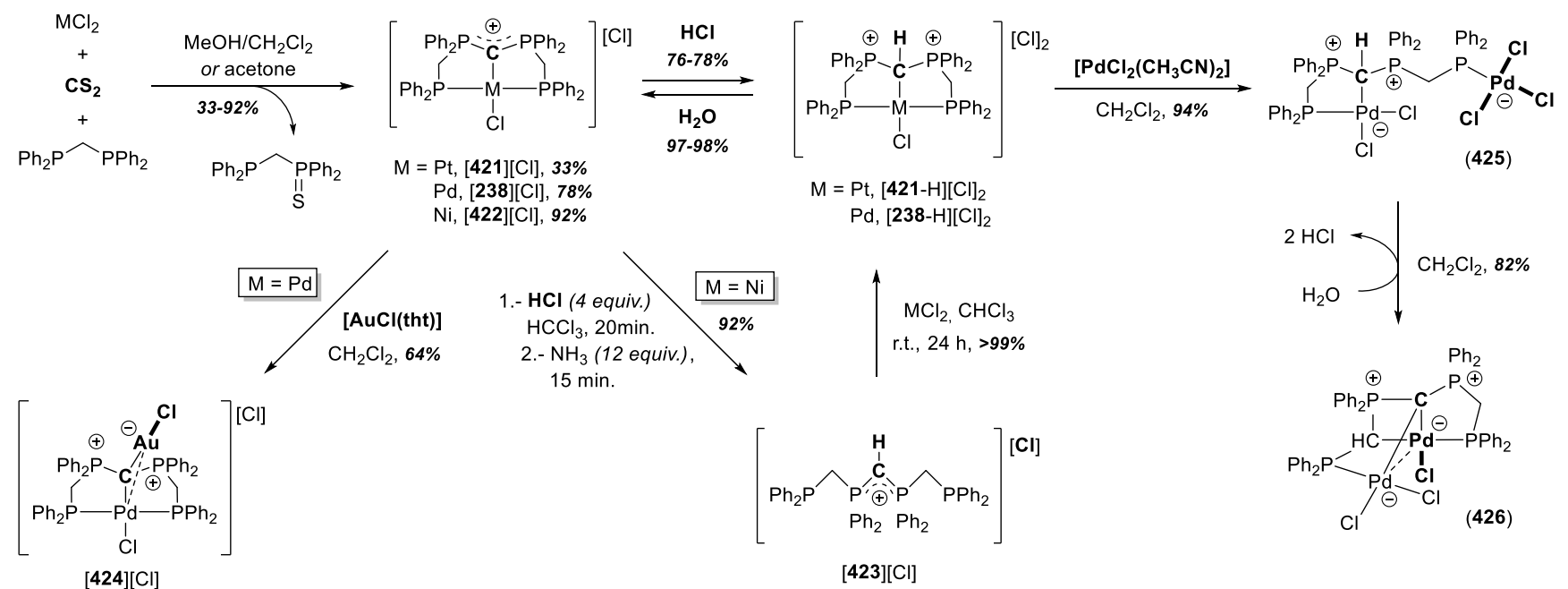

The nucleophilic character of the ylidic carbon of the carbodiphosphorane ligand $(\mathrm{dppm})_{2} \mathrm{C}$ was verified by addition of organometallic Lewis acids such as the $\mathrm{Au}(\mathrm{I})$-precursor [AuCl(tht)] yielding the heterobimetallic complex [424][Cl], the first fully characterized (including XRD studies) species bearing a Pdand a Au-center bonded to the same $C$-atom. ${ }^{400}$ The CDP-supported, air stable Pd ${ }^{\mathrm{II}} \bullet \bullet \mathrm{Au}^{\mathrm{I}}$ complex featuring $\mathrm{d}^{8} \bullet \bullet \mathrm{d}^{10}$ donor-aceptor interactions was isolated in modest yield. The presence of these metallophilic interactions was concluded by the authors on the basis of the structural parameters such as the remarkably short $\mathrm{Pd}-\mathrm{Au}$ bond distance of $2.8900(3) \AA$ and a more acute $\mathrm{Pd}-\mathrm{C}-\mathrm{Au}$ angle of $86.80(11)^{\circ}$ versus the $\mathrm{Pd}-\mathrm{C}-\mathrm{H}$ angle of $102(2)^{\circ}$ measured in $[238-\mathrm{H}][\mathrm{Cl}] .{ }^{311}$

The strong donating capacity of the $(\mathrm{dppm})_{2} \mathrm{C}$ ligand platform also supports the preparation and isolation of homobimetallic complexes 425 and 426 (Scheme 207). ${ }^{401}$ The betaine complex 425 was ob283 
tained upon addition of precursor $\left[\mathrm{PdCl}_{2}\left(\mathrm{CH}_{3} \mathrm{CN}\right)_{2}\right]$ to the $P, C, P$-pincer complex $[\mathbf{2 3 8}-\mathrm{H}][\mathrm{Cl}]$. Interestingly, double deprotonation was achieved by the washing of $\mathbf{4 2 1}$ with water to yield the new homobimetallic $\mathrm{Pd}^{\mathrm{II}} \bullet \bullet \mathrm{Pd}^{\mathrm{II}}$ species 426. These elegant transformations occurs in high yield, and the structures of 425 and 426 were established by NMR and definitively confirmed by XRD analysis of single crystals.

In $2018,{ }^{402}$ Langer studied the reactivity of the $P, C, P$-pincer Ni(II)-complex [422][Cl]. The appropriate choice of Brönsted acid $\left(\mathrm{HBF}_{4}\right)$ permitted the selective protonation at the $\mathrm{C}_{\text {ylide }}$ position of the CDP framework in moderate yield (Scheme 208). [422][Cl] reacts with $\mathrm{AlMe}_{3}$ to reach the methylsubstituted $P, C, P$-pincer complex $[427]\left[\mathrm{AlCl}_{2} \mathrm{Me}_{2}\right]$ in excellent yield via ligand metathesis instead deprotonation of the ligand backbone that was observed upon addition of MeLi. Using LiHMDS the selectivity completely switched towards deprotonation of the $\mathrm{CH}_{2}$ moiety at the ligand backbone to give the neutral $P, C, P$-pincer platform 428. New deprotonation step with excess LiHMDS enforced the second deprotonation at the ligand backbone creating a novel $P, C, C$-pincer scaffold. The building of the novel $P, C, C$-pincer ligand provoked the phosphine arm dissociation that is trapped by another $P, C, C$ pincer Ni(II)-complex giving the Ni-dimer 429 in reasonable yield. Surprisingly, protonolysis of 429 with hydrochloric acid in diethyl ether did not reverse the reaction. Instead, a distinct Ni-dimer $\mathbf{4 3 0}$ was isolated in nearly quantitative yield. Bonding analysis of the CDP-Ni(II) complexes was analyzed by computational means (QTAIM, NBO and NPA calculations) and confirmed the negligible $\pi$-donation of the $\mathrm{C}_{\text {ylide }}$ to the Ni-center. Proton affinities for the CDP-Ni(II) complex [422][Cl] and the analogous species bearing amine-based $(P, N, P)$ and borane-based $(P, B, P)$ pincer ligands were determined computationally and proved the lowest values for the former case. The authors concluded that these CDP$\mathrm{Ni}(\mathrm{II})$ complexes have potential in proton relay catalysis thanks to metal-ligand cooperation. 
Scheme 208. Reactivity of the $P, C, P$-pincer Ni(II)-complex [422][CI] bearing the carbodiphosphorane ligand (dppm) $)_{2} \mathrm{C}$ vs Bronsted acids, Bronsted bases, and $\mathrm{AIMe}_{3}$ (Langer).

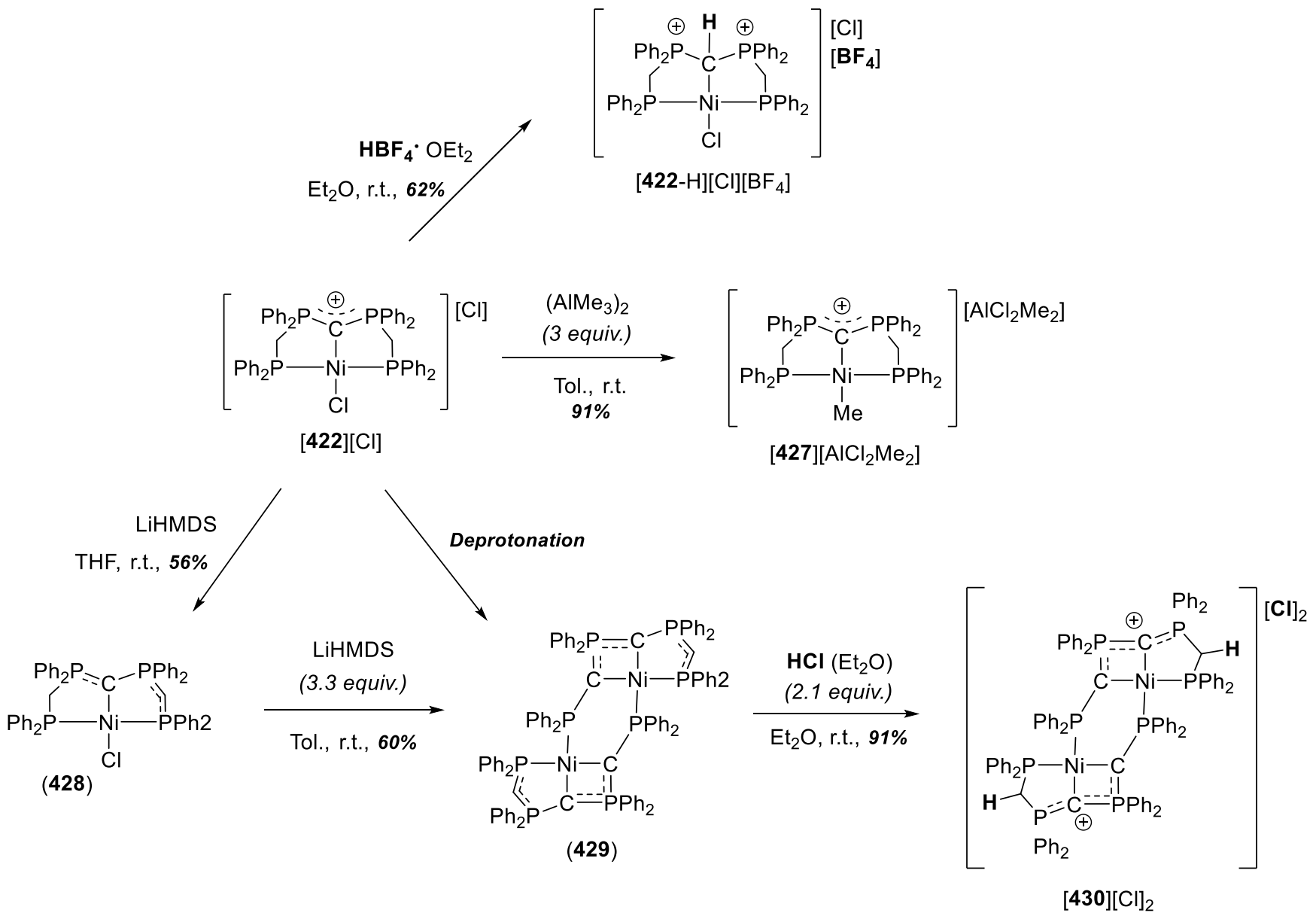

In 1974, seminal work by Kaska introduced briefly the synthesis of the tricarbonyl Ni(0)-complex 431 in $93 \%$ yield starting from 130 and $\left[\mathrm{Ni}(\mathrm{CO})_{4}\right]$ in refluxing diethyl ether along with its characterization by IR and EA. ${ }^{385,386}$ This work was revisited two decades later by Petz and Frenking. ${ }^{403}$ The authors proved the crucial impact of the choice of solvent in the synthesis of $\mathbf{4 3 1} v s$ the crystals formation of the dicarbonyl $\mathrm{Ni}(0)$ complex 432, which represented two rare examples of stable zero-valent Ni-complexes stabilized by a carbodiphosphorane motif. 130 reacts cleanly with $\left[\mathrm{Ni}(\mathrm{CO})_{4}\right]$ in toluene at room temper- 
ature to yield 431 in good yield (Scheme 209). The use of THF instead of toluene produced 431 but accompanied by some crystals of nickel dicarbonyl derivative 432 . The high propensity of $\mathrm{Ni}(0)-$ complexes to adopt a trigonal planar geometry to form $16 \mathrm{e}^{-}$complexes allowed to isolate crystalline material of 432, the first reported $\mathrm{L} \rightarrow \mathrm{Ni}(\mathrm{CO})_{2}$ complex, by dissolving the nickel tricarbonyl 431 in $\mathrm{THF}$ that underwent $\mathrm{CO}$ releasing slowly but steadily. The structures of both carbonyl complexes were elucidated by ${ }^{31} \mathrm{P}$ NMR, IR, EA, and XRD analysis. Their solid state structures confirmed the presence of long $\mathrm{C}_{\text {ylide }}-\mathrm{Ni}$ bond distances, short $\mathrm{P}-\mathrm{C}_{\text {ylide }}$ bond distances and trigonal planar geometry at the donating carbon (i.e. $\mathrm{sp}^{2}$ hybridation). In accordance with the crystallographic features, bonding analysis was carried out by DFT calculations and suggested that there is mainly an $\sigma$ donating bond from the CDP to the Ni-center, with small $\pi$ back donation from the metal to the $C$-atom. Nevertheless, the loss of a carbonyl ligand going from 431 to $\mathbf{4 3 2}$ increased both the $\sigma$ donating interaction and the $\pi$ back bonding from the nickel d-orbitals.

Scheme 209. Synthesis of $130 \rightarrow \mathrm{Ni}(\mathrm{CO})_{\mathrm{n}}(\mathrm{n}=2,3) 431$ and 432 reported by Petz and Frenking.
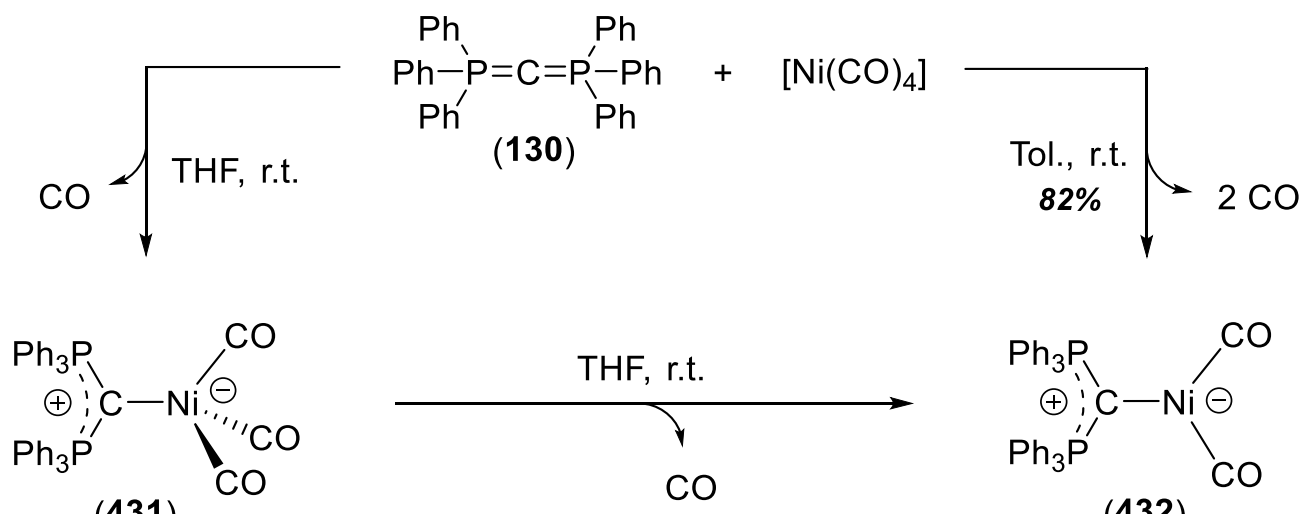

(431)

CO

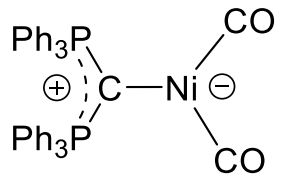

(432)

\subsubsection{Coordination to Group 11 (Coinage) Metals}


Owing to the isolobal analogy between cationic gold(I) species and the proton, ${ }^{404}$ the coordination chemistry of carbodiphosphoranes and related bis(ylide)s to gold(I) cations emerged as the test of choice [along with protonolysis experiments of the bis(ylide) itself] to validate the ylidic nature of the central donor carbon. Even more relevant, the classical coordination test to gold(I) cations allows to quantify the donating capacity of the corresponding bis(ylide) and discern between a unique $\sigma$ lone pair donation $v s$ the four electron donating $(\sigma+\pi$ lone pairs) behavior at carbon. The first $\mathrm{CDP} \rightarrow \mathrm{Au}$ complex was prepared by Schmidbaur in 1976, when CDP 135 was coordinated to [AuMe(PMe 3$)$ ] affording the geminal diaurated complex $\left[\mathbf{1 3 5}-(\mathrm{AuMe})_{2}\right]$ in nearly quantitative yield (see Scheme 210), thus validating their initial hypothesis concerning the two lone pair availabilty at the $\mathrm{C}_{\text {ylide. }}{ }^{405}$ In 1983 , the same group proved the coordination ability of $\mathbf{1 3 0}$ towards $[(\mathrm{CO}) \mathrm{AuCl}]$ that underwent formation of the monomeric Au-species 433 and CO releasing. ${ }^{406}$ This chemistry was later explored deeply by Vicente et al. who reported a more convenient, high-yielding route of access to 433 starting from 130 the precursor $[\mathrm{AuCl}(\mathrm{tht})] .^{407}$ The synthesis of monoaurated species of the type [bis(ylide) $\left.\rightarrow \mathrm{AuCl}\right]$ was extended to a broad variety of bis(ylides) $(\mathbf{2 6 0}, \mathbf{2 6 2} \mathbf{a}, \mathbf{b}, \mathbf{2 6 4 a}, \mathbf{b}) .^{321-322}$ Vicente demonstrated the synthetic utility of the $\mathrm{Au}(\mathrm{I})$-complex $\mathbf{4 3 3}$ as an organometallic synthon which was then applied to obtain the $\mathbf{1 3 0} \rightarrow \mathrm{Au}(\mathrm{acac})$ complex 439, the first isolated acetylacetonate Au-complex. ${ }^{407}$ The presence of intramolecular base in 439 allowed the $\mathrm{C}-\mathrm{H}$ bond breaking of alkynes to generate the alkynyl derivatives $440 \mathrm{a}-\mathbf{e}$, in which the Au-atom is bonded to two distinct $C$-based ligands, i.e. the ylidic carbon of $\mathbf{1 3 0}$ and an alkyne (Scheme 210). The authors achieved the geminal diaurated species 441 as well by adding two equivalents of [AuCl(tht)] to $\mathbf{1 3 0}$ upon otherwise identical conditions proved the availability of both $\sigma$ and $\pi$ lone pairs at carbon. Following similar procedure, the analogous geminal diaurated complexes 442 and [264b$\left.(\mathrm{AuCl})_{2}\right]$ supported by the $\mathrm{P}, \mathrm{S}^{\mathrm{IV}}$-mixed bis(ylide) 258 and the phosphallene 264b were prepared. ${ }^{[323,324]}$ 
Similar set of reactions, using an halide abstractor allowed the synthesis of the cationic bis(ylide) $\rightarrow \mathrm{AuPPh}_{3}$ complexes $\mathbf{4 4 3 - 4 4 6}$ with yields ranging from $50 \%$ to $97 \% .{ }^{273,321,322}$ The strategic installation of the pyridine ring in CDP 144 assists the incorporation of a second coinage metal center to yield the original geminal bimetallic complexes $[448]\left[\mathrm{SbF}_{6}\right](\mathrm{Au}-\mathrm{Au})$ and $[449]\left[\mathrm{SbF}_{6}\right](\mathrm{Au}-\mathrm{Cu})$. Crystal structures of cations 448 and 449 confirmed weak $\mathrm{Cu}^{\mathrm{I}} \cdot \bullet \mathrm{Au}^{\mathrm{I}}$ closed shell interactions, whereas $\mathrm{Py} \rightarrow \mathrm{Au}$ and $\mathrm{Au}^{\mathrm{I}} \bullet \cdot \mathrm{Au}^{\mathrm{I}}$ interactions were absent in $\mathbf{4 4 8}$.

Scheme 210. Coordination chemistry of bis(ylide)s to Au(I)-precursors: mono- vs geminaldiauration at carbon. 

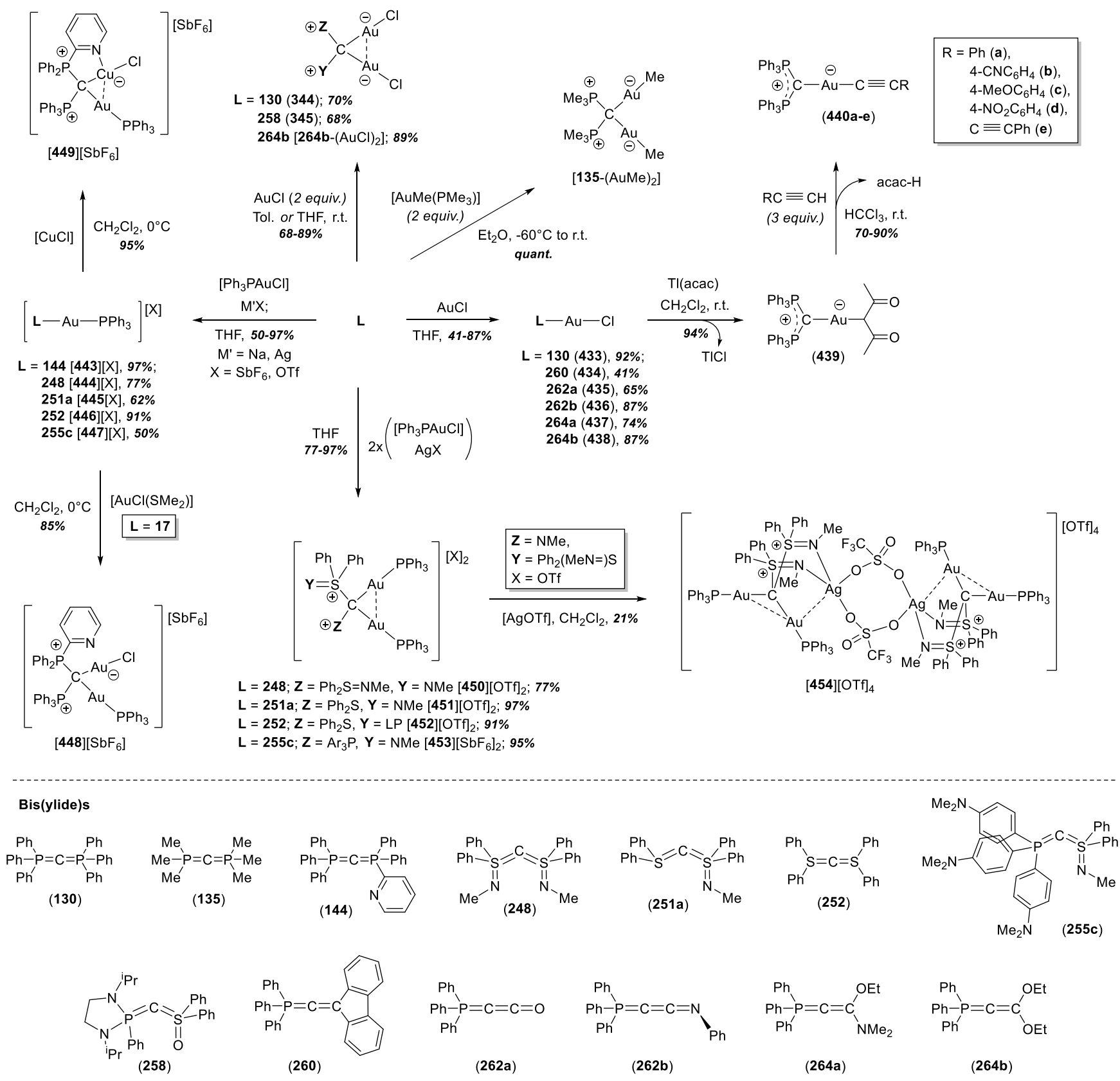

Fujii reported the isolation of the $\mathrm{Ph}_{3} \mathrm{P}$-substituted bimetallic dications $[\mathbf{4 5 0}]^{2+}-[\mathbf{4 5 3}]^{2+}$ by reacting the corresponding bis(ylide) with the in situ formed $\left[\mathrm{Au}\left(\mathrm{PPh}_{3}\right)\right]^{+}$cation (Scheme 210). ${ }^{321-322}$ Starting from $[450]\left[\mathrm{SbF}_{6}\right]_{2}$ that contains the symmetrical carbobis(iminosulfane)s $\mathbf{2 4 8}$, an $\mathrm{Au}_{4} \mathrm{Ag}_{2}$ cluster could be isolated in ca. $20 \%$ yield. 
Inspired by Peringer's work on CDP-Pd(II) chemistry, ${ }^{[311,399-401]}$ Hackl and co-workers proposed an approach to prepare the only known $\mathrm{Au}(\mathrm{III})$-complexes to date bearing a carbodiphosphorane ligand. ${ }^{408}$ From the cationic $\mathrm{Au}(\mathrm{I})$-precursor $[455][\mathrm{Cl}]$ halide abstraction with TlOTf allowed the isolation of the dication $[456]^{2+}$. From these two precursors, the $2 \mathrm{e}^{-}$oxidation was carried out with $\mathrm{HNO}_{3}$ or the combination of $\mathrm{I}_{2}$ and TlOTf to efficiently yield complexes $[\mathbf{4 5 7}]\left[\mathrm{NO}_{3}\right]_{2}$ and $[\mathbf{4 5 8}][\mathrm{OTf}]_{2}$ (see Scheme 211).

Scheme 211. Synthesis of $P, C, P$-pincer Au(III)-complexes $[457]\left[\mathrm{NO}_{3}\right]_{2}$ and $[458][\mathrm{OTf}]_{2}$ bearing a carbodiphosphorane framework.

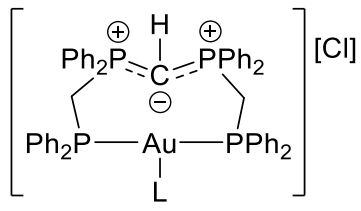

$[455][\mathrm{Cl}]$

or

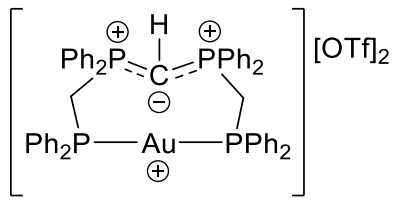

$[456][\mathrm{OTf}]_{2}$

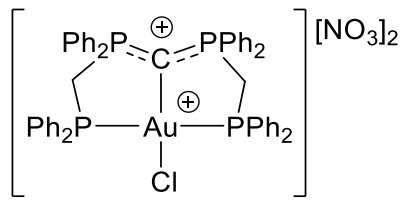

$[457]\left[\mathrm{NO}_{3}\right]_{2}$

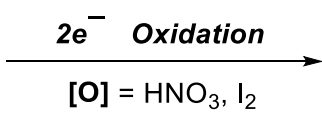

77-94\%

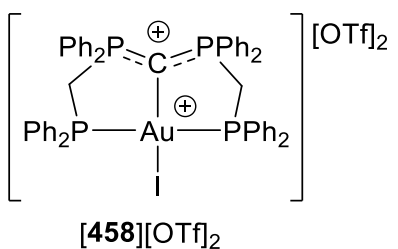

Meticulous control of the reaction stoichiometry allowed the access to the mono-, di- and triauration products with the potentially 6 electrons donor phosphinocarbodiphosphorane 235 described by Weigand. ${ }^{310}$ The respective complexes $\mathbf{4 5 9 - 4 6 1}$ were isolated in excellent yields and appropriately characterized, including by VT NMR and ${ }^{31} \mathrm{P}-{ }^{31} \mathrm{P}$ EXSY NMR experiments due to fluxionality of the polymetallic compounds 460 and 461.

Scheme 212. Weigand's synthesis of Au(I)-complexes stabilized by CDP 235. 

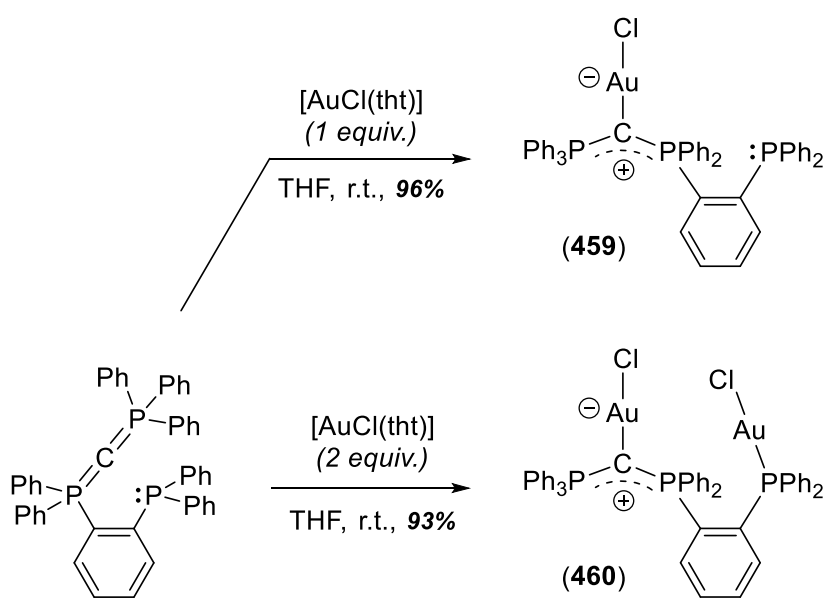

(235)
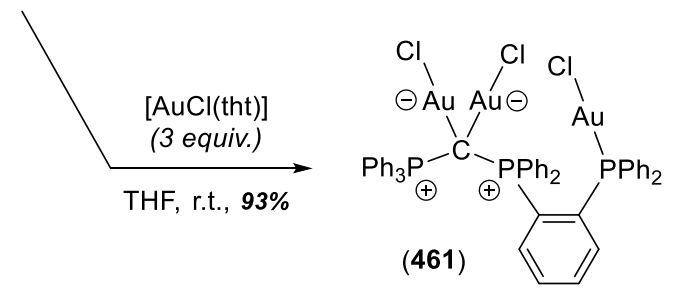

In 2011, Gandon used CDP 130 as ancillary ligand in gold catalysis. ${ }^{409}$ In this thorough study, the authors have performed a comparative study covering the catalytic activity of monometallic $\mathrm{Au}(\mathrm{I})$ complexes 462-464, 433 and the geminal diaurated compound 441 that are stabilized by a set of ligands with very distinct electronic properties $\left[\right.$ i.e. $(\mathrm{ArO})_{3} \mathrm{P}, \mathrm{Ph}_{3} \mathrm{P}, \mathrm{IPr}$ and $\left.\mathrm{C}\left(\mathrm{PPh}_{3}\right)_{2}(\mathbf{1 3 0})\right]$. In particular, they demonstrated the beneficial effect of the CDP 130 in organic transformations typically mediated by cationic $\mathrm{Au}(\mathrm{I})$-species (Scheme 213). ${ }^{409}$

Scheme 213. Catalytic processes influenced by the strong donor capacity of 130 in the Au(I)complexes 433 and 441. 


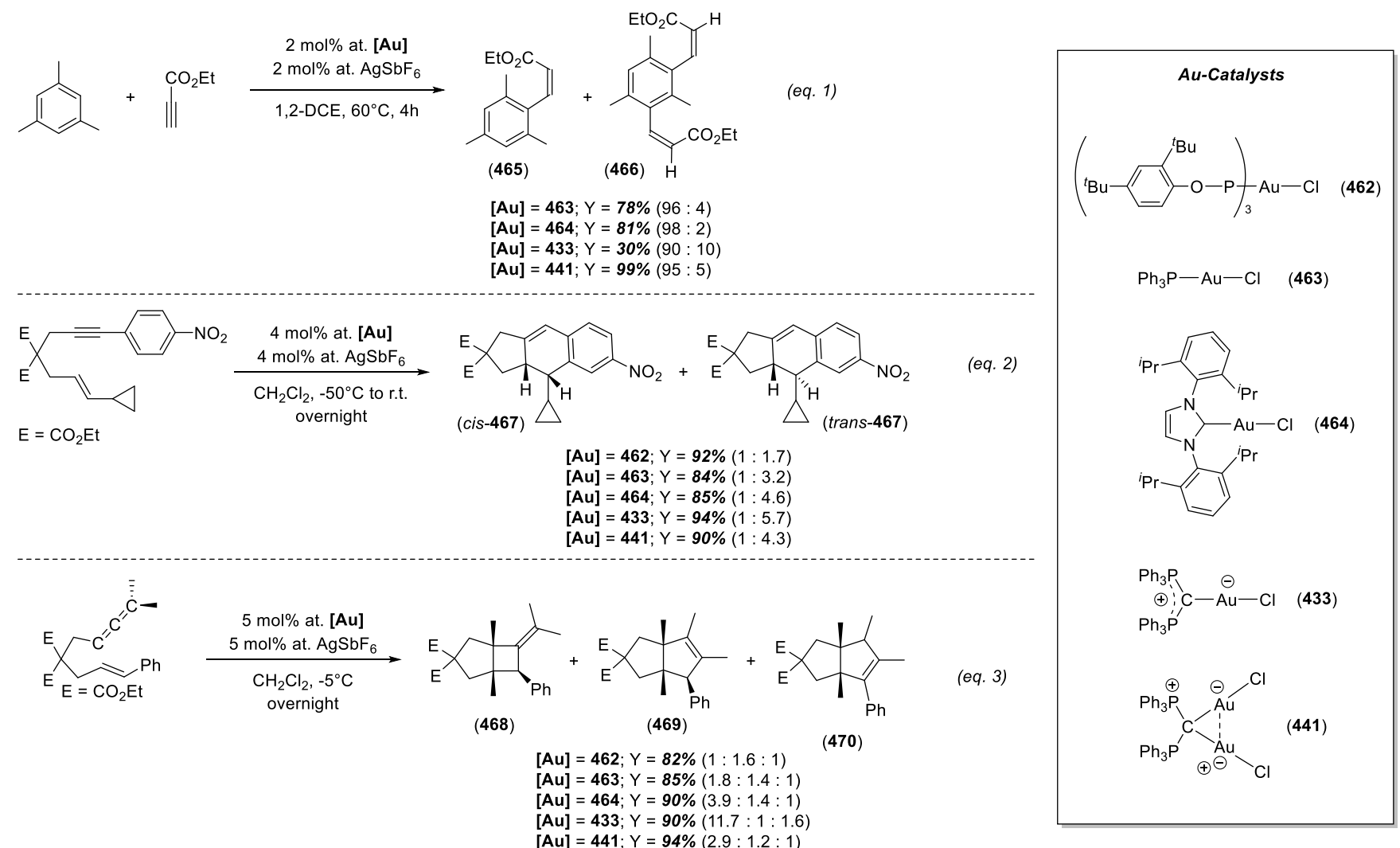

Pioneering work on catalysis using a $\mathrm{CDP} \rightarrow \mathrm{M}(\mathrm{M}=\mathrm{Cu}, \mathrm{Au})$ complex was done by Kato, Peris and Baceiredo in $2009 .^{410}$ They reported on the hydroamination and hydroalkoxylation reactions of acrylonitrile upon mild conditions using $[(\mathbf{2 2 8 b}) \mathrm{M}(\mathrm{O} t \mathrm{Bu})]$ 471-472 $(\mathrm{M}=\mathrm{Au}$ and $\mathrm{Cu}$, respectively) (Scheme 214). Catalysts 471 and 472 were prepared in modest yields by one-pot deprotonation of precursor $[\mathbf{2 2 8 b}-\mathrm{H}][\mathrm{OTf}]$ with $\mathrm{KO} t \mathrm{Bu}$ in the presence of the corresponding $\mathrm{MCl}$ salt. The strong donating capacity of CDP 228b was reflected by the high catalytic activity of these two catalysts that overpasses the one reported before by $\mathrm{NHC} \rightarrow \mathrm{Cu}(\mathrm{I})$ catalysts. ${ }^{411}$

Scheme 214. Synthesis of $\mathrm{Au}(\mathrm{I})$ and $\mathrm{Cu}(\mathrm{I})$ complexes 471-473 bearing the cyclic carbodiphosphorane $228 b$ and catalytic activity of 471 and 472 for the hydrofuctionalization of acrylonitrile. 
Organometallic Synthesis

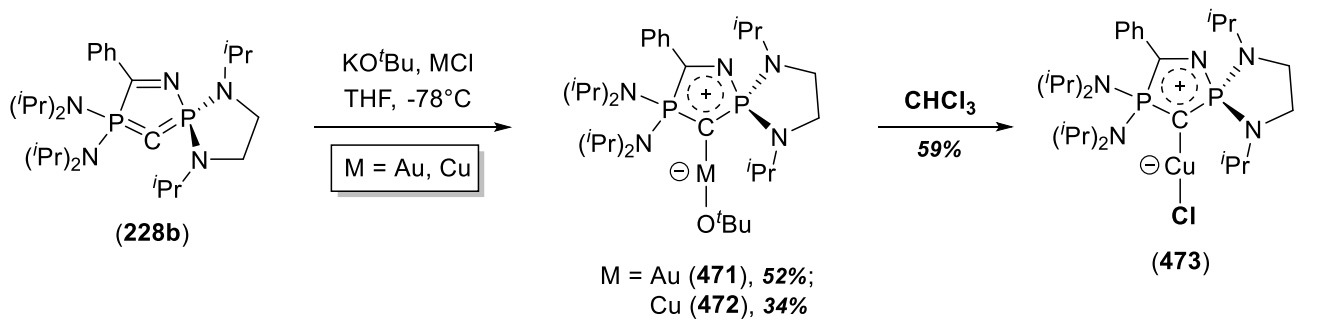

Catalytic Application to the Acrylonitrile Hydroamination or Hydroalkoxylation

\begin{tabular}{|c|c|c|c|c|c|c|c|}
\hline \multirow{2}{*}{$\mathrm{RX}-\mathrm{H}$} & \multirow{2}{*}{$+\mathrm{NC} \curvearrowright$} & & & & & & \\
\hline & & Entry & $\mathrm{RX}-\mathrm{H}$ & M & $\mathrm{T}\left({ }^{\circ} \mathrm{C}\right)$ & $t(h)$ & $Y(\%)$ \\
\hline$X=N H, O$ & & 1 & $\mathrm{PhNH}_{2}$ & $\mathrm{Cu}$ & 25 & 1.5 & 83 \\
\hline \multirow{3}{*}{$\mathrm{C}_{6} \mathrm{D}_{6}, \mathrm{~T}$} & & 2 & & $\mathrm{Au}$ & 25 & 1 & 10 \\
\hline & $\begin{array}{c}5.5 \mathrm{~mol} \% \\
{\left[(228 \mathbf{b}) \mathrm{M}\left(\mathrm{O}^{t} \mathrm{Bu}\right)\right]}\end{array}$ & 3 & $\mathrm{PhOH}$ & $\mathrm{Cu}$ & 25 & 40 & 72 \\
\hline & r & 4 & & $\mathrm{Au}$ & 25 & 40 & 60 \\
\hline & $\mathrm{H}$ & 5 & & $\mathrm{Au}$ & 25 & 23 & 10 \\
\hline $\mathrm{N}$ & & 6 & $\mathrm{MeOH}$ & $\mathrm{Au}$ & 80 & 12 & 76 \\
\hline
\end{tabular}

The first report dealing with carbodiphosphorane containing silver complexes appeared in $1983 .^{406}$ In this work, Schmidbaur explored the synthesis of the complex [474] THF upon coordination of CDP 130 to $\mathrm{AgCl}$ in $\mathrm{THF}$ (eq. 1 in Scheme 215). The isolated material, postulated to be the neutral species 474 on the basis of its NMR data and EA, was later used by Zybill to obtain complex $\mathbf{4 7 5}$ in modest yield by salt metathesis with LiCp*. ${ }^{412}$ However, Petz et al. were unable to confirm these results. ${ }^{413}$ Instead, and despite the addition of a unique equivalent of 130 s $\mathrm{AgCl}$, direct formation of salts $[\mathbf{4 7 6}][\mathrm{X}](\mathrm{X}=\mathrm{Cl}$ or $\mathrm{BF}_{4}$ ) were isolated and fully characterized by ${ }^{31} \mathrm{P}$ NMR, IR, EA and XRD analysis. ${ }^{413}$ The crystal structure of the isolated material undeniably confirmed atom connectivity displaying cation $[130 \rightarrow \mathrm{Ag} \leftarrow \mathbf{1 3 0}]^{+}$

Extensive work regarding the selective synthesis of bis(ylide)-stabilized silver complexes was carried by Fujii’s group since 2015. ${ }^{[321,322,414]}$ Triflate to chloride anion exchange of bis(ylide) precursors [248- 
$\mathrm{H}][\mathrm{OTf}]$, [251a-H][OTf] and [252-H][OTf] was performed and the subsequent reactivivity towards $\mathrm{Ag}_{2} \mathrm{O}$ in methanol yielded the complexes 477 and 478 or the salt [479][ $\left.\mathrm{AgCl}_{2}\right]$ containing the homoleptic cation $[\mathbf{2 5 2} \rightarrow \mathrm{Ag} \leftarrow \mathbf{2 5 2}]^{+}$(see eq. 2 in Scheme 215). ${ }^{321}$ Silver to Au transmetalation was possible from these complexes, leading to the geminal diaurated coordination compounds [450][OTf], [451][OTf] and [452][OTf]. ${ }^{321}$ The $\mathrm{P}, \mathrm{S}^{\mathrm{IV}}$-mixed bis(ylide)s 255a,c were coordinated to AgCl as well to form the neutral organometallics $\mathbf{4 8 0}$ and $\mathbf{4 8 1}$ or the homoleptic $[\mathbf{2 5 5 c} \rightarrow \operatorname{Ag} \leftarrow \mathbf{2 5 5 c}]^{+}$cation $[\mathbf{4 8 2}]^{+}($see eq. 3 below in Scheme 215). ${ }^{322}$ Again, the silver species 480 and 481 underwent the high-yielding transmetalations with $\left[\mathrm{AuClPPh}_{3}\right]$ affording selectively the cations $[\mathbf{4 8 3}]^{+}$and $[\mathbf{4 4 6}]^{+}$, or the geminal diaurated dications $[\mathbf{4 8 4}]^{2+}$ and $[\mathbf{4 5 3}]^{2+}$ in function of the applied stoichiometry. ${ }^{322}$

Scheme 215. Synthesis and reactivity of silver species bearing of hexaphenylcarbodiphosphorane (130) or the bis(ylide)s 248, 251a, 252 and 255a,c. Conditions: $i$ ) Filtration through an Amberlite IRA-410 ion-exchange resin (chloride form), $\mathrm{MeOH}$, r.t. After filtration and evaporation, $\operatorname{Ag}_{2} \mathrm{O}$ (1.0 equiv.) in $\mathrm{CH}_{2} \mathrm{Cl}_{2}$ is added at r.t., $24 \mathrm{~h}$; ii) addition of [AuCIPPh $\mathrm{Al}_{3}$ (1.0 equiv.) and $\mathrm{AgSbF}_{6}(1.0$ equiv.) in $\mathrm{THF}$ at $-7^{\circ} \mathrm{C}$ and slow warming up to r.t. overnight; iii) addition of [AuCIPPh${ }_{3}$ (1.0 equiv.) and $\mathrm{AgSbF}_{6}\left(1.0\right.$ equiv.) in $\mathrm{THF}$ at $-78^{\circ} \mathrm{C}$ and slow warming up to r.t. overnight. 


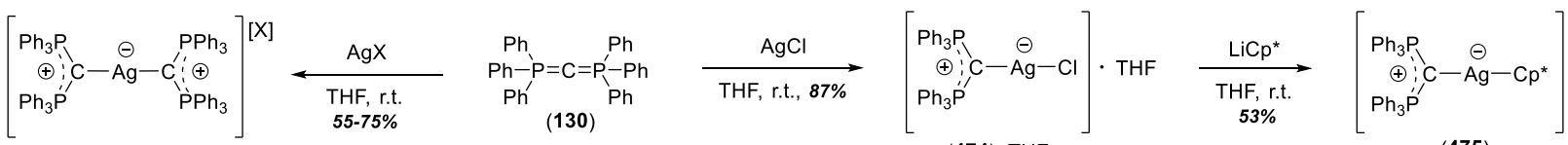

$[476][\mathrm{Cl}], 75 \%$

$(\mathbf{4 7 4 )} \cdot \mathrm{THF}$

(475)

$[476]\left[\mathrm{BF}_{4}\right], 55 \%$

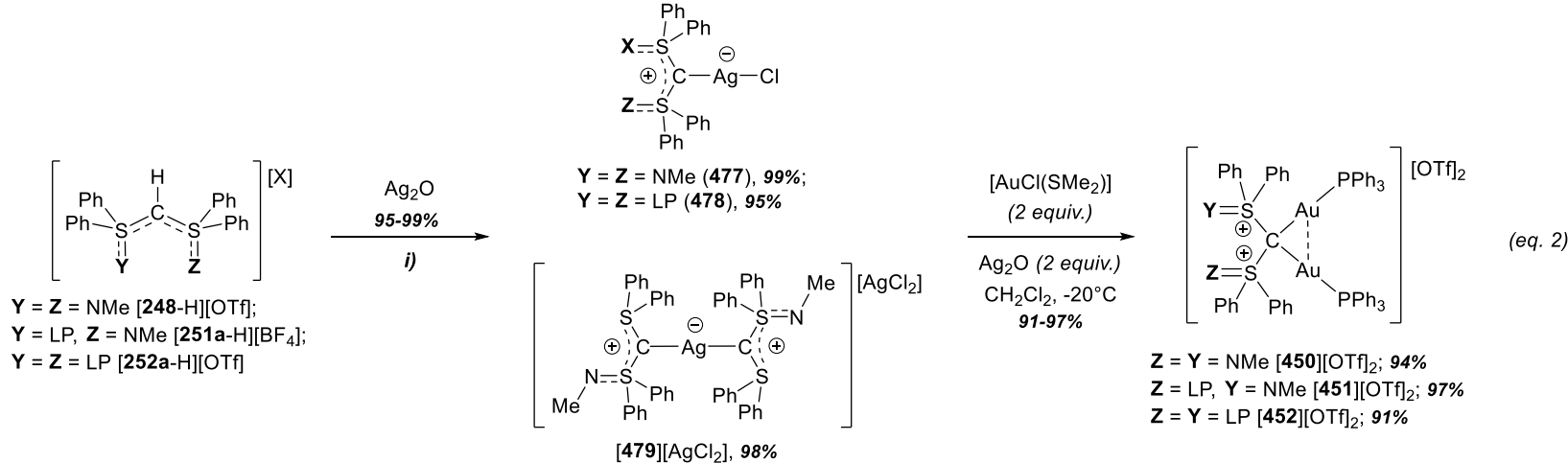

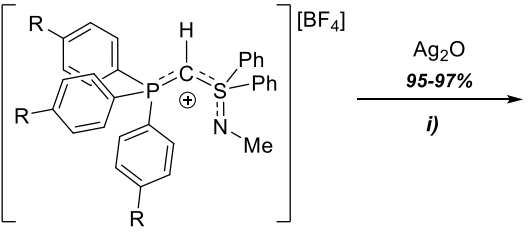

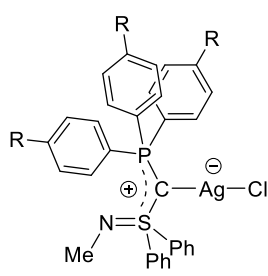

$\mathrm{R}=\mathrm{H}(\mathbf{4 8 0}), \mathbf{9 7 \%}$;

$\mathrm{Me}_{2} \mathrm{~N}(481), 95 \%$

= $\mathrm{H}[255 \mathrm{a}-\mathrm{H}][\mathrm{OTf}]$

$\mathrm{Me}_{2} \mathrm{~N}[255 \mathrm{c}-\mathrm{H}][\mathrm{OTf}]$
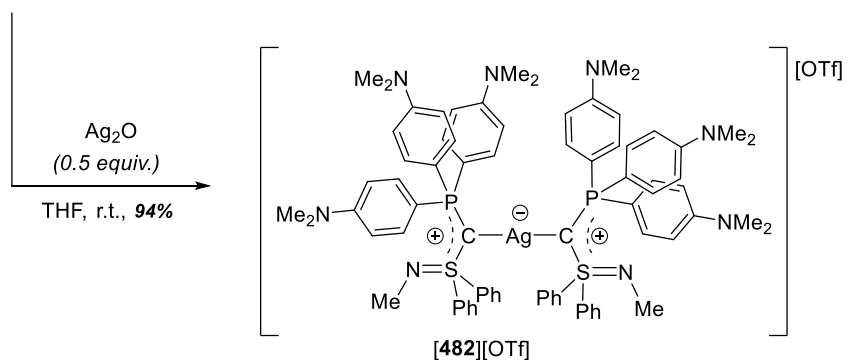
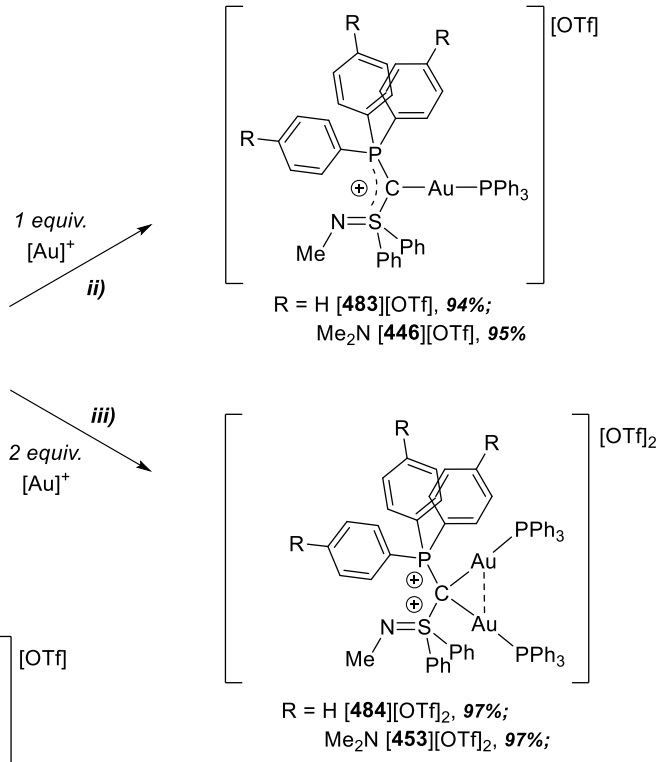

Outstanding work was recently reported by Fujii's group describing the high-yielding, on demand isolation of bis(ylide)-supported silver complexes with diverse nuclearity. ${ }^{414}$ Taking advantage of the coordinating ability of available $\mathrm{Ph}_{2} \mathrm{~S}=\mathrm{NMe}$ sidearms at bis(ylide)s 248 and 251a,b along with the positive 295 
impact of argentophilic interactions in the stabilization of polymetallic $\mathrm{Ag}(\mathrm{I})$-species, the authors isolated and characterized three varied silver platforms namely: $i$ ) mono Ag salts [485-487][OTf] containing the homoleptic cations $\left[\mathbf{C}_{\mathbf{y l i d e}} \rightarrow \mathrm{Ag} \leftarrow \mathbf{C}_{\text {ylide }}\right]^{+}$; ii) the dimer, dicationic salts [488-490][OTf $]_{2}$; and the $\mathrm{Ag}_{4}$ clusters $[\text { 491-493][OTf }]_{4}$ (Scheme 216). The crystal structures of these three platforms proved unambiguously the proposed nuclearity and atom connectivity. The 4 electron ( $\sigma+\pi$ lone pairs) donating character of this particular class of bis(ylide)s was illustrated by the ligation of the $\mathrm{C}_{\mathrm{ylide}}$ to two different $\mathrm{Ag}$ cations in clusters 491-493. The remarkably short $\mathrm{Ag}-\mathrm{Ag}$ bond distances found in the polymetallic cations 488 and 491-493 revealed the presence of argentophilic interactions in the absence of coordinating anions.

Scheme 216. Strategic synthesis of silver species with varied nuclearity stabilized by bis(ylide)s 248 and 251a,b. 
<smiles>[X]/C(=C\[SH](=NC)(c1ccccc1)c1ccccc1)c1ccccc1</smiles>

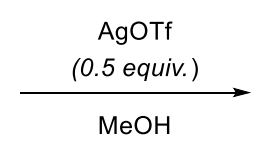

$E=S, X=N M e(248)$

$E=S, X=L P(251 a)$

$E=\operatorname{Se}, X=\operatorname{LP}(\mathbf{2 5 1 b})$
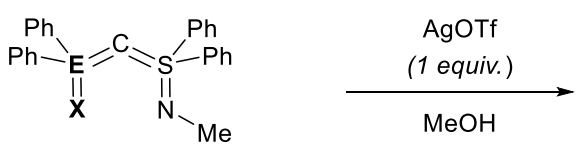

$E=S, X=N M e(248)$

$E=S, X=L P(251 a)$

$E=\operatorname{Se}, X=L P(251 b)$
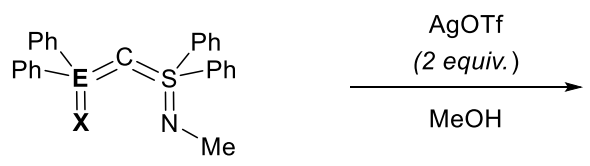

$E=S, X=N M e(248)$

$E=S, X=L P(251 a)$

$E=\operatorname{Se}, X=\operatorname{LP}(\mathbf{2 5 1 b})$

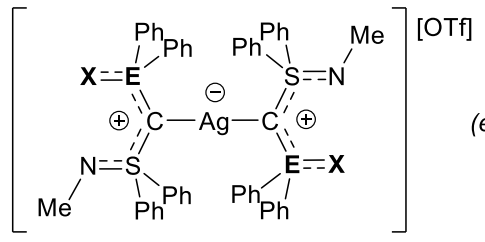

(eq. 1)

$E=S, X=N M e$ [485][OTf], $97 \%$;

$E=S, X=L P$ [486][OTf], $72 \%$;

$E=\mathrm{Se}, X=\mathrm{LP}$ [487][OTf], $78 \%$

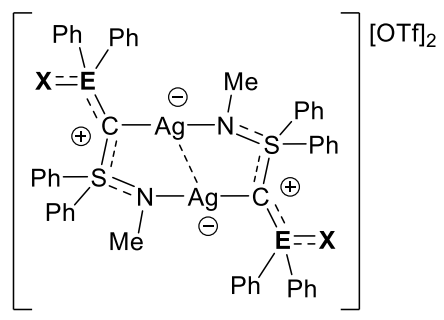

(eq. 2)

$E=S, X=N M e$ [488] $[\mathrm{OTf}]_{2}, 95 \%$;

$E=S, X=L P[489][O T f]_{2}, 66 \%$;

$E=\mathrm{Se}, \mathbf{X}=\mathrm{LP}[490][\mathrm{OTf}]_{2}, 60 \%$

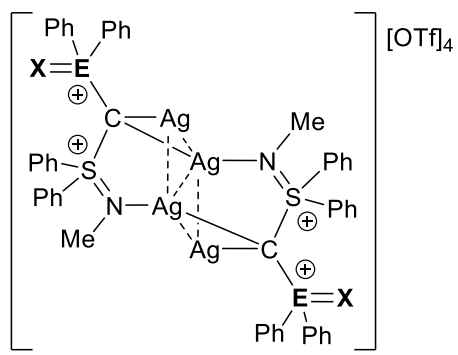

(eq. 3)

$E=S, X=N M e[491][O T f]_{4}, 95 \%$;

$E=S, X=L P[492][O T f]_{4}, 90 \%$;

$E=\mathrm{Se}, \mathbf{X}=\mathrm{LP}[\text { [493][OTf] }]_{4}, 75 \%$

Following the same procedure, Schmidbaur and Zybill explored the coordination chemistry of CDP $\mathbf{1 3 0}$ to $\mathrm{CuCl}$ getting access to the synthesis of the neutral complex $[\mathbf{1 3 0} \rightarrow \mathrm{CuCl}](\mathbf{4 9 4})$ that was isolated in 92\% yield (Scheme 217). ${ }^{406} 494$ was used to accomplish the synthesis of the $130 \rightarrow \mathrm{Cu}(\mathrm{I})$ species $\mathbf{4 9 5 a}$ and 495b bearing $\mathrm{Cp}$ or $\mathrm{Cp} *$ ligands, respectively (Scheme 217). ${ }^{412}$ The homoleptic $[\mathbf{1 3 0} \rightarrow \mathrm{Cu} \leftarrow \mathbf{1 3 0}]^{+}$ cation $[\mathbf{4 8 6}]^{+}$was not reported until very recently, when Petz, Neumüller and Frenking reported its selective isolation in crystalline form starting from $\mathrm{CuI}$ instead of $\mathrm{CuCl}$ (Scheme 217) ${ }^{415}$ 
In 2007, Baceiredo prepared the fully characterized copper amido complex 497 isolated in modest yield (Scheme 217). ${ }^{312}$ Their continuous efforts in synthesizing novel bis(ylide) platforms stabilized by heteroatoms and evaluating their reactivity has culminated in the discovery of the unprecedented geminal dicuprated species 499 that is supported by the presence of the $\mathrm{P}, \mathrm{Si}^{\mathrm{IV}}$-mixed bis(ylide) 243c. The synthesis of bimetallic 499 requires $\mathrm{CuCl}$ in excess (Scheme 217). ${ }^{316}$ Alternatively, 499 can be constructed in a two-step procedure involving addition of stoichiometric amounts of $\mathrm{CuCl}$ to $243 \mathrm{c}$ giving the organocopper intermediate 498 that evolves upon addition of extra $\mathrm{CuCl}$ to form 499 via unexpected $\mathrm{Si}^{\mathrm{IV}}$ mediated chloride abstraction and concomitant phosphine-group migration from the $\mathrm{Si}^{\mathrm{IV}}$-fragment to the $\mathrm{Cu}$-atom. The structure of both organocopper entities were crystallographically established exhibiting plausible cuprophilic interactions.

Scheme 217. Coordination of CDP 130 and the bis(ylide)s 241a and 243c to Cu(I)-precursors.

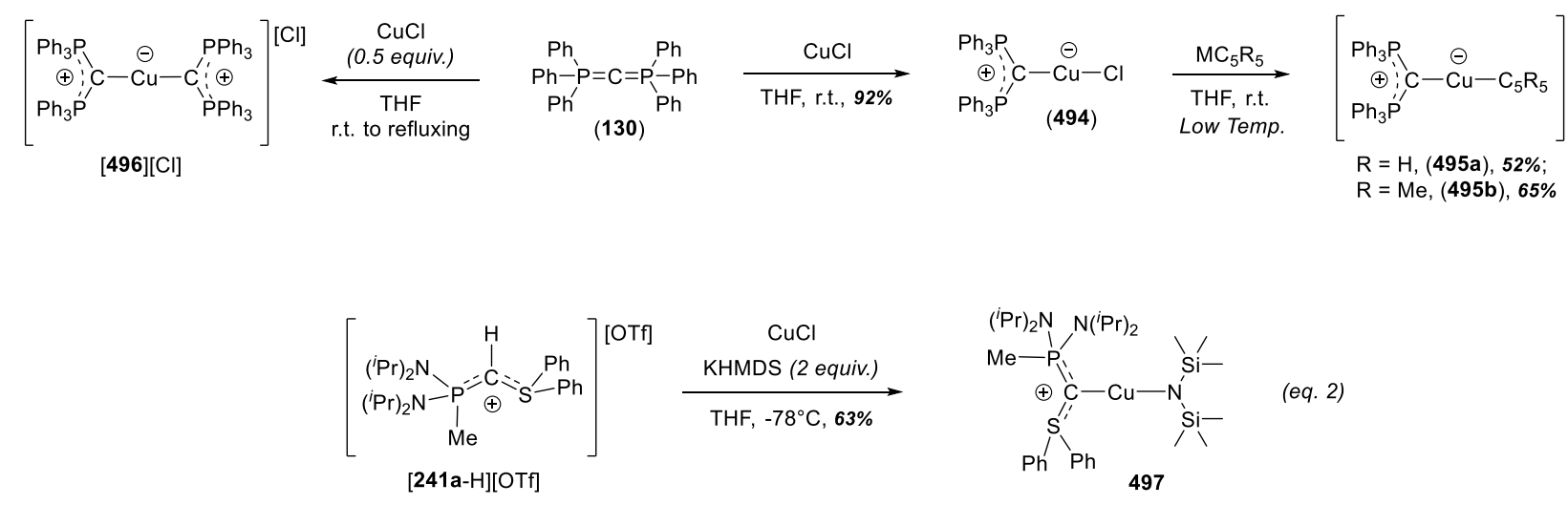

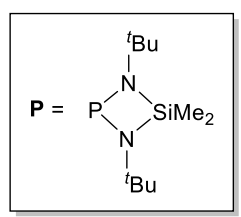
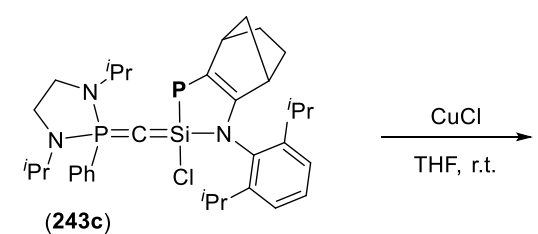

(243c)

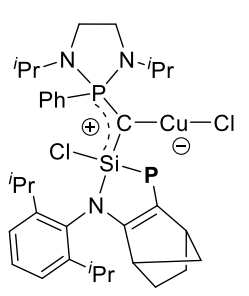

(498)

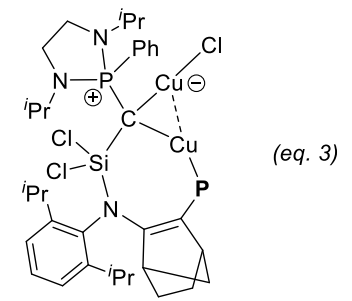

(499) 


\subsubsection{Coordination to Group 12 Metals}

The unique investigations dealing with the coordination chemistry of carbodiphosphoranes and related species to group 12 metals were done by Petz et al. in 2011. ${ }^{415,416}$ Complexation of CDP $\mathbf{1 3 0}$ to the corresponding $\mathrm{MI}_{2}$ salts led to complexes $\mathbf{5 0 0 ,} \mathbf{5 0 1}$ and $[\mathbf{5 0 2}]\left[\mathrm{Hg}_{2} \mathrm{I}_{6}\right]$ exhibiting varied structures depending on the metal nature $\left(\mathrm{M}=\mathrm{Zn}, \mathrm{Cd}\right.$ or $\mathrm{Hg}$; Scheme 218) ${ }^{415,416}$ The formation of the $\mathrm{Zn}$ (II)-monomer $\mathbf{5 0 0}$ and the $\mathrm{Cd}(\mathrm{II})$-dimer 501 takes place exclusively in 1-fluoro-2-bromobenzene preventing undesired protonolysis of 130. ${ }^{415}$ The different nuclearity in $\mathbf{5 0 0}$ and $\mathbf{5 0 1}$ was attributed to the smaller ionic radius of $\mathrm{Zn}^{2+}$ compared to $\mathrm{Cd}^{2+}$ thus impeding dimerization due to sterics created by the phenyl rings of 130. In sharp contrast, the coordination of $\mathbf{1 3 0}$ to $\mathrm{HgI}_{2}$ proceeds in THF but undergoes $\mathrm{HgI}_{2}$ dismutation into the homoleptic dication $[\mathbf{1 3 0} \rightarrow \mathrm{Hg} \leftarrow \mathbf{1 3 0}]^{2+}$ and $\left[\mathrm{H}_{2} \mathrm{I}_{6}\right]^{2-}$ that crystallized from the reaction media. ${ }^{416}$

Scheme 218. Coordination of CDP 130 to group 12 metals performed by Petz.

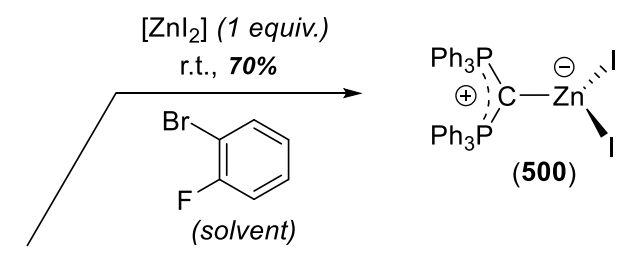

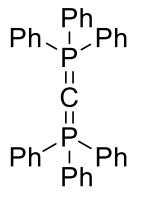

(130)

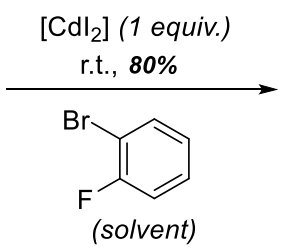

$\left[\mathrm{Hgl}_{2}\right]$ (1.3 equiv.)

THF, r.t.
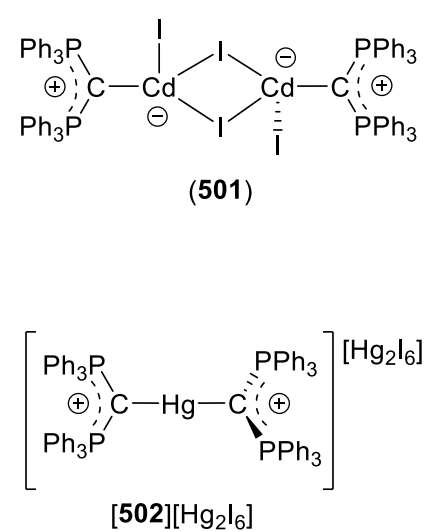
Complexes 500, 501 and $[\mathbf{5 0 2}]\left[\mathrm{Hg}_{2} \mathrm{I}_{6}\right]$ were characterized by NMR, IR, XRD and the bonding situation in the homoleptic dication $[\mathbf{5 0 2}]^{2+}$ was analyzed by quantum chemical calculations. The crystallographic data provided their solid structures proving the $\mathrm{sp}^{2}$ hybridation at the $\mathrm{C}_{\mathrm{ylide}}$ (trigonal planar geometry in 500, whereas slight pyramydalization is observed in 501 and 502). The energy decomposition analysis performed for dication $[\mathbf{5 0 2}]^{2+}$ revealed a bonding situation having mainly electrostatic attractions contributing to the metal-ligand bond, with $c a .70 \%$ of the global $\Delta \mathrm{E}_{\text {orb }}$ contribution being due to the $\sigma$ lone pair donation from the $\mathrm{C}_{\text {ylide }}$ to the $\mathrm{Hg}^{2+}$.

\subsection{Reactivity of double ylides towards main group elements.}

The strong donating capacity of carbodiphosphoranes and related species encouraged many research groups to address the coordination ability of this particular class of compounds towards main group elements due to their Lewis acid character.

\subsubsection{Group 13}

The interest in the preparation of Lewis adducts between CDPs and boranes was shown immediately after the seminal work by Ramirez in 1961. Indeed, in 1962 Matthews and co-workers prepared the mesomeric inner salt $\mathbf{5 0 3}$ in modest yield by refluxing of $\mathbf{1 3 0}$ and $\mathrm{BPh}_{3}$ in dry-diglyme (Scheme 219), and proved its photochromism (color change from white to orange upon irradiation). ${ }^{257,417}$ In 1981 , Schmidbaur reported the high yielding synthesis of the mesomeric inner salt $\mathbf{5 0 4}$ by addition of $\mathrm{BH}_{3} \cdot \mathrm{THF}$ to the 6-membered cyclic CDP 157, and the isolated material was characterized by IR and NMR. ${ }^{281}$ The first crystallographic data for a Lewis adduct of a carbodiphosphorane and a borane was provided in 2009 when Petz, Neumüller and Frenking reported on the synthesis, characterization and reactivity of the adduct $\mathbf{5 0 5}$ which was obtained by reaction of $\mathbf{1 3 0}$ and $\mathrm{B}_{2} \mathrm{H}_{6}$ in toluene. ${ }^{261,418}$ An improved synthesis, us300 
ing $\mathrm{BH}_{3} \mathrm{SMe}_{2}$ was later described by Alcarazo and $\mathbf{5 0 5}$ was isolated in nearly quantitative yield. ${ }^{419}$ Interestingly, the chemical behavior of $\mathbf{5 0 5}$ strongly depends of the nature of solvent. Thus, whereas $\mathbf{5 0 5}$ is hydrolyzed by treatment with THF in the presence of extra $\mathrm{B}_{2} \mathrm{H}_{6}$ to form the salt $[\mathbf{1 3 0}-\mathrm{H}]\left[\mathrm{B}_{3} \mathrm{H}_{8}\right]$, the use of DME in presence of $\mathrm{B}_{2} \mathrm{H}_{6}$ led to the formation of salt $[\mathbf{5 0 6}]\left[\mathrm{B}_{2} \mathrm{H}_{7}\right] .{ }^{418}$ Of particular importance is the fact that the structure found for $[\mathbf{5 0 6}]\left[\mathrm{B}_{2} \mathrm{H}_{7}\right]$ displays the participation of the two lone pair at the carbon atom to bind the $\mathrm{B}_{2} \mathrm{H}_{5}$ motif, which represents a new coordination mode of a carbodiphosphorane to main group elements (distinct from proton or a methyl group). The formation of [506][ $\left.\mathrm{B}_{2} \mathrm{H}_{7}\right]$ was attributed by the authors to the initial formation of the intermediate XXVII formed by addition of a second equiv. of $\mathrm{BH}_{3}$ to $\mathbf{5 0 5}$, and the subsequent hydride abstraction from XXVII by the remaining $\mathrm{B}_{2} \mathrm{H}_{6}$ (see below in Scheme 219). ${ }^{418}$

Scheme 219. Reactivity of hexaphenylcarbodiphosphorane (130) vs boron derivatives. 


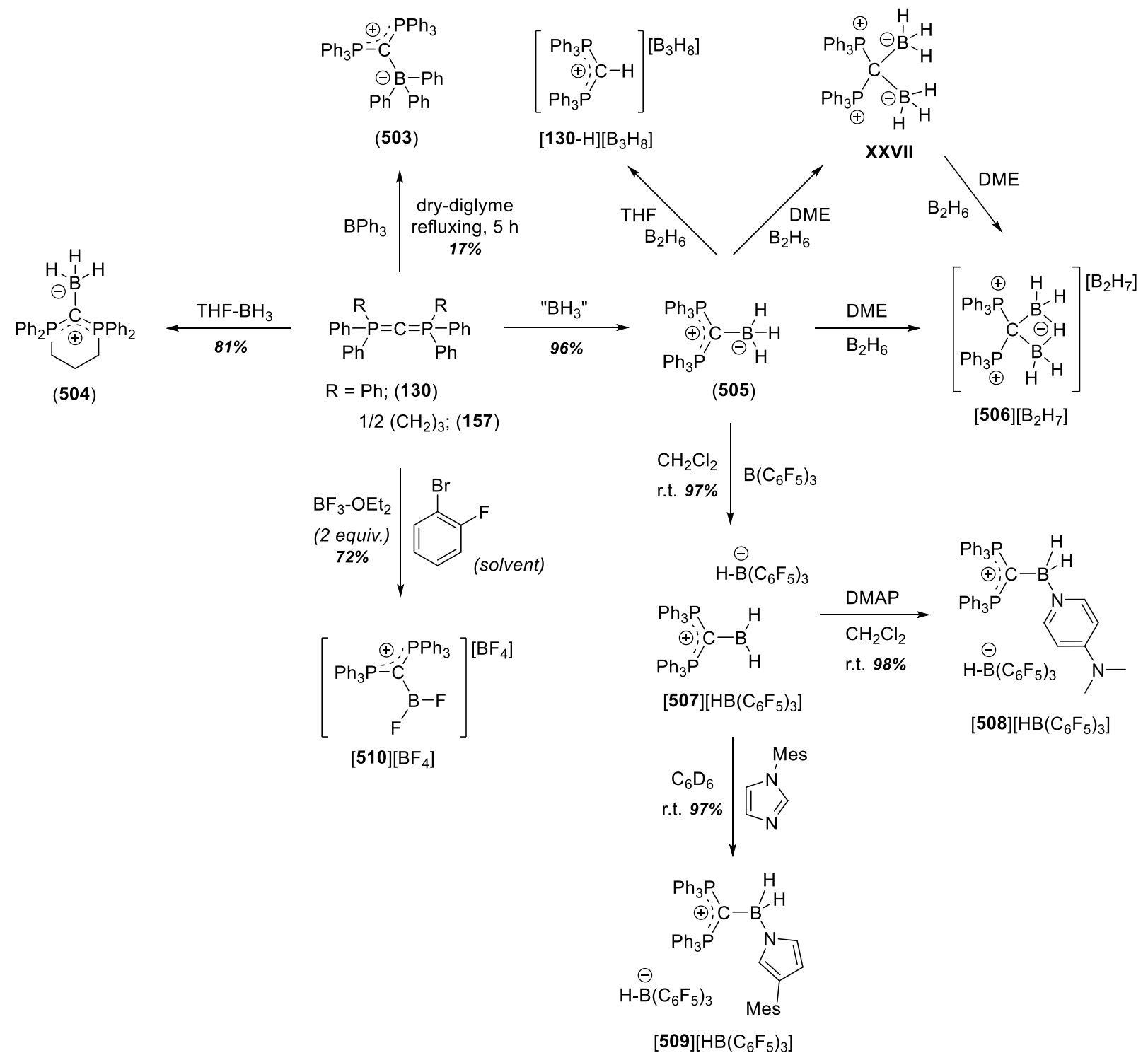

Alcarazo succeeded in the transformation of $\mathbf{5 0 5}$ into the dihydrido borenium cation $[\mathbf{5 0 7}]\left[\mathrm{HB}\left(\mathrm{C}_{6} \mathrm{~F}_{5}\right)_{3}\right]$ by selective hydride abstraction with $\mathrm{B}\left(\mathrm{C}_{6} \mathrm{~F}_{5}\right)_{3}$ in $\mathrm{CH}_{2} \mathrm{Cl}_{2}$. The cationic borenium motif was fully characterized, including by XRD analysis of monocrystal. Despite the double $\sigma+\pi$ donation from 130 to the borenium cation, the boron center remains electrophilic enough to be reacted with N-based Lewis bases and the corresponding boronium cations $[\mathbf{5 0 8}]\left[\mathrm{HB}\left(\mathrm{C}_{6} \mathrm{~F}_{5}\right)_{3}\right]$ and $[\mathbf{5 0 9}]\left[\mathrm{HB}\left(\mathrm{C}_{6} \mathrm{~F}_{5}\right)_{3}\right]$ were thereby isolated in quantitative yields upon addition of $p$-dimethylaminopyridine (DMAP) or 1-mesitylimidazole, re302 
spectively (Scheme 219). Interestingly, the determined C-B bond distance in $\mathbf{5 0 8}$ is considerably reduced upon DMAP coordination to boron [from 1.5030(17) $\AA$ to $1.6376(16) \AA$ ], thus indicating a significant decrease in the $\mathrm{C}-\mathrm{B}$ bond order. ${ }^{419}$ Given the potential $\sigma+\pi$ lone pairs donation capacity of CDPs, Alcarazo and colleagues demonstrated how helpful hexaphenylcarbodiphosphorane can be when dealing with the stabilization of uncommon, highly electrophilic main group species such as the borenium and boronium cations $[\mathbf{5 0 7 - 5 0 9}]\left[\mathrm{HB}\left(\mathrm{C}_{6} \mathrm{~F}_{5}\right)_{3}\right]$.

More recently, Kuzo and co-workers reacted 130 with $\mathrm{BF}_{3} \cdot \mathrm{OEt}_{2}$ (2 equiv.) in 1-bromo-2-fluorobenzene thus resulting in the initial coordination of $\mathbf{1 3 0}$ to $\mathrm{BF}_{3}$ and the following fluoride abstraction to afford the salt $[\mathbf{5 1 0}]\left[\mathrm{BF}_{4}\right]$. The structure of $[\mathbf{5 1 0}]\left[\mathrm{BF}_{4}\right]$ displaying the interactions of the fluorine atoms from both the $\mathrm{BF}_{4}$ anion and the $\mathrm{BF}_{2}$ unit with the phenyl rings was confirmed by XRD analysis of monocrystal. $^{420}$ Advanced NMR analyses were carried out and confirmed the strong ion pairing of the fluoroborenium cation and the $\mathrm{BF}_{4}^{-}$anion in solution as well. In addition, computational analysis (Energy Decomposition Analysis) for the adduct $\mathbf{5 1 0}$ pointed to the double $\sigma+\pi$ lone pairs donation from 130 to the $\mathrm{BF}_{2}^{+}$fragment, which resulted in the highest interaction energy found for a Lewis adduct involving a carbodiphosphorane moiety.

The coordination ability of $\mathbf{1 3 0}$ was also evaluated against $\mathrm{AlBr}_{3}$ and $\mathrm{InMe}_{3}$ by Petz et al. to afford the respective adducts 511 and 512 in excellent yields (Scheme 220). ${ }^{421}$

\section{Scheme 220. Reactivity of CDP 130 vs $\mathrm{InMe}_{3}$ and $\mathrm{AlBr}_{3}$.}




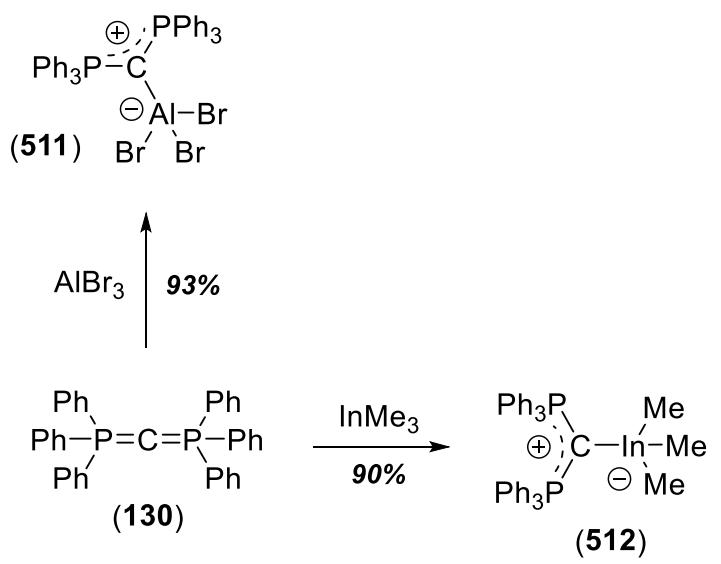

The Gallium-containing Lewis adducts 513 and 514 were prepared by the Gandon group by reaction the corresponding carbodiphosphorane (130 or 157) with $\mathrm{GaCl}_{3}$ (1 equiv.) in THF at room temperature (Scheme 221). ${ }^{422}$ Similar adducts containing strongly donor Lewis bases such as the NHCs and CAACs ligands were additionally prepared and analyzed. With all the spectroscopic and crystallographic data in hand, their relative electronic properties were evaluated and compared. The authors concluded that the sum of the $\mathrm{Cl}-\mathrm{Ga}-\mathrm{Cl}$ angles in $\mathrm{L} \rightarrow \mathrm{GaCl}_{3}$ adducts can be used to predict the electronic properties of the ligand and allowed to illustrate the significantly higher donation capacity of CDPs (along with their parent compounds carbodicarbenes) vs the well-known strong donor NHCs and CAACs ligands.

Few years before, Fürstner and co-workers reported the synthesis of the $\mathrm{GaCl}_{3}$-adducts $\mathbf{5 1 5}$ and $\mathbf{5 1 6}$ from the bisylures 264a,b (Scheme 221). ${ }^{324}$ Careful analysis of the crystallographic data provided insightful information regarding the donation ability of the bisylures $\mathbf{2 6 4 a}, \mathbf{b}$. In fact, while the diethoxycarbene moiety remains almost planar in the structure of $\mathbf{5 1 3}$, the $\mathrm{NMe}_{2}$-group in $\mathbf{5 1 5}$ is significantly twisted out of the plane. The authors argued that these conformational changes result in an efficient orbital overlap between the lone pairs at the oxygen atom and the carbene center in 516, whereas the distortion at the $\mathrm{NMe}_{2}$-group in $\mathbf{5 1 5}$ is due to the efficient stabilization of the carbenic center by both OEt 
and $\mathrm{NMe}_{2}$ groups. In terms of reactivity, this is reflected by a reduced donation capacity of bisylure 264a $v s$ 264b, as clearly highlighted by the single auration of 264a upon addition of [AuCl( $\left.\left.\mathrm{SMe}_{2}\right)\right]\left(\mathrm{due}^{2}\right.$ to the exclusive participation of the $\sigma$-lone pair), whilst the reaction of $\mathbf{2 6 4 b}$ with the same precursor delivers the geminal diaurated compound $\left[\mathbf{2 6 4 b}-(\mathrm{AuCl})_{2}\right]$ (involving the participation of both $\sigma+\pi$ lone pairs; vide supra in the Coordination chemistry of double ylides to metallic species section). ${ }^{324}$

Scheme 221. Reactivity of the cyclic CDP 157 and the mixed P,C-bis(ylide)s (264a,b) towards $\mathrm{GaCl}_{3}$ reported by Gandon (eq. 1) and (eq. 2) and Fürtsner (eq. 3).

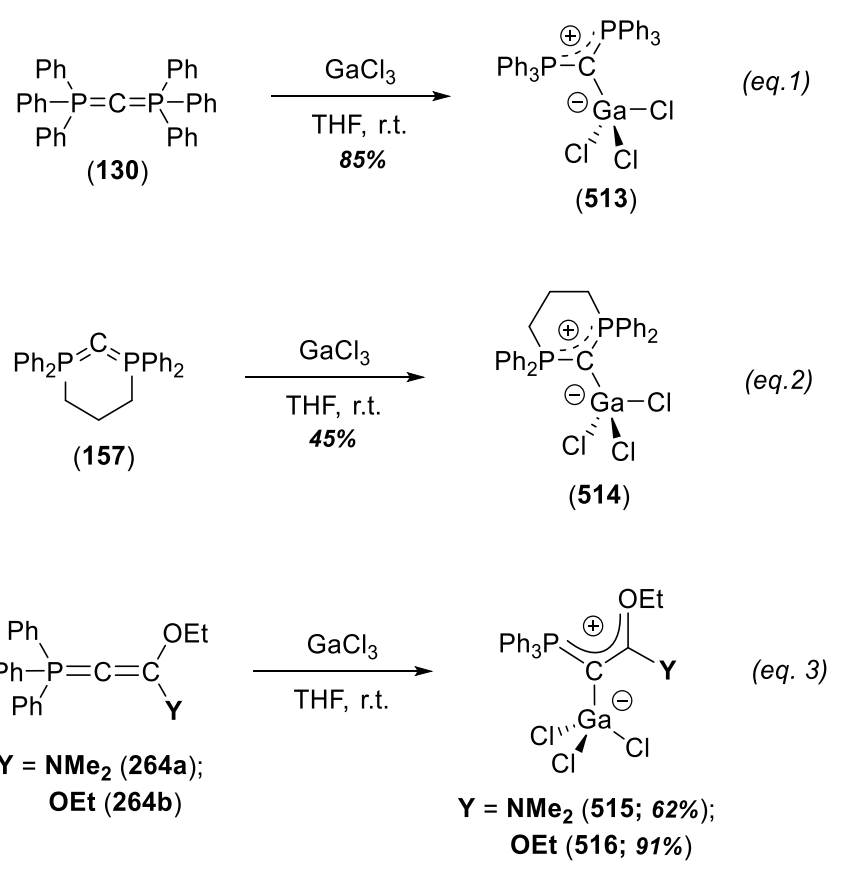

Motivated by the $\mathrm{C}^{0}$-description of carbodiphosphoranes popularized by Tonner and Frenking and their remarkable strong donor capacity attributed to the presence of two orthogonal lone pairs (see the Electronic strucutre of carbodiphosphoranes and other related heteroatom-stabilized bis(ylide)s section), Alcarazo and co-workers evaluated the cooperative action of hexaphenylcarbodiphosphorane (130) and 
$\mathrm{B}\left(\mathrm{C}_{6} \mathrm{~F}_{5}\right)_{3}$ to cleave small molecules, thereby the couple $130 / \mathrm{B}\left(\mathrm{C}_{6} \mathrm{~F}_{5}\right)_{3}$ behaving as a rare example of a Frustrated Lewis Pair (FLP) having a $C$-based Lewis base (see Scheme 222). ${ }^{423}$

In fact, 130 reacts with $\mathrm{B}\left(\mathrm{C}_{6} \mathrm{~F}_{5}\right)_{3}$ to form the zwitterion 517. In contrast, rigorous control of the reaction temperature allowed for the $\mathrm{H}_{2}$-spliting at $-78^{\circ} \mathrm{C}$ induced by $130 / B\left(\mathrm{C}_{6} \mathrm{~F}_{5}\right)_{3}$ to afford the salt $[130-\mathrm{H}][\mathrm{H}$ $\left.\mathrm{B}\left(\mathrm{C}_{6} \mathrm{H}_{5}\right)_{3}\right]$ in excellent $91 \%$ yield. Because of the highly reactive nature of $130 / B\left(\mathrm{C}_{6} \mathrm{~F}_{5}\right)_{3}$, ring opening reactions resulted upon addition of THF, ethylene carbonate (519a) or 2,2-dimethyl- $\gamma$-butyrolactone (519b) yielding the zwitterions 518 and 520a-b in 76\%, 84\% and 71\% yield, respectively. Further FLPtype reactivity of the couple $130 / \mathrm{B}\left(\mathrm{C}_{6} \mathrm{~F}_{5}\right)_{3}$ was also evidenced by addition of different substrates. The addition of the fluoroalkane formed quantitatively the salt $[471]\left[\mathrm{F}-\mathrm{B}\left(\mathrm{C}_{6} \mathrm{~F}_{5}\right)_{3}\right]$, which represents the first case of $\mathrm{C}-\mathrm{F}$ bond breaking promoted by a FLP. In the case of phenylacetylene, deprotonation is the major pathway, forming the salt $[\mathbf{1 3 0}-\mathrm{H}]\left[\mathrm{PhCC}-\mathrm{B}\left(\mathrm{C}_{6} \mathrm{~F}_{5}\right)_{3}\right]$ in $\mathbf{7 8 \%}$ yield, but the "FLP-type-adduct" $\mathbf{5 2 2}$ is also formed in $12 \%$ yield. Finally, the synergetic action of $130 / B\left(C_{6} F_{5}\right)_{3}$ was demonstrated for the $\mathrm{Si}-\mathrm{R}$ bond activation of silanes (with $\mathrm{R}$ being proton or methyl group) to yield the corresponding salts $[\mathbf{5 2 4 a}, \mathbf{b}]\left[\mathrm{H}-\mathrm{B}\left(\mathrm{C}_{6} \mathrm{~F}_{5}\right)_{3}\right]$ and $[\mathbf{1 3 0}-\mathrm{Me}]\left[\mathrm{H}-\mathrm{B}\left(\mathrm{C}_{6} \mathrm{~F}_{5}\right)_{3}\right]$ in excellent yields $(87-93 \%)$.

Scheme 222. Frustrated Lewis Pair reactivity between hexaphenylcarbodiphosphorane (130) and tris(pentafluorophenyl)borane (BCF) shown by Alcarazo. 


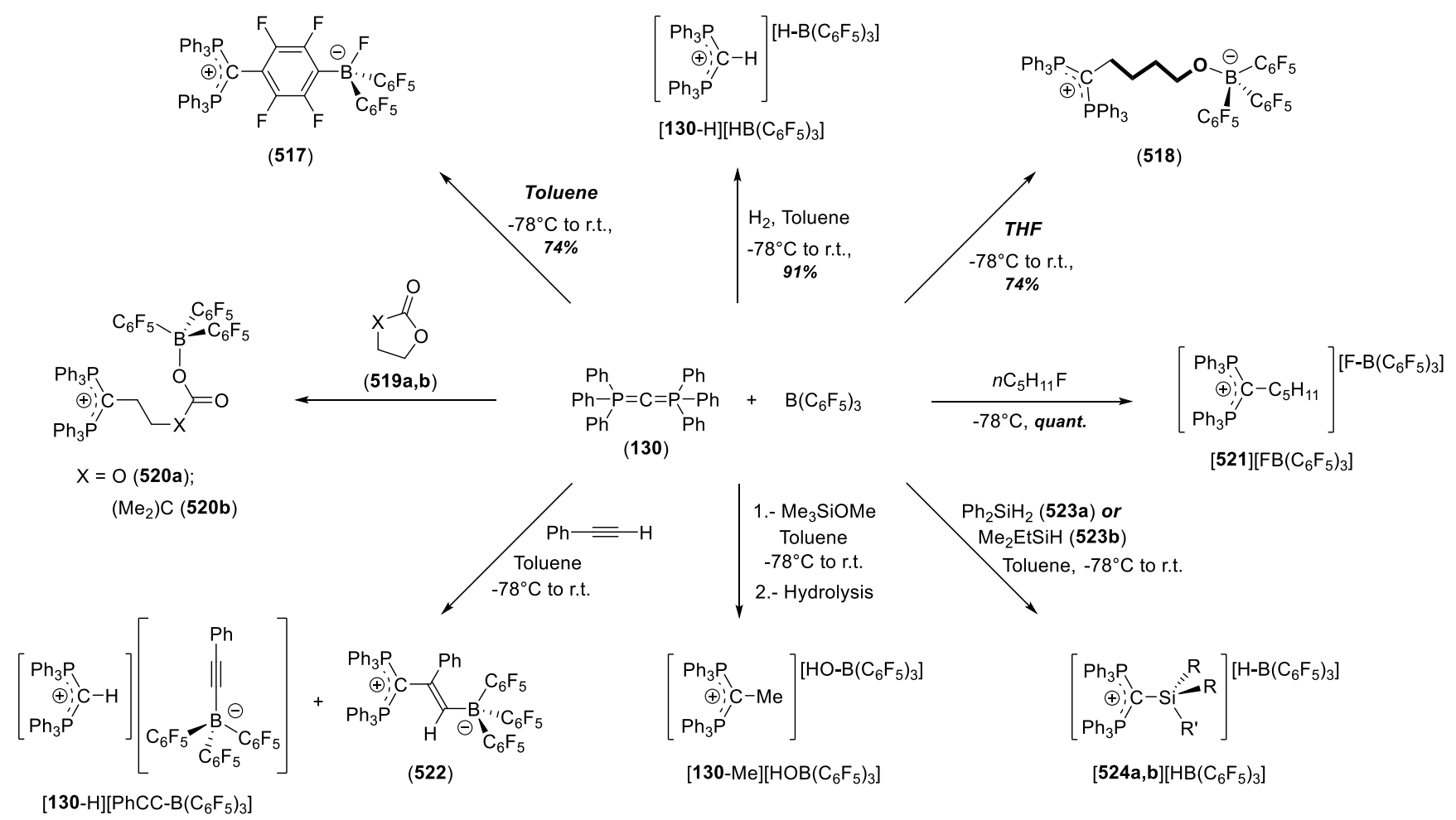

\subsubsection{Group 14}

The first reactivity attempts of carbodiphosphoranes with heavy group 14 elements were already performed in 1976 by Schmidbaur and co-workers, ${ }^{275}$ when they reacted CDP 154 with $\mathrm{Me}_{3} \mathrm{SiCl}$ to yield the silylated salt $[\mathbf{5 2 5}][\mathrm{Cl}]$, is however highly sensitive and was not isolated in pure form (Scheme 223). As previously exposed in the Reactivity of double ylides towards organic compounds section, Kuzu, Neümuller and Tonner succeeded to achieve the quantitative isolation of [2701][OTf] by reacting hexaphenylcarbodiphosphorane (130) with MeSiOTf in toluene few years ago. ${ }^{351}$ In contrast to [525][Cl], compound [2701][OTf] was stable enough to be completely characterized in both solution and solid state.

The access to CDP complexes going down in group 14 was more challenging. Petz reported in 2003 that CDP 130 does not react with $\mathrm{SnCl}_{2}$ or $\mathrm{Me}_{3} \mathrm{SnCl}$ in a productive way, instead conducting to hydrolysis 307 
and sidereactions. More recently, outstanding work deciphering the synthesis of coordinatively unsaturated $\left[\mathrm{Sn}{ }^{\mathrm{II}} \mathrm{Cl}\right]^{+}$and $\left[\mathrm{Ge}^{\mathrm{II}} \mathrm{Cl}\right]^{+}$cationic species conveniently stabilized by $\mathbf{1 3 0}$ via double $\sigma+\pi$ lone pairs donation to the main group element was accomplished by Alcarazo and colleagues (Scheme 223). ${ }^{424}$ Thus, 130 reacts with $\mathrm{GeCl}_{2}$ dioxane or $\mathrm{SnCl}_{2}$ to form the zwitterions 526 and 527 respectively in quantitative yield. The highly insoluble $\mathrm{GeCl}_{2}$-adduct 526 becomes soluble upon addition of an extra equivalent of $\mathrm{GeCl}_{2}$ 'dioxane and gives the bimetallic complex $\mathbf{5 2 8}$ displaying unsupported $\mathrm{Ge}^{\mathrm{II}} \rightarrow \mathrm{Ge}^{\mathrm{II}}$ dative bonds. The stability of this highly unusual $\mathrm{Ge}^{\mathrm{II}} \rightarrow \mathrm{Ge}^{\mathrm{II}}$ donor-acceptor complex $\mathbf{5 2 8}$ is due to the extraordinary donation ability of $\mathbf{1 3 0}$ towards the central Ge-atom as indicated by the shortening of the $\mathrm{C}-\mathrm{Ge}$ bond distance measured in the crystallographic data obtained for $\mathbf{5 2 6}(2.063 \AA)$ and $\mathbf{5 2 8}(1.960 \AA)$.

Fast chloride abstraction from $\mathbf{5 2 6}$ with $\mathrm{AlCl}_{3}$ in $\mathrm{CH}_{2} \mathrm{Cl}_{2}$ generated the cationic $\left[\mathrm{Ge}{ }^{\mathrm{II}} \mathrm{Cl}\right]^{+}$-derivative $[\mathbf{5 2 9}]\left[\mathrm{AlCl}_{4}\right]$ in good yield. The $\left[\mathrm{Ge}^{\mathrm{II}} \mathrm{Cl}\right]^{+}$derivative is solely stabilized by $\mathbf{1 3 0}$ and a chloride ligand. NMR, EI-MS and XRD of single crystals confirmed the geometry of the $\left[\mathbf{1 3 0} \rightarrow \mathrm{Ge}^{\mathrm{II}} \mathrm{Cl}\right]^{+}$cation having a $\mathrm{P}-\mathrm{C}-\mathrm{Ge}-\mathrm{Cl}$ torsion angle of only $8.1^{\circ}$ along with a short $\mathrm{C}-\mathrm{Ge}$ bond distance of $1.954 \AA$ A. These parameters point to an efficient orbital overlapping between the filled $\pi$ orbital at the central C-atom and the empty orbital at Ge. Given the highly acidic character of the $\left[\mathbf{1 3 0} \rightarrow \mathrm{Ge}^{\mathrm{II}} \mathrm{Cl}\right]^{+}$cation $\mathbf{5 2 9}$, reactivity towards Lewis bases was conducted. In fact, the addition of 4-dimethylaminopyridine (DMAP in Scheme 223) to the $\left[\mathrm{Ge}{ }^{\mathrm{II}} \mathrm{Cl}\right]^{+}$cation $\mathbf{5 2 9}$ enabled the formation of the cation $\mathbf{5 3 0}$ displaying a Ge $\leftarrow \mathrm{DMAP}$ adduct. Interestingly, and according to the particular bonding situation in $\mathbf{5 2 9}$, the coordination of DMAP to the $\left[\mathbf{1 3 0} \rightarrow \mathrm{Ge}^{\mathrm{II}} \mathrm{Cl}\right]^{+}$cation populates the LUMO $\left(\pi_{\mathrm{C}-\mathrm{Ge}}{ }\right)$ of $\mathbf{5 2 9}$ and thus prevent the $\pi$ lone pair donation from 130 to Ge resulting in the reduction of the measured $\mathrm{C}-\mathrm{Ge}$ bond distance $(2.053 \AA)$ of the cation 530. DFT calculations at the BP86/def2-TZVP level of theory were carried out to provide further insight to the electronic description of the $\left[\mathbf{1 3 0} \rightarrow \mathrm{Ge}^{\mathrm{II}} \mathrm{Cl}\right]^{+}$cation 529. In short, the HOMO is a $\sigma$ lone 308 
pair orbital mainly located at Ge, while the HOMO-1 is a $\pi$ orbital considerably polarized towards the carbon atom although retaining some $\mathrm{C}-\mathrm{Ge} \pi$ bonding. In addition, Wiberg bond indices (WBIs) were computed and showed a higher $\mathrm{C}-\mathrm{Ge}$ value $(0.84)$ for the $\left[\mathbf{1 3 0} \rightarrow \mathrm{Ge}^{\mathrm{II}} \mathrm{Cl}\right]^{+}$cation $\mathbf{5 2 9}$ vs the values found for both the $\mathrm{GeCl}_{2}$ precursor $526(0.54)$ and the DMAP-stabilized $\left[\mathbf{1 3 0} \rightarrow \mathrm{Ge}^{\mathrm{II}} \mathrm{Cl}\right]^{+}$cation $\mathbf{5 3 0}(0.64)$, which clearly illustrate the increased bond strength due to more efficient $\pi$ orbital overlap in 529. In spite of the partial $\pi$ lone pair delocalization, efficient oxidation of the $\left[\mathbf{1 3 0} \rightarrow \mathrm{Ge}^{\mathrm{II}} \mathrm{Cl}\right]^{+}$cation $\mathbf{5 2 9}$ by $\mathrm{S}_{8}$ was achieved to form dication $\mathbf{5 3 1 .}$

Scheme 223. Reactivity of CDPs 130 and 154 towards heavy (distinct from carbon) group 14 elements reported by Schmidbaur, Kuzu and Alcarazo. Conditions: i) addition of $\mathrm{GeCl}_{2} \cdot \operatorname{dioxane}(1$ equiv.) in toluene at room temperature and stirred overnight (quantitative yield); ii) one solution of 130 in toluene was added to a $\mathrm{THF}$ solution containing $\mathrm{SnCl}_{2}$ (1 equiv.) at room temperature and stirred overnight (quantitative yield). 


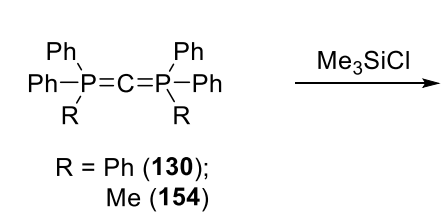

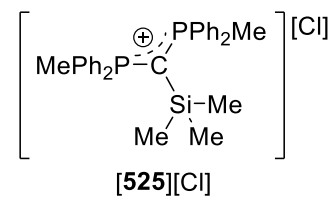
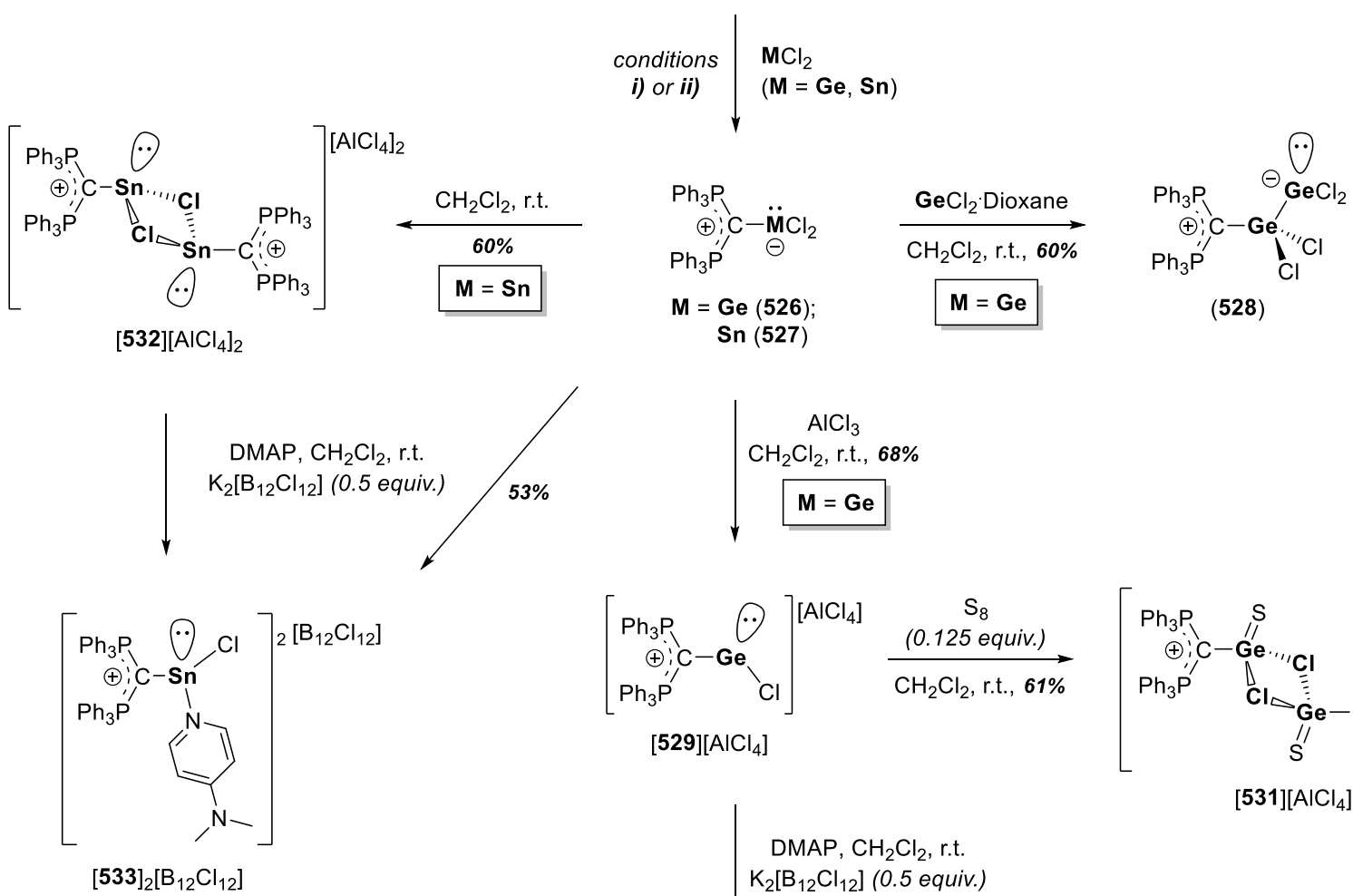

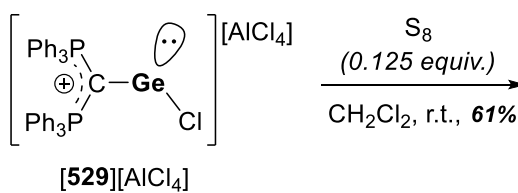

$[529]\left[\mathrm{AlCl}_{4}\right]$

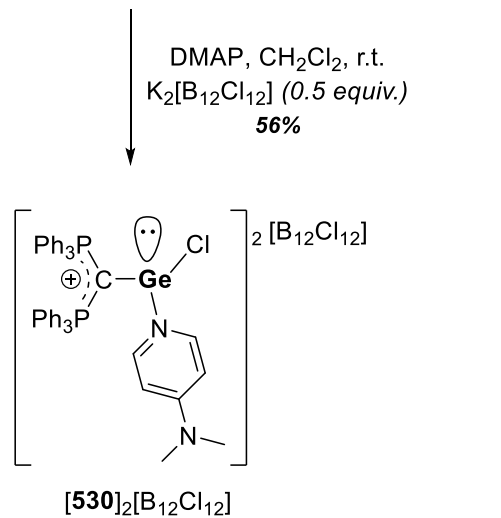

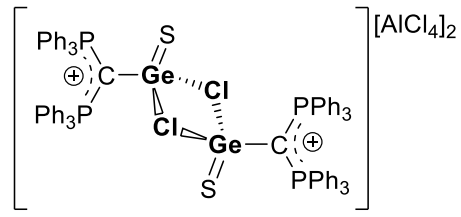

$[531]\left[\mathrm{AlCl}_{4}\right]_{2}$

With zwitterion $\mathbf{1 3 0} \rightarrow \mathrm{Sn}^{\mathrm{II}} \mathrm{Cl}_{2}(\mathbf{5 2 7})$ in hands, the chemistry was further extended by the same group to the synthesis of $\mathbf{1 3 0} \rightarrow \mathrm{Sn}$ adducts containing the $\left[\mathrm{Sn}^{\mathrm{II}} \mathrm{Cl}\right]^{+}$motif (Scheme 223). ${ }^{424}$ In contrast to the germanium chemistry, treatment of the zwitterion 527 with $\mathrm{AlCl}_{3}$ results in the formation of the dimer 
$[\mathbf{5 3 2}]\left[\mathrm{AlCl}_{4}\right]_{2}$ dication with the two $\mathrm{Sn}$ atoms connected to each other by bridging chloride ligands. The formation of this dimer structure is due to the weaker nature of the dative $130 \rightarrow \mathrm{Sn}^{\mathrm{II}} \pi$ interaction, which is consistent with the less efficient overlapping of the $C(2 p)$ and $\operatorname{Sn}(5 p)$ orbitals. Despite the distinct nuclearity found in the structures of the $\left[130 \rightarrow \mathrm{Ge}^{\mathrm{II}} \mathrm{Cl}\right]^{+}$cation $\mathbf{5 3 0}$ (monomer) and the $\left[\mathbf{1 3 0} \rightarrow \mathrm{Sn}^{\mathrm{II}} \mathrm{Cl}\right]^{+}$ cation 532 (dimer), they do behave similarly upon addition Lewis bases such as DMAP. Accordingly, the new $\left[\mathbf{1 3 0} \rightarrow \mathrm{Sn}^{\mathrm{II}} \mathrm{Cl}\right]^{+}$cation $\mathbf{5 3 3}$ was obtained.

\subsubsection{Group 15}

The use of CDPs in main group chemistry was addressed by Matthews immediately after the discovery of CDP 130 in $1961 .^{417}$ Few years later they tackled the issue of isolating cationic phosphines (Scheme 224). ${ }^{258}$ The heating of 130 and $\mathrm{ClPPh}_{2}$ in dry-diglyme allowed to isolate the adduct $\left[(\mathbf{1 3 0}) \mathrm{P}^{\mathrm{III}} \mathrm{Ph}_{2}\right]^{+}$ (534) in excellent 96\% yield. Despite its cationic nature, 534 underwent easy phosphorus oxidation to build the new adduct $\left[(\mathbf{1 3 0}) \mathrm{P}^{\mathrm{V}}(\mathrm{Cl}) \mathrm{Ph}_{2}\right]^{2+}(\mathbf{5 3 5}) .{ }^{258}$ Distinct $\mathrm{P}^{\mathrm{III}}$ to $\mathrm{P}^{\mathrm{V}}$ oxidations were achieved upon mild conditions by addition of $t \mathrm{BuOOH}$ or $\mathrm{S}_{8}$ to the cation 534 giving adducts $\left[(\mathbf{1 3 0}) \mathrm{P}^{\mathrm{V}}(\mathrm{O}) \mathrm{Ph}_{2}\right]^{+}(\mathbf{5 3 8})$ and $\left[(130) \mathrm{P}^{\mathrm{V}}(\mathrm{S}) \mathrm{Ph}_{2}\right]^{2+}\left(\right.$ 539) in $96 \%$ and $48 \%$ yield, respectively. ${ }^{258}$ Alternatively, the hydrolysis of dication 535 affords the adduct 538. The nucleophilic character of the $\mathrm{PPh}_{2}$ fragment in $\mathbf{5 3 4}$ was demonstrated by adding $\mathrm{MeI}, \mathrm{BnBr}$ and $\left[\mathrm{PhN}_{2}\right]\left[\mathrm{BF}_{4}\right]$ to give the corresponding phosphonium derivatives 536, 537 and 541 in similar yields (ca. 80\%), although strong heating $\left(145^{\circ} \mathrm{C}\right)$ and large excess of $\left[\mathrm{PhN}_{2}\right]\left[\mathrm{BF}_{4}\right]$ was

required in order to reach completion in the case of dications 537 and $\mathbf{5 4 1} .^{258}$ The availability of the lone pair at the $\mathrm{PPh}_{2}$ unit was also proved by coordination of cation 534 to $\mathrm{HgCl}_{2}$ (2 equiv.) giving access to the salt $[\mathbf{5 4 0}]\left[\mathrm{HgCl}_{3}\right]$. 
Almost two decades later, Appel and co-workers proved the ylide character of CDP 188a, towards several electrophiles including $\mathrm{ClPPh}_{2}$, forming the cationic adduct $\left[(\mathbf{1 8 8 a}) \mathrm{P}^{\mathrm{III}} \mathrm{Ph}_{2}\right]^{+}(\mathbf{1 9 0 a})$ in high yield.

Fifty years after the original work of Matthews, ${ }^{258}$ the Weigand group revisited the reactivity of CDP (130) and $\mathrm{ClPPh}_{2}$ (see Scheme 225). ${ }^{425}$ In fact the reaction of 130 with $\mathrm{ClPPh}_{2}$ in presence of $\mathrm{Me}_{3} \mathrm{SiOTf}$ yielded the more soluble triflate salt $[\mathbf{5 3 4}][\mathrm{OTf}]$ in $90 \%$ yield. ${ }^{425}$ Here also the availability of the lone pair at phosphorus was proved by the $\mathrm{P}^{\mathrm{III}}$ to $\mathrm{P}^{\mathrm{V}}$ oxidation with chlorine ${ }^{426}$ or $t \mathrm{BuOOH},{ }^{426}$ and through the phosphorus methylation ${ }^{426}$ and protonation ${ }^{426}$ reactions to yield the cation $\left[(\mathbf{1 3 0}) \mathrm{P}^{\mathrm{V}}(\mathrm{O}) \mathrm{Ph}_{2}\right]^{+}(\mathbf{5 3 8})$, and the corresponding dications $\mathbf{5 3 5}, \mathbf{5 3 6}$ and $\mathbf{5 4 2}$ in yields ranging from $81 \%$ to $97 \%{ }^{425,426}$

Scheme 224. Synthesis of cationic phosphines carried out by the groups of Matthews and Appel via nucleophilic substitution of $\mathrm{P}-\mathrm{Cl}$ bonds effected by carbodiphosphoranes 130 and $188 \mathrm{a}$. 
$\left[\begin{array}{ccc}\mathrm{Ph}_{3} \mathrm{P} & \oplus \mathrm{Cl} \\ \oplus & \mathrm{C} & -\mathrm{P} \\ \mathrm{Ph}_{3} \mathrm{P} & \mathrm{Ph}\end{array}\right]^{[\mathrm{Cl}]_{2}}$

$[535][\mathrm{Cl}]_{2}$
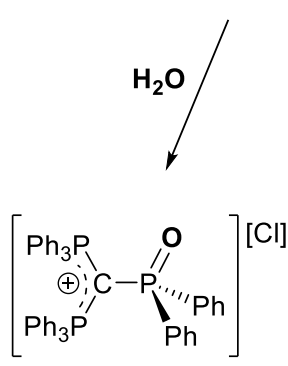

$[538][\mathrm{Cl}]$
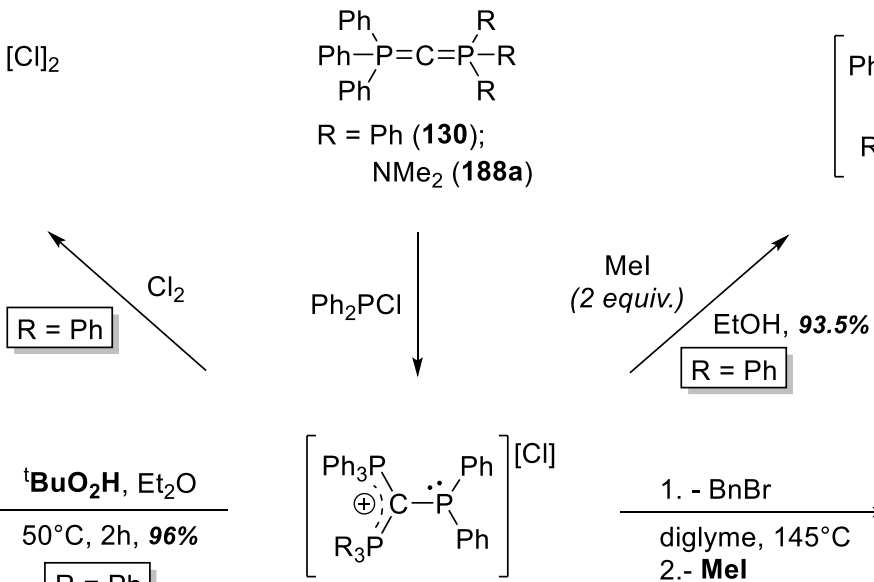

$\mathrm{R}=\mathrm{Ph}[534][\mathrm{Cl}], 96 \%$ $\mathrm{NMe}_{2}[190 \mathrm{a}][\mathrm{Cl}], 84 \%$

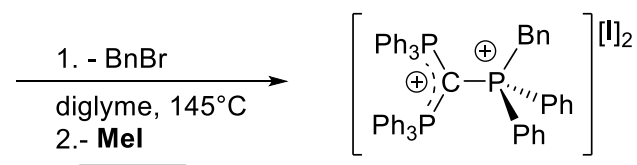

$[537][I]_{2}$
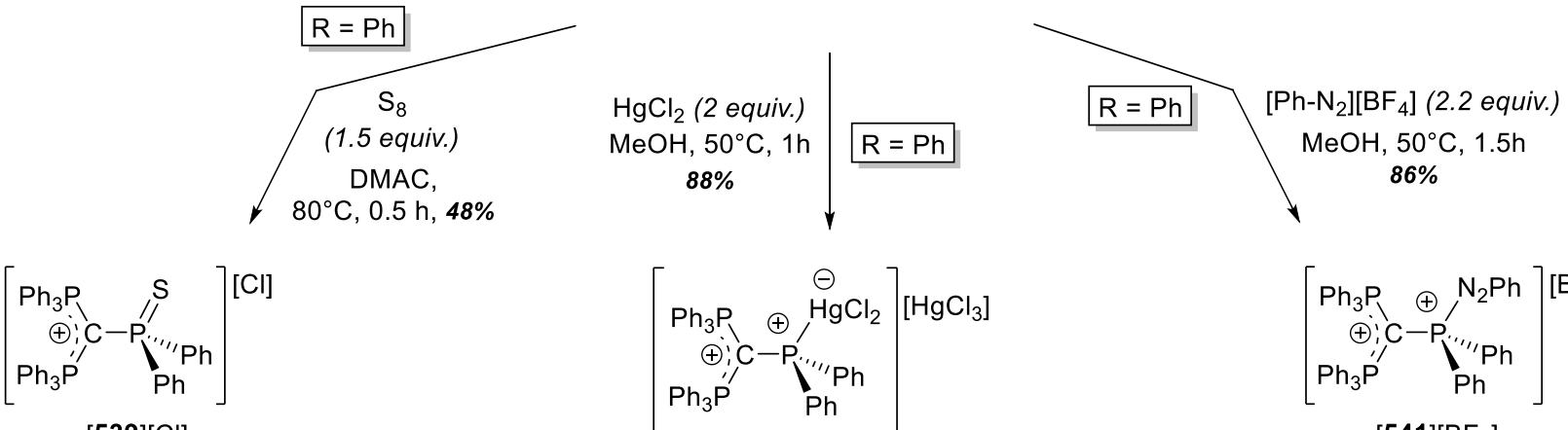

$[539][\mathrm{Cl}]$

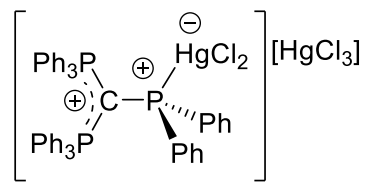

$[540]\left[\mathrm{HgCl}_{3}\right]$

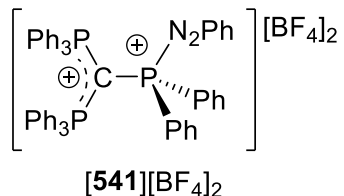

$[541]\left[\mathrm{BF}_{4}\right]_{2}$

The $\mathrm{P}=\mathrm{O}$ bond in the adduct $\mathbf{5 3 8}$ was further functionalized to give quantitatively the dication $\mathbf{5 4 3}$ upon addition of $\mathrm{Tf}_{2} \mathrm{O}$ in fluorobenzene at room temperature (Scheme 225). ${ }^{425}$ According to the presence of a good leaving group directly attached to the $\mathrm{PPh}_{2}$ fragment, this reaction can be reversed by addition of a Lewis base such as $\mathrm{PPh}_{3}$ or DMAP. In fact, the lability of the $\mathrm{P}-\mathrm{OTf}$ bond allowed for the synthesis of new tri(phosphonio)methanide derivatives such as the cation 545 bearing DMAP, ${ }^{425}$ or the dications 546-548 containing inorganic anions attached to phosphorus $\left(\mathrm{F}^{-}, \mathrm{SCN}^{-}\right.$and $\left.\mathrm{CN}^{-}\right) .{ }^{426}$ Interestingly, the fluorinated dication 546 can be reached through an alternative pathway involving a first oxidation step of 534 with $\mathrm{XeF}_{2}$ to isolate the difluorinated intermediate $\left[(\mathbf{1 3 0}) \mathrm{P}^{\mathrm{V}}(\mathrm{F})_{2} \mathrm{Ph}_{2}\right]^{+}(\mathbf{5 4 9})$, followed by selective fluoride abstraction with $\mathrm{Me}_{3} \mathrm{SiOTf}^{426}$ Crystallographic data were collected for the species $[\mathbf{5 4 3}][\mathrm{OTf}]_{2}$ 
and [549][OTf], thus providing a clear picture of these two cations. A distinct reactivity of dication $\mathbf{5 4 3}$ was performed upon addition of phenol that breaks the $\mathrm{O}-\mathrm{Tf}$ bond to give quantitatively the $\mathrm{OH}$ substituted dication $\mathbf{5 4 4}$ and phenyl triflate. ${ }^{425}$

In addition the dication $\mathbf{5 4 3}$ underwent intramolecular $\mathrm{C}-\mathrm{H}$ bond activation of a phenyl ring upon drastic conditions that cyclized into the unprecedented tri(phosphonio)methanide dication $\mathbf{5 5 0}$ in high yield. ${ }^{427}$ The ${ }^{31} \mathrm{P}$ NMR of dication $\mathbf{5 5 0}$ reflected an $\mathrm{AX}_{2}$ spin system which is consistent with the proposed structure. Definitive proof for the cyclization of $\mathbf{5 4 3}$ into $\mathbf{5 5 0}$ was provided by XRD analysis which showed the planarity of the bicyclic dication, having short $\mathrm{P}-\mathrm{C}$ bond distances as a consequence of the negative hyperconjugation of the $\pi$ lone pair at methanide $C$-atom across the $\sigma^{*}\left(\mathrm{P}-\mathrm{C}_{\mathrm{Ph}}\right)$ orbitals.

Scheme 225. Synthesis and reactivity of the cationic adducts $\left[(130) P^{I I I, V} P_{2}\right]^{+} 130 \rightarrow P^{I I I, V} P_{2}$ recently reported by Weigand. 


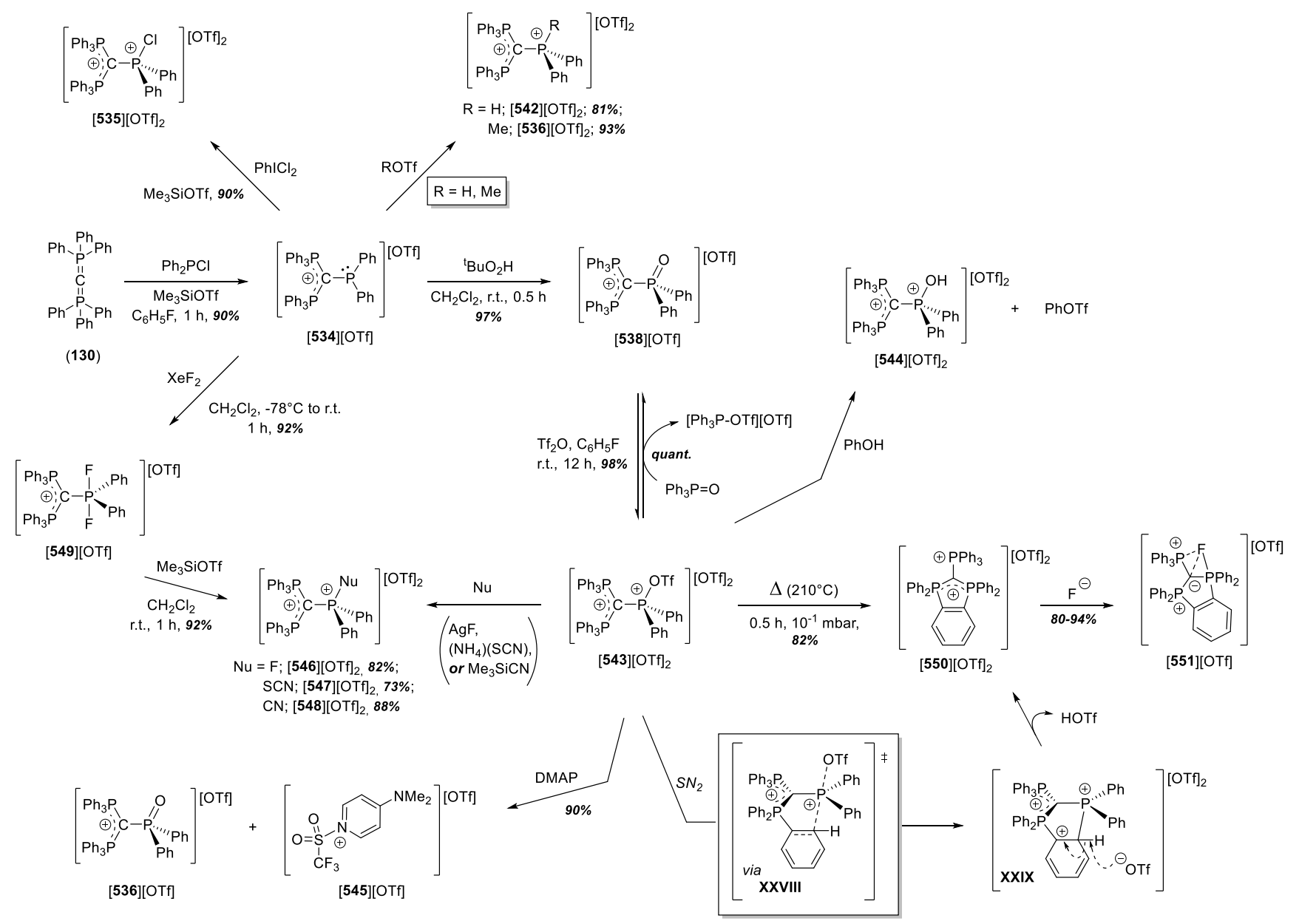

The pathway to convert 543 into 550 was computed and occurs via an intramolecular electrophilic aromatic substitution ( $\mathrm{S}_{\mathrm{E}} \mathrm{Ar}$; simplified mechanism is represented in Scheme 225). The cyclization step to bring dication $\mathbf{5 5 0}$ takes place through concerted OTf elimination and simultaneous backside attack of the arene to reach the Wheland Intermediate XXIX via transition state XXVIII. Subsequent deprotonation step by the triflate drives to the formation of the tri(phosphonio)methanide dication $\mathbf{5 5 0} .^{427}$

The dication $\mathbf{5 5 0}$ reacts with fluoride sources (either $\mathrm{KF}, \mathrm{AgF}$ or $\left[\mathrm{NBu}_{4}\right][\mathrm{F}]$ ) to yield the fluorinated cation 551 that is characterized in ${ }^{31} \mathrm{P}$ NMR by a AMUX spin system, with only two phosphorus nuclei correlating with the fluorine in ${ }^{19} \mathrm{~F}-{ }^{31} \mathrm{P}\left\{{ }^{19} \mathrm{~F}\right\}$ HOESY NMR. This NMR pattern suggested the interaction 
of the fluoride anion with exclusively two of the three phosphorus atoms, this observation being definitively confirmed by the crystallographic data obtained from monocrystalline material of [551][OTf]. The selectivity for the fluoride complexation by dication $\mathbf{5 5 0}$ vs other inorganic anions $\left(\mathrm{CN}^{-}, \mathrm{Cl}^{-}, \mathrm{I}^{-}\right.$, $\mathrm{SCN}^{-}, \mathrm{N}^{3-}, \mathrm{CO}_{3}{ }^{2-}$ ) was also demonstrated, along with its high sensitivity towards fluoride complexation. Indeed, dication $\mathbf{5 5 0}$ is able to detect at concentrations below $0.1 \mathrm{ppm}$. The high stability of [551][OTf] (both air and moisture stable) prompted the authors to investigate its use as an anhydrous source of fluoride anion. Thereby, a highly efficient 551-catalyzed trifluoromethylation of aldehydes was developed in presence of Ruppert's silane to reach the $\alpha$-trifluoromethylated silylalcoholates 553a-g in yields ranging from 76\% to 93\% (Scheme 226). Compound 551 thus emerged as an excellent agent for the reversible complexation and release of fluoride anion.

\section{Scheme 226. Trifluoromethylation of aldehydes catalyzed by the fluorinated cation 551.}

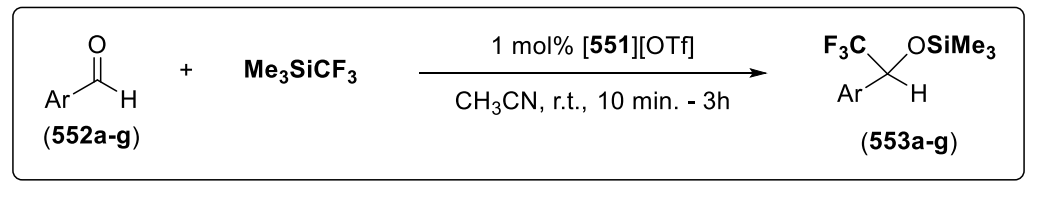

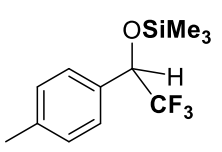

$553 a, 87 \%$

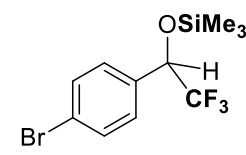

$553 b, 81 \%$

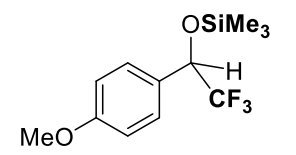

$553 \mathrm{c}, 83 \%$

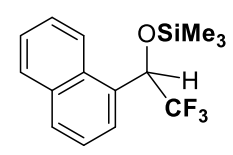

553d, 93\%

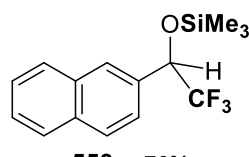

$553 e, 76 \%$

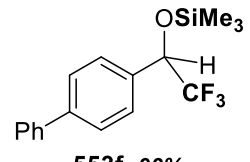

$553 f, 93 \%$

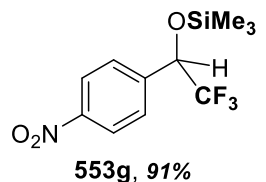

$553 \mathrm{~g}, 91 \%$

Vidović reported the synthesis and characterization of the chlorinated cations $\left[(\mathbf{1 3 0}) \mathrm{P}^{\mathrm{III}}(\mathrm{Cl}) \mathrm{Ph}\right]^{+}(\mathbf{5 5 4 a})$

and $\left[(\mathbf{1 3 0}) \mathrm{P}^{\mathrm{III}}(\mathrm{Cl})\left(4-\mathrm{F}_{-} \mathrm{C}_{6} \mathrm{H}_{4}\right)\right]^{+}(\mathbf{5 5 5})$ from 130 and the appropriate $\mathrm{Cl}_{2} \mathrm{PAr}$ in excess (Scheme 227). ${ }^{428} \mathrm{In}$ addition to the indicative NMR pattern, the atom connectivity of [555][Cl] was established by XRD 316 
analysis. Heating of $[\mathbf{5 5 4 a}][\mathrm{Cl}]$ at $100^{\circ} \mathrm{C}$ overnight in presence of $[\mathrm{Na}]\left[\mathrm{BAr}_{4}^{\mathrm{F}}\right](3$ equiv.) produced the fluorinated cation 557a in minimal amounts that precluded its isolation. Improved yields $(26 \%$ and $55 \%$ ) were achieved starting from the respective salts $[\mathbf{5 5 4 a}]\left[\mathrm{BAr}_{4}^{\mathrm{Cl}}\right]$ or $[\mathbf{5 5 5}]\left[\mathrm{BAr}_{4}^{\mathrm{Cl}}\right]$ and benzotrifluoride. Prolonged heating of $[\mathbf{5 5 4 a}]\left[\mathrm{BAr}_{4}^{\mathrm{Cl}}\right]$ in the presence of $\mathrm{KF}$ gave the fluorine-containing cation 557a in 95\% favoring its in situ characterization by NMR techniques and exact mass determination. This result confirms the ability of the presumably formed dication $\left[(\mathbf{1 3 0}) \mathrm{P}^{\mathrm{III}} \mathrm{Ph}\right]^{2+}$ to cleave $\mathrm{C}-\mathrm{F}$ bonds because of the accessibility of low-lying unoccupied orbitals. Confirmation of this hypothesis was achieved upon coordination of $\mathrm{PMe}_{3}$ that permitted the isolation of [556a] $\left[\mathrm{BAr}_{4}^{\mathrm{F}}\right]_{2}$ in $59 \%$ yield.

Scheme 227. Synthesis of cationic adducts $\left[(130) \mathrm{P}^{\mathrm{III}} \mathrm{Cl}(\mathrm{Ph})\right]^{+}$and $\mathrm{C}-\mathrm{F}$ bond cleavage of aromatics and benzotrifluoride mediated by an in situ formed dication $\left[(130) \mathrm{P}^{\mathrm{III}}(\mathrm{Ph})\right]^{2+}($ Vidović). 


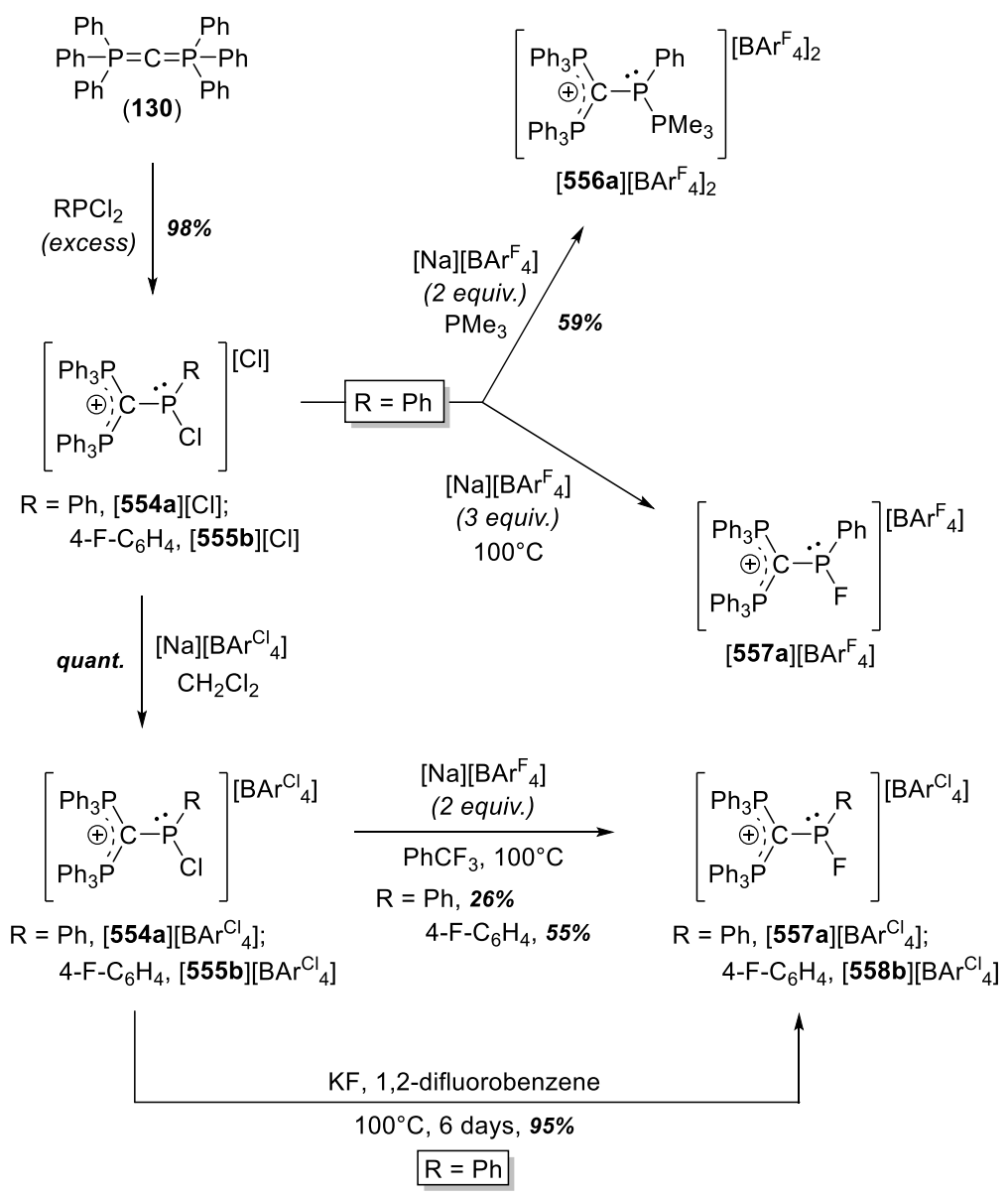

The same group extended this chemistry creating molecular diversity by modifying both the nature of the CDP (the linear CDP 130 vs the cyclic one 157) and the $\mathrm{R}^{\prime}$ group at phosphorus (R' = Ph (a), 4-F$\mathrm{C}_{6} \mathrm{H}_{4}(\mathrm{~b}), \mathrm{N}(i \mathrm{Pr})_{2}(\mathrm{c}), \mathrm{NCy}_{2}(\mathrm{~d}), t \mathrm{Bu}(\mathrm{e})$ and $\mathrm{N}=\mathrm{C}(\mathrm{N} t \mathrm{Bu})_{2}(\mathrm{CH})_{2}(\mathrm{f})$; Scheme 228). ${ }^{429-433}$ Reacting 130 or 157 with 3 equiv. of $\mathrm{Cl}_{2} \mathrm{PR}$ ' in benzene affords the chlorinated adducts $[\mathbf{5 5 4 a - e}][\mathrm{Cl}]$ and $[\mathbf{5 5 9 b}][\mathrm{Cl}]$ in variable yields $(55-90 \%)$. Chloride abstraction by addition of $\mathrm{AlCl}_{3}$ or $[\mathrm{Na}]\left[\mathrm{BAr}_{4}^{\mathrm{F}}\right]$ (2 equiv.) gives the corresponding dications in modest yields $(35-66 \%) .{ }^{429,430}$

Given the high oxophilicity of phosphorus and the low lying LUMO in the phosphenium dication 560c, ${ }^{430,431}$ it spontaneously reacts with water in $\mathrm{CH}_{2} \mathrm{Cl}_{2}$ at room temperature leading toto the dication 562c, whose isolation was however not possible. In contrast, the analogous adduct 318 
$\left[(3) \mathrm{P}^{\mathrm{V}}(\mathrm{H})(\mathrm{OMe}) \mathrm{N}(i \mathrm{Pr})_{2}\right]^{2+}$ was isolated in $c a$. 90\% upon addition of 1 equiv. of $\mathrm{MeOH}$ to $\left[(\mathbf{1 3 0}) \mathrm{P}^{\mathrm{III}} \mathrm{N}(i \mathrm{Pr})_{2}\right]^{2+}(\mathbf{5 6 0 c})$. Definitive proof for the formation of the dication $\left[(\mathbf{1 3 0}) \mathrm{P}^{\mathrm{V}}(\mathrm{H})(\mathrm{OH}) \mathrm{N}(i \mathrm{Pr})_{2}\right]^{2+}$ (562c) was given by addition of $\mathrm{NEt}_{3}$ to the reaction mixture and the salt $\left[\mathbf{5 6 2 c}-\mathrm{NEt}_{3}\right][\mathrm{X}]_{2}$ was isolated in $57 \%$ yield and fully characterized. ${ }^{430,431}$

The same group reported the selective $\mathrm{P}-\mathrm{N}$ bond activation instead of the $\mathrm{P}-\mathrm{Cl}$ of $\mathrm{MeNPCl}_{2}$ mediated by $\mathbf{1 3 0}$, yielding the cation $\left[(\mathbf{1 3 0}) \mathrm{P}^{\mathrm{III}} \mathrm{Cl}_{2}\right]^{+}(\mathbf{5 6 3}) .{ }^{432}$ Theoretical investigations were carried out at the B3LYP/6-31G(d) level and pointed to the formation of 563 involving a seemingly $\mathrm{S}_{\mathrm{N}} 2$ ' mechanism via intermediate XXX (see Scheme 228).

Hexaphenylcarbodiphosphorane (130) reacted with the dichlorophosphine 564 to afford quantitatively the salt $[\mathbf{5 5 4 f}][\mathrm{Cl}]$, and the double chloride abstraction with $\mathrm{AgSbF}_{6}$ gave quantitatively the desired dication 565f (Scheme 228). ${ }^{433}$ Careful analysis of the crystallographic data and the computed frontier orbitals for dication $\mathbf{5 6 5 f}$ indicated the dicationic iminophosphane resonance form (A in Scheme 228$)$ to contribute the most, with small contribution of the phosphorus mononitride resonance form (B in Scheme 228).

Scheme 228. Synthesis of cationic adducts between CDPs 130 and 157 with P-based fragments. 


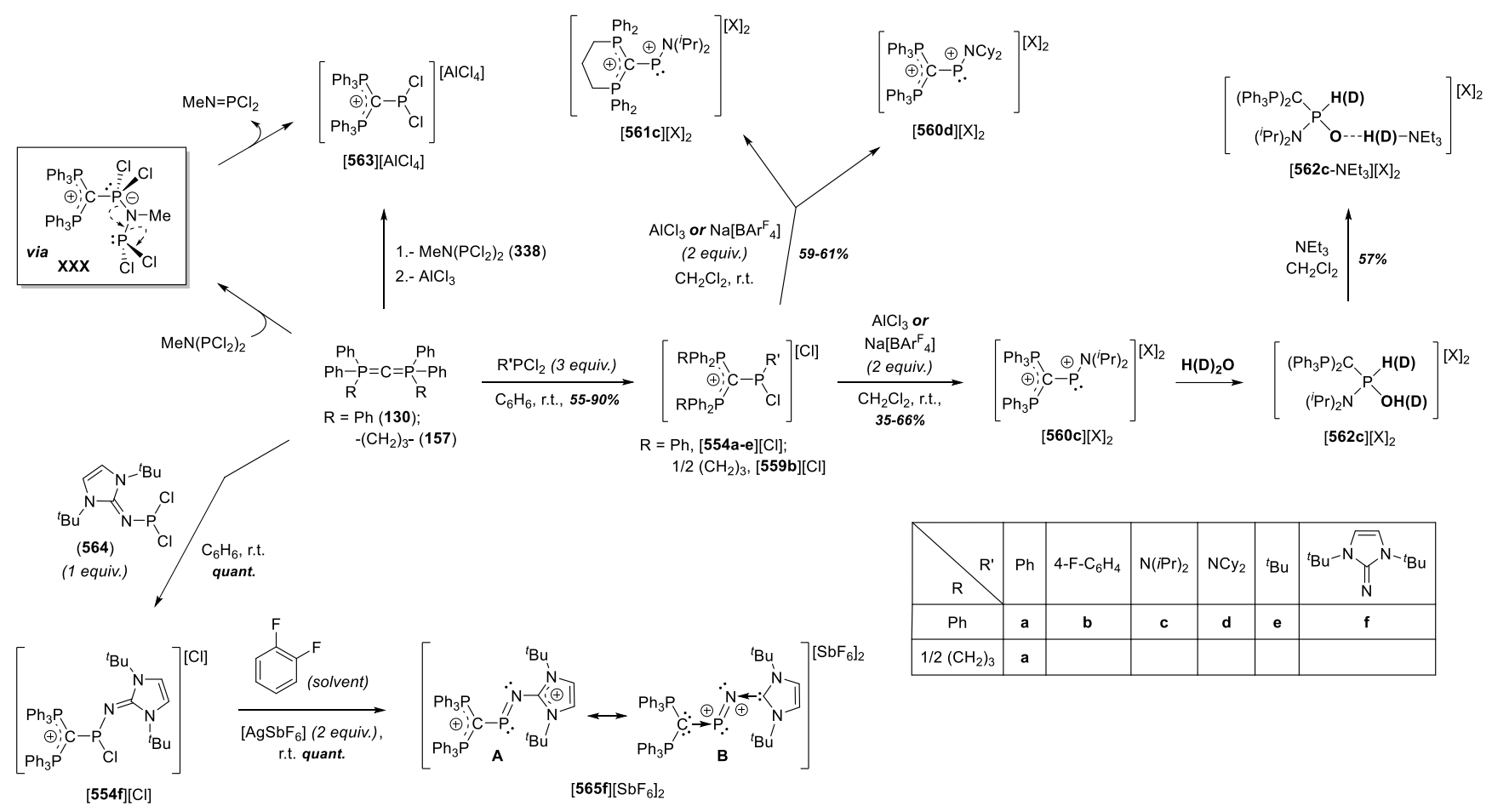

Interesting molecular diversity was created in 1997 by Schmidpeter et al. when they reported similar reactivity of 130 towards dichlorophosphines (566a-c) bearing an ylide moiety (Scheme 229). ${ }^{434}$ Thus, the reaction of 130 and $566 \mathrm{a}-\mathrm{c}$ at $0^{\circ} \mathrm{C}$ gave the dications $567 \mathrm{a}-\mathrm{c}$ in quantitative amounts. In sharp contrast, strict temperature control is required when using the phosphorus ylide 568 having two $\mathrm{PCl}_{2^{-}}$ substituents to selectively produce the cation 569 in modest yield (57\%), with the second $\mathrm{PCl}_{2}$ unit remaining untouched.

Scheme 229. Reactivity of 130 and functionalized dichlorophosphines. 


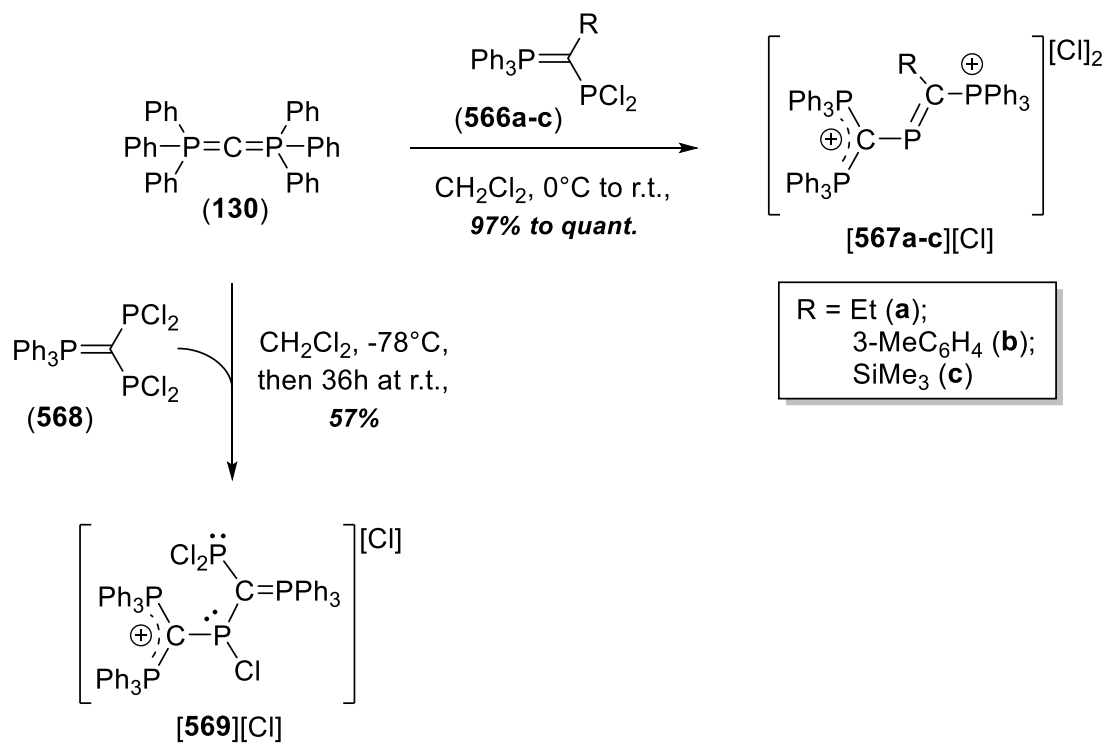

Alcarazo prepared the cationic phosphonites $\mathbf{5 7 1 a , b}$ by reaction of $\mathbf{1 3 0}$ and the corresponding chlorophosphites (570a,b in Scheme 230). ${ }^{435}$ The subsequent coordination of 571a,b to $\left[\mathrm{AuCl}\left(\mathrm{SMe}_{2}\right)\right]$ at $20^{\circ} \mathrm{C}$ gave quantitative access to the Au-complexes [571a,b-AuCl] $\left[\mathrm{SbF}_{6}\right]$. The Au-complex [571a$\mathrm{AuCl}]\left[\mathrm{SbF}_{6}\right]$ was evaluated for the catalytic enantioselective cyclization of the diyne substrate $\mathbf{5 7 2}$ aiming to isolate the [6]helicene (573). Instead, selective cyclization led to 576, while an analogous cationic phosphonite bearing the SIMes group provided an efficient entry to the [6]helicene (573) with excellent enantioselectivity $(\mathrm{ee}=91 \%){ }^{435}$

Scheme 230. Synthesis of cationic phosphonites 571a,b, coordination to AuCl (A), and unproductive use of [571a,b-AuCl] as catalysts for the enantioselective synthesis of [6]helicenes (B) reported by Alcarazo. Conditions: i) Stirring overnight at r.t. a 1:1 mixture of 130 and 570a. Then, $[\mathrm{Na}]\left[\mathrm{SbF}_{6}\right]\left(3\right.$ equiv.) was added in $\mathrm{CH}_{3} \mathrm{CN}$ to the isolated crude solid and the suspension was stirred overnight $($ Yield $=57 \%)$; ii) stirring overnight at r.t. a 0.9:1 mixture of 130 and 570b, followed by addition of 0.9 equiv. of 130 and heating at $60^{\circ} \mathrm{C}$ for additional $4 \mathrm{~h}$. Then, [Na][SbF 6 
night (Yield $=32 \%)$.

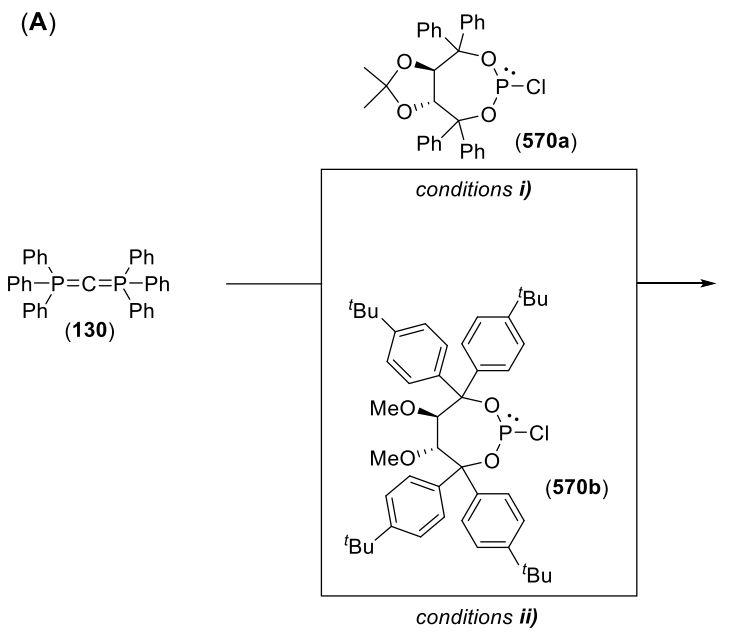

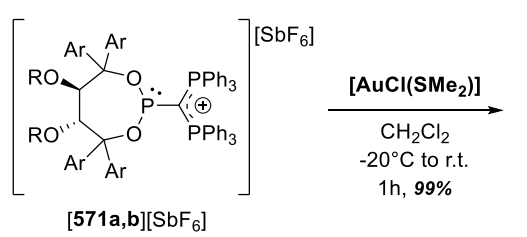

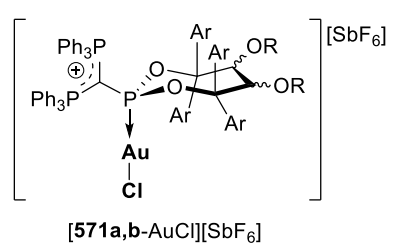

(B)

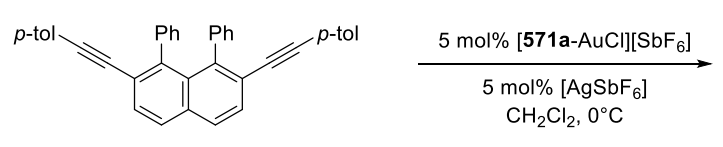

(572)

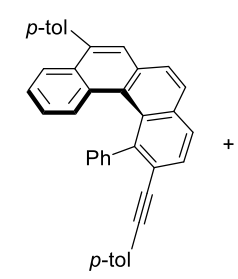

(574; 0\%)

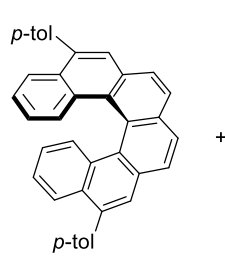

(573; 0\%)

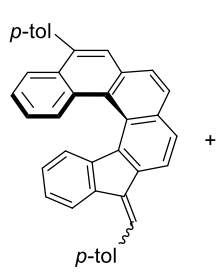

(575; 0\%)

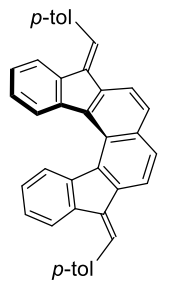

(576; 43\%)

Kato and Baceiredo reported the reactivity of the P,S ${ }^{I I}$ - bis(ylide) $241 \mathbf{b}$ against phosphenium salts (Scheme 231). ${ }^{436}$ The bis(ylide) was reacted with the phosphenium cation $\mathbf{5 7 7}$ to form the cationic phosphinocarbene $[\mathbf{5 7 8 b}]^{+}$that was characterized in situ due to high instability. Further proof on the carbenic nature of $\mathbf{5 7 8 b}$ was provided by its reactivity vs tertbutyl isocyanide leading to the cationic ketenimine $[\mathbf{5 7 9 b}]^{+}$. In sharp contrast, reacting $\mathbf{2 4 1 b}$ with 2 equiv. of the cyclic phosphenium cation $\mathbf{5 8 0}$ conducted to the isolation of the salt $[\mathbf{5 8 1 b}][\mathrm{OTf}]$ in $51 \%$ yield. Its complete characterization was performed by NMR and XRD analysis, and proved the presence of a 3-membered heterocycle having 4- $\pi$ electrons. 
Scheme 231. Reactivity of mixed P,S ${ }^{\text {II }}$-bis(ylide) $241 \mathrm{~b}$ vs phosphenium salts.<smiles>CCCN1CCN(CCC)P1(=C=S)c1ccccc1</smiles>

(241b)
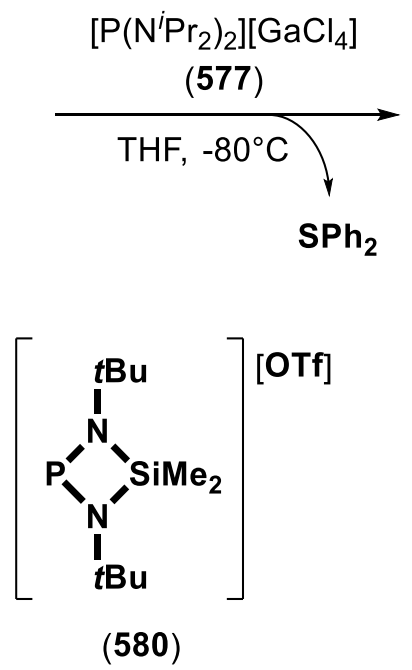

(580)

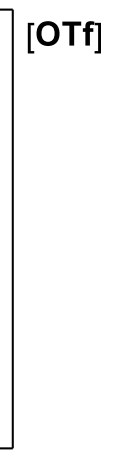

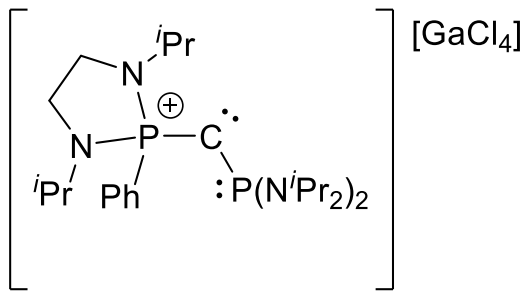

$[578 \mathrm{~b}]\left[\mathrm{GaCl}_{4}\right]$
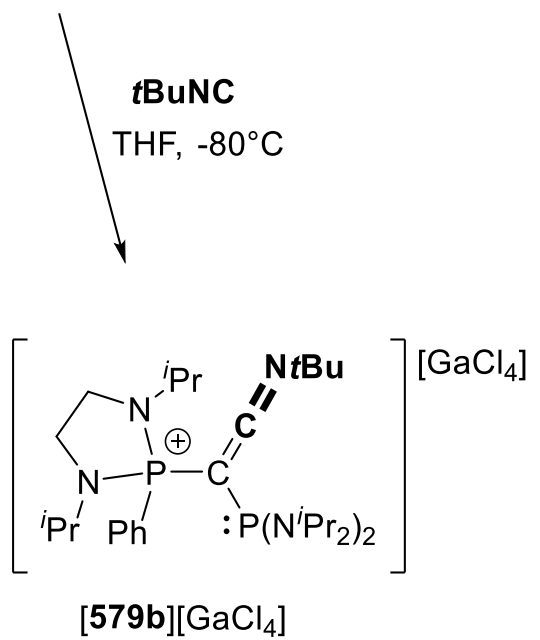

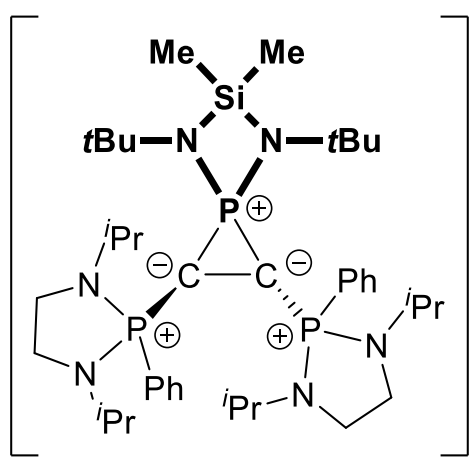

$[581 \mathrm{~b}]\left[\mathrm{GaCl}_{4}\right]$

\subsubsection{Group 16}

In 1977, Bestmann reviewed the chemistry of phosphacumulene ylides and reported the reactivity of 130 with $\mathrm{S}_{8}$ to produce the phosphacumulene 283 by trapping of in situ created $\mathrm{CS}_{2}$ with $\mathbf{1 3 0}{ }^{437}$ Few years later, Schmidbaur revisited this chemistry and found the reversible transformation of carbodiphosphoranes 130 and 142 into the sulfur derivatives 582 and 583 upon addition of equimolar amounts of $\mathrm{S}_{8}$ at $-50^{\circ} \mathrm{C} .^{438,439}$ The adducts $\mathbf{5 8 2}$ and $\mathbf{5 8 3}$ were isolated in excellent yield, and the former was further 
reacted with $\mathrm{MeSO}_{3} \mathrm{~F}$, benzyl chloride and $\mathrm{Me}_{3} \mathrm{SnCl}$ to yield the cations 584a-c in 51-87\% (Scheme 232). ${ }^{438,439}$

Scheme 232. Sulfuration of carbodiphosphoranes 130 and 142 to yield sulfides 353-354 and their reactions with electrophiles.

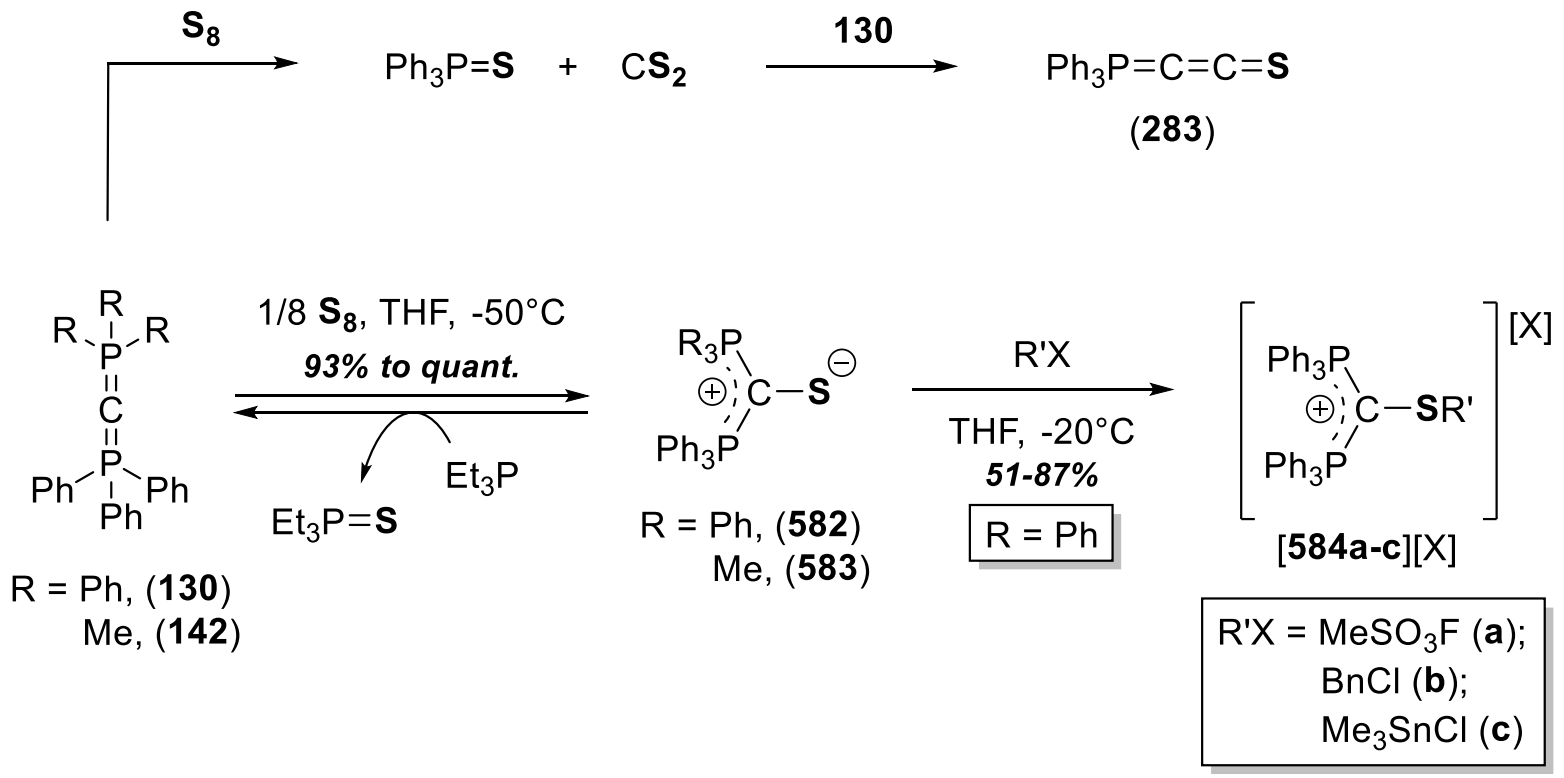

The same reactivity towards selenium ${ }^{438,439}$ and tellurium ${ }^{439}$ was explored by the same group (eq.1 and eq.2 in Scheme 233, respectively). More intriguing were the results achieved in presence of mild oxidants such as elemental bromine, elemental iodine or $\mathrm{FeCl}_{3}$ that formed the dication $\mathbf{5 8 6}$ through an oxidative coupling of two selenolate functions. ${ }^{439,440}$ The X-ray structures of the selenide cation [585] $]^{+}$ and dication $[\mathbf{5 8 6}]^{2+}$ proved the planarity of the ylidic carbon in both compounds, the dication displaying an unusual Se-Se bond distance of 2.492(2) A.

Scheme 233. Reactivity of CDP 130 with Se- and Te-reagents. Conditions: i) addition of $\mathrm{Br}_{2}$; ii) addition of $\mathrm{I}_{2}$; and iii) addition of $\mathrm{FeCl}_{3}$ in $\mathrm{CH}_{2} \mathrm{Cl}_{2}$. 


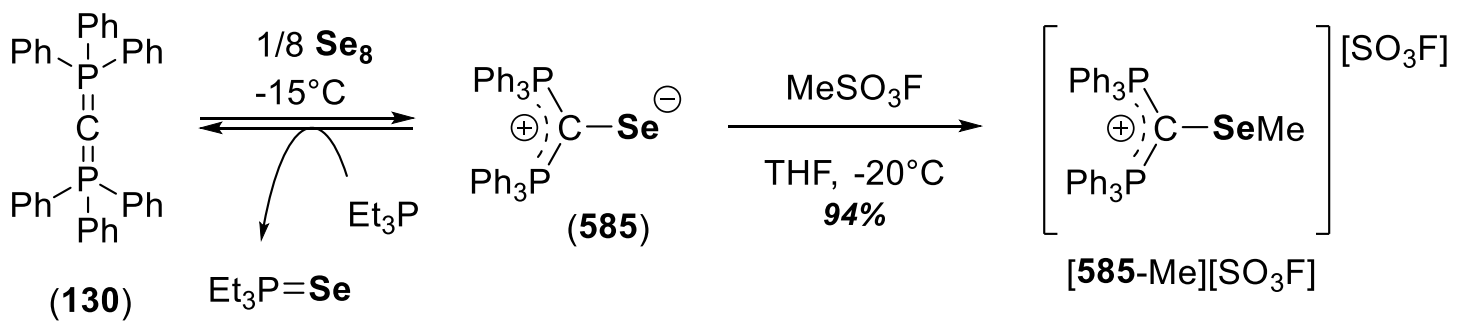

(eq. 1)
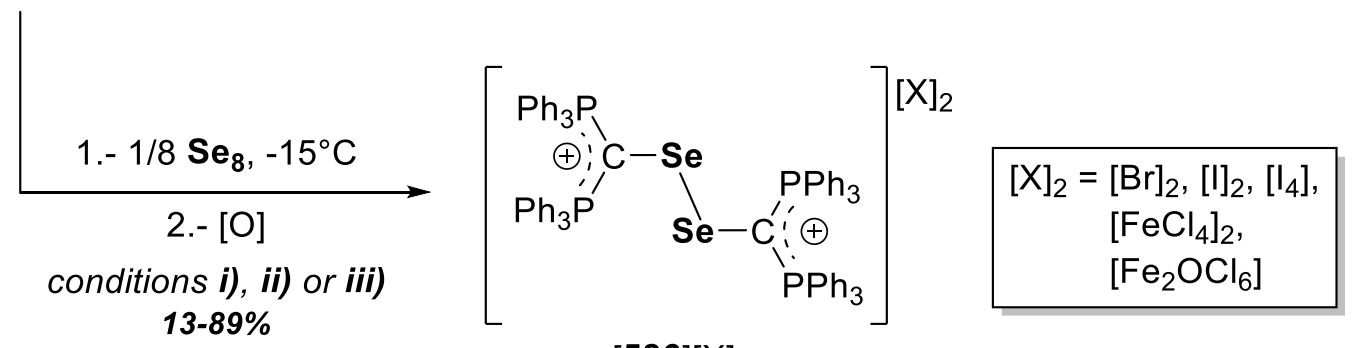

$[586][X]_{2}$

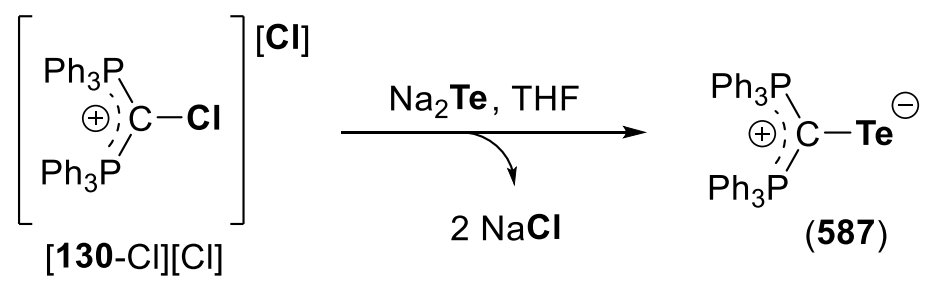

(eq. 2)

In addition, the air oxidation of the mixed $\mathrm{P}, \mathrm{S}^{\mathrm{IV}}$-bis(ylide) 255a has been reported by Fujii, with selective formation of $\mathrm{Ph}_{3} \mathrm{P}=\mathrm{O}$ in $95 \%$ yield (Scheme 162). ${ }^{322}$

\subsubsection{Group 17}

Oxidation reactions of CDP 130 were explored by Petz $z^{441,442}$ and Schmidbaur. ${ }^{439}$ The first report covering the oxidation of $\mathbf{1 3 0}$ by elemental iodine to form 130-I was published by Schmidbaur in 1985 (Scheme 234). Very recently, Petz reported an alternative way of synthesis for the cation 130-I in presence of iodine and methyl iodide. The salt $[130-\mathrm{I}]\left[\mathrm{I}_{3}\right]$ was crystallized in $10 \%$, allowing to confirm its structure by XRD analysis. ${ }^{441}$ 
Scheme 234. Oxidation reactions of CDP 130. Conditions: $i$ ) addition of $\mathrm{Br}_{2}($ Yield $=70 \%)$; ii) addition of $\mathrm{CBr}_{4}$.<smiles>BrC(Br)=P[Pb]=P[Pb]Cc1ccccc1</smiles>

$[130-\mathrm{Br}][\mathrm{Br}]$

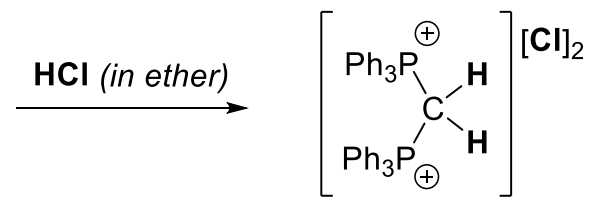

$\left[130-\mathrm{H}_{2}\right][\mathrm{Cl}]_{2}$

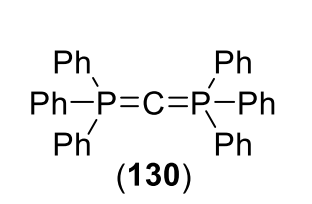

$\left.\begin{array}{l}\mathrm{I}_{2}(1 \text { equiv. }) \\ \text { Mel }(1 \text { equiv. })\end{array}\right\} 10 \%$
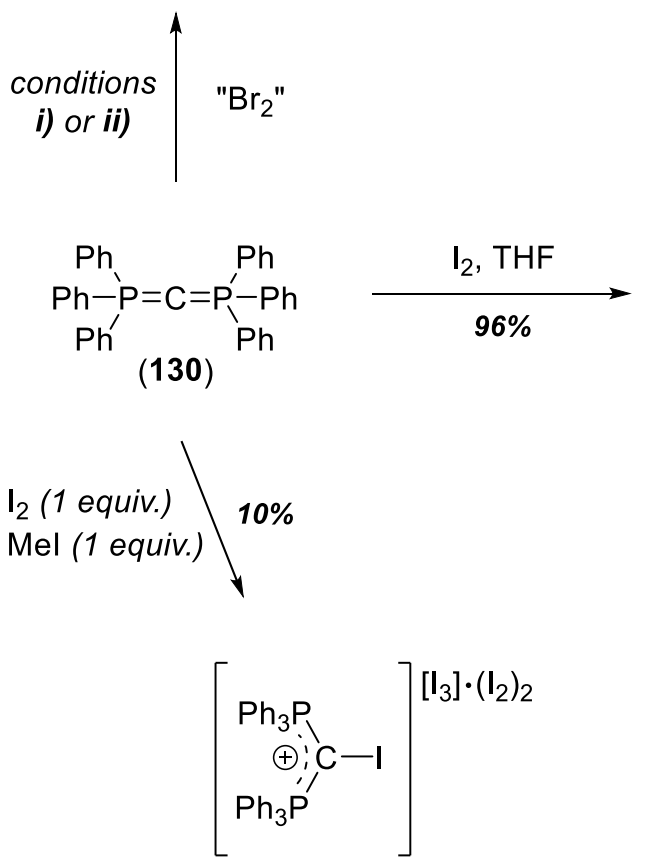

[130-I][I $]\left(I_{2}\right)_{2}$

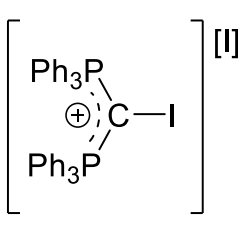

[130-I][I]

In his seminal work detailing the synthesis of 130, Ramirez pointed to the facile oxidation of 130 into the salt $[\mathbf{1 3 0}-\mathrm{Br}][\mathrm{Br}]$ by simple addition of $\mathrm{Br}_{2}$ (Scheme 234). ${ }^{255} 45$ years later, Petz and co-workers revisited the synthesis of the brominated cation $[130-\mathrm{Br}]^{+}$by using $\mathrm{CBr}_{4}$ as bromine source, being unequivocally characterized by XRD analysis. ${ }^{441}$ In addition, cation $[130-B r]^{+}$gets hydrolyzed upon addition of $\mathrm{HCl}$ to afford $\left[\mathbf{1 3 0}-\mathrm{H}_{2}\right][\mathrm{Cl}]_{2}{ }^{441}$ 


\subsection{Carbodicarbenes}

In a general perspective, the stability of geminal dianions, yldiides and carbodiphosphoranes can be understood in terms of negative hyperconjugation into low-lying antibonding (and thus empty) orbitals of two heteroatom-based substituents. This concept can be extended to carbon-based substituents, as far as an "empty orbital" of appropriate energy is present on an adjacent carbon, thus designing the main characteristic of a new family of neutral compounds bearing two lone pairs at carbon (Scheme 235, left). Being based on the (partial) conjugation of two carbon-centered lone pairs and two adjacent, carboncentered vacant $\mathrm{p}$ orbitals, these species are obviously closely related to allenes, and more specifically to "push-push bent allenes", which feature a strong electronic density at carbon. As exposed in Bertrand's

paper presenting the first carbodicarbene based on a NHC moiety, ${ }^{304}$ bending of allenes occurs either by a geometrical constraint applied on the $\mathrm{C}=\mathrm{C}=\mathrm{C}$ moiety, or by a weakening of each of the $\pi$ bond. This last option can be done by polarizing each of the two $\pi$ systems using for example strongly mesomeric donor substituents like nitrogen atoms. It also results in an important increase of the electronic density at carbon, in both $\pi$ systems, as shown by the mesomeric forms in Scheme 235, middle. If a heterolytic cleavage of the $\sigma$ bond between the central carbon and its stabilizing neighbor is formally envisioned, the electrons of the $\sigma$ bond being attributed to the stabilizing moiety, the resulting fragment belongs to the family of singlet carbenes (Scheme 235; right). For this reason, these species are denominated carbodicarbenes by analogy with carbodiphosphoranes, although the logical ground of this kind of heterolytic cleavage is still the subject of numerous discussions amongst the chemist's community. ${ }^{291,295,300,301}$ Similarities in electronic configuration between the two groups have been discussed earlier. 
Scheme 235 : Left: From carbodiphosphorane to carbodicarbene by changing the nature of the accepting orbital. Middle: typical push-push allene and a mesomeric form showing two lone pairs at carbon. Right: heterolytic cleavage of the C-C bond highlighting the analogy with carbodiphosphoranes.

Enlarging the stabilization mode of lone pairs at $\mathrm{C}$ to empty $\mathrm{C}$-based orbitals

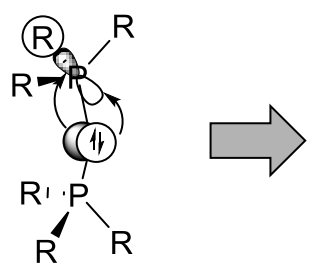

donation $L P(2) C$ to $\sigma^{*} P-R$

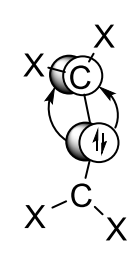

donation

$L P(2) C$ to $2 p_{C}$
Mesomeric forms justifying the belonging to the group of pushpush allenes

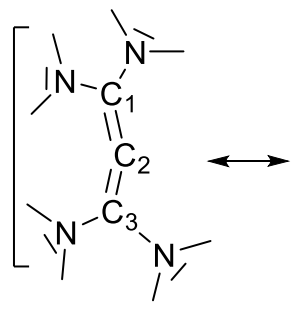

269
Heterolytic cleavage justifying the carbodicarbene denomination
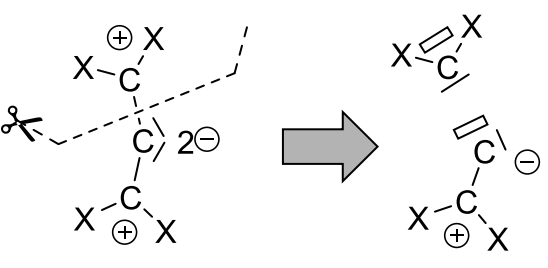

We will limit our scope to isolated molecules for which the $\mathrm{C}=\mathrm{C}=\mathrm{C}$ moiety is not constrained in a cycle, as well as those for which the two adjacent groups have been isolated as stable, neutral Lewis bases. The only exception to this last criteria will be tetrakis(dimethylamino)allene, which has been extensively studied and is presented as being at the frontier between electron-rich allenes and carbodicarbenes. ${ }^{297}$ The reactivity and properties of mixed species with a phosphorane and a carbene moieties are not included in this review, as they have been reviewed recently. ${ }^{443}$

\subsubsection{Synthesis}

Carbodicarbenes are mostly obtained by mono- or double deprotonation of the appropriate precursor, i.e. an allyl cation or a bis-iminium or bis-imidazolium salt, respectively. In 1973 was reported a synthesis of two allenetetramine by Lach et al. ${ }^{444}$ by deprotonation of 1,1,3,3-tetrakis(dimethylamino)allyl and 1,1,3,3-tetrakis(diethylamino)allyl to afford 269-Me and 269-Et, and a 1,3-bis(dimethylamino)-1,3- 
bis(diethoxy)allyl to afford species $\mathbf{5 8 8}$ (Scheme 236). The synthesis of compound 1 was later improved changing the counter anion of the allyl cation to tetrafloroborate and the base to sodium amide. ${ }^{445}$ If the X-ray structure of these species were not determined, the reactivity of the methylated compound (see below) clearly indicates that it should be set in the group of carbodicarbenes. In the case of $\mathbf{3}$, the deprotonation step required the use of sodium amide in liquid ammonia. Compound 269-Me is the only of the three for which an NMR characterization is affordable. ${ }^{445}$ Its ${ }^{13} \mathrm{C}\left\{{ }^{1} \mathrm{H}\right\}$ NMR spectra consist in three signals at $42.1,142.8$, and $157.0 \mathrm{ppm}$.

Scheme 236 : Synthesis of carbodicarbene 1, 2 and related species 3.
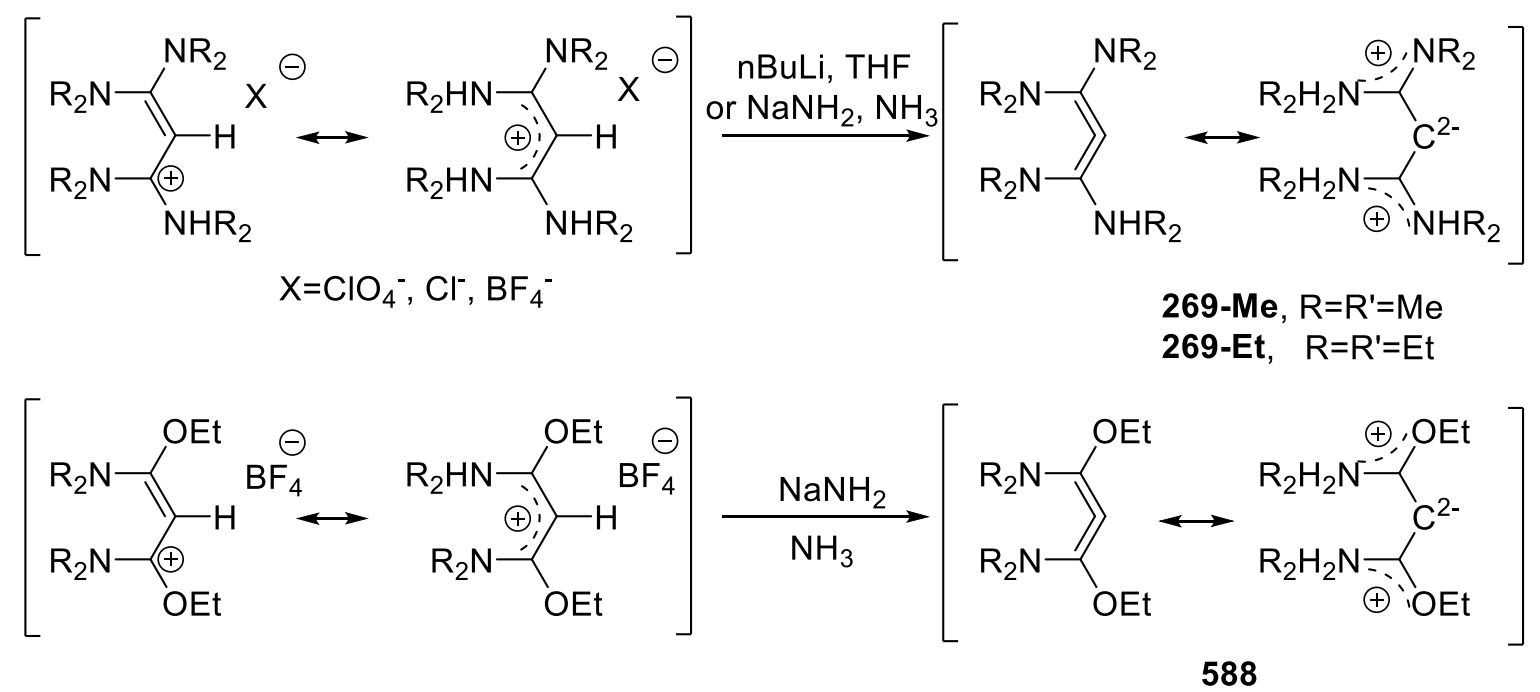

The publication in 2008 of the first example of a carbodicarbene (for which the substituent at carbon were known as stable free carbenes) marked a renewing interest in this field. Carbodicarbene 268-Me was obtained by double deprotonation of the corresponding bis-imidazolium salt using potassium hexamethyldisilazane (Scheme 237). The central $\mathrm{C}=\mathrm{C}=\mathrm{C}$ carbon was seen at $110.2 \mathrm{ppm}$ in ${ }^{13} \mathrm{C}\left\{{ }^{1} \mathrm{H}\right\} \mathrm{NMR}$, whereas the NCN carbons appeared at $144.8 \mathrm{ppm}$. This is to be compared to $142.8 \mathrm{ppm}$ (central carbon) 
and $157.0 \mathrm{ppm}(\mathrm{NCN})$ in $\mathbf{2 6 9}-\mathrm{Me}$, as well as the chemical shift of the central carbon in $\mathrm{H}_{2} \mathrm{CCCH}_{2}$ $(211.4 \mathrm{ppm}) .^{296}$

This species could be crystallized, and showed a relatively small $\mathrm{C}=\mathrm{C}=\mathrm{C}$ bond angle of $134.8(2)^{\circ}$ as well as a twist angle of $69^{\circ}$ between the two planes containing the carbene moieties. These structural parameters support a strong deviation from an allene structure, and thus the presence of two lone pairs at carbon according to the second mesomeric form represented in Scheme N. The (NCN)-C bond distance of 1.343(2) $\AA$ is however in the range of regular $\mathrm{C}=\mathrm{C}$ double bonds and slightly longer than $\mathrm{C}=\mathrm{C}$ allenic bond distances (1.318 $\AA$ in average according to CCDC) (Figure 2).

Scheme 237 : Synthesis of carbodicarbenes 268-R, R=Me,Cy, Py, iPr.<smiles>[Y][n+]1c(Cc2n(C)c3ccccc3[n+]2[R])n(C)c2ccccc21</smiles>

$\mathrm{R}=\mathrm{Me}, \mathrm{Cy}, \mathrm{Py} ; \mathrm{X}=\mathrm{OTf}$ $\mathrm{R}=\mathrm{iPr}, \mathrm{X}=\mathrm{I}$, OTf

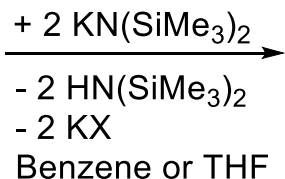

Benzene or THF

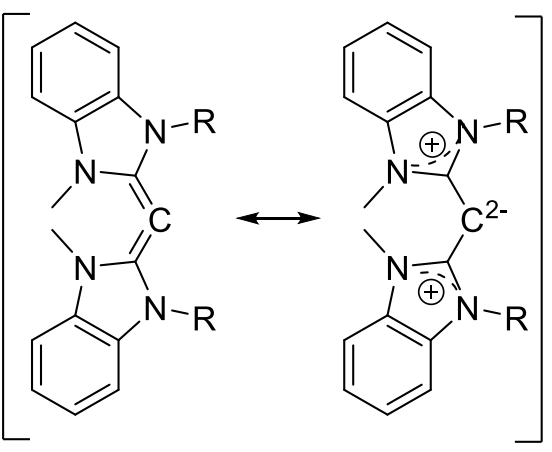

268-R 
Figure 2: $\mathrm{X}$-ray structure of compound 268-Me represented along its $\mathrm{C}_{2}$ axis, and compound 268Py.
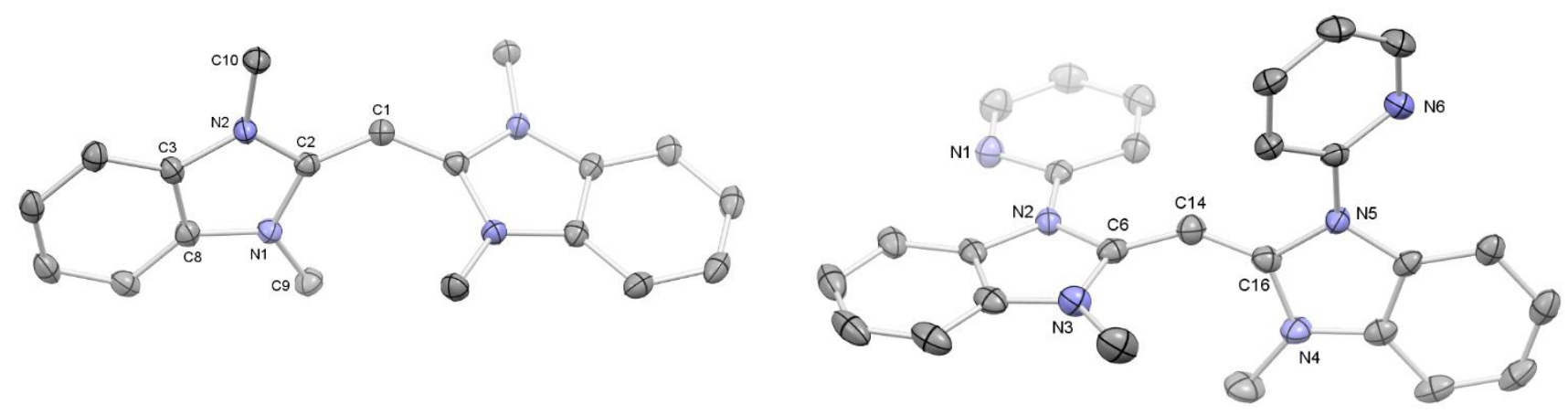

Carbodicarbene 268-Me was later decorated with isopropyl, cyclohexyl ${ }^{446}$ and pyridine ${ }^{447}$ substituents on one nitrogen atom of each imidazolium cycle by Ong et al., affording species 268-iPr, 268-Cy and 268-Py following the same synthetic protocol as for species 268-Me but changing potassium to sodium for the amide counteraction in the case of Py. Available structural parameters are summed up in Table 12 for comparison with 268-Me. If 268-Me and 268-iPr features similar $\mathrm{C}=\mathrm{C}$ bond lengths, $\mathrm{C}=\mathrm{C}=\mathrm{C}$ bond angle, N-C-C-N torsion angles, and ${ }^{13} \mathrm{C}-\mathrm{NMR}$ displacement for the $\mathrm{C}_{2}$ allenic carbon are very similar, the $\mathrm{C}=\mathrm{C}=\mathrm{C}$ bond angle in 268-Py appears to be broader as well as the $\mathrm{N}-\mathrm{C}-\mathrm{C}-\mathrm{N}$ torsion angle, attributed to an increased "allenic character", ${ }^{447}$ i.e. an increase of the double-bond character of $\mathrm{C}_{1}-\mathrm{C}_{2}$ and $\mathrm{C}_{3}-\mathrm{C}_{2}$ interactions. 
Table 12 : Characteristic bond lengts, angle, torsion angle and ${ }^{13} \mathrm{C}$ NMR displacement for species 268R, 589-R and $\mathbf{5 9 0}$.

\begin{tabular}{|l|l|l|l|l|}
\hline Specie & $\mathrm{C}=\mathrm{C}$ bond length $(\AA)$ & $\begin{array}{l}\mathrm{C}=\mathrm{C}=\mathrm{C} \quad \text { bond } \\
\text { angle }\left({ }^{\circ}\right)\end{array}$ & $(\mathrm{N}-\mathrm{C}-\mathrm{C}-\mathrm{N})$ torsion $\left(^{\circ}\right)$ & $\delta\left(\mathrm{C}^{2-}\right)(\mathrm{ppm})$ \\
\hline $\mathbf{2 6 8 - M e}$ & $1.343(2)$ & $134.8(2)$ & 64.3 & 110.2 \\
\hline $\mathbf{2 6 8}-$ iPr & $1.335(5)$ & $136.6(5)$ & 64.9 & 110.0 \\
\hline $\mathbf{2 6 8 - C y}$ & n.a. & n.a. & n.a. & 110.2 \\
\hline $\mathbf{2 6 8 - P y}$ & $1.333(2) / 1.324(2)$ & $143.61(15)$ & 76.5 & Not attributed \\
\hline $\mathbf{5 8 9 - i P r}$ & $1.3455(16) / 1.3401(16)$ & $137.55(12)$ & & Not attributed \\
\hline $\mathbf{5 8 9 - N H C}$ & $1.318(3) / 1.344(3)$ & $146.11(19)$ & & Not attributed \\
\hline $\mathbf{5 9 0}$ & n.a. & n.a. & n.a. & 105.5 \\
\hline
\end{tabular}

Ong et al. also proposed a variety of unsymmetrical carbodicarbene, which were synthesized through a simple $\mathrm{SN}_{2}$ reaction between a variety of nucleophilic, N-heterocyclic olefin and electrophilic 1-3dimethyl-2-(methylthio)benzoimidazolium (scheme 238). ${ }^{448}$

Scheme 238 : Synthesis of carbodicarbenes 589-R, R=Py, $i$ Pr, MeiPr, NHC.<smiles>[R]N1C(=C)N([R])c2ccccc21</smiles><smiles></smiles>

589-Py

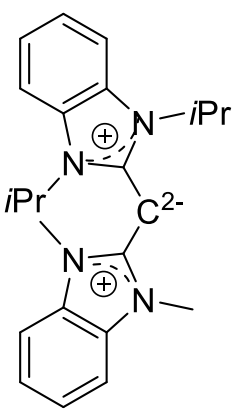

589-iPr<smiles></smiles>

589-MeiPr<smiles></smiles>

589-NHC 
Only compound 589-iPr and 589-NHC were structurally characterized. If the dissymetrization of 589$\boldsymbol{i P r}$ has little impact on the $\mathrm{C}=\mathrm{C}=\mathrm{C}$ structure, replacing a benzoimodazolium moiety by the imidazolium fragment lead to a shortening of the $\mathrm{C}-\mathrm{C}$ bond lengths next to the benzioimodazolium and presumably an increase of the $\mathrm{C}=\mathrm{C}$ double bond character, as alleged by the broad $\mathrm{C}=\mathrm{C}=\mathrm{C}$ angle (see Table 12).

Replacing one of the nitrogen atom of each imidazolium salt by an oxygen atom resulted in a decrease of the stability of the carbodicarbene. ${ }^{49}$ In fact, this change in the structure of the carbenic moieties lead to an increased electrophilicity of terminal carbons $\mathrm{C}_{1}$ and $\mathrm{C}_{3}$, which favored dimerization above $-20^{\circ} \mathrm{C}$. Stepwise methylation of bis(2-benzoxazolyl)methane lead to the formation of 3-methyl-2-[(3-methyl2(3H)-benzoxazolylidene) methyl]-benzoxazolylium triflate, which can be further deprotonated to afford carbodicarbene 590. If its structure could not be confirmed by X-ray diffraction analysis, it was characterized by ${ }^{1} \mathrm{H}$ and ${ }^{13} \mathrm{C}$ NMR spectroscopy at low temperature. In ${ }^{13} \mathrm{C}\left\{{ }^{1} \mathrm{H}\right\} \mathrm{NMR}$, the observation of a quaternary carbon at 105.5 ppm was consistent with the formation of carbodicarbene 590. Its dimer, obtained upon warming above $-20^{\circ} \mathrm{C}$, was structurally characterized by X-ray diffraction (scheme 239).

\section{Scheme 239: Synthesis of carbodicarbenes 590 and subsequent dimerization.}

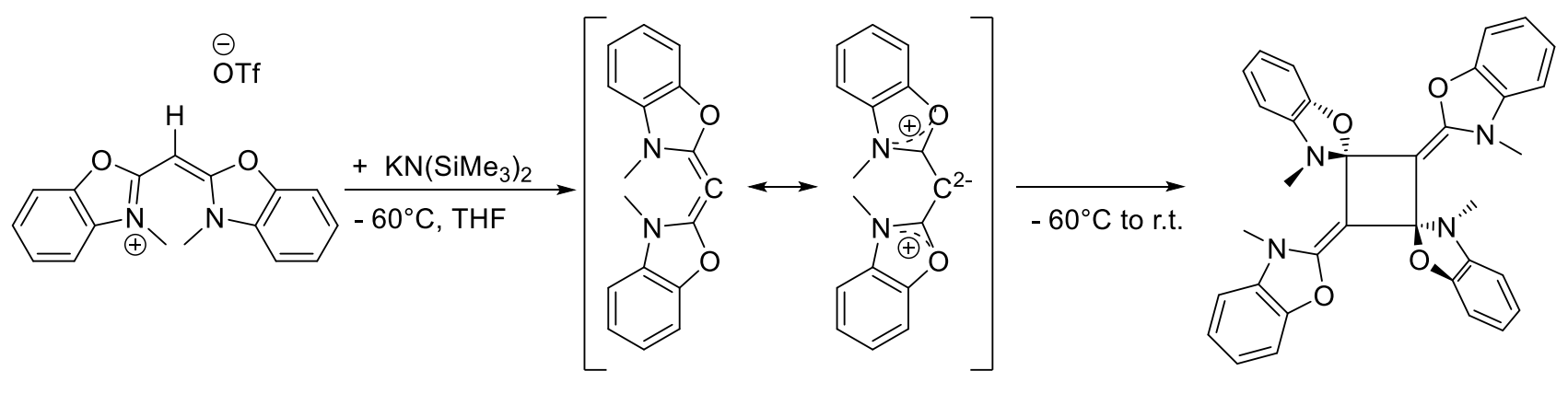

\subsubsection{Reactivity}


The reactivity of 1,1,3,3-tetrakis(dimethylamino)allen $\mathbf{2 6 9 - M e}$ and 1,3-bis(dimethylamino)-1,3bis(diethoxy)-allen $\mathbf{5 8 8}$ toward organic electrophiles was extensively explored as early as in 1973. In agreement with the presence of a strong charge density at $\mathrm{C}_{2}$, and in agreement with the reactivity of other electron-rich allenes which remains out of the scope of this review, ${ }^{450}$ compounds $269-\mathrm{Me}$ and 588 undergo a variety of electrophilic additions with strong $\left(\mathrm{CO}_{2}, \mathrm{CS}_{2}\right.$, phenylcyanate, $\left.\mathrm{SO}_{2}\right)$ or weak (elemental sulfur) electrophiles (scheme 240). ${ }^{444}$ Their reactivity toward electron-deficient allenes was also probed (carbodiimide, diazomaloester, tosylazide), affording dipoles that were presented as intermediates of polar cycloaddition of allenes. One-electron reduction by silver salts lead to dimerization. ${ }^{451}$

Scheme 240 : Reactivity of tetraaminoaallene 269-Me with various electrophiles.

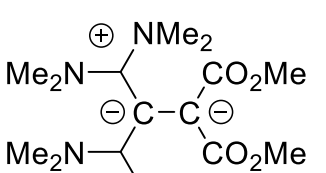

$\oplus \mathrm{NMe}_{2}$

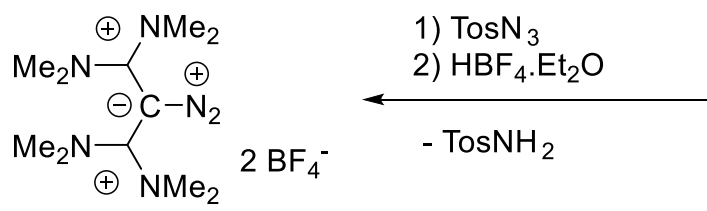

$\mathrm{Me}_{2} \mathrm{~N}$

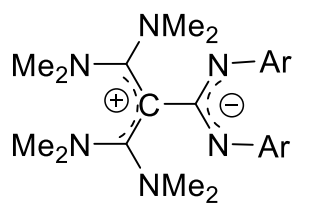

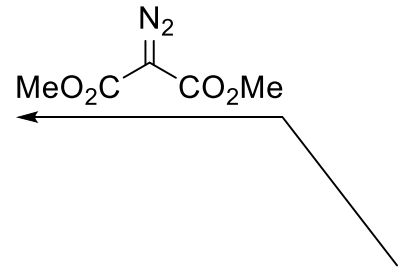
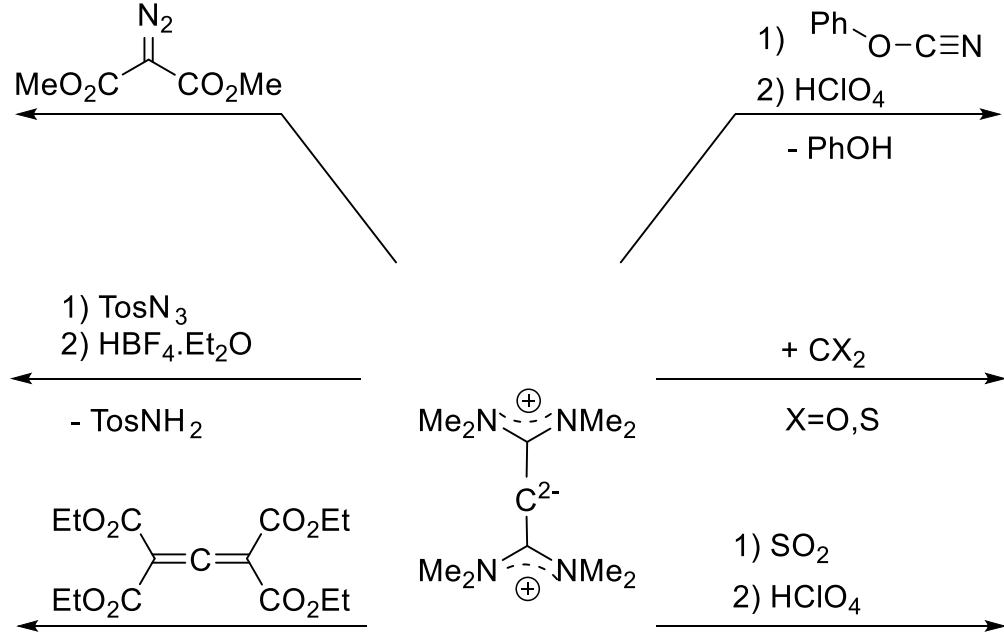

269-Me
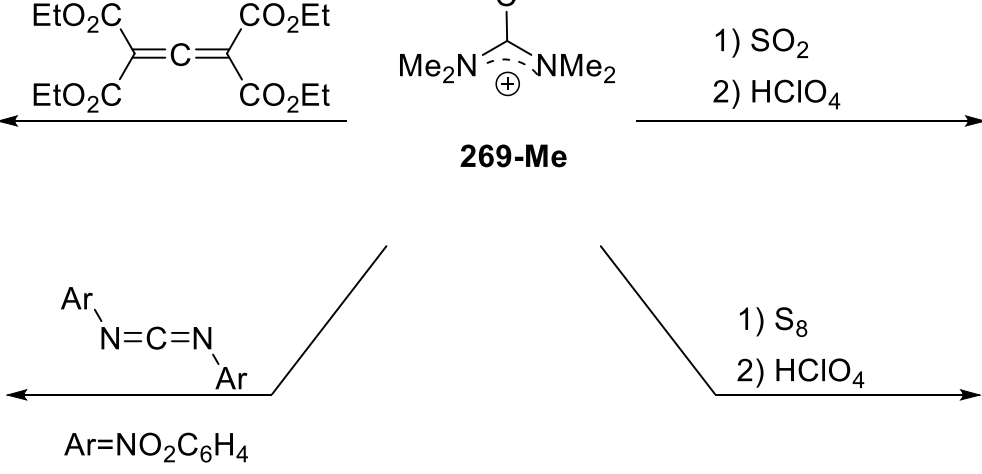
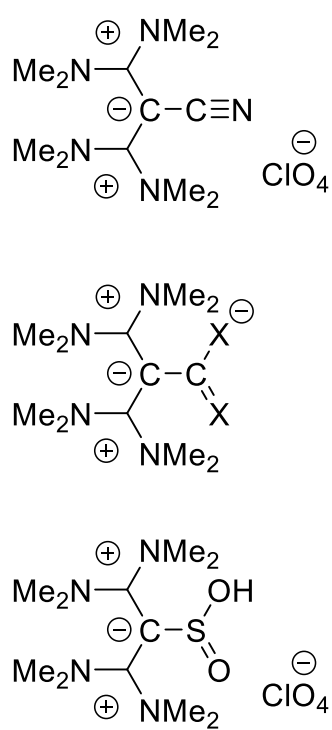

1) $S_{8}$

2) $\mathrm{HClO}_{4}$

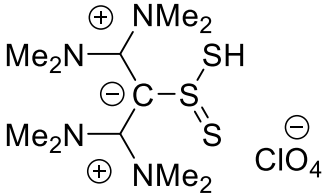

The interest for more recent, non cyclic carbodicarbene being centered on their electronic structure and coordination ability, their reactivity toward organic molecules is still in its infancy. 
Addition of methyliodide to 268-iPr lead to methylation of the central carbon, in agreement with the strong electronic density expected for a carbodicarbene. The presence of a second lone pair (or residual electronic density at $\mathrm{C}_{2}$ ) was highlighted by the addition of a strong base, which lead to deprotonation of one of the imidazolium methyl and subsequent cyclisation by nucleophilic addition to the terminal carbon of the "allenic" moiety, and leaved the $\mathrm{CH}_{3}-\mathrm{C}_{2}$ unchanged.

Scheme 241 : Electrophilic addition of iodomethane on carbodicarbenes 268-iPr.

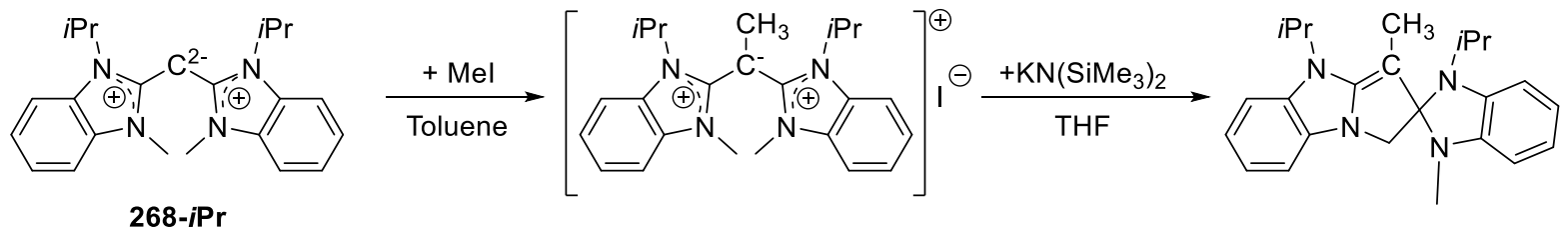

Addition of methyliodide to 268-iPr lead to methylation of the central carbon, in agreement with the strong electronic density expected for a carbodicarbene (scheme 241). The presence of a second lone pair (or residual electronic density at $\mathrm{C}_{2}$ ) was highlighted by the addition of a strong base, which lead to deprotonation of one of the imidazolium methyl and subsequent cyclisation by nucleophilic addition to the terminal carbon of the "allenic" moiety, and leaved the $\mathrm{CH}_{3}-\mathrm{C}_{2}$ unchanged.

Addition of trimethylsilylchloride to compound $\mathbf{5 9 0}$ resulted in the silylation of central carbon $\mathrm{C} 2$, as a proof of its strong nucleophilic character (scheme 242).

Scheme 242 : Electrophilic addition of trimethylsilyl chloride on carbodicarbenes 590.

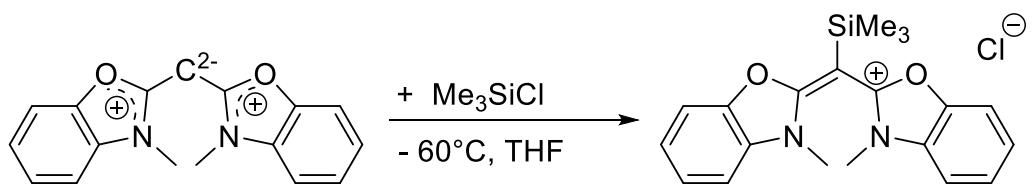

590

\subsubsection{Coordination chemistry}




\subsubsection{Group 2}

Beryllium-carbodicarbene adducts ${ }^{452}$ were obtained by adding beryllium dichloride diethylether adduct to a solution of carbodicarbene $\mathbf{2 6 8 - i P r}$ in benzene to afford $\left[\mathrm{Be}(\mathbf{2 6 8}-\mathbf{i P r}) \mathrm{Cl}_{2}\right]$ and $[\mathrm{Be}(\mathbf{2 6 8}-$ iPr $\left.\left\{\mathrm{N}\left(\mathrm{SiMe}_{3}\right)_{2}\right\} \mathrm{Cl}\right]$ after subsequent salt metathesis with $\left[\mathrm{KN}\left(\mathrm{SiMe}_{3}\right)_{2}\right]$ (scheme 243).

Scheme 243 : Coordination of carbodicarbenes 269-iPr to beryllium dichloride and subsequent ligand exchange at beryllium.
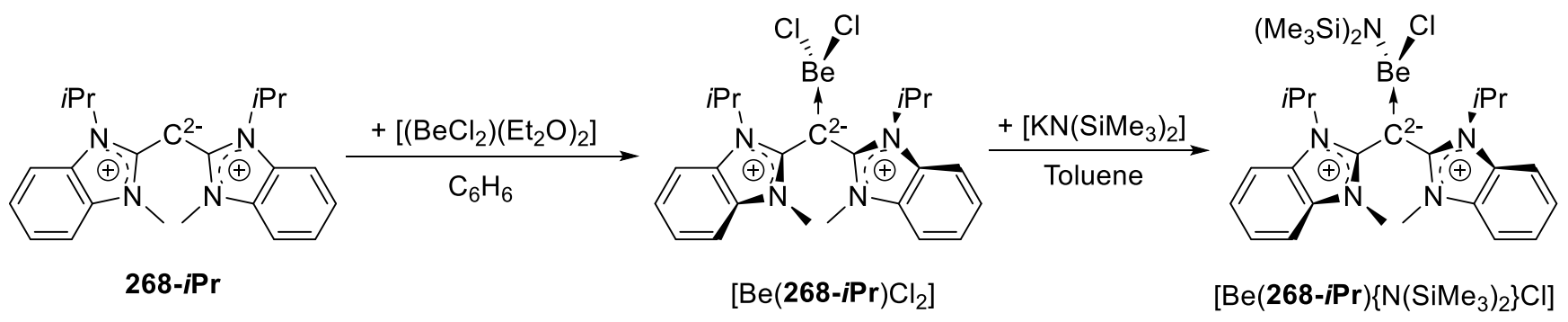

Structural parameters obtained from X-ray diffraction study are comparable to those obtained with the related carbodiphosphorane-beryllium adduct, and suggest a strong donation from the carbon to the beryllium (elongated $\mathrm{C}-\mathrm{C}$ and $\mathrm{Be}-\mathrm{Cl}$ bonds, short $\mathrm{C}-\mathrm{Be}$ bond length). The $\mathrm{CCBeCl}$ torsion angle of $46.07(18)^{\circ}$ excludes any $\pi$-donation from $\mathrm{C}$ to Be. The dative nature of the carbon-beryllium interaction in both complexes was confirmed by DFT calculations, showing low Wiberg bond indexes of 0.200 and 0.196 respectively for C-Be bonds. A strong residual density of $\pi$ symmetry with no overlap with beryllium is also seen in the Kohn-Sham HOMO orbital, confirming the absence of any $\pi$ donation. 


\section{Scheme 244 : Formation of a beryllium heterocycle.}

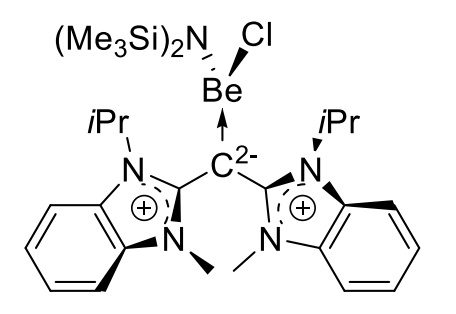

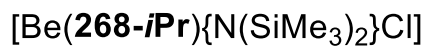

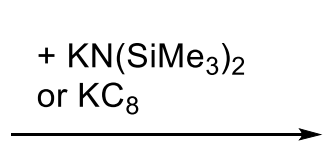

Upon addition of an additional equivalent of either potassium hexamethyldisilazane or potassium graphite to $\left[\mathrm{Be}(\mathbf{2 6 8}-\mathrm{iPr})\left\{\mathrm{N}\left(\mathrm{SiMe}_{3}\right)_{2}\right\} \mathrm{Cl}\right]$, deprotonation of the $\mathrm{N}$-methyl group occurs, leading to the formation of a beryllium metallacycle (scheme 244$)$. If the two $\mathrm{C}-\mathrm{Be}$ bond lengths in $\left[\mathrm{Be}\left(\kappa^{2}-\mathrm{C}, \mathrm{C}-\mathbf{2 6 8}-\right.\right.$ iPr $\left.)\left\{\mathrm{N}\left(\mathrm{SiMe}_{3}\right)_{2}\right\} \mathrm{Cl}\right]$ are quite similar $(1.790(5) \AA$ and $1.796(5) \AA)$, their Wiberg bond indexes are different ( 0.184 vs 0.254$)$, pointing to an increased covalent character for the $\mathrm{CH}_{2}$-Be bond in contrast to the dative carbon-Be one. The fact that better yield are obtained with the potassium graphite route suggest a radical process, and the possibility of $\mathrm{Be}^{\mathrm{I}}$ and $\mathrm{BeH}$ intermediates.

\subsubsection{Group 8}

Carbodicarbene 268-Py was quite recently shown to be able to stabilize iron in various oxidation states. $^{453}$ Complex $\left[\mathrm{Fe}(\mathbf{2 6 8}-\mathbf{P y})_{2}\right]^{2+}$, obtained by addition of freshly synthesized ligand 268-Py to $\left[\mathrm{Fe}\left(\mathrm{CH}_{3} \mathrm{CN}\right)_{2}(\mathrm{OTf})_{2}\right]$, was subsequently oxidized to $\left[\mathrm{Fe}(\mathbf{2 6 8}-\mathbf{P y})_{2}\right]^{3+}$ by addition of one equivalent of silver salts, and then to $\left[\mathrm{Fe}(\mathbf{2 6 8 - P y})_{2}\right]^{4+}$ and $\left[\mathrm{Fe}(\mathbf{2 6 8 - P y})_{2}\right]^{5+}$ by sequential addition of two equivalents of Tris(2,4-dibromophenyl)ammoniumyl hexachloroantimonate (scheme 245). A better purity for [Fe(268$\left.\mathbf{P y})_{2}\right]^{4+}$ and $\left[\mathrm{Fe}(\mathbf{2 6 8}-\mathbf{P y})_{2}\right]^{5+}$ was obtained by bulk electrolysis in the presence of $\mathrm{NOBF}_{4}$. 

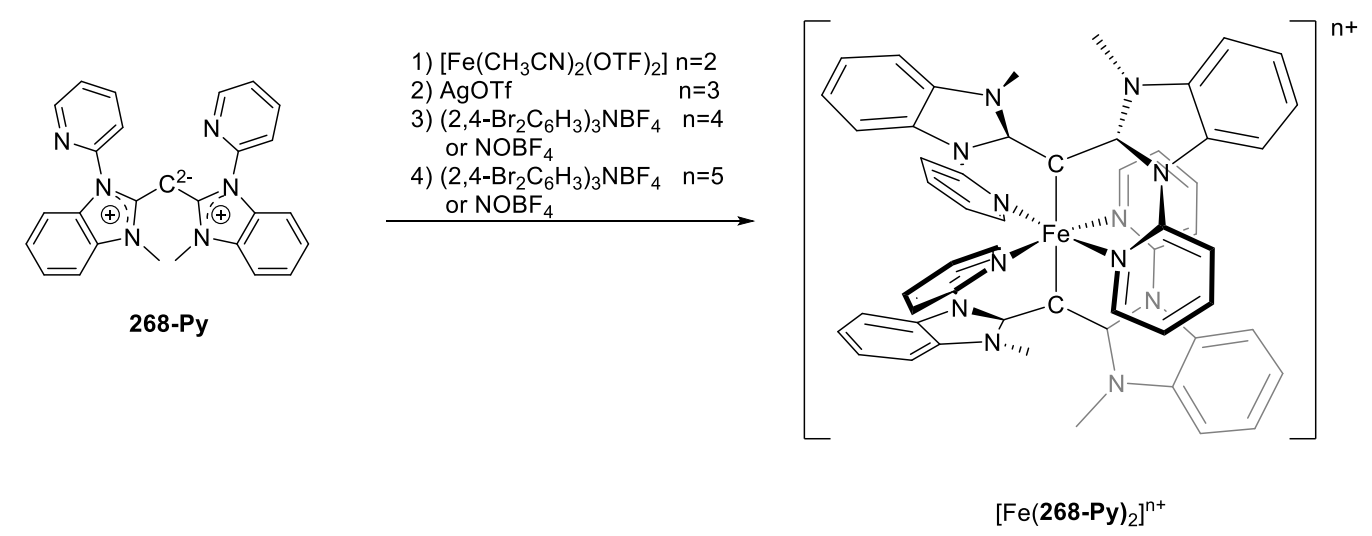

Apart from complex $\left[\mathrm{Fe}(\mathbf{2 6 8 - P y})_{2}\right]^{5+}$ which is not stable, all of them could be crystallized and are isostructural. X-ray structures showed two $\mathrm{sp}^{2}$-hybridized carbon in trans position one to the other, ideally arranged for a double $\pi$-donor interaction toward a same $\mathrm{d}$ orbital of the iron. The three of them showed a low-spin configuration. According to NMR spectroscopy, $\left[\mathrm{Fe}(\mathbf{2 6 8 - P y})_{2}\right]^{2+}$ is close to a spin crossover domain and thus not fully diamagnetic. More interestingly, the redox potential of the $[\mathrm{Fe}(\mathbf{2 6 8 -}$ $\left.\mathbf{P y})_{2}\right]^{4+} /\left[\mathrm{Fe}(\mathbf{2 6 8}-\mathbf{P y})_{2}\right]^{3+}$ couple $\left(0.27 \mathrm{~V}\right.$ vs $\left.\mathrm{Fc}^{+} / \mathrm{Fc}\right)$ is quite close to this of the 268-Py/268-Py ${ }^{+\bullet}$ couple $\left(0.16 \mathrm{~V}\right.$ vs $\left.\mathrm{Fc}^{+} / \mathrm{Fc}\right)$. The UV-vis spectrum of $\left[\mathrm{Fe}(\mathbf{2 6 8}-\mathbf{P y})_{2}\right]^{4+}$ showed a ligand-to-ligand intravalence charge transfer band at $1500 \mathrm{~nm}$, characteristic of a radical ligand and thus an iron center in its + III oxidation state. However, its ${ }^{1} \mathrm{H}$ NMR spectra is well resolved and in the range of diamagnetic, $\mathrm{S}=0$ complexes. This is compatible with a low spin iron (IV) center but also with a strong antiferromagnetic coupling between a radical ligand and an iron (III) center. Complex $\left[\mathrm{Fe}(\mathbf{2 6 8 - P y})_{2}\right]^{5+}$ was characterized by EPR spectroscopy. Its spectrum is characteristic of a ligand-centered unpaired spin, with a persistence of the EPR signal in solution at room temperature. Mössbauer spectroscopy showed little change from $\left[\mathrm{Fe}(\mathbf{2 6 8 - P y})_{2}\right]^{4+}$ to $\left[\mathrm{Fe}(\mathbf{2 6 8 - P y})_{2}\right]^{5+}$ with isomer shifts of $0.16 \mathrm{~mm} . \mathrm{s}^{-1}$ characteristic of low-spin iron (III). DFT calculations showed a high degree of C-Fe covalency in the frontier orbitals of a closed shell mod338 
el of $\left[\mathrm{Fe}(\mathbf{2 6 8}-\mathrm{Py})_{2}\right]^{4+}$ and allowed for the localization of an energetically close open-shell singlet featuring a strong antiferromagnetic coupling between an iron (III) center and a ligand-centered radical. Upon the strong geometrical constraint imposed by the ligand, the iron-centered oxidation lead to the homolysis of the C-Fe bond to afford a complex best described as $\left[\mathrm{Fe}^{3+}(\mathbf{2 6 8}-\mathbf{P y})(\mathbf{2 6 8}-\mathbf{P y})^{+\bullet}\right]$. Calculations performed on the complex $\left[\mathrm{Fe}(\mathbf{2 6 8}-\mathbf{P y})_{2}\right]^{5+}$ are consistent with an iron (III) center and two radical cations as ligands.

\subsubsection{Group 9}

Scheme 246 : Synthesis of carbodicarbene complexes of rhodium and iridium.<smiles></smiles>

268-Me

268-iPr

268-Cy

589-Py

589-NHC

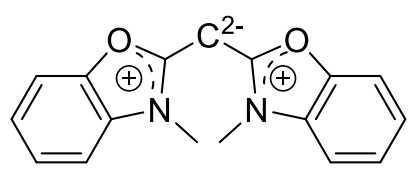

590

$$
\stackrel{+1 / 2\left[\left\{\mathrm{Rh}(\mathrm{CO})_{2} \mathrm{Cl}\right\}_{2}\right]}{\longrightarrow}
$$

Benzene

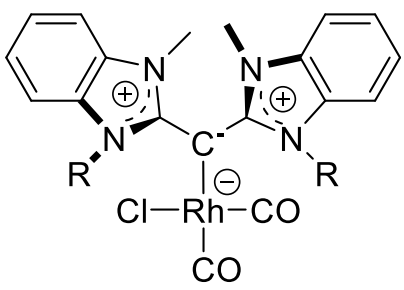

$\left[\mathrm{Rh}(\mathbf{N}-\mathbf{R})(\mathrm{CO})_{2} \mathrm{Cl}\right]$

$\mathrm{N}=268,589$

$\mathrm{R}=\mathrm{Me}, \mathrm{Pr}, \mathrm{Cy}, \mathrm{Py}, \mathrm{NHC}$

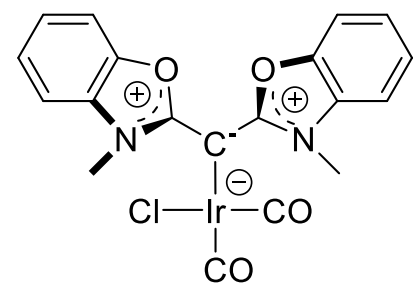

$$
\left[\operatorname{lr}(590)(\mathrm{CO})_{2} \mathrm{Cl}\right]
$$

Rhodium carbonyl complexes bearing carbodicarbene 268-Me, ${ }^{304}$ 268-iPr, 268-Cy, ${ }^{446}$ 589-Py and 589$\mathbf{N H C}^{448}$ as a ligand were obtained upon reaction with half a equivalent of $\left[\mathrm{Rh}(\mathrm{CO})_{2} \mathrm{Cl}\right]_{2}$ in benzene (scheme 246). The average CO stretching frequency of $2014 \mathrm{~cm}^{-1}$ for 268-Me, and the CO stretching frequencies of 2052 and $1976 \mathrm{~cm}^{-1}, 2051$ and $1975 \mathrm{~cm}^{-1}$ for 268-iPr and 268-Cy respectively, highlight 
the strong $\sigma$-donor character of ligand 268-Me, as well as a its poor $\pi$-accepting character, in agreement with the localization of a second lone pair at carbon. The $\mathrm{CO}$ bond frequencies are lowered down to 2045 and $1964 \mathrm{~cm}^{-1}$ with 589-NHC, highlighting its enhanced electron-donor character. Steric bulkiness of 589-Py and 589-NHC was hold for responsible of the $\mathrm{Rh}-\mathrm{C}_{\mathrm{CDC}}$ bond lengths increase from $[\mathrm{Rh}(\mathbf{2 6 8}-$ $\left.\mathbf{M e})(\mathrm{CO})_{3} \mathrm{Cl}\right](2.089(7) \AA)$ to $\left[\mathrm{Rh}(\mathbf{5 8 9}-\mathbf{R})(\mathrm{CO})_{3} \mathrm{Cl}\right](2.117(2) \AA$ and $2.116(2) \AA)$. Similarly, an iridium carbonyl complex featuring carbodicarbene $\mathbf{5 9 0}$ was obtained by adding iridium cyclooctadiene chloride dimer to a solution of $\mathbf{5 9 0}$ in $\mathrm{THF}$ at $-40^{\circ} \mathrm{C}$ and subsequent bubbling of $\mathrm{CO}$. If the X-ray structure of the resulting complex was not resolved, its IR spectra showed an CO bond stretching frequency of $2009 \mathrm{~cm}^{-}$ 1, situating ligand 590 between carbodicarbene of kind 268-R and NHCs in terms of $\sigma$ donation ability.

\subsubsection{Group 10}


Scheme 247 : Synthesis of carbodicarbenes palladium complexes.<smiles></smiles>

268-iPr

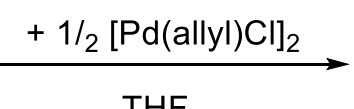

THF<smiles></smiles>

$\left[\mathrm{Pd}(268-\mathrm{Pr})\left(\mathrm{C}_{3} \mathrm{H}_{5}\right) \mathrm{Cl}\right]$

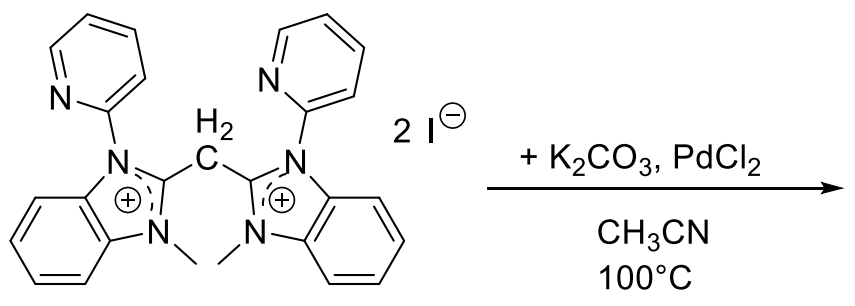

268-Py<smiles></smiles>

589-iPr

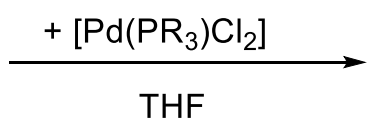

$\mathrm{R}=\mathrm{Ph}, p-\mathrm{Tol}$

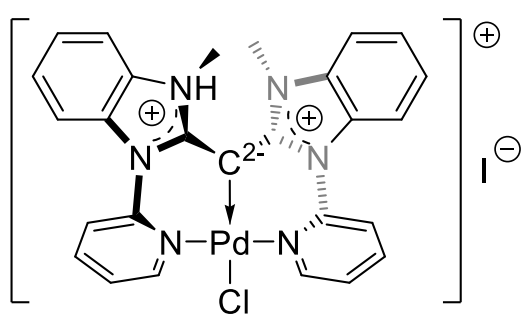

$[\mathrm{Pd}(268-\mathrm{Py}) \mathrm{Cl}]^{+}$<smiles></smiles>

$\left[\mathrm{Pd}(589-i \mathrm{Pr})\left(\mathrm{PR}_{3}\right) \mathrm{Cl}_{2}\right]$<smiles></smiles>

589-iPr

$\underset{+\left[\mathrm{Pd}\left(\mathrm{PCy}_{3}\right) \mathrm{Cl}_{2}\right]}{\longrightarrow}$ THF<smiles></smiles>

$\left[\mathrm{Pd}(589-i \mathrm{Pr})\left(\mathrm{PCy}_{3}\right) \mathrm{Cl}_{2}\right]$

Upon addition of palladium allyl chloride dimer, a palladium allyl chloride complex featuring 268-iPr as a neutral ligand was obtained (scheme 247). A strong trans-influence on the $\mathrm{Pd}-\mathrm{C}_{\text {allyl }}$ trans to the carbodicarbene was seen as an evidence of the strong $\sigma$-donor character of ligand 268-iPr. ${ }^{446}$ A palladium complex featuring carbodicarbene 268-Py was obtained by in situ deprotonation of the corresponding 
bisimidazolium salt in the presence of palladium salt. ${ }^{447}$ The palladium atom is coordinated in a $\mathrm{k}^{3}$ fashion by the tridentate ligand, the two pyridine groups of the carbodicarbene acting as two additional Ltype ligands. If the palladium is in an almost perfect square-planar environment, the carbodicarbene is distorded, each imidazolium ring being mostly localized upper or under the palladium coordination plane. According to the strong $\sigma$-donor property of the carbodicarbene, a clear trans-influence is observed with a long Pd-Cl bond distance of 2.4090(8) $\AA$ as measured by X-ray diffraction. The short CPd bond distance of 1.973(3) $\AA$ was attributed to a tight pincer effect. This complex was used as a catalyst for Mizoroki-Heck and Suzuki-Miyaura cross-coupling reactions, with relatively broad scopes in both cases. Using molten tetrabutylammonium bromide as a solvent and sodium acetate with $0.5 \% \mathrm{~mol}$ of complex $[\mathrm{Pd}(\mathbf{2 6 8}-\mathrm{Py}) \mathrm{Cl}]^{+}$, variously substituted bromo- and chloroaryls could be coupled with styrene or acrylates in good yield ( $90 \%$ to $99 \%$ for styrene, $78 \%$ to $94 \%$ for acrylates) and relatively good selectivity (from $75 \%$ to $95 \%$ yield) for the 1,2-substituted alkene. In Suzuki-Miyaura cross-coupling, $3.5 \%$ mol are required, using $\mathrm{K}_{3} \mathrm{PO}_{4}$ as a base and $2.65 \% \mathrm{~mol}$ of 3 -chloropyridine as an additive to perform the cross-coupling of arylboronic acids and bromoaryl in low to excellent yield (17\% for mesitylboronic acid and p-acetophenylbromide, and 99\% for phenylboronic acid and p-cyanophenylbromide, respectively). 
<smiles>[R1]c1cccc(Br)c1</smiles><smiles>[R]C=C</smiles>
$\mathrm{R}_{2}=\mathrm{Ph}, \mathrm{CO}_{2} \mathrm{C}_{4} \mathrm{H}_{9}$<smiles>[R]c1cccc([X])c1</smiles>

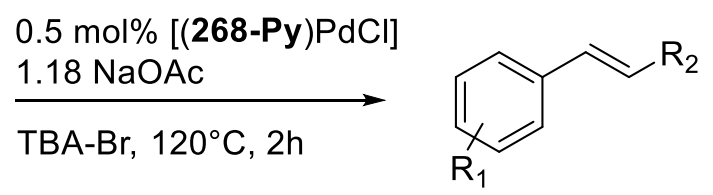

$\mathrm{R}_{2}=\mathrm{Ph}, 90 \%$ to $99 \%$

$\mathrm{R}_{2}=\mathrm{CO}_{2} \mathrm{C}_{4} \mathrm{H}_{9}, 78 \%$ to $94 \%$
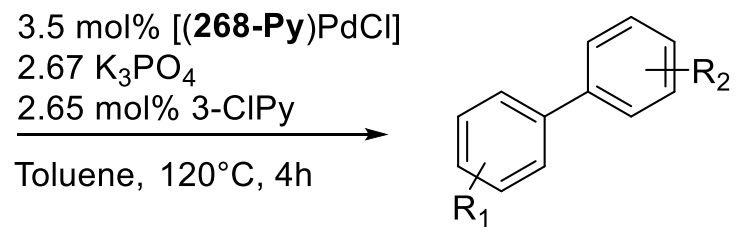

Suzuki-Miyaura cross coupling was also performed using complexes $\left[\mathrm{Pd}(\mathbf{5 8 9}-i \mathrm{Pr})\left(\mathrm{PR}_{3}\right) \mathrm{Cl}_{2}\right](\mathrm{R}=\mathrm{Ph}, p$ Tol) (scheme 248). ${ }^{454}$ These two complexes were readily synthesized by addition of carbodicarbene 589-iPr to the corresponding palladium triarylphosphine dichloride complex. X-ray diffraction analysis showed an unusual trans arrangement, which could be explained by intramolecular $\pi-\pi$ stacking between one aromatic ring of the phosphine and the benzimidazole ring of ligand $\mathbf{5 8 9 - i P r}$, with centroidcentroid distances of $3.25 \AA(\mathrm{R}=\mathrm{Ph})$ and $3.30 \AA\left(\mathrm{R}=p\right.$-Tol). Variable temperature ${ }^{1} \mathrm{H}$ NMR spectroscopy supports the existence of this "invisible bridging linkage" even in solution, with the absence of cis/trans isomerization upon heating and the resolution of broad signals in the aromatic range upon cooling. Replacing $\mathrm{PR}_{3}$ by $\mathrm{PCy}_{3}$ to preclude any intramolecular $\pi$ - $\pi$ stacking lead to the trans isomer of $\left[\mathrm{Pd}(\mathbf{5 8 9}-i \mathrm{Pr})\left(\mathrm{PCy}_{3}\right) \mathrm{Cl}_{2}\right]$, as expected considering the steric hindrance of both the phosphine and the carbodicarbene ligands and in the absence of any possible $\pi-\pi$ stacking. A difference in activity between $c i s$ complexes $\left[\mathrm{Pd}(\mathbf{5 8 9}-i \mathrm{Pr})\left(\mathrm{PR}_{3}\right) \mathrm{Cl}_{2}\right],(\mathrm{R}=\mathrm{Ph}, p$-Tol $)$ and trans complex $\left[\mathrm{Pd}(\mathbf{5 8 9 - i} \mathrm{Pr})\left(\mathrm{PCy}_{3}\right) \mathrm{Cl}_{2}\right]$ in SuzukiMiyaura cross-coupling was observed, the best results being obtained with $\mathrm{PPh}_{3}$ as phosphine ligand. 343 
The coupling reaction was particularly efficient for sterically hindered substrates, which was attributed to further $\pi-\pi$ stacking interactions along the catalytic cycle.

$[\operatorname{Pd}(\mathbf{2 6 8}-\mathbf{P y})($ acetate $)]$ was used in various cross-coupling/photoredox tandem catalysis processes,${ }^{455}$ in a very innovative way since the palladium complex itself promotes both the $2 \mathrm{e}^{-}-$based coupling processes and the $1 \mathrm{e}^{-}$photoredox activation of a substrate. This last process, quite unusual for $\operatorname{Pd}(\mathrm{II})$ complexes, is promoted by the strong $\sigma$-donor capacity of the carbodicarbene ligand which destabilizes the lowlying $\mathrm{d}$-d states and thus reduce the relaxation by thermal processes, as well as its chelating character which allows for the stabilization of the excited sate. The proof of concept of the photoredox relevance of complex $[\mathrm{Pd}(\mathbf{2 6 8}-\mathrm{Py})($ acetate) $)]$ was given by its use as a catalyst for the photomediated oxidative C$\mathrm{N}$ coupling of aldehydes and primary amine. It was shown that the complex $[\mathrm{Pd}(\mathbf{2 6 8 - P y})($ acetate)$)]$ promotes the generation of hydrogen peroxide from $\mathrm{O}_{2}$ and one equivalent of sacrificial amine. The in situ generated hydrogen peroxide is then able to oxidize the $\alpha$-aminoalcool generated by nucleophilic addition of the amine on the aldehyde into an amide (Scheme 249, a). The photoredox activity of complex $[\operatorname{Pd}(\mathbf{2 6 8 - P y})($ acetate) $)]$ being established, it was used as a catalyst for the generation of aryl radicals from aryl diazonium tetrafluoroborate salts (Scheme 249, b). The generated radical is then included in a $\operatorname{Pd}(\mathrm{II}) / \mathrm{Pd}(\mathrm{III}) / \mathrm{Pd}(\mathrm{IV})$ cycle, $\mathrm{Pd}(\mathrm{III})$ being formed by the addition of the radical and Pd(IV) by oxidation of the [Pd(III) (268-Py)] species generated during the photocatalytic cycle. Finally, a stepwise, one-pot reaction was probed, combining a Suzuki-Miyaura reaction with the oxidative C-N coupling presented above (Scheme 249, c). 
Scheme 249 : Use of complex $[\mathrm{Pd}(4-\mathrm{Py})($ acetate)] as a photoredox catalyst in various transformations.

a) Photomediated C-N coupling reaction

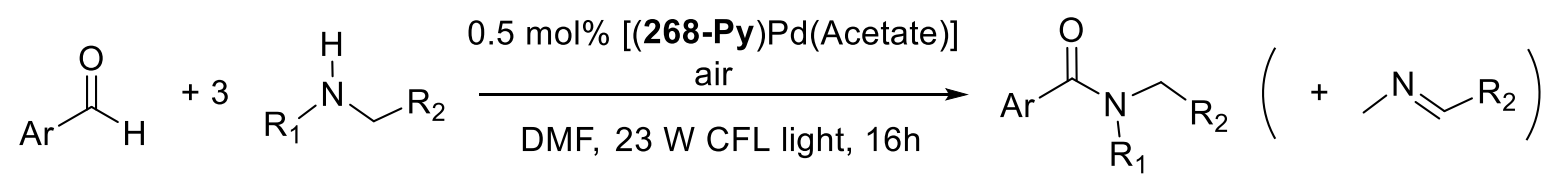

b) Photomediated $\mathrm{Ar}-\mathrm{N}_{2}$ dissociation and $\mathrm{Pd}(\mathrm{II}) / \mathrm{Pd}(\mathrm{IV})$-based $\mathrm{C}-\mathrm{C}$ coupling reaction

6

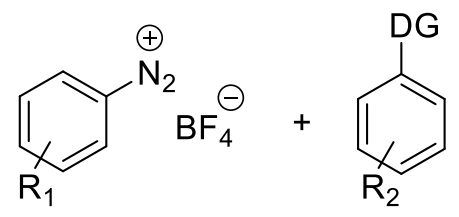
5-10 mol\% [(268-Py)Pd(Acetate)]<smiles>COCCCC(C(=O)OCc1ccccc1)C(=O)OCc1ccccc1</smiles>

DMF, 23 W CFL light, $6 \mathrm{~h}$ DG: directing group<smiles>[R]c1ccccc1-c1ccccc1</smiles>

c) Sequential one-pot Suzuki-Miyaura cross-coupling and photomediated C-N coupling reaction

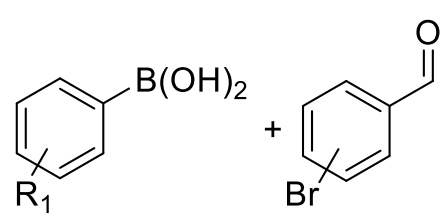

1) $2.5-5 \mathrm{~mol} \%$ [(268-Py $) \mathrm{Pd}($ Acetate $)]$ $2 \mathrm{~K}_{2} \mathrm{CO}_{3}$ DMF, $120^{\circ} \mathrm{C}, 5 \mathrm{~h}$

2) $\mathrm{R}_{2} \mathrm{NHCH}_{2} \mathrm{R}_{3}$, +1 mol\% [(268-Py)Pd(Acetate)] DMF, 23 W CFL light, 6h<smiles>[R]CN([R2])C(=O)c1ccc(-c2ccc([R])cc2)cc1</smiles>

\subsubsection{Group 11}

Scheme 250 : Coordination of tetraaminoallene 269 to gold.

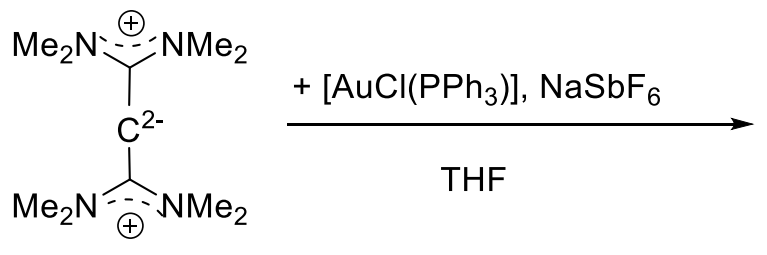

269<smiles>C[C@H](c1ccccc1)C([C@H](C)N(C)C)[C@H](C)N(C)C</smiles>

$\left[\mathrm{Au}(\mathbf{2 6 9})\left(\mathrm{PPh}_{3}\right)\right]$

Coordination of compound 269 to gold was performed as late as in 2008 (scheme 250). ${ }^{456}$ Addition of one equivalent of triphenylphosphine gold chloride to a solution of tetraaminoallene $\mathbf{2 6 9}$ in the presence of $\mathrm{NaSbF}_{6}$ as chloride scavenger afforded complex $\left[\mathrm{Au}(\mathbf{2 6 9})\left(\mathrm{PPh}_{3}\right)\right]$ in good yield (72\%). X-ray diffrac345 
tion study showed a planar structure at $\mathrm{C}$ in the solid phase with a $\mathrm{C}-\mathrm{C}-\mathrm{C}$ bond angle of $118.5^{\circ}$, suggesting the remaining of a $\mathrm{sp}^{2}$ lone pair at $\mathrm{C}$, and the coordination of the gold atom to the in-plane carboncentered lone pair. The possibility of the coordination of a second gold atom at $\mathrm{C}$ or any double metalation was discussed in a later article, stating that this was incompatible with the strong $\pi$-accepting ability of the adjacent carbon atoms. ${ }^{302}$

\subsubsection{Reactivity with main group elements}

\subsubsection{Group 13}

When reacted with two equivalents of $\mathrm{BH}_{3}$.THF adduct, carbodicarbene 268-iPr lead to the formation of a carbodicarbene-stabilized hydrido boron dication ${ }^{457}\left\{\left[(\mathbf{2 6 8}-\mathbf{i P r})_{2} \mathrm{BH}\right]^{2+}\left[\mathrm{BH}_{4}{ }^{-}\right]_{2}\right\}$ after abstraction of two hydrides from the boron by the excess of borane present in solution to generate $\mathrm{BH}_{4}{ }^{-}$(scheme 251). The environment around boron is trigonal planar as determined by X-ray diffraction. B-C bond lengths

are quite short (1.534(7) $\AA$ and 1.523(7) $\AA$ ) compared to NHC-supported borenium cations for which BC bond lengths reach $1.58 \AA$ A. A DFT study confirmed a $\pi$ donation from carbon to boron, and thus partial $\pi$-bond character for the C-B bond as shown by NBO analysis. Charge delocalization occurs through each allenic system. In the presence of $\mathrm{AlCl}_{3}$, compound 268-iPr leads to the formation of a carbodicarbene-aluminum adduct which could be structurally characterized. C-C bond lengths of the allenic moieties are elongated from $1.335 \AA$ in 268-iPr to $1.453(3)$ and $1.374(4) \AA$ in $\left[(\mathbf{2 6 8}-\mathbf{i P r}) \mathrm{AlCl}_{3}\right]$, suggesting a reduction of the bond order by donation toward the aluminum atom, thus reducing the occupancy of $\pi$ bonding C-C orbitals. 


\section{Scheme 251 : Reactivity of carbodicarbenes 268-iPr toward borane and trichloroaluminum.}

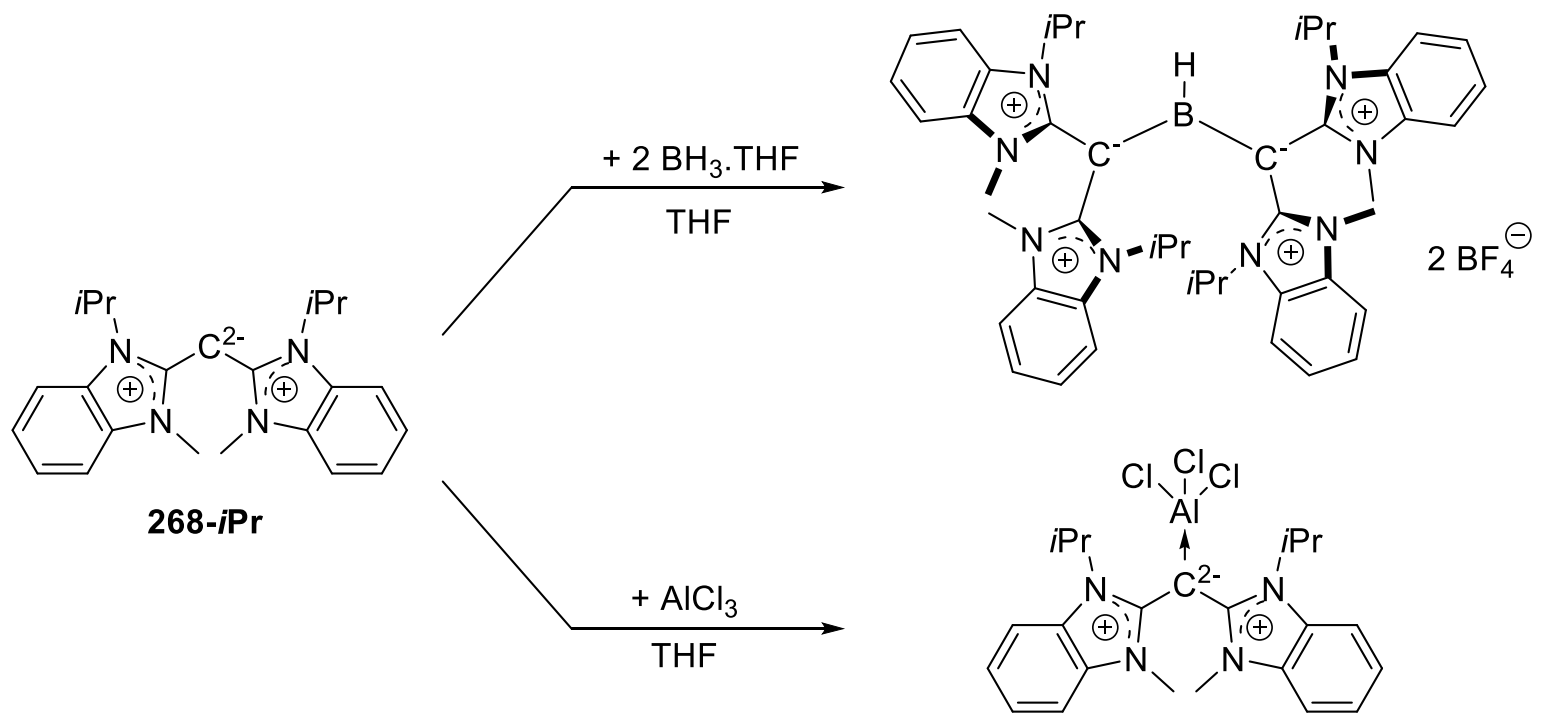

9- $\mathrm{BBN}$ was found to perform a regioselective 1,2 addition on the $\mathrm{C}=\mathrm{C}$ bond adjacent to the benzoimidazolium moiety (scheme 252). ${ }^{448}$ The resulting organoboron species proved to be a catalyst for the methylation of secondary amines using $\mathrm{CO}_{2}$ and 9-BBN. In this process, the benzoimidazolium carbon seems to behave as a hydrogen-transfer site, in cooperation with the central C-B moiety. In a more straightforward procedure, this same reaction can be performed starting from 589-NHC, compound 591 being presumably formed in situ. Using this protocol, a wide range of primary and secondary amine could be methylated with moderate $\left(\mathrm{R}=\mathrm{p}-\mathrm{Tol}, \mathrm{R}^{\prime}=\mathrm{Me}, 37 \%\right)$ to excellent (tetramethylpiperidine, 97\%) yields. Carbodicarbene 268-iPr, 589-iPr, and 589-MeiPr were also used as (pre)-catalysts in this process, but showed lower activities. 
Scheme 252 : Reaction of carbodicarbenes 589-NHC with 9-BBN and activity of the resulting product as catalyst for the reductive coupling of $\mathrm{CO}_{2}$ and amines.

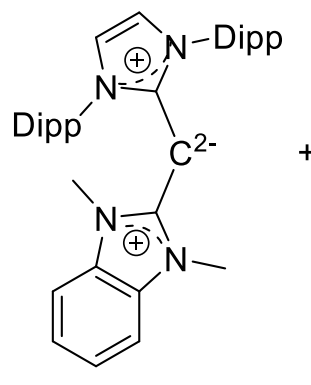

589-NHC

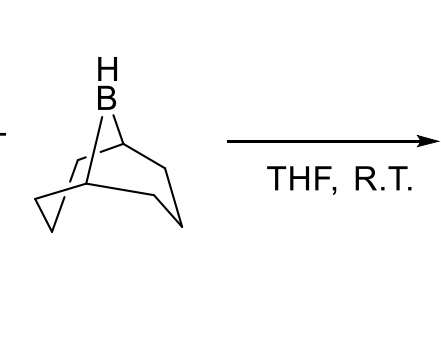

$\mathrm{Ph}^{-\stackrel{\mathrm{N}_{1}}{\mathrm{H}}{ }_{-\mathrm{Ph}}}+\mathrm{CO}_{2}$

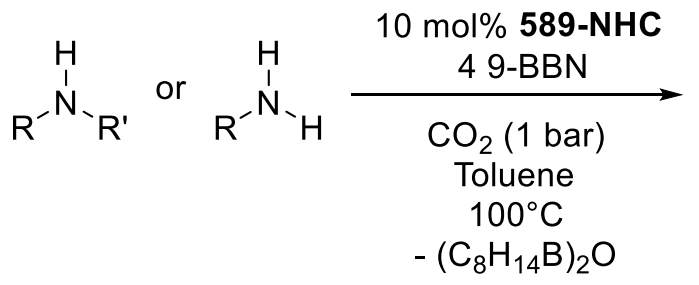<smiles>CN1c2ccccc2N(C)C1/C(B1C2CCCC1CC2)=C1\c2ccccc2N1[Pb]</smiles>

591<smiles>CN(c1ccccc1)c1ccccc1</smiles><smiles>[R]N([R])N(C)C</smiles>

This first example of the use of a carbodicarbene in organocatalysis highlights the relative stability of such species, as well as the possible regeneration of catalytically competent intermediates via facile cleavage of C-H and C-B bonds of enhanced polarity.

\section{Conclusion}

In conclusion, the chemistry of isolable geminal dianions of type I (two neutral substituents at the C center, charge compensation by two group 1 metals) has gained momentum since the independent synthesis by Cavell et al. and Stephan et al. of the bis-iminophosphorane derivative 6aLi2. Indeed, they 
could show for the first time that such species could be obtained in very satisfactory yield under stoichiometric conditions. Compared to earlier examples of type I geminal dianions, this species possesses two strongly electron accepting phosphorus substituents which allow the desired efficient stabilization of the two charges at the same $\mathrm{C}$ atom, as well as a very convenient NMR probe $\left({ }^{31} \mathrm{P}\right)$ which allows a careful following of the reactions involving these highly sensitive species. These two features were the key to the development of several examples of geminal dianions in which both electronics and sterics could be tuned. The chemistry of type III geminal dianions (two cationic substituents at the C center, with an intramolecular charge compensation), with the most emblematic representatives being carbodiphosphoranes, has been extensively studied since the seminal report of Ramirez in 1961, mostly in organic chemistry. A renewed interest in these species has been seen since 2006, when the electronic structure of the $\mathrm{R}_{3} \mathrm{P}=\mathrm{C}=\mathrm{PR}_{3}$ was reinvestigated by calculations, followed by the development of carbodicarbene derivatives. By comparison, the chemistry of stable yldiides, i.e. geminal dianions of type II, has suffered from a slower development. Its recent renewal benefited from the impetus given by the development of geminal dianions of type I. The generation of yldiides fragments in the coordination sphere of metals had been intensively developed before the isolation of structurally characterized specimens.

In these three types of geminal dianions, the presence of the two lone pairs at $\mathrm{C}$ provides several opportunities. Firstly, successive and selective reactivity can be expected toward electrophiles. If this reactivity has been seldom studied with isolated type I geminal dianions, it was extensively probed with type III and II. In the latter two cases, because phosphonium is present in many stable derivatives, a Wittig reaction is often considered as one of the two successive bond-forming processes. Secondly, they can be used in coordination chemistry, in order to either generate species featuring a $\mathrm{M}=\mathrm{C}$ double bond interaction (at least formally) or to bind two metals (homo bimetallic or heterobimetallic) in a bridging manner. 
In this matter, the overwhelming number of examples has been obtained with geminal dianions of type I, and among them the vast majority belongs to the first class. In fact, one of their main uses was devoted to the chemistry of carbene complexes of early transition metals, lanthanides and actinides. Indeed, these species would provide the four electrons required for the formal double $\mathrm{M}=\mathrm{C}$ interaction, as shown in scheme 253 (left).

Scheme 253 : Evolution of the $\mathrm{C}=\mathrm{M}$ bonding scheme in dianion-based carbene complexes along the periodic table.

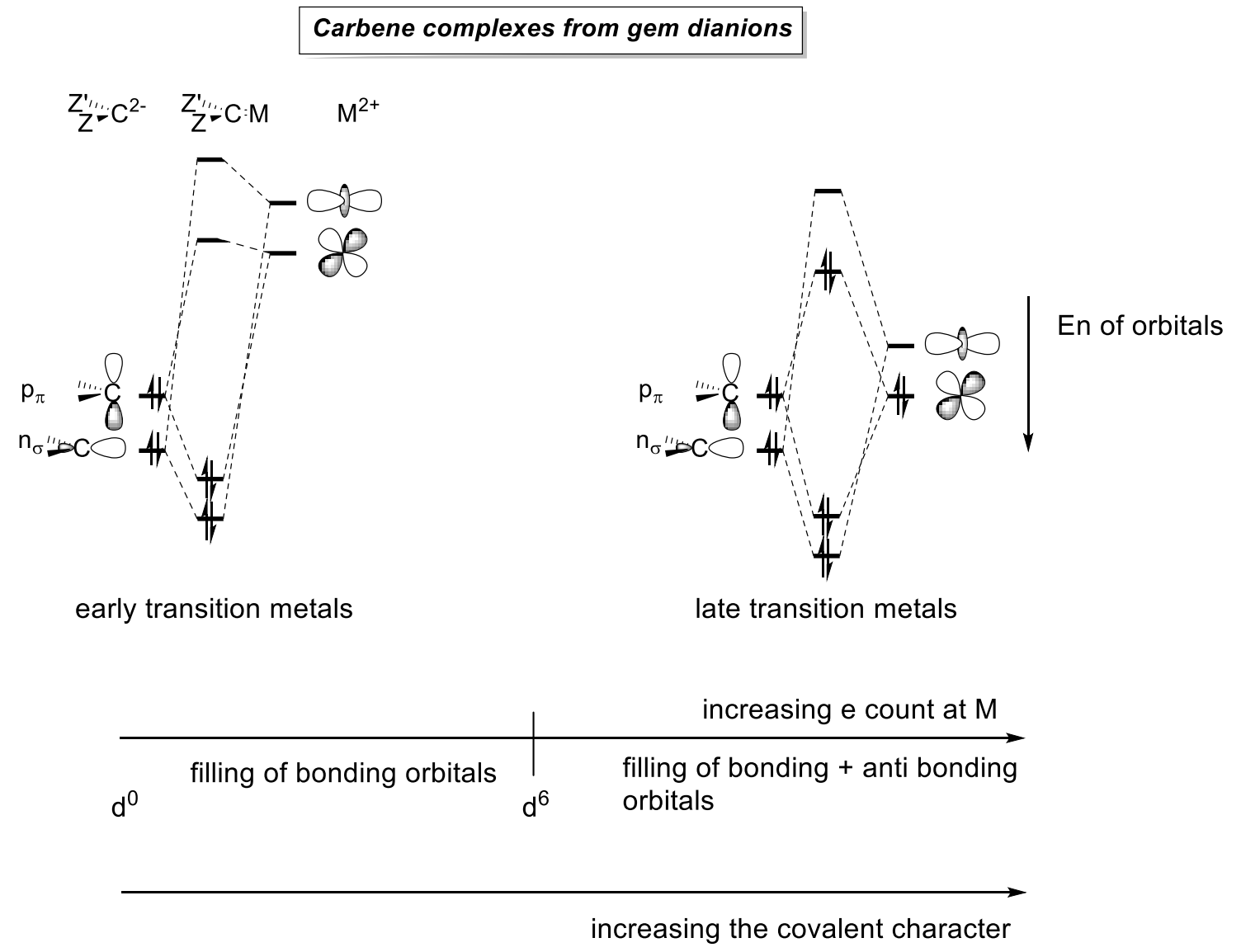

Once the syntheses of these complexes had been realized, the nature of the $\mathrm{M}=\mathrm{C}$ bond was studied and the $\pi$ interaction was shown to be mainly ionic, with a covalent strongly polarized character (high nega350 
tive charge at $\mathrm{C}$ ), as expected from the large difference in electronegativities of $\mathrm{C}$ and $\mathrm{M}$. This rationalizes nicely the marked nucleophilic character generally observed for these complexes. For these metals, the chemistry of geminal dianions of type I and II possesses strong resemblances. It is important to realize that a competition will always occur between stabilization of the two lone pairs by the substituents at $\mathrm{C}$ and donation to the metal center. The resulting balance will guide the subsequent reactivity of the formal $\mathrm{M}=\mathrm{C}$ bond.

Scheme 254 : Competing processes for the stabilization of the charge at carbon in complexes of type I and type II geminal dianions.

$\pi$ lone pair interactions
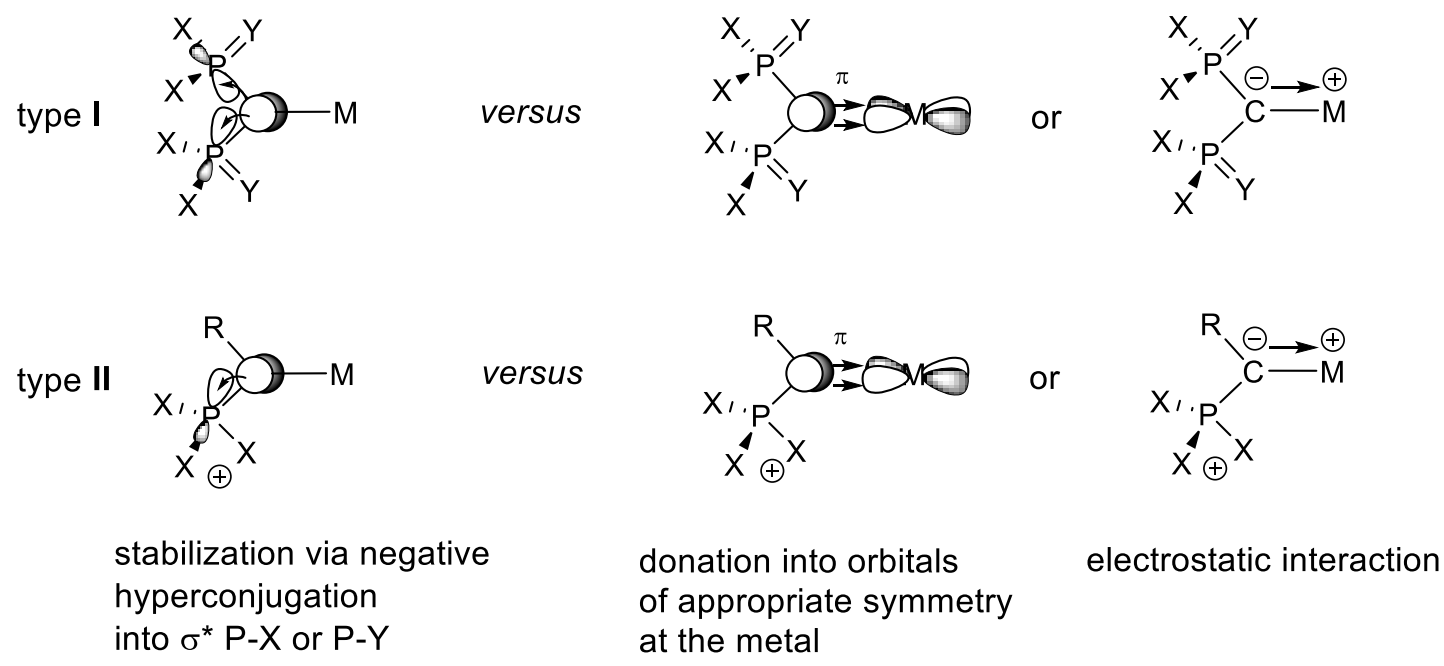

Moving toward the right of the periodic table, the metals become more electronegative and the energies of the orbitals drop which increases the covalent character in the bonding. Conversely, the nucleophilic character typically decreases (Scheme 253, right). When the electron count at the metal is higher than six, the $\pi^{*}$ orbital of the $\mathrm{M}=\mathrm{C}$ interaction has to be filled, which then result in an increase of the nucleophilic character. 
It is interesting to note that although stable examples of type III geminal dianions had been known long time before, their coordination chemistry was very little developed, and mostly toward metal centers favoring double sigma donation. The close relationship between type I and III, in terms of stabilization and bonding situation implying multiple bond character, has lately been evidenced with examples of main group (B) as well as uranium. We believe that many more examples of coordination of type III geminal dianions involving $\mathrm{M}=\mathrm{C}$ bond should be discovered in the near future.

So far, rare examples of complexes featuring these geminal dianions have been used as catalysts. Cavell showed in 2002 that a bimetallic Al complex with bridging ligand $\mathbf{6 a}$ is an efficient catalyst for ethylene polymerization. ${ }^{151}$ In 2004, Piers reported that the ruthenium complex 124 (scheme 122) and related ones showed remarkable catalytic activity in ring-closing olefin metathesis at room temperature. They feature type II dianions. ${ }^{242}$ Concerning the use of dianions of type III in organometallic catalysis, Kato, Peris and Baceiredo proved the unique electronic properties of the cyclic CDP $228 \mathbf{b} v s$ NHC ligands that enabled to enhance the catalytic activity of $[(\mathbf{2 2 8 b}) \mathrm{M}(\mathrm{O} t \mathrm{Bu})]$ species $(\mathrm{M}=\mathrm{Au}$ and $\mathrm{Cu})$ in hydrofunctionalization reactions of acrylonitrile, ${ }^{410}$ whereas Gandon demonstrated the beneficial effect of CDP 130 in gold catalysis. ${ }^{409}$ The development of the photochemistry of related carbodicarbenes complexes of palladium in 2018 by Ong, ${ }^{455}$ and the demonstration of the ability of carbodicarbenes to behave as redox-active ligands by Ye and England the same year open a promising field in the domain. To date, these behaviors have not been extended to heteroatom-based bisylides, which we believe to be an interesting perspective for the use of type I-III geminal dianions.

The strongly polarized $\mathrm{M}=\mathrm{C} \pi$ interaction found in most complexes bears analogy with ligands acting as "non-innocent", such as the $\mathrm{M}=\mathrm{N} \pi$ interaction used by Noyori for the catalyzed hydrogenation of polar bonds. Gessner was the first to report in 2015 a similar catalysis using a Ru complex fea352 
turing ligand 11 (mixed $\mathrm{PS} / \mathrm{SO}_{2} \mathrm{Ph}$ ). ${ }^{130}$ In this case, the reactivity between the $\mathrm{Ru}=\mathrm{C}$ and $\mathrm{iPrOH}$ allowed the formal 1,2 addition of $\mathrm{H}_{2}$ across the $\mathrm{Ru}=\mathrm{C}$ bond. In 2016, Mézailles reported a second example of non-innocence behavior for $\mathrm{M}=\mathrm{C}$ in catalysis. ${ }^{152}$ In this case, the $\mathrm{B}=\mathrm{C}$ formal double bond reacts with $\mathrm{BH}_{3}$ in an ambiphilic manner to generate a catalytically active species for the $\mathrm{CO}_{2}$ reduction by $\mathrm{BH}_{3}$.

Scheme 255 : Type I and II geminal dianions as cooperative ligand for the hydrofunctionalization of unsaturated molecules.
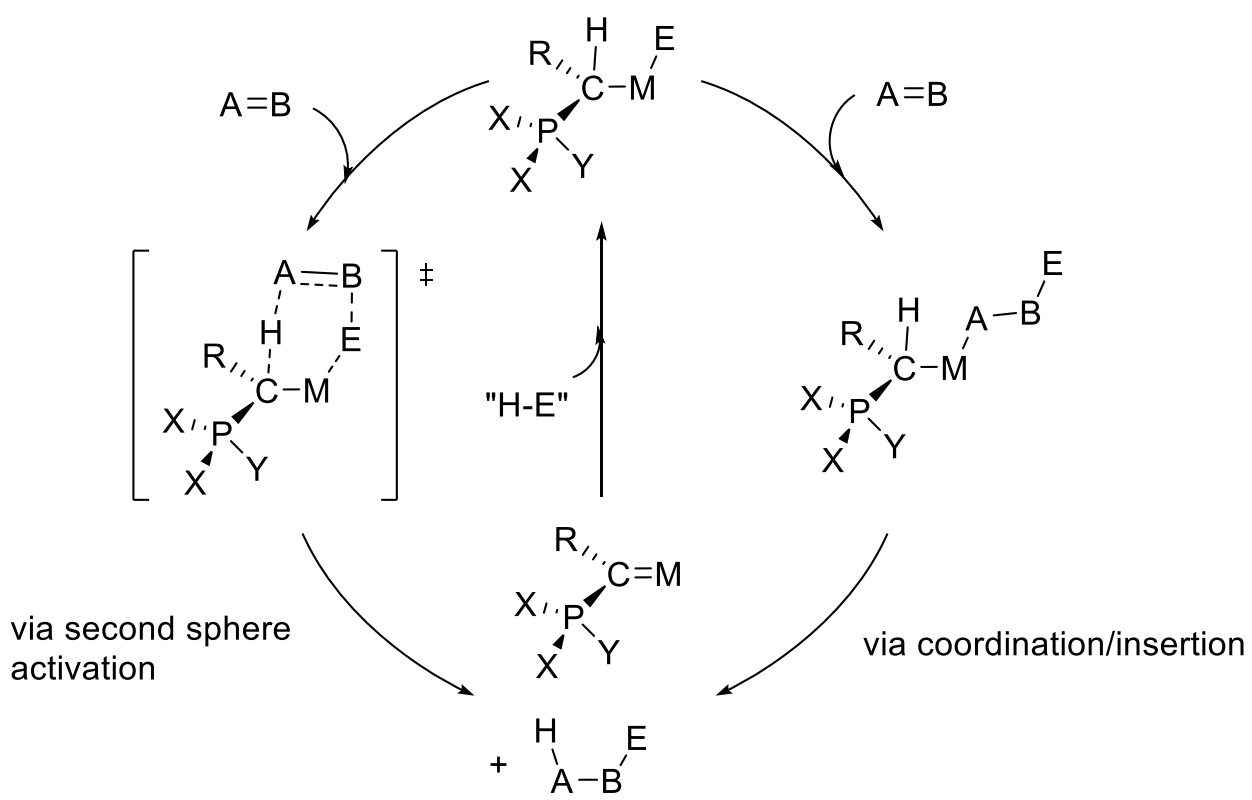

As shown in this review, the nature of the $\mathrm{M}=\mathrm{C} \pi$ interaction can be tuned to a large extent by the nature of the substituents at C, and the analogy between type I and II geminal dianions does provide more flexibility in this matter. We thus believe that many more examples of cooperative catalysis using geminal dianions should be developed in the future. In particular, addition of $\mathrm{H}-\mathrm{E}$ on less/non polar $\mathrm{A}=\mathrm{B}$ molecules should be a viable and rewarding target (scheme 255). 


\section{Acknowledgements}

The authors thank the CNRS and the Université de Toulouse (Université Paul Sabatier) for funding.

Note: the authors declare "no competing financial interest".

\section{References}

(1) Wittig, G.; Harborth, G. Über Das Verhalten Nichtaromatischer Halogenide Und Äther Gegenüber Phenyl-Lithium. Ber. Dtsch. Chem. Ges. 1944, 77, 306-314.

(2) West, R.; Rochow, E. G. Reactions of Dibromoalkanes with Lithium Metal. J. Org. Chem. 1953, $18,1739-1742$.

(3) Ziegler, K.; Nagel, K.; Patheiger, M. Metallorganische Verbindungen. XX. Lithium- Und Magnesium-Methylen. Z. Anorg. Allg. Chemie 1955, 282, 345-351.

(4) van Eikema Hommes, N. J. R.; Bickelhaupt, F.; Klumpp, G. W. Bis Trimethylsilyldilithiomethane. Tetrahedron Lett. 1988, 29, 5237-5240.

(5) Vollhardt, J.; Gais, H.-J.; Lukas, K. L. Dilithio(Phenylsulfonyl)Trimethylsilylmethane : Synthesis, I3C/ 'H-NMR Characterization, and Lithium-Titanium Exchange. Angew. Chem. Int. Ed. 1985, 24, 696-697.

(6) Gais, H. J.; Vollhardt, J.; Günther, H.; Moskau, D.; Lindner, H. J.; Braun, S. Solid-State and Solution Structure of Dilithium Trimethyl((Phenylsulfonyl)Methyl)Silane, a True Dilithiomethane Derivative. J. Am. Chem. Soc. 1988, 110, 978-980.

(7) Marek, I.; Normant, J.-F. Synthesis and Reactivity of $\mathrm{sp}^{3}$-Geminated Organodimetallics. Chem. Rev. 1996, 96, 3241-3268.

(8) Langer, P.; Freiberg, W. Cyclization Reactions of Dianions in Organic Synthesis. Chem. Rev. 2004, 104, 4125-4149.

(9) Vollhardt, J.; Gais, H.-J.; Lukas, K. L.; Jurgen, B.; Gais, V. H.; Lukas, K. L. 1,1- and 1,oDilithioallyl Phenyl Sulfone: Synthesis, Geminal Cycloalkylation, and Lithium-Titanium Exchange. Angew. Chem. Int. Ed. Engl. 1985, 24, 610-611.

(10) Crowley, P. J.; Leach, M. R.; Meth-Cohn, O.; J Wakefield, B. Do the Compounds $\mathrm{PhCH}_{2} \mathrm{Y} \mathrm{Give}$ Geminal Dianions on Addition of Two Equivalents of Strong Base ? Tetrahedron Lett. 1986, 27, 2909-2912.

(11) Zarges, W.; Marsch, M.; Harms, K.; Boche, G. X-Ray Structure Analysis of Lithiophenylacetonitrile Lithium Diisopropyl Amide 2-Tetramethylethylenediamine. A ”Quasi-Dianion Complex" Angew. Chem. Int. Ed. Engl. 1989, 28, 1392-1394. 
(12) Zarges, W.; Marsch, M.; Harms, K.; Boche, G. $\quad\left[\left\{\mathrm{Li}_{2}\left(\mathrm{Me}_{3} \mathrm{SiCCN}\right)\right\}_{12}\left(\mathrm{Et}_{2} \mathrm{O}\right)_{6}\left(\mathrm{C}_{6} \mathrm{H}_{14}\right)\right]$, Kristallstruktur Mit Dem Trimethylsilylacetonitril-Dianion. Chem. Ber. 1989, 122, 1307-1311.

(13) Corset, J.; Castellà-Ventura, M.; Froment, F.; Strzalko, T.; Wartski, L. Study of the Lithiated Phenylacetonitrile Monoanions and Dianions Formed According to the Lithiated Base Used (LHMDS, LDA, or n-BuLi). 1. Evidence of Heterodimer ("Quadac") or Dianion Formation by Vibrational Spectroscopy. J. Org. Chem. 2003, 68, 3902-3911.

(14) Strzalko, T.; Wartski, L.; Corset, J.; Castellà-Ventura, M.; Froment, F. Study of the Lithiated Phenylacetonitrile Monoanions and Dianions Formed According to the Lithiated Base Used (LHMDS, LDA, or n-BuLi). 2. Alkylation and Deuteriation Mechanism Study by Vibrational and NMR Spectroscopy and Quantum Chemistry Calculations. J. Org. Chem. 2012, 77, 6431-6442.

(15) Müller, J.; Neuburger, M.; Spingler, B. X-Ray Structure of a Heterochiral, SulfoximineStabilized Dilithiomethane Derivative. Angew. Chem. Int. Ed. 1999, 38, 3549-3552.

(16) Müller, J. F. K.; Neuburger, M.; Spingler, B. Structural Investigation of a Dilithiated Phosphonate in the Solid State. Angew. Chem. Int. Ed. 1999, 38, 92-94.

(17) Ong, C. M.; Stephan, D. W. Lithiations of Bis-Diphenyl-NTrimethylsilylphosphiniminomethane: An X- Ray Structure of a 1,1-Dilithiomethane Derivative. J. Am. Chem. Soc. 1999, 121, 2939-2940.

(18) Kasani, A.; Kamalesh Babu, R. P.; McDonald, R.; Cavell, R. G. $\left[\mathrm{Ph}_{2} \mathrm{P}\left(\mathrm{NSiMe}_{3}\right)\right]_{2} \mathrm{CLi}_{2}$ : A Dilithium Dianionic Methanide Salt with an Unusual Li4C2 Cluster Structure. Angew. Chem. Int. Ed. 1999, 38, 1483-1484.

(19) Henderson, K. W.; Kennedy, A. R.; MacDougall, D. J.; Shanks, D. Solid-State and Theoretical Model Structures of Monolithiated (Organosulfonyl)Acetonitriles and the Characterization and Reactivity of Their Geminated Dilithio Derivatives. Organometallics 2002, 21, 606-616.

(20) Cantat, T.; Mézailles, N.; Ricard, L.; Jean, Y.; Le Floch, P. A Bis(Thiophosphinoyl)Methanediide Palladium Complex: Coordinated Dianion or Nucleophilic Carbene Complex? Angew. Chem. Int. Ed. Engl. 2004, 43, 6382-6385.

(21) Cantat, T.; Ricard, L.; Le Floch, P.; Mézailles, N. Phosphorus-Stabilized Geminal Dianions. Organometallics 2006, 25, 4965-4976.

(22) Demange, M.; Boubekeur, L.; Auffrant, A.; Mézailles, N.; Ricard, L.; Le Goff, X.; Le Floch, P. A New and Convenient Approach towards Bis(Iminophosphoranyl)Methane Ligands and Their Dicationic, Cationic, Anionic and Dianionic Derivatives. New J. Chem. 2006, 30, 1745-1754.

(23) Cooper, O. J.; McMaster, J.; Lewis, W.; Blake, A. J.; Liddle, S. T. Synthesis and Structure of $\left[\mathrm{U}\left\{\mathrm{C}\left(\mathrm{PPh}_{2} \mathrm{NMes}_{2}\right\}_{2}\right]\left(\mathrm{Mes}=2,4,6-\mathrm{Me}_{3} \mathrm{C}_{6} \mathrm{H}_{2}\right)\right.$ : A Homoleptic Uranium Bis(Carbene) Complex with Two Formal U=C Double Bond. Dalton Trans. 2010, 5074-5076.

(24) Cooper, O. J.; Wooles, A. J.; McMaster, J.; Lewis, W.; Blake, A. J.; Liddle, S. T. A Monomeric Dilithio Methandiide with a Distorted Trans-Planar Four-Coordinate Carbon. Angew. Chem. Int. Ed. 2010, 49, 5570-5573.

(25) Feichtner, K.-S.; Gessner, V. H. Synthesis and Stability of Li/Cl Carbenoids Based on Bis(Iminophosphoryl)Methanes. Dalt. Trans. 2014, 43, 14399-14408. 
(26) Collins, J. B.; Dill, J. D.; Jemmis, E. D.; Apeloig, Y.; Schleyer, P. V. R.; Seeger, R.; Pople, J. A. Stabilization of Planar Tetracoordinate Carbon. J. Am. Chem. Soc. 1976, 98, 5419-5427.

(27) Sorger, K.; Schleyer, P. von R.; Fleischer, R.; Stalke, D. Toward Planar Tetracoordinate Carbon in the Puckered Ladder Structures of Chelated Cyclopropenyllithium Aggregates. J. Am. Chem. Soc. 1996, 118, 6924-6933.

(28) Schröter, P.; Gessner, V. H. Tetrahedral versus Planar Four-Coordinate Carbon: A SulfonylSubstituted Methandiide. Chem. - Eur. J. 2012, 18, 11223-11227.

(29) Chen, J.-H.; Guo, J.; Li, Y.; So, C.-W. Synthesis and Structure of $\left[\mathrm{Li}_{2} \mathrm{C}\left(\mathrm{PPh}_{2}=\mathrm{NSiMe}_{3}\right)\left(\mathrm{PPh}_{2}=\mathrm{S}\right)\right]:$ A Geminal Dianionic Ligand. Organometallics 2009, 28, 46174620 .

(30) Heuclin, H.; Le Goff, X. F.; Mézailles, N. Mixed ( $\mathrm{P}=\mathrm{S} / \mathrm{P}=\mathrm{O})$-Stabilized Geminal Dianion: Facile Diastereoselective Intramolecular C-H Activations by a Related Ruthenium-Carbene Complex. Chemistry 2012, 18, 16136-16144.

(31) Heuclin, H.; Fustier-Boutignon, M.; Ho, S. Y. F.; Goff, X. F. Le; Carenco, S.; So, C. W.; Mézailles, N. Synthesis of Phosphorus(V)-Stabilized Geminal Dianions. the Cases of Mixed $\mathrm{P}=\mathrm{X} / \mathrm{PBH}_{3}(\mathrm{X}=\mathrm{S}, \mathrm{O})$ and $\mathrm{P}=\mathrm{S} / \mathrm{SiMe} 3$ derivatives. Organometallics 2013, 32, 498-508.

(32) Gessner, V. H. Formation of a Palladium Thioketone Complex from a Thiophosphinoyl Stabilized Li/Cl Carbenoid. Organometallics 2011, 30, 4228-4231.

(33) Heuclin, H.; Carenco, S.; Le Goff, X.-F.; Mézailles, N. Rhodium (Thiophosphinoyl)(Trimethylsilyl)Methanide and Bis(Thiophosphinoyl)Methanide Complexes: S S vs. C S Coordination. Eur. J. Inorg. Chem. 2012, 2012, 1453-1461.

(34) Heuclin, H.; Fustier-Boutignon, M.; Ho, S. Y.; Goff, X.-F. Le; Carenco, S.; So, C.; Mézailles, N. Synthesis of Phosphorus(V)-Stabilized Geminal Dianions. The Cases of Mixed $\mathrm{P}=\mathrm{X} / \mathrm{P} \rightarrow \mathrm{BH}_{3}(\mathrm{X}$ $=\mathrm{S}, \mathrm{O}$ ) and $\mathrm{P}=\mathrm{S} / \mathrm{SiMe}_{3}$ Derivatives. Organometallics 2013, 32, 498-508.

(35) Gessner, V. H.; Meier, F.; Uhrich, D.; Kaupp, M. Synthesis and Bonding in Carbene Complexes of an Unsymmetrical Dilithio Methandiide: A Combined Experimental and Theoretical Study. Chem. - Eur. J. 2013, 19, 16729-16739.

(36) Feichtner, K. S.; Englert, S.; Gessner, V. H. Preparation and Isolation of a Chiral Methandiide and Its Application as Cooperative Ligand in Bond Activation. Chem. - Eur. J. 2016, 22, 506510.

(37) Feichtner, K.-S.; Gessner, V. Synthesis and Characterization of a Sulfonyl- and IminophosphorylFunctionalized Methanide and Methandiide. Inorganics 2016, 4, 40-52.

(38) Hull, K. L.; Noll, B. C.; Henderson, K. W. Structural Characterization and Dynamic Solution Behavior of the Disodio and Lithio-Sodio Geminal Organodimetallics $\left[\left\{\left\{\mathrm{Ph}_{2} \mathrm{P}\left(\mathrm{Me}_{3} \mathrm{Si}\right) \mathrm{N}\right\}_{2} \mathrm{CNa}_{2}\right\}_{2}\right]$ and $\left[\left\{\left\{\mathrm{Ph}_{2} \mathrm{P}\left(\mathrm{Me}_{3} \mathrm{Si}\right) \mathrm{N}\right\}_{2} \mathrm{CLiNa}\right\}_{2}\right]$. Organometallics 2006, 25, 40724074.

(39) Hull, K. L.; Carmichael, I.; Noll, B. C.; Henderson, K. W. Homo- and Heterodimetallic Geminal Dianions Derived from the Bis(Phosphinimine) $\left\{\mathrm{Ph}_{2} \mathrm{P}\left(\mathrm{NSiMe}_{3}\right)\right\}_{2} \mathrm{CH}_{2}$ and the Alkali Metals Li, Na, and K. Chem. - Eur. J. 2008, 14, 3939-3953. 
(40) Orzechowski, L.; Jansen, G.; Harder, S. Methandiide Complexes $\left(\mathrm{R}_{2} \mathrm{CM}_{2}\right)$ of the Heavier Alkali Metals ( $\mathrm{M}=$ Potassium, Rubidium, Cesium): Reaching the Limit? Angew. Chem. Int. Ed. 2009, 48, 3825-3829.

(41) Sindlinger, C. P.; Stasch, A. Syntheses, Structures and Flexible Coordination of Sterically Demanding Di- and "Tri”-Lithiated Methandiides. Dalt. Trans. 2014, 43, 14334-14345.

(42) Cantat, T.; Jacques, X.; Ricard, L.; Le Goff, X. F.; Mézailles, N.; Le Floch, P. From a Stable Dianion to a Stable Carbenoid. Angew. Chem. Int. Ed. 2007, 46, 5947-5950.

(43) Konu, J.; Chivers, T. Formation of a Stable Dicarbenoid and an Unsaturated $\mathrm{C}_{2} \mathrm{P}_{2} \mathrm{~S}_{2}$ Ring from Two-Electron Oxidation of the $\left[\mathrm{C}\left(\mathrm{PPh}_{2} \mathrm{~S}\right)_{2}\right]_{2}$-Dianion. Chem. Commun. 2008, 40, 4995-4997.

(44) Heuclin, H.; Ho, S. Y. F.; Le Goff, X. F.; So, C. W.; Mézailles, N. Facile B-H Bond Activation of Borane by Stable Carbenoid Species. J. Am. Chem. Soc. 2013, 135, 8774-8777.

(45) Molitor, S.; Gessner, V. H. Reactivity of Stabilized Li/Cl Carbenoids towards Lewis Base Adducts of $\mathrm{BH}_{3}$ : B-H Bond Activation versus Carbene Dimerization. Chem. - Eur. J. 2013, 19, $11858-11862$.

(46) Becker, J.; Gessner, V. H. On the Structure and Ambiphilicity of a Sulfonyl Substituted $\alpha$-Chloro Lithium Base. Dalt. Trans. 2014, 43, 4320.

(47) Molitor, S.; Gessner, V. H. Alkali Metal Carbenoids: A Case of Higher Stability of the Heavier Congeners. Angew. Chem. Int. Ed. 2016, 55, 7712-7716.

(48) Konu, J.; Chivers, T.; Tuononen, H. M. Synthesis and Redox Behaviour of the Chalcogenocarbonyl Dianions $\left[(\mathrm{E}) \mathrm{C}\left(\mathrm{PPh}_{2} \mathrm{~S}\right)_{2}\right]_{2}$ : Formation and Structures of Chalcogenchalcogen Bonded Dimers and a Novel Selone. Chem. - Eur. J. 2010, 16, 12977-12987.

(49) Orzechowski, L.; Jansen, G.; Harder, S. Synthesis, Structure, and Reactivity of a Stabilized Calcium Carbene: $\mathrm{R}_{2}$ CCa. J. Am. Chem. Soc. 2006, 128, 14676-14684.

(50) Guo, J.; Lee, J. S.; Foo, M. C.; Lau, K. C.; Xi, H. W.; Lim, K. H.; So, C. W. Synthesis and Characterization of Magnesium and Aluminum Bis(Phosphoranyl)Methanediide Complexes. Organometallics 2010, 29, 939-944.

(51) Leung, W.-P.; Wan, C.-L.; Mak, T. C. W. Synthesis and Structure of Magnesium and Group 13 Metal Bis(Thiophosphinoyl)Methanediide Complexes. Organometallics 2010, 29, 1622-1628.

(52) Orzechowski, L.; Jansen, G.; Lutz, M.; Harder, S. Calcium Carbene Complexes with Boranophosphorano Side-Arms: $\mathrm{CaC}\left[\mathrm{P}(\mathrm{Ph})_{2} \mathrm{BH}_{3}\right]_{2}$. Dalt. Trans. 2009, 0, 2958.

(53) Orzechowski, L.; Harder, S. Isolation of an Intermediate in the Catalytic Trimerization of Isocyanates by a Monomeric Calcium Carbene with Chelating Iminophosphorane Substituents. Organometallics 2007, 26, 2144-2148.

(54) Orzechowski, L.; Harder, S. Syntheses, Structures, and Reactivity of Barium Carbene Complexes with Chelating Bis-Iminophosphorano Arms. Organometallics 2007, 26, 5501-5506.

(55) Giesbrecht, G. R.; Gordon, J. C. Lanthanide Alkylidene and Imido Complexes. Dalt. Trans. 2004, 16, 2387-2393.

(56) Clark, D. L.; Gordon, J. C.; Hay, P. J.; Poli, R. Existence and Stability of Lanthanide-Main 
Group Element Multiple Bonds. New Paradigms in the Bonding of the $4 \mathrm{f}$ Elements. A DFT Study of $\mathrm{Cp}_{2} \mathrm{CeZ}\left(\mathrm{Z}=\mathrm{F}^{+}, \mathrm{O}, \mathrm{NH}, \mathrm{CH}^{-}, \mathrm{CH}_{2}\right)$ and the Ligand Adduct $\mathrm{Cp}_{2} \mathrm{Ce}\left(\mathrm{CH}_{2}\right)\left(\mathrm{NH}_{3}\right)$. Organometallics 2005, 24, 5747-5758.

(57) Hong, J.; Zhang, L.; Yu, X.; Li, M.; Zhang, Z.; Zheng, P.; Nishiura, M.; Hou, Z.; Zhou, X. Syntheses, Structures, and Reactivities of Homometallic Rare-Earth-Metal Multimethyl Methylidene and Oxo Complexes. Chem. - Eur. J. 2011, 17, 2130-2137.

(58) Zhang, W. X.; Wang, Z.; Nishiura, M.; Xi, Z.; Hou, Z. $\mathrm{Ln}_{4}\left(\mathrm{CH}_{2}\right)_{4}$ cubane-Type Rare-Earth Methylidene Complexes Consisting of " $\left(\mathrm{C}_{5} \mathrm{Me}_{4} \mathrm{SiMe}_{3}\right) \mathrm{LnCH}_{2}$ " Units ( $\mathrm{Ln}=\mathrm{Tm}$, Lu). J. Am. Chem. Soc. 2011, 133, 5712-5715.

(59) Dietrich, H. M.; Törnroos, K. W.; Anwander, R. "Ionic Carbenes": Synthesis, Structural Characterization, and Reactivity of Rare-Earth Metal Methylidene Complexes. J. Am. Chem. Soc. 2006, 128, 9298-9299.

(60) Scott, J.; Fan, H.; Wicker, B. F.; Fout, A. R.; Baik, M.-H.; Mindiola, D. J. Lewis Acid Stabilized Methylidene and Oxoscandium Complexes. J. Am. Chem. Soc. 2008, 130, 14438-14439.

(61) Aparna, K.; Ferguson, M.; Cavell, R. G. A Monomeric Samarium Bis (Iminophosphorano) Chelate Complex with a Sm=C Bond. J. Am. Chem. Soc. 2000, 122, 726-727.

(62) Liddle, S. T.; Mills, D. P.; Wooles, A. J. Bis(Phosphorus-Stabilised)Methanide and Methandiide Derivatives of Group 1-5 and f-Element Metals. In Organometallic Chemistry; The Royal Society of Chemistry, 2010; pp 29-55. .

(63) Panda, T. K.; Roesky, P. W. Main-Group and Transition-Metal Complexes of Bis(Phosphinimino)Methanides. Chem. Soc. Rev. 2009, 38, 2782.

(64) Heuclin, H.; Fustier, M.; Auffrant, A.; Mezailles, N. Bis-Phosphorus(V) Stabilized Carbene Complexes. Lett. Org. Chem. 2010, 7, 596-611.

(65) Liddle, S. T.; Mills, D. P.; Wooles, A. J. Early Metal Bis(Phosphorus-Stabilised)Carbene Chemistry. Chem. Soc. Rev. 2011, 40, 2164-2176.

(66) Buchard, A.; Auffrant, A.; Ricard, L.; Le Goff, X. F.; Platel, R. H.; Williams, C. K.; Le Floch, P. First Neodymium(Iii) Alkyl-Carbene Complex Based on Bis(Iminophosphoranyl) Ligands. Dalt. Trans. 2009, 3, 10219-10222.

(67) Wooles, A. J.; Cooper, O. J.; Mcmaster, J.; Lewis, W.; Blake, A. J.; Liddle, S. T. Synthesis and Characterization of Dysprosium and Lanthanum Bis (Iminophosphorano) Methanide and Methanediide Complexes. Organometallics 2010, 29, 2315-2321.

(68) Liddle, S. T.; Mills, D. P.; Gardner, B. M.; McMaster, J.; Jones, C.; Woodul, W. D. A Heterobimetallic Gallyl Complex Containing an Unsupported Ga-Y Bond. Inorg. Chem. 2009, $48,3520-3522$.

(69) Liddle, S. T.; McMaster, J.; Green, J. C.; Arnold, P. L. Synthesis and Structural Characterisation of an Yttrium-Alkyl-Alkylidene. Chem. Commun. 2008, 78, 1747-1749.

(70) Mills, D. P.; Cooper, O. J.; McMaster, J.; Lewis, W.; Liddle, S. T. Synthesis and Reactivity of the Yttrium-Alkyl-Carbene Complex $\left[\mathrm{Y}(\mathrm{BIPM})\left(\mathrm{CH}_{2} \mathrm{C}_{6} \mathrm{H}_{5}\right)(\mathrm{THF})\right]\left(\mathrm{BIPM}=\left\{\mathrm{C}\left(\mathrm{PPh}_{2} \mathrm{NSiMe}_{3}\right)_{2}\right\}\right)$. Dalt. Trans. 2009, 23, 4547-4555. 
(71) Mills, D. P.; Wooles, A. J.; Mcmaster, J.; Lewis, W.; Blake, A. J.; Liddle, S. T. Heteroleptic $\left[\mathrm{M}\left(\mathrm{CH}_{2} \mathrm{C}_{6} \mathrm{H}_{5}\right)_{2}(\mathrm{I})(\mathrm{THF})_{3}\right]$ Complexes $(\mathrm{M}=\mathrm{Y}$ or Er): Remarkably Stable Precursors to Yttrium and Erbium T-Shaped Carbenes Suporting Informations. Organometallics 2009, 28, 6771-9776.

(72) Gregson, M.; Lu, E.; McMaster, J.; Lewis, W.; Blake, A. J.; Liddle, S. T. A Cerium(IV)-Carbon Multiple Bond. Angew. Chem. Int. Ed. 2013, 52, 13016-13019.

(73) Wooles, A. J.; Mills, D. P.; Lewis, W.; Blake, A. J.; Liddle, S. T. Lanthanide Tri-Benzyl Complexes: Structural Variations and Useful Precursors to Phosphorus-Stabilised Lanthanide Carbenes. Dalt. Trans. 2010, 39, 500-510.

(74) Marshall, G.; Wooles, A.; Mills, D.; Lewis, W.; Blake, A.; Liddle, S. Synthesis and Characterisation of Lanthanide N-Trimethylsilyl and -Mesityl Functionalised Bis(Iminophosphorano)Methanides and -Methanediides. Inorganics 2013, 1, 46-69.

(75) Gregson, M.; Chilton, N. F.; Ariciu, A.-M.; Tuna, F.; Crowe, I. F.; Lewis, W.; Blake, A. J.; Collison, D.; McInnes, E. J. L.; Winpenny, R. E. P.; et al. A Monometallic Lanthanide Bis(Methanediide) Single Molecule Magnet with a Large Energy Barrier and Complex Spin Relaxation Behaviour. Chem. Sci. 2016, 7, 155-165.

(76) Ortu, F.; Gregson, M.; Wooles, A. J.; Mills, D. P.; Liddle, S. T. Yttrium Methanide and Methanediide Bis(Silyl)Amide Complexes. Organometallics 2017, 36, 4584-4590.

(77) Cantat, T.; Jaroschik, F.; Nief, F.; Ricard, L.; Mézailles, N.; Le Floch, P. New Mono- and BisCarbene Samarium Complexes: Synthesis, X-Ray Crystal Structures and Reactivity. Chem. Commun. 2005, 41, 5178-5180.

(78) Cantat, T.; Jaroschik, F.; Ricard, L.; Le Floch, P.; Nief, F.; Mézailles, N. Thulium Alkylidene Complexes: Synthesis, x-Ray Structures, and Reactivity. Organometallics 2006, 25, 1329-1332.

(79) Fustier, M.; Le Goff, X. F.; Le Floch, P.; Mézailles, N. Nucleophilic Scandium Carbene Complexes. J. Am. Chem. Soc. 2010, 132, 13108-13110.

(80) Fustier, M.; Le Goff, X.-F.; Lutz, M.; Slootweg, J. C.; Mézailles, N. Scandium Carbene Complexes: Synthesis of Mixed Alkyl, Amido, and Phosphido Derivatives. Organometallics 2015, 34, 63-72.

(81) Wang, C.; Zhou, J.; Zhao, X.; Maron, L.; Leng, X.; Chen, Y. Non-Pincer-Type Mononuclear Scandium Alkylidene Complexes: Synthesis, Bonding, and Reactivity. Chem. - Eur. J. 2016, 22, $1258-1261$.

(82) Mao, W.; Xiang, L.; Lamsfus, C. A.; Maron, L.; Leng, X.; Chen, Y. Highly Reactive Scandium Phosphinoalkylidene Complex: C-H and H-H Bonds Activation. J. Am. Chem. Soc. 2017, 139, 1081-1084.

(83) Mills, D. P.; Soutar, L.; Lewis, W.; Blake, A. J.; Liddle, S. T. Regioselective C - H Activation and Sequential C - C and C - O Bond Formation Reactions of Aryl Ketones Promoted by an Yttrium Carbene. J. Am. Chem. Soc. 2010, 132, 14379-14381.

(84) Mills, D. P.; Lewis, W.; Blake, A. J.; Liddle, S. T. Reactivity Studies of a T-Shaped Yttrium Carbene: $\mathrm{C}-\mathrm{F}$ and $\mathrm{C}-\mathrm{O}$ Bond Activation and $\mathrm{C}=\mathrm{C}$ Bond Formation Promoted by $\left[\mathrm{Y}(\mathrm{BIPM})(\mathrm{I})(\mathrm{THF})_{2}\right]\left(\mathrm{BIPM}=\mathrm{C}\left(\mathrm{PPh}_{2} \mathrm{NSiMe}_{3}\right)_{2}\right)$. Organometallics 2013, 32, 1239-1250. 
(85) Mills, D. P.; Soutar, L.; Cooper, O. J.; Lewis, W.; Blake, A. J.; Liddle, S. T. Reactivity of the Yttrium Alkyl Carbene Complex [Y(BIPM) $\left.\left(\mathrm{CH}_{2} \mathrm{C}_{6} \mathrm{H}_{5}\right)(\mathrm{THF})\right]\left(\mathrm{BIPM}=\left\{\mathrm{C}\left(\mathrm{PPh}_{2} \mathrm{NSiMe}_{3}\right)_{2}\right\}\right)_{2}-$ : From Insertions, Substitutions, and Additions to Nontypical Transformations. Organometallics 2013, 32, 1251-1264.

(86) Chen, Y.; Wang, C.; Xiang, L.; Yang, Y.; Fang, J.; Maron, L.; Leng, X.; Mao, W. Monomeric Rare-Earth Metal Silyl-Thiophosphinoyl-Alkylidene Complexes: Synthesis, Structure and Reactivity. Chem. - Eur. J. 2018, 24, 13903-13917.

(87) Fustier-Boutignon, M.; Heuclin, H.; Le Goff, X. F.; Mézailles, N. Transmetalation of a Nucleophilic Carbene Fragment: From Early to Late Transition Metals. Chem. Commun. 2012, 48, 3306-3308.

(88) a) Wang, C.; Xiang, L.; Yang, Y.; Fang, J.; Maron, L.; Leng, X.; Chen, Y. Dianionic CarbonBridged Scandium-Copper/Silver Heterobimetallic Complexes: Synthesis, Bonding, and Reactivity. Chem. - Eur. J. 2018, 24, 5637-5643. b) Mao, W.; Xiang, L.; Lamsfus, C. A.; Maron, L.; Leng, X.; Chen, Y. Are Sc-C and Sc-P Bonds Reactive in Scandium Phosphinoalkylidene Complex? Insights on a Versatile Reactivity. Chin. J. Chem. 2018, 36, 904-8.

(89) Cramer, R. E.; Maynard, R. B.; Paw, J. C.; Gilje, J. W. A Uranium-Carbon Multiple Bond. Crystal and Molecular Structure of $\left(\eta^{5}-\mathrm{C}_{5} \mathrm{H}_{5}\right)_{3} \mathrm{UCHP}\left(\mathrm{CH}_{3}\right)_{2}\left(\mathrm{C}_{6} \mathrm{H}_{5}\right)$. J. Am. Chem. Soc. 1981, 103, 3589-3590.

(90) Cantat, T.; Arliguie, T.; Noël, A.; Thuéry, P.; Ephritikhine, M.; Floch, P. Le; Mézailles, N. The $\mathrm{U}=\mathrm{C}$ Double Bond: Synthesis and Study of Uranium Nucleophilic Carbene Complexes. J. Am. Chem. Soc. 2009, 131, 963-972.

(91) Tourneux, J.-C.; Berthet, J.-C.; Thuéry, P.; Mézailles, N.; Le Floch, P.; Ephritikhine, M. Easy Access to Uranium Nucleophilic Carbene Complexes. Dalt. Trans. 2010, 39, 2494-2496.

(92) Tourneux, J.; Berthet, J.; Cantat, T.; Thuéry, P.; Mézailles, N.; Le Floch, P.; Ephritikhine, M. Uranium(IV) Nucleophilic Carbene Complexes. Organometallics 2011, 30, 2957-2971.

(93) Ma, G.; Ferguson, M. J.; McDonald, R.; Cavell, R. G. Actinide Metals with Multiple Bonds to Carbon: Synthesis, Characterization, and Reactivity of U(IV) and Th(IV) Bis(Iminophosphorano)Methandiide Pincer Carbene Complexes. Inorg. Chem. 2011, 50, 65006508.

(94) Tourneux, J.-C.; Berthet, J.-C.; Cantat, T.; Thuéry, P.; Mézailles, N.; Ephritikhine, M. Exploring the Uranyl Organometallic Chemistry: From Single to Double Uranium-Carbon Bonds. J. Am. Chem. Soc. 2011, 133, 6162-6165.

(95) Cooper, O. J.; Mills, D. P.; McMaster, J.; Moro, F.; Davies, E. S.; Lewis, W.; Blake, A. J.; Liddle, S. T. Uranium-Carbon Multiple Bonding: Facile Access to the Pentavalent Uranium Carbene $\left[\mathrm{U}\left\{\mathrm{C}\left(\mathrm{PPh}_{2} \mathrm{NSiMe}_{3}\right)_{2}\right\}(\mathrm{Cl})_{2}(\mathrm{I})\right]$ and Comparison of $\mathrm{U}(\mathrm{V})=\mathrm{C}$ and $\mathrm{U}(\mathrm{IV})=\mathrm{C}$ Bonds. Angew. Chem. Int. Ed. Engl. 2011, 50, 2383-2386.

(96) Sarsfield, M. J.; Steele, H.; Helliwell, M.; Teat, S. J. Uranyl Bis-Iminophosphorane Complexes with in- and out-of-Plane Equatorial Coordination Dalton Trans. 2003, 0, 3443-3449.

(97) Mills, D. P.; Cooper, O. J.; Tuna, F.; McInnes, E. J. L.; Davies, E. S.; McMaster, J.; Moro, F.; Lewis, W.; Blake, A. J.; Liddle, S. T. Synthesis of a Uranium(VI)-Carbene: Reductive Formation 
of Uranyl(V)-Methanides, Oxidative Preparation of a $\left[\mathrm{R}_{2} \mathrm{C}=\mathrm{U}=\mathrm{O}\right]^{2+}$ Analogue of the $[\mathrm{O}=\mathrm{U}=\mathrm{O}]^{2+}$ Uranyl Ion $\left(\mathrm{R}=\mathrm{Ph}_{2} \mathrm{PNSiMe}_{3}\right)$, and Comparison of the Nature of $\mathrm{U}(\mathrm{IV})=\mathrm{C}, \mathrm{U}(\mathrm{V})=\mathrm{C}$, and $\mathrm{U}(\mathrm{VI})=\mathrm{C}$ Double Bonds. J. Am. Chem. Soc. 2012, 134, 10047-10054.

(98) a) Mills, D. P.; Moro, F.; McMaster, J.; van Slageren, J.; Lewis, W.; Blake, A. J.; Liddle, S. T. A Delocalized Arene-Bridged Diuranium Single-Molecule Magnet. Nat. Chem. 2011, 3, 454-460. b) Wooles, A. J.; Mills, D. P.; Una, F.; McInnes, E. J.L.; Law, G. T.W.; Fuller, A. J.; Kremer, F.; Ridgway, M.; Lewis, W. Gagliardi, L.; Vlaisavljevich, B.; Liddle, S. T. Uranium(III)-carbon multiple bonding supported byarene $\delta$-bonding in mixed-valence hexauranium nanometre-scale rings. Nat. Commun. 2018, 9, 2097-2108.

(99) O'Grady, E.; Kaltsoyannis, N. On the Inverse Trans Influence. Density Functional Studies of $\left[\mathrm{MOX}_{5}\right] \mathrm{N}-(\mathrm{M}=\mathrm{Pa}, \mathrm{n}=2 ; \mathrm{M}=\mathrm{U}, \mathrm{n}=1 ; \mathrm{M}=\mathrm{Np}, \mathrm{n}=0 ; \mathrm{X}=\mathrm{F}, \mathrm{Cl}$ or $\mathrm{Br})$. J. Chem. Soc. Dalt. Trans. 2002, 6, 1233-1239.

(100) La Pierre, H. S.; Meyer, K. Uranium-Ligand Multiple Bonding in Uranyl Analogues, $[\mathrm{L}=\mathrm{U}=\mathrm{L}] \mathrm{N}^{+}$, and the Inverse Trans Influence. Inorg. Chem. 2013, 52, 529-539.

(101) Lu, E.; Cooper, O. J.; McMaster, J.; Tuna, F.; McInnes, E. J. L.; Lewis, W.; Blake, A. J.; Liddle, S. T. Synthesis, Characterization, and Reactivity of a Uranium(VI) Carbene Imido Oxo Complex. Angew. Chem. Int. Ed. 2014, 53, 6696-6700.

(102) Lu, E.; Tuna, F.; Lewis, W.; Kaltsoyannis, N.; Liddle, S. T. Uranium Metalla-Allenes with Carbene Imido $\mathrm{R}_{2} \mathrm{C}=\mathrm{U}^{\mathrm{IV}}=\mathrm{NR}$ ' Units $\left(\mathrm{R}=\mathrm{Ph}_{2} \mathrm{PNSiMe}_{3} ; \mathrm{R}^{\prime}=\mathrm{CPh}_{3}\right)$ : Alkali-Metal-Mediated PushPull Effects with an Amido Auxiliary. Chem. - Eur. J. 2016, 22, 11554-11558.

(103) Lu, E.; Cooper, O. J.; Tuna, F.; Wooles, A. J.; Kaltsoyannis, N.; Liddle, S. T. Uranium-CarbeneImido Metalla-Allenes: Ancillary-Ligand-Controlled Cis-/Trans-Isomerisation and Assessment of Trans Influence in the $\mathrm{R} 2 \mathrm{C}=\mathrm{UIV}=\mathrm{NR}$ ' Unit $\left(\mathrm{R}=\mathrm{Ph}_{2} \mathrm{PNSiMe}_{3} ; \mathrm{R}^{\prime}=\mathrm{CPh}_{3}\right)$. Chem. - Eur. J. 2016, 22, 11559-11563.

(104) Gregson, M.; Lu, E.; Mills, D. P.; Tuna, F.; McInnes, E. J. L.; Hennig, C.; Scheinost, A. C.; McMaster, J.; Lewis, W.; Blake, A. J.; et al. The Inverse-Trans-Influence in Tetravalent Lanthanide and Actinide Bis(Carbene) Complexes. Nat. Commun. 2017, 8, 1-11.

(105) Lu, E.; Boronski, J. T.; Gregson, M.; Wooles, A. J.; Liddle, S. T. Silyl-Phosphino-Carbene Complexes of Uranium(IV). Angew. Chem. Int. Ed. 2018, 57, 5506-5511.

(106) Cooper, O. J.; Mills, D. P.; McMaster, J.; Tuna, F.; McInnes, E. J. L.; Lewis, W.; Blake, A. J.; Liddle, S. T. The Nature of the U=C Double Bond: Pushing the Stability of High-Oxidation-State Uranium Carbenes to the Limit. Chem. - Eur. J. 2013, 19, 7071-7083.

(107) Gregson, M.; Lu, E.; Tuna, F.; McInnes, E. J. L.; Hennig, C.; Scheinost, A. C.; McMaster, J.; Lewis, W.; Blake, A. J.; Kerridge, A., Liddle, S. T. Emergence of Comparable Covalency in Isostructural Cerium(iv)- and Uranium(iv)-carbon Multiple Bonds. Chem. Sci. 2016, 7, 32863297.

(108) Cavell, R. G.; Kamalesh Babu, R. P.; Kasani, A.; McDonald, R. Novel Metal-Carbon Multiply Bonded Twelve-Electron Complexes of Ti and Zr Supported by a Bis(Phosphoranimine) Chelate. J. Am. Chem. Soc. 1999, 121, 5805-5806.

(109) Babu, R. P. K.; Mcdonald, R.; Decker, S. A.; Klobukowski, M.; Cavell, R. G. New Zirconium 
Hydrocarbyl Bis ( Phosphoranimino ) "Pincer” Carbene Complexes. Organometallics 1999, 18, 4226-4229.

(110) Kamalesh Babu, R. P.; McDonald, R.; Cavell, R. G. Nucleophilic Reactivity of the Multiply Bonded Carbon Center in Group 4-Pincer Bis(Iminophosphorano)Methanediide Complexes. Organometallics 2000, 19, 3462-3465.

(111) Aparna, K.; Babu, R. P. K.; Mcdonald, R.; Cavell, R. G. The First Biscarbene Complex of a Group 4. Angew. Chem. Int. Ed. 2001, 40, 4400-4402.

(112) Gamer, M. T.; Rastätter, M.; Roesky, P. W. Reaction of $\mathrm{Cp}_{2} \mathrm{ZrCl}_{2}$ with Inorganic Amides Reaktionen von $\mathrm{Cp}_{2} \mathrm{ZrCl}_{2}$ Mit Anorganischen Amiden. Z. Anorg. Allg. Chem. 2002, 628, 22692272.

(113) Müller, J. F. K.; Kulicke, K. J.; Neuburger, M.; Spichty, M. Carbanions Substituted by Transition Metals: Synthesis, Structure, and Configurational Restrictions of a Lithium Titanium Phosphonate. Angew. Chem. Int. Ed. 2001, 12, 2890-2893.

(114) Cantat, T.; Ricard, L.; Mézailles, N.; Le Floch, P. Synthesis, Reactivity, and DFT Studies of S-C-S Zirconium(IV) Complexes. Organometallics 2006, 25, 6030-6038.

(115) Lafage, M.; Heuclin, H.; Le Goff, X.-F.; Saffon-Merceron, N.; Mézailles, N. PhosphorusStabilized Titanium Carbene Complexes: Synthesis, Reactivity and DFT Studies. Chem. - Eur. J. 2014, 20, 16995-17003.

(116) Oulié, P.; Nebra, N.; Saffon, N.; Maron, L.; Martin-Vaca, B.; Bourissou, D. 2-Indenylidene Pincer Complexes of Zirconium and Palladium. J. Am. Chem. Soc. 2009, 131, 3493-3498.

(117) Heuclin, H.; Grünstein, D.; Le Goff, X.-F.; Le Floch, P.; Mézailles, N. Phosphorus Stabilized Carbene Complexes: Bisphosphonate Dianion Synthesis, Reactivity and DFT Studies of O C O Zirconium(IV) Complexes. Dalton Trans. 2010, 2, 492-499.

(118) Becker, J.; Gessner, V. H. Synthesis and Electronic Structure of Carbene Complexes Based on a Sulfonyl-Substituted Dilithio Methandiide. Organometallics 2014, 33, 1310-1317.

(119) Kasani, A.; McDonald, R.; Cavell, R. G. Chromium Bis(Phosphoranimine) Complexes; Bridging Chromium Carbenes with No CO or Cp Supporting Ligands. Chem. Commun. 1999, 19, 19931994.

(120) Leung, W.-P.; So, C.-W.; Wang, J.-Z.; Mak, T. C. W. A Novel Synthesis of Metallogermacyclopropane and Molybdenum Bis(Iminophosphorano)Carbene Complexes from Bisgermavinylidene. Chem. Commun. 2003, 0, 248-249.

(121) Cadierno, V.; Díez, J.; García-Álvarez, J.; Gimeno, J.; Calhorda, M. J.; Veiros, L. F. Bis(Iminophosphorano)Methane Derivatives as Precursors of Unusual Ruthenium Carbene Complexes: A Synthetic and DFT Study. Organometallics 2004, 23, 2421-2433.

(122) Cadierno, V.; Diíez, J.; García-Álvarez, J.; Gimeno, J., Novel ( $\eta^{6}$-Arene)-Ruthenium(II) Complexes Containing Bis(Iminophosphorano)Methanide and Methandiide Ligands. $J$. Organomet. Chem. 2005, 690, 2087-2096.

(123) Cadierno, V.; Díez, J.; García-Álvarez, J.; Gimeno, J. Iminophosphorane-Based Nucleophilic Ruthenium(II) Carbene Complexes: Unusual C-C Coupling and C-H Activation Promoted by the 
Addition of Alkynes to the Ru=C Bond. Organometallics 2005, 24, 2801-2810.

(124) Cadierno, V.; García-Álvarez, J.; Gimeno, J.; Rubio-García, J. Reaction of Isocyanides with Iminophosphorane-Based Carbene Ligands: Synthesis of Unprecedented Ketenimine-Ruthenium Complexes. J. Organomet. Chem. 2005, 690, 5856-5862.

(125) Cadierno, V.; Díez, J.; García-Álvarez, J.; Gimeno, J. ( $\eta^{6}$-Arene)-Ruthenium(II) Complexes Containing Methanide and Methandiide Anions of $\mathrm{Ph}_{2} \mathrm{P}(=\mathrm{S}) \mathrm{CH}_{2} \mathrm{P}(=\mathrm{NR}) \mathrm{Ph}_{2}$ : Unprecedented Insertion of Isocyanide into a Ruthenium-Carbene Bond. Organometallics 2008, 27, 1809-1822.

(126) Cadierno, V.; Diez, J.; García-Álvarez, J.; Gimeno, J. Access to the First (Iminophosphoranyl)(Selenophosphoranyl)Methane Ligands $\quad \mathrm{Ph}_{2} \mathrm{P}(=\mathrm{Se}) \mathrm{CH}_{2} \mathrm{P}(=\mathrm{NR}) \mathrm{Ph}_{2}$ : Coordination of Their Methanide and Methandiide Anions to Ruthenium. Dalt. Trans 2010, 39, 941-956.

(127) Cantat, T.; Demange, M.; Mézailles, N.; Ricard, L.; Jean, Y.; Le Floch, P. A Bis(Thiophosphinoyl)Methylene Ruthenium Carbene Complex: Synthesis, X-Ray Crystal Structure, and DFT Calculations of Its Thermally Promoted Reverse $\alpha$-Hydride Migration Process. Organometallics 2005, 24, 4838-4841.

(128) Becker, J.; Modl, T.; Gessner, V. H. Methandiide as a Non-Innocent Ligand in Carbene Complexes: From the Electronic Structure to Bond Activation Reactions and Cooperative Catalysis. Chem. - Eur. J. 2014, 20, 11295-11299.

(129) Feichtner, K. S.; Scherpf, T.; Gessner, V. H. Cooperative Bond Activation Reactions with Ruthenium Carbene Complex $\mathrm{PhSO}_{2}\left(\mathrm{Ph}_{2} \mathrm{PNSiMe}_{3}\right) \mathrm{C}=\mathrm{Ru}(\mathrm{p}-\mathrm{Cymene}): \mathrm{Ru}=\mathrm{C}$ and $\mathrm{N}-\mathrm{Si}$ Bond Reactivity. Organometallics 2018, 37, 645-654.

(130) Weismann, J.; Gessner, V. H. Catalytic Transfer Hydrogenation with a Methandiide-Based Carbene Complex: An Experimental and Computational Study. Chem. - Eur. J. 2015, 21, 1610316112.

(131) Weismann, J.; Scharf, L. T.; Gessner, V. H. Cooperative P-H Bond Activation with Ruthenium and Iridium Carbene Complexes. Organometallics 2016, 35, 2507-2515.

(132) Weismann, J.; Gessner, V. H. Si-H Activation by Means of Metal Ligand Cooperation in a Methandiide Derived Carbene Complex. Chem. Commun. 2015, 51, 14909-14912.

(133) Scharf, L. T.; Weismann, J.; Feichtner, K. S.; Lindl, F.; Gessner, V. H. Versatile Modes of Cooperative B-H Bond Activation Reactions in Ruthenium-Carbene Complexes: Addition, RingOpening and Insertion. Chem. - Eur. J. 2018, 24, 3439-3443.

(134) Weismann, J.; Gessner, V. H. Selective [2+2] Cycloaddition Reactions of Isocyanates and Thioisocyanates across the $\mathrm{M}=\mathrm{C}$ Bond in a Ruthenium Carbene Complex. Eur. J. Inorg. Chem. 2015, 2015, 4192-4198.

(135) Fang, M.; Jones, N. D.; Lukowski, R.; Tjathas, J.; Ferguson, M. J.; Cavell, R. G. A Bimetallic, Coordinated-Ketene Complex Formed from a Bimetallic Lithium-Carbon Spirocycle by LithiumMediated Insertion of CO into a Rhodium-Carbon Bond. Angew. Chem. Int. Ed. 2006, 45, 30973101.

(136) Min, F.; Jones, N. D.; Friesen, K.; Guanyang, L.; Ferguson, M. J.; McDonald, R.; Lukowski, R.; 
Cavell, R. G. Bimetallic, Spirocyclic, Methylene-Bridged Carbene Complexes of Rhodium and Palladium Derived by Stepwise Metalations of Lithiated Bis(Diphenylphosphoranotrimethylsilylimido)Methandiide. Organometallics 2009, 28, $1652-$ 1665.

(137) Weismann, J.; Waterman, R.; Gessner, V. H. Metal-Ligand Cooperativity in a MethandiideDerived Iridium Carbene Complex. Chem. - Eur. J. 2016, 22, 3846-3855.

(138) Browning, J.; Dixon, K. R.; Hilts, R. W. Reactivity of Coordinated $\left[\mathrm{Ph}_{2} \mathrm{PCHP}(\mathrm{S}) \mathrm{Ph}_{2}\right]-$ and $\left[\mathrm{Ph}_{2} \mathrm{P}(\mathrm{S}) \mathrm{CHP}(\mathrm{S}) \mathrm{Ph}_{2}\right]-:$ Two-Center, Regiospecific Reactivity in Rhodium and Iridium Complexes and Formation of a Disubstituted Methylene Bridge between Platinum Atoms. Organometallics 1989, 8, 552-554.

(139) Jones, N. D.; Lin, G.; Gossage, R. A.; McDonald, R.; Cavell, R. G. Synthesis , Structure , and Reactivity of an Unusual Platinum Olefin Carbene Complex , $\left[\left(\eta^{4}-\mathrm{Cod}\right) \mathrm{Pt}\left\{=\mathrm{C}\left(\mathrm{Ph}_{2} \mathrm{P}=\mathrm{NSiMe}_{3}\right)_{2}-\right.\right.$ $\kappa C, \kappa N\}]$. Organometallics 2003, 22, 2832-2841.

(140) Lin, G.; Jones, N. D.; Gossage, R. A.; McDonald, R.; Cavell, R. G. A Tris(Carbene) Pincer Complex: Monomeric Platinum Carbonyl with Three Bound Carbene Centers. Angew. Chem. Int. Ed. 2003, 42, 4054-4057.

(141) Cantat, T.; Mézailles, N.; Ricard, L.; Jean, Y.; Le Floch, P. A Bis(Thiophosphinoyl)Methanediide Palladium Complex: Coordinated Dianion or Nucleophilic Carbene Complex? Angew. Chem. Int. Ed. 2004, 43, 6382-6385.

(142) Panda, T. K.; Roesky, P. W.; Larsen, P.; Zhang, S.; Wickleder, C.;. Reactions of Potassium Bis ( Phosphinimino ) Methanide with Group 11 Compounds. Inorg. Chem. 2006, 45, 7503-7508.

(143) Pujol, A.; Lafage, M.; Rekhroukh, F.; Saffon-Merceron, N.; Amgoune, A.; Bourissou, D.; Nebra, N.; Fustier-Boutignon, M.; Mézailles, N. A Nucleophilic Gold(III) Carbene Complex. Angew. Chem. Int. Ed. 2017, 56, 12264-12267.

(144) Bollwein, T.; Westerhausen, M.; Pfitzner, A., Zinc Bis [ $\mu-N, N$ '-Chlorozinc-Bis(N-TrimeMethanediide ]:A Zinc Derivative of a Geminal Carbodianion. Z. Naturforsch. B. 2003, 58b, 493-496.

(145) Layh, M.; Uhl, W. Synthesis and Molecular Structure of a Bis[Di(Alkyl)Alanyl]Methane; $\mathrm{R}_{2} \mathrm{AlCH}_{2} \mathrm{AlR}_{2}\left[\mathrm{R}=\mathrm{CH}\left(\mathrm{SiMe}_{3}\right)_{2}\right]$. Polyhedron 1990, 9, 277-282.

(146) Robinson, G. H.; Lee, B.; Pennington, W. T.; Sangokoya, S. A. Facile Cleavage of C-H Bonds. Reaction of Trimethylaluminum with Bis(Diphenylphosphinoyl)Methane: Synthesis and Molecular Structure of $\left[\mathrm{Al}\left(\mathrm{CH}_{3}\right)\right]\left[\left(\mathrm{C}_{6} \mathrm{H}_{5}\right)_{2} \mathrm{P}(\mathrm{O}) \mathrm{CP}(\mathrm{O})\left(\mathrm{C}_{6} \mathrm{H}_{5}\right)_{2}\right]_{2}\left[\mathrm{Al}\left(\mathrm{CH}_{3}\right)_{2}\right]_{2}$. J. Am. Chem. Soc. 1988, 110, 6260-6261.

(147) Robinson, G. H.; Self, M. F.; Pennington, W. T.; Sangokoya, S. A. Organoaluminum Chemistry of Bidentate Phosphine Ligands. Reaction of Diisobutylaluminum Hydride with Bis(Diphenylthiophosphinoyl)Methane: Synthesis and Molecular Structure of $\left[\mathrm{Al}\left(\mathrm{C}_{4} \mathrm{H}_{9}\right)\right]_{2}\left[\left(\mathrm{C}_{6} \mathrm{H}_{5}\right)_{2} \mathrm{P}(\mathrm{S}) \mathrm{CP}\left(\mathrm{C}_{6} \mathrm{H}_{5}\right)_{2}(\mathrm{~S})_{2}\right]\left[\mathrm{Al}\left(\mathrm{C}_{4} \mathrm{H}_{9}\right)_{2}\right]_{2}$. Organometallics 1988, 7, 2424-2426.

(148) Aparna, K.; Mcdonald, R.; Ferguson, M.; Cavell, R. G. Novel Dialkyl Aluminum Bis ( Iminophosphorano ) Methanide and Methanediide Complexes. Organometallics 1999, 18, 42414243. 
(149) Guo, J.; Lee, J.-S.; Foo, M.-C.; Lau, K.-C.; Xi, H.-W.; Lim, K. H.; So, C.-W. Synthesis and Characterization of Magnesium and Aluminum Bis(Phosphoranyl)Methanediide Complexes. Organometallics 2010, 29, 939-944.

(150) Aparna, K.; McDonald, R.; Cavell, R. G. Carbon-Carbon Double Bond Formation Reactions of the Unique Spirocyclic Aluminum Bis(Iminophosphorano) Methandiide Complex: Insertion of Heteroallenes into Aluminum-Carbon Bonds. J. Am. Chem. Soc. 2000, 122, 9314-9315.

(151) Cavell, R. G.; Aparna, K.; Kamalesh Babu, R. P.; Wang, Q. Aluminum Bis(Iminophosphorano)Methanide and Methandiide Complexes - transition Metal-Free Ethylene Polymerization Cationic Catalyst Precursors. J. Mol. Catal. A Chem. 2002, 189, 137-143.

(152) Lafage, M.; Pujol, A.; Saffon-Merceron, N.; Mézailles, N. $\mathrm{BH}_{3}$ Activation by PhosphorusStabilized Geminal Dianions: Synthesis of Ambiphilic Organoborane, DFT Studies, and Catalytic $\mathrm{CO}_{2}$ Reduction into Methanol Derivatives. ACS Catal. 2016, 6, 3030-3035.

(153) Inés, B.; Patil, M.; Carreras, J.; Goddard, R.; Thiel, W.; Alcarazo, M. Synthesis, Structure, and Reactivity of a Dihydrido Borenium Cation. Angew. Chem. Int. Ed. 2011, 50, 8400-8403.

(154) Brook, A. G.; Abdesaken, F.; Gutekunst, B.; Gutekunst, G.; Kallury, R. K. A Solid Silaethene: Isolation and Characterization. J. Chem. Soc. Chem. Commun. 1981, 4, 191-192.

(155) Ottosson, H.; Steel, P. G. Silylenes, Silenes, and Disilenes: Novel Silicon-Based Reagents for Organic Synthesis? Chem. - Eur. J. 2006, 12, 1576-1585.

(156) Ottosson, H.; Eklöf, A. M. Silenes: Connectors between Classical Alkenes and Nonclassical Heavy Alkenes. Coord. Chem. Rev. 2008, 252, 1287-1314.

(157) Fischer, R. C.; Power, P. P. Pi-Bonding and the Lone Pair Effect in Multiple Bonds Involving Heavier Main Group Elements: Developments in the New Millennium. Chem. Rev. 2010, 110, 3877-3923.

(158) Leung, W.-P.; Wang, Z.-X.; Li, H.-W.; Mak, T. C. W. Bis(Germavinylidene) $\left[\left(\mathrm{Me}_{3} \mathrm{SiN}=\mathrm{PPh}_{2}\right)_{2} \mathrm{C}=\mathrm{Ge} \rightarrow \mathrm{Ge}=\mathrm{C}\left(\mathrm{Ph}_{2} \mathrm{P}=\mathrm{NSiMe}_{3}\right)\right] \quad$ and 1,3-Dimetallacyclobutanes $\quad\left[\mathrm{M}\left\{\mu_{2^{-}}\right.\right.$ $\left.\left.\mathrm{C}\left(\mathrm{Ph}_{2} \mathrm{P}=\mathrm{NSiMe}_{3}\right)_{2}\right\}\right]_{2}(\mathrm{M}=\mathrm{Sn}, \mathrm{Pb})$. Angew. Chem. Int. Ed. 2001, 40, 2501-2503.

(159) Leung, W.-P.; Wan, C.-L.; Kan, K.-W.; Mak, T. C. W. Synthesis, Structure, and Reactivity of Group 14 Bis(Thiophosphinoyl) Metal Complexes. Organometallics 2010, 29, 814-820.

(160) Leung, W.; Kan, K.; Chong, K. Reactions of Some Organogermanium(II) Chlorides. Coord. Chem. Rev. 2007, 251, 2253-2265.

(161) Guo, J.; Lau, K.-C.; Xi, H.-W.; Lim, K. H.; So, C.-W. Synthesis and Characterization of a Tin(II) Bis(Phosphinoyl)Methanediide Complex: A Stannavinylidene Derivative. Chem. Commun. 2010, 46, 1929-1931.

(162) Foo, C.; Lau, K.-C.; Yang, Y.-F.; So, C.-W. Synthesis and Characterization of a Germanium Bismethanediide Complex. Chem. Commun. 2009, 5, 6816-6818.

(163) Leung, W.-P.; Chan, Y.-C.; Mak, T. C. W. Synthesis and Structural Characterization of a Tin Analogue of Allene. Inorg. Chem. 2011, 50, 10517-10518.

(164) Leung, W.-P.; Chiu, W.-K.; Mak, T. C. W. Synthesis and Structural Characterization of BaseStabilized Oligomeric Heterovinylidenes. Inorg. Chem. 2013, 52, 9479-9486. 
(165) Leung, W.-P.; Chan, Y.-C.; Mak, T. C. W. Synthesis and Structural Characterization of Lithium, Potassium, Magnesium, and Heavier Group 14 Metal Complexes Derived from 2-QuinolylLinked (Thiophosphorano)Methane. Organometallics 2013, 32, 2584-2592.

(166) Chai, Z.-Y.; Wang, Z.-X. Synthesis and Characterization of $\mathrm{Sn}(\mathrm{II}), \mathrm{Pb}(\mathrm{II})$ and $\mathrm{Yb}(\mathrm{II})$ Complexes Supported by $\left[\mathrm{C}\left(\mathrm{Ph}_{2} \mathrm{P}=\mathrm{NSiMe} 3\right)\left\{6-\left(2-\mathrm{RC}_{5} \mathrm{H}_{3} \mathrm{~N}\right)\right\}\right]_{2^{-}}$or $\left[\mathrm{CH}\left(\mathrm{Ph}_{2} \mathrm{P}=\mathrm{NSiMe} 3\right)\left\{6-\left(2-\mathrm{RC}_{5} \mathrm{H}_{3} \mathrm{~N}\right)\right\}\right]-(\mathrm{R}$ = 3,5-Dimethyl-1-Pyrazolyl or Iminophosphoranyl) Ligands. Dalt. Trans. 2009, 38, 8005-8012.

(167) Hitchcock, P. B.; Lappert, M. F.; Linnolahti, M.; Severn, J. R.; Uiterweerd, P. G. H.; Wang, Z.-X. Synthesis and Structures of the Dinuclear Tin(II) Complexes $[\mathrm{R}=\mathrm{Ph}, \mathrm{X}(\mathrm{Z})=\mathrm{CPh} ; \mathrm{R}=\mathrm{SiMe}$, $\left.\mathrm{X}(\mathrm{Z})=\mathrm{PPh}_{2}\right]$ and of Related Compounds. J. Organomet. Chem. 2009, 694, 3487-3499.

(168) Leung, W.-P.; Kan, K.-W.; Mak, T. C. W. Synthesis of Heavier Group 14 Metal Compounds from 2,6-Lutidylbis(Phosphoranosulfide). Organometallics 2010, 29, 1890-1896.

(169) Yang, Y.-F.; Foo, C.; Ganguly, R.; Li, Y.; So, C.-W. Synthesis of a Tin(II) 1,3Benzobis(Thiophosphinoyl)Methanediide Complex and Its Reactions with Aluminum Compounds. Organometallics 2012, 31, 6538-6546.

(170) Sigal, N.; Apeloig, Y. Theoretical Study of Heavier Group 14 Analogues of Allene. Organometallics 2002, 21, 5486-5493.

(171) Leung, W.; Kan, K.; So, C.; Mak, T. C. W. Formation of Germenes from Bis(Germavinylidene). Organometallics 2007, 26, 3802-3806.

(172) Leung, W.; So, C.; Kan, K.; Chan, H.; Mak, T. C. W. Synthesis of Novel Metal-Germavinylidene Complexes from Bisgermavinylidene. Organometallics 2005, 24, 50335037.

(173) Leung, W.-P.; So, C.-W.; Kan, K.-W.; Chan, H.-S.; Mak, T. C. W. Synthesis of a Manganese Germavinylidene Complex from Bis(Germavinylidene). Inorg. Chem. 2005, 44, 7286-7288.

(174) Leung, W.-P.; So, C.-W.; Wang, Z.-X.; Wang, J.-Z.; Mak, T. C. W. Synthesis of Bisgermavinylidene and Its Reaction with Chalcogens. Organometallics 2003, 22, 4305-4311.

(175) Leung, W.; Kan, K.; So, C.; Mak, T. C. W. Some Addition Reactions of Bisgermavinylidene. Appl. Organomet. Chem. 2007, 21, 814-818.

(176) Leung, W.-P.; Kan, K.-W.; Chan, Y.-C.; Mak, T. C. W. Synthesis of Hetero-Binuclear Complexes from Bisgermavinylidene. Inorg. Chem. 2013, 52, 4571-4577.

(177) Guo, J.-Y.; Li, Y.; Ganguly, R.; So, C.-W. Reactivity of a Tin(II) (Iminophosphinoyl)(Thiophosphinoyl)Methanediide Complex toward Isocyanates and Rhodium(I) Chloride. Organometallics 2012, 31, 3888-3893.

(178) Guo, J.-Y.; Xi, H.-W.; Nowik, I.; Herber, R. H.; Li, Y.; Lim, K. H.; So, C.-W. Reactivity of a Tin(II) (Iminophosphinoyl)(Thiophosphinoyl)Methanediide Complex toward Sulfur: Synthesis and 119Sn Mössbauer Spectroscopic Studies of $\left[\left\{(\mu-\mathrm{S}) \mathrm{SnC}\left(\mathrm{PPh}_{2}=\mathrm{NSiMe}_{3}\right)\left(\mathrm{PPh}_{2}=\mathrm{S}\right)\right\}_{3} \mathrm{Sn}(\mathrm{M} 3-\right.$ S)]. Inorg. Chem. 2012, 51, 3996-4001.

(179) Yang, Y.-F.; Ganguly, R.; Li, Y.; So, C.-W. Reactivity of a Tin(II) 1,3Benzodi(Thiophosphinoyl)Methanediide Complex toward Gallium, Germanium, and Zinc Compounds. Organometallics 2013, 32, 2643-2648. 
(180) Gessner, V. H. Reactivity and Applications of $\alpha$-Metalated Ylides. In Structure and Bonding; 2017; Vol. 44, pp 117-155.

(181) Corey, E. J.; Kang, J. $\alpha$-Lithiomethylenetriphenylphosphorane, a Highly Reactive Ylide Equivalent. J. Am. Chem. Soc. 1982, 104, 4724-4725.

(182) Buckle, J.; Harrison, P. G. The Stannylation of Carbonyl-Stabilised Phosphorus Ylids, and TinAssisted Elimination Reactions. J. Organomet. Chem. 1974, 77, C22-C24.

(183) Schlosser, M.; Kadibelban, T.; Steinhoff, G. Nucleophilic Ligand Exchange by Phosphoranes. Angew. Chem. Int. Ed. 1966, 5, 968-969.

(184) Corey, E. J.; Kang, J.; Kyler, K. Activation of Methylenetriphenylphosphorane by Reaction with T-Butyl- or Sec-Butyllithium. Tetrahedron Lett. 1985, 26, 555-558.

(185) Schaub, B.; Schlosser, M. New Evidence for and New Reactions of Ortho-Lithio Ylids. Tetrahedron Lett. 1985, 26 (13), 1623-1626.

(186) Schaub, B.; Jenny, T.; Schlosser, M. Ortho-Lithiation of Triphenylphosphonio-Methylid and, Also, Triphenylphosphine Oxide. Tetrahedron Lett. 1984, 25, 4097-4100.

(187) Mckenna, E. G.; Walker, B. J. The Mechanism and Stereochemistry of Wittig Reactions of Phosphonium Ylide-Anions. Phosphorus, Sulfur Silicon Relat. Elem. 1990, 49-50, 445-448.

(188) Bestmann, H. J.; Besold, R.; Sandmeier, D. Über Die Umsetzung von Äthoxycarbonyl-MethylenTriphenylphosphoran Mit Phenyl- Und Butyllithium. Tetrahedron Lett. 1975, 16, 2293-2294.

(189) Bestmann, H. J.; Sandmeter, D. Einfache Synthese Des Ketenyliden-Triphenylphosphorans Und Seines Thioanalogen. Angew. Chem. 1975, 87, 630-630.

(190) Bestmann, H. J.; Schmidt, M. Synthesis of Nitriles via the Ylide Anion of Sodium Cyanotriphenylphosphoranylidenemethanide. Angew. Chem. Int. Ed. Engl. 1987, 26, 79-81.

(191) Baumgartner, T.; Schinkels, B.; Gudat, D.; Nieger, M.; Niecke, E. Lithium Phosphoranylidene Ylides Mes*-P(E)C(H)Li(THF) $)_{3}\left(\mathrm{E}=\mathrm{NMes}^{*}, \mathrm{C}\left(\mathrm{SiMe}_{3}\right)_{2}\right)$ : Synthesis, Crystal Structure, and Transmetalation. J. Am. Chem. Soc. 1997, 119, 12410-12411.

(192) van Leusen, A. M.; Reith, B. A.; Iedema, A. J. W.; Strating, J. Sulfonyl-Stabilized Phosphonium Ylids. Recl. Trav. Chim. Pays-Bas 2010, 91, 37-49.

(193) Goumri-Magnet, S.; Gornitzka, H.; Baceiredo, A.; Bertrand, G. Synthetic Utility of Stable Phosphanylcarbenes: Synthesis and Crystal Structure of An $\alpha$-(Lithiomethylene)Phosphorane. Angew. Chem. Int. Ed. 1999, 38, 678-680.

(194) Scherpf, T.; Wirth, R.; Molitor, S.; Feichtner, K. S.; Gessner, V. H. Bridging the Gap between Bisylides and Methandiides: Isolation, Reactivity, and Electronic Structure of an Yldiide. Angew. Chem. Int. Ed. 2015, 54, 8542-8546.

(195) Garduno-Alva, A.; Lenk, R.; Escudié, Y.; González, M. L.; Bousquet, L.; Saffon-Merceron, N.; Toledano, C. A.; Bagan, X.; Branchadell, V.; Maerten, E.; et al. Synthesis, Structure, and Reactivity of a Stable Phosphonium-Sulfinyl Yldiide. Eur. J. Inorg. Chem. 2017, 2017, 34943497.

(196) Alcaraz, G.; Reed, R.; Baceiredo, A.; Bertrand, G. Synthesis and Evolution of 
Phosphanylcarbene-borane Adducts. J. Chem. Soc., Chem. Commun. 1993, 4, 1354-1355.

(197) Schinkels, B.; Ruban, A.; Nieger, M.; Niecke, E. Synthesis , Crystal Structure and Rearrangement of a Methylene(Ylene)-Phosphorane Containing a $\mathrm{CH}_{2}$-Moiety at an $\mathrm{sp}^{2}$-Hybridized Phosphorus(V) Centre. Chem. Commun. 1997, 612, 293-294.

(198) A CCDC Search on C-K Bond Distances Gives a Mean Value at 3.159 Angstrom on a Population of 229 Bonds (November, 20th 2018).

(199) Scharf, L. T.; Andrada, D. M.; Frenking, G.; Gessner, V. H. The Bonding Situation in Metalated Ylides. Chem. - Eur. J. 2017, 23, 4422-4434.

(200) McDowell, R. S.; Streitwieser, A. Ab Initio SCF-MO Study of (.Alpha.Lithiomethylene)Phosphorane. J. Am. Chem. Soc. 1984, 106, 4047-4048.

(201) Bestmann, H. J.; Kosb, A. J.; Witzgall, K.; Schleyer, P. V. R. Heterosubstituenteneinflusse Auf Die Stabilitat von Phosphoniumylidene. Eine Ab-Initio-MO-Studie. Chem. Ber. 1986, 119, 13311349.

(202) Scharf, L. T.; Gessner, V. H. Metalated Ylides: A New Class of Strong Donor Ligands with Unique Electronic Properties. Inorg. Chem. 2017, 56, 8599-8607.

(203) Schlosser, M.; Christmann, F. K.; Piskala, A.; Coffinet, D. Alpha-Substitution plus Carbonyl Olefination via Beta-Oxido Phosphorus Ylids (S.C.O.O.P.Y.-Reactions) Scope and Stereoselectivity. Synthesis 1971, 01, 29-31.

(204) Schlosser, M.; Tuong, H. B.; Respondek, J.; Schaub, B. SCOOPY and Oxirane Reactions: Alpha-Lithio-Ylides vs . Conventional Ylides. Chimia 1983, 37, 10-11.

(205) Shiozaki, M.; Kobayashi, Y.; Arai, M.; Haruyama, H. Synthesis of 6-epi-trehazolin from Dribonolactone: evidence for the non-existence of a 5,6-ring fused structural isomer of 6-epitrehazolin. Tetrahedron Lett. 1994, 35, 887-890.

(206) Jiang, $\quad$ F.; Shapiro, P. J.; $\quad$ Fahs, $\quad$ F.; $\quad$ Twamley, B. Phenyl $\{$ bis(Triphenylphosphanemethylenido)\}borane: A Zwitterionic Chelating Ligand Exhibiting Allyl-Type Coordination. Angew. Chem. Int. Ed. 2003, 42, 2651-2653.

(207) Morosaki, T.; Iijima, R.; Suzuki, T.; Wang, W. W.; Nagase, S.; Fujii, T. Synthesis, Electronic Structure, and Reactivities of Two-Sulfur-Stabilized Carbones Exhibiting Four-Electron Donor Ability. Chem. - Eur. J. 2017, 23, 8694-8702.

(208) Bestmann, H. J.; Schmidt, M. Synthese von Gamma-Butyrolactonen Und Alpha-MethylenoGamma-Butyrolactonen Aus Epoxiden Und Natrium-[Cyan-(Triphenylphosphoranyliden)Methanid]. Tetrahedron Lett. 1987, 28, 2111-2114.

(209) Dellus, N.; Kato, T.; Bagán, X.; Saffon-Merceron, N.; Branchadell, V.; Baceiredo, A. An Isolable Mixed P,S-Bis(Ylide) as an Asymmetric Carbon Atom Source. Angew. Chem. Int. Ed. 2010, 49, 6798-6801.

(210) Churchill, M. R.; Rotella, F. J. Crystal Structure and Molecular Configuration of $\mathrm{Fe} 2(\mathrm{CO}) 6[\mathrm{C}(\mathrm{CHO}) \mathrm{P}(\mathrm{Ph} 2 \mathrm{C} 6 \mathrm{H} 4)]$, a Species with an Ortho-Dimetalated Phenyl Ring. Inorg. Chem. 1978, 17, 2614-2621.

(211) Watson, P. L. Facile C-H Activation by Lutetium-methyl and Lutetium-hydride Complexes. J. 
Chem. Soc., Chem. Commun. 1983, 276-277.

(212) Rufanov, K. A.; Müller, B. H.; Spannenberg, A.; Rosenthal, U. Synthesis and Molecular Structures of the First Phosphoranylidene Complexes of Rare Earth Metals. New J. Chem. 2006, 30, 29-31.

(213) Mao, W.; Xiang, L.; Maron, L.; Leng, X.; Chen, Y. Nonchelated Phosphoniomethylidene Complexes of Scandium and Lutetium. J. Am. Chem. Soc. 2017, 139, 17759-17762.

(214) Cramer, R. E.; Maynard, R. B.; Gilje, J. W. Crystal and Molecular Structure of a Biscyclopentadienyluranium(IV) Phosphoylide Dimer, $[\mu$ $\left.(\mathrm{CH})\left(\mathrm{CH}_{2}\right) \mathrm{P}\left(\mathrm{C}_{6} \mathrm{H}_{5}\right)_{2} \mathrm{U}\left(\mathrm{C}_{5} \mathrm{H}_{5}\right)_{2}\right]_{2}\left(\mathrm{C}_{2} \mathrm{H}_{5}\right)_{2} \mathrm{O}$. J. Am. Chem. Soc. 1978, 100, 5562-5564.

(215) Cramer, R. E.; Maynard, R. B.; Gilje, J. W. Reaction of $\left(\eta^{5}-\mathrm{C}_{5} \mathrm{H}_{5}\right)_{3} \mathrm{UCl}$ with Lithiated Phosphoylides. Preparation of Some Mono-, Bis-, and Tris(Cyclopentadiene)Uranium(IV) Phosphoylide Complexes. Inorg. Chem. 1981, 20, 2466-2470.

(216) Cramer, E.; Bruck, A.; Higa, T.; Panchanetheswaran, K.; Gilje, J, R. E. Cramer, M. A. Bruck, K. T. Higa, K. P. Organoactinoid Chemistry with Phosphoylids. Inorg. Chim. Acta 1985, 110, 139143.

(217) Rungthanaphatsophon, P.; Bathelier, A.; Castro, L.; Behrle, A. C.; Barnes, C. L.; Maron, L.; Walensky, J. R. Formation of Methane versus Benzene in the Reactions of $\left(\mathrm{C}_{5} \mathrm{Me}_{5}\right)_{2} \mathrm{Th}\left(\mathrm{CH}_{3}\right)_{2}$ with $\left[\mathrm{CH}_{3} \mathrm{PPh}_{3}\right] \mathrm{X}(\mathrm{X}=\mathrm{Cl}, \mathrm{Br}, \mathrm{I})$ Yielding Thorium-Carbene or Thorium-Ylide Complexes. Angew. Chem. Int. Ed. 2017, 56, 12925-12929.

(218) Rungthanaphatsophon, P.; Huang, P.; Walensky, J. R. Phosphorano-Stabilized Carbene Complexes with Short Thorium(IV)- and Uranium(IV)-Carbon Bonds. Organometallics 2018, 37, 1884-1891.

(219) Fortier, S.; Walensky, J. R.; Wu, G.; Hayton, T. W. Synthesis of a Phosphorano-Stabilized U(IV)-Carbene via One-Electron Oxidation of a U(III)-Ylide Adduct. J. Am. Chem. Soc. 2011, 133, 6894-6897.

(220) Smiles, D. E.; Wu, G.; Hrobárik, P.; Hayton, T. W. Synthesis, Thermochemistry, Bonding, and 13C NMR Chemical Shift Analysis of a Phosphorano-Stabilized Carbene of Thorium. Organometallics 2017, 36, 4519-4524.

(221) Baldwin, J. C.; Keder, N. L.; Strouse, C. E.; Kaska, W. C. The Synthesis of Organometallic Ylides Interaction of Methylenetriphenylphosphorane with Bis(Eta 5 -Cyclopentadienyl)Zirconium and -Hafnium Dichlorides and the Molecular Structure of Bis $\left(\eta^{5}\right.$ Cyclopentadienyl)Chlorozirconylmethylenetriphenylphosphoran. Z. Naturforsch. B 1980, 35b, 1289.

(222) Belmonte, P.; Schrock, R. R.; Churchill, M. R.; Youngs, W. J. Preparation of a Stabilized Formyl Complex from Carbon Monoxide and Hydrogen and the Crystal Structure of a Derivative in Which the C-O Bond Has Been Cleaved. J. Am. Chem. Soc. 1980, 102, 2858-2860.

(223) Churchill, M. R.; Youngs, W. J. Crystal Structure and Molecular Geometry of a Dinuclear "Disrupted Formyl" Complex of Tantalum, $\left[\left(n_{5}-\mathrm{C}_{5} \mathrm{Me}_{4} \mathrm{Et}\right) \mathrm{TaCl}_{2}\right]_{2}(\mathrm{H})\left(\mu-\mathrm{CHPMe}_{3}\right)(\mu-\mathrm{O})$. Inorg. Chem. 1981, 20, 382-387. 
(224) Schmidt, S.; Sundermeyer, J.; Möller, F. Higher-Valent Derivatives of the d-Metal Acids. J. Organomet. Chem. 1994, 475, 157-166.

(225) Roland Kreissl, F. Zur Umsetzung von Trans-Bromotetracarbonyltolylcarbinchrom Mit Trimethylphosphin. J. Organomet. Chem. 1975, 99, 305-308.

(226) Uedelhoven, W.; Neugebauer, D.; Kreissl, F. R. $\mu$-Ylidkomplexe von Chrom, Wolfram Und Rhenium. J. Organomet. Chem. 1981, 217, 183-194.

(227) Sundermeyer, J.; Weber, K.; Nürnberg, O. ( $\alpha$-Triphenylphosphonio)Methylidene Imido Complexes of Molybdenum, Tungsten and Rhenium: The First Complexes Exhibiting Metalligand Multiple-Bonding with Two Carbon as Well as Two Nitrogen Centres. J. Chem. Soc., Chem. Commun. 1992, 1631, 1631-1633.

(228) Sundermeyer, J.; Weber, K.; Pritzkow, H. Synthese Des Ersten Stabilen 2-Chromaoxetans Und Seiner Homologen Über $\alpha$-Phosphonio(Methyliden)-Komplexe von Sechswertigem Chrom, Molybdän Und Wolfram. Angew. Chem. 1993, 105, 751-753.

(229) Sundermeyer, J.; Putterlik, J.; Pritzkow, H. Organometall-Oxide - Höhervalente Derivate Der dMetall-Säuren, 6. Tris(3,5-Dimethyl-1-Pyrazolyl)Boranato-Substituierte Alkyl(Dioxo)1-, Methylenphosphoranyl(Dioxo)1- Und s1-Allyl(Dioxo)1-Komplexe Des Molybdäns Und Wolframs. Chem. Ber. 1993, 126, 289-296.

(230) Filippou, A. C.; Wössner, D.; Kociok-Köhn, G.; Hinz, I. Metal-carbon Multiple Bonds: HalfSandwich Phenylcarbyne Complexes of Chromium - synthesis, Structure, Electrochemistry and Reactions with PMe3. J. Organomet. Chem. 1997, 541, 333-343.

(231) Li, X.; Schopf, M.; Stephan, J.; Harms, K.; Sundermeyer, J. Heavily $\pi$-Bond-Loaded Tungsten Phosphonio-Alkylidyne Complexes via a Domino Transylidation Cascade at (Organoimido)Tungsten Tetrachlorides. Organometallics 2002, 21, 2356-2358.

(232) VenkatRamani, S.; Schrock, R. R.; Hoveyda, A. H.; Müller, P.; Tsay, C. Synthesis of HighOxidation-State $\mathrm{Mo}=\mathrm{CHX}$ Complexes, Where $\mathrm{X}=\mathrm{Cl}, \mathrm{CF}_{3}$, Phosphonium, CN. Organometallics 2018, 37, 1641-1644.

(233) Kaska, W. C.; Reichelderfer, R. F.; Mitchell, D. K.; Korte, W. D. The Interaction of Phosphorus Ylides with Transition Metal Carbonyl Compounds. Triphenylphosphinemethylene and Bis(Triphenylphosphine)Carbon. Comparative Chemistry. J. Am. Chem. Soc. 1974, 96, 28472854.

(234) Wong, W. K.; Tam, W.; Gladysz, J. A. Electrophile-Induced Disproportionation of the Neutral Formyl $\left(\eta-\mathrm{C}_{5} \mathrm{H}_{5}\right) \mathrm{Re}\left(\mathrm{PPh}_{3}\right)(\mathrm{NO})(\mathrm{CHO})$. Generation of Cationic Rhenium Carbenes of the Formula $\left[\left(\eta-\mathrm{C}_{5} \mathrm{H}_{5}\right) \mathrm{Re}\left(\mathrm{PPh}_{3}\right)(\mathrm{NO})(\mathrm{CHX})\right]^{+}\left(\mathrm{X}=\mathrm{H}, \mathrm{OCH}_{3}, \mathrm{OH}\right)$. J. Am. Chem. Soc. 1979, 101, 5440-5442.

(235) Kreißl, F. R.; Stückler, P.; Meineke, E. W. Zur Darstellung Kationischer, ÜbergangsmetallSubstituierter Phosphor-Ylide. Chem. Ber. 1977, 110, 3040-3045.

(236) Kreißl, F. R.; Friedrich, P. Molecular Structure of $\left[\eta-\mathrm{C}_{5} \mathrm{H}_{5}(\mathrm{CO})_{2} \mathrm{Re}=\mathrm{C}\left(\mathrm{C}_{6} \mathrm{H}_{5}\right) \mathrm{P}\left(\mathrm{CH}_{3}\right)_{3}\right]\left[\mathrm{BCl}_{4}\right]$. Angew. Chem., Int. Ed. Engl. 1977, 16, 543-544.

(237) Jeffery, J. C.; Navarro, R.; Razay, H.; Stone, F. G. A. Chemistry of Di- and Tri-Metal Complexes with Bridging Carbene or Carbyne Ligands. Part 9. Reactivity of the Cations $[\operatorname{MPt}(\mu-$ 
$\left.\left.\mathrm{CC}_{6} \mathrm{H}_{4} \mathrm{Me}_{4}\right)(\mathrm{CO})_{2}\left(\mathrm{PR}_{3}\right)_{2}\left(\eta-\mathrm{C}_{5} \mathrm{H}_{5}\right)\right]^{+}\left(\mathrm{M}=\mathrm{Mn}\right.$ or $\mathrm{Re}, \mathrm{PR}_{3}=\mathrm{PMe}_{3}$ or $\left.\mathrm{PMe}_{2} \mathrm{Ph}\right)$ towards Tertiary Phosphines and the Toluene. J. Chem. Soc., Dalt. Trans. 1981, 2471-2478.

(238) Kao, S. C.; Lu, P. P. Y.; Pettit, R.; Lu, P. P. Y. Preparation and Properties of Bis $\left(\eta^{5}-\right.$ Cyclopentadienyl)- $\mu$-Methylene-Diiron Tricarbonyl and Some of Its Derivatives. Organometallics 1982, 1, 911-918.

(239) Churchill, M. R.; Korzenski, M. B.; Janik, T. S. Synthesis and Crystal Structure of a Dinuclear Organometallic Phosphonium Ylid Complex, $\left[\left(\eta^{5}-\mathrm{C}_{5} \mathrm{H}_{5}(\mathrm{CO}) \mathrm{C}_{2}(\mu-\mathrm{CO})\left(\mu-\mathrm{CHP}\left(\mathrm{C}_{6} \mathrm{H}_{5}\right)_{3}\right)^{+}\right]\left[\mathrm{PF}_{6}{ }^{-}\right] . J\right.$. Chem. Crystallogr. 1996, 26, 683-690.

(240) Churchill, D. G.; Churchill, M. R.; Janik, T. S. Synthesis and Crystal Structure of $\left[\{\mathrm{CpFe}(\mathrm{CO})\}_{2}(\mu-\mathrm{CO})-\left(\mu-\mathrm{CHPMe}_{3}\right)^{+}\right]\left[\mathrm{PF}_{6}{ }^{-}\right]$. J. Chem. Crystallogr. 1997, 27, 667-671.

(241) Hogarth, G.; Knox, S. A. R.; Lloyd, B. R.; Macpherson, K. A.; Morton, D. A. V; Orpen, A. G. Reactivity of Bis(Diphenylphosphino) Methane at a Di-Iron Centre: Thermally Induced Rearrangements of Dimetallacyclopentenone Complexes $\left[\mathrm{Fe}_{2}(\mathrm{CO})_{5}\left\{\mu-\sigma: \eta^{3}-\mathrm{C}(\mathrm{O}) \mathrm{CRCR}\right\}(\mu-\right.$ Dppm)]. Inorg. Chim. Acta 1996, 251, 167-176.

(242) Romero, P. E.; Piers, W. E.; McDonald, R. Rapidly Initiating Ruthenium Olefin-Metathesis Catalysts. Angew. Chem. Int. Ed. 2004, 43, 6161-6165.

(243) Dubberley, S. R.; Romero, P. E.; Piers, W. E.; McDonald, R.; Parvez, M. Synthesis, Characterization and Olefin Metathesis Studies of a Family of Ruthenium Phosphonium Alkylidene Complexes. Inorg. Chim. Acta 2006, 359, 2658-2664.

(244) Leitao, E. M.; Van Der Eide, E. F.; Romero, P. E.; Piers, W. E.; McDonald, R. Kinetic and Thermodynamic Analysis of Processes Relevant to Initiation of Olefin Metathesis by Ruthenium Phosphonium Alkylidene Catalysts. J. Am. Chem. Soc. 2010, 132, 2784-2794.

(245) Qiao, W.; Shao, M.; Wang, J. Synthesis, Structure and Catalytic Study of Chloro-Bridged TwoCore Ruthenium Carbene Complexes. J. Organomet. Chem. 2012, 713, 197-202.

(246) Macnaughtan, M. L.; Johnson, M. J. A.; Kampf, J. W. Olefin Metathesis Reactions with Vinyl Halides: Formation, Observation, Interception, and Fate of the Ruthenium-Monohalomethylidene Moiety. J. Am. Chem. Soc. 2007, 129, 7708-7709.

(247) Chiu, T. W.; Liu, Y. H.; Chi, K. M.; Wen, Y. S.; Lu, K. L. Synthesis, Structure, and Transformation of Novel Osmium Azine and Ylide Complexes. Inorg. Chem. 2005, 44, 64256430.

(248) Zurawinski, R.; Donnadieu, B.; Mikolajczyk, M.; Chauvin, R. Chiral Phosphino(Sulfinylmethyl)Triarylphosphonium Ylide Ligands: Rhodium Complexes and Catalytic Properties. Organometallics 2003, 22, 4810-4817.

(249) Zurawinski, R.; Lepetit, C.; Canac, Y.; Mikolajczyk, M.; Chauvin, R. From Neutral to Anionic $\eta$ 1 -Carbon Ligands: Experimental Synthesis and Theoretical Analysis of a Rhodium-Yldiide Complex. Inorg. Chem. 2009, 48, 2147-2155.

(250) König, H.; Klein, H. F.; Joëlle Menu, M.; Dartiguenave, M.; Dartiguenave, Y. Synthesis of Novel Polyfunctional Nickel(II)-Nickel(II) Dimer $\mathrm{Ni}_{2} \mathrm{Cl}_{2}\left[\mathrm{C}\left(\mathrm{SiMe}_{3}\right)\left(\mathrm{PMe}_{3}\right)\right]_{2}$ by Photolysis of the First [(Trimethylsilyl)Diazomethyl]Nickel(II) Complex Ni[C(N $\left.\left.\mathrm{N}_{2}\right) \mathrm{SiMe}_{3}\right] \mathrm{Cl}\left(\mathrm{PMe}_{3}\right)_{2}$. J. Am. Chem. Soc. 
1990, 112, 5351-5353.

(251) Vicente, J.; Chicote, M. T.; Saura-Llamas, I.; Jones, P. G.; Meyer-Bäse, K.; Erdbrügger, C. F. Synthesis of Gold(I), Gold(III), and Silver(I) Complexes with Ylide Ligands Derived from Carbonylbis(Methylenetriphenylphosphonium) Diperchlorate. Crystal and Molecular Structures of $\left.\quad\left[\mathrm{Au}_{2}\left\{\mu-\left\{\left\{\mathrm{CHPPh}_{3}\right)\right\} \mathrm{CO}\right\}\right\}_{2}\right]\left(\mathrm{ClO}_{4}\right)_{2}, \quad\left[\left(\mathrm{PhPCCl}_{2}\right) \mathrm{SCO}\right]\left[\mathrm{AuCl}_{4}\right]\left(\mathrm{ClO}_{4}\right), \quad\left[(\mathrm{AuL})_{2}\{\mu-\right.$. $\left.\left.\left.\mathrm{C}\left(\mathrm{PPh}_{3}\right) \mathrm{C}(\mathrm{O}) \mathrm{CH}\left(\mathrm{PPh}_{3}\right)(\mathrm{AuL})\right\}\right\}\right]\left(\mathrm{ClO}_{4}\right)_{2} \quad\left(\mathrm{~L} \quad=\quad \mathrm{PPh}_{3}\right), \quad$ and $\quad\left[\left\{\mathrm{Au}\left(\mathrm{PMe}_{2} \mathrm{Ph}\right)\right\}_{4}\{\mu-\right.$ $\left.\left.\left\{\left\{\mathrm{C}\left(\mathrm{PPh}_{3}\right)\right\}_{2} \mathrm{CO}\right\}\right\}\right]\left(\mathrm{ClO}_{4}\right)_{2}$ Organometallics 1988, 7, 997-1006.

(252) Vicente, J.; Chicote, M.-T.; Lagunas, M.-C.; Jones, P. G. A New Class of $\mathrm{Au}_{2}^{\mathrm{I}} \mathrm{Ag}^{\mathrm{I}}$ Cluster. J. Chem. Soc. Chem. Commun. 1991, 24, 1730-1731.

(253) Gimeno, M. C.; Laguna, A.; Laguna, M.; Sanmartín, F.; Jones, P. G. Reactions of [Au(Acac) $\mathrm{PPh}_{3}$ ] with Diphosphine Derivatives: Different Coordination Modes of Gold to the Ligand Systems. X-Ray Structure of $\left[\mathrm{SPPh}_{2} \mathrm{C}\left(\mathrm{AuPPh}_{3}\right)_{2} \mathrm{PPh}_{2} \mathrm{CH}\left(\mathrm{AuPPh}_{3}\right) \mathrm{COOMe}_{\mathrm{ClO}}\right.$ and $\left[\mathrm{Au}_{5}\left(\mathrm{C}_{6} \mathrm{~F}_{5}\right)\left\{\left(\mathrm{SPPh}_{2}\right)_{2} \mathrm{C}\right\}_{2}\left(\mathrm{PPh}_{3}\right)\right]$. Organometallics 1993, 12, 3984-3991.

(254) Schmidbaur, H.; Gabbaï, F.; Schier, A.; Riede, J. Hypercoordinate Carbon in Protonated Tetraauriomethane Molecules. Organometallics 1995, 14, 4969-4971.

(255) Ramirez, F.; Desai, N. B.; Hansen, B.; McKelvie, N. Hexaphenylcarbodiphosphorane, $\left(\mathrm{C}_{6} \mathrm{H}_{5}\right)_{3} \mathrm{PCP}\left(\mathrm{C}_{6} \mathrm{H}_{5}\right)_{3}$. J. Am. Chem. Soc. 1961, 83, 3539-3540.

(256) Ramirez, F.; Pilot, J. F.; Desai, N. B.; Smith, C. P.; Hansen, B.; McKelvie, N. A New Type of Stable Tetrapolar Phosphorus Ylide. J. Am. Chem. Soc. 1967, 89, 6273-6276.

(257) Driscoll, J. S.; Grisley, D. W.; Pustinger, J. V.; Harris, J. E.; Matthews, C. N. Properties and Reactions of Mesomeric Phosphonium Salts. J. Org. Chem. 1964, 29, 2427-2431.

(258) Birum, G. H.; Matthews, C. N. Mesomeric Phosphonium Dications. J. Am. Chem. Soc. 1966, 88, 4198-4203.

(259) Zybill, C.; Muller, G. Mononuclear Complexes of Copper(I) and Silver(I) Featuring the Metals Exclusively Bound to Carbon: Synthesis and Structure of (T)5-Pentamethylcyclopentadienyl) [(Trlphenylphosphonio)-(Triphenylphosphoranylidene)Methyl]Copper (I). Organometallics 1987, 6, 2489-2494.

(260) Gruber, M.; Bauer, W.; Maid, H.; Schöll, K.; Tykwinski, R. R. Synthetic and NMR Studies on Hexaphenylcarbodiphosphorane $\left(\mathrm{Ph}_{3} \mathrm{PCPPh}_{3}\right)$. Inorg. Chim. Acta 2017, 468, 152-158.

(261) Bestmann, H. J.; Oechsner, H. Reaktionen Des Hexaphenylcarbodiphosphorans, IV [1] Reaktionen Des Hexaphenylcarbodiphosphorans Mit Halogenverbindungen. Diphosphaallylkationen. Z. Naturforsch. 1983, 38b, 861-865.

(262) Vincent, A. T.; Wheatley, P. J. Crystal Structure of Methanetetraylbis (Triphenylphosphorane)(Hexaphenylcarbodiphosphorane). J. Chem. Soc. D Chem. Commun. 1971, 11, 582 .

(263) Vincent, A. T.; Wheatley, P. J. Crystal Structure of Bis(Triphenylphosphoranylidene)Methane [Hexa-Phenylcarbod Iphosphorane, $\mathrm{Ph}_{3} \mathrm{P}: \mathrm{C}: \mathrm{PPh}_{3}$ ]. J Chem Soc Dalt. Trans 1972, 617-622.

(264) Hardy, G. E.; Kaska, W. C.; Chandra, B. P.; Zink, J. I. Triboluminescence-Structure Relationships in Polymorphs of Hexaphenylcarbodiphosphorane and Anthranilic Acid, Molecular 
Crystals, and Salts. J. Am. Chem. Soc. 1981, 103, 1074-1079.

(265) Quinlivan, P. J.; Parkin, G. Flexibility of the Carbodiphosphorane, $\left(\mathrm{Ph}_{3} \mathrm{P}\right)_{2} \mathrm{C}$ : Structural Characterization of a Linear Form. Inorg. Chem. 2017, 56, 5493-5497.

(266) Gasser, O.; Schmidbaur, H. Bis(Trimethylphosphoranylidene)Methane, $\left(\mathrm{CH}_{3}\right)_{3} \mathrm{PCP}\left(\mathrm{CH}_{3}\right)_{3}$. J. Am. Chem. Soc. 1975, 97, 6281-6282.

(267) Schmidbaur, H.; Gasser, O.; Hussain, M. S. Doppelylide, I. Synthese Und Eigenschaften von Hexamethyl-Undsym-Tetramethyldiphenylcarbodiphosphoran. Chem. Ber. 1977, 110, 35013507.

(268) Appel, R.; Knoll, F.; Schöler, H.; Wihler, H.-D. Simplified Synthesis of Bis(Triphenylphosphoranylidene)Methane. Angew. Chem. Int. Ed. Engl. 1976, 15, 702-703.

(269) Miller, N. E. Trimethylsilyl Ylides. Inorg. Chem. 1965, 4, 1458-1463.

(270) Bowmaker, G. A.; Herr, R.; Schmidbaur, H. Carbodiphosphorane Isomers Based on a 1,3Diphosphaindane Skeleton, and Their Precursors. 1983, 3579, 3567-3579.

(271) Appel, R.; Erbelding, G. Über Die Darstellung Und Eine Neue Umlagerungsreaktion Von (Trialkylphosphoranyliden)(Triphenylphosphoranyliden)-Methanen (Carbodiphosphoranen). Tetrahedron Lett. 1978, 19, 2689-2692.

(272) Schmidbaur, H.; Herr, R.; Zybill, C. E. Synthesen Unsymmetrischer Methyl/Phenylcarbodiphosphorane Durch Aufbau Oder Umlagerung. Chem. Ber. 1984, 117, 3374-3380.

(273) Alcarazo, M.; Radkowski, K.; Mehler, G.; Goddard, R.; Fürstner, A. Chiral Heterobimetallic Complexes of Carbodiphosphoranes and Phosphinidene-carbene Adducts. Chem. Commun. 2013, 49, 3140-3142.

(274) Canac, Y.; Lepetit, C.; Abdalilah, M.; Duhayon, C.; Chauvin, R. Diaminocarbene and Phosphonium Ylide Ligands: A Systematic Comparison of Their Donor Character. J. Am. Chem. Soc. 2008, 130, 8406-8413.

(275) Hussain, M. S.; Schmidbaur, H. Ein Gemischt Methyl/Phenyl-Substituiertes Carbodiphosphoran. Darstellung, Reaktionen Und Verwandte Verbindungen / A Mixed Methyl-/Phenyl-Substituted Carbodiphosphorane. Synthesis, Reactions, and Related Compounds. Zeitschrift für Naturforsch. B 1976, 31, 2-7.

(276) Schmidbaur, H.; Hasslberger, G.; Deschler, U.; Schubert, U.; Kappenstein, C.; Frank, A. Problem of the Structure of Carbodiphosphoranes, $\mathrm{R}_{3} \mathrm{PCPR}_{3}$ : New Aspects. Angew. Chem. Int. Ed. 1979, $18,408-409$.

(277) Schubert, U.; Kappenstein, C.; Milewski-Mahrla, B.; Schmidbaur, H. Molekül- Und Kristallstrukturen Zweier Carbodiphosphorane Mit P-C-P-Bindungswinkeln Nahe $120^{\circ}$. Chem. Ber. 1981, 114, 3070-3078.

(278) Wohlleben, A.; Schmidbaur, H. "Carbodiphosphoranes" by a New Rearrangement of Phosphorus Ylides. Angew. Chem. Int. Ed. Engl. 1977, 16, 417-418.

(279) Schmidbaur, H.; Wohlleben-Hammer, A. Doppel-Ylide, VI. Ylidbildung Und Umlagerung Bei 1,3-Diphosphoniumsalzen. Chem. Ber. 1979, 112, 510-516. 
(280) Schmidbaur, H.; Costa, T.; Milewski-Mahrla, B.; Schubert, U. Ring-Strained Carbodiphosphoranes. Angew. Chem. Int. Ed. Engl. 1980, 19, 555-556.

(281) Schmidbaur, H.; Costa, T. Ein Cyclisches Carbodiphosphoran Und Eine Offenkettige Vergleichsverbindung. Chem. Ber. 1981, 114, 3063-3069.

(282) Schmidbaur, H.; Costa, T. Synthese Eines Doppel-Carbodiphosphorans Und Seiner Vorstufen. Zeitschrift fur Naturforsch. - Sect. B J. Chem. Sci. 1982, 37b, 677-679.

(283) Schmidbaur, H.; Schnatterer, S. Gerüstumlagerungen Der Methyltrimesitylphosphonium- Und Methylenbis(Methyldimesitylphosphonium)-Kationen Bei Der Basenbehandlung. Chem. Ber. 1983, 116, 1947-1954.

(284) Schmidbaur, H.; Pollok, T. Notizen. Synthese Eines Unsymmetrischen Carbodiphosphorans Durch Gerüstumlagerung Einer Cyclopropyliden-Vorstufe. Chem. Ber. 1987, 120, 1911-1912.

(285) Appel, R.; Knoll, F.; Michel, W.; Morbach, W.; Wihler, H.-D.; Veltmann, H. Reaktionen Im Zweikomponentensystem Triphen Ylphosphin/Tetrachlormethan. Chem. Ber. 1976, 109, 58-70.

(286) Appel, R.; Milker, R.; Ruppert, I. Notiz Über Chlormethin-Verbrückte MethylphosphoniumSalze. Chem. Ber. 1977, 110, 2385-2387.

(287) Appel, R.; Waid, K. Bis(chlorophenylphosphoranediyl)methane. Angew. Chem., Int. Ed. Engl. 1979, $18,169$.

(288) Appel, R.; Geisler, K.; Schöler, H.-F. On a New Synthesis of Methylenebis(diorgany1phospbanes) and an Unusual Decomposition by Alkali Metals. Chem. Ber. 1979, 112, 648-653.

(289) Appel, R.; Waid, K. Synthesis of Symmetrical Diaminocarbodiphosphoranes $\mathrm{R}_{2} \mathrm{NPh}_{2} \mathrm{P}=\mathrm{C}=\mathrm{PPh}_{2} \mathrm{NR}_{2}$. Z. Naturforsch. 1981, 36b, 131-134.

(290) Appel, R.; Baumeister, U.; Knoch, F. Synthesis and Molecular Structure of Amino Substituted Carbodiphosphoranes. Chem. Ber. 1983, 116, 2275-2284.

(291) Appel, R.; Wihler, H.-D. (Chlorodiphenylphosphoranylidene)(triphenylphosphoranylidene)methane, $\mathrm{Ph}{ }_{3} \mathrm{P}=\mathrm{C}=\mathrm{PPh}_{2} \mathrm{Cl}$. Chem. Ber. 1978, 111, 2054-2055.

(292) Appel, R.; Knoll, F.; Wihler, H.-D. Synthesis of a Stabilized $1 \lambda^{5}, 3 \lambda^{5}$-Diphosphacyclobutadiene. Angew. Chem., Int. Ed. Engl. 1977, 16, 402-403.

(293) Appel, R.; Baumeister, U. Synthesis of Diorganylamino Substituted Carbodiphosphoranes. $Z$. Naturforsch. 1980, 35b, 513-516.

(294) Fluck, E.; Neumuller, B.; Braun, R.; Heckmann, G.; Simon, A.; Borrmann, H. Fluoro Substituted and other New Carbodiphosphoranes. Z. Anorg. Allg. Chem. 1988, 567, 23-38.

(295) Fluck, E.; Braun, R. Alkyl- and Aryldifluorphosphorane. Synth. React. Inorg. Met.-Org. Chem. 1988, $18,727-738$.

(296) Holmes, R. R.; Holmes, J. M.; Day, R. O.; Swamy, K. C. K.; Chandrasekhar, V. Pentacoordinated Molecules. Synthesis and Molecular Structures of Fluorophosphoranes, $\mathrm{R}_{3} \mathrm{PF}_{2}$, Isoelectronic with Anionic Fluorosilicates. Phosphorus, Sulfur Silicon Relat. Elem. 1995, 103, 153-169.

(297) Plass, W.; Spahn, M.; Heckmann, G.; Fluck, E. New Carbodiphosphoranes. Note on the Reaction 
between Bis(dimethylamino)fluoromethylidene-phosphorane and $n$-Butyllithium. Z. Naturforsch. 1992, 47b, 947-951.

(298) Svara, J.; Fluck, E. Phosphorus Fluoroylides. Phosphorus, Sulfur Silicon Relat. Elem. 1985, 25, 129-137.

(299) Fluck, E.; Neumüller, B.; Riffel, H. Synthesis and NMR Spectra of $\lambda^{5}$-diphosphetes. Structure of 2,4-diphenyl-1,1,3,3-tetrakis(diethylamino)-1 $\lambda^{5}, 3 \lambda^{5}$-diphosphete. Z. Anorg. Allg. Chem. 1989, 576, 81-98.

(300) Soleilhavoup, M.; Baceiredo, A.; Bertrand, G. The "Phosphonioyl(phosphoranediyl)carbene" $\left[\left({ }^{i} \operatorname{Pr}_{2} \mathrm{~N}\right)_{2} \mathrm{P}(\mathrm{H}) \mathrm{CP}\left(\mathrm{N}^{i} \mathrm{Pr}_{2}\right)_{2}\right]^{+}$as a Source of New 1,3-Diphosphaallene Ylides: The First Carbodiphosphoranes with P-H Bonds. Angew. Chem., Int. Ed. 1993, 32, 1167-1169.

(301) Soleilhavoup, M.; Baceiredo, A.; Treutler, O.; Ahlrichs, R.; Nieger, M.; Bertrand, G. Synthesis and X-ray Crystal Structure of $\left[\left({ }^{i} \mathrm{Pr}_{2} \mathrm{~N}\right)_{2} \mathrm{P}(\mathrm{H}) \mathrm{CP}\left(\mathrm{N}^{i} \mathrm{Pr}_{2}\right)_{2}\right]^{+} \mathrm{CF}_{3} \mathrm{SO}_{3}{ }^{-}$: A Carbene, a Cumulene, or a Phosphaacetylene?. J. Am. Chem. Soc. 1992, 114, 10959-10961.

(302) Menu, M. J.; Dartiguenave, M.; Dartiguenave, Y.; Bonnet, J. J.; Bertrand, G.; Baceiredo, A. First Structural Characterization of an $\alpha$-diazophosphane: Crystal Structure of bis[bis(diisopropylamino)phosphanyl]diazomethane $\left[\left({ }^{i} \mathrm{Pr}_{2} \mathrm{~N}\right)_{2} \mathrm{P}\right]_{2} \mathrm{CN}_{2}$. J. Organomet. Chem. 1989, $372,201$.

(303) Shevchenko, I. An Unusual Reaction of Hexafluoroacetone with Methylenediphosphines. Facile Synthesis of Carbodiphosphoranes. Chem. Commun. 1998, 1203-1204.

(304) Shevchenko, I.; Mikolenko, R.; Loss, S.; Grützmacher, H. An Unusual Reaction of Hexafluoroacetone with Methylenediphosphines: Facile Synthesis of Carbodiphosphoranes. Eur. J. Inorg. Chem. 1999, 1665-1671.

(305) Shevchenko, I. V.; Mikolenko, R. N.; Lork, E.; Röschenthaler, G.-V. Interaction of Some Methylenediphosphanes with Hexafluoroacetone and Hexafluorothioacetone Dimer. Eur. J. Inorg. Chem. 2001, 2377-2383.

(306) Shevchenko, I. V.; Mikolenko, R. N.; Chernega, A. N.; Rusanov, E. B.; Grützmacher, H. An Unusual Oxidation of 1,5-Dimethyl-2,4-bis(dialkylamino)-1,5-diaza-2,4-diphosphinan-6-one with Hexafluoroacetone. Eur. J. Inorg. Chem. 2001, 195-199.

(307) Shevchenko, I. V.; Furmanova, M. V.; Kukhar, V. P; Schmutzler, R. cis-trans-Isomerism in 1,5Diaza-2,4-diphosphorinan-6-ones. Z. Naturforsch. 1992, 47b, 258-262.

(308) Marrot, S.; Kato, T.; Gornitzka, H.; Baceiredo, A. Cyclic Carbodiphosphoranes: Strongly Nucleophilic $\sigma$-Donor Ligands. Angew. Chem., Int. Ed. 2006, 45, 2598-2601.

(309) Marrot, S.; Kato, T.; Cossío, F. P.; Gornitzka, H.; Baceiredo, A. Cyclic CarbodiphosphoraneDiphosphinocarbene Thermal Interconversion. Angew. Chem., Int. Ed. 2006, 45, 7447-7450.

(310) Yogendra, S.; Schulz, S.; Hennersdorf, F.; Kumar, S.; Fischer, R.; Jan J. Weigand, J. J. Reductive Ring Opening of a Cyclo-Tri(phosphonio)methanide Dication to a Phosphanylcarbodiphosphorane: In Situ UV-Vis Spectroelectrochemistry and Gold Coordination. Organometallics 2018, 37, 748-754.

(311) Stallinger, S.; Reitsamer, C.; Schuh, W.; Kopacka, H.; Wurst, K.; Peringer, P. Novel Route to 
Carbodiphosphoranes Producing a new P,C,P Pincer Carbene Ligand. Chem. Commun. 2007, 510-512.

(312) Pascual, S.; Asay, M.; Illa, O.; Kato, T.; Bertrand, G.; Saffon-Merceron, N.; Branchadell, V.; Baceiredo, A. Synthesis of a Mixed Phosphonium-Sulfonium Bisylide $\mathrm{R}_{3} \mathrm{P}=\mathrm{C}=\mathrm{SR}_{2}$. Angew. Chem., Int. Ed. 2007, 46, 9078-9080.

(313) Dellus, N.; Kato, T.; Bagán, X.; Saffon-Merceron, N.; Branchadell, V.; Baceiredo, A. An Isolable Mixed P,S-Bis(ylide) as an Asymmetric Carbon Atom Source. Angew. Chem., Int. Ed. 2010, 49, 6798-6801.

(314) Gau, D.; Kato, T.; Saffon-Merceron, N.; De Cózar, A.; Cossío, F. P.; Baceiredo, A. Synthesis and Structure of a Base-Stabilized C-Phosphino-Si-Amino Silyne. Angew. Chem. Int. Ed. 2010, 49, 6585-6588.

(315) Rodriguez, R.; Gau, D.; Contie, Y.; Kato, T.; Saffon-Merceron, N.; Baceiredo, A. Synthesis of a Phosphine-Stabilized Silicon(II) Hydride and Its Addition to Olefins: A Catalyst-Free Hydrosilylation Reaction. Angew. Chem. Int. Ed. 2011, 50, 11492-11495.

(316) Troadec, T.; Wasano, T.; Lenk, R.; Baceiredo, A.; Saffon-Merceron, N.; Hashizume, D.; Saito, Y.; Nakata, N.; Branchadell, V.; Kato, T. Donor-Stabilized Silylene/Phosphine-Supported Carbon(0) Center with High Electron Density. Angew. Chem., Int. Ed. 2017, 56, 6891-6895.

(317) Fujii, T.; Ikeda, T.; Mikami, T.; Suzuki, T.; Yoshimura, T. Synthesis and Structure of $(\mathrm{MeN}) \mathrm{Ph}_{2} \mathrm{~S}=\mathrm{C}=\mathrm{SPh}_{2}(\mathrm{NMe})$. Angew. Chem. Int. Ed. 2002, 41, 2576-2578.

(318) Fujii, T.; Suzuki, T.; Sato, T.; Horn, E.; Yoshimura, T. Synthesis, Structure, and Reactivity of Iminosulfonium Ylides bearing an $\alpha$-Carbonyl Group. Tetrahedron Lett. 2001, 42, 6151-6154.

(319) Yoshimura, T.; Ohkubo, M.; Fujii, T.; Kita, H.; Wakai, Y.; Ono, S.; Morita, H.; Shimasaki, C.; Horn, E. Synthesis, Structure, and Thermolysis Mechanism of S-Alkoxythiazynes. Bull. Chem. Soc. Jpn. 1998, 71, 1629-1637.

(320) Morosaki, T.; Suzuki, T.; Wang, W.-W.; Nagase, S.; Fujii, T. Syntheses, Structures, and Reactivities of Two Chalcogen-Stabilized Carbones. Angew. Chem. Int. Ed. 2014, 53, 9569-9571.

(321) Morosaki, T.; Iijima, R.; Suzuki, T.; Wang, W.-W.; Nagase, S.; Fujii, T. Synthesis, Electronic Structure, and Reactivities of Two-Sulfur-Stabilized Carbones Exhibiting Four-Electron Donor Ability. Chem. Eur. J. 2017, 23, 8694-8702.

(322) Morosaki, T.; Wang, W.-W.; Nagase, S.; Fujii, T. Synthesis, Structure, and Reactivities of Iminosulfane- and Phosphane-Stabilized Carbones Exhibiting Four-Electron Donor Ability. Chem. Eur. J. 2015, 21, 15405-15411.

(323) Lozano Gonzalez, M.; Bousquet, L.; Hameury, S.; Alvarez Toledano, C.; Saffon-Merceron, N.; Branchadell, V.; Maerten, E.; Baceiredo, A. Phosphine/Sulfoxide-Supported Carbon(0) Complex. Chem. Eur. J. 2018, 24, 2570-2574.

(324) Alcarazo, M.; Lehmann, C. W.; Anoop, A.; Thiel, W.; Fürstner, A. Coordination chemistry at carbon. Nature Chem. 2009, 1, 295-301.

(325) Bestmann, H. J.; Schmid, G. Cumulated Ylides, IX: New Synthesis of N-substituted (Triphenylphosphoranylidene)ketenimines and (Triphenylphosphoranylidene)thioketene. Chem. 
Ber. 1980, 113, 3369-3372.

(326) Matthews, C. N.; Birum, G. H. Carbophosphoranes. Acc. Chem. Res. 1969, 2, 373-379.

(327) Bestmann. H. J. Phosphacumulene Ylides and Phosphaallene Ylides. Angew. Chem. Int. Ed. 1977, 16, 349-364.

(328) Bestmann, H. J.; Saalfvank, R. W.; Snyder, J. P. Cumulated Ylides, I: Synthesis of (2,2Diethoxyvinylidene)triphenylphosphorane and its Reaction with Fluorenone. Chem. Ber. 1973, 106, 2601-2609.

(329) Vicente, J.; Chicote, M. T.; Lagunasa, M. C.; Jones, P. G. Synthesis and Structural Characterization of Gold-(I), -(III) and Silver(I) Complexes of the Ylide Ligand $\mathrm{Ph}_{3} \mathrm{P}=\mathrm{CHC}(\mathrm{O}) \mathrm{NMe}_{2}$. Crystal Structure of $\left[\left(\mathrm{AuPPh}_{3}\right)_{2}\left\{\mu-\mathrm{C}\left(\mathrm{PPh}_{3}\right) \mathrm{C}(\mathrm{O}) \mathrm{NMe}_{2}\right\}\right] \mathrm{ClO}_{4}$. J. Chem. Soc. Dalton Trans. 1991, 2579-2583.

(330) Schmidbaur, H, Nusstein, P. Synthesis of the First Carbodiarsane and Related Arsenic Ylides. Organometallics 1985, 4, 344-346.

(331) Schmidbaur, H. Phosphorus Ylides in the Coordination Sphere of Transition Metals: An Inventory. Angew. Chem. Int. Ed. Engl. 1983, 22, 907-927.

(332) Ostoja Starzewski, K. A.; Tom Dieck, H.; Bock, H. Photoelectron Spectra and Molecular Properties. 57. Electronic Structure and Reactivity of Ylidic Systems. 7. Phosphorus Ylides: Gas Phase Ionization Potentials and Charge Distribution. J. Am. Chem. Soc. 1976, 98, 8486-8494.

(333) Speziale, A. J.; Ratts, K. W. Reactions of Phosphorus Compounds. III. Synthesis of Phosphinedihalomethylenes via Dihalocarbenes. A Novel Synthesis of 1,1-Dihaloolefins. J. Am. Chem. Soc. 1962, 84, 854-859.

(334) Kaska, W. C.; Mitchell, D. K.; Reichelderfer, R. F. Transition Metal Complexes of Hexaphenylcarbodiphosphorane. J. Organomet. Chem. 1973, 47, 391-402.

(335) Schmidbaur, H.; Schier, A. Coordination Chemistry at Carbon: The Patchwork Family Comprising $\left(\mathrm{Ph}_{3} \mathrm{P}\right)_{2} \mathrm{C},\left(\mathrm{Ph}_{3} \mathrm{P}\right) \mathrm{C}\left(\mathrm{C}_{2} \mathrm{H}_{4}\right)$, and $\left(\mathrm{C}_{2} \mathrm{H}_{4}\right)_{2} \mathrm{C}$. Angew. Chem. Int. Ed. 2013, 52, 176-186.

(336) Albright, T. A.; Hofmann, P.; Rossi, A. R. A Study of the Bonding and Geometry in Phosphacumulene Ylides. Zeitschrift für Naturforsch. B 1980, 35, 343-351.

(337) Glidewell, C. Skeletal Structures of Hexa-Organo Substituted Triatomics $\mathrm{R}_{3} \mathrm{XYZR}$ : $\mathrm{A}$ Rationalisation Using the Second-Order Jahn-Teller Effect. J. Organomet. Chem. 1978, 159, 2330 .

(338) Schmidbaur, H. Réplique: A New Concept for Bonding in Carbodiphosphoranes? Angew. Chem. Int. Ed. 2007, 46, 2984-2985; author reply 2986-2987.

(339) Tonner, R.; Öxler, F.; Neumüller, B.; Petz, W.; Frenking, G. Carbodiphosphoranes: The Chemistry of Divalent Carbon(0). Angew. Chem. Int. Ed. 2006, 45, 8038-8042.

(340) Tonner, R.; Frenking, G. C(NHC) $)_{2}$ : Divalent Carbon(0) Compounds with N-Heterocyclic Carbene Ligands - Theoretical Evidence for a Class of Molecules with Promising Chemical Properties. Angew. Chem. Int. Ed. 2007, 46, 8695-8698.

(341) Tonner, R.; Frenking, G. Divalent Carbon(0) Chemistry, Part 1: Parent Compounds. Chem. - Eur. 
J. 2008, 14, 3260-3272.

(342) Tonner, R.; Frenking, G. Divalent Carbon(0) Chemistry, Part 2: Protonation and Complexes with Main Group and Transition Metal Lewis Acids. Chem. - A Eur. J. 2008, 14, 3260-3289.

(343) Zhao, L.; Hermann, M.; Holzmann, N.; Frenking, G. Dative Bonding in Main Group Compounds. Coord. Chem. Rev. 2017, 344, 163-204.

(344) Himmel, D.; Krossing, I.; Schnepf, A. Dative or Not Dative? Angew. Chem. Int. Ed. 2014, 53, 6047-6048.

(345) Himmel, D.; Krossing, I.; Schnepf, A. Dative Bonds in Main-Group Compounds: A Case for Fewer Arrows! Angew. Chem. Int. Ed. 2014, 53, 370-374.

(346) Alcarazo, M., On the metallic natuer of carbon in allenes and heterocumulenes. Dalton. Trans. 2011, 40, 1839-1845.

(347) Bertrand, G. Rethinking Carbon. Nat. Chem. 2010, 1, 265-266.

(348) Dyker, C. A.; Lavallo, V.; Donnadieu, B.; Bertrand, G. Synthesis of an Extremely Bent Acyclic Allene (A "Carbodicarbene" ): A Strong Donor Ligand. Angew. Chem. Int. Ed. 2008, 47, 32063209.

(349) Petz, W.; Öxler, F.; Aicher, K.; Neumüller, B. Formation and Crystal Structures of Lewis Acid Adducts of $\mathrm{Ph}_{3} \mathrm{PCHP}(\mathrm{O}) \mathrm{Ph}_{2}$; New Neutral and Cationic Species. Z. Anorg. Allg. Chem. 2010, 636, 1751-1759.

(350) Petz, W.; Neumüller, B. On the Alkylation of $\mathrm{Ph}_{3} \mathrm{PCHP}(\mathrm{O}) \mathrm{Ph}_{2}$ : Formation and Crystal Structures of Neutral and Cationic Addition Compounds. Eur. J. Inorg. Chem. 2014, 1218-1224.

(351) Kuzu, I.; Kneusels, N.-J. H.; Bauer, M.; Neumüller, B.; Tonner, R. Synthesis and Characterization of the Silylated HexaphenylCarbodiphosphorane $\left[\mathrm{Me}_{3} \mathrm{SiC}\left(\mathrm{PPh}_{3}\right)_{2}\right]\left[\mathrm{CF}_{3} \mathrm{SO}_{3}\right] . \mathrm{Z}$. Anorg. Allg. Chem. 2014, 640, 417-422.

(352) Appel, R.; Knoll, F.; Veltmann, H. (Dich1oromethylene)triphenylphosphorane. Angew. Chem., Int. Ed. Eng. 1976, 15, 315-316.

(353) Speziale, A. J.; Marco, G. J.; Ratts, K. W. A Novel Synthesis of 1,1-Dihaloolefins. J. Am. Chem. Soc. 1960, 82, 1260.

(354) Speziale, A. J.; Ratts, K. W. Reactions of Phosphorus Compounds. III. Synthesis of Phosphinedihalomethylenes via Dihalocarbenes. A Novel Synthesis of 1,1-Dihalolefins. J. Am. Chem. Soc. 1962, 84, 854-859.

(355) Rabinowitz, R.; Marcus, R. Ylid Intermediate in the Reaction of Triphenylphosphine with Carbon Tetrachloride. J. Am. Chem. Soc. 1962, 84, 1312-1313.

(356) Appel, R.; Knoll, F.; Michel, W.; Morbach, W.; Wihler, H. D.; Veltmann, H. Reactions in the System Triphenylphosphine/Carbon Tetrachloride. Chem. Ber. 1976, 109, 58-70.

(357) Appel, R. Tertiary Phosphane/Tetrachloromethane, a Versatile Reagent for Chlorination, Dehydration, and P-N Linkage. Angew. Chem. Int. Ed. Engl. 1975, 14, 801-811.

(358) Matthews, C. N.; Driscoll, J. S.; Birum, G. H. Mesomeric Phosphonium Inner Salts. J. Chem. Soc., Chem. 1966, 736-737. 
(359) Matthews, C. N.; Birum, G. H. Triphenylphosphoranylidene. Tetrahedron Lett. 1966, 7, 57075710.

(360) Birum, G. H.; Matthews, C. N. Cycloaddition Reactions of Triphenylphosphoranylideneketene. J. Am. Chem. Soc. 1968, 90, 3842-3847.

(361) Petz, W.; Neumüller, B. Reaction of $\left(\mathrm{PPh}_{3}\right)_{2} \mathrm{C}-\mathrm{CO}_{2}$ with Halogenated Hydrocarbons; Formation and Crystal Structure of a Cationic Ester with 1,2-Dichloroethane. Z. Anorg. Allg. Chem. 2012, 638, 987-991.

(362) Ross, F. K.; Hamilton, W. C.; Ramirez, F. Crystal and Molecular Structure of Ethylene-1,1bis(triphenylphosphonium)-2,2-bis(phenylamide): $\left[\left(\mathrm{C}_{6} \mathrm{H}_{5}\right)_{3} \mathrm{P}\right]_{2} \mathrm{C}-\mathrm{C}\left(\mathrm{N}-\mathrm{C}_{6} \mathrm{H}_{5}\right)_{2}$. Acta Cryst. 1971, B27, 2331-2334.

(363) Ross, F. K.; Manojlovic-Muir, L.; Hamilton, W. C.; Ramirez, F.; Pilot, J. F. Crystal and Molecular Structure of Ethylene-1-(diphenylphosphino)-1-(triphenylphosphonium)-2(diphenylamino)-2-(phenylamide), $\quad\left[\left(\mathrm{C}_{6} \mathrm{H}_{5}\right)_{2} \mathrm{P}\right]\left[\left(\mathrm{C}_{6} \mathrm{H}_{5}\right)_{3} \mathrm{P}\right]_{2} \mathrm{C}-\mathrm{C}\left(\mathrm{N}-\mathrm{C}_{6} \mathrm{H}_{5}\right)_{2}\left[\mathrm{~N}\left(\mathrm{C}_{6} \mathrm{H}_{5}\right)\right] . \quad$ Phenyl Migration from Four-Coordinated Phosphorus to Two-Coordinated Nitrogen. J. Am. Chem. Soc. 1972, 94, 8738-8743.

(364) Matthews, C. N.; Birum, G. H. Carbophosphoranes. Acc. Chem. Res. 1969, 2, 373-379.

(365) Birum, G. H, Matthews, C. N. Reactions of Triphenyl-2,2bis(trifluoromethyl)vinylidenephosphorane, Synthesized from a Cyclic Ylide-Ketone Adduct. $J$. Org. Chem. 1967, 32, 3554-3559.

(366) Chioccola, G.; Daly, J. J. The crystal structure of a Wittig intermediate containing a fourmembered ring. 4,4-Bis(trifluoromethyl)2,2,2-triphenyl-3-(triphenyl-phosphoranylidene)-1,2oxaphosphetane. J. Chem. Soc. A, 1968, 0, 568-577.

(367) Bestmann, H. J.; Kloeters, W. Simple Synthesis of (Arylethyny1)triphenylphosphonium Salts. Angew. Chem., Int. Ed. Eng. 1977, 16, 45-46.

(368) Bestmann, H. J.; Kloeters, W. Zur Umsetzung von o-Salicylaldehyd mit Hexacarbodiphosphoran. Tetrahedron Lett. 1977, 18, 79-80.

(369) Bestmann, H. J.; Kloeters, W. Ober die Reaktion von Hexaphenylcarbodiphosphoran mit Cyclischen Aromatischen Carbonsäureanhydriden. Tetrahedron Lett. 1978, 19, 3343-3344.

(370) Said, M. M.; Maigali, S. S.; Abd-El-Maksoud, M. A.; Soliman, F. M. Chemistry of Phosphorus Ylides. Part 25. Interaction of Hexaphenylcarbodiphosphorane with Carbonyls, Hydrazone, and Mannich Bases. A Synthesis of Phosphoranylidenes, Phosphobetaines, and Oxaphosphinin. Monatsh. Chem. 2008, 139, 1299-1306.

(371) Maigali, S. S; Abd-El-Maksoud, M. A.; Soliman, F. M. Chemistry of Phosphorus Ylides. Part 33. Synthesis and Antitumor Activities of Some New Chromenone Derivatives. Arch. Pharm. Chem. Life Sci. 2011, 344, 442-450.

(372) Maigali, S. S.; Abd-El-Maksoud, M. A..; Soliman, F. M. Chemistry of Phosphorus Ylides 31: Reaction of Azidocoumarin with Active Phosphonium Ylides, Synthesis and Antitumour Activities of Chromenones. J. Chem. Sci. 2013, 125, 1419-1428.

(373) Maigali, S. S.; Said, M. M.; Abd-El-Maksoud, M. A.; Soliman, F. M. Chemistry of Phosphorus 
Ylides. Part 24. A Route for the Synthesis of Oxazine Derivatives via the Reaction of Phosphacumulenes and Phosphallene with di- and tri-ketone Monoximes. Monatsh. Chem. 2008, 139, 495-501.

(374) Zeid, I. F.; Said, M. M., Darwish, S. A.; Soliman, F. M. Chemistry of Phosphorus Ylides. Part 38: Synthesis and Anticancer Activity of Cyclobutane, Oxaphosphetane, Oxaphosphinine, Azaphosphetidene, and Pyridazine Derivatives. Monatsh. Chem. 2014, 145, 639-650.

(375) Maigali, S. S.; El-Hussieny, M.; Soliman, F. M. Chemistry of Phosphorus Ylides. Part 37. The Reaction of Phosphonium Ylides with Indoles and Naphthofurans. Synthesis of Phosphanylidenes, Pyrans, Cyclobutenes, and Pyridazine as Antitumor Agents. J. Heterocyclic Chem. 2015, 52, 15-23.

(376) Holle, S.; Escudero, D.; Inés, B.; Rust, J.; Thiel, W.; Alcarazo, M. On the Reactivity of Tetrakis(trifluoromethyl)cyclopentadienone towards Carbon-Based Lewis Bases. Chem. Eur. J. 2015, 21, 2744-2749.

(377) Roundhill, D. M.; Wilkinson, G. A New Ylide from Tetrakis(trifluoromethyl)cyclopentadienone and Triphenylphosphine. J. Org. Chem. 1970, 35, 3561-3562.

(378) Burk, M. J.; Calabrese, J. C.; Davison, F.; Harlow, R. L.; Roe, D. C. The Chemistry of Tetrakis(trifluoromethyl)cyclopentadienone. J. Am. Chem. Soc. 1991, 113, 2209-2222.

(379) Petz, W.; Dehnicke, K.; Holzmann, N.; Frenking, G.; Neumüller, B. The Reaction of $\mathrm{BeCl}_{2}$ with Carbodiphosphorane $\mathrm{C}\left(\mathrm{PPh}_{3}\right)_{2}$; Experimental and Theoretical Studies. Z. Anorg. Allg. Chem. 2011, 637, 1702-1710.

(380) Su, W.; Pan, S.; Sun, X.; Wang, S.; Zhao, L.; Frenking, G.; Zhu, C. Double Dative Bond Between Divalent Carbon(0) and Uranium. Nat. Commun. 2018, 9, 4997.

(381) Karsch, H. H.; Grauvogl, G.; Kawecki, M.; Bissinger, P. Zirconocene Derivatives with Phosphinomethanide Ligands: Metal-Promoted Ligand Metalations: Tuning of Regioselectivity and Formation of Novel Zirconaphosphaheterocycles. Organometallics 1993, 12, 2757-2766.

(382) Kaska, W. C.; Mitchell, D. K.; Reichelderfer, R. F. Transition Metal Complexes of Hexaphenylcarbodiphosphorane. J. Organomet. Chem. 1973, 47, 391-402.

(383) Petz, W.; Neumüller, B.; Tonner, R. Reaction of Double Ylide $\mathrm{C}\left(\mathrm{PPh}_{3}\right)_{2}$ with $\left[\mathrm{W}(\mathrm{CO})_{6}\right]-$ Crystal Structures of $\left[(\mathrm{CO})_{5} \mathrm{~W}(\mathrm{CCPPh})\right]$ and $\left[(\mathrm{CO})_{5} \mathrm{~W}\left\{\eta^{1}-\mathrm{O}_{2} \mathrm{C}_{2}\left(\mathrm{PPh}_{3}\right)_{2}\right\}\right]$ and Bonding Analyses of [TM(CCPR 3$)]$ Compounds. Eur. J. Inorg. Chem. 2010, 1872-1880.

(384) Bruce, A. E.; Gamble, A. S.; Tonker, T. L.; Templeton, J. L. Cationic Phosphonium Carbyne and Bis(phosphonium) Carbene Tungsten Complexes: $\left[\mathrm{Tp}^{\prime}(\mathrm{OC})_{2} \mathrm{WC}\left(\mathrm{PMe}_{3}\right)_{n}\right]\left[\mathrm{PF}_{6}\right](\mathrm{n}=1,2)$. Organometallics 1987, 6, 1350-1352.

(385) Kaska, W. C.; Mitchell, D. K.; Reichelderfer, R. F.; Kortelb, W. D. The Interaction of Phosphorus Ylides with Transition Metal Carbonyl Compounds. Triphenylphosphinemethylene and Bis(triphenylphosphine) carbon. Comparative Chemistry. J. Am. Chem. Soc. 1974, 96, 28472854.

(386) Mitchell, $\quad$ D. K.; Korte, W. $\quad$ D.; Kaska, W. C. Bromotetracarbonyltriphenylphosphoranylideneketenmanganese(I): an Organometallic Ylide. $J$. 
Chem. Soc. D 1970, 1384-1385.

(387) Goldberg, S. Z.; Duesler, E. N.; Raymond, K. Crystal and molecular structure of $\left[\mathrm{Mn}(\mathrm{CO})_{4}\left(\mathrm{C}_{2} \mathrm{P}\left(\mathrm{C}_{6} \mathrm{H}_{5}\right)_{3}\right) \mathrm{Br}\right]$. Coordination compound of the unusual carbonyl-ylide reaction product $\left(\mathrm{C}_{6} \mathrm{H}_{5}\right)_{3} \mathrm{P}^{+}-\mathrm{C} \equiv \mathrm{C}^{-}$. Inorg. Chem. 1972, 11, 1397-1401.

(388) Petz, W.; Öxler, F.; Ronge, R.; Neumüller, B. An Unusual Product from the Reaction of C $\left(\mathrm{PPh}_{3}\right)_{2}$ with $\left[\mathrm{Mn}_{2}(\mathrm{CO})_{10}\right]$ : $\quad$ Formation and Crystal Structure of $\left[\mathrm{Mn}\left(\mathrm{OPPh}_{3}\right)_{2}\left\{\mathrm{O}_{2} \mathrm{CC}\left(\mathrm{PPh}_{3}\right)_{2}\right\}_{2}\right]\left[\mathrm{Mn}(\mathrm{CO})_{5}\right]_{2}$. Z. Anorg. Allg. Chem. 2008, 634, 1415-1420.

(389) Sundermeyer, J.; Weber, K.; Peters, K.; von Schnering, H. G. Modeling Surface Reactivity of Metal Oxides: Synthesis and Structure of an Ionic Organorhenyl Perrhenate Formed by LigandInduced Dissociation of Covalent $\mathrm{Re}_{2} \mathrm{O}_{7}$. Organometallics 1994, 13, 2560-2562.

(390) Pranckevicius, C.; Iovanb, D. A.; Stephan, D. W. Three and Four Coordinate Fe Carbodiphosphorane Complexes. Dalton Trans. 2016, 45, 16820-16825.

(391) Petz, W.; Weller, F. Z. Reaction of $\mathrm{Ph}_{3} \mathrm{P}=\mathrm{C}=\mathrm{PPh}_{3}$ with $\mathrm{Fe}(\mathrm{CO})_{5}$; Molecular Structures of $(\mathrm{CO})_{4} \mathrm{Fe}=\mathrm{C}=\mathrm{C}=\mathrm{PPh}_{3}$ and $\mathrm{Fe}_{3}(\mathrm{CO})_{9}\left(\mu^{3}-\eta^{2}-\mathrm{C} \equiv \mathrm{C}-\mathrm{PPh}_{3}\right)$. Z. Naturforsch. 1996, 51b, 1598-1604.

(392) Kaska, W. C.; Reichelderfer, R. F. The Interaction of Hexaphenylcarbodiphosphorane with Iridium Olefin Cations. Metalation of Coordinated Ligands. J. Organomet. Chem. 1974, 78, C47C50.

(393) Kubo, K.; Jones, N. D.; Ferguson, M. J.; McDonald, R. M.; Cavell, R. G. Chelate and Pincer Carbene Complexes of Rhodium and Platinum Derived from Hexaphenylcarbodiphosphorane, $\mathrm{Ph}_{3} \mathrm{P}=\mathrm{C}=\mathrm{PPh}_{3}$. J. Am. Chem. Soc. 2005, 127, 5314-5315.

(394) Petz, W.; Kutschera, C.; Neumüller, B. Reaction of the Carbodiphosphorane $\mathrm{Ph}_{3} \mathrm{P}=\mathrm{C}=\mathrm{PPh}_{3}$ with Platinum(II) and -(0) Compounds: Platinum Induced Activation of C-H Bonds. Organometallics 2005, 24, 5038-5043.

(395) Petz, W.; Neumüller, B. New Platinum Complexes with Carbodiphosphorane as Pincer Ligand via Ortho Phenyl Metallation. Polyhedron 2011, 30, 1779-1784.

(396) Petz, W.; Andrada, D. A.; Hermann, M.; Frenking, G.; Neumüller, B. A C 2 Fragment as FourElectron $\sigma$ Donor. Z. Anorg. Allg. Chem. 2017, 643, 1096-1099.

(397) Baldwin, J. C.; Kaska, W. C. The Interaction of Hexaphenylcarbodiphosphorane with the Trimethylplatinum(IV) Cation. Inorg. Chem. 1979, 18, 686-691.

(398) Kubo, K.; Okitsu, H.; Miwa, H.; Kume, S.; Cavell, R. G.; Mizuta, T. Carbon(0)-Bridged Pt/Ag Dinuclear and Tetranuclear Complexes Based on a Cyclometalated Pincer Carbodiphosphorane Platform. Organometallics 2017, 36, 266-274.

(399) Reitsamer, C.; Stallinger, S.; Schuh, W.; Kopacka, H.; Wurst, K.; Obendorf, D.; Peringer, P. Novel Access to Carbodiphosphoranes in the Coordination Sphere of Group 10 Metals: Template Synthesis and Protonation of PCP Pincer Carbodiphosphorane Complexes of C(dppm $)_{2}$. Dalton Trans., 2012, 41, 3503-3514.

(400) Reitsamer, C.; Schuh, W.; Kopacka, H.; Wurst, K.; Peringer, P. Synthesis and Structure of the First Heterodinuclear PCP-Pincer-CDP Complex with a Pd-Au $\mathrm{d}^{8}-\mathrm{d}^{10}$ Pseudo-Closed-Shell Interaction. Organometallics 2009, 28, 6617-6620. 
(401) Reitsamer, C.; Schuh, W.; Kopacka, H.; Wurst, K.; Ellmerer, E. P.; Peringer, P. The First Carbodiphosphorane Complex with Two Palladium Centers Attached to the CDP Carbon: Assembly of a Single-Stranded di-Pd Helicate by the PCP Pincer ligand C(dppm $)_{2}$. Organometallics 2011, 30, 4220-4223.

(402) Maser, L.; Herritsch, J.; Langer, R. Carbodiphosphorane-Based Nickel Pincer Complexes and Their (De)protonated Analogues: Dimerisation, Ligand Tautomers and Proton Affinities. Dalton Trans. 2018, 47, 10544-10552.

(403) Petz, W.; Weller, F.; Uddin, J.; Frenking, G. Reaction of Carbodiphosphorane $\mathrm{Ph}_{3} \mathrm{P}=\mathrm{CPPh}{ }_{3}$ with $\mathrm{Ni}(\mathrm{CO})_{4}$. Experimental and Theoretical Study of the Structures and Properties of $(\mathrm{CO})_{3} \mathrm{NiC}\left(\mathrm{PPh}_{3}\right)_{2}$ and $(\mathrm{CO})_{2} \mathrm{NiC}\left(\mathrm{PPh}_{3}\right)_{2}$. Organometallics 1999, 18, 619-626.

(404) Raubenheimer, H. G.; Schmidbaur, H. Gold Chemistry Guided by the Isolobality Concept. Organometallics 2012, 31, 2507-2522.

(405) Schmidbaur, H.; Gasser, O. The Ambident Ligand Properties of Bis(trimethylphosphoranylidene)methane. Angew. Chem. Int. Ed. Engl. 1976, 15, 502-503.

(406) Schmidbaur, H.; Zybill, C. E.; Müller, G.; Krüger, C. Coinage Metal Complexes of Hexaphenylcarbodiphosphorane-Organometallic Compounds with Coordination Number 2. Angew. Chem. Int. Ed. Engl. 1983, 22, 729-730.

(407) Vivente, J.; Singhal, A. R.; Jones, P. C. New Ylide-, Alkynyl-, and Mixed Alkynyl/Ylide-Gold(I) Complexes. Organometallics 2002, 21, 5887-5900.

(408) Reitsamer, C.; Hackl, I.; Schuh, W.; Kopacka, H.; Wurst, K.; Peringer, P. Gold(I) and Gold(III) Complexes of the $\left[\mathrm{CH}(\mathrm{dppm})_{2}\right]^{+}$and $\mathrm{C}(\mathrm{dppm})_{2} \mathrm{PCP}$ Pincer Ligand Systems. J. Organomet. Chem. 2017, 830, 150-154.

(409) El-Hellani, A.; Bour, C.; Gandon, V. Evaluation of the Electronic Properties of a Carbodiphosphorane through Gold Catalysis. Adv. Synth. Catal. 2011, 353, 1865-1870.

(410) Corberán, R.; Marrot, S.; Dellus, N.; Merceron-Saffon, N.; Kato, T. Peris, E.; Baceiredo, A. First Cyclic Carbodiphosphoranes of Copper(I) and Gold(I) and Their Application in the Catalytic Cleavage of X-H Bonds ( $\mathrm{X}=\mathrm{N}$ and $\mathrm{O}$ ). Organometallics 2009, 28, 326-330.

(411) Munro-Leighton, C.; Blue, E. D.; Gunnoe, T. B. Anti-Markovnikov N-H and O-H Additions to Electron-Deficient Olefins Catalyzed by Well-Defined $\mathrm{Cu}(\mathrm{I})$ Anilido, Ethoxide, and Phenoxide Systems. J. Am. Chem. Soc. 2006, 128, 1446-1447.

(412) Zybill, C.; Müller, G. Mononuclear Complexes of Copper(I) and Sllver(I) Featuring the Metals Exclusively Bound to Carbon. Synthesis and Structure of $\left(\eta^{5}\right.$ Pentamethylcyclopentadienyl)[(triphenylphosphonio)(triphenylphosphoranylidene)methyl]copper (I). Organometallics 1987, 6, 2489-2494.

(413) Petz, W.; Öxler, F.; Neumüller, B. Syntheses and Crystal Structures of Linear Coordinated Complexes of $\mathrm{Ag}^{+}$with the Ligands $\mathrm{C}\left(\mathrm{PPh}_{3}\right)_{2}$ and $\left(\mathrm{HC}\left\{\mathrm{PPh}_{3}\right\}_{2}\right)^{+}$. J. Organomet. Chem. 2009, 694, 4094-4099.

(414) Morosaki, T.; Suzuki, T.; Fujii, T. Syntheses and Structural Characterization of Mono-, Di-, and Tetranuclear Silver Carbone Complexes. Organometallics 2016, 35, 2715-2721. 
(415) Petz, W.: Neumüller, B.; Klein, S.; Frenking, G. Syntheses and Crystal Structures of $\left[\mathrm{Hg}\left\{\mathrm{C}\left(\mathrm{PPh}_{3}\right)_{2}\right\}_{2}\right]\left[\mathrm{Hg}_{2} \mathrm{I}_{6}\right]$ and $\left[\mathrm{Cu}\left\{\mathrm{C}\left(\mathrm{PPh}_{3}\right)_{2}\right\}_{2}\right] \mathrm{I}$ and Comparative Theoretical Study of Carbene Complexes $\left[\mathrm{M}(\mathrm{NHC})_{2}\right]$ with Carbone Complexes $\left[\mathrm{M}\left\{\mathrm{C}\left(\mathrm{PH}_{3}\right)_{2}\right\}_{2}\right]\left(\mathrm{M}=\mathrm{Cu}^{+}, \mathrm{Ag}^{+}, \mathrm{Au}^{+}, \mathrm{Zn}^{2+}\right.$, $\mathrm{Cd}^{2+}, \mathrm{Hg}^{2+}$ ). Organometallics 2011, 30, 3330-3339.

(416) Petz, W.; Neumüller, B. Reaction of $\mathrm{C}\left(\mathrm{PPh}_{3}\right)_{2}$ with $\mathrm{MI}_{2}$ Compounds $(\mathrm{M}=\mathrm{Zn}, \mathrm{Cd})$ - Formation and Crystal Structures of $\left[\mathrm{I}_{2} \mathrm{Zn}\left\{\mathrm{C}\left(\mathrm{PPh}_{3}\right)_{2}\right\}\right],\left[\left(\mathrm{I}_{2} \mathrm{Cd}\left\{\mathrm{C}\left(\mathrm{PPh}_{3}\right)_{2}\right\}\right)_{2}\right]$ and the Salt-Like Compounds $\left(\mathrm{HC}\left\{\mathrm{PPh}_{3}\right\}_{2}\right)\left[\mathrm{MI}_{3}(\mathrm{THF})\right]$ and $\left(\mathrm{HC}\left\{\mathrm{PPh}_{3}\right\}_{2}\right)_{2}\left[\mathrm{ZnI}_{4}\right]$. Eur. J. Inorg. Chem. 2011, 4889-4895.

(417) Matthews, C. N.; Driscoll, J. S.; Harris, J. E.; Wineman, R. J. Photochromism in Mesomeric Phosphonium Salts. J. Am. Chem. Soc. 1962, 84, 4349-4350.

(418) Petz, W.; Öxler, F.; Neumüller, B.; Tonner, R.; Frenking, G. Carbodiphosphorane $\mathrm{C}\left(\mathrm{PPh}_{3}\right)_{2}$ as a Single and Twofold Lewis Base with Boranes: Synthesis, Crystal Structures and Theoretical Studies on $\left[\mathrm{H}_{3} \mathrm{~B}\left\{\mathrm{C}\left(\mathrm{PPh}_{3}\right)_{2}\right\}\right]$ and $\left[\left\{(\mu-\mathrm{H}) \mathrm{H}_{4} \mathrm{~B}_{2}\right\}\left\{\mathrm{C}\left(\mathrm{PPh}_{3}\right)_{2}\right\}\right]^{+}$. Eur. J. Inorg. Chem. 2009, 45074517.

(419) Inés, B.; Patil, M.; Carreras, J.; Goddard, R.; Thiel, W.; Alcarazo, M. Synthesis, Structure, and Reactivity of a Dihydrido Borenium Cation. Angew. Chem. Int. Ed. 2011, 50, 8400-8403.

(420) Münzer, J. E.; Oña-Burgos, P.; Arrabal-Campos, F. M.; Neumüller, B.; Tonner, R.; Fernández, I.; Kuzu, I. Difluoroborenium Cation Stabilized by HexaphenylCarbodiphosphorane: A Concise Study on the Molecular and Electronic Structure of $\left[\left(\mathrm{Ph}_{3} \mathrm{P}\right)_{2} \mathrm{C}=\mathrm{BF}_{2}\right]\left[\mathrm{BF}_{4}\right]$. Eur. J. Inorg. Chem. 2016, 3852-3858.

(421) Petz, W.; Kutschera, C.; Tschan, S.; Weller, F.; Neumüller, B. Reaction of $\mathrm{Ph}_{3} \mathrm{P}=\mathrm{C}=\mathrm{PPh}_{3}$ with Lewis Acids of Main Group Elements; Syntheses, Structures, and Reactions of the Addition Compounds $\left[\mathrm{Br}_{3} \mathrm{Al}\left\{\mathrm{C}\left(\mathrm{PPh}_{3}\right)_{2}\right\}\right]$ and $\left[\mathrm{Me}_{3} \mathrm{In}\left\{\mathrm{C}\left(\mathrm{PPh}_{3}\right)_{2}\right\}\right]$. Z. Anorg. Allg. Chem. 2003, 629, $1235-$ 1244.

(422) El-Hellani, A.; Monot, J.; Tang, S.; Guillot, R.; Bour, C.; Gandon, V. Relationship between Gallium Pyramidalization in $\mathrm{L} \cdot \mathrm{GaCl}_{3}$ Complexes and the Electronic Ligand Properties. Inorg. Chem. 2013, 52, 11493-11502.

(423) Alcarazo, M.; Gomez, C.; Holle, S.; Goddard, R. Exploring the Reactivity of Carbon(0)/BoraneBased Frustrated Lewis Pairs. Angew. Chem. Int. Ed. 2010, 49, 5788-5791.

(424) Khan, S.; Gopakumar, G.; Thiel, W.; Alcarazo, M. Stabilization of a Two-Coordinate [GeCl] $]^{+}$ Cation by Simultaneous $\sigma$ and $\pi$ Donation from a Monodentate Carbodiphosphorane. Angew. Chem. Int. Ed. 2013, 52, 5644-5647.

(425) Yogendra, S.; Hennersdorf, F.; Bauzá, A.; Frontera, A.; Fischer, R.; Weigand, J. J. Carbodiphosphorane Mediated Synthesis of a Triflyloxyphosphonium Dication and its Reactivity Towards Nucleophiles. Chem. Commun. 2017, 53, 2954-2957.

(426) Yogendra, S.; Hennersdorf, F.; Bauzá, A.; Frontera, A.; Fischer, R.; Weigand, J. J. DonorAcceptor Interactions in Tri(phosphonio)methanide Dications $\left[\left(\mathrm{Ph}_{3} \mathrm{P}\right)_{2} \mathrm{CP}(\mathrm{X}) \mathrm{Ph}_{2}\right]^{2+}(\mathrm{X}=\mathrm{H}, \mathrm{Me}$, CN, NCS, OH, Cl, OTf, F). Dalton Trans. 2017, 46, 15503-15511.

(427) Yogendra, S.; Hennersdorf, F.; Bauzá, A.; Frontera, A.; Fischer, R.; Weigand, J. J. Selective and Reversible Fluoride Complexation from Water by a Cyclic Tri(phosphonio)methanide Dication. Angew. Chem. Int. Ed. 2017, 56, 7907-7911. 
(428) Đorđević, N.; Tay, M. Q. Y.; Muthaiah, S.; Ganguly, R.; Dimić, D.; Vidović, D. C-F Bond Activation by Transient Phosphenium Dications. Inorg. Chem. 2015, 54, 4180-4182.

(429) Tay, M. Q. Y.; Lu, Y.; Ganguly, R.; Vidovic, D. A Carbone-Stabilized Two-Coordinate Phosphorus(III)-Centered Dication. Angew. Chem. Int. Ed. 2013, 52, 3132-3135.

(430) Tay, M. Q. Y.; Ilić, G.; Werner-Zwanziger, U.; Lu, Y.; Ganguly, R.; Ricard, L.; Frison, G.; Carmichael, D.; Vidović, D. Preparation, Structural Analysis, and Reactivity Studies of Phosphenium Dications. Organometallics 2016, 35, 439-449.

(431) Tay, M. Q. Y.; Lu, Y.; Ganguly, R.; Vidović, D. Oxidative Addition of Water and Methanol to a Dicationic Trivalent Phosphorus Centre. Chem. Eur. J. 2014, 20, 6628-6631.

(432) Gurnani, C.: Đorđević, N.; Muthaiah, S.; Dimić, D.; Ganguly, R.; Petković, M.; Vidović, D. Extending the Chemistry of Carbones: P-N Bond Cleavage via an $\mathrm{SN}_{2}$ '-Like Mechanism. Chem. Commun. 2015, 51, 10762-10764.

(433) Loh, Y. K.; Gurnani, C.; Ganguly, R.; Vidović, D. A Dicationic Iminophosphane. Inorg. Chem. 2015, 54, 3087-3089.

(434) Schmidpeter, A.; Jochem, G.; Klinger, C.; Robl, C.; Nöth, H. Bis(ylide)-Substituted Phosphenium and Phosphonium Halides. J. Organomet. Chem. 1997, 529, 87-102.

(435) Nicholls, L. D. M.; Marx, M.; Hartung, T.; González-Fernández, E.; Golz, C.; Alcarazo, M. TADDOL-Derived Cationic Phosphonites: Toward an Effective Enantioselective Synthesis of [6]Helicenes via Au-Catalyzed Alkyne Hydroarylation. ACS Catal. 2018, 8, 6079-6085.

(436) Dellus, N.; Kato, T.; Saffon-Merceron, N.; Branchadell, V.; Baceiredo, A. Synthesis and Characterization of a Stable Cyclic gem-Bis(phosphaylide): a $4 \pi$-Electron Three-Membered Heterocycle. Inorg. Chem. 2011, 50, 7949-7951.

(437) Bestmann; H. J. Phosphacumulene Ylides and Phosphaallene Ylides. Angew. Chem. Int. Ed. Engl. 1977, 16, 349-364.

(438) Schmidbaur, H.; Zybill, C. E.; Neugebauer, D. Synthesis, Structure, and Reactions of Primary Adducts of Sulfur or Selenium with Hexaphenylcarbodiphosphoran. Angew. Chem. Int. Ed. Engl. 1982, 21, 310-311.

(439) Schmidbaur, H.; Zybill, C. E.; Neugebauer, D.; Müller, G. Addition of the Heavy Chalkogen Atoms and Halogenonium Ions to Carbodiphosphoranes. Z. Naturforsch. 1985, 40b, 1293-1300.

(440) Schmidbaur, H.; Zybill, C. E.; Neugebauer, D. Oxidative Coupling of the Selenolate Functions in $\left(\mathrm{C}_{6} \mathrm{H}_{5}\right)_{3} \mathrm{PC}(\mathrm{Se}) \mathrm{P}\left(\mathrm{C}_{6} \mathrm{H}_{5}\right)_{3}$ : Crystal Structure of $\left\{\left[\left(\mathrm{C}_{6} \mathrm{H}_{5}\right)_{3} \mathrm{P}\right]_{2} \mathrm{C}(\mathrm{Se})\right\}_{2}{ }^{2+} \mathrm{Fe}_{2} \mathrm{OCl}_{6}{ }^{2}-\quad \cdot \mathrm{CH}_{2} \mathrm{Cl}_{2}$ Containing a Linear Fe-O-Fe Axis. Angew. Chem. Int. Ed. Engl. 1983, 22, 156-157.

(441) Petz, W.; Heimann, S.; Öxler, F.; Neumüller, B. Formation and Crystal Structure of the Salt $\left(\mathrm{IC}\left(\mathrm{PPh}_{3}\right)_{2}\right)_{2} \mathrm{I}\left[\mathrm{I}_{3}\right] \cdot\left(\mathrm{I}_{2}\right)_{2}$ with a new Polyiodide Chain. Z. Anorg. Allg. Chem. 2007, 633, 365-367. 
(442) Petz, W.; Kuzu, I.; Frenking, G.; Andrada, D. M.; Neumüller, B.; Fritz, M.; Mìnzer, J. E. Proton Affinities of Cationic Carbone Adducts $\left[\mathrm{AC}\left(\mathrm{PPh}_{3}\right)_{2}\right]^{+}(\mathrm{A}=$ Halogen, Hydrogen, Methyl) and Unusual Electronic Structures of the Cations and Dications [AC(H)(PPh $\left.)_{2}\right]^{2+}$. Chem. Eur. J. 2016, 22, 8536-8546.

(443) Ong, T.-G. Carbodicarbenes and Its Captodative Behavior in Catalysis. ChemCatChem 2017, $1483-1498$.

(444) Viehe, H. G.; Janousek, Z.; Gompper, R.; Lach, D. Allenetetramine and Dialkoxydiaminoallene. Angew. Chem. Int. Ed. Engl. 1973, 12, 566-567.

(445) Fürstner, A.; Alcarazo, M.; Krause, H. Tetrakis(Dimethylamino)Allene. Org. Synth. 2010, 86, 298-307.

(446) Chen, W. C.; Hsu, Y. C.; Lee, C. Y.; Yap, G. P. A.; Ong, T. G. Synthetic Modification of Acyclic Bent Allenes (Carbodicarbenes) and Further Studies on Their Structural Implications and Reactivities. Organometallics 2013, 32, 2435-2442.

(447) Hsu, Y. C.; Shen, J. S.; Lin, B. C.; Chen, W. C.; Chan, Y. T.; Ching, W. M.; Yap, G. P. A.; Hsu, C. P.; Ong, T. G. Synthesis and Isolation of an Acyclic Tridentate Bis(Pyridine)Carbodicarbene and Studies on Its Structural Implications and Reactivities. Angew. Chem. Int. Ed. 2015, 54, 2420-2424.

(448) Chen, W. C.; Shen, J. S.; Jurca, T.; Peng, C. J.; Lin, Y. H.; Wang, Y. P.; Shih, W. C.; Yap, G. P. A.; Ong, T. G. Expanding the Ligand Framework Diversity of Carbodicarbenes and Direct Detection of Boron Activation in the Methylation of Amines with CO2. Angew. Chem. Int. Ed. 2015, 54, 15207-15212.

(449) Ruiz, D. A.; Melaimi, M.; Bertrand, G. Carbodicarbenes, Carbon(0) Derivatives, Can Dimerize. Chem. - Asian J. 2013, 8, 2940-2942.

(450) Hoffmann, R. W.; Schäfer, W. The Adduct of Tetramethoxyallene and Tetracyanoethylene. Angew. Chem. Int. Ed. Engl. 1970, 9, 733-733.

(451) Gompper, R.; Schelble, J.; Schneider, C. S. Dikationen Und Zwitterionen Aus Dialkylaminoallenen. Tetrahedron Lett. 1978, 19, 3897-3900.

(452) Walley, J. E.; Breiner, G.; Wang, G.; Dickie, D. A.; Molino, A.; Dutton, J. L.; Wilson, D. J. D.; Gilliard, R. J. S-Block Carbodicarbene Chemistry: C( $\left.\mathrm{sp}^{3}\right)-\mathrm{H}$ Activation and Cyclization Mediated by a Beryllium Center. Chem. Commun. 2019, 55, 1967-1970.

(453) Chan, S.-C.; Gupta, P.; Engelmann, X.; Ang, Z. Z.; Ganguly, R.; Bill, E.; Ray, K.; Ye, S.; England, J. Observation of Carbodicarbene Ligand Redox Noninnocence in Highly Oxidized Iron Complexes. Angew. Chem. Int. Ed. 2018, 57, 15717-15722.

(454) Shih, W. C.; Chiang, Y. T.; Wang, Q.; Wu, M. C.; Yap, G. P. A.; Zhao, L.; Ong, T. G. Invisible Chelating Effect Exhibited between Carbodicarbene and Phosphine through $\pi-\pi$ Interaction and Implication in the Cross-Coupling Reaction. Organometallics 2017, 36, 4287-4297.

(455) Hsu, Y. C.; Wang, V. C. C.; Au-Yeung, K. C.; Tsai, C. Y.; Chang, C. C.; Lin, B. C.; Chan, Y. T.; Hsu, C. P.; Yap, G. P. A.; Jurca, T.; et al. One-Pot Tandem Photoredox and Cross-Coupling Catalysis with a Single Palladium Carbodicarbene Complex. Angew. Chem. Int. Ed. 2018, 57, 
4622-4626.

(456) Fürstner, A.; Alcarazo, M.; Goddard, R.; Lehmann, C. W. Coordination Chemistry of Ene-1,1Diamines and a Prototype "Carbodicarbene." Angew. Chem. Int. Ed. 2008, 47, 3210-3214.

(457) Chen, W. C.; Lee, C. Y.; Lin, B. C.; Hsu, Y. C.; Shen, J. S.; Hsu, C. P.; Yap, G. P. A.; Ong, T. G. The Elusive Three-Coordinate Dicationic Hydrido Boron Complex. J. Am. Chem. Soc. 2014, 136, 914-917.

Bios

Marie Fustier-Boutignon was born in Lyon in 1985. She studied at the Ecole Normale Superieure de Cachan from 2006 to 2010 and then received her Ph.D. degree from the Ecole Polytechnique, Palaiseau, in 2012. She was a research associate with Prof. Peter Roesky at KIT , Karlsruhe, Germany, and is currently Associate Professor at the Université Paul Sabatier at the Laboratoire Hétérochimie Fondamentale et Appliquée. She is presently working on the use of geminal dianions as a versatile tool for the development of new catalytic processes.

Dr. Noel Nebra was born in Pravia (Asturias, Spain) in 1981. He carried out bachelor studies in chemistry at the University of Oviedo, and completed his PhD in 2009 at the IUQOEM (University of Oviedo) mentored by Prof. J. Gimeno and Dr. V. Cadierno. He then performed two distinct postdoctoral research stays at LHFA (Toulouse, France) with Dr. D. Bourissou and at ICIQ (Tarragona, Spain) with Dr. V. Grushin. Since October 2014, Dr. Nebra holds a CNRS tenured position at LHFA (Toulouse) and develops a research project dealing with the use of high-valent organometallics [mainly $\mathrm{Ni}(\mathrm{III})$ and $\mathrm{Ni}(\mathrm{IV})]$ to forge industrially-relevant organofluorine materials.

Nicolas Mézailles was born in Normandy in 1969. After receiving an engineering degree in chemistry from "Ecole Nationale Supérieure de Chimie de Toulouse", he obtained a Ph.D. degree in chemistry from Purdue University in 1997 (with prof. C. P. Kubiak). He moved back to France for a post doctoral stay at the Ecole Polytechnique (with profs. P. Le Floch and F. Mathey). He joined the CNRS in 1998 at the Ecole Polytechnique, and moved to in Toulouse in 2012, to create a group within the LHFA. His interests encompass the chemistry of geminal dianions, the use of transition metal fragments to functionalize $\mathrm{N}_{2}$ as well as nanoparticle synthesis.

TOC 


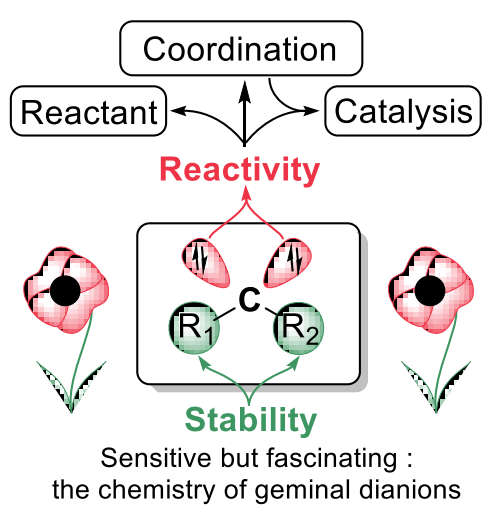

